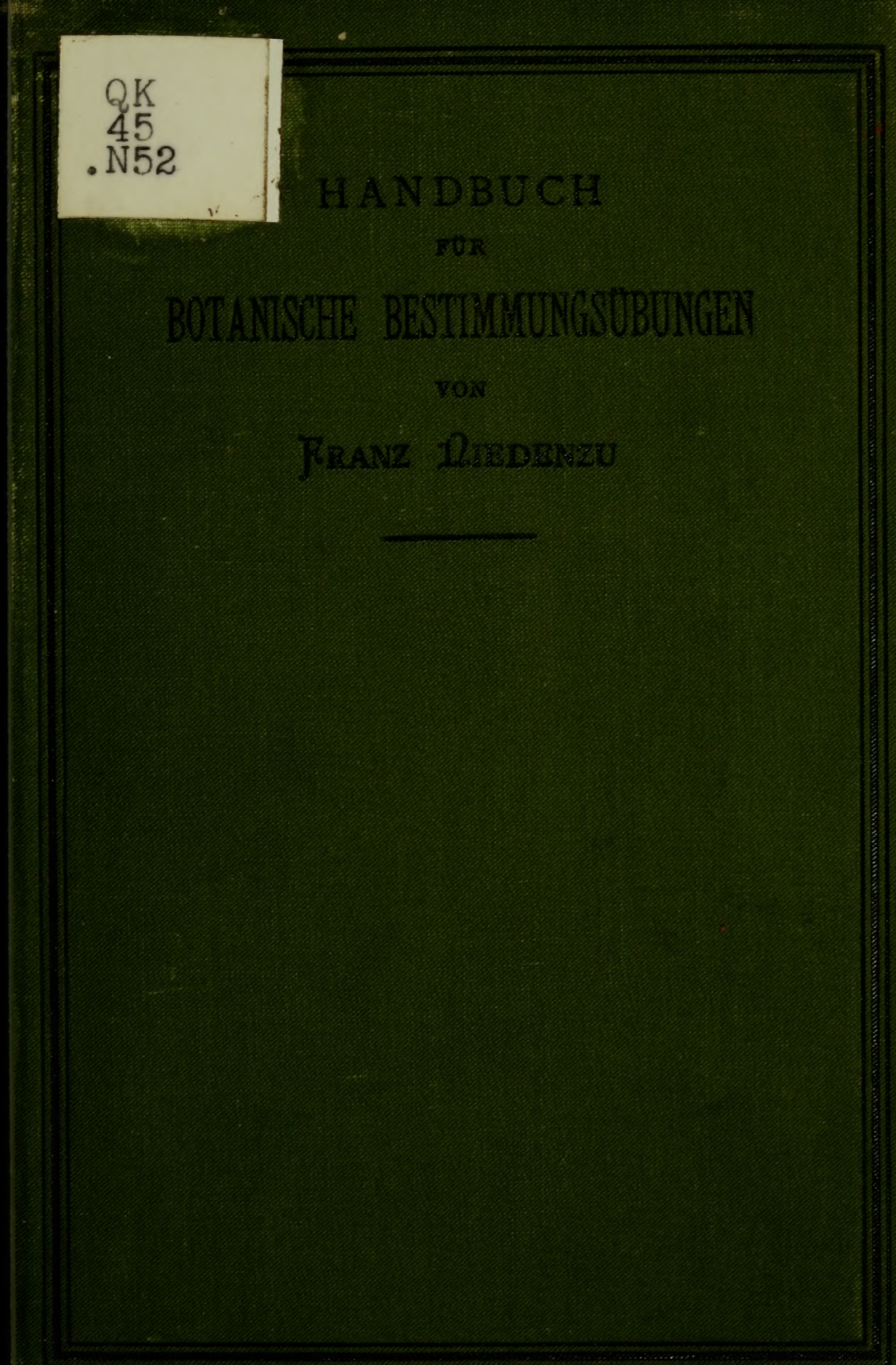


(3) कर्य. (-)

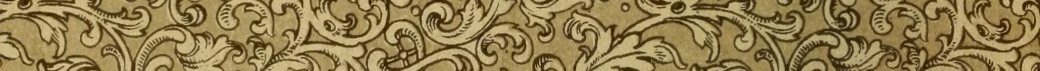

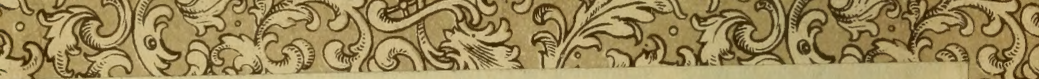
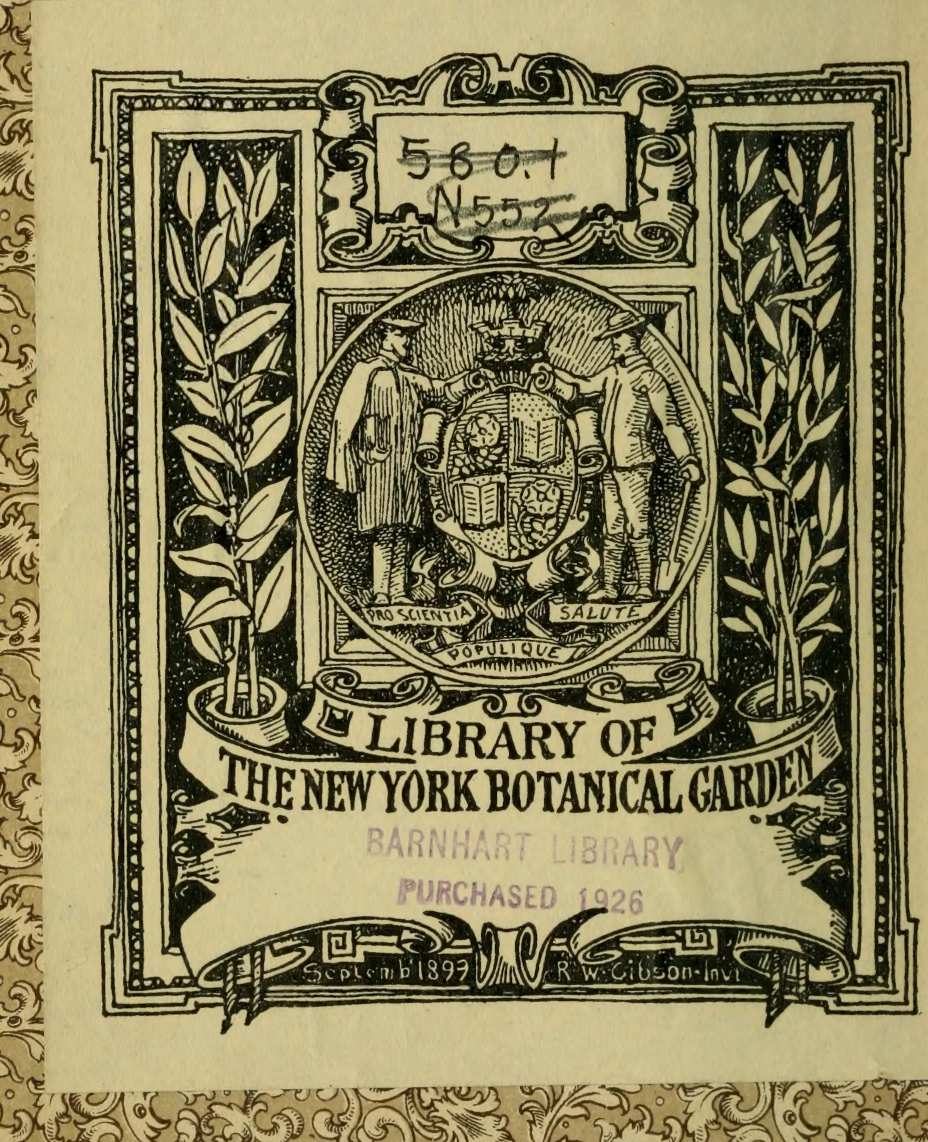

20

15

1) 4

$\sqrt[5]{5}$

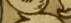

परिए

तु

(2) 5

(2)

बiा

(3)

4

$6^{\circ} 6$

$\sum_{3}$ ?

जิ

वि

B)

(3)

of

$5 \mathrm{c}$

(ख)

64

का

पूती

की

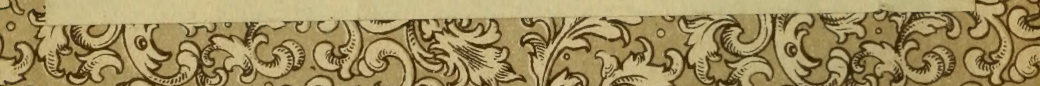
rरn (G)

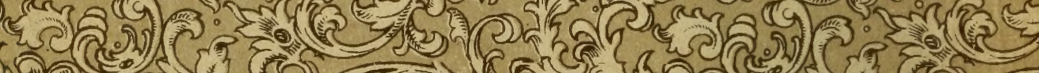
(9) (1)

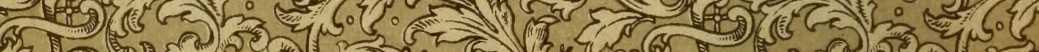
(2) (2) यु. 




\title{
HANDBUCH
}

FÜR

\section{BOTANISCHE BESTIMMUNGSÜBULGEN}

\begin{abstract}
VON
DR. FRANZ NIEDENZU

๑. ö. PROFESSQR UND LEITER DES BOTANISCHEN GARTENS AM KGL. LYCEUM HOSIANUM ZU BRAUNSBFRG, O.-PR.
\end{abstract}

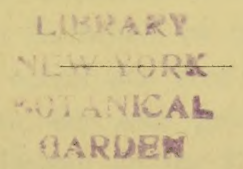

MIT 15 FIGUREN IM TEXT

L E I P Z I G

VERLAG VON WILHELM ENGELMANN

1895. 
. $\mathrm{NS}_{2}$

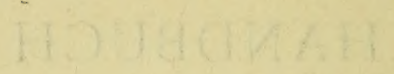

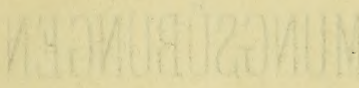

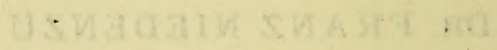

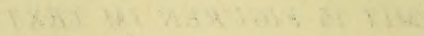




\section{Vorwort.}

In den botanischen Bestimmungsübungen, welche die Systematiker - abgesehen von der Übung im Bestimmen selbst - teils zur Befestigung und Vertiefung des im Kolleg Mitgeteilten, teils zur Erzielung der nötigen Summe von Spezialkenntnissen mit ihren Zuhörern abzuhalten pflegen, war man bis jetzt auf die Benutzung von Florenwerken angewiesen. Bei aller Wertschätzung, welche unseren deutschen floristischen Handbüchern ganz gewiss gebührt, wird man indes doch nicht leugnen können, dass dieselben, weil eben für einen anderen Zweck geschrieben, für den Gebrauch als Handbücher in den erwähnten Bestimmungsübungen naturgemäss nur als ein Notbehelf zu gelten vermögen -, von anderem abgesehen, schon aus dem Grunde, weil sie nahezu nichts enthalten von der sehr grossen Zahl ausländischer Gewächse, die der Docent an der Hochschule, dem ja ausser der einheimischen Flora jederzeit noch ein botanischer Garten mit seinem reichen Pflanzenmaterial zur Verfügung steht, seinen Zuhöhrern gern vorlegen möchte und muss. Diesè Lücke auszufüllen ist das vorliegende Büchlein bestimmt. Es enthält wohl alle Gattungen und die meisten und wichtigsten Arten der Phanerogamen, Archegoniaten, Flechten und grösseren Pilze, welche entweder wildwachsend in der deutschen Flora häufiger vorkommen oder zu dem eisernen Bestande der botanischen Gärten zählen, also jedenfalls für 
die betreffenden Kollegien mit geringer Mühe frisch zu beschaffen sind. Um eine so reichliche Auswahl zu ermöglichen, ohne durch übermässige Ausdehnung des Handbuches seine Anschaffung seitens der Studierenden zu erschweren und somit seinen Zweck zu beeinträchtigen, sah ich mich gezwungen, sowohl bezüglich der zu verwendenden Charaktere mich auf die Anziehung der wichtigsten und auffälligsten zu beschränken, folglich von ausführlichen Beschreibungen abzusehen, als auch den sprachlichen Ausdruck in die möglichst knappe Form zu bringen (hoffentlich, ohne dabei unverständlich zu werden). In solchem Falle, wo immer die Wichtigkeit und Zweckmässigkeit der anzuführenden Pflanzen wie nicht minder der vorzubringenden Merkmale und des sprachlichen Ausdruckes in Erwägung zu ziehen ist, wird wohl zunächst immer gelten „Quot capita, tot sensus"; nur jahrelange, allgemeine Erfahrung wird hier das endgiltige entscheidende Wort zu sprechen vermögen. Ich bin zufrieden, wenn mir seitens meiner Herren Kollegen kein prinzipieller Widerspruch in diesem Pụkte entgegentritt; für Belehrungen im Einzelfalle werde ich sehr dankbar sein.

Da das Büchlein ausdrücklich zunächst als Handbuch für die unter Anleitung des Docenten gehaltenen Bestimmungsübungen verfasst ist, glaubte ich von der nochmaligen Erklärung der Kunstausdrücke absehen zu dürfen, in der Annahme, dass der Studierende dieselben entweder schon vom Kolleg her kennt oder gegebenenfalls vom Docenten sofort Aufschluss erhält; denn hierbei ist das mündliche, nötigenfalls durch Beispiele oder Zeichnungen erläuterte Wort viel erfolgreicher als eine schriftliche Erklärung. 'Zur Unterstützung dieser mündlichen Erläuterungen in besonders schwierigen Fällen sind einige Figuren beigegeben.

Die Bestimmungstabellen führen zunächst auf die Klasse, dann die Familie und schliesslich auf die Gattung und event. Art; nur bei den Gramineen und Compositen hielt ich es 
für zweckmässig, eine besondere Bestimmungstabelle der Gruppen einzuschalten. - Soweit möglich, ist hinter dem Familiennamen die Zahl der in der Familie enthaltenen Gattungen und Arten, hinter dem Gattungsnamen die Zahl der von der Gattung umfassten Arten in Klammern beigefügt. - Um Raum zu sparen, ist in dem Falle, wo von den Arten einer Gattung nur eine einzige für erwähnenswert gehalten wurde, der Name unmittelbar hinter den Gattungsnamen gesetzt. Um nun in dem zuletzt vorausgegangenen Texte das allein für die Art Geltende gegenüber dem auf die ganze Gattung Bezüglichen kenntlich zu machen, ist Ersteres durch einen Gedankenstrich von Letzterem getrennt gehalten. - Aus dem gleichen Streben nach Raumersparnis heraus habe ich pflanzengeographische Notizen nur bei den ausserdeutschen Arten angeführt und in dem Falle, wo die Tabelle nur bis auf die Gattung führt, die sich ja gewöhnlich über ein umfangreicheres Gebiet als die einzelne vorgelegte Art verbreitet, lieber ganz weggelassen. - Eine Angabe über die Blütezeit bez. Zeit der Sporenentwickelung hielt ich nur bei den Kryptogamen und Gymnospermen für erforderlich.

In den weitaus meisten Fällen hielt ich es für lehrreich, die Namen der Unterfamilien und Gruppen am Schlusse der jeweils für die ganze Abteilung geltenden Charakteristik in Parenthese beizufügen. - Nicht minder hielt ich es für erspriesslich, in besonders interessanten Fällen auch mikroskopische Merkmale mit herbeizuziehen, da nach meinen Erfahrungen heutigentags jeder Teilnehmer an botanischen Bestimmungsübungen, sei er stud. rer. nat. oder pharm. oder auch med., mit dem Gebrauch des Mikroskopes vertraut ist, die Verwendung mikroskopischer Merkmale aber in den betreffenden Fällen immer eine absolut sichere Bestimmung ermöglicht; doch möchte ich in dieser Verwendung nicht zu weit gehen. So will ich denn hoffen, dass dieses Büchlein die schnelle und sichere Bestimmung eines reichhaltigen, besonders wich- 
tigen Pflanzenmateriales ermöglichen und zugleich die feste Einprägung der für den Studierenden der Botanik nötigen, systematischen Kenntnisse fördern werde.

Schliesslich drängt es mich, Herrn Geh. Reg.-Rat Prof. Dr. A. Engler, meinem hochverdienten Lehrer, an dieser Stelle meinen herzlichsten Dank für die Anregung und Unterstützung in dieser Arbeit auszusprechen, namentlich auch für die Überlassung der im vorliegenden Handbuch eingeflochtenen Abbildungen aus den „Natürlichen Pflanzenfamilien“. Auch Herrn Prof. Dr. F. Pax bin ich zu Dank verpflichtet.

Braunsberg, im April 1895.

F. Niedenzu. 


\section{Erkliirung der Abkiirzungen und Zeichen.}

A. = Anthere, Staubbeutel

$\mathrm{Ae} .=\ddot{A} h r c h e n($ der Gramineen)

B. = Blatt

Bl. = Blüte

Blb. = Blumenb.

Blh. = Blütenhïlle

Blhb. = Blütenhülllb.

Blkr. = Blumenkrone

E. = Embryo, Keimling

Fr. = Frucht

Frk. = Fruchtkelch

Frkn. = Fruchtknoten

Gr. = Griffel

K. $=$ Kelch

Kb. $=$ Kelchb.

Kf. $=$ Köpfehen (der Com-
$\mathrm{Kr} .=$ Krone $=$ Blkr.

$\mathrm{Krb} .=$ Kronenb.

N. = Narbe

$\mathrm{S} .=$ Same

Sa. $=$ Samenanlage

Stb. $=$ Staubb.

Stf. = Staubfaden, Filament

б = mäunlich

$q=$ weiblich

$\S=$ zwitterig

$\$$ = Untergattung oder Section

$\odot=$ einjährig

(.) = zweijährig

$4=$ ausdauernd

$\pm=$ mehr oder weniger

$0=$ fehlend

positen)

$\infty=$ zahlreich.

Die übrigen Casus sowie der Plural der abgekürzten Wörter sind nur durch das Zeichen des Singularnominativs bezeichnet.

Die angegebenen Abkürzungen sind vielfach auch in $\mathrm{Zu}$ sammeusetzungen angewendet, z. B. Hüllb., Teilfr., B.grund. B.chen, Bl.stiel, K.zipfel, N.lappen u. s. w.

Pflanzengeographische Abkürzungen, z. B. O.-As., MI.-Eur.. S.-Afr., N.-Am. etc. sowie gelegentliche anderweitige Kürzungen bedürfen gewiss keiner Erläuterung.

Die römischen Ziffern in den Artcharakteristiken der Pilze, Bryophyten, Pteridophyten und Gymnospermen gehen die Monate der Bl.- bez. Sporenentwickelung an. 



\section{Uebersicht der Klassen.}

A. Thallophytische, chlorophyll- und gefässlose Parasiten oder Saprophyten mit rein ungesch]echtlicher Fortpflanzung (mittelst sporen).

I. Tungi [incl. Lichenes] (S. 3, 17).

B. Neist chlorophyllgrüne Autophyten mit Generationswechsel, seltener chlorophyllose Parasiten oder Saprophyten, dann aber stets Gefäss-Cormophyten. [Embryophyta.]

a. Generationswechsel deutlich sichtbar, indem sowohl die geschlechtslose embryonale, wie die geschlechtliche prombryonale Generation unfangreichere Gebilde sind. Proembryonale Generation allermeist chlorophyllualtig und autophytisch.

Keimzellen Spermatozoiden mit sellustïndiger Bewegung. [Embryophyta zoidiogama $=$ Archegoniatae. $]$

a. Proembryonale Generation die stets chlorophyllhaltige, gefässlose, oft cormophytische, meist aus einem fädlichen Vorkeim (Protonema) hervorgegangene Pflanze, welche die emloryonale Generation als ein aus dem Archegonium hervorwachsendes, isospores, kapselartiges, nicht selten gestieltes Sporogon trägt. [Bryophyta.]

I. Sporogon stets olne Haube (Calyptra) und Mittelsäulchen (Columella), entweder in der Archegonienwandung eingeschlossen bleibend oder sie am Scheitel durchbrechend, oft mit Schleuderzellen zwischen den Sporen, meist mit Klappen sich öffnend; Kapselstiel fehlend oder zart. II. Hepaticae (S.21).

II. Sporogon stets (ausser bei den Sphagnaceae) mit Haube d.i. der an ihrem Grunde abgesprengten und von ihm emporgehobenen Archegonienwand, stets (ausser bei deu Archidiaceae) mit Columella, stets ohne Schleuderzellen, meist mit abspringendem Deckel sich öffnend; Kapselstiel derb. selten fehlend. Proembryonale Generation stets cormophytisch.

III. Musci (S. 31).

$\because$ Proembryonale Generation ein winziges (chlorophyllhaltigautophytisches oder parasitäres) Prothallium. Embryonale Generation die grosse, cormophytische, chlorophyllhaltige Gefässpflanze. [Pteridophyta.]

I. B. im Verhältnis zum Stamm kräftig entwickelt, oft sehr ansehnlich und reich gegliedert, in der Jugend meist spiralig eingerollt. Sporangienb. nicht auf besondere Sprosse oder 
abgeschlossene Regionen der Sprosse beschränkt; Sporangien an deren Rande oder Unterseite, meist in Soris und einzelligen Ursprungs.

IV. Filicales (S. 50).

II. B. im Verhältnis zum Stamm meist klein, stets einfach. Sporangienb. besondere abgeschlossene Formationen bildend; Sporangien aus Zellkomplexen gebildet.

1. Stengel gegliedert, an den Knoten mit einem Quirl zu einer geschlossenon, gezähnten Scheide verwachsener B. Sporangien $\mathrm{zu}$ mehreren auf der Unterseite schildförmiger, in Quirlen zu einer endständigen, ährenartigen Bl. angeordneter Schuppenb.

V. Equisetales (S. 58).

2. Stengel ungegliedert; B. meist spiralig. Sporangien einzeln am Grunde der Blattoberseite oder in der Blattachsel. Sporophylle meist endständige Bl. bildend. Wurzeln dichotom.

VI. Lycopodiales (S. 59).

b. Generationswechsel in der Fruchtbildung versteckt, indem 0 , wie $q$ Prothallien auf unselbständige, winzige Gebilde (Pollenkorn und Embryosack) reduziert sind. Keimzelle ohne Eigenbewegung (Pollenschlauch). Embryonale Generation eine (nur bei Lemna halbthalloidische, sonst immer) cormophytische Gefässpflanze. [Embryophyta siphonogama = Phanerogamae.].

$\alpha$. Sa. (wenigstens in der Bl.) offen liegend. Frb. (wenigstens in der Bl.) nie geschlossen, zuweilen fehlend, stets ohne $\mathrm{N}$. Sämtlich Holzgewächse. [Gymnospermae.]

I. Gefässe im sekundïren Holz und eigentliche Blh. fehlend.

1. Stamm meist einfach, selten schwach verzweigt. B. fiederteilig oder gefiedert, am Stammgipfel einen Schopf bildend.

VII. Cycadales (S. 60).

2. Stamm verzweigt. B. meist ungeteilt und schmal, spiralig längs des Stammes gestellt.

VIII. Coniferae (S. 61).

II. Gefässe auch im sekundären $\mathrm{Holz}$ und wirkliche Blh. vorhanden. B. ungeteilt. Bl. in Blütenständen, \pm von Hochb. bedeckt. IX. Gnetales (S. 66).

B. Sa von den vollständig (nur bei Reseda nicht ganz) geschlossenen Frb. bedeckt. Gynaeceum stets mit N. Stets Gefässe im sekundären Holz und fast immer Blh. vorhanden. [Angiospermae.]

I. Stamm mit geschlossenen Fibrovasalsträngen. B. allermeist parallelnervig. E. mit nur 1 Keimb.

X. Monocotyledoneae (S. 66).

II. Stamm mit offenen Fibrovasalsträngen. B. allermeist netzaderig. E. mit 2 Keimb. (höchst selten mit 3 oder infolge Abortes mit nur 1 oder olne Ausgliederung von Keimb.)

XI. Dicotyledoneae (S. 124). 


\section{Grössere Pilze oder Schwämme (Fungi-Mycomycetes).}

I. Fortpflanzung durch Endosporen, welche in bestimmter Zahl in Schläuchen (Asci) entstehen. [Ascomycetes.]

1. Fruchtkörper kegelig oder flaschenförmig, am Scheitel von einem Porus durchbrochen, mit einer meist papillösen Mündung. Häufig Sclerotien. [Pyrenomycetes.]

A. Fruchtkörper in ein Fruchtlager vereinigt. samt diesem fleischig und lebhaft gefärbt. [Hypocreales.] Hypocreaceae (S. 5).

B. Fruchtkörper von einem etwaigen Fruchtlager gesondert, häutig, lederig oder holzig. [Sphaeriales.] Xylariaceae (S. 6).

2. Fruchtkörper scheiben- oder becherförmig, anfangs geschlossen, zur Reifezeit sich öffnend. [Discomycetes.]

A. Fruchtkörper auf der anfangs verschlossenen Innenseite die Fruchtschicht tragend.

a. Fruchtkörper im feuchten Zustande gallertartig, durch Austrocknen hornig.

Bulgariaceae.

Fruchtkörper in Rasen auf Fagaceenholz, kreiselförmig. dunkelbraun, $1-2^{1 / 2} \mathrm{~cm}$ breit. Spätherbst.

b. Fruchtkörper fleischig.

Bulgaria inquinans $\mathrm{Fr}$.

Pezizaceae (S, 6).

B. Fruchtkörper auf der Aussenseite mit der Fruchtschicht iiberkleidet.

Helvellaceae (S. 7).

3. Fruchtkörper mit vollständig geschlossener Hiille ohne Mündung, das Gehäuse zuletzt verwitternd. [Perisporiales]. Fruchtkörper gekammert, \pm kugelig.

Tuberaceae (S. 5).

II. Fortpflanzung durch Conidien, welche in bestimmter Zahl an Basidien gebildet werden. [Basidiomycetes.] Basidien bei den grösseren Basidiomyceten zu einem häutigen Fruchtlager $\left(\mathrm{Hy}^{-}\right.$ menium) vereinigt.

1. Basidien quer- oder längsgeteilt, an jeder Teilzelle eine Basidiospore. [Protobasidiomycetes.]

A. Basidien aus Dauersporen hervorgehend, quergeteilt. [Uredinaceae.]

B. Basidien direkt am Mycel entstehend. Fruchtkörper gallertartig.

a. Basidien quergeteilt in meist 4 übereinander stehende Zellen.

Auriculariaceae (Auricularia).

b. Basidien durch zwei Längswände geteilt. Tremellaceae (S. 7).

2. Basidien ungeteilt, \pm keulig, mit (meist 4) apical gestellten Sterigmen [Autobasidiomycetes]

A. Basidien langkeulenfg.,mit 2 lang.,gegabelten Sterigmen. Fruchtkörper gallertartig. [Dacryomycetes.] Dacryomycetaceae (S.7). 
B. Basidien nicht lang keulenförmig, mit (meist 4) kurzen, ungeteilten Sterigmen. Fruchtkörper meist nicht gallertartig.

a. Hymenium entweder von Anfang an frei oder anfangs beschleiert, zur Zeit der Sporenbildung aber frei. [Hymcnomycetes.]

I. Hymenophor glatt oder schwach warzig oder runzelig.

1. Fruchtkörper häutig oder lederig, flach, muschel-, trichteroder hutförmig. Thelephoraceae (S. 7).

2. Fruchtkörper fleischig oder zäh, keulenförmig oder \pm ästig verzweigt. Clavariaceae (S. 8).

II. Hymenophor deutliche Warzen, Stacheln oder sägezahnartige Platten bildend, die aussen von dem Hymenium überzogen sind. $\quad$ Hydnaceae (S. 8).

III. Hymenophor Falten oder Röhren bildend, deren Höhlungen vom Hymenium überzogen sind.

1. Fruchtkörper fleischig, lederig oder holzig. Hymenophor faltig, grubig oder röhrig.

2. Fruchtkürper häutig oder fleischig. Hymenophor strahlige, gegen den Rand hin dichotomisch verzweigte Falten oder Leisten bildend. Cantharellaceae (S. 11).

3. Fruchtkiirper meist fleischig. Hymenophor einfache radiale Lamellen bildend.

Agaricaceae (S. 11).

b. Fruchtkörper vor der Reifo kugelig orler eiförmig, wenigstens bis zur Sporenbildung von einer fleischigen Hülle (Peridie) vollständig umschlossen.

a. Peridie bei der Reife durchbrochen und als grundständige Scheide zurückbleibend. [Phalloideae.]

I. Fruchtkörper eine einfache kugelige Masse darstellend, die bei der Reife durch Aufquellen der mittleren und Emporwälhung der inneren Hüllenschicht fortgeschleudert wird.

Sphaerobolaceae.

Fruchtkörper orangegelb, sternförmig zerreissend. Faulendes Holz, Kräuterstengel etc. in Gärten und IVäldern. $\mathrm{VIl}$-XI.

Sphaerobolus Carpobolus L.

II. Fruchtkörper in einen stielförmigen, bei der Reife sich schnell streckenden Fruchtträger (Receptaculum) und einen nur an der Spitze mit diesem zusammenhängenden, fingerhutförmigen Sporenträger (Glebia) gesondert, der labyrinthförmige, mit einem schnell zerfliessenden Hymenium ausgekleidete Kammern und Gänge enthält.

Phallaceac.

Hut schmutzig-weisslich, von dunkel-olivengrïnem Sporenschleim ïberzogen. Gärten und Wälder. IX-X. „Stink-, Gicht- od. Giftmorchel."

Phallus impudicus L.

F. Peridie bis über die Reifezeit der Sporen fest geschlossen, zuletzt regelmässig oder unregelmässig zerreissend; Gleba meist mit Kammern oder gewundenen Gängen, die von dem Hymenium an den Wänden überzogen oder ausgefüllt sind. [Gasteromycetes.]

I. Fruchtkörper bei und nach der Sporenreife von einem System reichlicher haarartiger Fäden (Capillitium) durchsetzt. 


\section{Tuberaceae. - Hypocreaceae.}

1. Fruchtkïrper auf gesondertem streckbarem Stiel; Gleba ohne Kammern und Gänge. Sterigmen in ungleicher Höhe an der Seite der Basidien entspringend.

Tylostomaceae.

Fruchtkörper rundlich, äussere Peridie in Fetzen abfallend, innere derbhäutig. Haide, Dämme. X-III.

Tylostoma mammosum (Micheli) Fries

2. Fruchtkïrper abgerundet, olne gesonderten Stiel; Gleba aus kleinen Kammern bestehend. Sterigmen am Scheitel der Basidien entspringend.

II. Fruchtkörper ohne eigentliches Capillitium.

Lycoperdaceae (S. 15).

1. Fruchtkörper bei der Reife erhärtend; Gleba in rundliche, \pm ausdauernde Kammern geteilt.

1'. Fruchtkörper' rundlich, oft mit stielförmigem Grunde; Kammern anfangs mit basidientragenden Knäueln erfüllt.

Sclerodermataceae.

Hülle korkig, aussen fast glatt, schmutzig lederbraun, oberwärts meist rissig aufspringend. Innemmasse anfangs weiss, später schiefergrau, zuletzt schwarz. Weideplätze, Waldwege. VII-XI.

Scleroderma vulgare Hornem.

2'. Fruchtkörper bei der Reife becherförmig, weitmündig; Wandungen der linsenförmigen Kammern (Sporangiolen) rom Hymenium flach ïberzogen.

Nidulariacene (S. 16).

2. Fruchtkörper bei der Reife fleischig, zuletzt faulend, knollenförmig, ungestielt; Gleba mit labyrintlıförmig gewundenen, anastomosierenden Gängen, deren Wandungen rom Hymenium überzogen sind.

Hymenogastraceae (S. 16).

\section{Tuberaceae.}

A. Kammerwände des Fruchtkörpers dünn, spinnweheartig, Rinde korkartig oder holzig. Sporen \pm glatt.

Elaphomyces.

Fruchtkörper etwa ron Wallnussgrösse, von aussen anfangs gelblich, später bräunlich, stumpfwarzig. (tebirgswälder. Herbst.

E. granulatus Fr.

B. Kammerwände und Pinde des Fruchtkörpers fleischig, erstere teils dunkler, teils heller. Sporen deutlich stachelig oder netziggrubig. "Trüffel.“

Tuber.

\section{Hypocreaceae.}

A. Fruchtkörper dem polster- oder halbkugelförmigen Fruchtlager aufsitzend. Sporen 2-zellig.

Nectria.

Zinnoberrot oder bräunlich. Auf Aesten und 'Zweigen. Herbst.

B. Fruchtkörper dem Fruchtlager eingesenkt.

N. cinnabarina Tode

$A_{1}$. Fruchtlager ansgebreitet oder polsterfürmig.

A2. Auf den Blättern von Prunus domestica und spinosa. Das

Fruchtlager im Spätsommer anfangs ein rotgelbes, $2 \mathrm{~cm}$ breites Polster, auf den abgefallenen Blättern fast schwärzlich, die Sporen erst im Frühjahr reifend.

Polystigma rubrum DC. 
B2. An Blattscheiden lebender Wiesengräser. Fruchtlager anfangs weiss, später goldgelb, durch die Fruchtkörper rötlich punktiert. Spätsommer.

B1. Fruchtlager keulig oder kopfförmig, gestielt.

A2. Fruchtlager keulig, direkt heranwachsend, Fruchtkörper etwas aus ihm hervorragend. Sporen vielzellig, in Glieder zerfallend. Im Herbst auf toten Raupen und Schmetterlingen in feuchter Walderde. Cordyceps militaris Fr.

B. Fruchtlager kopfig, aus dem ausgesäeten Dauerlager (Sclerotium, "Mutterkorn") hervorwachsend. Fruchtkörper kopfig, dem Fruchtlager eingesenkt. Sporen 1-zellig. Besonders am Frkn. des Roggens. "Mutterkorn." Claviceps purpurea Fr.

\section{Xylariaceae.}

A. Fruchtlager ausgebreitet, polsterförmig bis kugelig.

A1. Fruchtlager ausgebreitet, polsterförmig, bis $8 \mathrm{~cm}$ breit und $2 \mathrm{~cm}$ dick, anfangs korkartig, später kohlig. Sporen spindelförmig, schwarz. An Laubholzstümpfen etc. Herbst.

Ustulina vulgaris Tul.

B1. Fruchtlager meist halbkugelig bis kugelig, zuerst braun, später schwarz. Sporen braun.

Hypoxylon.

a. Fruchtkörper mit warzenartig vorstehender Mündung. Fruchtlager bis $3 \mathrm{~cm}$ lang, $1 \mathrm{~cm}$ breit. Sporen spindelförnig. Auf Laubholz. Im ganzen Jahr.

H. multiforme Fr.

b. Fruchtkörper mit nabelartig vertiefter Mündung. Fruchtlager bis $8 \mathrm{~mm}$ breit. Sporen länglich. Auf blossem Holz. Durch's ganze Jahr.

H. fuscum Pers.

B. Fruchtlager aufrecht, gestreckt, bisweilen verästelt, braun bis schwarz, $2-8 \mathrm{~cm}$ hoch. Auf altem Holz.

Xylaria.

\section{Pezizaceae.}

A. Fruchtkörper nur am Grunde stielartig zusammengezogen oder sehr kurz gestielt.

Peziza.

a. Fruchtkörper innen lebhaft orangerot, aussen blasser, und weisslich bereift, bis $6 \mathrm{~cm}$ breit. Auf schwerem Valdboden zwischen Moos herdenweise. Herbst.

$P$. aurantia Müll.

b. Fruchtkörper blassgelb oder hellbräunlich mit dunklerer Scheibe, am Rande gekerbt-körnig, bis $9 \mathrm{~cm}$ breit. Auf fettem Gartenund Ackerland. Sommer.

P. vesiculosa Bull.

B. Fruchtkörper mit einem bis $11 / 2 \mathrm{~cm}$ hohen Stiel, bis $2 \mathrm{~cm}$ breit, hell fleischfarben, etwas filzig, Scheibe scharlachrot. Auf faulendem Holz in feuchtem Waldboden. Frühjahr.

Sarcoseypha coccinea Fr.

\section{Helvellaceae.}

A. Eigentlicher Fruchtkörper zusammengedrückt-keulenförmig, schwärzlich. Sporen fädlich-spindelförmig.

a. Fruchtkörper rauhhaarig. Moorwiesen. Spätsommer. 
b. Fruchtkörper kahl. Grasplätze. Herbst.

G. glabrum Pers.

B. Eigentlicher Fruchtkörper („Hut) kegel- oder: mützenförmig: Sporen ellipsoidisch.

A1. Hut eikegelig bis glockig, durch stark vortretende Rippen eckig-gefeldert.

Morchella.

Hut dem glatten, weisslichen Stiel längs angewachsen, stumpfkegelig, graugelb bis gelbbraun. Grasplätze zwischen Gehölz. IV-VI. "Morchel."

M. esculenta Pers.

B1. Hut blasig, mützenförmig, glatt, grubig oder wellig. Helvella.

Stiel bis $6 \mathrm{~cm}$ hoch, später hohl, blassrütlich, feinfilzig; Hut dem Stiel t längs angewachsen, durch darmartig in einander verschlungene Wülste kraus, rot- oder dunkelbraun, bis $8 \mathrm{~cm}$ breit. Sandige Nadelwälder. Frühjahr. H. esculenta Pers.

\section{Tremellaceae.}

A. Fruchtkörper etwas gestielt, scheiben- oder muschelfürmig, auf der ganzen Oberseite rom Hymenium iiberzogen, erst braun, später dunkler, bis $2 \mathrm{~cm}$ breit. Hymenium warzig. An abgefallenen Laubzweigen.

Exidia gelatinosa Bull.

B. Fruchtkörper gehirnartig, wellig-faltig, goldgelb oder orange, am Grunde weisslich, bis $4 \mathrm{~cm}$ breit. An abgefallenen Laubzweigen. $\mathrm{XI}-\mathrm{V}$.

Tremella mesenterica Schaeff.

C. Fruchtkörper \pm halbkreis-hutförmig, etwas gestielt, unterseits mit pfriemeligen, rom Hymenium überzogenen Stacheln, weissgrau, später bräunlich, bis $7 \mathrm{~cm}$ breit, oberseits körnig. An faulenden Coniferenstümpfen. VII-XI. Tremellodon gelatinosus Scop.

\section{Dacryomycetaceae.}

A. Fruchtkörper rundlich, becher- oder schüsselförnig, allseitig vom Hymenium überzogen, später unregelmässig gefaltet, gelb, bis $10 \mathrm{~cm}$ breit. Auf altem Holz. Das ganze Jahr hindureh. Dacryomyces deliquescens (Bull.) Duby

B. Fruchtkörper flach-keulenförmig, I korallenartig verzweigt, goldgelb oder orange, klebrig, bis $6 \mathrm{~cm}$. Nadelbaumstümpfe. VIII-XII.

Calocera viscosa (Pers.) Fries

\section{Thelephoraceae.}

A. Sporenmembran farblos, glatt.

A1. Fruchtkörper krustenartig, der Lnterlage flach aufliegend, ungeschichtet, lederartig oder fleischig. An altem Holz und Rinde.

Corticium.

B1. Fruchtkörper im oberen Teile \pm muschel- oder halbkreisförmig frei vorstehend, verschieden geschichtet. An alten Stümpfen, Aesten.

Stereum.

$\mathrm{C}_{1}$. Fruchtkörper trıchter- oder kreiselförmig, aussen (unten) vom Hymenium überkleidet. Auf WTaldboden. Craterellus.

B. Sporenmembran, braun, stachelig. Meist auf Waldboden. 


\section{Clavariaceae.}

A. Fruchtkörper einfach keulenförmig oder mit stielrunden Aesten.

Clavaria.

Fruchtkörper verästelt, bis $12 \mathrm{~cm}$ hoch (Stamm bis $4 \mathrm{~cm}$ dick), weisslich, gelblich, oberwärts anfangs etwas rötlich. Waldboden. VII -X. O. Botrys Pers.

B. Fruchtkörper stark verästelt (Aeste blattartig, gekrümmt oder kraug), im ganzen kohlkopfartig, weisslich bis bräunlich, bis $3 \mathrm{dm}$ breit. Nadelwälder. VIII-XI. Sparassis ramosa (Schaeff.) Schröt.

\section{Hydnaceae.}

A. Hymenophor mit deutlichen Stacheln dicht u. regelmässig besetzt. A. Sporenmembran farblos.

Hydnum.

Fruchtkörper gestielt, weisslich bis ockerfarben; Hut bis

$15 \mathrm{~cm}$ breit. Sporemmembran glatt. Valdboden. VII-XI.

B1. Sporenmembran braun.

$H$. repandum $\mathrm{L}$.

Fruchtkörper central gestielt; Hut bis $20 \mathrm{~cm}$ breit. Sporen höckerig-stachlig. Kiefernwälder. IX-XI.

P. imbricatus (L.) Schröt.

B. Hymenophor mit flachen, \pm zahnartig ausgezackten Blättern.

Sistotrema.

Fruchtkörper 上 von der Unterlage abstehend, kurz gestielt, fleischrot, violett oder hriumlich. Kiefernstiimpfe. Das ganze Jahr hindurch. S. fuscoviolaceum (Schrader) Sommerfeld

\section{Polyporaceae.}

I. Fruchtköryer flache Gruben oder unregelmässig-netzartig verbundene Zellen und Gänge bildend. [Merulieae.]

A. Sporenmembran farblos.

Merulius.

Fruchtkörver gallertartig, anfangs fest aufgewachsen, später \pm lappig abstehend, weisslich oder graufilzig, Hymenium auch gelblich bis rötlich. Laubholzstümpfe und alte Laubbäume. Herbst.

M. tremellosus Schrader

B. Sporenmembran braun:

Serpula.

Fruchtkörper weichfleischig, später häutig-lederig, teils aufliegend, teils abstehend. Hymenium goldgelb oder rotbraun, am Rande schimmelig und dick. "Hansschwamm."

S. lacrimans (Wulf.) Karsten

II. Fruchtkürper mit tiefen Röhren oder Gängen.

1. Hymenium nicht als besondere Schicht vom übrigen Fruchtkörper ablöslich.

1'. Gänge oder Röhren dicht mit einander verwachsen. [I'olyporeac.]

A. Hymenophor langgestreckte, meist gewundene Gänge bildend.

A1. Gänge nur am Rande rundlich oder labyrinthförmig, in weiter zurückliegenden Teilen an die Blätter der Agaricaceac erinnernd.

A2. Substanz des Fruchtkörpers weiss, filzig-korkig; Oberfläche grau, ockerfarben oder bräunlich, regelmässig gezont. Laubholzstiimpfe. Herbst-Frühjahr. Lenzites betulina (L.)Fries 
B.. Substanz des Fruchthörpers braun, filzig-korkig; Oberfläche zottig-striegelhaarig, dunkelkastanienhram, gezont, hïckerisfilzig; Blätter rotbraun. Kiefernstümpfe.

Gloeophyllum saepiarium (Wulf.) Karsten B1. Gänge durchaus ziemlich gleichmässig labrrinthfg. Daedalea.

Fruchtkürper \pm halbkreisförmig abstehend, bis $2 \mathrm{dm}$ lang, $12 \mathrm{~cm}$ breit, am Ansatz $8 \mathrm{~cm}$ dick, korkig, blass holzfarbig, oberseits kahl, höckerig, undeutlich gezont. Fagaceenstümpfe. D. quercina (L.) Pers. B. Hymenophor Rühren bildend. [Polyporus i. weit. Sinne.] A1. Sporenmembran farblos.

A. Substanz des Fruchtkörpers weiss iseltener violett. rot oder gelblich).

a. Fruchtkörper ungestielt, flach ausgebreitet.

Polyporus.

a. Fruchtkörper der Unterlage völlig anliegend, holzig, bis $1^{1} \geq \mathrm{cm}$ dick. Baumstämpfe. I'. Medulla panis (Pers.) Fries Fruchtkürper von der Tnterlage wenigstens im oberen Teile abstehend; Röhren abwärts gerichtet

I. Fruchtkörper wïsserig-fleischig, schmutzigweiss oder hellbrämlich, imen gezont. Oberfäche rundlich, wellig. Tiefernstämpfe und Holz. $P$. destruetor (Schrader) Fries

II. Fruchtkörper von Anfang an trocken, saftlos.

1. Fruchtkörper faserig, nicht holzig.

+ Fruchtkörper lederartig; Oherfläche fein sammetartig. mit konzentrischen Zonen; Mündungen eng.

(E) Oberfläche des Fruchtkörpers seidenglïnzend, mit verschiedenfarbigen, konzentrisclien Zonen. Alte Baumstümpfe.

P. versicolor (L.) Fries

(- Oberfläche des Fruchtkörpers nicht glänzend, mit schwachen Zonen. Alte Baumstümpfe.

$P$. zonatus (Nees) Fries

$+\frac{1}{+}$ Fruchtkörper korkig; Oberfläche zottig, weiss oder grau, ohne Zonen; Mündungen ziemlich weit. Alte Weiden.

2. Fruchtkörper holzig, überwinternd.

$P$. suaveolens (L.) Fries

+ Fruchtkörper ziemlich dünn, schalenfürmig; Oberfläche mit zahlreichen Zonen. Forstgefährlich, auf Nadelhölzern.

$P$. annosus Fries ++ Fruchtkörper dick, polster-, huf- oder konsolenfg. Nadelhölzer.

b. Fruchtkörper gestielt.

P. pinicola (Swartz) Fries

a. Stiel seitenständig.

I. Fruchtkörper anfangs weichfleischig, trocken briichig; zahlreiche (bis 100) Exemplare am Grunde in einen melirfach verzweigten Strunk vereinigt; Oberfläche graubraun, kahl. Laubwaldboden, besonders bei Eichen. VIII X.

$P$. frondosus (Fl. dan.) Fries

II. Fruchtkörper anfangs zähfleischig, später fast holzig; Oberfläche hell-oder ockergelb mit breiten, braumen, angedrückten Schuppen. Lebende Laubbäume, bes. Wallnuss. IV-X. 
ß. Stiel mittelständig. Fruchtkörper fleischig, trocken brüchig. Wïlder und Hohlwege. VIII, IX. P. ovinus (Schaeff) Fries B2. Substanz des Fruchtkörpers rostbraun Ochroporus.

a. Fruchtkörper hufförmig oder polsterartig. Röhren mehrschichtig; Mündungen fein, anfangs grau bereift.

a. Substanz wergartic-korkig. Feuerschwamm. An allen Baumstïmmen, bes. Rotbuche und Birke. O fomentarius (L.) Schröt.

§. Substanz sehr hartholzig. An Laubbäumen, bes. Bruchweide, Pflaum- und Apfelbaum, diesen schädlich.

O. igniarius (L.) Schröt.

b. Fruchtkörper flach halbkreisförmig, korkig-holzig. Röhren nicht mehrschichtig, Mündungen \pm weit, anfangs gelb. Alte Kiefernstämme, ihnen sehr schädlich. O. Pini (Thore) Schröt. B1. Sporenmembran braun.

Phaeoporus.

Fruchtkörper korkig-holzig, rostbraun, gestielt; Stiel seitenständig. Am Grunde alter Laubbäume.

$P$. lucidus (Leysser) Schröt.

2'. Röhren isoliert stehend. [Fistulineae.]

Fistulina.

Fruchtkörper anfangs fleischig, voll blutroten Saftes, seit-

lich zungen-oder polsterfürmig von der Unterlage abstehend, mit anfangs körnigen, spätor zapfenartigen Hervorragungen des Hymenophors. Eichenstämme. VIII-X.

F. hepatica (Schäff.) Bull.

2. Hymenophor eine vom Hut leicht abtrenmbare Röhrenschicht. Fruchtkörper fleischig. Röhren fest aneinander liegend, unter sich trennbar. [Boleteae]

Membran der Sporen gelb oder bräunlich, Pulver braun. Boletus.

a. Röhren anfangs weiss, später grau werdend. Mündungen gleichfarbig.

๘. Hut später flach; Fleisch weichschwammig, unveränderlich weiss oder schmutziggrau werdend; Oberfläche später schmierig, meist trübbraun; Schleier fehlend. VI-XI. Essbar. "Kuhpilz, Graseschwappe, Graukappe."

B. scaber Bull.

अ. Hut stets gewölbt, mit Schleier; Fleisch fest, weiss, bei Verletzung meist bläulich oder rötlich werdend; Oberfläche später schuppig, meist rotbraun. Besonders unter Birken. VII-XI. Essbar. "Rotkappe."

B. rufus Schaeff.

b. Röhren von Anfang an oder vor der Sporenreife \pm gelb.

a. Schleier fehlend.

I. Stiel knollig-bauchig, später keulig. Röhren nach dem Stiele $\mathrm{zu}$ verkürzt, scharf von diesem abgesetzt, anfangs weiss, später grünlichgelb.

1. Mündungen wie die Röhren. Fleisch unveränderlich weiss. Waldboden. VII-XI. Essbar. "Eich- od. Steinpilz."

B. bulbosus Schäff.

2. Röhren wie bei vor., Mündungen lebhaft gelbrot. Fleisch weiss, bei Verletzung rötlich, dann bläulich werdend. Waldboden. VIII, IX. Giftig. B. Satanas Lenz

II. Stiel nicht knollig. Röhren an den Stiel angewachsen, gelb oder gelbbraun. Hut von einer glatten, anfangs klebrigschleimigen Haut ïberzogen. 
1. Stiel glatt.

+ Hut polsterförmig, am Rande eingerollt; Fleisch schwach blau, Röhren grün werdend. Waldboden. VIII-X. Essbar.

B. badius Fries

++ Hut ziemlich flach; Fleisch rötlich werdend, Röhren graugelb. Kiefernwälder. VIII-XI. Essbar. B. bovinus L.

2. Stiel besonders oberwärts mit körnigen Schüppchen. Oberfläche des Hutes gelb. Fleisch hellgelb; Röhren anfangs mit weissem Saft, später hellgelb. In und an Wäldern zwischen Rasen und Moos. VI-X.

B. granulatus L.

P. Hut mit häutig-fädigem Schleier.

I. Stiel oberhalb des Ringes mit anfangs weissen, später bräunlichen, flockigen Punkten. Fleisch des Hutes weiss; Röhren fein, rundlich. Waldränder und Waldwiesen. VI-XI. Essbar, $B$. luteus L.

II. Stiel oberhalb des Ringes mit rotbrauner Netzzeichnung. Fleisch des Hutes lebhaft gelb; Röhren gross, eckig. Nadelwälder. VII-XI. Essbar.

B. flavus With.

\section{Cantharellaceae.}

Fruchtkörper fleischig, mit mittelständigemStiele.Cantharellus.

a. Fruchtkörper festfleischig, dottergelb oder orange. Falten dick, niedrig, aderförmig, abgerundet, entfernt von einander stehend, vielfach dichotom verzweigt. Waldboden. TI-XI. Essbar. "Pfifferling, Galluschel." C. cibarius Fries

b. Hut weichfleischig, orange, etwas filzig. Falten blattartig, mit dünner Schneide, regelmässig wiederholt dichotom verzweigt, ziemlich eng aneinander stehend. Wälder, namentl. Nadelw., zwischen Moos und an alten Baumstïmpfen. VIII-XI.

C. aurantiacus (Wulf.) Fries

\section{Agaricaceae.}

I. Lamellen zuletzt zerfliessend, von verschiedener Länge. Basidien einzeln stehend, von einander durch zahlreiche unfruchtbare Zellen (Paraphysen) getrennt. [Coprineae.] Sporenpulver schwarz.

Coprinus.

Hut ohne Schleier, mit dichtem, anfangs weissem, mehligkleiigem, später grauem, zottig-schuppigem Ueberzug. Stiel zart, fädlich, bis $8 \mathrm{~cm}$ lang. Auf Mist. C. stercorarius iBull.) Fries

II. Lamellen gewöhnlich nicht zerfliessend. Basidien dichtstehend, nur mit einzelnen vorragenden unfruchtbaren Zellen (Cystiden) gemischt.

1. Lamellen sehr dick, fleischig, fast wachsartig, abwechselnd verschieden lang. [Hygrophoreae.]

A. Fruchtkörper ausser den gewöhnlichen Basidiensporen reichliche, kettenförmig zusammenhängende Chlamydosporen am Ende der Hyphenäste bildend. Auf anderen Agaricaceae.

Nyctalis.

B. Fruchtkörper nur regelmässige Basidiensporen bildend, ohne Schleier.

2. Lamellen häutig, mässig dick. 
1'. Grundsubstanz des Fruchtkörpers aus runden Bündeln weiter Rühren und diese umbüllenden dünnen Hyphen bestehend. [Russuleae.]

A. Fruchtkörper nicht milchend.

A1. Sporenpulver weiss oder gelblichweiss.

Russula. Hut dünnfleischig; Rand gefurcht; Oberfläche blutod. purpurrot; Lamellen grauweiss. Giftig, scharf schmeck. Feuchte Wiesen, Wälder. VII-XI. R. emetica (Schaeff.) Fries

$\mathrm{B}_{1}$. Sporenpulver ockerfarben.

Russulina.

a. Sporenpulver hell ockerfarben. Hut dünntleischig; Rand häutig, höckerig, gefurcht; Oberfläche rot oder violett bis gelblich oder bräunlich. Lamellen anfangs weiss, später gelblich. Essbar, mild schmeckend. Gebüsch VII-X. $R$. integra (L.) Schröt.

b. Sporenpulver lebhaft ockerfarhen. Hut fleischig; Rand dünn, später höckerig gestreift; Oberfläche blut-, purpur- oder rosenrot; Lamellen anfangs gelb, später lederfarben. Essbar, mild schmeckend. Wälder. VIII $-\mathrm{X}$.

$R$. alutacea (Pers.) Schröt.

B. Fruchtkörper bei Verletzung milchend. Sporeupulver weiss oder gelblichweiss.

Lactaria.

a Saft und Sporenpulver weiss.

a. Oberfläche des Hutes trocken, nicht klebrig.

I. Oberfläche des Hutes kahl, glatt, gleichmïssig rotgelb bis gelbhram; Rand glatt, eingerollt. Geschmack mild. Essbar. Wälder. VI-XI. "Milchreissker." L. volema Fries II. Oberfliiche des Hutes anfangs kleinflockig, rotbraun, schimmernd, ohne Zonen; Rand anfangs eingerollt, filzig. Geschmack sehr scharf, bremmend. Giftig. Nadelwälder. VII-XI.

T. Oberfiiche les Hutes sehwachklebris, hell il (Scop.) Fries Obernache des Hutes schwachklebrig, hell Áleischrot, gelblich oder weisslich, oft mit deutlichen, rötlichen Zonen; Rand anfangs eingerollt, mit weissen, striegelig-zottigen Haaren. Geschmack scharf. Giftig. Laubwälder, namentlich unter Birken. VII-XI. L. torminosa (Schaeff.) Fries

b. Fleisch gelbrot; Saft und Lamellen anfangs lebhaft gelbrot, bei Verletzung grïlich werdend, Sporenpulver hell ockerfarben. Oberfliche glatt, feucht schleimig, ziegel- oder orangerot, später grünlich, gezont. Geschmack mild. Lisshar. Wälder und Wiesen. VI-XI. "Reissker." L. deliciosa (L.) Fries

2'. Grundsubstauz des Fruchtkörpers aus ziemlich gleichartigem Hyphengewebe bestehend.

1“. Fruchtkörper zäh, bei der Reife lederig oder holzig, vertrocknend. [Marasmieae.]

A. Fruchtkörper sitzend, seitlich angeheftet. Lamellen bei der Reife der Länge nach in zwei nach aussen umgerollte Hälften gespalten. Laubbäume. Schizophyllum alncum (L.) Schröt. B. Fruchtkörper gestielt. Lamellen nicht gespalten.

A1. Hut dickfleischig, in den Stiel übergehend, seitlich gestielt oder unregelmässig. 
Pilz durchaus ockerfarben. Hut nieren- oder halbkreisförmig; Oberfläche anfangs glatt, später kleiig-schuppig. Laubholzstümpfe.

L. stypticus (Bull.) Schröt.

B. Hut \pm dünn, vom Stiel scharf abgesetzt, regehnässig schirmförmig.

Narasmius.

a. Hut häutig, sehr dünn; Rand anfangs anliegend, bald gerade, zuletzt flach ausgebreitet.

ж. Hut rötlichbraun, seltener weisslich; Stiel schwärzlich; Lamellen ungleich lang, an den Stiel angewachsen. Waldboden. $M$. androsaceus (L.) Fries

3. Hut weisslich, in der Mitte oft bräunlich; Stiel unten schwarz, oberwärts braun, an ter Spitze weiss; Lamellen gleich lang, hinten zu einer Röhre verwachsen. An abgefallenen Zweigen etc. VII-X. II. Rotula (Scop.) Fries b. Hut zälıfleischig, weisslich, fleischfarben oder brïunlich ; Rand anfangs eingerollt; Lamellen angewachsen; Stiel dunkelrotbraun, nach oben heller. Essbar. Waldränder und Haide, auf Graswurzeln und alten Baumstöcken. VI-X. "Muscheron."

2“. Fruchtkörper fleischig, faulend. [Agariceac.]

A. Sporenmembran gefärbt, die Farbe des Sporenpulvers bedingend. A. Sporempulver tief schwarz. Hut ohne Schleier. Coprinarius. $B_{1}$. Sporenpulver dunkel violettbraun. Hut durch einen Schleier mit dem Stiele verbunden.

A2. Schleier seidenfädig, schnell schwindend.

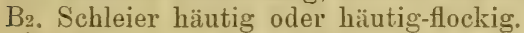

A3. Stiel ohne Ring; Schleier nur am Hutrande hängend.

Hypholoma.

a. Hutoberfläche, Fleisch und Stiel weisslich oder bräunlich. Am Grunde von Baumstümpfen. VI-X.

H. apperdiculatum (Bull.) Karsten

b. Hutoberfläche, Fleisch und Stiel gelb. An Baumstümpfen und unter Rasen faulendem Holz. V-XI.

H. fasciculare (Huds.) Sace.

B3. Schleier als deutlicher Ring am Stiele bleibend. Psalliota.

a. Hut anfangs fast kugelig oder halbkugelig; Oberfläche unverändert weisslich oder bräunlich; Hleisch weiss, bei Verletzung rötlich werdeud; Stiel voll; Lamellen anfangs rosenrot, später schwarzbraun. Triften, Gärten etc. VI-X. Essbar. "Champignon." P. campestris (L.) Schröt.

b. Hut anfangs cylindrisch-kegelig mit abgeflachtem Scheitel; Oberfläche weiss, durch Berührung gelb werdend; Fleisch unveränderlich weiss; Stiel hohl; Lamellen anfangs weisslich, später rötlich. zuletzt schwarzbraun. Wiesen, Wälder, Gärten etc. VIII-X. Essbar. P. arvensis (Schaeff.) Schröt.

$\mathrm{C}_{1}$. Sporenpulver trüb- oder gelbbraun oder ockerfarben.

A. Hut ohne merkliche Hülle oder Schleier.

Derminus.

Hut wässerig; Oberfläche honiggelb oder gelbbraun. Zwischen Moos und Gras. VII-XI. D. hypni (Batsch) Schröt. $B_{2}$. Hut mit dem Stiele durch eine Hülle verbunden. 
A3. Hülle zart seidenfädig.

A4. Sporenpulver und -membran trübbraun. Schneide der Lamellen mit Cystiden besetzt.

Inocybe.

Bt. Sporenpulver rost- oder zimmtbraun. Schneide der Lamellen ohne merkliche Cystiden.

Cortinarius.

Hut dünn-trockenfleischig, gelb oder gelbbraun, seidenhaarig oder kleinschuppig; Lamellen gelb bis blutrot. Wälder, bes. sandige, zwischen Moos. VJI-XI.

C. cinnamomeus (L.) Fries

B3. Hülle dickhäutig oder flockig, am Stiele als Ring zurückbleibend.

B. Sporenmembran farblos.

$A_{1}$. Sporeninhalt rotbraun und infolgedessen das Sporenpulver rost- oder fleischrot.

A2. Sporen eckig oder stachelig.

Hyporrhodius.

B. Sporen elliptisch oder eiförmig, glatt.

Rhodosporus.

$B_{1}$. Sporeninhalt gleichfalls farblos, darum Sporenpulver weiss.

A2. Sporenmembran stachelig punktiert. - Hut ohne Schleier, anfangs gewölbt, später flach ausgebreitet; Fleisch wässerig und, wie Oberfläche und Stiel, rötlich oder violett. Wälder, zwischen Gras und Moos. VI-XI.

Russuliopsis laccata (Scop.) Schröt.

B. Sporenmembran schwach punktiert oder glatt.

A3. Fruchtkörper ohne Schleier.

Agaricus.

a. Hut häutig oder dünnfleischig, am Rande meist gestreift; Rand anfangs dem Stiele anliegend, später gerade. Stiel dünn, knorpelig, am Grunde behaart.

a. Hut am Rande gestreift, hell rosenrot oder violett, seltener weiss oder in der Mitte rotbrämulich. Geruch rettigartig. Auf altem Laub. VIII-XI. A. roseus Bull.

३. Hut grau oder graubraun; Baumstämme. V-XII.

A. galericulatus Scop.

b. Hut fleischig, gelb oder olivenbraun, meist kleinschuppig, schleimig-klebrig. Stiel fleischig, in das Hutfleisch übergehend, feinschuppig, schwefelgelb. Kieferwälder. IX-XII. A. equestris L.

B3. Fruchtkörper mit Schleier, der am Stiel als Ring bleibt. A4. Fruchtkörper ohne äussere Hülle.

A5. Sporen dünnwandig, beim Trocknen zusammenfallend und undeutlich werdend.

Armillaria.

Hut honiggelb, mit haarig-zottigen, später bräunlichen Schuppen; Lamellen am Stiel herablaufend, anfangs weisslich, später fleischfarben. Stiel mittelständig, blass fleischfarben, über der Mitte mit einem weiten, weissen, flockighäutigen Ring. Essbar. Am Grunde alter Stämme IX-XI. "Hallimasch."

B. Sporen dickwandig, dauerhaft. A. mellea (Vahl) Quelet

Hut weisslich oder graubraun, Oberhaut bald in faserigzottige Schuppen zerreissend; Lamellen frei, vom Stiel durch einen feinen Ring getrennt. Stiel am Grunde knollig angeschwollen, weisslich mit bräunlichen Schup- 
pen und dickem, beweglichem Ring. Wälder, Haiden. VIII-X. IL. procera (Scop.) Quelet

B.. Fruchtkörper auch noch mit einer äusseren Hülle, die als Scheide am Grunde des Stieles und als ablösliche Fetzen oder Warzen an der Hutoberfläche bleiben.

Amanita.

a. Hutoberfläche scharlachrot mit weissen oder gelblichen Fetzen; Lamellen weiss. Besonders Birkenwälder. VII-XI. Sehr giftig. "Fliegenpilz." A. muscaria (L.) Pers.

b. Hutoberfläche weiss, gelblich oder grünlich. Stiel später an der Spitze hohl, mit häutigem, weissem oder gelblichem, gestreiftem Ringe, am Grunde knollig-angeschwollen, auf dem Scheitel der Knolle mit weiter, häutiger Scheide. Wälder. VII-XI. Aeusserst giftig. A. bulbosa (Bull.) Schröt.

\section{Lycoperdaceae.}

A. Aeussere Peridie der inneren angewachsen, nicht aufspringend. Basidien mit 4 Sterigmen.

A1. Basis des Fruchtkörpers unfruchthar, aus dickem, schwammigem Gewebe bestehend, meist stielförmig. Lycoperdon.

a. Fruchtkörper bei der Reife mit einer kleinen runden Mündung, im oberen Teile rundlich, im unteren fast stielförmigcylindrisch. Aeussere Peridie weiss, stachelig oder warzig. Capillitium und sporen olivenbraun. Trıften. Wälder, Haide. VI-IX, trocken durch's ganze Jahr. L. gemmatum Batsch

b. Oberer Teil der Peridie bei der Reife völlig zerfallend, so dass der geöffnete Pilz becherförmig erscheint. Fruchtkörper cylindrisch-sackförmig, am Scheitel flach. Aeussere Peridie weiss, später ockerfarben, oben felderig-schuppig, unten feinkürnig. Capillitium und Sporen olivenbraun. Wiesen, Weideplätze. IX-XI. I. caelatum Bull.

B. Selten am Grunde des kugeligen Fruchtkörpers eine kleine unfruchtbare, nicht stielförmige Partie, meist Gleba durchweg in Sporen und Capillitium zerfallend.

A2. Aeussere Peridie bei der Reife papierartig, glatt. Sporen bei der Reife gestielt.

Bovista.

Innere Peridie blaugrau, innere Masse bei der Reife dunkelbraun. Wiesen, Triften, Haide. VII-XI, trocken den Winter überdauernd.

B. piumbea Pers.

B.. Aeussere Peridie dickfleischig oder warzig, brüchig. Sporen bei der Reife ungestielt.

Globaria.

a. Durchmesser des Fruchtkörpers 1-2 $\mathrm{cm}$. Aeussere Peridie kleiig-flockig, weiss, später gelbbraun; Inireres gelblich-olivenbraun, nur am Grunde mic dünner, unfruehtbarer Schicht. Haide. Waldränder. IX-XI. G. furfuracea (Schaeff.) Quelet

b. Durchmesser des Fruchtkörpers $1-3 \mathrm{dm}$. Aeussere Peridie weich, sehr gebrechlich, fast glatt, weiss, später ockerfarben; Inneres gelblich-olivenbraun, durchaus fruchtbar. Gärten, Aecker. $V-X$.

G. Bovista (L.) Quelet

B. Aeussere Peridie von der inneren durch eine später scbwindende 
Gallertschicht getrennt, sternförmig anfreissend, nur am Grunde mit der inneren fest verbunden. Basidien mit 6-8 Sterigmen.

Geaster.

a. Innere Peridie ohne besonders entwickelte Mündung, am Scheitel umregelmässig orler sternförmig zerreissend. A eussere Peridie sehr dick, fast korkartig, aussen grau, innen rissig, Lappen bis zum firunde reichend. Wälder, bes. Nadelw., zwischen Moos. VIII-XI, trocken überwinternd. $G$. stellatus (Scop.) Schröt.

b. Innere Peridie mit \pm scharf abgegrenzter, kegeliger, gewimperter Mündung; ïussere Peridie papierartig-häutig, aussen weisslich, innen glatt, Lappen bis zur Mitte reichend. Wälder. VIII-X.

G. fimbriatus Fries

\section{Nidulariaceae.}

A. Sporangiolen frei. Fruchtkörper anfangs fast kugelig, später etwas niedergedrïckt. In Wäldem anf abgefallencm, faulenden Aesten.

Nidularia.

B. Sporangiolen durch einen Strang an die Peridie befestigt.

Ar. Fruchtkörper anfangs fast kugelig, später kurz cylinirisch. Peridie aus einfacher, dickfilziger Haut gehildet, am Scheitel mit kreisformig abgegrenztem, gleichartigem. schwindendem Deckel, ohne Schleier. Abgefallene Zwoige, Kräuturstengel, Holzsplitter, Balken etc. VII - XI. C'rucilonlum vulgare Tulasne

B. Fruchtkörper anfings ei-cylindrisch, später kreiselförmig.

Peridie ans melneren verschiedenartigen Lagen gehildet, am Scheitel mit centraler Oefïnung aufspringend, noch eine Zeit lang von einem dïnnhäutigen Schleier greschlossen. Cyathus.

a. Peridie aussen grau orler blass ockerfarben, filzig, zuletzt glatt, immen glatt, hleigrau oder brätmlich; Nündung später wellig zurückguschligen. Auf faulendem Holz. VII-XI. C. Olla (Batsch) Pers.

b. Peridie aussen rost- bis umbrabraun, zottig-filzig, innen gestreift bleigrau; Mündung mit scharfem, kreisförmigem Rand, der von aufrechitstehenden, zottigen Hairen bekrönt ist. Alte Holzstücke. VII-XI. C. striatus (Huds.) Hoffm.

\section{Hymenogastracea.}

A. Fruchtkörper weder am Grunde noch an der Oberfläche mit wurzelartigenMycelsträngen. Basidien mit2Sterigmen. Hymenogaster. Gleba anfangs weiss, später rostbräunlich. Laubwälder, auf Gartenerde, in Gewächshäusern bes. auf Myrtaceen- und Acacienkübeln. 1X-XI.

H. Klotzschii Tulasne

B. Fruchtkörper an frunde, oft auch an der Oberfläche mit wurzelartigen Mycelsträngen. Basidien mit 6-8 Sterigmen. Wälder. VII-X.

Rhizopogon.

Fruchtkörper unregelmässig rundlich, Oberfläche mit Fasern und Strängen überzogen; Peridie anfangs weiss, dann gelblich, zuletzt olivenbraun; Gleba anfangs weiss, später olivengrau. Haide, sandige TVälder. VII-X. R. virens Albertini et Schweiniz 


\section{Anhang: Lichenes, Flechten.}

I. Der flechtenbildende Pilz ein Pyrenomycet (S. 3). [Pyrenolichenes oder Lich. pyrcnocarpi.]

1. Thallus homoiomer $d . h$. Pilz und Alge im ganzen Thallus nahezu gleichmässig verteilt. Stigonema-Gonidien. Lager ein einschichtiges, fädiges, schwärzliches Polster. (Byssacei, F' a d enflechten.) Feuchte Felsen. Ephebe pubescens L.

2. Thallus heteromer, d. h. Alge in einzelnen Schichten des Thallus reichlicher vorhanden.

1'. Thallus krustig, über die Unterlage flach ausgebreitet und derselben mit der ganzen Lnterseite angewachsen. [Kryoblasti, Krustenflechten.] Trentepohlia-Gonidien.

A. Lager gleichförmig krustig:

A1. Lager auf Rinden, \pm häutig bis knorpelig. Sporen 2- bis 8-zellig.

A2. Sporen farblos. Lager grau.

Arthropyrenia.

B:. Sporen braun. Lager weisslich oder \pm olivenfarben.

Pyrenula.

B1. Lager an Felsen und Mauern, weinsteinartig, trocken fast staubig, brämnlich oder weisslich. Sporen 1 zellig, farblos.

Vericuria.

B. Lager schuppig-krustig, lederartig, der Lnterlage fest angewachsen, braun. Sporen 1-zellig, farblos. Mauern und kahler Erdboden.

Endopyrenium.

2. Thallus laubartig, über die Unterlage laub- oder blattartig wagerecht ausgebreitet und an derselben durch eine Haftscheibe oder vereinzelte Haftfasern befestigt. [Phylloblasti, La ubflechten.]

Lager knorpelig-lederig, starr, braun, weisslich bereift. Sporen 1-zellig. Felsen.

Endocarpon.

II. Der flechtenbildende Pilz ein Discomycet. (S. 3.) [Discolichenes oder Lich, discocarpi.]

1. Thallus homoiomer, feucht gallertartig-bräunlich, trocken oft bleigrau, mit \pm geteilten, oft krausen Lappen. [Gelatinosi, Gallertflechten.] Nostoc-Gonidien. Sporen durch Längsund Querwände vielzellig. Felsen, Mauern, Erdboden.

A. Lager mit undeutlicher Rindenschicht.

B. Rindenschicht des Lager's deutlich.

Collema.

2. Thallus heteromer. Vorherrschend Pleurococcus und Chlorococcum als Gonidien.

1'. Thallus krustig. [K'ryoblasti, Krustenfle ch ten.] (Vgl. I, 2, 1'.)

1“. Apothecien (Fr.) meist punktförmig, selten scheibenartig: erweitert. Rinden oder Steine.

Pertusaria.

2“. Fr. deutlich geöffnet.

A. Fr. \pm strich- oder fleckenförmig.

A1. Thallus freudiggrün. Nadelholzrinden.

Xylographa parallela Ach.

$B_{1}$. Thallus gelbgriin oder \pm bramrot; auf allerlei Rinden. Trentepohlia-Gonidien. 
A2. Fr. nur vom kohligen Gehäuse umgeben. Sporen \pm spindelförmig, 4- bis 8-zellig.

Opegiapha.

$\mathrm{B}_{2}$. Fr. vom Gehäuse und vom Thallus \pm berandet. Sporen raupenförmig, 8- bis 12-zellig. Graphis scripta L.

B. Fr. scheiben-, schüssel-, napf- oder krugförmig, bei A1 auch gestielt-kopfig.

A1. Fr. nicht vom Thallus berandet, ohne Gonidien, von Anfang an offen.

A2. Fr. scheiben- bis krugförmig, nicht gestielt.

$\mathrm{A}_{3}$. Thallus gleichförmig einfach-krustig.

At. Fr. kohlig, hart und dunkel; Scheibe schwarz.

A5. Weinsteinartige, \pm körnig-staubige Rindenflechte. Sporen 2 zellig.

B5. Steinflechte.

A6. Thallus krustig. Sporen 1-zellig.

A7. Boden der Fr. weich, nicht kohlig-spröde, hell bis dunkelbraun. (Auch aut Rinden.)

Lecidella.

B7. Boden der Fr. kohlig hart, schwarz, oft spröde. Lecidea. B6. Thallus weinsteinartig, gefeldert. Sporen vielzellig.

Rhizocarpon.

Bt. Fr. weich, hell; Scheibe (wenigstens feucht.) nie schwarz. A5. Sporenschläuche wenigsporig.

A6. Sporen 1-zellig.

Biatora.

a. Thallus von veränderlicher Konsistenz, hellfarbig. Fr. anfänglich mit Lagerrand. Felsen, Erdboden.

B. coarctata (Ach.) Sm.

b. Thallus körnig oder staubig, rotbraun bis schwarz. Fr. nie mit Lagerrand.

๙. Fr. angedrüickt. Feuchter, somniger Erdboden.

B. uliginosa Schrad.

ß. Fr. fast eingesenkt. Alte Stämme, Holzzäune, Schindeldächer

B. fulinimea Ach.

B. Sporen 2-zellig.

Biatorina.

B.. Sporenschläuche 8-sporig. Sporen 4- oder mehrzellig.

Aв. Sporen länglich oder spindelfürmig.

Bs. Sporen nadelförmig, gerade.

Bilimbia.

Bacidia.

B3. Thallus schuppig oder krustiy, am Rande strahlig gelappt,

hellfarbig, fettig schimmernd Altes Holz.

Psora.

B2. Fr. gestielt, kopfig-rundlich oder fast hutförmig, weich, hell.

A3. Fr. fast kugelig, rosenrot, weisslich bereift, im Innern spinnwebig-locker. Sporen spindelig. Haideboden.

Baeomyces roxeus Pers.

B3. Fr. hutförmig, fleischrot-bräunlich, innen derb. Sporen länglich. Feuchter Erdboden.

Sphyridium hyssoides L.

B1. Fr. vom Thallus berandet, Gonidien enthaltend, anfangs geschlossen.

A2. Thallus gleichförmig einfach-krustig.

A3. Fr. nicht krugförmig, einfach flach oder gewölbt, sitzend oder dem Thallus eingesenkt.

At. Sporen 4- bis mehrzellig. Thallus weinstein- oder mehlartig, hell. Meist Felsen und Mauern. Haematomma. 
B. Sporen 2-zellig. Thallus und Fr. gelb. Ueberall.

C. Sporen 1-zellig.

Callopisma vitellina (Mass.) Ehrh.

A5. Sporen sehr gross, ellipsoidisch, dickhäutig. 'Thallus dïnnhäutig, später rissig bis körnig, hell. Rinden, Steine, Erdboden. Zur Lackmusbereitung. Ochrolechia.

B5. Sporen klein. Lecanora.

a. Thallus braun. Felsen, erratische Blöcke etc. L. badia Pers. b. Thallus weiss oder grau.

a. Fruchtscheibe rein schwarz, glänzend. Felsen, Steine.

$\beta$. Fruchtscheibe rotbraun bis schwärzlich. Meist Holz.

L. subfusca $\mathrm{L}$. $\gamma$. Fruchtscheibe weisslich, gelblich, rötlich oder bräunlich. Laub- oder Nadelholz.

L. pallida Schreb.

B3. Fr. krugförmig, mit kohligem, eigenem Innen- und vom Thallus gebildeten Aussengehäuse, dauernd eingesenkt, schwärzlich. Sporen vielzellig. Thallus weiss oder grau. Felsen etc. Urceolaria scruposa L.

B2. Thallus schuppig oder krustig, am Kande gelappt. Sporen 1- oder 2-zellig.

A3. Hellgrüne Pleurococcus-oder Chroococcum-Gonidien. Thallus ohne "Vorlager".

At. Sporenschläuche vielsporig. Thallus braun. Felsen.

B4. Sporenschläuche 8-sporig

\section{Acarospora.}

A5. Sporen 1-zellig, \pm ellipsoidisch. 'Thallus grau oder grünlichgelb. Ueberall.

Placodium.

B5. Sporen 2-zellig, tönnchenförmig. Thallus gelb bis ziegelrot. Ueberall.

Gasparinia murorum Hoffm.

B3. Blaugrüne Phycochromaceen-Gonidien. Thallus auf schwarzem "Vorlager", grau oder braun. Erdboden, bemooste Felsen, Baumwurzeln.

Pannaria.

2'. Thallus laubig. [Phylloblasti, L a u b fle ch ten.] (Vgl. 1, 2, 2'.) A. Thallus einfach laubig; Fr. dem Thallus einfach ansitzend.

A1. Thallus mittelst Haftfasern an die Unterlage angewachsen.

A2. Thallus unterseits nicht oder nur unvollständiy berindet. Fr. schildförmig, nicht vom Thallus berandet, ohne Gonidien.

A3. Fr. auf der Oberseite vorgezogener Thalluslappen, in der frühen Jugend von einem Thallusschleier bedeckt. Thallus unterseits nicht-berindet, aber deutlich geadert. Sporen 4- und mehrzellig, farblos.

Peltigera.

B3. Fr. auf dem Thallus zerstreut, tief eingesenkt Thallus unterseits fleckenweise berindet, hellyrau oder grünlich. Sporen 2-zellig, braun.

Solorina saccata L.

B. Thallus beiderseits berindet, blätterig oder strahlig gelappt.

Fr. schüsselförmig, vom Thallus berandet, mit Gonidien.

Аз. Thallus durchaus laubig.

A4. Thallus kleinblättrig, aufsteigend, gelb. Schläuche mit 16-32 Sporen; diese 2-zellig, farblos. Laubholz. Candelaria.

$\mathrm{B}_{\star}$. Thallus grosslaubig, anliegend. Schläuche mit 8 Spcren. 
A5. Thallus unterseits einfach gefürbt und einfach faserig. Fr. auf dem Thallus zerstreut. Sporen stumpf, 1. oder' 2-zellig.

A6. Sporen 1-zellig, tönnchenförmig, farblos. Parmelia.

a. Thallus olivenfarben, häutig; Lappen breit, abgerundet. Bäume, Holzwerk, Steine. $P$. olivacea L.

b. Thallus grïnlichgelb, wellig-faltig; Läppchen gerundet. Bäume, Holzwerk, Steine. $P$. caperata L. B6. Sporen 2-zellig, biscuitförmig.

A7. Sporen farblos. Thallus gelb, fast matt, dachziegeliggelappt. Allerwärts, bes. Bäume.

Xanthoria parietina (L.) Fr.

B7. Sporen braun oder schwärzlich.

Physcia.

B5. Thallus unterseits filzig-sammetbraun mit kleinen weisslichen Grübchen (rundlichen entrindeten Stellen). Fr. meist randständig. Sporen 2- bis 4-zellig, spindelförmig. Sticta. Gonidienschicht lebhaft- oder gelbgrün. Laubbäume, Felsen.

S. Pulmonaria L.

$B_{3}$. Thallus stellenweise stielartig verengt.

Cetraria.

a. Lager mehr schlaff blattartig, grau- oder blaugrün. Fr. randstïndig, mit gezähntem Rande. Holzwerk, Felsen. C. glauca L.

b. Lager strauchig, knorpelig, braun. Fr. auf der Vorderseite der Lappen, ganzrandig. Haiden.

C. islandica L.

$B_{1}$. Thallus durch eine mittelständige Haftscheibe (Nabel) der Unterlage aufgewachsen, beiderseits berindet. Fr. nicht vom Lager berandet, ohne Gonidien.

A2. Thallus feucht grünlich. trocken graubraun, unterseits grubig, kahl. Fr. einfach. Schläuche 8-sporig. Sporen braun, durch Längs- und Querwände vielzellig. Felsen, Steine.

Umbilicaria pustulata L.

B2. 'Thallus unterseits meist faserig oder filzig. Fr. faltig oder höckerig. Schläuche 1- oder 2-sporig. Sporen 1-zellig, farblos.

Gyrophora.

B. Thallus schuppig oder faserig, mit fast stielrunden, verzweigten oder trichterförmigen Fruchtkörperstielen.

A1. Fruchtkörperstiele \pm röhrig, einfach walzen- oder becherförmig oder strauchartig verästelt. Fr. immen hohl. Sporen länglich, 1 zellig.

Cladonia.

a. Schuppiger oder blätteriger Grundthallus vorhanden. Fruchtkörperstiele einfach becherig oder walzenförmig oder verïstelt, die unfruchtbaren \pm pfriamelig.

o. Fruchtkörperstiele hornartig berindet, glatt. Astenden durchbohrt. Wailder, Haiden, Wegränder u. s. w. C. furcata Huds.

ß. Astenden geschlossen.

I. Fruchtkörperstiele kleiig oder körnig-warzig, becherförmig. Wald, Haide. C. pyxidata $\mathrm{L}$.

II. Fruchtkörperstiele mehlig bestäubt, pfriemelig oder walzlich. Waldränder, Nadelwaid.

C. cornuta L.

Ђ. Girundthallus fehlend. Fruchtkörperstiele walzlich vielästig. strauchig, nie Becher bildend. Wald, Haide. C. rangiferina L. 
B1. Fruchtkörperstiele mit fester Markschicht, strauchig, oberwärts schuppig. Fr. nicht hohl, braunrot. Sporen reihig-4oder mehrzellig, nadel- oder spindelförmig. Stereocanlon.

a. Stiele anfangs dünnfilzig, bald kahl. Fr. meist endständig. flach. Waldränder, Haide, Steine. S. paschale L.

b. Stiele dicht-hellgrau-spinnwebig-filzig. Fr. seitenständig, fast kugelig. Nadelwald, Haide.

S. tomentosum Fr.

3'. Thallus rein strauchartig. [Thamnoblasti, Strauch flech ten.] Aeste stielrund oder verbreitert, durch Hyphen der Markschicht an die Unterlage befestigt. Apothecien breit scheibenförmig: Gonidien auch in ihrem Gehäuse.

A. Thallusäste \pm verflacht oder zusammengedrückt. Auf Bäumen, Holzwerk, Steinen. Felsen.

A1. Fr. dem Lager fast gleichfarbig. meist zahlreich. Sporen 2-zellig.

Ramalina.

B1. Fr. braun, selten. Lager oberseits meist grau. Sporen 1-zellig.

Evernia.

B. Thallusäste stielrund oder kantig schwach zusammengedrïckt. A1. Thallus aufrecht, auf Land und Haide, brüchig starr. Fr. schildförmig.

Cornicularia aculeata Schreb.

$B_{1}$. Thallus meist hängend auf Bäumen und Holzwerk. zäh.

A2. Fr. klein, schüsselförmig. braun. Mark-und Rindenschicht des Thallus fest zusammenhaltend Bryopogon jubatum L.

B2. Fr. ${ }^{1 / 2}-1 \mathrm{~cm}$ im Durchm.. schildförmig; hell gefärbt. Markschicht des Thallus sich leicht von der Rindenschicht lösend, fadenartig-holzig.

Usmea barbata L.

\section{Hepaticae.}

I. Proembryonale Generation ein laubartiger 'Thallus aus rerschiedenen Gewebsschichten, zu oberst das Chlorophyllgewebe mit meist sehr entwickelten Luftkammern und meist mit Spaltöffnungen, Enterseite mit reihenweise geordneten schuppenb. sowie mit glatten und zugleich Zäpfchenrhizoiden. Sporogon stets ohne Columella, seine Wandung unregelmässig oder mit Zähnen oder Deckel aufspringend. [Marchantiales.]

A. Jufthöhlen fehlend oder ohne Assimilationsgewebe. Spaltöffnungen fehlend oder rudimentär. Das sitzende Sporogon nur fertile Zellen enthaltend. Die zarte Sporogonwand später resorbiert und dann die reifen Sporen frei im Archegonbauch liegend.

Ricciaceae (S. 22).

B. Luftkammern mit einem Geflecht chlorophyllhaltiger Fäden erfüllt. Auf der Oberseite ring-oder tonnenförmige Spaltöffnungen Archegonien und Antheridien in oft gestielten Ständen. Das gestielte Sporogon durchbricht bei der Reife die Kalyptra und springt mit Zähnen oder Ringspalt auf; es enthält neben den Sporen auch sterile Zellen (meist als Elateren). Marchantiaceae (S. 23).

II. Proembry onale Generation ein blattartiger, unbeblätterter Thallus oder ein beblättertes Stämmchen; Rhizoiden glatt. Sporogon mit Fuss, entweder schotenförmig mit 2 nier mit 4 Längs klappen aufspringend, sterile und fertile Zellen enthaltend. 
1. Stets Thallus mit Spaltöffnungen auf der Unter-, öfters auch Oberseite. Sexualorgane eingesenkt. Sporogon schotenförmig, 2 klappig, ohne Stiel, meist mit einer das Archespor kuppelförmig überdachenden Columella; im Archespor neben den fertilen auch sterile, häufig als Elateren entwickelte Ze-llen. [Anthocerotales.]

Anthocerotaceae (S. 25).

2. Proembryonale Generation ohne Spaltöffnungen, meist cylindrisches, beblättertes Stämmchen. Sexualorgane in Gruppen, selten eingesenkt, nie auf gestielten Receptakeln. Sporogon gestielt, bei der Reife die Haube durchbrechend, 4-klappig aufspringend, mit sterilen und fertilen Zellen, aber ohne Columella. [Jungermanniales.]

A. Archegonien am Riicken (Oberseite) der weiterwachsenden Śprosse, von einem Iuvolucrum umgeben. Anacrogynae (S.25).

B. Archegonien den Scheitel am Stämmchen oder an den Aesten einnehmend. Sprosse bilateral, am Rücken mit 2 Reihen grösserer Oberb., auf der Bauchseite meist mit 1 Reihe kleinerer Unterb.

Acrogynae (S. 26).

\section{Ricciaceae.}

A. Antheridien ïber die Thallusoberfläche zerstreut. Sporogon ohne Andeutung einer besonderen Hiille.

Riceia (107)

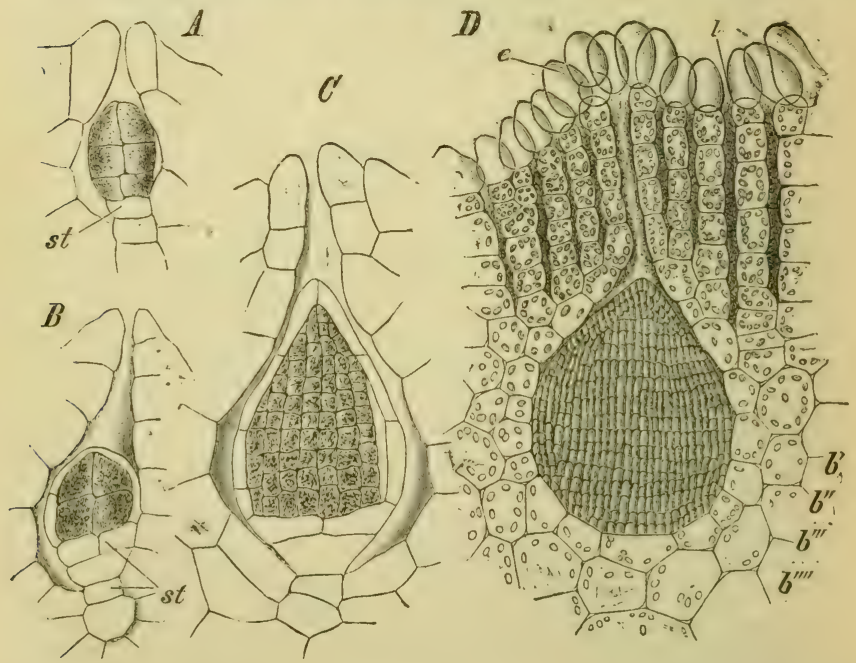

Fig. 1.

Entwickelung des Antheridiums von Ricria: $\Lambda$ - $C$ R. glauca L.; $\Lambda$ junges Antheridım im optischen Längsschnitt (st Stielzelle), in das Gewebo versenkt; 1) ältoros Stadium (WTandschicht anıelegt, Stiel if mehrzellig); $C$ noch älteres Stadium, das Innore teilt sich in dio spermatozndenmutterzellon $(100 / 1) ; D$ reifes Antheridium $\nabla$ on $R$. minima L.; e blasire Eptdermiszellen, $l$ Luftgänge im 
a. Thallus halbe oder ganze Rosetten auf feuchter Erde (und Felsen) bildend; Fr. auf der Oberseite des Thallus hervortretend und bei der Reife durchbrechend.

a. Rosetten bis $2 \mathrm{~cm}$ Durchm., beiderseits blaugrün, ohne Lufthöhlen. Sporogone längs der Mittellinie der Lappen. Herbst. R. glauca $\mathrm{I}$.

$\beta$. Rosetten ${ }^{1 / 2}-2 \mathrm{~cm}$ Durchm., beiderseits licht- oder gelbgrün, durch blasig aufgetriebene Lufthöhlen erst gedunsen, nach deren Oeffnung grubig. Sporogone am Grunde der Lappen. Spätsommer. $R$. crystallina L.

b. Thallus dichotom, nicht Rosetten bildend, im Wasser schwimmend steril und ohne Bauchschuppen und Rhizoiden, auf Schlamm mit Rhizoiden und fruchtend; mit geschlossenen Luftkammern und Andeutung ron Spaltöffnungen. Fr. auf der Unterseite des Thallus vortretend und durchbrechend. Herbst. $R$. fluitans L. ( $R$. canaliculata Hoffim.)

B. Antheridien zu Ständen vereinigt. Sporogon von \pm deutlichen, kegelförmigen Hüllen überdeckt.

Ricciocarpus (1).

In einzelnen, $1 \mathrm{~cm}$ langen Laubstücken in Teichen schwimmend. IX-X.

$R$. natans (L.) Corda

\section{Marchantiaceae.}

1. Luftkammern ohne chlorophyllreiche Zellfäden. Oberer Teil der Kapsel als Deckel oder stückweise abfallend, unterer als Urne stehen bleibend. [Operculatae.]

A1. Hüllen 2-klappig muschelfürmig, ron der reifen Kapsel nicht ganz ausgefüllt.

Reboulia (2).

Thallus $5-15 \times 6 \mathrm{~mm}$, herz-oder keilfürmig. Begraste Bergabhänge. R. hemisphaerica (L.) Raddi B1. Hüllen weitglockig, von der Kapsel ganz ausgefuillt und noch überragt.

Grimaldia (7).

Thallus 5-15×5 mm, linear-keilförmig. Sonniger Basalthumus.

G. fragrans (Balb.) Corda

2. Luftkammern deutlich polyedrisch begrenzt und mit Assimilationsfäden erfüllt. Kapsel mit meist umregelmässigen Klappen aufspringend. [Compositre.]

A. Keine Brutbecher auf der Thallusoberseite. Antheridienstände sitzend. Fruchtbodenträger mit 1 Wurzelrinne. In jeder Hülle des kegeligen Fruchtköpfchens nur 1 Fr. Pseudoperianth fehlend. [Fequatella.]

Thallus bis $2^{1} 2(-3) \mathrm{dm} \times 1 \mathrm{~cm}$. Schattige Abhänge, bemooste Felsen, Wurzeln, Quellen. IV, V. C. conicus (L.) Neck. B. Thallusoberseite mit Brutbechern.

$A_{1}$. Brutbecher halbmondförmig, ganzrandig. Antheridienstände sitzend. Fruchtbodenträger ohne Wurzelrimme. Hüllen meist. zu 4, kreuzweis ausgebreitet, röhrig, einfrüchtig. Perianth fehlend.

Lumularia (1).

Thallus $1-2 \mathrm{~cm} \times$ ○־ $8 \mathrm{~mm}$. Gewächshäuser, Blumentöpfe etc.

B1. Brutbecher fast hohl, halbkugelig, am Rande gezähnt. 

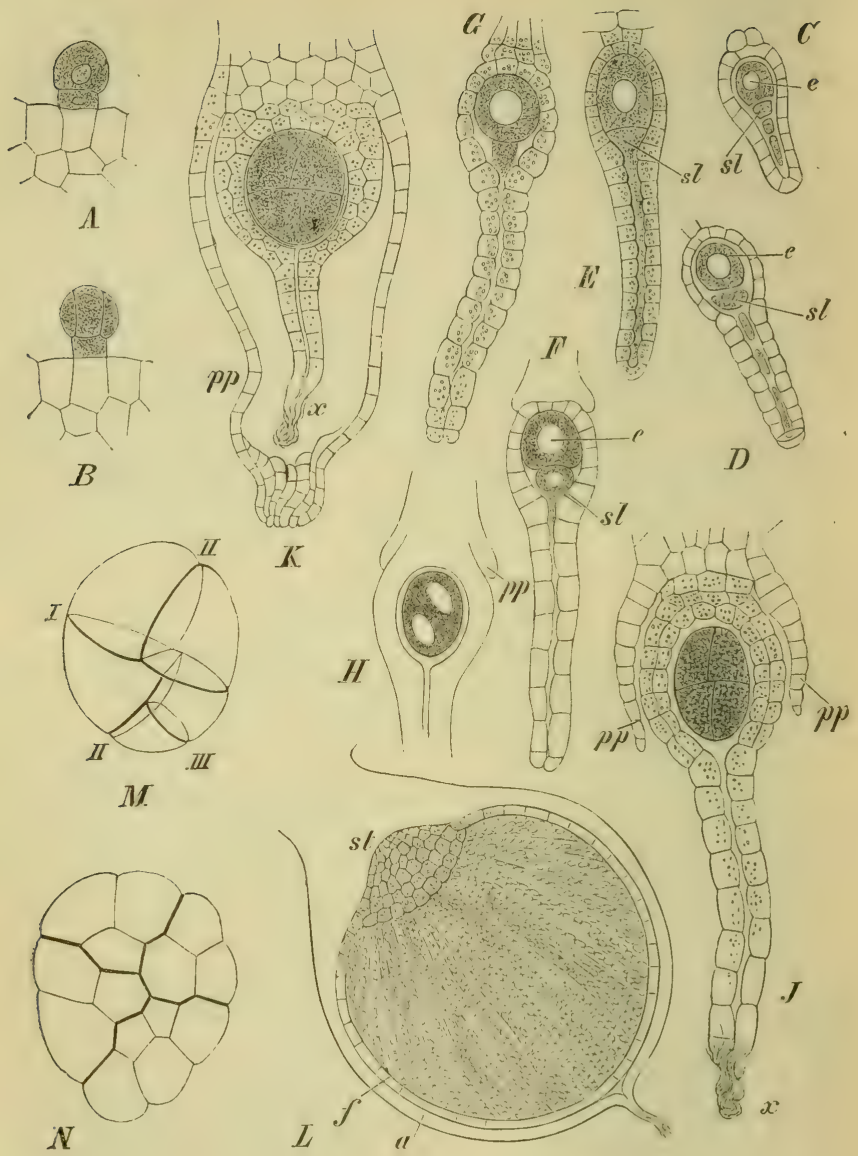

Fig. 2.

Entwickelung des Archogoniums und des Sporogons ron Marchantia polymorpha. $A, B$ erte Entwickolungsstufon des Archegoniums, $C-G$ ältere Stadien (e Eizelle, sl Bauchkanalzolle, in $G$ aufgelöst; Halskanalzellen in $C$ u. $D$ sichibar, in $E$ u. $F$ aufgelöst; ( $;$ zur Bofruchtıng reif); $I I$ Arch. mit dor erston Teilung der befruchtoten Eizelle u. Anląre dos Pseudonerianthiums $p p, J$ u. $K$ altere Stadien ( $x$ dio nach der Bofruchtung erschlafften Iiindungszoilen des Haises); $L$ unreifes Spirogon in dem zur Kalyptra ausurowachsenen Archogoniumbauch la Sporogrowand, st Stiol; $f$ die strahlig ngeorineten Elateren, dazwischen die Sporen); $M$ u. $N$ isolierte Embryonen ( $N$ dem Stadium $K$ entsprechend; in $M$ geben die Ziffern die Aufeinanderfolge der Teilungen an). 
Antheridienstände gestielt. Fruchtstandträger mit 2 Wurzelrinnen. Fruchtköptehen sternförmig. Hüllen mehrfrüchtig. Perianth vorhanden.

Marchantia (52).

Thallus $2-10 \times{ }^{1}-2 \mathrm{~cm}$, am Ende ausgerandet, am Saume lappig und wellig. Allerhand feuchter Boden, gemein. VI, VII.

M. polymorpha L.

\section{Anthocerotaceae (Anthoceros).}

a. Thallus dunkelgrün, fast fettglänzend, flach, fast glatt, in Rosetten ron 5-25 mm Durchmesser, ohne Lufthöhlen. Kapsel gelbbraun; Sporen gelb. Aecker, Gräben, Teiche, W'aldränder etc. VIII, IX.

A. laevis $\mathrm{L}$.

b. Thallus frisch hellgrïn, welligkraus (durch die aufsteigenden Sprosse), warzig, in Rosetten ron $5-10 \mathrm{~mm}$ Durchmesser, mit Lufthöhlen. Kapsel grauschwarz; Sporen schwarz. Aecker, feuchte Raine, Graben- und Waldränder etc. Herbst.

\section{Anacrogyna.}

I. Geschlechtsorgane auf sehr verkürzten Sprossen. Elateren zum Teil als pinselförmige Büschel auf den Spitzen der Klappen stehen bleibend. Thallus stets laubig.

1. Mittelrippe des Thallus allmählich gegen die Ränder verflacht. Geschlechtsorgane auf verkürzten seitenzweigen, doch die 오 nachträglich öfter + auf die Unterseite grerïckt. Hülle des Sporogons wulstig. - Riceardia (111).

Thallus ungeteilt bis zersehlitzt. $1-5 \times^{1}-1 \mathrm{~cm}$. Haube + behaart. Feuchter Boden. III, IT. R. pinguis (L.) Ś. F. Gray

2. Mittelruppe des Thallus scharf von den einschichtigen Rändern abgesetzt. Geschlechtsorgane auf sehr verkürzten Sprossen der Lnterseite. Hülle des Sporogons eine meist die direkte Fortsetzung des Sprosses bildende herzförmige Schuppe. $\triangle$.

IIetzgeria $\left(36^{\circ}\right)$. Thallus $1 / 2-5 \mathrm{~cm} \times 1 / 2-1 \mathrm{~cm}$, handförmig. Felsen, Rinden, Wurzeln. $\quad M$. furcata (L.) Lindb.

II. Geschlechtsorgane am Rücken oder an der Śpitze gewöhnlicher Sprosse. Elateren am Grumde der Kapsel angeheftet oder abfällig.

1. Proembryonale Generation stets mit Rhizoiden. Kapsel kugelig.

A. Proembryonale Generation ein laubiger Thallus ohne quer verlaufende Lamellen auf der Oberseite.

A1. Thallus ohne Schuppenb. auf der Unterseite und ohne Brutkörper. Sporen mehrzellig.

Pellia (3). Thallus bis $5 \times 1.2 \mathrm{~cm}$. Kelchartige Hülle an den Seitenrändern mit der Lauboberfläche verwachsen, taschenförmig gegen das weitersprossende Laub geöffnet. Feuchte Stellen. IV.

P. epiphylla Dill.

$B_{1}$. Thallus unterseits mit unregelmässig oder in 2 Längsreihen angeordneten Schuppenb. und oberseits mit flaschenfürmigen Brutbechern. Sporen einzellig.

Blasia (1). 
Thallus 3-4 cm im Durchmesser, unregelmässig strahligrosettig. Feuchter Lehm und Sand. III, IV. B. pusilla L. B. Proemlryonale Generation ein oberseits abgeflachtes Stämmchen mit schräg inserierten, unterschlächtigen B., Rasen bildend. Hülle glockig-becherförmig, oben weit geöffnet.

Fossombronia (26).

Gräben, feuchte Aecker u. Waldwege. VII-X.

F. cristata Lindb.

2. Proembryonale Generation ohne Rhizoiden, ein \pm deutlıch 3-reihiy beblättertes, aus einem rhizomähnlichen Basalteil entspringendes Stämmchen. Fr. endständig, ohne Hülle; Archegonien mit B. untermischt, gegen die St:mmspitze stehend, Antheridien am Stengel ringsum zerstreut. Haplomitrium (1).

Stengel $0,21 \mathrm{~cm}$ hoch, einzeln oder in Räschen bis $3 \mathrm{~cm}$ Durchm.; B. rundlich eilänglich, entfernt ausgeschweift-gezähnt, $\mathrm{zu}{ }^{1 / 3}$ umfassend. Nasse, sandige, kurzberaste Flächen, selten, VII-XI. H. Hookeri (Lyell) N. v. Es.

\section{Acrogynae.}

I. B. unterschlächtig (d. h. der untere Rand deckend) oder quer inseriert, d h. die Insertionslinie einen Winkel bildend. Amphigastrien fehlend oder klein oder den B. unähnlich. Kapsel bis zur Basis 4-klappig kilateren 2-spirig, an beiden knden zugespitzt, abfällig.

1. B. Hach oder rinnig hohl, ganz oder 2-teilig, selten 3 - bis 5-spitzig. Blh. fehlend orler gewöhnlich von der Seite zusammengedrückt oder 3-kantig ( 2 seitliche und 1 dorsale Kante) oder cylindrisch bis eiförmig. [Epigoniantheae.]

A. Blh. fehlend.

$A_{1}$. O Blütenstand normal akrogen, nicht in einem Fruchtbeutel. $\mathrm{B}$. quer inseriert, rinnig, hohl, 2-zeilig, 2-lappig. Amphigastrien fehlend.

Gymnomitrium (18).

B. O Bliitenstand am Knde fleischig-sackartiger, aus den Achseln von Amphigastrien entspringender, bewurzelter Fruchtaiste. Amphigastrien 2-teilig Saccogyna (6).

Rasen flach, verwebt. Stengel kriechend, dicht bewurzelt, wenigästig. B. flach, scharf, 2-zähnig. Bachufer, feuchte Felsen. V, VI. S. graveolens (Schrad.) Lindb. B. Blh. vorhanden. \& Blütenstand normal.

A. Involucralb. \pm wenigstens am Grunde mit der Blh. verwächsen.

A2. B/h. mit den Involucralb. hoch hinauf verwachsen und ganz von ihnen eingeschlossen. B. quer inseriert. 2-teilig, rinnig-hohl. Amphigastrien fehlend. Marsupella (24).

Rasen sehr dicht. Stengel $1 \mathrm{~cm}$ lang, knieförmig aufsteigend. Waldränder und Fussstege auf kiesig-thonigem Boden. V, VI. MI. Funckii (Web. et M.) Dum.

B2. Blh. mit den Involucralb. verschieden weit verwachsen. B. schief inseriert, alternierend, gewöhnlich ganz, rundlich. 
a. Amphigastrien pfriemelig. Blh. klein und zart, in das Involucrum eingesenkt und mit diesem hoch hinauf verwachsen; Basis des Gynaeceums bulbusartig verdickt. B. meist ganz. Stengel kaum $1 \mathrm{~cm}$, keiltörmig aufsteigend. Kiesig-thoniger Haideboden.

N. haematosticta (N. v. Es.) Lindb.

b. Amphigastrien fehlend. Blh. nur mit der Basis der inneren Involucralb. verwachsend, weit hervorragend.

a. Wurzelhaare rötlich. B. fast kreisrund, etwas ausgeschweift und wellig. Zellen gleichgross, sehr weit, an den Ecken dreieckig-rerdickt. Blh. eiförmig mit 5 -kantig gefalteter, geschnäbelter Mündung. III-V. Sandig. thoniger Boden an Waldabhängen, Wald- und Hohlwegen. N. hyalina (Lyell) Lindb.

5. Wurzelhaare weisslich. B. breit ei- oder halbkreisförmig, oft durch eine Reihe sehr grosser, dickwandiger, quadratischer Zellen gesäumt. Blh. fast bis zum Grunde t-kantig. Kanten oberwärts scharf, zuweilen gezähnt. Stengel bis $12 \mathrm{~cm}$. III, IV. Wegränder, Hohlwege, auch Sümpfe auf kiesig-thonigem Boden. $\quad N$. crenulata (Sm.) Lindb.

$B_{1}$. Blh. vollkommen frei von den unter sich nicht verwachsenen Involucralb.

A2. + Blütenstand akrogen (d. h. endständig am Stengel oder an verlängerten Aesten), manchmal pseudolateral oder pseudodorsal.

A3. Blh. drehrund oder von der Seite zusammengedrïckt, bauchig mit zusammengezogener, einfacher, 2-lippiger Mündung, meist mehrfaltig.

At. B. und Involucralb. ganz, rundlich bis kreisförmig.

Aplozia (20).

a. Blh. von der Seite her etwas zusammengedrückt. B. kreisförmig. Amphigastrien 3-eckig-pfriemelig. Pflanze zwischen Sumpfmoosen kriechend. IX, X. (Jungermannia Schraderi Mart.)

A. autumnalis (D. C.) Schiffn.

b. Blh. eylindrisch, ungefaltet, an der Mündung plötzlich in ein nabelförmiges Spitzchen zusammengezogen. B. Jänglichrund. Amphigastrien fehlend. Stengel bis $3 \mathrm{~cm}$, kriechend. Schattige Waldschluchten auf thouig-kiesigem Grund, Bachufer etc. III-V. A. lanceolata (N. v. Es.) Schiffn.

B. B. 2- bis mehrteilig. Stengel kriechend, durchaus bewurzelt. B. ausgebreitet.

a. B. schräg oder fast längs inseriert.

a. Stengelb. 2-lappig, Hüllb. häufig mehrteilig. Amphigastrien fehlend oder nur in den Blütenzweigen vorhanden. Blh. mit kegelförmiger, mehrfaltiger Spitze.

I. Stengel kriechend, $1,2 \mathrm{~cm}$, Hülle nur oberwärts faltig. B. hohl; Zellen des Blattgrundes kleiner, dickwandig, besonders an den Ecken. Sandig-thonige Waldwege. III, IV, IX, X. L. bicrenata (Schmid.) Dum. II. Stengel bis $3 \mathrm{~cm}, \pm$ aufsteigend. Hülle bis unter die Nitte 
herab faltig; Zellen weit, dünmwandig. Schattige Felsen, sandig-thoniger Boden. $\mathrm{X}$. $J$. ventricosa (Dicks.) Dum. ß. Stengelb. 3-bis 5-teilig. Amphigastrien 2-teilig, gefranst. Blh. eiförmig, weit herab gefaltet. Stengel $2-6 \mathrm{~cm}$, niedergestreckt.

I. Rasen olivengrün oder bräunlichgelb. Stengel braun, mit kurzen Wurzelhaaren. B. flach, fast quadratisch, mit 3-5) Zühnen, Zellen in den Ecken kaum verdickt. Waldränder, Wald- u. Hohlwege, Baumwurzeln, Felsen. VI, VII. L. barbatx (Schreb.) Dum. II. Rasen hellgrün. Stengel grünlich, mit langen Wurzelhaaren. B. kraus, hohl, rundlich, mit 3-5 Zähnen. V-VII. L. quinquedentata (Huds.) Schiffn.

b. B. quer inseriert, 2-teilig, selten 3-spitzig. Amphigastrien fehlend. Blh. eiförmig, mehrfaltig.

a. Herdenweise oder rasig. Stengel aufsteigend, mit Wurzelhaaren. Unterer Blattlappen eilanzettlich, vielmal grüsser als der abstehende zahnartige obere. Felsen, sandigthonige Waldlichtungen und Hohlwege. IV, V.

L. exsecta (Schmid.) Dum.

$\beta$. Rasig. Stengel niederliegend oder aufsteigend, kaum wurzelhaarig. B. fast bis zur Mitte scharf gespalten in $2 \mathrm{am}$ Kiel gegen cinander gehrochene, stumpfliche, gleichgrosse Lappen. Erdboden, Quadersandsteinfelsen. VIII, IX.

L. minuta (Crantz) Schiffn.

B3. Blh. von der Seite her zusammengedrüickt, mit breiter, 2-lippiger Mündung.

At. Stengel kriechend, bewurzelt. B. ganz, ganzrandig. Amphigastrien ungeteilt, frei.

IIylia (3).

Modernde Stämme, Moortümpel, Sindsteinfelsen. VII,VIII. M. Taylori (Hook.) S. F. Gray

B. Stengel aus rhizomartiger, bewurzelter Basis aufsteigend bis aufrecht, rhizoidenlos. B. und Blh. gezähnt oder gefranst.

Plagiochila (463).

Lockerrasig. Stengel bis $3 \mathrm{dm}$, mit aufrechten Aesten. Blh. doppelt so lang als die Huillb. Schattiger Waldboden. V. $P$. asplenoirles (L.) Dum.

$\mathrm{C}_{3}$. Blh. 3-kantig-prismatisch; Kiele oft geflügelt; Mündung weit geöffnet, 3-lippig, mit zerschlitzten Lippen. Lophorolea (149).

a. Einzeln oder lockerrasig. Stengel \pm aufsteigend, spürlich ästig und wurzelharig, $2-5 \mathrm{~cm}$. B. durch eine stumpfe Bucht in 2 ungleiche, pfriemelig-lanzettliche Zühne geteilt. Amphigastrien viel kleiner, Zipfel mit 2-pfriemeligen Zähnen. Schattig-feuchter Erdboden, morsche Baumstümpfe, Quellen, Sumpfwiesen. X, XI.

$L$ bidentata (L.) Dum.

b. Flachrasig. Stengel kriechend, dicht verästelt und wurzelhaarig, $2 \mathrm{~cm}$. B. eiquadratisch, obere ganz, quergestutzt oder seicht ausgerandet, mit rundlichen Ecken, untere buchtigstumpf, 2-lappig. Amphigastrien fast halb so gross als die B., Zipfel schwach gezähnt, pfriemelig. Waldboden, morsches Holz. Felsen. V-VIJ. L. heterophylla (Schrad.) Dum. B2. $q$ Blütenstand cladogen, d. h. auf sehr verkürzten Aesten. 
A3. Haube mit der Innenwand der Blh. verwachsen.

B3. Haube frei von der Blh.

At. Blh. von der Seite zusammengedrïckt. Mündung breit, gestutzt.

Pedinophyllum (1).

Bı. Blh. 3-kantig, Mündung erweitert. Haube fleischig, oft vorragend.

Chiloseyphus (77).

Stengel $2-5 \mathrm{~cm}$, schlaff, an der Insertion der mit lineal-pfriemeligen Zipfeln versehenen Amphigastrien wurzellaarig. B. \pm rundlich mit rundlicher, quergestutzter oder seicht einge đrüickter Spitze. Waldboden etc. IV, I.

C. polyanthus (L.) Corda

2. B. gefaltet-2-lappig (Oberlappen kleiner), meist gesägt oder gefranst. Amphigastrien fehlend. $\subsetneq$ Blitenstand acrogen. Blh. vom Rücken her flachgedrückt. [Scapanieae.] Scapania.

a. B. nicht Hïgelig-gekielt.

a. B. fast gleichlappig, rundlich-herzförmig, obere meist kleingezähnt; beide Lappen gleichlaufend, der obere oft einwärts gekrïmmt. Feuchter Lehm- und Haideboden. IV, T.

S. compacta (Roth) Lindb.

3. B. bis zur Mitte 2-lappig, unterer Lappen 2-3 mal grösser, eirundlich, oberer quadratisch oder 3-eckig. Sandiu-thonige Grabenränder, Felsen. JII. S. curta (Mart.) X. v. Es.

b. B. flïgelig-gekielt, unterer Lappen 2-3mal grösser.

๑. Blh. mit zahnloser oder unregelmässig kleingezähnter Mündung. B. schlaff, trocken kraus. Lockerrasig, auch flutend, 1-10 cm. Steiniger Grund von Gräben und Bächen. V-VII:

S. undulata ( $\left.\mathrm{I}_{\text {. }}\right) \mathrm{M}$. et $\mathrm{N}$.

¡. Blh. gross $(4 \mathrm{~mm})$, an der Mündung wimperig-gezähnt. B. straff. Flachrasig. Stengel aufsteigend, an der Sritze niederwärts gebogen, $1-8 \mathrm{~cm}$. Waldboden, Felsschluchten (bes. an Sandstein). III-V. S. nemorosa (L.) N. v. Es.

II. B. oberschlächtig (d. h. der obere Rand deckend).

I'. Kapsel und Elateren wie bei I.

1. Amphigastrien fehlend. B. gefaltet. 2-lappig; der \pm flache Unterlappen, aus dessen Fläche Rhizoidenbüschel bervortreten, kleiner als der Oberlappen. \& Blïtenstand acrogen. Blh. vom Rücken her flachgedrückt, glatt, mit breit gestutzter Mündung. [Stephanineae.]

Radula.

Rasen flach, strahlig. Stengel 2-8 cm, kriechend, unregelmässig fiederästig. B. dicht dachziegelig, fast kreisrund, ganzrandig. Laubholzstämme, morsches Holz, absestorbene Laubmoose, Felsen. V, VI. $\quad T$. complanata (L.) Dum.

2. Amphigastrien klein bis mittelgross, den B. unähnlich. Stengel oft mit peitschenförmigen, blattlosen oder kleinblätrigen Aesten. B. an der Spitze meist 2- bis t-zähnig oder handförmig 2- bis 6-teilig. \& Bl. cladogen auf ventralem Spross. Blh. schmal und lang, 3-kantig (2) seitliche, 1 ventrale Kantei.

A. Stengel fiederästig. B. klein, fast quadratisch, 4-lappig bis 4-teilig. 
Dicht- $u$. flachrasig. Stengel $1-3 \mathrm{~cm}$, niederliegend. Feuchter Waldboden, faules Holz, Felsen. IV-VI.

L. reptans (L.) N. v. E's.

B. Stengel gabel- oder einseitsästig. B. ansehnlich (bis $5 \mathrm{~mm}$ ), an der Spitze 3-zähnig, unsymmetrisch eiförmig. [Mastigobryum.]

Bazzania.

Stengel längs der Mitte des Rückens gewölbt, $3-15 \mathrm{~cm}$. Amphigastrien fast nierenförmig. Feuchte Abhänge, Hohlwege, Ufer, Felsen, morsche Stümpfe. VIII, IX.

B. trilobata (L.) Gray

3. Amphigastrien ansehnlich, den B. ähnlich oder gleich. Unterlappen der B. ein Oehrchen am Grunde des bedeutend grösseren Oberlappens.

1'. B. handförmig geteilt, rings in einfache oder ästige, haarfeine, gegliederte Wimpern aufgelöst. ㅇ Blütenstand acrogen oder auf lateralen Aesten. [Ptilidieae.]

A. Blh. fehlend. Stengel ohne Wurzelhaare. B. fast bis zum Grunde handförmig geteilt.

Trichocolea.

Rasen schwammig. Stengel bis $10 \mathrm{~cm}$, bis 3 -fach-fiederästig, niederliegend. Fruchtast fleischig, lang, keulig, rauhhaarig. Quellen, Bäche, sumpfige Wiesen. IV, V.

T. Tomentella (Ehrh.) N. v. Es.

B. Blh. mehrmals länger als die Hüllb., stielrund, oberwärts mehrfaltig, an der verengten Mïndung gewimpert. Stengel mit kurzen Wurzelhaaren. B. bis unter die Mitte 4-spaltig.

Ptilidium.

Rasen flach-verworren bis schwammig-polsterförmig. Stengel bis $6 \mathrm{~cm}$, einfach- oder doppelt-fiederïstig. Auf verschiedenartigem, feuchtem Untergrund. V, VI.

$P$. ciliare (L.) N. v. Es.

2'. B. gefaltet-2-lappig; Oberlappen rundlich-eiförmig, Unterlappen (Ohr) länglich-eiförmig. O Blütenstand cladogen auf lateralen Aestchen. Blh. an der Mündung anfünglich verengt, später tief-2-lippig klaffend, wimperig gezähnt. Kapsel nur bis $\mathrm{zu}^{2} / 3$ von oben her 4 -spaltig. [Belluncinzeae.] Madotheca.

Rasen sehr gross und dicht, glanzlos dunkelgrün bis gelb. braun. Stengel bis $1 \mathrm{dm}$, unregelmässig gefiedert. B. stumpflich, breit-schief eiförmig, ganzrandig; Ohr ebenso. In Laubwäldern an Stämmen, Felsen, seltener auf der Erde. VI-VIII. M. platyphylla (L.) Dum.

II'. Kapsel kurz gestielt, von der Spitze bis etwa zur Mitte 4-klappig. Elateren an den Klappen angeheftet bleibend, stets einspirig, an dem freien Ende gestutzt bis trompetenartig erweitert. B. aus Oberlappen und Oehrchen bestehend, ganzrandig. Amphigastrien breit. Rhizoiden meist in Bündeln aus der Mitte oder dem Grunde der Amphigastrien. \& Blütenstand nur mit 1 oder 2 Archegonien. [Jubuleae.]

A. Bleichgrün. B. schräg inseriert, zarthäutig. Blattohr platt, am Grunde mit dem Oberlappen grösstenteils zusammenhängend. Amphigastrien ganz oder schwach ausgerandet. Kapselklappen zusammenneigend. 
Stengel $2 \mathrm{~cm}$, niederliegend, mit zahlreichen Seitensprossen. Feuchtschattige Stellen. VII-IX. L. serpyllifolen (Dicks.) Lib.

B. Bräunlich. B. quer inseriert. derbhäutig. Blattohr helmartig ausgehöhlt, wenig mit dem Oberlappen verwachsen. Amphigastrien ausgerandet bis 2-spaltig. Kapselklappen aufrecht abstehend.

Fiullania.

a. Rasen flach auliegend, glanzlos. Stengel $3 \mathrm{~cm}$, kriechend, unregelmässig fiederästig. Blattohr grösser als die Amphigastrien Blh. beiderseitig durch Brutknospen höckerig, an den Kanten zahnartıg gekerbt. Laubholz- (auch Obstbanm-) stämme, Felsen. Herbst und Frühjahr. F. dilatuta (L.) N. v. Es.

b. Rasen polsterförmig, glänzend. Stengel 2-5 cm, straff, meist doppelt-fiederästig. Blattuhr schmäler als die Amphigastrien. Blh. glatt, länglich. Erilabhänge, Stammgrund und Felsen in Wäldern. Herbst u. Frühjahr.

F. Tamarisci (L.) N. v. Es.

\section{Musci.}

I. In der Achse der Kapsel eine Columella, welche die sporenbildende Schicht nicht durchsetzt, sondern von ihr überdacht wird. Sporensack aussen unmittelbar an die Kapselwand angrenzend Sporogon sitzend. bis zur Reife vom Archegonium umbüllt und mit diesem von einem Pseudopodium (stielartig verlängt. Zweig) emporgehoben.

1. Bei der Reife die Archeyoniumwandung uuregelmässig zerrissen. Kapsel mit Deckel, ohne Peristom. B. ohne Mittelrippe, aus gestreckten Chlorophyll- und weitlumigen Hyalinzellen (deren Wände runde Löcher und Ring-oder Spiralverdickungen besitzen) gebildet. Aelınliche Hyalinzellen auch in der Stencelrinde. [Sphagnales.]

Sphagnaceae (S. 34).

2. Bei der Reife die Archegoniumwand in Siheide und Haube sich sondernd. Kapsel mit 4 seitlichen Längsrissen (laternenartis) sich öffnend. Blattzellen \pm gleichartig. Stengelrindenzellen nicht weiter differenziert. [Andreaeales.]

Andreaenceae (S. 35).

II. In der Kapsel keine Columella, sondern fertile und sterile Zellen durcheinander gemengt. Kapsel sitzend, ohne Pseudopodium. Haube unregelmässig abgesprengt. Kapsel ohne Deckel; Kapselwandung unregelmässig aufreissend oder faulend. [Archidiales.]

Arehidiaceae (S. 35).

III. In der Achse der Kapsel eine Columella, welche das Archespor durchsetzt. Zwischen Sporensack und Kapselwand ein cylindermantelartiger Hohlraum. Sporogon in die Kapsel und eine (oft noch sehr kurze, aber meist sehr lange) Seta gegliedert. Arehegonwandung in Scheide und Haube gesondert. [Bryales.]

1. Kapsel ohne Deckel. Kapselwandung unregelmässig autreissend oder faulend. [Cleistocarpae.] 
A. Columella schliesslich wieder resorbiert. B. stets am Rande flach oder eingebogen, ohne Papillen.

a. B. lineal-lanzettlich. Grünes Protonema ausdauernd.

Ephemeraceae (S. 35).

b. B. verkehrt-eilänglieh oder breit eiförmig. Grünes Protonema früh verschwindend. Physcomitrellaceae (S. 35).

B. Columella stets bleibend, nicht resorbiert.

a. B. glïnzend, am Rande flach oder eingebogen; ohne Papillen.

Bruchiaceae (S. 35).

b. B. glanzlos, am Rande + zurückgebogen, eirundlich bis eilanzettlich, nie borstenförmig. Grünes Protonema nicht ausdauernd.

Phascaceae (S. 36).

2. Kapsel durch Abfallen eines ringsumschriebenen Deckels sich öffinend. [Stegocarpae.]

1'. Archegonien an Hauptsprossen gipfelständig und später die Kapseln endständig. [Acrocarpae.]

A. B. wie bei Sphagnum aus zweierlei Zellen gebildet, 3- und mehrschichtig: Innenzellen chlorophyllführend und klein, Oberflächenzellen porös, lufthaltig, parenchymatisch. Kapsel kropfig. Peristom wie bei Dicranum. Lencobryaceae (S. 37).

B. B. aus \pm gleichartigen Zellen gebildet, 1-schichtig oder stellenweise mehrschichtig. Aussenwände der Zellen nie durchbrochen.

a. Sterile Stengel farnblattartig mit 2-zeilig longitudinal inserierten, am Grunde seitlich verschmelzenden B.; fertile Stengel am Grunde 2-zeilig, an der Spitze mehrreihig beblïttert.

Schistostegaceate (S. 41).

b. Stengel gleichartig (nur hei den Mnieae die fertilen und sterilen etwas verschieden). B. ausser bei Fissidens) 3- und mehrreihig.

a. B. unterseits mit einem breiten Dorsalflügel, 2-zeilig. Peristom wie bei Dicranum. Fissidentaceae (S. 37).

3. B. unterseits ohne breiten Dorsalflügel.

I. Peristomzähne nicht gegliedert.

1. Kapsel regelmässig oder symmetrisch. Peristom einfach. + 4 Peristomzïhne, aus dem Deckelgewebe selbst bestehend.

Georgiaceae (S. 45). + + 32 oder 64 Peristomzähne, aus bastfaserähnlichen, längsstreifigen Zellen bestehend, deren Spitzen durch die Paukenhaut verbunden sind. Polytricharceae (S. 44).

2. Kapsel unsymmetrisch, mit schief aufsitzendem Deckel. Peristom doppelt, das innere in Form eines gestutzten Tubus von einer 16 - bis 32-kielfaltigen Haut gebildet.

II. Peristomzähne gegliedert.

Buxbaumiaceae (S. 45).

1. Die 16-32 Einzelzälme des stets einfachen Peristoms (bez. die Schenkel der Zühne) aussen ohne Längslinie. + B. ohme Rippe (Hedwigia). Grimmiaceae p. p. (S. 39). ++ B. mit Rippe.

- Peristomzähne auf der Aussenseite vertikal gestreift. 
C. Peristomzähne aussen nicht längsstreifig, entweder glatt oder papillös.

$\uparrow$ Peristom ohne Grundmembran, aus 16 gesonderten, zuweilen geteilten Zähnen bestehend.

$\times$ Peristomzaihne oft rudimentär oder fehlend, meist ungeteilt.

B. schmal linealisch bis pfriemelig; Blattzellen parenchymatisch.

Weisiaceae (S. 36).

B. breit eifürmig bis länglich-spatelig; Blattzellen oben gestreckt, oder wenn \pm quadratisch. dann die Rippe oberseits mit $2-4$ Längslamellen. Pottiaceae (S. 38').

$\times \times$ Peristomzähne vielfach durchlöchert oder bis zur Mitte. seltener bis zur Basis ?-spaltig. Grimmiaceae p. p. (S. 39).

$\uparrow \uparrow$ Peristom mit \pm entwickelter Grundmembran.

$x$ Peristomzähne schräg aufsteigend, unten durch Quer- und Schrägglieder verkoppelt. [Cinclidotus.]

Grimmiaceae p. p. (S. 39).

$X \times$ Peristomzähne gerade aufrecht, nicht verkoppelt.

Ditrichaceae (S. 38).

2. Die 16 Einzelzähne des einfachen oder des äusseren Peristoms aussen mit einer Längslinie, die meist aus Wandstücken ron 3 oder 4, seltener aus ganzen Zellen besteht.

+ Peristom stets einfach. Kapsel mit sehr grosser Apophyse. Splachnaceae (S. 41).

+- Peristom der Anlage nach doppelt. Kapsel olme oder mit nur kleiner Apophyse.

(-) Inneres Peristom olne Grundmembran, nur in Form ron Cilien vorhanden oder fehlend.

^ Kapsel nicht gestreift. Spaltüffnungen schildfürmig.

$\uparrow \uparrow$ Kapsel längsstreifig:

Funariaceae (S. 41).

$\times$ Haube cylindrisch-glockig, unter die Kapsel herabreichend, nicht längsfaltig und nicht behaart.

Encalyptaceae (S. 40).

$\times \times$ Haube meist müitzenförmig-glockig, selten den Kiapselgrund erreichend, längsfaltig, oft behaart.

Orthotrichaceae (S. 48).

C. Inneres Peristom meist am Grunde, selten in seiner ganzen Länge aus einer \pm deutlich kielfaltigen Membran gebildet. Zühne des äusseren Peristoms nie durchbrochen.

Bryaceae (S. 41).

2'. Archegonien blattachselständig am Hauptstengel oder an den Aesten. [Pleurocarpae.]

A. Flutende, reich verzweigte Wassermoose. Blattzellnetz grossmaschig, prosenchymatisch. Haube mützenförmig oder einseitig. Inneres Peristom eine gitterartige, offene Luppel darstellend.

Fontinalaceae (S. 45).

B. Rasen oder Polster bildende, nicht flutende Moose. Blattzellnetz kleinmaschig. Haube kappenförmig.

a. B. glanzlos, papillös oder warzig: Blattzellen parenchymatisch. 
b. B. meist glänzend, ohne Papillen und Warzen. Blattzellen prosenchymatisch, rhombisch bis linealisch.

a. Stengel und Aeste verflacht-2-zeilig beblättert.

1. Kapsel gerade auf dem Stiel aufsitzend.

1. Hauptäste regelmässig fiederästig. Inneres Peristom kürzer als das äussere, ohne Wimpern, mit schmaler Grundhaut und kurzen Zähnen.

Neckeraceae (S. 46).

2. Hauptäste unregelmässig verästelt. Inneres Peristom länger als das äussere, mit hober Grundhaut, mit oder ohne Wimpern. [Homalia.] Hypnaceae p. p. (S. 46, 48).

II. Kapsel übergeneigt, gekrümmt. [Plagiothecium.]

Hypnaceae p. p. (S. 46, 48).

3. Stengel und Aeste allseitswendig beblättert.

Hypnaceae p. p. (S. 46).

\section{Sphagnaceae.}

Torf bildende Moose. B. ohne Mittelrippe, aus hyalinen und Chlorophyllzellen bestehend. Monöcisch oder diöcisch.

Sphagnum.

a. Chlorophyllzellen der Astb. an einer der beiden Blattflächen zwischen die hyalinen eingelagert, im Querschnitt 3-eckig, 3-eckig-oval bis paralleltrapezoidisch.

a. Chlorophyllz. d. A. an der Blattinnenfläche; daher an der Aussenfläche die Mehrzahl der Poren und stärker konvexe Seite der Hyalinzellen. Stengelrinde porös, aussen mehrmals durchbrochen.

I. Stengelrinde fibrös. Astb. mit kappenförmig abgerundeter, ungezähnter Spitze. Stengelb. zungenförmig, abgerundet und fransig. VII, VIII. S. cymbifolium Ehrh.

II. Stengelrinde ohne Fasern. Astb. mit deutlich gezähnter Spitze. Stengelb. am Grunde sehr breit gesïumt.

1. Oberflächenzellen aussen durchbrochen. Stengelb. an der gestutzten Spitze ausgefranst, stets ohne Fasern. Rasen nie rot.

+ Stengelb. breit-verkehrt-eiförmig, von der Spitze bis zur Mitte stark gefranst. VII, VIII. S. fimbriatum Wils. ++ Stengelb. fast rechteckig (Seitenränder nach innen geschweift), nur an der abgestutzten Spitze gefranst. VI-VIII.

S. Girgensohnii Russ.

2. Oberflïchenzellen aussen nicht durchbrochen. Stengelb. kurz zugespitzt, eilïnglich, an der Spitze meist 3- bis 6-zähnig, fast stets mit Fasern und Poren. Rasen oft rötlich. VII, VIII.

S. acutifolium Ehrh.

3. Chlorophyllz. d. A. an der Blattaussenfläche; daher an der Innenfläche die stärker konvexe Seite der Hyalinzellen und die Mehrzahl der Poren. Stengelrinde nicht porös, aussen nicht durchbrochen. Stengelb. verlängert-3-eckig bis länglich, unten breit gesäumt. Astb. schmal lanzettlich bis pfriemelig. VII, VIII.

S. cuspidatum Ehrh.

b. Chlorophyllzellen der Astb. in der Mitte zwischen beiden Blatt- 
flächen eingelagert, im Querschnitt \pm rechteckig, die hyalinen daher beiderseits gleichmässig. Stengelrinde mit sehr kleinen Poren: viele Oberflächenzellen aussen mit verdünnter, zuletzt durchbrochener Membran. Stengelb. zungenförmig, abgerundet, fransig, sehr schmal gesäumt. Astb. sparrig abstehend. länglich-lanzettlich. VII, VIII.

S. squarrosum Pers.

\section{Andreaeaceae (Andreaea).}

Rasen meist zerfallend, grüngelb bis schwarzbraun. Stengel $1-2(-3) \mathrm{cm}$. Laubl. ohne Mittelrippe, eilanzettlich. kurz-schiefzugespitzt, Zellen reichlich mit Tüpteln und grossen Papillen. Einhäusig. Felsen, einzelne Blöcke. VI, VII. A. petrophila Ehrh.

\section{Archidiacene (Archidium).}

Rasenbildendes, Pleuridium-ähnliches Erdmoos; Stengel 1 bis $1^{1 / 2} \mathrm{~cm}$. B. schmal-eilanzettlich, zugespitzt, flach, mit starker Mittelrippe. Einhäusig. IV, V. A. phascordes Bridel

\section{Éphemeraceae.}

2-häusig. Haube kegelig. Kapsel mit Spaltöffnungen, meist mit gelber Wand.

Ephemerum.

B. ohne Rippe. Spaltöffnungen nur am Grunde der Kapselwand. Der Vorkeim bildet auf Uferschlamm und feuchten. thonigen Aeckern smaragdgrüne Teberzüge, auf denen die meist nur $1 \mathrm{~mm}$ hohen Pflänzchen gesellig auftreten. X-IV.

E. serratum (Schreb.) Hampe

\section{Physcomitrellaceae (Pliyscomitrella).}

Einhäusig. Herdenweise auf nacktem Schlamm, saftig-grün. etwas fleischig, bis $3 \mathrm{~mm}$ hoch. Kapselwand am Grunde mit schildförmigen Spaltöffnungen. IX, X. P.patens (Hedw.) Br. et Sch.

\section{Bruchiaceae.}

A. Grünes Protonema nicht ausdauernd. B. lineallanzettlich bis pfriemelig. Kapsel ohne Hals, auf kurzer Seta. Pleuridium.

a. B. gleichartig, nicht schopfig, an der. Spitze weder borstenförmig noch rinnig, weich: Rippe schwach, meist gegen die Spitze erlöschend. Stengel bis 5, B. bis $2 \mathrm{~mm}$. Uferschlamm. Wiesen. IX, X. $\quad P$. nitidum (Hedw.) Rabenh.

b. B. rinnig, steif; obere grösser und schopfig gedrängt; Rippe breit, die ganze Pfriemenspitze ausfüllend. Grosser Luftraum mit Spannfäden in der Kapsel. B. bis $4 \mathrm{~mm}$. Waldränder, Abhänge, Mauererde. III, IV. P. subulatum (Huds.) Rabenh.

B. Grünes Protonema ausdauernd. B. aus breiterem Grunde lang borstenförmig mit breiter, die rinnige Pfriemenspitze ausfüllender Rippe. Kapsel ohne Hals. 
Stengel bis $1^{1 / 2}$, B. bis $2^{1 / 2} \mathrm{~mm}$. Wände von Wiesengräben. IV, V. S. palustris (Bry. eur.) Hampe

\section{Phascaceae.}

A. B. ohne Papillen. Kapsel kugelrund, ohne Spitzchen. Acaulon. Herdenweise, bis $2 \mathrm{~mm}$ hohe Pflänzchen. Schopfb. breit und hohl, ausgeschweift-gezähnt. Aecker, Waldlichtungen, Mauererde. $\mathrm{X}-\mathrm{V}$.

A. muticum (Schreb.) C. Müll.

B. B. \pm warzig-papillös. Kapsel mit Spitze.

Phascum.

Haube kappenförmig. Kapsel eikugelig, kurzgespitzt; Luftraum ohne Spannfäden. Seta kürzer als Kapsel. Bis $10 \mathrm{~mm}$ hohe Pflänzchen, herdenweise. B. länglich-lanzettlich, zugespitzt, hohl, mit starker Rippe. Brachäcker. I[-V.

$P$. cuspidatum Schreb.

\section{Weisiaceae.}

A. Peristom fehlend. Mündung der Urne nach dem Abfall des Deckels noch längere Zeit geschlossen. Hymenostomm. Einhäusig; $\sigma^{\top} \mathrm{Bl}$. zuletzt knospenförmig am Fusse des q Sprosses oder in einer Gabelung. Bis $5 \mathrm{~mm}$, Perichätialb. bis $3 \mathrm{~mm}$. Seta rechts gedreht, bis i) $\mathrm{mm}$; Kapsel länglich. Erdblössen, Wald- und Grabenränder. Frühjahr.

H. microstomum (Hedw.) R. Br.

B. Unenmündung durch die Entdeckelung geöffnet. Peristom \pm ausgebildet.

Ar. Blattflïgelzellen fehlen. Peristomzähne sehr ungleich, hinfällig.

Weisia.

Rasen locker, bis $5 \mathrm{~mm}$ hoch. B. abstehend, verbogen. trocken kraus, aus lanzettlicher Basis lineal-pfriemelig. Seta 3-7 $\mathrm{mm}$; Kapsel fast cylindrisch lïnglich. Wald- und Wegränder, Waldwiesen. XI-V. W. viridula (L.) Hedw.

B1. B. mit erweiterten Blattfliigelzellen.

Dicranoweisia.

Stengel bis $2 \mathrm{~cm}$. B. lineal-lanzettlich. Kapsel cylindrisch. Stroh- und Schindeldächer, Holzzäune, Stammgrund und Wurzeln von Bäumen. III, IV. D. cirrhata (L.) Lindb.

\section{Dicranaceae.}

A. Kapsel mit Spaltöffnungen. Seta gerade. Haubenrand glatt. Peristomzähne bis zur Mitte 2- bis 3-schenkelig.

A1. Hals so lang wie die Urne, mit Schwammparenchym und vielen Spaltöffnungen.

Trematodon.

Rasen bis $10 \mathrm{~mm}$. B. aus länglichem Grunde plötzlich zugespitzt. Kapsel länglich. Feuchter Boden. VI, VII.

T. ambiguus (Hedw.) Hornsch.

B1. Hals kurz, Gewebe dicht, Spaltöffnungen meist spärlich.

A. Besondere Blattflïgelzellen fehlend.

Dicianella,

Zweihäusig. Rasen $1-3 \mathrm{~cm}$. B. aus schmal-lanzettlichem Grunde allmählich lang-rinnig-pfriemenförmig; Rippe 
breit, mit 2 Stereidenbändern. Kiapsel eiförmig, geneigt. Erdmoos. $\mathrm{X}-\mathrm{V}$. $\quad$ D. heteromalla (Dill., L.) Schimp. B2. Blattflïgelzellen erweitert, oft 2-schichtig.

Dicranum.

a. B. glatt, ohne Querrunzeln, lanzettlich-pfriemelig. Seta einzeln. Kapsel mit oft dem Deckel anhaftendem Ring. Rasen bis $4 \mathrm{~cm}$. Felsen, Baumwurzeln etc. VII, VIII. D. scoparium (L.) Hedw.

b. B. querwellig, aus lïnglichem (irunde lineal-lanzettlich. Seten zu $2-5$. Rasen bis $12 \mathrm{~cm}$. Gemein. VJI, VIII. D. undulatum Ehrh. B. Tapsel ohne Spaltöffnumgen. Seta schwanenhalsartig.

A1. l'eristomzähne bis zur Hitte 2-schenkelig. Haube gewimpert. Kapsel gefurcht. Blattriple sehr breit. Campylopus.

Kleine Räschen, bis $4 \mathrm{~cm}$. Stengel spärlich beblättert. Kapsel länglich, gelbgrünlich, Deckel rötlich. Torfiger Waldboden. V, VI. $\quad$ C. turfaceus Bryol eur.

B1. Peristomzähne bis zum Grunde in 2 fïdliche Schenkel geteilt. Haube am firunde mit 1-3 Einschnitten. Kapsel glatt.

Dicranodontium.

Rasen bis $7 \mathrm{~cm}$. B. oft sichelförmig-einseitswendig, lang horstlich, Kapsel länglich. Waldboden, zwischen Steinen und Wurzeln. $\mathrm{X}-\mathrm{V}$.

D. longirostre (Starke) Schimp.

\section{Leucobryaceae.}

Weissgrinliches Sumpfmoos in dichten Polstern, bis 2 dm hoch. B dicht, ohne Rippen und ohne Blattflïgelzellen. Kapsel ohne Spaltöffinungen u. Luftraum.

Lencobryum.

B. aus länglichem Grunde langlanzettlich. Kapsel mit kroptigem, kurzem Hals, länglich, mit 8 rippenartigen Läugsstreifen. Winter; Frühjahr.

L. glaucum (L.) Schimp.

\section{Fissidentaceae.}

Stengel mit Centralstrang. Blattlamina einschichtig. Kapsel mit Spaltöffnungen.

Fissidens.

a. Schenkel der Peristomzähne knotig. Kapsel meist geneigt und symmetrisch. B. ungesäumt, \pm scharf-gesägt, zugespitzt.

๘. Bl. und Kapsel am Hauptspross endständig. B. breit-zungenförmig, am knde plötzlich zusammengezogen, kurz zugespitzt. Dichtrasig, bis $6 \mathrm{~cm}$. Torfwiesen, Holzwehre. VII-X.

F. osmundoides (Swartz) Hedw.

ק. Bl. und Kapsel auf seitlichen Kurztrieben.

I. Bl. und Liapselstiel am Grunde des Stengels. B. gleichmässig gezühnt, Rippe als Stachelspitzchen rortretend. Rïschen locker, bis $2 \mathrm{~cm}$. Erdblüssen in Gebüschen und Grasgärten. $\mathrm{X}-\mathrm{V}$. F. taxifolins (L.) Hedw.

II. BI. und Kapselstiel an der Nitte des Stengels. B. ungleich(an der Spitze scharf-) gesiigt. Rasen locker. bis $12 \mathrm{~cm}$. Sümpfe, Quellen, nasse Felsen. F. adiantoides (L.) Hedw.

b. Schenkel der Peristomzähne spiralig verdickt. B. mit hyalinen Prosenchymzellen gesäumt. Rasig, bis $1 \mathrm{~cm}$. Schattige Erdblössen, Hohlwege etc. $\mathrm{X}-\mathrm{IV}$. F. bryoides (L.) Hedw. 


\section{Ditrichaceac.}

A. Kapsel wenig geneigt und gekrümmt, fast regelmässig-schmalcylindrisch, weder gestreift noch gefurcht.

Trichodon.

B. aus anliegender, halbscheidiger Basis rasch lang-rinnigpfriemenförmig, sparrig abstehend und verbogen. Blattzellen im Scheidenteile linear. im Pfriementeile rechteckig. Herdenweise, bis $1 \mathrm{~cm}$. Waldränder, Hohlwege. VI-VIII.

T. cylindricus (Hedw.) Schimp.

B. Kapsel stärker geneigt, symmetrisch, meist kropfig, gestreift und gefurcht.

Ceratodon.

B. länglich-lanzettlich, gekielt; Blattrand umgerollt; Blattzellen glatt. Seta rot. Peristomzähne gesäumt. Oft kissenförmig-rasig, 2-10 cm. Gemein auf Dächern, Mauern, Felsen, Erdboden. IV, V.

C. purpureus (L..) Brid.

\section{Pottiacene.}

A. B. meist \pm breit (ei- bis spatelfürmig); Nittelrippe nur mit einem Stereidenband auf der Unterseite.

A1. 0 oder 16 flache Peristomzähne, aufrecht oder steil seitwärts gerichtet.

a. Peristom fehlend.

Pottia.

๘. Sporen igelstachelig. Haube schwach papillös. Deckel kegeliggewölbt, stumpfgespitzt. Herdenweise, bis 5 mm, Seta gleichfalls bis $5 \mathrm{~mm}$. Brachäcker, Ërdblössen. X-III.

P. minutula (Schleich.) Bryol. eur.

ß. Sporen feinwarzig. Haube glatt. Deckel flach gewölbt, schief geschnäbelt. Kleine Räschen, bis $4 \mathrm{~mm}$. Ufer, feuchte Wiesen. X-IV. $P$. truncalula (L.) Lindb.

b. Peristomzihne rudimentiir. Deckel \pm schief geschnäbelt. Haube glatt. Lockerrasig, bis $15 \mathrm{~mm}$. Mehr trockene Dämme, Mauern. X-IV. $P$. intermedia (Turn.) Fürnr. c. Peristom deutlich. Decke] schief geschnäbelt. Lockerrasig, bis $6 \mathrm{~mm}$. Mehr trockene Dämme, Mauern. III, IV.

$P$. lanceolata (Hedw.) C. Müll.

R. 32 Jange, stielrund-fädliche, gewundene Peristomzähne.

A2. B. ohne besondere Assimilationsorgane, am Rande meist \pm zurïckgerollt.

a. B. am Rande durch dickwandige Zellen gesïunt.

a. B. breit, nicht in ein Haar auslaufend, stachelspitzig. Blattsaum wulstig, oberwärts 2- bis 3-schichtig. Tubus des Peristoms hoch. Kasen, 1-3 cm. Schattige Abhänge, erdbedeckte Mauern, Felsen, Baumwurzeln, Waldboden. V, VI.

T. subulata (L.) Hedw.

3. B. schmal, obere in ein glattes, am Grunde rotes Haar auslaufend. Blattsaum 1-schichtig. Tubus des Peristoms niedrig. Polster, 5-15 $\mathrm{mm}$ hoch. Dïcher, Nauern, Felsen. V, VI. T. muralis (L.) Hedw.

b. B. am Rande nicht gesäumt, in ein Haar auslaufend.

a. Stengel ohne Centralstrang.' B. ohne Brutzellen. Locker 
rasig, bis $8 \mathrm{~cm}$. Dächer, Manern, Stämme. Sandfelder, schlechte Wiesen. V, VI. T. ruralis (L.) Ehrh.

f. Stengel mit Centralstrang. B. oberseits an der Rippe mit kugeligen Brutknospen. Lockerrasig, bis $8 \mathrm{~mm}$. Stämme frei stehender Bäume. Nur steril bekannt. T. papillosa Wils. $\mathrm{B}_{2}$. Obere Blatthälfte innenseitig an der Rippe mit besonderen Assimilationsorganen. Blattrand flach.

A3. Assimilationsorgane von 2-6 Längslamellen gebildet.

Pterygoneurum.

B3. B. an der Spitze meist kappenförmig. Obere Blatthälfte innenseitig an der sehr breiten Rippe mit einem Polster gegliederter. dichotomisch geteilter, grüner Zellfäden. Aloina. Haube fast bis zur trnenmitte reichend. Lockerrasig, bis $5 \mathrm{~mm}$, Seta bis $15 \mathrm{~mm}$. Erdblössen, Mauerritzen, Felsspalten. $\mathrm{X}-\mathrm{IV} . \quad$ A. rigida (Hedw.) Lindb.

B. B. länglich-lanzettlich. stachelspitzig; Nittelrippe mit einem oberen und einem unteren Stereidenband. Stengel mit deutlichem Centralstrang.

A1. 16 t tief 2-schenkelige oder durch enge Spalten durchbrochene Peristomzähne, aufrecht oder steil seitwärts gerichtet.

Didymodon.

Blattgrund rötlich, Zellen dünnwandig, durchscheinend, verlängert. Blattspitze ganzrandig. Pasen bis $2^{11}$ - cm. Felsen, Mauern, Erde, Rinde, Dächer. VIII-XI. D. mibellus (Hoffm.) Bryol. eur. B1. 32 spiralig gedrehte Peristomïste.

Barbula.

a. Rasen locker. ${ }^{3}{ }_{t}-3 \mathrm{~cm}$, nicht wurelhaarig-verwebt. B. stumpf und stachel-spitzig, Rand \pm umgerollt. Perichaetialb. nicht verschieden. Erdboden, Mauern, Felsen. X-IV.

B. unguiculata (Huds.) Hedw.

b. Rasen dicht. innen wurzelhaarig-verwebt, ${ }^{1} 2-2 \mathrm{~cm}$. Perichaetialh. röhrig-scheidig. B. kurz zugespitzt. am Rande meist Hach. Seta gelb. Trockener Erdboden, Nauern. V, VI. B. convoluta Hedw.

\section{Grimmiaceae.}

A. B. ohne Rippe, mit gewimperter Haarspitze. Kiapsel ohne Peristom. Seta meist kürzer als die Liapsel. Lockerrasig, bis $10 \mathrm{~cm}$. Felsen, Steine. IV, V. H. albicans (Web.) Lindb.

B. B. mit Rippe. Kapsel mit Peristom.

A. Kapsel ohme Luftraum; Spaltöffnungen fehlend oder funktionslos.

A2. Aeste gleichhoch. ๆ $\mathrm{Bl}$. endständig. Haube mützenförmig. Spaltöffnungen funktionslos. Kapsel eingesenkt.

Schistidium.

Centralstrang des Stengels fehlend oder undeutlich. Rasen kissenförmig, bis $2 \mathrm{~cm}$. B. länglich-lanzettlich, zugespitzt. Felsen, Haueru. III, IV. S. apocarpum (L.) Bryol. eur.

B2. Aeste verkürzt. o $\mathrm{Bl}$. astständig. Haube kegelig. Spaltöffnungen fehlend. Stattliche TVassermoose. Cinclidotus. 
Rasen büschelig, locker, bis $2 \mathrm{dm}$. B. weich, lanzettlich, gekielt. In fliessenden Gewässern an Steinen, Wehren, Brücken etc. V, VI. C. fontinaloides (Hedw.) P. Beauv. B. Kapsel mit Luftraum und Spaltöffnungen.

A2. Peristomzähne ungeteilt, durchbrochen oder an der Spitze gespalten. Seta oft gekrümmt.

Grimmia.

Flache Polster, $1^{1 / 2} \mathrm{~cm}$. B. an der stumpfen Spitze in ein langes, feingesägtes Haar auslaufend, Ränder bis oberhalb der Blattmitte umgerollt, Rippe ziemlich gleichbreit. Kapsel mit 9-10 Längsrippen, Haube schief mützenförmig. TrockeneFelsen, Blöcke, Mauern, Dächer, Züune. IV, V. G. pulvinata (L.) Sm.

B.. Peristomzähne bis zum Girunde fadenförmig-zweischenkelig. Seta meist gerade. Blattzellen oft linear. Racomitrium.

Rasen zerfallend, bis $10 \mathrm{~cm}$. B. aus eiförmigem Grunde schmal-lanzettlich-zugespitzt, in ein papillöses, schwach gezïhntes Haar auslaufend. Seta bis $2^{1 / 2} \mathrm{~cm}$, geschlïngelt aufrecht; Kapsel mit farbigen Längsstreifen. Sandige Haide, steinige Triften, zerbröckeltes ('estein. III, IV. R. canescens (Weis) Brid.

\section{Orthotrichaceae.}

A. Haube kappenförmig, olne Falten, klein, hinfällig, nackt.

Zygodon.

Rasen sehr weich, 1-2 cm. In den Blattachseln Brutkörper anf dichotomisch verzweigten Träigern. B. länglich-lanzettlich. Kapsel rot, 8-furchig. Laubholzstïmme in Wäldern. Frühling. Z. viridissimus (Dicks.) R. Br.

B. Haube kegelig-glockig, gross. mit 11-16 Lü̈ngsfalten.

A1. B. trocken kraus, am firunde eiförmig und meist mit wasserhellem saume. Spaltöftinungen im Halsteil. Haube dicht mit krausen Haaren.

Ulota.

Polster weich, bis $2 \mathrm{~cm}$. B. lineal-lanzettlich, feucht geschlängelt. Walubäume. VII, VIII. U. crispa (L.) Brid.

B1. B. nicht kraus, am (irunde nicht eiförmig und ohne wasserhellen Saum. Spaltöffnungen im Crinenteil. Haube oft nackt. Peristom oft doppelt.

Orthotrichum.

a. Aeusseres Peristom mit 8 Doppelzähnen. Haube \pm behart. Lockerrasig, bis $4 \mathrm{~cm}$. Kapsel mit 8 Längsstreifen. Bäume, Sträucher, Steine. V, VI.

b. Aeusseres Peristom mit 16 Zühnen. Haube spärlich papillösbehaart.

๑. Finhäusig. Kapsel glatt, ohne Streifen. Polster, bis $3 \mathrm{~cm}$. Einzelne Laubbäume. V. O. leiocarpum Bryol. eur.

अ. Zweihäusig. Kapsel mit 8 Längsstreifen. Rasen bis 1',2 cm. Frei stehende Bäume, Züune, Schindeldächer. IV, V. O. obtusifolium Schrad.

\section{Encalyptaceae (Encalypta).}

Polsterchen bis $1 \mathrm{~cm}$. B. länglich-zungenförmig, Rippe sehr breit. Seta rot. Kapsel ungestreitt, glatt. Peristom fehlend. Erdlehnen, Hohlwege, Maner- und Felsspalten. IV-VI. E. vulgaris (Hedw.) Hoffm. 
Schistostegaceae. - Splachnaceae. - Funariaceae. - Bryaceae. 41

\section{Schistostegaceae (Schistostega).}

Das oberirdische Protonema leuchtend. Sterile Zweige farnblattartig. Rasen locker, weich, bis $10 \mathrm{~mm}$. Felshöhlen. Erdlöcher etc. V, VI.

S. osmundacea (Dicks.) Mohr

\section{Splachmaceae.}

Apophyse (Hals) breiter als die Urne, aufgeblasen. Peristomzäline innen gekammert. Stengel mit echten Blattspuren. Auf Exkrementen.

Splachnum.

Rasen weich, $2(-4) \mathrm{cm}$. Obere B. bis 4 mal grösser. B. aus verschmälertem (irunde verkehrt-eiförmig, nach der Spitze hin unregelmässig gezähnt. Seta $5(-10) \mathrm{cm}$. Apophrse birnfürmig. In Sümpfen und Nooren auf Rindermist. VII, Vill. S. ampullaceum L.

\section{Funariaceae.}

A. Kapsel regelmässig, aufrecht, fast kugelig oder kurz birnfürmig. ohne Luftraum.

A. Haube mützenförmig 3. bis 5-lappig, hinfällig. Peristom fehlend.

Physcomitrium.

Kapsel engmündig, mit bis 15 Reihen niedriger, querrechteckiger Zellen; Ring 2-reihig. B. verkehrt-eilanzettlich, bis zur Nitte herab gesägt. Herdenweise, bis $5(-10) \mathrm{mm}$. Feuchte Aecker, Wiesen. Ufer. V. P. pyriforme (L.) Brid.

$B_{1}$. Haube blasenförmig, gross, lange bleibend.

A.. Haube zur Fruchtreife kappenförmig bis zur Urnenmitte reichend. Peristom rudimentïr oder einfach. Eutosthodon.

Blattrand nicht gesäumt. Seta gerade, Kapsel aufrecht. $\mathrm{V}, \mathrm{VI}$.

E. fascicularis (Dicks.) C. Müll.

B. Haube zur Fruchtreife die ganze Trne eimhüllend, 4-kantig. Peristom fehlend.

Pyramidula.

Räschen locker, bis $2 \mathrm{~mm}$. B. verkehrt-eilïnglich, lang zugespitzt. Feuchte Aecker und Abhänge, Ufer. VI.

P. tetragona Brid.

B. Kapsel schief birnförmig, geneigt oder hängend; Haube blasigkappenförmig; Peristom doppelt. Zwischen Sporensack und Urnenwand ein weiter Luftraum mit langen Spannfäden.

Funaria.

Kapsel gestreift, tief gefurcht, entleert weitmündig; Ping sich abrollend. Rasen ziemlich dicht, bis $3 \mathrm{~cm}$. B. verkehrteilänglich. kurz zugespitzt. Gemeines Erdmoos. VI-IX.

F. hygrometrica (L.) Sibth.

\section{Bryaceae.}

I. Kapsel nicht lïngsstreifig. Inneres Peristom nur an der Basis aus einer 16-kielfaltigen Membran gebildet.

1. Seta gerade; Kapsel aufrecht oder geneigt, verlängert, langhalsig. [Meeseeae.] 
A. Beide Peristome gleichlang, Zühne spitz. Blattzellen mamillös. Paluclella.

Rasen dicht, bis $1 j \mathrm{~cm}$. B. eilanzettlich, hakig zurückgekrümmt. Tiefe Sümpfe. VI, VII. P. squarrosa (L.) Brid. B. Zähne des ausseren Peristomes stumpf, kürzer als die des inneren. Blattzellen glatt.

A1. Blattzellen locker, dünnwandig, rhombisch bis 6-seitig. Inneres Peristom ohne Wimpern und hinfällige Netzhaut. Amblyodon.

Rasen locker, bis $15 \mathrm{~cm}$. B. aufrecht abstehend, länglichlanzettlich. 'Torfwiesen. VI. A. dealbatus (Dicks.) P. Beauv. B1. Blattzellen oben derbwandig, klein, meist rechteckig. Inneres Peristom mit rudimentären Wimpern und hinfälliger Netzhaut.

Meesea.

Rasen bis $15 \mathrm{~cm}$. B. 3-zeilig geordnet, flachrandig, aus eilänglichem Grunde scharf zugespitzt, sparrig abstehend. 'T'orfmoore, schaukelnde Sümpfe. VI. MI. triquetra (I.) Aongstr.

2. Seta an der Spitze hakig gebogen, Kapsel dadurch nickend oder hängend. Inneres Peristom so lang als das äussere, mit \pm klaffenden, kieligen Fortsätzen und meist mit Cilien: Zähne des äusseren innen mit Querlamellen. Blattzellen ohne Papillen.

1. Blattzellen oben parenchymatisch ti-seitig. o Bl. scheibenförmig. Paraphysen keulig. liapsel mit undeutlichem Hals, eilänglich oder elliptisch. Wimpern zwischen den Zähnen des inneren Peristomes ohne hakige Anlä̈ngsel. [Mnieac.] An feuchten, schattigen Stellen im Walle.

Mnimin.

a. B. nicht von einem verdickten liande gesäumt. Blattzellen nicht in schiefen Reihen geordnet, oben gleich gross. Rasen weich, bis $6 \mathrm{~cm}$. V.

M. stellare Reich.

b. B. von einem gewöhnlich verdickten Rande gesäumt.

a. Blattzellen nicht in schiefen Reihen geordnet.

I. Blattsaum einschichtig. Blattzellen nach der Rippre zu viel grüsser werdend. B. schmal zungenförmig. emreihi@ gesägt, wellig. Bäumchenförmig, bis $12 \mathrm{~cm}$. V, VI.

M. undulatum (L.) Weis

II. Blattsaum dickwulstig, mehrschichtig. Blattzellen oben gleichgross. B. schmal, wellig, am Rande zweireihig kurz gezïhnt. Rasen bis $6(-10) \mathrm{cm}$, dicht, oft schwellend. IV, V.

M. hornum L.

Blattzellen in divergenten Reihen, vom Rande gegen die Rippe allmählich viel grösser.

I. Blattsaum einschichtig, am Rande einreihig gesägt.

1. ૪. Sporogone immer einzeh. Kapsel elliptisch. Blattzähne 1 - bis 2-zellig. Rasen locker, bis $4 \mathrm{~cm}$. IV, V.

M. cuspidatum (L.) Leyss.

2. Zweihäusig. Sporogone oft zu $2-5$. Kapse] länglich. Blattzähne 2. bis 4-zellig. Rasen locker, bis $8 \mathrm{~cm}$. V. M. affine Bland.

II. Blattsaum ganzrandig, breit, dickwandig, meist wulstig. Kapsel oval. Rasen locker, bis $5(-10) \mathrm{cm}$. SpätherbstFrühling. M. punctatum (L.) Hedw. 
2. Blattzellen oben rhombisch-6-seitig. 그. Bl. knospenförmig. Paraphysen fädlich. Kapsel durch den oft sehr ansehnlichen Hals birnen- oder keulenförmig. mit Ring. Wimpern knotig oder mit Anhängseln. [Bryeae.]

A. B. schmal lanzettlich, meist glänzend; Blattzellen eng. oberwärts verschmälert rhombisch bis linear.

A1. B. lineal-lanzettlich. schmalrippig. abstehend, trocken geschlängelt.

Webera.

B1. B. langpfriemelig, breitrippig. Auf mebr trockenem Waldund Torfboden.

Leptobryum.

Rasen lucker, 2-3 cm. Lockerer Sand, Torf. Mauerritzen, Schutt etc. V, VI. L. pyriforme (L.) Schimp.

B. B. breiter, eifürmig oder eilanzettlich. Blattzellen lockerer, oberwärts nur rhombisch bis rhomboidisch.

Bryum.

a. Inneres Peristom dem äusseren \pm anhängend. Cilien ohne Anhängsel, meist rudimentär. Rasen dicht, bis $1 \mathrm{~cm}$. Erdblüssen. Mauern, Felsen. V. TI. B. pendulum Hornsch.) Schimp.

b. Inneres Peristom frei. Wimpern vollständig, mit Anhängseln.

\%. $\mathrm{B} \pm$ abstehend. Blattränder gesäumt.

I. B. breit eiförmig. in eine gezähnte, lange Haarspitze ausgezogen, trocken spiralig um den Stengel gedreht. Saum einschichtig: Pasen ziemlich dicht. weich, bis $3 \mathrm{~cm}$. Mässig feuchte standorte. VI-VIII. B. capillare L. II. B. durch die austretende Rippe lang zugespitzt, trocken nicht verbogen, längs ungerollt, am Rande undeutlich gesäumt. Kissen, $2^{1} 2 \mathrm{~cm}$. Gemein. T, VI. B. crespiticium L.

¿. B. dicht dachziegelıg anliegend, am Pande nicht gesäumt. flach- und ganzrandig, mit scharfer, verlängerter Spitze. Rasen bis - $\mathrm{cm}$, hellgrün bis silberweiss, trocken seidenglänzend. Gemein. Frühling, Herbst. B. argenteum L.

II. Kapsel längsstreifig, aufrecht oder geneigt auf gerader Seta.

1. Kapsel fast kugelig. Inmeres Peristom kürzer. Wimpern fehlend oder kurz. [Bartramieae.]

A. Stengel monopodial oder dichasial verzweigt; Aussenrinde kleinzellig. Blattgrundzellen verlängert-rechteckig oder linear. Blattrand umgerollt. gesägt. Erdmoose.

Bartramia.

a. Blattgrund halbscheidig. zart und weiss. Seta kurz. niedergebogen. B. einseitswendig, trocken geschlängelt. Rasen bis $15 \mathrm{~cm}$. VI, VII.

B. Halleriana Hedw.

b. B. kraus; Blattgrund nicht scheidig. gelbgrün. Seta verlängert. Rasen bis \& cm. VI. VII. B. pomijormis (L.) Hedw.

B. Stengel quirlästig verzweigt; Aussenrinde wie bei Sphagnum. Blattgrundzellen locker.

Philonotis.

Pasen bläulich- bis gelbgriun, 5 bis $15 \mathrm{~cm}$. B. eilanzettlich. Quellen, nasse Felsen, Bäche, Sümpfe. V, VI.

P. fontana (L.) Brid.

2. Kapsel länglich-cylindrisch. Inneres Peristom mit klaffenden Fortsätzen und $2-4$ knotigen Wimpern. [Aulacomieae.]

A. Blattgrundzellen einschichtig, grün, von den nächsthöheren nicht verschieclen. Bl. knospenfürmig.

Aulacomnium. 
Rasen dicht polsterförmig, 1-5 cm. Oft kurze, wenigblättrige Pseudopodien, die ein kugeliges Köpfchen mit Brutknospen tragen. B. lanzettlich, in der unteren Hälfte am Rande umgerollt, an der scharfen Spitze ausgefressen-gezähnt. Feuchtschattige Baumstïmpfe, IVurzeln, Felsen. VI-VIII. $A$ androgynum (L.) Schwägr.

B. Blattgrundzellen 2- bis 3-schichtig, gebrïunt, etwas aufgeblasen. o $\mathrm{Bl}$. scheibenförmig.

Rasen fast locker, $10-12 \mathrm{~cm}$. B. lanzettlich, gekielt, an der meist scharfen Spitze ausgefressen-gezähnt. Sümpfe. V, VI.

G. palustris (L.) Fries

\section{Polytrichaceae.}

A. Kapsel ohne Spaltïffnungen, stielrund. Epidermis nicht getüpfelt.

A1. Epidermis der Urne glatt. Haube nackt, an der Spitze rauh. B. nicht scheidig, Ränder wulstig-gesäumt, doppelzähnig. Lamellen spärlich, auf die Rippe beschränkt. Catharinaea.

Herienweise, $1-8 \mathrm{~cm}$. Untere B. schuppenförmig, mittlere lanzettlich, oberste schmal zungenförmig, querwellig. Erdmoos. Spätherbst bis Frihling. C. undulata (L.) Web. et Mohr B1. Epidermis der Urme mit Ausstiilpungen oder papillös. Haube filzig. B. scheidig, Ränder einschichtig, nicht gesäumt, einfach gesägt. Lamellen zahlreich, nicht auf die Rippe beschränkt.

Pogonatum.

a. Herdenweise, olivengrïn bis rotbraun; Stengel einfach, 4 bis $10 \mathrm{~mm}$. Urnenepidermis dicht und fein papillös. Innerer Sporensack mit der Columella verschmolzen. Krdmoos. Winter, Frühling. P. nanum (Schreb.) P. Beauv.

b. Herdenweise; Stengel einfach $1-2 \mathrm{~cm}$. Urnenepidermis mit Ausstiilpungen. Sporensack beiderseits mit spannfäden. Erdmoos. Spätherbst. Winter. $P$. aloides (Hedw.) P. Beaur.

c. Rasen locker, 2-3(-10) cm, bäulich griin, später braun. Stengel hochstaimmig, gabelig oder büschelig geteilt. Urnenepid. u. Sporens. wie bei h. Erdmoos. Winter. P. umigerum (L.) P. Beauv.

B. Kapsel mit Spaltöffnungen, 4- bis 6-kantig. Haube dicht-filzig: B. scheidig; Lamellen zahlieich, nicht auf die Rippe beschränkt.

Polytrichum.

a. Epidermis der Une ohne Tüpfel; Hals halbkugelig, undeutlich gesondert. B. am Rande scharf gesägt; Lamellen nicht oder nur undeutlich gezähnelt, aus gleichartigen, nicht verdickten Zellen gebildet.

๘. Zellen der Blattspreite gross. Kapsel kantig-eiförmig. Grunchaut des Peristoms nicht vortretend. Rasen dicht, $3-10 \mathrm{~cm}$, gelbgrün; Stengel unterwärts stark filzig. Torf. V, VI.

$P$. gracile Dicks.

$\beta$. Zellen der Blattspreite klein. Kapsel prismatisch. Grundhaut des Peristoms deutlich vortretend. Rasen locker, 10 bis $15 \mathrm{~cm}$, sattgrün; Stengel nur am tiefsten Grunde filzig. Waldboden. V, VI.

P. formosum Hedw. 
Georgiaceae. - Buxbaumiacene. -- Fontinalaceae. - Leskenceae. 45

b. Epidermis der Lme mit Tüpfeln; Hals abgeschnürt scheibenförmig. Blattlamellenrand durch grössere Zellen gesäumt und gezähnelt.

๗. Blattränder grob und scharf gezähnt, schmal, flach; Lamellenrand mit Längsfurche. Rasen locker, $20-40 \mathrm{~cm}$. Grösstes Frdmoos, gemein, aber Kalk meidend. V-VII. P. commune L.

5. Blattränder ungezähnt, breit, eingebogen; Lamellenrand ohne Längsfurche.

I. Blattgranne kurz, braumrot, stark gesïgt. Bis 48 Lamellen. Rasen 5-10 cm. Haide, Abhänge, schlechte Wald- und Bergwiesen. VII, VIII. $P$. juniperinum Willd. II. Blattgranne weisslich, feingesïgt. 20-32 Lamellen. Rasen $2-3(-5) \mathrm{cm}$. Diurre, sandige oder steinige Orte. V-VII. $P$. piliferum Schreb.

\section{Georgiaceae.}

Blattrippe deutlich. Haube nur bis unter den Deckel reichend. Kapsel cylindrisch, ohne Spaltöffnungen. Sporensack direkt anliegend.

Georgia.

Rasen bis $3 \mathrm{~cm}$, mit Brutsprossen, die den o ähneln und in einer meist aus 4 breit herzförmigen B. gebildeten, becherartigen Hülle zahlreiche zartgestielte, linsenförmige Brutscheiben zwischen os Paraphysen tragen. Feuchtschattige Baumstïmpfe, Wurzeln, Torf boden. Felsen. V-TII. G. pellucida (L.) Rab.

\section{Buxbaumiaceae.}

A. Kapsel fast sitzend, in die Perichätialb. eingeschlossen.

Diphyscium.

Rasen bis $6 \mathrm{~mm}$. B. lineal-zungenförmig, Rippe in lange Granne auslaufend. Waldwege, Gräben, Schluchten. VII, VIIl.

D. foliosum L.

B. Kapsel auf roter, warziger, bis $2 \mathrm{~cm}$ langer Seta. B. bei der Sporenreife verschwunden.

Buxbaumia.

Einzeln oder truppenweise, Stengel kaum $1 \mathrm{~mm}$. B. klein, eiförmig, durch eine Medianwand halbiert, ohme Spur von Mittelrippe. Hohlwege und Erdlehnen in Nadel- und Buchenwäldern. IV-VII.

B. aphyila $\mathrm{L}$.

\section{Fontinalaceae.}

B. rippenlos. Kapsel eingesenkt. Haube kegelmützenfürmig.

Fontinalis.

Stengel $2-3 \mathrm{dm}$, ästig, scharf 3-kantig beblättert. B. einachenförmig, längs des Kieles stark gefaltet. Im Wasser. VII, VIII. F. antipyretica (Dill.) L.

\section{Leskeaceae.}

1. Kapsel aufrecht, gerade, walzenförmig; inneres Peristom ohne Wimpern. Stengel zerstreut-ästig. Stengelb. und Astb. gleichgestaltet. [Leskeeae.] 
A. Stengel sehr zart, kurzfädlich, ohne Ausläufer. Kapsel stengelständig. Zweigspitzen nicht schopfig verdickt. Leskea.

a. Rasen verworren. B. hohl, kurz zugespitzt. Kapsel gelbrötlich, oft sanft gekrïmmt. Züihne des inneren Peristoms so lang wie die äusseren. Weiden, einzelne Steinblöcke. V, VI. L. polycarpa Frh.

b. Rasen dicht. B. etwas hohl, lang zugespitzt. Kapsel braun, gerade. Zähne des inneren Peristoms kürzer als die des iusseren. Stämme, Felsen. V, VI. L. nervosa (Schwägr.) Rah).

B. Stengel stärker und länger, mit gebüschelten, aufrechten, Ausläufer treibenden Aesten. Kapsel astständig. Zweige meist schopfig verdickt.

Anomodon.

a. Stengel und Aeste dünn. B. aus schmalerem, herablaufendem Grunde eilanzettlich. Seta hellpurpurrot. Kapsel ringlos. Stämme, Wurzeln, Felsen. IX, X. A. attenuatus (Schreb.) Hüben.

b. Stengel und Aeste ziemlich kräftig. B. aus eiförmigem Grunde länglich-lanzettlich. Seta strohgelb. Kapsel mit schmalem Ring. Feuchtschattig: Erde, Stämme, Felsen. Winter, Frühling. A. viticulosus (L.) Hook et Tayl.

2. Kapsel ïbergeneigt und einwärts gekrümmt. Inneres Peristom mit langen Wimpern. Stengel wedelartig, fiederig-ästig. Stengelb. und Astb. verschieden gestaltet. [Thuidieae.]

Thuidium.

a. Stengel mit roten Wurzeln angeheftet und abwechselnd bogig aufsteigend, 2- bis 3-fach gefiedert.

a. Stengel zierlich 3-fach gefiedert. Stengelb. aus 3eckig-herzförmigem Grunde lang zugespitzt, gezähnt. Perichätialb. in eine lange Spitze mit fadenförmigen Wimpern auslaufend. Kapsel ohne Ring. Waldboden, Felsen. VIII, IX.

T. tamariscinum (Hedw.) Br. et Sch.

¡. Stengel meist doppelt gefiedert. Stengelb. am Grunde deutlich 3eckig. Perichätialb. mit nur gezïhnter Spitze. Kapsel mit schmalem Ring. Wälder, Steine, trockene Wiesen. VI, VII. T. delicatulum (L.) Br. et Sch.

b. Stengel aufsteigend, ungeteilt oder einfach gefiedert. Stengelb. breit eilanzettlich. Kapsel mit breitem Ring. Sonnige Abhänge. V, VI.

T. abietinum (L.) Br. et Sch.

\section{Neckeraceae (Neckera).}

a. 2-häusig. Kapsel eingesenkt. Hauptäste bis $1 \mathrm{dm}$ lang, steif aufrecht. B. länglich-zungenförmig, querwellig, rippenlos. Laubbäume. III, IV.

N. pennata (Dill.) Hedw.

b. 1-häusig. Kapsel länger gestielt, über die Perichätialb. hervortretend.

a. B. querwellig. Hauptäste bis $2 \mathrm{dm}$. Bäume, Felsen. V, VI.

N. crispa (L.) Hedw.

ß. B. flach. Hauptäste bis $1 \mathrm{dm}$. Eichen, Buchen, Felsen. N. complanata (L.) Hüben.

\section{Hypnaceae.}

I. Kapsel aufrecht, symmetrisch, nicht oder nur wenig gekrümmt. Seta (ausser bei Homalothecium) glatt. 
1. Inneres Peristom, wenn vorhanden, ohne Wimpern, ohne oder mit nur sehr schmaler Grundhaut. [Cylindrothecieae.]

A. Peristom einfach, 16-zähnig. B. rippenlos, scharf längsfaltig. Stengel kriechend, mit bogig aufsteigenden Aesten. B. breit eiförmig, zugespitzt. Seta rötlich. Haube die längliche Kapsel ganz einhüllend. Stämme, Felsen. Winter.

Lencodon sciuroides (L.) Schwaegr.

B. Peristom doppelt.

A1. B. ohne Rippe, nicht gefaltet. Haube über die halbe Kiapsel hinabgezogen, Ring 3-reihig.

Platygyrium.

B. schmal eiförmig, in eine Spitze zusammengezogen. Bäume, Zäune, Strohdächer. V. VI. P. repens (Brid.) Br. et Sch. B1. B. mit Rippe, gefaltet. Kapsel ohne Ring.

A2. Wuchs bäumchenförmig. Haube die ganze Kapsel einhüllend.

Climacium.

Hauptstengel unterirdisch kriechend. B. ei- oder länglichlanzettlich. Feuchte Wiesen etc. X, XI.

$C$. dendroides (Dill.) W. et $\mathrm{M}$.

B2. Hauptstengel kriechend, Hauptäste hängend oder liegend. fast fiederig. Haube die halbe Kapsel einhüllend.

Antitrichia.

B. eilanzettlich, zugespitzt, an der Spitze gezähnt, am Rande umgerollt. Waldbäume, Felsen. III, IV.

A. curtipendula (L.) Brid.

2. Inneres Peristom mit Wimpern und mit einer sehr hohen, 16 mal kielig gefalteten Grundhaut. Haube etwa die halbe Kapsel einhüllend. [Pylaisieae.]

A. Stengel rund beblättert. Deckel nicht oder gerade-geschnäbelt. A1. B. ohne Rippe. Deckel ohne Schnabel. Seta glatt.

A2. Hauptstengel kriechend. B. nicht gefaltet. Kapselring 1-reihig. Inneres Peristom länger als das äussere.

Pylaisia.

Hauptstengel fast fiederästig, bis $5 \mathrm{~cm}$. B. aus breitem Grunde lanzettlich; Zellen linear, in den Flïgeln \pm quadratisch. Stämme und Wrurzeln einzeln stehender Bäume. $\mathrm{X}$-III.

$P$. polyantha (Schreb.) Schimp.

B2. Hauptstengel niederliegend. B. gefaltet. Kapselring 2-reihig. Inneres Peristom so lang als das äussere. Orthothecium.

B. lanzettlich-pfriemelig. Felsen. VIII.

O. intricatum (Hartm.) Br. et Sch.

B1. B. mit Rippe. Deckel geschnäbelt. Kapselring 3-reihig.

A2. Seta glatt. B. nicht gefaltet.

Isothecium.

B. eilänglich, kurz zugespitzt, hohl, oberwärts gezähnt. Aeste bis $1 \mathrm{~cm}$ lang. Wälder, auf Baumwurzeln und Steinen. Spätherbst und Frühling. I. myurum (Poll.) Brid.

B. Seta sehr rauh. B. gefaltet.

Homalothecium.

Haube am Grunde oft kurzhaarig. B. länglich-lanzettlich, feingesägt. Perichätialb. pfriemelig zugespitzt. Stengel bis $10 \mathrm{~cm}$, Aeste 2-zeilig, gekrümmt. Stammgrund, Felsen, Mauern. XI-III. H. sericeum (L.) Br. et Sch. 
B. Stengel und Aeste verflacht-2reihig-beblïttert. Deckel schief geschnäbelt.

Homalia.

B. zuletzt abwärts gekrümmt, länglich bis fast elliptisch. stumpflich, am Grunde schmäler, an einer Seite umgeschlagen; untere Zellen linearisch, mittlere rhomboidalisch, obere rhombisch, in den Flügeln wenige quadratische. Stammgrund $u$. Gestein in schattigen Wäldern. VIII, IX.

H. trichomanoides (Schreb.) Br. et Sch.

II. Kapsel übergeneigt, unsymmetrisch, \pm gekrümmt. Seta oft rauh. Inneres Peristom auf einer hohen Grundhaut, fast immer mit Wimpern. [Camptocarpae.]

1. Kapseldeckel kegelig, stumpf oder mit kurzer Spitze. [Hypneae.] A. Blattzellen nie lineal.

A1. Kapsel \pm länglich bis cylindrisch. Seta stets glatt.

A. Aeste nicht verflacht-beblïttert. Blattzellen (wenigstens im unteren Teile des B.) parenchymatisch. B. ohne oder mit einfacher Rippe.

Amblystegium.

a. B. eilanzettlich. Alle Blattzellen weit parenchymatisch, dïnnwandig, locker, am Grunde quadratisch; Blattrippe wenig deutlich. Erde, Holz, Steine, Mauern. V.

A. serpens (L.) Br. et Sch.

b. Stengelb. einseitswendig, lanzettlich, ganzrandig. Zellen am Blattgrunde parenchymatisch, die übrigen prosenchymatisch (schmal u. spitz 6-seitig). Feuchtes Holz, Steine in und an Gewässern. VI, VII. A.riparium (L.) Br. et Sch.

B.. Aeste \pm verflacht-beblättert, an ihrem Grunde die Kapseln. B. scheinbar 2-zeilig, mit doppelter Rippe; Blattzellen rhomboidisch.

Plagiothecium.

a. B. hellgrïn, seidenglänzend, ungleichseitig, eilanzettlich; zuweilen an der Spitze gezähnt. Seta $1-2 \mathrm{~cm}$. In Wïldern. V-VIII. P. denticulatum (Dill.) Br. et Sch.

b. B. weisslichgrün, eilanglich, kurz zugespitzt, querrunzeligwellig. Seta $5 \mathrm{~cm}$. VII, VIII. P. undulatum (L.) Br. et Sch.

B1. Kapsel kurz-eiförmig. B. gerippt. Blattzellen rhomboidisch6-scitig, an den Flïgeln quadratisch. Brachythecium.

a. Seta glatt.

๙. Einhäusig, seidenglänzend. kriechend, 7-12 cm. B. eilanzettlich, gesägt, ziemlich breit zugespitzt. Deckel kegelig. Erde und Baumwurzeln in Wäldern und Gärten, Strohdächer. X-III. B. salebrosum (Hoffim.) Schimp.

\%. Zweihäusig, strohfarben, auf'steigend, $5-8 \mathrm{~cm}$. B. eilänglich, ganzrandig, mit deutlicher Haarspitze. Deckel gespitztkegelig. Trockensandige und grasige Stellen. Frühling.

B. albicans (Neck.) Br. et Sch.

b. Seta rauh. B. lanzettlich, lang zugespitzt.

o. Seta nur oberwärts rauh. B. gedrängt, an der Spitze schwach gesägt. Deckel zugespitzt. Kapselring schmal. Baumwurzeln, Steine. IX-IV. B. populeum (Hedw.) Br. et Sch.

F. Seta vom Grunde an warzig-rauh. B. \pm locker, abstehend, durchaus gesägt. Deckel spitz. Kapselring breit. Wälder. IV, V. B. velutinum (Dill.) Br. et Sch. 
B. Blattzellen sehr schmal, linealisch.

t. B. nicht gefaltet, ungefurcht oder gefurcht. S'eta glatt.

A2. Kapsel walzenförmig oder ]änglich.

a. B. allseitswendig. Nebenb. fehlend.

Hурити.

$\because$ B. sparrig, an den Astspitzen sternförmig-abstehend, eilanzettlich, ganzrandig, rippenlos. Stengel aufrecht oder kriechend, deste \pm nicderliegend. Sumpfwiesen. VII. VIII.

H. stellatum Schreb.

F. B. aufrecht-abstehend oder anliegend, meist stumpf eilänglich. Stengel kräftig, aufrecht.

I. Sumpfmoose. B. aufrecht-alsstehend, ganzrandig.

1. Einhäusig. Stengel schlank, über $10 \mathrm{~cm}$, wenig ästig. oder astlos. B. herzeiförmig. T. VI. H. cordifolizm Hedw.

2. Zweihäusig. Stengel \pm fiederästig.

+ Rasen sehr kräftig, grün, 2-3 dm. B. herzeiförmig. Kapsel klein, ohne Ring. V, VI. H. giganteum Schimp. ++ Rasen weniger kräftig, $5-10 \mathrm{~cm}$. B. eilanzettlich, stumpf oder kurz zugespitzt. Kapsel gross mit breitem Ring. V, VI.

II. Wald- und Wiesenmoose. B. \pm anliegend.

1. Stengel entferntblätrig, braunrot durchschimmernd. B. fast flach, eilänglich, ganzrandig. Kapsel obne Ring. Spätherbst, Winter.

H. Schreberi Willd.

2. Stengel dichtheblättert. B. breit-eielliptisch. Kapsel mit breitem Ring. VIII-XI.

H. purum L.

๖. B. -einseitswendig, meist scharf zugespitzt, sichelförmig gekrïmmt bis schneckenförmig eingerollt.

\%. Nebenb. fehlend. Stengel unregelmässig gefiedert, nicht bewurzelt. B. sichelförmig, nicht gewellt, mit deutlicher einfacher Rippe; Zellen linear, an den Flügeln quadratisch.

1. Zweihäusig. B. eilänglich, kurz zugespitzt, ganzrandig. Stengel selır dick, kräftig, 1-3 dm; Aeste herabgekrümmt. Sümpfe. V, VI.

H. scorpioides L.

II. Einhäusig. B. sichelfürmig, lang zugespitzt. Stengel schwach, meist niederliegend.

1. B. nicht gefurcht, meist ganzrandig. Sümpfe. V, VI und Spätherbst.

H. fluitans L.

2. B. tief gefurcht, zart gesägt. Stämme, Felsen, Geröll, Grasplätze. V-VII. H. uncinatum Hedw.

?. Nebenh. \pm zahlreich. B. schmal sichelfürmig, mit \pm schneckenförmig eingerollter Spitze. Stengel \pm niederliegend, bewurzelt, \pm regelmässig gefiedert.

I. Stengel entfernt gefiedert. B. hohl, ganzrandig oder nur an der Spitze gesägt. Erde, Felsen, Dächer, Bäume. XI-IT.

H. cupressiforme L.

II. Stengel dicht kammartig gefiedert. B. ungefaltet, rings kleingesägt. Waldboden, nasse Felsen, Gräben, Sümpfe. V-VIII.

H. molluscum Hedw.

B.. Kapsel eiförmig, kurz und dick. B. kurz zweirippig.

Hylocomium.

a. Ohne Nebenb. Stengel einfach fiederig-ästig. Stengelb. breit- 
eiförmig aus fast scheidigem frunde, am Rücken durch Zähne rauh, fast ringsum scharf gesägt. Wälder. V-IX. H. triquetrum (L.) Br. et Sch.

b. Mit grossen, gabelig oder handfürmig geteilten Nebenb. Stengel regelmässig doppelt-fiederäistig. Stengelb. eilänglich, etwas querfaltig, rings klein gesägt. Wälder. [V-VI.

H. splendens (Hedw.) Br. et Sch.

B1. B. tief lïngsfaltig, lanzcttlich, steif, aufrecht abstehend, einrippig. Kapsel länglich-walzenförmig, gekrümnt.

Camptothecium.

a. Kapselstiel glatt, $4 \mathrm{~cm}$ lang. Stengel aufrecht, mit braunem Wurzelfilz. Sumpfwiesen. (¿ nitens (Schreb.) Schimp.

b. Kapselstiel rauh, $1-2^{1}, \mathrm{~cm}$. Stengel niederliegend, mit aufsteigenden Aesten, olne Wrurzelfilz. Grasplätze. IV, V.

C. lutescens (Huds.) Br. et Sch.

2. Kapseldeckel lang geschnäbelt. [Eurhynchieae.]

A. Bäumchenartig. Zellen am (irunde und Rande des B. länglich, an seiner Spitze klein 6-eckig. quadratisch oder rumdich, parenchymatisch.

Thamnium.

Hauptstengel meist unterirdisch kriechend. Fruchtstengel bis zur Mitte astlos. Aeste fist genau 2-reihig. B. allseitswendig, eilänglich his lanzettlich, gesägt. Quellen, feuchte Schluchten etc. IX-IV. T. alopecurum (L.) Br. et Sch.

B. Nicht häumchenartig. Blattzellen meist lang und schmal. rhomboidisch- his lineal-scehsseitig.

a. Seta glatt.

\%. Finhä̈usig. B. nicht gefurcht. S'tengelh. dachziegelig, sehr hohl, stumpf oder plïtzlich ganz kurz zugespitzt, ganzrandig. Flach- und dichtrasig. Feuchte Steine und Mauern. III, IV. E. murale (Hedw.) Br. et Sch.

F. Zweihäusig. 13. \pm gefurcht. Stengelh. gedrängt, fast sparrig. aus breit herzförmiger Basis plötzlich lanzettlich, kurz zugespitzt, rings schwach gesaigt. Bogig kriechend. lockerrasig Waldbolen. XL-IT. E. striatum (schreb.) Br. et Sch.

b. Seta warzig rauh. Zweihäusig. B. \pm gefurcht, \pm dicht, aufrecht-abstehend, langeiförmig, plötzlich haarspitzig, gegen die Spitze gesägt, hohl. hriechend, lockerrasig. Wälder, Gräben. quellige Wiesen. III-T. E. piliferum (Schreb.) Br. et Sch.

\section{Filicales.}

I. Einerlei Sporangien und Sporen. Prothallien selbständig, relativ gross. [Filnces.]

1. Sporangien frei auf der Lnterseite meist gewöhnlicher, selten einigermassen umgeformter B. entstehend. Prothallien oberirdisch, Hach, in der von Archegonien freien Region nur einschichtig ['lanithallosae.]

1'. Ohme Nebenb. Sporangien nur aus einer Epidermiszelle entstehend; Ring (d. i. eine besonders hervortretende Zellgruppe der Sporangienwand) meist sehr deutlich. 
A. Ring unvollstindig (d. i. nicht geschlossen), meridian (d.i.senkrecht über den Scheitel verlaufend. PolyporliaceatS. S1).

B. Ring vollständig, parallel zum Aequator oder schief verlaufend.

Ar. Ring einen wirklichen Gïrtel, nicht geschlossene Kappe bildend.

A2. Ring (ekliptikartig) schief über die Mitte verlaufend.

Cyatheaceae (S. 56).

B.. Ring äquatorial äber die Nitte oder nahezu so verlantend.

A3. Sori nahe am Blattrande den Nerrenenden aufsitzend, von einem Indusium umgeben. Mesophyll allermeist einschichtig.

Hymenophyllaceae (S. 51).

$\mathrm{B}_{3}$. Sori an der Blattunterseite dem Rücken der Nerven aufsitzend, ohme Indusium. Mesophyll mehrschichtig.

Gleicheniaceae (Gleichenia).

C.. Ring parallel zum Aequator nahe am Scheitel (also wie ein Breitenkreis) verlanfend. Áchizaeaceate (S. 5\%).

B. Ring rudimentär, eine nahe am Scheitel des Sporangiums auf seiner Aussenseite sitzende, wenigzellige Kappe bildend.

Osmundaceae (S. 57).

2'. Mit grossen Nebenb. Sporangien aus einer (iruppe von Epidermiszellen herrorgehend, in der liegel mehrfächerig: Ring sehr rudimentär (wie bei den Osmunrlacecac) oder ganz fehlend.

Narattiaceae (S. 57).

2. Sporangien als randständige Gewebegruppen im Innern umgeformter Blattabschnitte entstehend, ohme Ring. Prothallien unterirdisch, mehrschichtig. [Tuberithallosae.]

Blattscheide und Nebenb. umschliessen die Stammspitze samt den jüngeren $\mathrm{B}$.

Ophioglossaceac (S. ว\&).

II. Makrosporangien mit einer Makrospore und Mikrosporangien mit zahlreichen Mikrosporen: Frh, Sori) die Sporangien völlig umschliessend und als reife $\mathrm{Fr}$. abfallend, in diesen dann die Sporen keimend. [Hydropterides.]

1. Sori (Frb.) eingeschlechtlich. q Prothallien mit einigen Archegonien.

Salviniaceae (S. 58).

2. Sori (Frb.) zweigeschlechtlich. o Prothallien mit nur 1 Archegonium.

Marsiliaceae (S. 58).

\section{Hymenophyllaceae (200).}

A. Indusium sehr tief 2-klappig. Receptaculum \pm kegelig, aus den Sporangien meist nicht herausragend. Hymenophyllum.

B. kahl; Stiel 1-4 cm, oberwärts oft geflïgrelt; Spreite \pm eilänglich doppelt fiederteilig mit geflügelter Spindel; Abschnitte gerundet, entfernt gesaigt. Feuchtschattige Sandsteinfelsen: Sächs. Schweiz, 'Trier, Ardennen. VII!, H. tumbridgense Sm.

B. Indusium becher-, trichter-oder röhrenförmig. meist gestutzt. Receptaculum fädlich, gewöhnlich über die sporangien weit herausragend.

\section{Polypodiaceae (3000).}

Trichomanes.

I. Sori nur einzelne Stellen der Blattunterseite bedeckend.

I'. Sporen radiär (3-strahlig). Sori direkt randständig oder dem Rande genähert. 
1. Haare aus Zellreihen bestehend. Sori randständig, mit Indusium. [Lonchitideae.]

A. Sorus linienförmig auf einer Nervenanastomose längs des ganzen Randes verlaufend, von 2 schmalen, linearen, unterständigen Schleiern verhïllt, von denen sich der der Oberseite des Segmentes angehörende nach Art eines Blattrandes umrollt. VII, VIII. Pteridium (1) aquilinum (L.) Kuhn

B. Sori von einander getrennt, \pm kurz; Indusium halbmondförmig.

Lonchitis.

2. Trichome aus Zellflächen bestehend (Spreuschuppen). Sori nahe dem Rande, ohne Schleier. [P'terideae.]

A. Sori dicht am Blattrande, stets vom umgeschlagenen Blattrande iiberdeckt.

A1. Sorus lang linienförmig längs des ganzen Blattrandes.

Pteris (70).

a. Spreite einfach-fiederschnittig; Segmente entfernt, lineallanzettlich, fertile schmäler, untere fast bis zum Grunde gespalten; Stiel mit Ausnahme des äussersten (trundes kahl. Sporen rotbraun. Von der Linie Nizza-Kapland ostwärts bis zu den Anden.

$P$. cretica L.

b. Spreite lanzettlich, einfach-fiederteilig; Segmente genähert, aus ungleich-herz- bis pfeilförmigem Grunde linealisch. Sporen gelblich. Spanien, Italien, Griechenland, Tropen. P. longifolia L.

B1. Getrennte Sori, gewöhnlich von den Ründern besonderer Blattlappen bedeckt.

A2. Fruchtbare Nerven an dem den Sorus tragenden Ende angeschwollen.

Cheilanthes (60).

B2. Fruchtbare Nerven an ihrem den Sorus tragenden Ende nicht oder kaum merklich verdickt.

Adiantum (113).

Blattstiel bis 22 dm lang, $1 \mathrm{~mm}$ dick, glänzend schwarzbraun, nur am Grunde mit Spreuschuppen. Spreite eiförmig, etwa 2-3 $\times 2 \mathrm{dm}, 2$ - bis 4 -fach fiederschnittig; Segmente sehr veränderlich, meist \pm aus keilförmigem Grunde verkehrt-eiförmig, oft handförmig eingeschnitten. England, Mastricht, sïdl. Alpen. subtrop. Gbt. u. Tropen. A. Capillus Veneris L.

B. Sori etwas vom Blattrande entfernt, wenigstens bei der Reife nicht von ihm ïberdeckt.

A1. Sori stets nur das letzte Ende der Nerven einnehmend, anfänglich vom schleierartig zurïckgerollten Blattrande iiberdeckt.

Cryptogramme (Allosorus) (5).

Rhizom kriechend oder aufsteigend, büschelig verzweigt, $3 \mathrm{~mm}$ dick. B. dicht spiralig, in bis $3^{1}$, dm hohen Büscheln; Stiel reichlich mit Spreuschuppen, der der (inneren) fertilen B. viel länger; unfruchtbare Spreiten meist 3-eckig-eiförmig, fruchtbare meist länglich, alle 3 - bis t-fach-fiederschnittig; Segmente eingeschnitten-gekerbt. Europa, alpin u. subalpin. VIII, IX.

C. crispa (L.) R. Br.

$B_{1}$. Sori \pm weit die fruchtbaren Nerven rückwärts begleitend, niemals vom Blattrande bedeckt. 
A. Sori \pm dicht zu einer randständigen Reihe zusammenschliessend.

Nothochlaena $(40)$.

Rhizom dicht spreuschuppig. dicht 2-zeilig beblättert.

B. 5 dm. Blattstiel und Spreitenunterseite dicht spreuschuppio; Spreite ein- bis 3-fach-fiederschnittig. Mähren bis Canaren, Abyssinien, Himalaya. VI, VII.

N. Marantae (L.) R. Br.

B. Sori ziemlich weit von einander getrennt. länglich, längs der Nerven zurücklaufend.

II'. Sporen bilateral. Sori unterseits stehend.

Gymnogramme.

1. Sori länglich bis linienförmig. [Aspleneae.

A. Sori mit deutlichem, seitlichem Indusium. Blattspreite ohme Spreuschuppen.

A1. Je 2 Sori einander genähert, an ihren Ausenwänden die Indusien.

A2. Sori längs Anastomosen von Quernerven, die dem Mittelnerr parallel verlaufen. Spreuschuppen zartwandig.

Blechnum (60).

Rhizom und Blatstielgrund spreuschuppig. B. dichtbüschelig, kahl. einfach fiederschnittig. sterile strahlig dem Boden aufliegend, fertile straff aufrecht; Abschnitte lineal-länglich-sichelfürmig bez. lineal. Europa: Bachufer. feuchte Waldränder etc. VII-IX. B. Spicant (L.) Sm.

B.. Sori längs gewöhnlicher Verven. Sprenschuppen gegittert. Seolopendrium (2).

B. büschelig: aus heizförmigem (irunde zungenförmig. bis $1 \mathrm{~m}$ lang. I leterig. Euroua: Feuchte Felsen. steinige, schattige $\bar{W}$ älder. VII-IX. S. vulgare Sm.

B1. Sori einzeln.

A2. Spreuschuppen zartwandig. In den Blattstiel treten ? bandartige. weiter aufwärts sich zn einem rimnen-. im Querschnitt hufeisenförmigen Strange vereinigende Gefässbündel. Rhizom aufrecht bis aufsteigend. B. doppelt- bis 3-fach-fiederschnittig. bis 1 (bez. $1^{1}$ ) $\mathrm{m}$.

Athyrim.

a. Sori relativ gross. länglich bis nierenförmig. Indusium kräftig. bleibent. Sporen hell-gelbbram. ihre Oberfläche ron äusserst kleinen Wärchen feinkürnig his glatt. Feuchte Waldstellen. TII-IX A. Filir fomina (L.) Roth

b. Sori klein, später kreisrund. Indusiam klein, bald rerschrumpfend. Sporen dunkelbraum, ihre Oberflïche von hohen Leisten netzig. Subalpin. TII-IX. A. alpestre Nyl.

B.. Spreuschuppen gegittert. In den Blattstiel 1 oiler 2 Giefässbündel tretend, welch letztere sich weiter aufwärts zu einem im Querschnitt nie hufeisenförmigen Strange vereinigen. Rhizom kriechend.

Asplenum.

a. B. einfach-fiederschnittig; Segmente rundlich bis länglich, meist nur gekerbt, die unteren kleiner oder ebenso gross, als die oberen: Nervatur mit Nittelrippe und fiederigen Seitennerven. Blattstiel meist kurz.

๙. Blattstiel unterwärts braun, oberwärts samt Rhachis griin, ungeflügelt. mit Längsfurche. Xỵlem (ausser im 
obersten Teil der Rhachis) durchgehends 4-schenkelig. Spreuschuppen meist ohne Scheinnerv. B. bis 20, Stiel bis $6 \mathrm{~cm}$. Feuchte, schattige Felsen etc. VII, VIII. A. viride Huds. ア. Blattstiel und gesamte Rhachis braunrot, ohne Längsfurche. Xylem nur im Blattstielgrunde 4-schenkelig. Spreuschuppen meist mit Scheinnerv. B. bis 32 , Stiel bis $6 \mathrm{~cm}$. Felsspalten etc. VII, VIII.

A. Trichomanes L.

b. B. 2-bis 4-fach fiederschnittig, die untersten Primärsegmente die grössten, die Spreite daher lanzettlich bis meist 3-eckig-eiförmig̣.

๔. Segmente letzter Ordnung liinglich. Nervatur fiederig mit Mittelrippe. Blattstiel höchstens ${ }^{2 / 3}$ so lang als die Spreite, die länglich oder lanzettlich und bis $1 \mathrm{~m}$ lang ist. In den Winkeln der Blättchen häufig Brutpflänzchen. Natal, Ostindien, Australien, Mexico.

A. bulbiferum Forst.

f. Segmente letzter Ordnung aus keilförmigem Grunde selten länglich, meist eiförmig, rhombisch oder verkehrt eifürmig. Nervatur strahlig ohne deutlichen Mittelnerv. Blattstiel lang. I. Schleier ganzrandig B. bis $12 \times 40 \mathrm{~cm}$, Stiel etwa so lang als Spreite. Felsen, Mauern, Hohlwege. VII, TIII. A. Adiantum nigrum L.

II. Schleier umregelmässig gekerbt, gezähnt oder gewimpert. b. 4-20 cm lang, fast gleich hreit; Stiel meist länger als Spreite. Mauern, Felsenritze. VII-1X. A. Ruta muraria L.

B. Sori ohne oder mit sehr kleinem, hinfälligem Indusium. Blattspreite dicht mit gegitterten Spreuschuppen besetzt. Ceterach.

B. dicht büschelig, 6-12 (-20) cm lang (Stiel kürzer), lineallanzettlich, einfach fiederschnittig. Jelsen. VI-X.

C. officinarum Willd.

2. Sori rundlich mit Indusium. [Aspidicae z. gr. 'T.]

A. Indusium oberständig, rundlich-nierenförmig und in der Einbuchtung hefestigt oder kreisrund und schildförmig angeheftet.

Aspidium.

a. Indusium nierenfürmig, mit der Einbuchtung dem Nerven aufsitzend.

a. Blattstiel mit 2 Gefässbündeln. B. einfach-fiederteilig, Abschnitte ganzrandig. Indusium klein, hinfällig.

I. Blattstiel viel kürzer als die Spreite; Spreite beiderseits stark verschmälert, unterseits mit zerstreuten goldgelben Drüsen. Fiederchen stumpt. VII, VIII. A. montanum (Vogl.) Aschers.

II. Blattstiel etwa so lang als die spreite, die am Grunde kaum verschmälert, unterseits drüsenlos; Fiederchen spitzlich. Torfwiesen, Sumptwälder. VII,VIII. A. Thelyptcris (L.) Sw.

5. Blattstiel mit 5-11 Gefässbündeln: Primärfiedern weiter geteilt; Schlussabschnitte (olt stachelspitzig-) gesägt. Indusium ziemlich gross, andauernd.

I. B. fiederschnittig mit fiederspaltigen bis fiederteiligen Primärsegmenten, selten am Grunde doppelt-fiederschnittig.

1. Blattstiel ziemlich kurz, nebst Spindel dicht spreuschuppig. Fiedern langlanzettlich, zugespitzt; Fiederchen stumpf, kerbig-gesägt bis fiederspaltig. IVälder. VII-IX. A. Filix mas (L.) Sw. 
2. Blattstiel ziemlich lang. spärlich spreuschuppig. Spindel kahl. Fiedern eilanzettlich, stumpf: Fiederchen stachelspitzig wezähnt. Sümpfe, Torfmoore. VII. TIII. A. cristatum (L.) Sw.

II. B. doppelt- bis t-fich-fiederschnittig, langgestielt. Schlusssegmente stachelspitzig-gesägt-gezähnt. Wäller. VII, VIII.

A. spinulosum $\mathrm{Sw}$.

b. Indusium kreisrund, schildfürmig dem Scheitel des Peceptaculums angeheftet. B. I lederartig. kurzgestielt. Sprenschuppen auch auf der Spreite zahlreich. Spreite \pm länglichlanzettlich.

\%. B. einfach-gefiedert. Fiedern aufwärts sichelfürmig, fast dornig-gezähnt, am Grunde stark geöhrt. Felsige Bergwälder. VIII, IX. A. Lonchitis (L.) Sw.

$\therefore$ B. \pm doppelt-gefiedert. Fiederchen stachelspitzig-gesägt. Bergwälder. VII, VIII. A. lobatum (Huds.) Siv.

B. Indusium unterständig.

A1. Indusium nur halbseitig entwickelt.

A. Fertile und sterile B. gleich gestaltet. Blattrand flach, die Sori nicht verhüllend. Indusium lïfrelartig-lauzettlich, erst den Sorus ïberdeckend, später zurückgeschlagen.

Cystopteris (10).

B. 1-3i-j) dm lang (Stiel kïrzeri, eilïnglich, doppeltgefiedert; Fiederchen schwach gekerbt bis fiederspaltiggezähnt. Abhänge, Felsen, Mauern. VII-IX.

C. fragilis (L.) Bernh.

B.2. Sterile B. an Aspidinm montanum erimnernd, fertile kleiner, ihr Rand bis zur Mittelrippe zurïckgerollt, die Sori vällig bedeckend. Indusium taschenartig mit gezähntem Rande.

Onoclea (3).

Rhizom stammartig aufrecht. B. schopfartig-trichterig gestellt; unfruchtbare bis $1^{1}: 2 \mathrm{~m} \times 35 \mathrm{~cm}$ (Stiel bis $12 \mathrm{~cm}$ ). fruchtbare nur einfach-gefiedort. Nasse Waldwiesen, feuchte Gehüsche, Ufer. TII-IX. O. Struthiopteris (I.) Hoffm.

B1. Indusium rings um die Basis des Receptaculums angeheftet, napf- oder schüsselförmig. am Pande tief (stellenweise bis fast zum (Grunde) haarartig zerschlitzt, anfangs den Sorus ganz verhiillend, später ausgebreitet.

Woodsia (16).

Rhizom vielküpfig. B. fiederschnittig bis fiederteilig, an Stiel. Spindel und Spreitenunterseite mit schmalen Sprenschuppen, schmallänglich: Spreite $3-11 \times 1-2{ }^{1 / 2} \mathrm{~cm}$; jederseits 8-14 rundliche. \pm fiederteilige Primärsegmente. Felsspalten. VIII, IX.

\section{Sori rundlich, ohne Indusium.}

1'. Sori auf dem Rücken von darunter hinweglaufenden Nerven. Blattstiel ungegliedert. [Aspidieae z. T']

Nephrodium (Phegopteris) (100).

a. B. behaart, 3-eckig-eiförmig, lang zugespitzt, fiederschnittigfiederteilig; Primärsegmente sämtlich sitzend, das unterste Paar kaum grösser als die folgenden. Gefässbündel sich in der unteren Hälfte des Blattstieles zi einen rimnenförmigen 
Strange vereinigend. Sporangien auf dem Scheitel behart. Feuchte, schattige Stellen. VII, VIII. N. I'hegopteris (L.) PrantI

b. B. kahl oder drüsig, breit 3-eckig, doppelt- bis 3 -fach-gefiedert. Gefässbündel durch die ganze Länge des Blattstieles getrennt verlaufend. Sporangien mit kahlem Scheitel.

^. B. kahl, zart, bis $45 \mathrm{~cm}$. Stiel '2-3 mal so lang als die zurückgebrochene, scheinbar 3.zühlige Spreite. Segmente 3. Ordnung lïnglich, stumptlich, ganzrandig, gekerbt oder fiederspaltig. Schattige Stellen. VII, VIII. N. Dryopteris (L.) Mchx.

B (ausser der Oberseite) \pm dicht mit kurzen, blassgelben Drïsenharen. Segmente 2. Ordnung fiederschnittig. Moosige Blöcke. Felsspalten, Mauern, auch Erdboden. VII, VIII.

\section{N. Robertianum (Hoffm.) Prantl}

2'. Sori am Ende der fertilen Nervenäste. Blattstiel gegen das Rhizom abgegliedert; die abgestorbenen $B$. tremnen sich vollständig vom Rhizom mit Hinterlatsung einer rundlichen Narbe; B. meist 2-zeilig auf dem Rïeken des kriechenden Rhizoms. [Polypodieac.]

Polypodium.

B. $1-3 \mathrm{dm}$. kahl, länglich-lanzettlich, tief fiederteilig; Fiedern länglich, stumpf, fast canzrandig. Felsen, schattige Abhänge, zwischen Moos. VIII, IX. P. vulgare L.

II. Sporangien grosse Flecken oder die ganze Blattunterseite bedeckend. [Acrosticheae.]

A. Sporangien grosse Flecken anf der Blattunterseite bedeckend. Platycerium.

Fruchtbare B. bis ¿- $m$, keilfömig 2-lappigr unficuchtbare sehr gross, fast kreisrund. Hinterindien. Philippinen, Nordaustralien.

B. Sporangien die ganze Blattunterseite bedeckend.

$P$. grande Sm.

Acrostichum (200).

\section{Cyatheaceae (200).}

A. Indusium minutiös oder fehlend. heceptaculum crhaben.

Alsophila (60).

B. dopreltgefiedert: Fiederehen 2. Ordnung linear-lanzettlich, tief fiederspaltig; Abschnitie eiförmis. spitz, mit $1-5$ Soris. N.S. Wales, T'Tasmania. A. australis R. Br. B. Indusium deutlich.

A1. Indusium niedrig, halhmond-becherförmig, den Sorus auf der der Mittelrippe des Fiederchens zugekehiten (unteren) Seite umschliessend.

B1. Indusium den Sorus rings umgebend.

Hemitelia (18).

A2. Indusium den Sorus nicht ganz geschlossen iiherdeckend.

A3. Indusium völlig ans cinem besonderen fiewehe gebildet, 2.lappig. Receptaculum wenig erbaben. Sporangienring \pm vollständig.

Cibotium (8).

B. doppelt gefiedert: Schlussfiederchen lanzettlich, fein zucespitzt. fiederspaltig: Abschnitte etwas sichel-eifürmig, spitz. Centralamerika. C. Schiedei Ch. et Schl.

B. Indusium zumteil aus dem fiewehe eines Blattlappens ge- 
bildet, 2-lappig oder ungeteilt. Receptaculum erhaben. Sporangienring unvollständig. Dicksonia (55).

B. vielfach-gefiedert; Schlussfiederchen und -segmente eiförmig. stechend-spitz. Tasmania. D. antarctica Lab.

B.. Indusium den Sorus anfangs kugelkappenfürmig überdeckend. später am scheitel mit einer sich immer mehr erweiternden kreisförmigen Oeffnung und dann \pm becherförmig. Receptaculum kugelig oder verlängert.

Cyathea $(40)$.

\section{Schizaeaceae (70).}

A. Aufrechte Farne. Sporangien ohne Indusium.

A. Sporangien ohne besondere Ordnung sehr zahlreich in rispenartigen Fruchtständen an getrennten Auszweigungen der B.

Aneimia.

B. Sporangien ährenartig in 2-4 Längsreihen auf der hohlen Seite ron linealischen Blattlappen sitzend, die kugelradienartig von der Spitze der B. oder Blattabschnitte ausstrahlen. Schizaea.

B. Kletterfarne. Die einzelnen (seltener gepaarte) Sporangien in den Achseln hohlziegelförmiger Indusien, die ährenartig in zwei Längsreihen auf fächerförmig rom Rande der Fiedern ausstrahlenden Lappen stehen.

Lygodium.

\section{Osmundaceae (11).}

A. Sporangien an gewöhnlichen B.

Todea.

B. Sporangien :ihrenförmig an parenchymlosen Blattzipfelchen, die rispenartig an einem metamorphosierten Blattahschnitt oder B. stehen.

Osmunda.

B. doppelt-gefiedert; Fiederchen länglich, stumptlich. unregelmässig geschweift-gekerht. Fertile Partie an der Spitze des B. VI, VII.

O. regalis $\mathrm{L}$

\section{Marattiaceae (25.)}

A. Sporangien zu j-20 immer einen dem Ende eines Seitennerven eines Fiederchens aufsitzenden, zweireihigen Sorus bildend; jedes Sporangium mit mehrschichtiger Wand. welche auf dem Scheitel einen rudimentären Ring erkemen lässt und sich von hier aus mit einem Längsriss öffnet.

Angiopteris.

Stamm bis über ${ }^{1} 2 \mathrm{~m}$ diek und hoch. B. his $6 \mathrm{~m}$. Hauptfiedern bis $1 \mathrm{~m}$ lang: Spindel am Grunde angeschwollen. Schlussfiederchen bis $30 \times 4 \mathrm{~cm}$, zuweilen gestielt, linear-länglich, zugespitzt, ganzrandig oder gezähut. Madagaskar bis Polynesien.

A. evecta Hoffim.

B. Sporangien zu einem 2-reihig-länglichen bis 1-reihig-kreisring. förmigen Fächersorus vereinigt: jedes Fach durch einen Längsriss sich öffnend; die mehrschichtige Wand ohne Andeutung eines Ringsegmentes.

A. Sporangien zweireihig einen hootförmigen Sorus bildend.

$B_{1}$. Sporangien zu einem einreihig-kreisringfürmigen Sorus vereinigt. 
58 Ophioglossaceae. - Salviniaceae. - Marsiliaceae - V. Equisetales.

\section{Ophioglossaceae (12).}

A. Unfruchtbarer Blattteil fiederspaltig bis doppelt-gefiedert, fruchtbarer rippig, selten nahezu ïhrig.

Botrychium.

B. Unfruchtbarer Blattteil ganzrandig, fruchtbarer lineal-ährenfürmig, die Sporangien 2-reihig.

Ophioglossum.

Unfruchtbarer Blattteil stumpf eilänglich, etwa von der Mitte des längeren fruchtbaren sich abzweigend. VI, VII. O. vulgatum L.

\section{Salviniaceae (9).}

A. Wurzeln fehlend, ersetzt durch vielzipfelige, behaarte, die untere der 3 Blattzeilen bildende Wasserb., die B. der beiden anderen Zeilen auf dem Wasser schwimmend.

Salvinia (5).

Schwimmb. eielliptisch, etwas herzförmig, oberseits hellgrün mit behaarten Wïrzchen, unterseits dunkler, meist rötlich oder bräunlich. VIII, IX.

B. Wirkliche Wurzeln vorhanden.

S. natans (L.) Azolla All.' (4).

\section{Marsiliaceae (35).}

A. Sporangien oberhalb des Blattstielgrundes, bohnenförmig. B. kleeähnlich mit 4 Blättchen.

Marsilia (32).

B. Sporangien am Blattstielgrunde, kugelig. B. spreitenlos, pfriemelig, binsenartig. VIII, IX. Pilularia (3) globulifera L.

\section{Equisetales.}

\section{Equisetaceae (Equisetum, 24).}

a. Spaltöffnungen im grünen Stengel nahezu im Niveau der benachbarten Oberhantzellen, Cuticularspalt parallel über der Spaltöffnung.

๘. Gefässbündel der Stengelinternodien mit Einzelschutzscheiden. Sterile und fertile Stengel gleich, ziemlich dick, ïusserlich nur gestreift (nicht gefurcht), sehr glatt, meist einfach, 3-10 dm. Scheiden eng anliegend, 1.)- bis 20-zähnig; Zühne pfriemelig, schmalhäutig-berandet. V, Vl. E. limosum L.

ß. Gefässbuindelkreis der Stengelinternodien mit äusserer Gesamtschutzscheide.

I. Spaltöffnungen in den Rillen ein einziges breites, aus zahlreichen unregelmässigen Linien bestehendes Band bildend. Sterile und fertile Stengel gleichgestaltet, düm, tief gefurcht, kaum rauh, meist ästig, 2-5 dm. Scheiden locker, 5-10zähnig; Zähne 3-eckig-lanzettlich, breit-häutig-berandet. V, VI. E. palustre L.

II. Spaltöffnungen fehlend bisweilen \pm bei $E$.Telmateja: oder mitten in den. Rillen in 2 einander sehr genäherten, durch einen spaltöffnungsfreien Streifen getrennten Reihell. Fruchtbare Sprosse fleischfarben, bräunlich oder weiss, chlorophyll-, spaltöffinungs. und meist astlos, vor den sterilen erscheinend, nach der Sporenreife meist rasch absterbend. 
1. Scheiden der fruchtbaren, fleischfarbenen oder rötlichbramen Stengel 8- bis 12-zähnig, Zühne lanzettlich: 1-3̈ dm: III, IV. Sterile Stengel \pm griu, $1^{1}: 2-5 \mathrm{dm}$, im sommer, mit 6-18 konvexen Rippen.

2. Beiderlei Stengel elfenbeinweiss oder bleichgrün. fertile 2-4 dm, IV u. T, sterile 5-15) dm, im Sommer. Scheiden der fruchtbaren Stengel mit 20-30 pfriemeligen Zähnen. Sterile Stengel mit 20-40 schwach konvexen Riplen.

E. Telmateja Ehrh.

III. Spaltöffnungen in 2 sehr entfernten, aus je $1-2$ Linien gebildeten Reihen ummittelhar nehen den Kanten. Fruchtbare Sprosse mit den sterilen ziemlich gleichzeitig erscheinend, aber anfangs (V. VI) denen von $E$. arcense ähnlich, nach der Sporenreife in den oberen Intermodien den sterilen ähnlich werdend.

1. Scheiden der fruchtibaren Stengel bauchig, oberwärts rotbraun, in 3-6 stumpfliche. 2- bis 1 -zähnige Zipfel gespalten. Sterile Stengel reich verzweigt, mit 10-18 flachen, durch je 1-2 randständige Reihen gespreizter, einfacher Zïhne rauhen Rippen, die viel schmïler sind als die Rillen; $2-6 \mathrm{dm}$. E. silvaticum L.

2. Scheiden der fruchtbaren Stengel trichterig, bläulichgrün, 10-15-zähnig. Sterile Stengel armästig. mit $8-20$ konvexen, durch 1 - bis 12-fïcherige Lappen rauhen Rippen, welche viel breiter sind als die Rillen; $1-3 \mathrm{dm}$. E. pratense Ehrh.

b. Spaltöfnumgen \pm weit unterbalb des Niveaus der benachbarten Oberhautzellen im Grunde einer Grube liegend, die von der darïber von den Oberhautzellen rorspringenden Cuticularhaut bis auf einen zu ihr \pm schrägen Spalt iberdeckt wird. in den Rillen 2 sehr regelmässige Reinen aus je $1-4$ Linien bildend. Gefässbündelkreis der Stengelinternodien mit äusserer und innerer Gesamtschutzscheide. Sterile und fertile Stengel gleich, einfach oder nur am Grunde ästig, 18-bis 20-furchig, rauh, 3 bis $10 \mathrm{dm}$. Scheiden cylindrisch, eng anliegend, infolge frühzeitigen Abfallens der Zähne am Rande gestutzt. VII, VIII. E. hiemale L.

\section{Lycopodiales.}

I. Blätter ohne Ligula. Sporangien und Sporen gleichartig. [Isosporae.]

Lycoporliaceate (Lycopodium, 100).

a. Sporangien nicht in besonderen Aehren, sondern nur an bestimmten Stellen der Stengel und Zweige fast achselständig auf der Basis gewöhnlicher Blätter. Stengel aufsteigend, gabelästig. Aeste fast gleich hoch in dichten Büscheln; an der Spitze der Zweige nicht selten beblätterte, hald abfallende Brutknospen. VIII, IX.

L. Selago L.

b. Sporamgien fast achselständig am Grunde \pm abweichend gestalteter, bleicher oder \pm gelber, zuletzt meist trockenhäutiger Blätter, zu Aehren vereinigt.

๘. Alle Laubb. gleichgestaltet, spiralig oder ab und zu wirtelig. I. Fruchtb. laubblattähnlich, aus breiteiförmigem Grunde lang- 
und schmal-linealisch-zugespitzt. Sporangien auf der Vorderseite uiber dem Grunde mit Querspalten aufspringend. Stengel kurz kriechend, sparsam verzweigt und mit zahlreichen Wurzeln dem Boden angeheftet. Aehren ungestielt, meist einzeln. VII, VIII.

$L$. inundatum L.

II. Fruchtb. kiirzer als die Laubb. und abweichend gestaltet. zuletzt trockenhäutig. Sporangien auf dem Scheitel muschelförmig-zweiklappig aufspringend. Stengel lang kriechend, reich verzweigt, zerstreut bewurzelt.

1. Aehren einzeln, ungestielt. Fruchtb. rundlich-oder 3-eckigeiförmig, kurz zugespitzt. B. meist 5-, bisweilen 8-reihig, lineallanzettlich, stechend, horizontal bis zurickgebrochen. VII, VIII.

$L$. annotinum $\mathrm{I}$.

2. Aehren meist zu 2 auf gegabe!ten Stielen. Fruchtb. breiteiförmig, langweisshaarig-zugespitzt. Laubb. vielreihig, aufwärts gekrïmmt, linealisch und in ein langes weisses Haar auslaufend. VII, VIII.

L. clavatum L.

3. B. der Thuja-artig flachgedrückten sterilen Seitenzweige vierzeilig und an Grösse und Form \pm verschieden von den spiralig. gestellten übrigen.

I. Aehren einzeln, ungestielt. Hauptachse oberirdisch kriechend. VIII, IX.

L. alpinum L.

II. Aehren meist zu 2-6 auf langen, ein- bis mehrfach gegabelten Stielen. Hauptachse unterirdisch kriechend. VIII, IX.

L. complanatum L.

II. B. mit Ligula. Sporangien u. Sporen ungleichartig. [Hcterosporac.]

1. Stamm in die Länge wachsenit, monopodial, scheinbar gabelig verzweigt, meist dorsiventral. Laubb. kurz, meist Oberb. kleiner. Fruchth. in Aehren, in ihren Achseln die Sporangien.

Selaginellaceae (Selaginella, 400).

a. Stengel wenigästig. B. spiralig allseitswendig, gleichgestaltet. wimperig-gezähnt. VH, VIII. S. sclaginoides (L.) Lk.

b. Stengel vielästig. B. ganzrandix, 4-reihig, 2.gestaltig, seitliche rechtwinklig-abstehend, eilinglich, stumpflich, die der Flachseiten aufrecht ïbereinanderliegend, eiförmig, kleiner. VII, VIII.

S. helvetica (L.) Lk.

2. Stamm kurzknollig in die Dicke wachsend. Laubl. grasartio, die fertilen der verschiedenen lahrginge durch einige sterile getrennt, beiderlei gleichgestaltet. Sporangien in (truben der Oberseite der Frb., von lufthaltigen Zellfäden (Trabeculat) durchzogen.

VI-IX.

Isoëtaceae (Isoëtes, 50) I. lacustris L.

\section{Cycadales. Cycadaceae $(9 ; 85)$.}

A. Frb mit 8-4 (-2) horizontal oder aufrecht alsstehenden Sa. Stamm die o Bl. durchwachsend. Blattfierlern nur mit 1 Mittelnerv.

Cycas (16).

Fiedern lineal, am Rande zurückgerollt. Spreite der braunfilzigen Frb. tief fiederspaltig. Südjapan. Im Stammmark Sago. 
B. Frb. stets mit 2 umgewendeten Sa. Stamm die 2 Bl. nicht durchwachsend. Blattfiedern längsnervig.

A. Zapfenschuppen schildförmig.

A2. Stamm zuletzt bis $3 \mathrm{~m}$ hoch, säulenfürmig, gepanzert. Afrika, bes. im S.-O.

Encephalartos (12).

B2. Stamm niedrig, oft mehrköpfig, zuletzt nackt. Trop. Amer.

Zamia (30).

B1. Zapfenschuppen zweihörnig. Mexiko.

Ceratozamia (6).

\section{Coniferae $(34 ; 350)$.}

Vorbemerkungen :

1. Schizogene Harzgänge fehlen nur bei Taxus.

2. Ho ftüp fel an den Radialwänden der Tracheiden bei Arancaria und Agathis (zuweilen auch bei Ginkgo) in mehreren Lüngsreihen, sonst nur in 1 Reihe; ausserdem bei Taxus, Torreya und Cephalotaxus noch spiralige Terdickungen.

3. Die B. bei Arancaria \$ Colymbea, Agathis, Podocarpus \$ Nageia und Ginkgo besitzen mehrere, frei endigende Gefässbündel; sonst sind die B. stets einnervig.

I. BJ. 2-häusig; ㅇ zu $1-t$ beisammen ohne eigentliche Zapfenbildung. S. ptlaumenähnlich oder das fleischige, äussere Integument am Scheitel nicht zusammenschliessend; S. ohne Frb. oder dasselbe meist überragend. [Taxaceae.]

1. Sa. geradläufig aufrecht. [Taxene.]

A. + Bl. aus der blossen Sa. ohne Frb. bestehend, zu 1-2 am Scheitel eines kurzen Sprösschens stehend.

A1. \& Blütensprüsschen am Scheitel rings um die Sa, ein lederartiges (rebilde entwickelnd, sonst unbeschappt. Laubb. breit, 2- oder mehrlappig, vielnervig. Ostasien. Ginkgo (1) biloba L. $B_{1}$. Blütensprösschen von mehreren kleinen Laubb. beschuppt. Laubb. nadelförmig, 1-nervig.

A2. Sa. einzeln. Stb, mit 6-8 Pollensäckchen. B. ohne Harzgang, unterseits nicht gestreift.

a. B. $1-3 \mathrm{~cm}$ lang, scharf zugespitzt. IV. T. baccata L.

b. B. 5-12 mm lang, stumpf, kurz stachelspitzig. Japan. $T$. tardiva Lawson

B.. Sa. zu 2. Sth. mit 2 Pollensäckchen. B. mit Harzgang und unterseits 2 Streifen.

Torleya (4).

B. $2-3^{1 / 2} \mathrm{~cm}$ lang, $2-3 \mathrm{~mm}$ breit. Rinde rotbraun. P Blütensprösschen in Laubblattachseln vorjähriger Zweige. Japan.

T. nucifera Sieb. et Zuce.

B. Sa, in den Achseln von Frb. seitlich an den Bliitensprösschen.

A. Nur Langtriebe gewöhnlicher Art vorhanden. Frb. mit je 2 Sa. B. lineaiisch, unterseits mit 2 Längsstreifen.

Cephalotaxus (4).

B. $3-5 \mathrm{~cm}$ lang, $4 \mathrm{~mm}$ breit, oberseits gï̈nzend dunkelgrïn. Ostasien. V, VI. C. pedunculata Sieb. et Zuce. B. Neben gewöhnlichen Langtrieben phyllocladienartige Kurztriebe, beide mit zahnförmigen B. Frb. mit je 1 Sa. 
Phyllocladien verkehrt-eiförmig, \pm schief, lappig gezähnt. Neuseeland.

$P$. trichomanoides Don

2. Sa. \pm umgewendet. Frb. 1-samig. [Podocarpcac.] Podocarpus (40). Gebiet.

B. lineal-lanzettlich, mit 1 Mittelnerr. Ostind.-malayisches

$P$. neriifolia $\mathrm{R}$. Br.

II. Bl. meist 1-häusig, $q$ als deutliche Zapfen, Frb. die Sa. und die reifen $\mathrm{S}$. olne eigene fleischige Hülle völlig bedeckend. [Pinaceae.]

1. B. spiralig. Sa. fast stets anatrop. [Pnoideae.]

1. Frb. einfach, höchstens mit zahnförmigem Fortsatz auf der Innenseite. Auf der Mitto des Frh. 1 umgewendete Sa. B. oft mehrnevig. Hoftiipfel an den Radialwänden der Tracheiden in mehreren Limssreihen. [Araucaricac: Araucaria (10), Agathis (4)].

'2'. Trb. in Deck- und Fruchtschuppen gegliedert oder doch mit Anschwellung auf der Innenseite. B. 1-nervig. Hoftiipfel an den Radialwänden der Tracheiden in 1 Längsreihe.

1“. Sa. 2-8, achselständig und aufrecht oder auf der Flïche des B. und (zuletzt) umgewendet, damn aber zu3-8. [Taxodicac.] A1. Sa. umgewendet.

12. Frb. schildförmig, ohne deutliche Innenschuppe. Serquoja (2). B. zweizeilig gescheitelt, Hach, unterseits mit 2 weisslichen Streifen. Kalifornien. S. sempcrvirens Endl.

B. Frb. mit schmalem Hautrande quer oberhalb des S. B. etwas gescheitelt, sichelförmig. Südchina.

B. Sa. aufrecht.

Cumninghamia (1) sinensis $\mathrm{R} . \mathrm{Br}$.

A.. Frb. schildförmig, ohne dentliche Innenschuppe. Sa. 2.

Taxodium (2).

Einjährige Blattzweige im Herbst abfallend. Ati. Nordam. V. T. distichum Rich.

B. Frb. mit gezähnter Innenschuppe. Sa. 3 (-6). Ostasien.

Cryptomeria (1) japonica (L.) Don

2". Fruchtschuppe gross, Deckschuppe meist viel kleiner. 2 umgewendete Sa. auf der Fruchtschuppe. [-Abieterc.]

A. Nur Langtriebe mit einzeln spiralig gestellten, bleihenden B.

A1. B. meist 4-kantig, mit $0-2$ Harzgängen. Blattnarben auf stark vorspringenden und abstehenden Fortsätzen der herahlanfenden, durch scharfe Furchen getrennten Blattkissen. Zapfen hängend, mit bleibenden Schuppen. Pollenkörner mit Flugblasen.

Picea (18).

a. Fruchtschuppen bis zur Reife fest zusammenschliessend.

B. meist allseitig mit etwa gleichviel Spaltöffuungen.

๙. Triebe kahl oder sehr spärlich behaart.

I. Zapfen 8-16 cm lang. B. \pm stechend spitz. $V$.

$P$. excelsa (Lam.) Link.

II. Zapfen $2-5 \mathrm{~cm}$ lang. B. stumpflich, durch die Spaltöffnungen \pm bläulich-weiss. V. Atl. Nordam.

P. alba (Ait.) Link

Triebe \pm dicht kurzhaarig. B. stumpf, dunkelgrün.

I. Zapfen $5-8 \mathrm{~cm}$ lang. Fruchtschuppen breit abgerundet mit g]änzendem Rande. V. Vorderasien. P. orientalis (L.) Link 
II. Zapfen eiförmig. $3-4 \mathrm{~cm}$ lang. B. mit weisslichen Spaltöffnungslinien. V. Atl. Nordam. P. nigra (Ait.) Link

b. Fruchtschuppen von frïh an locker, dïmn, längsfaltig. ausgefressen gezähnelt.

\%. B. 4-kantig. \pm blaugrau bis silberweiss, starr und stechend. N.-Am.: Felsengebirge.

P. pungens Engelm.

¿. B. oberseits abgeflacht, mit 2) silberweissen spaltöffnungsstreifen. nadelspitz. Pacif. Nordam. P. sitehensis Trautr. et Mey.

$B_{1}$. B. flach, oberseits mit Rimne, unterseits mit 2 seitlichen Streifen. Blattnarben wenig oder gar nicht vorragend.

A.. B. unterseits gekielt, mit 1 Harzgang im Kiel. Zapfen hängend. als Ganzes abfallend. Deckschuppen versteckt. Tsuga (6). B. oberwärts fein gesägt. Jüngste Triebe zottig. Noriam. IV, $\mathrm{V}$.

T. canadensis (L.) Barr.

B. B mit 2 (-4) seitlichen Harzgängen. Deckschuppen so lang oder länger als die Fruchtschuppen.

A3. Zapfen häng ud. als Ganzes abfillend. Deckschuppen 3spitzig. Pollen ohne Flugblasen. Pacif. Tordam. IT. T.

Psendotsuga (1) Douglasii Carr.

B3. Zapfen steif aufrecht. Schuppen bei der Reife ron der stehenbleibenden Spindel abfallend. Pollen mit Flugblasen. Abies (2:2) .

a. Harzgänge der B. nichtbliihender Triebe mitten im Parenchym. B. oberseits \pm glïnzend dunkelgrün mit Längsrinne. unterseits mit 22 weissen Spaltüftnungsstreifen. Kinospen harzbedeckt.

\%. Unterbrochene Schicht mechanischer Zellen unter der Epi. dermis der $\mathrm{B}$.

I. Junge Triebe langzottig. Deckschuppen die Fruchtschuppen fast verdeckend. Alleghanies.

II. Junge Triebe kurzhaarig oder kahl. Deckschuppen rersteckt. Spanien.

A. Fraseri Lindl.

A. Pinsapo Boiss.

- Leine oder sehr vereinzelte mechanische Zellen in den B.

I. B. an der Oberseite meist gescheitelt: die weissen Streifen mit je 6 spaltüffnumgsreihen. Rinde mit vielen Harzbenlen. Atl. Nordam.

A. balsamea (L.) Mill.

II. B. sehr dicht, die der Oberseite sich deckend; je 3-4 Spaltüffnungsreihen in den weissen Streifen. Sibirien. N.-O.-Russland.

A. Pichta (Fisch.) Forb.

h. Harzgänge der B. nichtblühender Triebe an der Eipidermis der Unterseite.

a. B. wie bei den vorigen.

I. Deckschuppen versteckt. Knospen stets harzig. Schicht mechanischer Zellen oberseits kaum unterbrochen. Himalaya. A. Webbiana Lindl.

II. Deckschuppen vorragend und zurückgebogen begrannt.

1. Knnospen dünm mit Harz überzogen B. zugespitzt, stechend. Griechenland.

2. Knospen harzlos. B. ausgerandet.

+ B. oberseitig und seitwärts aufrecht abstehend, Seitenzweige mit den B. somit halbwalzenförmig. Kaukasus. Y.

A. Nordmanniana Lk. 
++ B. meist deutlich gescheitelt. V. A. alba Mill.

3. B. matt- bis blaugrün.

I. Deckschuppen versteckt oder kaum vorragend. B. $3-8 \mathrm{~cm}$ lang, meist spitzlich. Pacif. Nordam. A. concolor Lindl.

II. Deckschuppen ziemlich weit vorragend, zurückgeschlagen. B. 1-4 cm lang, dicklich, meist schwach ausgerandet. Pacif. Nordam.

A. nobilis Lindl.

B. Ausser den Langtrieben noch seitliche Kurztriebe in Form von $\infty$ - bis 2-(selten 1-) nadeligen, am Grunde von häutigen Schuppen umscheideten Büscheln.

A. Kurztriebe $\infty$-nadelig. Langtriebe mit Nadelb. wie bei A.

A2. B. flach, zum Winter abfallend. Zapfen mit 1-jähriger Reife.

a. Deckschuppen kürzer als die Fruchtschuppen.

Larix (8).

๘. Fruchtschuppen an der Spitze gerade vorgestreckt, Rand dicklich. B. ohne weisse Streifen. IV, V. L. decidua Mill.

F. Fruchtschuppen an der Spitze abgebogen, Rand dünn. B. unterseits mit 2 bläulich-weissen Streifen. Japan.

L. leptolepis (Sieb. et Zucc.) Gord.

b. Deckschuppen so lang oder länger als Fruchtschuppen, über diese senkrecht zurückgeschlagen. Himalaya.

L. Griffithii Hook. f. et Th.

B2. B. 4-kantig, ausdanernd. Zapfen mit 2- bis 3-jähriger Reife und bleibenden Schuppen. Deckschuppen versteckt. Cedrus (3).

a. B. breiter als dick. Kronenwipfel aufrecht. C. Libani Barr.

b. B. dicker als breit. Kronenwipfel überhängend.

C. at'antica Manetti

B1. Kurztriebe 5- bis 1-nadelig. Langtriebe nur mit Schuppenb.

Pinus (70).

a. B. mit einfachem Gefässbündel im Centralstrang, zu 3-5. Scheiden der Kurztriebe ganz abfallend. A. mit Endknopf, Zahn oder unvollständigem Kamm. Endfläche der Fruchtschuppen nicht gewölbt, mit endständigem Nabel.

\%. Harzgänge der B. an der Epidermis, B. an den Kanten rauh, 10-12 cm lang. Zapfen lang, hängend, dünnschuppig. S. langgeflïgelt. Nördl. atl. Nordam. V. I'. Strobus L.

3. Harzgänge der B. im Parenchym, B. fein gesägt, $5-7 \mathrm{~cm}$ lang. Zapfen $6-8 \mathrm{~cm}$ lang, $5 \mathrm{~cm}$ dick. S. ungeflügelt. Alpen bis Sibirien. VI. I. Cembra L.

b. B. mit doppeltem Gefässbündel, stets feingesägt-rauh, zu 2. Scheiden als festgeschlossene, höchstens an der Spitze zerschlissene Röhren bleibend. A. mit halbkreis- oder kreisförmigem Kamm. Kndfläche der Fruchtschuppen gewölbt bis pyramidal, Nabel auf der Mitte, oft mit Spitze.

ø. Harzgänge der B. im Parenchym. Zapfen meist aus Knospen am Längstrieb zwischen zwei Quirlen. S. flugfähig, auf der einen Seite weiter als auf der anderen vom Flügel zangenförmig umfasst. Südeur., Vorderasien. V. P. Laricio Poir.

$\therefore$ Harzgänge der B. an der Epidermis. Zapfen meist aus Quirlknospen. 
I. Unter der Blattepidermis Gruppen mechanischer Zellen, die auch die Harzgänge umfassen.

1. B. 7-9 cm lang. Zapfen länglich. Schuppenendfläche glatt. S. Hlugfähig, 6-7 mm, Flügel $20-25 \mathrm{~mm}$ lang. Mittelmgbt. $P$. halepensis Mill.

2. B. $13-20 \mathrm{~cm}$ lang. Zapfen breiteiförmig. Schuppenendfläche mit 5-6 strahligen Seiten. S. $2 \mathrm{~cm}$ lang, $1 \mathrm{~cm}$ dick, mit kleinem Flügel. Mittelmgbt.

P. Pinen L.

II. Subepidermale mechanische Zellen ganz fehlend oder nur um die Harzgänge ausgebildet.

1. Epidermiszellen klein, mit punktförmigem Lumen. Zapfen gestielt, hakenförmig herabgebogen. V, VI. P. silvestris L.

2. Epidermiszellen doppelt so hoch als bei allen anderen Arten, mit kurz strichförmigem Lumen. Zapfen sitzend, \pm wagerecht abstehend. VI, VII.

P. mortana Mill.

2. B. gegen- oder quirlständig anch innerhalb der Bl.). Sa. aufrecht. [Cupressoideae-Cupresseae.]

1'. Zapfen holzig.

1“. Frb. dachig. [Throjopidinae.]

A. Frb. mit 4-5 Sa. Japan. Thujopsis (1) dolabrala Sieb. et Zucc. B. Frb. mit $2(1-3)$ Sa.

A1. 3-4 Frh.-kreise, davon 2 fruchtbar.

Thuja (ว).

a. Neist 8 Frb., das unterste und oberste Paar steril, die Frb. der beiden mittleren Paare mit je 2 geflügelten $\mathrm{S}$. (je 2 seitliche schmale Flügel). Verzweigung in \pm wagerechter Éhene. Atl. Nordam. IV, $T$. T. occidentalis L.

b. 6 Frb., die obersten steril, die mittleren 1-, die untersten 2-samig. S. ungeflügelt. Verzweigung in vertikaler Ebene. Ostasien. IV, V.

$T$. orientalis $\mathrm{L}$.

B1. 3 Frb.-kreise, davon allein die mittleren Frb. fruchtbar, die obersten zu einem sterilen Mittelsäulchen verwachsen, die untersten kleinere sterile Schuppen. Pacif. Nordam. IV, V.

Libocedius (8) decurrens Torr.

2“. Frb. schildförmig, sich nur mit den Rändern berïhrend. [Cupressinae.]

A. Frb. mehr als 5-samig.

Cupressus (11).

a. 4-7 Paar Frb. Zapfen eirundlich. Zweige ausgebreitet. Griechenl., Vorderasien.

C. sempervirens L.

b. 3-4 Paar Frb. Zapfen \pm kugelig. Zweige hängend. China. C. funebris Endl.

B. Frb. 2- bis 5-samig.

Chamaecyparis (5).

a. Frb. 3-bis 5-samig. Kaliforn. IV, V. C. Lawsoniana Murr.) Parl.

b. Frb. 2-samig.

\%. S. mit Harzbläschen. Japan. C. obtusa Sieb. et Zuce. F. S. ohne Harzbläschen.

I. Zweige graugrün. Flächenb. nit Drüsenhöcker. Zapfen 4-6 mm dick. S. mit 2 viel schmaleren Flïgeln. Kanada, N.-Karolina. C. sphaeroidea Spach

II. Zweige dunkelgrün, unterseits heller. Flächenb. mit Drüsenfurche. Zapfen 8-10 $\mathrm{mm}$ dick. Die 2 Flügel so breit wie der S. Nördl. pacif. Nordam. C.nutkaënsis Spach 
$2^{\prime}$. Zapfen beerenartig oder infolge der holzigen, zuweilen verwachsenen S. steinfruchtartig. B. nur oberseits mit Spaltöffnungsstreifen. [Juniperinae.]

Juniperus (30).

a. Knospen nackt. B. teils nadel-, teils schuppenförmig, herablaufend, gegenständig, auf dem Rücken mit Harzdrüse. Bl. 1- oder 2-häusig, auf längerem, schuppig beblättertem Stiel. Fr. aus 4-6 Frb. gebildet.

๘. Beere mit faserigem Fleisch, glänzend, rot. S.-Eur., N.-Afr.

$\beta$. Beere mit breiigem Fleisch, meist bereift.

$J$. phoenicea $\mathrm{I}$.

I. Hauptstamm niederliegend. Beeren auf übergebogenen Stielen hängend, blauschwarz, fast kugelig. IV, V. J. Sabina L.

II. Hauptstamm aufrecht. Beeren aufrecht oder nickend, kurzoval, braunviolett. Atlant. Nordam. IV, V. J. virginiana L.

b. Knospen behüllt. Alle B. nadelförmig, am Grunde abgegliedert, in 3-zähligen Quirlen, innen mit Harzgang. Bl. 2-häusig, blattwinkelständig, mit kurzem, schuppig beblättertem Stiel. Fr. nur aus $3 \mathrm{Frb}$. gebildet.

a. B. oberseits mit einer weissen Längsbinde, die nur zuweilen unterwärts von einem feinen, grünen Nerv durchzogen wird. Beere schwarzbraun.

1. Aufrecht. B. gerade, \pm abstehend. IV, V. J. communis L. II. Niederliegend. B. fast kahnförmig aufwärts gebogen. V.

J. nana Willd.

ß. B. oberseits mit 2 weissen Längshinden. Beere braunrot. Mittelmgbt. J. Oxycedrus L.

\section{Gnetales. Gnetaceae $(3 ; 45)$.}

Schachtelhalmähnliche Strïucher mit gegenständigen, scheidenförmig verwachsenen Schuppenb. $\sigma^{\lambda} \mathrm{Bl}$. in Aehren; die A. auf der die 2-blättrige Blh. überragenden Achse sitzend. o Bl. zu $1-3$, mit je $1 \mathrm{Sa}$, deren Integument (Hals) die bei der Reife verholzende Blh. überragt.

Ephedra (30).

Fruchtstand scheinbeerenartig von rotfleischigen Hochb. umschlossen. [I'seudobaccatae.]

a. Hals der Sa. gerade. Mittelmgbt., W.-Frankr., S.-Russland bis Centr.-Asien.

E. distachya L.

b. Hals der Sa. gedreht. W.- u. C.-Alpen. E. helretica C. A. Mey.

\section{Monocotyledoneae.}

I. Sehr kleine, thalloidische, im Wasser schwimmende Pflänzchen.

II. Grössere, cormophytische Gewächse.

Lemnaceae (S. 94).

1. Bl. in kolbenähnlichen, von 1 oder mehreren sehr grossen Hochb. ( "Spatha") gestützten (u. meist umhüllten) Blütenständen. A. Kolben eingeschlechtig, wenigstens die q kugelig oder eiförmig.

a. Bl. völlig nackt, ohne Deckb. Pandanaceae (Pandanus). 
b. Bl. mit häutigen Blhb., die 9 immer mit Deckb.

B. Kolben gestreckt.

Sparganiaceae (S. 68).

a. Bl. eingeschlechtig.

๙. бo und + Bl. in gesetzmässiger Anordnung untermischt.

Cyclanthaceae (S. 91).

3. - und $q$ Bl. in getrennten Kolben oder $c$ oben und $q$ unten an demselben Kolben.

I. Pflanzen strauch- oder baumartig.

II. Pflanzen krautig.

1. B. linealisch, ungestielt.

+ Bl. ohne Deckb. B. ungegliedert. Typhaceae (S. 68). ++ Bl. mit Deckspelzen. B. in Scheide u. Spreite gegliedert. Gramineae p. p. (Zea Mays, S. 85).

2. B. gestielt, mit breiter Spreite. Araceae p. p. (S. 91).

b. Bl. wenigstens ein Teil derselben) $\Varangle$. Araceae p. p. (S 91).

2. Blïtenstand nicht kolbenartig oder, wenn kolbenähnlich, dann nicht mit Spatha.

$1^{\natural}$. Ein einziges oder mehrere unter sich \pm froie Frb.

1“. Bl. nackt oder nur mit borstenfürmiger oder aus Anhängseln der Connective bestehender Blh.

A. Mehrere Frb. mit je $1 \mathrm{~N}$. Deckb. fehlend oder nicht spelzenartig.

Potamogetonaceae p. p. (S. 68).

B. 1 Frb. mit 2-3 N. Deckb. spelzenartig.

a. Bl.nur mit Deckspelzen, ohneVorspelzen. Cyperaceae (S. 85).

b. Bl. ausser der Deckspelze noch mit 1 oder mehr Yorspelzen.

$2^{\prime \prime}$. Bl. mit wirklicher Blh.

Gramineae (S. 71).

A. Blh. becherförmig.

a. 4 Frb., über die Blh. weit vorragend.

Potamogetonaceae p. p. (S. 68, 69).

b. 1 Frb., demselben die Blh. ringsum angewachsen.

Najadaceae (S. 69).

B. Blh. aus $3+3$ (selten $2+2$ ) B. bestehend.

a. Blh. homoiochlamydeisch, prophylloid.Juncaginaceae (S. 69).

b. Blh. in K. und Blkr. gesondert.

ๆ. $\infty$ Sa. die ganzen Innenflächen der Frb. (ausser der Mittelrippe) bedeckend.

3. Frb. mit 1 Sa.

2'. $2-\infty$ (allermeist 3 ) mit einander verwachsene Frb.

A. Placenten parietal.

A1. Frkn. oberständig.

B1. Frkn. unterständig.

Liliaceae p. p. (Lapageria, S. 100).

a. Bl $\oplus$, eingeschlechtig. Wasserpfl. Hydrocharitaceae (S. 70).

b. Bl. $\cdot \cdot$, , \&. Landpflanzen.

๑. Blhb. beider Kreise petaloid, nicht mit einander verwachsen.

Orchidaceae (S. 113).

३. Aeusserer Kreis der Blhb. kelchblattartig, verwachsenblättrig.

B. Placenten centralwinkelständig.

a. Bl. homoiochlamydeisch ${ }^{1}$ ).

1) Hierzu auch Galanthus nivalis gerechnet. 
Frkn. oberständig.

I. Blh. prophylloid. 3 langfederige $\mathrm{N}$. Juncaceae (S. 95).

II. Blh. allermeist petaloid. N. einfach rund oder kurz 3-lappig.

1. Nährgewebe fleischig oder knorpelig Liliaceae (S. 97).

2. Nährgewebe mehlig.

ア. Frkn. unterständig.

I. Blh. prophylloid. Bl. diöcisch. Dioscoreaceae (S. 108:

II. Blh. petaloid. Bl. \&.

1. Alle 6 Stb. fruchtbar.

Amaryllidaceae (S. 106).

2. Die 3 inneren Stb. völlig abortiert. Iridaceae (S. 109).

3. Das hintere Stb. fehlend oder staminodial. MIusaceae (S. 111).

b. Bl. heterochlamydeisch, in $\mathrm{K}$. und $\mathrm{Kr}$. gegliedert.

๗. Frkn. oberständig

I. Zahlreiche anatrope Sa.in jedemF ach. Bromeliaceae p.p.(S.94).

II. Wenige orthotrope Sa. in jedem Fach. Commelinaceae (S.95). ア. Frkn. unterständig (oder halbunterständig).

I. Alle 6 Stb. fruchtbar. Bromeliaceae p. p. (S. 94).

II. Die 5 vorderen Stb. fruchtbar, das 6 . (hintere) fehlend oder staminodial.

Musaceae (S. 111).

III. Nur 1 Stb. fruchtbar, dic übrigen staminodial oder abortiert.

1. Beide Hälften des Stb. fruchthar. Zingiberaceae (S. 111).

2. Die eine Hailfte des Stb. fruchtbar, die andere petaloid.

+ Blattstiel ohne Anschwellung Im inneren Kreis des Andröceums ausser dem zur Hälfte fruchtbaren Stb. nur noch 1 Staminodium. Cannaceae (S. 113).

-f + Blattstiel mit einer Anschwellung am Ende. Innerer Kreis des Andröceums 3-gliederig. Marantaceae (\$. 113).

\section{Typhaceae (Typha, 12).}

a. Fr. mit einer Lï̈ngsfurche, im Wasser aufspringend; S. nicht mit der Fruchtschale verwachsen.

a. N. spatelförmig. ㅇ Bl. ohne Tragb.

ア. N. lineal. o Bl. mit Tragb

b. Fr. eine Caryopse ohne Längsfurche, im Wasser nicht aufspringend.

T. Laxmanni Lepech.

\section{Sparganiaceate (Sparoganium, 8).}

a. Blütenstand iistig.

S. ramosum Huds.

b. Blütenstand nicht ästig.

๙. Pflanze mit $\infty$ Blütenkörfen.

I. Stengel und B. aufrecht.

II. Pflanze flutend.

Pflanze mit nur 1 Blütenkopfe, schlaff.

S. simplex Huds.

S. natans Fries

S. minimum F'ries

\section{Potamogetonaceae $(9 ; 75)$.}

1. Bl. in einfachen Achren mit stielrunder Achse, 3. N. \pm sitzend. [Potamogetoneae.]

A. Aehre \pm vielblütig. 4 Stb., an Rücken blütenhüllïhnliche, die A. weit überragende Connectivanhängsel. 'Teilfr. sitzend. 
a. Laubb. (mit Ausnahme der beiden der Aehre vorausgehenden) durch gestreckte Internodien getrennt, stets mit Blatthäutchen.

a. Blattscheiden fehlend oder sehr kurz. Blatthäutchen ansehnlich.

I. B. Janzettlich bis fast kreisrund, wenigstens die oberen nie linealisch.

1. Stengel stielrund. Quernerven der B. zahlreich, genähert. Teilfr. frei.

+ Stengel bis zum 1. Blütenstande unverzweigt. B. sämtlich gestielt, am Rande glatt, die obersten stets schwimmend, lederartig.

(.) Die untergetauchten B. mit Spreite. P. fluitans Roth - Die untergetauchten B. stielrunde Phyllodien. P.natans L. ++ Laubstengel verzweigt. Untergetauchte B. sitzend.

- B. mit tief herzförmigem Grunde stengelumfassend. Aehrenstiele gleich dick. $\quad P$. perfoliatus L.

B. am Grunde nicht herzförmig, die schwimmenden oval bis lanzettlich, die untergetauchten lanzettlich.

$P$. gramineus $\mathrm{L}$.

2. Stengel zusammengedrückt. Quernerven der B. entfernt. Teilfr. am Grunde verwachsen.

P. crispus L.

II. Sämtliche B. untergetaucht, linealisch, sitzend. Laubstengel ästig.

1. B. mit deutlichen Quernerven.

+ Stengel etwas zusammengedrückt. Aehrenstiel verdickt. B. 3- bis 5-nervig; Blatthäutchen in 2 seitliche Hälften gespalten

I'. mucronatus Schrad. t+ Stengel fast stielrund. Aehrenstiele nicht verdickt. B. meist 3-nervig

2. B. ohne deutliche Quernerven. Nur 1 Frb. P. pusilius L.

P. trichoides Ch. et Schltd.

F. Blattscheiden lang. Blatthäutchen viel kürzer. P.pectinatus L.

b. B. paarweise (selten zu 3) genähert, aber 2-zeilig, nicht gekreuzt-gegenständig, sämtlich olne Scheide und (bis auf das oder die beiden obersten) ohne Blatthäutchen. $P$. densus L.

B. Aehre 2-blütig. 2 Stb., mit sehr kurzen, ron den Antherenhälften ïberragten Anhängseln des Connectivs. Teilfr. in einen \pm langen Stiel ausgezogen.

2. $\bar{B}$. einzeln, eingeschlechtlich, $\subseteq$ mit becherförmiger Blh. Deutlicher Gr.

Zamnichellia (1) palustris L.

\section{Najadaceae (Najas, 10).}

a. Pflanze diöcisch. Stengel und Blattrücken stachelig. N.major All. b. Pflanze monöcisch. Stengel u. Blattrïcken stachellos. N. minor All.

\section{Juncaginaceae $(4 ; 15)$.}

A. Frb. mehrsamig.

B. Frb. einsamig.

a. $3 \mathrm{Frb}$. Zwiebeln bildend.

b. 6 Frb. Schräg aufsteigende Grundachse.
Scheuchzeria (1) palustris L. Triglochin (12). T. palustris L. T. maritima L. 


\section{Alismaceae $(10 ; 50)$.}

A. Blütenboden gewölbt. Bl. eingeschlechtlich. Stb. $\infty$, spiralig. Frkn. kopfig angeordnet. Sagittaria (10) sagittifolia L.

B. Blütenboden flach. Bl. Stb. 6, in einen Kreis gestellt. Frkn. gleichfalls \pm kreisförmig angeordnet.

A1. Mikropyle der Sa. dem Rücken der Frkn. zugewendet und dieser daher höher gewölbt. Alisma (2) Plantago L.

B1. Mikropyle der Sa. der Bauchnaht des Frkn. zugewendet und daher diese Seite höher gewölbt. Elisma (1)natans (L.) Buchenau

\section{Butomaceae $(4 ; 6)$.}

A. 9 fruchtbare Stb. Keimling gerade. Butomus (1) umbellatus L. B. $\infty$ innere fruchtbare Stb. und äussere Staminodien. Keimling hufeisenförmig gekrümmt. Trop. Amerika.

Hydrocleis (1) nymphaeoides (H. et B.) Buchenau

Hydrocharitaceae $(14 ; 60)$.

I. 3 (selten 2, 4, 5) Frb.; Placenten wenig in das Innere des Frkn. vorspringend, ungeteilt.

1. Laubb. in Quirlen. B Bl. in 1- bis 3-bliitigen, sitzenden Spathen, sich nicht loslösend. [Hydrilleae.]

A. 3 Stb. Sa. meist umgewendet. Laubzweige mit 1 dorsalen, stengelumfassenden Vorb. Laubblattquirle 2- bis 8-blättrig. Osteur. bis Neuholl. Hydrilla (1) verticillata (L. f.) Casp. B. 3-9 Stb. Sa. geradläufig. Laubzweige mit 2 seitlichen, nicht stengelumfassenden Vorb. Laubblaitquirle stets 3-blättrig. Amerika.

Elodea (5) canadensis (Rich.) Casp. (P).

2. Laubh. spiralig (selten fast quirlig oder anscheinend 2-zeilig). $\mathrm{Bl}$. in vielblütigen, langgestielten Spathen, sich von ihrer Einfügung loslösend. Trop. und subtropisch. [Vallisnericae.]

Vallisneria (2) spiralis L.

II. 6-15 Frb. Placenten (ausser bei Hydromystria) weit in das Innere des Frkn. vorspringend, sich in der Mitte berührend. Laubb. spiralig, in Rosetten. [Stratiotoideae.]

1. Mit Ausläufern. Laubb. sämtlich schwimmend, ganzrandig, gestielt. A. 4-fächerig, Placenten ungeteilt. Sa. geradläufig. [Hydrochariteae.]

A. B1. meist einhäusig. Spathen beider Geschlechter 2-blättrig. Keine Honigdrüsen. o Bl. mit Vorb.; A. lineal. Laubb. unterseits schwammig aufgetrieben. - Mexiko bis Paraguay.

Hydromystria (3) stolonifera G. F. W. Mey.

B. Bl. zweihäusig. Spatha der $\mathrm{Bl}$. 1-blättrig. und Bl. mit Honigdrüsen. $\sigma \mathrm{Bl}$. ohne Vorb.; A. länglich. Laubb. flach, mit Anhängen am Stiel. Hydrocharis (2) Morsus ranae L.

\%. Mit Ausläufern. Laubb. wenigstens teilweise untergetaucht, sitzend, breit linealisch, zugespitzt, stachelig gesägt. A. 2fächerig. Placenten 2-schenkelig. Sa. umgewendet. [Stratioteae.] 


\section{Gramineae (315; 3600).}

I. Aehrchenspindel meist oberhalb der Hüllsp. gegliedert, so dass diese beim Ausfallen der Fruchtsp. stehen bleiben; Ae. meist 2- bis $\propto$-blütig und dann immer mit deutlichen Internodien zwischen den Bl. - oder seltener 1-blütig und dann oft mit Achsenfortsatz uiber der Bl.

1. Halm (wenigstens am Grunde) holzig. Blattspreite oft mit kurzem Stielchen, zuletzt gliedartig ron der Scheide sich lösend.

I. Bambuseae (S. 72).

2. Halm krautig, 1-jährig. Blattspreite stiellos, ohne Gliederung in die Scheide verlaufend.

A. Ae. auf deutlichen (mitunter sehr kurzen) Stielen in Rispen, ährenförmigen Rispen oder Trauben (ohne Ausschnitte der Hauptspindel gestellt.

a. Ae. $\infty$ - bis 2-blütig.

๘. Decksp. länger als Hüllsp., unbegrannt oder aus (selten unter) der Spitze begrannt, Granne ohne Knie. II. Festuceae (S. - 2 ).

F. Decksp. kürzer als Hüllsp., auf dem Rücken mit einer geknieten Granne, selten aus der Spitze begrannt oder wehrlos und dann immer mit 2 fast gegenständigen $\mathrm{Bl}$. ohne Achsenfortsatz.

b. Ae. 1-blütig.

III. Areneae (S. 76).

a. Ae. mit 2 (selten ohne) Hüllsp.; Torsp. 2-nervig.

IV. Agrostideae (S. 77).

F. Ae. mit 4 Hüllsp.: Torsp. 1-nervig. V. Plıalarirleae (S.80).

B. Ae. in 2 einander genäherten Reihen, eine einseitige Aehre oder Traube mit ungegliederter Spindel bildend VI. Chlorideat S.80).

C. Ae. in 2 (selten mehr) gegenüberstehenden Reihen eine gleichseitige (sehr selten einseitige) Aehre bildend und an den Spindelauszahnungen sitzend.

a. Decksp. grannenlos oder aus der Spitze begrannt.

VII. Hordeeae (S. 81).

b. Granne der Decksp. tief rückenständig. Gaudinia (Arenee).

II. Ae. bei der Reife als Ganzes rom Stiele oder samt gewissen Gliedern der Aehrenspindel abfallend, allermeist 1-biütig ohne Achsenverlängerung über die Bl. hinaus (selten 2-blütig, wobei die untere Bl. unvollkommen); Aehrchenspindel gestaucht, so dass die Sp., bez. Bl. neben einander stehen.

1. Ae. von der Seite zusammengedrückt. Hilum lineal.

VIII. Oryzeae (S. 83).

2. Ae. stielrund oder noch öfter etwas vom Rücken zusammengedrückt. Hilum punktförmig.

A. Decksp. und Torsp. \pm knorpelig, leder- oder papierartig; Hüllsp. zarter, meist krautig, die 1. (äusserste) meist kleiner. Ae. einzeln von den $Z$ weiglein einer Rispe oder allermeist ungegliederten Aehrenspindel sich lösend. IX. Paniceae (S. 83).

B. Decksp. und Vorsp. zarthäutig oder letztere ganz fehlend; Hüllsp. krautig oder häufiger derbhäutig, papier- oder lederartig oder knorpelig. 
a. Meist die 1. (äusserste) Hüllsp. Kleiner oder schmäler als die folgenden. Hauptspindel bei der Reife ungegliedert stehen bleibend; Ae. in Gruppen von der ungegliederten Aehrenspindel sich ablösend.

X. Zoysieae.

In wärmeren Ländern. Tragus (2) racemosus (I.) Desf.

b. Die 1. (äusserste) Hüilsp. am grössten, mit den Rändern alle anderen umschliessend. Ae. meist in Trauben oder Aehren, die sich bei der Reife gliedern.

๙. Ae. oder , und $₹$ Ae. in demselben Blütenstande so gemischt, dass ein, neben einem steht. XI. Andropogoneae (S. 84).

$\because$ und Ae. in getrennten Blïtenständen oder in getrennten Partien desselben Blütenstandes. XII. Maydeae (S. 85).

\section{Bambuseae.}

A. 3 Stb. Gr. frei.

B. 6 Stb. Gr. \pm verwachsen.

Arundinaria (24) japonica Sieb. Bambusa (46).

\section{Festuceac.}

A. Decksp. ganzrandig oder 2-zähnig bis 2-spaltig, wehrlos oder mit 1 Granne.

A1. Aehrchenspindel und Decksp. (wenigstens der fruchtbaren Bl.) \pm mit langen, die Sp. verhüllenden Haaren. Hochwüchsige Rohrgräser.

A2. Alle Ae. behart. Pflanze \&, sehr selten 2-häusig. Аз. Decksp. zarthäutig, 光-nervig.

At. Haare aus der Decksp. entspringend; Ae. Spindel kahl. - Mmglot. Arundo (6) Donax L.

B. Haare nur aus der Ae.-Spindel entspringend.

Phragmites (3) communis Trin.

B3. Decksp. derbhäutig, 5-nervig. Mmgbt.

Ampelodesmus (1) tenax Link

B2. Pflanze 2 häusig. Ae behaurt, kahl. - S.-Brasil., Argentinien.

Gynerium (3) argenteum Nees

B1. Aehrchenspindel und Decksp. kahl oder kurz behaart; Haare viel kürzer als Sp.

A2. N. mit längeren, fiederig gestellten Aestchen, verhältnismässig kurz, sitzend oder auf kurzen Gr., aus der Seite der Decksp. hervortretend.

A3. Alle Ae. gleichgestaltet.

At. Decksp. nicht 2- bis 3-zähnig oder -spitzig.

A5. Decksp. 1- bis 3-nervig, alle mit \& Bl. oder nur die oberste mit \& Bl. oder leer.

Ac. Rispenäste spiralig gestellt.

A. Ae. dicht und vielblütig, mit meist zäher Spindel.

Eragrostis (100).

B7. Ac. locker 2- bis 4-blütig, conisch mit brïchiger Spindel.

Molinia (1) coerulea (L.) Mönch

B. Primäre Rispenäste 2-zeilig geordnet, meist an der Basis weiter verzweigt.

A7. Rispe ausgebreitet, mit zarten, langen Zweigen.

Catabrosa (1) aquatica (L.) P. Beauv. 
B. Rispe sehr zusammengezogen, dicht.

Koeleria (15).

a. Decksp. wehrlos oder kurz stachelspitzig. K. cristata (L.) Pers.

b. Decksp. aus oder unterlialb der Spitze kurz begrannt. IImgbt.

$K$. phlcoides $\mathrm{P}$.

B.. Decksp. 5 - bis $\propto$-nerrig, alle mit $\fallingdotseq \mathrm{Bl}$. oder nur die oberste (sehr selten mehrere) mit $=\mathrm{Bl}$. oder leer.

A6. Jedes Ae. mit $\ddot{\partial}-6$ Hiillsp. $-\mathrm{N}$.-Am. Uniola $(5)$ latifolia L. B6. Jedes Ae. mit 2 Hüllsp.

Ar. Decksp. am Grunde herzfürmig ausgeschnitten.

B7. Decksp. am Grunde nicht herzförmig.

Briza (12) media L.

As. Ae. in Rispen oder Trauben, weder geknäuelt noch dachziegelig sich deckend.

A9. Die beiden N. dem Scheitel des Frkn. (oder ganz nahe demselben) eingefü̈nt. Hüllsp. unbegrannt.

Aro. Seitennerven der Decksp. fast parallel zu einander, vom Mittelnerven getrennt bleibend.

A11. Hüllsp. wenig oder nicht kürzer als die anstossenden Decksp. Scolochloa (2) festucacea (Lilj.) Lk.

B11. Hüllsp. viel kürzer als die anstossenden Decksp.

A12. Gr. fehlend. Schüppchen frei. Decksp. undeutlich 5-nervig.

Atropis (14).

a. Ohne Ausläufer. Rispenäste rauh, während der Blütezeit abstehend, später herabgeschlagen, untere meist zu 4. A. distans (L.) Griseb.

b. Nichtblühende Stengel niederliegend, ausläuferartig. Rispenäste meist glatt, fruchttragende zusammengezogen, untere meist zu 2. A. maritima (C. Koch) Griseh.

$\mathrm{B}_{1}$. (ir. deutlich. Schüppchen rerwachsen. Decksp. dentlich 7-nervig.

a. Rispe schmal. te. lineal, lan walzlich. Decksp. spitzlich.

b. Rispe ausgebreitet.

Glyceria (16).

G. fluitans (L.) R. Br. G. aquatica (L.) Thhlbg.

B10. Seitennerven der Decksp. bogig, oben gegen den Mittelnerv konvergierend.

A11. Aehrchenspindel steif gewimpert. Nordamer.

Graphephorum (1) melicoides Desv.

Bis. Aehrchenspindel kahl, flaumig oder vertiorren behaart.

A12. Decksp. auf dem Rücken stark gekielt. Hilum punktförmig.

a. Decksp. mit 5 schwachen Nerven.

Poa (100).

c. Beide Hüllspelzen 3-nervig. Pflanze ausdauernd.

I. Halm stielrundlich. Kiel und Randnerven der Decksp. \pm seidenhaarig.

1. Blatthäutchen länglich, spitz.

+ Untere Rispenäste meist zu 1 oder 2 (-4). Stengelgrund zwiebelartig. Oberste Blattscheide länger als ihr B.

P. bulbosa L.

++ Untere Rispenäste zu 3-5. Stengelgrund nicht zwiebelartig. Oberste Blattscheide kiirzer als ihr B.

$P$. palustris Roth 
2. Blatthäutchen sehr kurz, gestutzt. Oberste Blattscheide kürzer als ihr B.

$P$. nemoralis $\mathrm{L}$.

II. Halm zweischneidig zusammengedrückt. Oberste Scheide länger als ihr B. Decksp. (abgesehen von den verbindenden Zotten) kahl.

P. compressa L.

3. Untere Hüllsp. 1-, obere 3-nervig. Decksp. (abgesehen von den verbindenden Zotten) kahl. Rispe einseitswendig. P. annua L.

b. Decksp. mit 5 starken Nerven. Obere Hüllsp. 3-, untere 1nervig. Rispenäste abstehend, rauh, die unteren zu $3-5$. Oberste Scheide länger als ihr B.

ๆ. Pflanze rasig, Wurzel faserig, Ausläufer fehlend.

I. Halm stielrund, nebst den Scheiden etwas rückwärts rauh. Blatthäutchen länglich, spitz.

$P$. trivialis $\mathrm{L}$.

II. Halm und Scheiden zweischneidig. Blatthäutchen kurz. B. an der Spitze plötzlich zugespitzt und mützenförmig zusammengezogen.

P. Chaixi Vill.

5. Wurzelstock mit langen Ausläufern weit umherkriechend. Halm und Scheiden kahl. Oberste Scheide viel länger als ihr B. Blatthäutchen kurz, gestutzt.

B12. Decksp. auf dem Rücken (wenigstens unten) rundlich.

A13. Vorsp. auf den Kielen rauh oder fein gewimpert. Hilum lineal.

Festuca (80).

a. Die 3 Stb. und N. zur Blütezeit aus den Sp. hervortretend. Rispenästchen dünn. Pflanzen ausdauernd.

\%. Alle B. flach, linealisch bis lineal-lanzettlich.

I. Blatthäutchen länglich. Frkn. oberwärts behaart. Fr.von der Spelze lose umgeben oder frei. F. silvatica (Poll.) Vill.

II. Blatthäutchen sehr kurz, gestutzt. Frkn. kahl. Fr. von der Spelze eng umschlossen.

1. Decksp. unbegrannt oder mit einer sehr kurzen Granne. + Untere Blattscheiden und Oberseite der B. rauh. Rispe ausgebreitet, ihre Aeste mit 5-15 Ae. Ae. 4-bis 5-blütig. F. arundinacea Schreb. ++ B. ziemlich, Scheiden ganz glatt. Rispe einseitswendig, zusammengezogen, nur während der Bl. offen. Aeste mit 2-5 Ae. Ae. 6- bis 12-blütig.

$F$. elatior L.

2. Decksp. unter der Spitze eine sie an Länge übertreffende, geschlängelte Granne tragend.

$F$. gigantea (L.) Vill.

3. B. alle oder wenigstens die grundständigen borstlich zusammengefaltet.

I. Blatthäutchen länglich oder eirund, nicht 2-öhrig. Spelzen am Rande breit-trockenhäutig, die Fr. nur lose umgebend.

F. varia Haenke

II. Blatthäutchen sehr kurz, 2-öhrig. Spelzen am Rande sehr schmal-trockenhäutig, die Fr. eng umschliessend.

1. Halmb. flach.

+ Pflanze ohne Ausläufer, dicht rasig. Ae. meist grün.

$F$. heterophylla Haenke

+ + Pflanze mit Ausläufern, locker rasig. Ae. meist graugrün.

2. Auch die Halmb. borstlich. $F$. rubra L. $F$. ovina L. 
b. Meist nur 1 Stb., dieses und die N. während der Blütezeit meist zwischen den Sp. bleibend. 1- oder '2-jährig. Aehrchenstiele dick oder an der Spitze verdickt. Granne länger als die Sp.

a. Stengel oberwärts ohne Blattscheiden, glänzend. Rispe aufrecht, grösstenteils traubig, der unterste Ast halb so lang als dieselbe.

$F$. sciuroides Roth

ア. Stengel bis zur Spitze von Blattscheiden eingehüllt. Rispe einseitswendig, ährenförmig, oben überhängend ; der unterste Ast mehrmals kürzer als dieselbe.

B13. Vorsp. auf den Kielen kammförmig gewimpert.

a. Traube aufrecht. Granne kürzer als Decksp

Brachypodium (6).

B. pinnatum (L.) P. Beauv.

b. Traube nickend. Granne so lang oder Jänger als Decksp., dünn, öfter geschlängelt. B. silvaticum (Huds.) P. Beauv.

B9. Die beiden N. auf der Vorderseite des Frkn. beträchtlich unter dem Gipfel entspringend. Hüllsp. wehrlos. Bromus (40).

a. Untere Hüllsp. 1-, obere 3-nervig. Ae. von der Seite zusammengedrückt. Decksp. gekielt und aus der 2-zähnigen oder 2-spaltigen Spitze begrannt.

э. Decksp. kurz begrannt. Vorsp. auf den Kielen sehr kurz gewimpert. Ae, nach der Spitze verschmälert.

I. Rispe schlaff, locker, überhängend. B. asper Murr.

II. Rispe dicht, aufrecht.

1. Pflanze rasig. Untere Blattscheiden behaart. B. entfernt gewimpert. Grannen halb so lang als die Sp. B. erectus Huds.

2. Pflanze mit Ausläufern. B. und Blattscheiden kahl. Grannen sehr kurz oder fehlend.

$B$. inermis Leyss.

F. Ae. während und nach der Bl. oben verbreitert. Granne so lang oder länger als die Decksp.

I. Halm kahl. Granne länger als die lineal-pfriemelige, starknervige Decksp.

B. sterilis L.

II. Halm unter der Rispe kurzhaarig. Granne etwa so lang als die lanzettliche, undeutlich nervige Decksp. B. tectorum L.

b. Untere Hüllsp. 3- bis 5-, obere und Decksp. 5- bis 9-nervig. A e. eiförmig oder lanzettlich. Decksp. auf dem Rüicken rund, ungezähnt; Granne unterhalb der Spitze eingefügt, oft spreizend, selten fehlend. Kiel der Vorsp. kammförmig gewimpert.

\%. Decksp. zur Fruchtzeit eingerollt, daher dann die Bl. stielrund, sich nicht mehr dachziegelig deckend. Blattscheiden kahl. B. secalinus L.

F. Bl. auch zur Fruchtzeit sich am Grunde dachziegelig deckend. Wenigstens die unteren Blattscheiden behaart.

I. Decksp. und Vorsp. genau gleichlang, erstere 2-zähnig.

II. Decksp. deutlich länger als die Vorsp.

1. Decksp. ziemlich tief 2-spaltig; Granne ziemlich tief entspringend, meist auswärts gebogen. B. patulus M. et Koch

2. Decksp. seicht 2-spaltig. Granne gerade, dicht unter der Spitze entspringend.

+ Rispe auch nach dem Verblühen locker. Ae. länglichlanzettlich. 
+ + Rispe nach dem Verblühen zusammengezogen. Ae. eilänglich.

(-) Halm oberwärts kahl. Aeste rauh. Ae. kahl. B. racemosus L.

(.) Halm oberwärts mit abwärts gerichteten Haaren. Aeste und Ae. weichhaarig. B. mollis L.

c. Hüllsp. und Decksp. vielnervig, gekielt. Frkn. deutlich 3-höckerig. Amerika.

B. unioloides Kth.

Bs. Ae. in kleinen Knäueln, die in eine lappige Rispe vereinigt sind.

Dactylis (1) glomerata L.

$\mathrm{C}_{5}$. Decksp. meist 7 - bis 9-nervig, 2 bis mehrere oberste Sp. des Ae. leer (selten mit Bl.), einander angepresst, oft sich gegenseitig umschliessend.

Melica $(30)$.

a. Ae, in einseitswendiger, lockerer Traube nickend, kahl. M. nutans $\mathrm{L}$.

b. Ae. in walzenförmiger Scheinühre; Decksp. am Rande dicht wimperig-zottig, Vorsp. kurz gewimpert. M. ciliata L. Bt. Decksp. 2- oder 3-zähnig oder 3-spitzig, meist 3-nervig; Randnerven und Callus meist behaart.

Triodia (26) decumbens (L.) P. Beauv.

B3. Ae. 2-gestaltig, die fruchtbaren 1-bis 3-blütig, von sterilen, aus zahlreichen Sp. bestehenden umgeben.

At. Fruchtbare Ae. 2 -bis 3 -blütig, sterile mit begrannten oder spitzen Spelzen.

Cynosurus (5).

a. Decksp. und unfruchtbare Sp. nur stachelspitzig, nicht begrannt.

b. Sp. begrannt.

C. cristatus L.

C. echinatus L.

B. Fruchtbare Ae. 1-blütig, sterile mit stumpfen Sp. Mmgbt.

Lamarckia (1) aurea (L) Mönch

B. N. mit sehr kurzen, ringsum entspringenden Aestchen auf verlängerten, freien Gr., aus der Spitze der Decksp. hervortretend. Rispe sehr dicht, ähren-oder köpfchenfürmig. Die untersten Ae. mit Tragsp. Sesleria (10) coerulea (L.) Ard. B. Decksp. an der Spitze in 9-23 gramenförmige Zipfel zerspalten.

Pappophorum (20).

\section{Aveneac.}

A. Die Fruchtsp. von den stehen bleibenden Hüllsp. sich abgliedernd. A1. Ae. 2 - bis vielblütig, mit A chsenfortsatz ïber die obere Bl. hinaus.

A2. Gramne zwischen den (häufig begramnten) Lappen oder Zähnen der Decksp. entspringend. Danthonia (100 prorincialis. D.C.

B2. Granne der Decksp. riickenständig, d. i. unterhalb der Zähne der Spitze entspringend.

A3. Ae. in einer (zuweilen ährenfürmigen) Rispe, nicht in einer echten Aehre.

At. Alle Bl. \& oder die oberste Bl. ó oder steril.

A5. Fr. frei, ungefurcht. Ae. meist klein (unter $1 \mathrm{~cm} \mathrm{lang).}$ A6. Decksp. unregelmässig gezähnelt oder 2-lappig mit gezähnelten Lappen oder ganzrandig.

A7. Granne ungegliedert, mit feiner Spitze. Deschampsia (20).

a. Granne gerade. Dichtrasig; B. flach, sehr lang.

D. caespitosa (L.) P. Beauv. 
b. Granne gekniet. Lockerrasig; B. borstenfürmig.

B7. Granne gegliedert, mit keuliger Spitze. D. flexuosa (L.) Trin. Corynephorus (3) canescens (L.) P. Beauv. B. Decksp. 2-spaltig oder 2-zähnig bis 2-grannig.

Trisetum (50) flavcscens (L.) P Beauv. B.. Fr gefurcht, meist den $\mathrm{Sp}$. angewachsen. Ae. über $1 \mathrm{~cm}$ gross.

Avena (50).

a. Ae. wenigstens nach der Bl. hängend, 15̆-30 $\mathrm{mm}$ lang. Hüllsp 5- bis 11-nervig.

\%. Bl. von der Aehrchenachse abgegliedert, bei der Reife sogleich abfallend. Ae. 3-bliitig. Aehrehenachse und untere Hälfte der Decksp. von meist rotbraunen Haaren zottig. A. fatua $\mathrm{L}$.

3. Bl nicht von der Aehrchenachse abgegliedert, bleibend. Aehrchenachse kabl oder nur am Grunde der Bl. behaart. I. Ae. meist 3-blütig. Hüllsp. kürzer als die Bl. A. nuda L.

II. Ae meist 2-blütig. Hüllsp. so lang oder länger als die Bl.

1. Aehrchen chse unter den Bl behaart. Decksp. beider Bl. mit geknieter Riickengranne und 2 in gerade, kurze Grannen auslaufenden Spitzen. A. strigosa Schreb.

2. Aehrchenachse kahl. Decksp. mit 2 unbegramuten Spitzen und aussen öfter mit zwei Seitenzähnchen; nur die Decksp. der unteren Bl. oder keine begrannt.

+ Rispe allseitswendig, mit abstehenden Aesten. A. sativa L. ++ Rispe einseitswendig, mit anliegenden Aesten.

A. orientalis Sehreb.

b. Ae. aufrecht. mittelgross oder klein. Hüllsp. 1- his 3-nervig.

๑. B. flach, glatt, besonders die unteren nebst den Scheiden kurzzottig Haarbüschel unter der 2. Bl. halb so lang als diese. Untere Hüllsp 1-nervig, behaart. A pubescens L.

3. P. zusammengefaltet, kahl, oben und am Rande rauh; Scheiden (bes. die unteren) ruickwärts rauh. Haarbüschel unter der zweiten $\mathrm{Bl}$. vielmal kïrzer als diese. Beide Hüllsp. 3-nervig.

B. Obere Bl. \&, untere of und stark begrannt.

A. pratensis L.

Arrhenatherum (3) avenaccum (Scop.) P. Beauv.

B3. Ae. denen von Aven ähnlich, aber in einer echten. einfachen, zweizeiligen Adhre. - Mmght. Gaudinia (2) fragilis P. Beauv. $\mathrm{B}$. Ae. streng 2-bliitig, ohne Achsenfortsatz über die obere $\mathrm{Bl}$. hinaus.

B. Ae. als (Ganzes sich ablösend, 2-blütig; obere Bl. (selten \&), untere $§$, wehrlos.

Holeus (8).

a. Granne der Bl. die Hüllsp. weit überragend, gekniet. Wurzelstock weitkriechend.

$H$. mollis L.

b. Granne der o Bl. nur wenig vortretend, zuletzt hakig. Wurzel faserig.

H. lanatus $\mathrm{L}$.

\section{Agrostideae.}

A. Decksp. bei der Reife meist zarthäutig, wenigstens zarter als die Hüllsp., die Fr. gar nicht oder nur locker umschliessend. 
A1. N. federig (2-seitig-langästig), oberhalb der Basis des Ae. vortretend, selten in demselben eingeschlossen bleibend.

A2. Hüllsp. bei der Reife an dem ungegliederten Ae.-Stiele verbleibend.

A3. Hüllsp. weder federartig behaart, noch am Grunde blasig.

A4. Callus oder Stielfortsatz mit einem Haarbüschel, das mindestens $1 / 3$ so lang als die Decksp. ist.

A5. Untere Hüllsp. etwas kürzer als die obere, beide wenig länger als die unbegrannte Decksp. B. borstlich eingerollt, oberseits an den Nerven weichhaarig, sonst kahl und glatt. Rispe auch während der Bl. zusammengezogen, schmal ährenförmig. Ammophila (1) arenaria (L.) Lk.

B. Untere Hüllsp. etwas länger als die obere, beide betrïichtlich länger als die begrannte Decksp. B. meist flach, bes. oberseits und am Rande rauh. Rispe während der Bl. ausgebreitet.

Calamagrostis (130).

a. Mit meist behaartem Achsenfortsatz. Callushaare der Decksp. so lang oder kürzer als diese, die gestutzt oder 2-zähnig und nur etwas länger als die Vorsp. Granne rückenständig. Rispe vor und nach der Bl. ährenförmig.

๘. Callushaare $4 \mathrm{mal}$ kürzer als die Decksp. Granne gekniet, die Hüllsp. weit überragend. C. arundinacca (L.) Rth.

f. Callushaare so lang oder halb so lang als die Decksp. I. Granne gekniet, die Hüllsp. weit überragend. C. varia Lk.

II. Granne meist gerade, die Decksp. kaum, die Hüllsp. nicht überragend.

C. neglecta (Whrh.) Fr.

b. Ohne Achsenfortsatz über die Bl. hinaus. Callushaare länger als die Decksp., die 2-spitzig und beträchtlich länger als die Vorsp.

๙. Granne rïckenständig, die Decksp. überragend. Rispe auch während der Bl. geknäuelt-lappig, steif aufrecht; Aeste dick.

(`. Epigeios (L.) Rth.

$\beta$. Granne endständig. Rispe während der Bl. gleichmässig ausgebreitet; Aeste dünn.

I. Granne halb so lang als die Decksp. Hüllsp. linealpfriemelig, an der Spitze seitlich zusammengedrückt.

C. Pseudophragmites (Hall. f.) Aschs.

I1. Granne die Spitzen der Decksp. kaum überragend. Hüllsp. lanzettlich, zugespitzt.

C. lanceolata Rth.

B. Callus oder Stielfortsatz nur mit sehr kurzen, spärlichen Haaren oder kahl oder überhaupt undeutlich.

A5. Decksp. unbegrannt oder häufiger Granne unter der Mitte des Rückens, gekniet.

Agrostis (100).

a. Vorsp. deutlich ausgebildet. B. flach, in der Knospenlage gerollt.

๙. Blatthäutchen länglich. Rispe nach der Bl. zusammengezogen.

A. alba L.

ß. Blatthäutchen sehr kurz, abgestutzt. Rispe auch nach der $\mathrm{Bl}$. ausgebreitet.

$A$ vulgaris With.

b. Vorsp. sehr klein oder fehlend. Untere B. zusammengefaltet borstlich. Blatthäutchen länglich.

A. canına L. 
B5. Decksp. mit einer unterhalb der Spitze entspringenden zarten Granne von mehrfacher Länge der Sp.

Apera (2) Spica venti (L.) P. Beaur.

$\mathrm{B}_{3}$. Hüllsp. am Grunde blasig erweitert, vielmal länger als die Decksp. Mmgbt. Gastridium (2) australe P. Beauv.

$\mathrm{C}_{3}$. Hüllsp.lang, federartig behaart. Mmgbt. Lag'urus (1) ovatus L.

B. Ae. bei der Reife als Ganzes oft mit einem Teile oder dem ganzen Ae.-Stiel abfallend, der oft eine schon zur Blütezeit sichtbare Gliederung besitzt. 1. und 2. Hüllsp. begrannt. - Mmgbt. Polypogon (10) monspeliensis Desf. B1. N. schmal, pinselfürmig (rundum kurzästig), aus der Spitze der nur wenig sich öffnenden Sp. hervortretend.

A2. Ae. in einer aus kleinen, doldenförmigen Büscheln bestehenden Rispe. Hüllsp. fehlend. M.-Eur., Norwegen, Amur, Oregon.

Coleanthus (1) subtilis Seidl.

B2. Ae. in einer dichten, oft verkürzten Scheinähre; das oberste B. keine Hülle bildend.

A3. Huillsp. bei der Reife am Ae.-Stiele haftend, in eine Spitze oder kurze Granne auslaufend; Decksp. meist ausfallend, wehrlos.

Phleum (10).

a. Achse des Ae. etwas über die Bl. hinaus verlängert. Kiel der schief abgestutzten Hüllsp. nach aussen gewölbt, warzig rauh.

P. Boehmeri Wib.

b. Achse des Ae. nicht über die Bl. hinaus verlängert. Kiel der Hüllsp. gerade, steifhaarig gewimpert. P. pratense L.

B3. Ae. bei der Reife sich als Ganzes rom Stiele lösend. Hüllsp. wehrlos; Decksp. meist mit rückenständiger, geknieter Granne.

Alopecurus (20).

ฯ. Hüllsp. nur am Grunde verwachsen. Halm knickig-aufsteigend, glatt.

I. Ae. elliptisch. Decksp. aus der Mitte begrannt.

A. fulvus Sm. II. Ae, eilänglich. Decksp. unter der Mitte begrannt. A. geniculatus L.

?. Hüllsp. bis unterhalb der Mitte verwachsen. Halm gerade aufrecht.

$\mathrm{C}_{2}$. Ae. in einem umhüllten Köpfchen.

A3. Köpfchen \pm kugelig, rom obersten Stengelb. als einer glockenförmigen Hülle umschlossen. Orient.

Cornucopiae (1) cucullatum L.

B3. Köpfchen flach (breiter als lang), $\mathrm{zwischen} 2$ gegenständige, bauchige Scheiden mit dornartigen Spreiten eingeschlossen. Mmgbt.

Crypsis (1) aculeata Ait. B. Decksp. bei der Reife erhärtend, wenigstens härter als Hüllsp., die Fr. eng umschliessend.

A1. Decksp. unbegrannt.

Bi. Decksp. begrannt.

Milium (6) cffusum L.

A2. Granne der Decksp. einfach.

A3. 2 Lodiculae. Vorsp. häutig. Granne zart, zuweilen eine blosse Spitze.

Muehlenbergia (60).

B3. 2 oder 3 Lodiculae. Deck- und Vorsp. zuletzt sehr hart. 
At. Decksp. breit, mit zarter, nach dem Verblühen abfallender Granne.

Oryzopsis (15).

B. Decksp. schmal, mit gedrehter, kräftiger, bis zur Fr bleibender Granne.

Stipa (100).

a. Granne kahl, zuletzt verworren hin- u. hergebogen. S. capillata L.

b. Granne lang, federig.

S. pennata L.

B. Gramne der Decksp. 3-teilig (Seitenteile manchmal sehr kurz). Aristida (100).

\section{Phalarideae.}

A. 3. und 4. Hüllsp. (oder wenigstens die 4.) grösser als 1. und 2. 6 oder 3 Stb.

Ehrharta (24).

B. 3. und 4. Hïllsp. kleiner oder höchstens so lang als 1. und 2. 2 oder 3 Stb.

$\mathrm{A}_{1}$. 3. und 4. Hüllsp. oder wenigstens die 3. mit einer $\mathrm{Bl}$, fast so lang als die 1. und 2., wehrlos oder kurz begrannt.

Hierochloë (13).

a. Aehrchenstiele kahl. ; Bl. grannenlos oder unter der Spitze mit kurzer, gerader Granne.

H. odorata (L.) Whlbg.

b. Aehrchensticle unter den Ae. mit einem Haarbüschel. Obere Bl. auf dem Rücken mit mässig langer, geknieter (tranne. $H$. australis (Schrad.) R. et Sch.

B1. 3. und 4. Hüllsp. leer, klein.

Az. 3. und 4. Hiillsp. auf dem Rücken begrannt, braunhaarig. Schïppchen fehlend. 2Sth. Anthoxanthum (4) odoratum L.

B. 3. und 4. Hiillsp). zu kleinen Schïppchen reduziert, wehrlos. 3 Stb.

Phalaris (10)

a. Blattscheiden glatt. Rispe verlängert, abstehend. Hüllspelzenkiele ungeflügelt.

b. Blattscheiden rauh. Rispe ährig. Hüllspelzenkiele einen ganzrandigen Flügel bildend.

$P$. canariensis L.

\section{Chlorideae.}

A. Jedes Ả. mit $2-3 \& \mathrm{Bl}$.

A1. Hüllsp. am Stielchen verbleihend, Decksp. ausfallent.

Aะ. Ae. deutlich alternierend. Aehren auseinander gerïckt.

Leptochloa (12).

B.. Ae. sehr dicht gecirängt. Aehren meist gefingert. Eleusine(6). B. Ae. als Gamzes sich ahlüsend. Ostemr, gem. As., N.-Am.

B. Nur 1 (sehr selten 2) $\&$ Bl. in jedem Ae.

$A_{1}$. Oberhalb der Bl. 1 bis mehrere leere Sp., selten mit einer Bl. in der Achsel. Blïtenstand aus 2 oder mehr in Scheinquirlen oder doch dicht ïber einander stehenden Aehren bestehend. Decksp. der BI. mit 1 Granne oder wehrlos.

Chloris (40).

B1. Keine leeren Sp. oder Bl. und nur selten ein kurzes Stielchen oberhalb der $\&$ Bl. Ae. unbegrannt.

1. Hüllsp. an der 2- bis 6-fingerigen Aehrenachse verbleibend. - Trop. und subtrop.

Cynodou (4) Dactylon Pers.

B. Ae. als Ganzes von der Aehrenachse abfallend. - N.-Am. 


\section{Hordeeae.}

A. Aehre gleichmässig 2-seitig. $2 \mathrm{~N}$.

A. $2-6$ Ae. an jedem Ausschnitt der Hauptspindel.

12. Ae. 2- bis vielblïtig. Elymis (30) arenarius L. B. Ae. 1-blïtig (höchstens mit dem Rudiment einer 2. Bl.).

Hordeum (16).

a. Gipfel-Ae. mit 2 opponierten Hüllsp. in der Mediane der Decksp. Fruchts1. sich ron einem deutlichen Stiele abgliedernd.

H. europaeum (L.) All.

b. Gipfel-Ae, verkïmmert. Fruchtsp, sich nicht rom dehrchenstiel abgliedernd.

\%. Seitliche Ae. j. kurz gestielt. Alle Ae. begramnt. Grammen haardünn. Sp. lanzettlich.

I. Hüllsp. der mittleren Ae. lineallanzettlich, gewimpert.

II. Hüllsp. aller de. borstlich, scharf, nicht gewimpert.

\section{H. murinum L.}

H. secalinum Schreb.

Seitliche Ae gleichfalls sitzend. Grannen flach ausgebreitet. Von H. spontanum C. Koch (Tord.-As.). H. satium Jessen

I. Nur das Mittel-Ae. jedes Drillings fruchtbar und begrannt. H. sat. distichon (L.) Hack.

II. Alle Ae. fruchtbar und begrannt.

1. Die 6 Zeilen deutlich gesondert. H. sat. herastichon (L.) Hack.

2. Nur die Mittelzeilen deutlich gesondert, die Seitenzeilen in einander greifend.

H. sat. vulgare (L.) Hack.

$B_{1}$. Ae. einzeln an den Ausschnitten der Hauptspindel.

A. Ae. transversal zur Hauptspindel, also mit den Seiten der Ausschnittsfläche zugewendet.

A3. Ae. 2- bis rielbïitig, in meist dicker Aehre, deren Glieder sich bei der Reife gar nicht oder mit je 1 darüłer sitzenden Ae. ablösen.

At. Decksp. ohme Callus, bei der Fruchtreife stehen bleibend. Fr. frei.

As. Hüllsp. pfriemelig, 1-nervig.

Secale (2).

a. Hüllsp. pfriemelig zugespitzt, nicht begrannt, die Decksp. nicht überragend. Von S. montan. Guss. (Mmgbt., C.-As.)

S. cereale L.

b. Hüllsp. begrannt, ihre Grannen die Decksp. weit überragend. Ungarn, S.-Russl.

B. Hüllsp. eifürmig. 3- bis vielnervig.

$S$. fragile M. Bieb.

a. Hüllsp. flach gewölht, nicht oder nur undeutlich gekielt. S.-Eur.

b. Hüllsp. scharf gekielt.

T. oratum (L.) Hack.

\%. Gipfel-Ae. entwickelt. Torsp. ungeteilt bleibend. Seiten. zahn der Hüllsp. stumpf.

I. Hüllsp. so lang odler länger als alle Decksp., papierartig, lanzettlich; Torsp. der untersten Bl. hall so lang als Decksp. T. polonicum L.

II. Hüllsp. kürzer als die sämtl. Decksp., pergamenartig: Vorsp. so lang als Decksp.

T. sativum Lam. 
1. Aehrenspindel bei der Reife zerhrechlich. Körner von den Sp. ganz eingeschlossen, heim Dreschen nicht ausfallend (doch nicht angewachsen).

+ Aebre locker, mit quadratischem Querschnitt. Hüllsp. oberwärts breit gestutzt, mit sehr kurzem, stumpfem Mittelzahn, stumpf gekielt. subsp. Spelta (L.)

++ Aehre sehr gedrungen, von der Seitr zusammengedrückt. Hïllsp. oberwärts spitz verschmälert, mit spitzem Mittelzahn, scharf gekielt. subsp. dicoccum (Schrk.)

2. Aehrenspindel hei der Reife nicht brïchig. Körner zwischen den etwas klaffenden Fruchtsp. hervorsehend, leicht ausfallend.

subsp. tenax Hack.

+ Hüllsp. in der oberen Hälfte deutlich gekielt, in der unteren gewölbt oder schwach gekielt.

- Aehre lang, \pm locker, etwas vom Rücken zusammengedrïickt.

$\odot(\cdot)$ Aehre kurz, dicht, im Querschnitt quadratisch.

++ Hüllsp. bis zur Basis scharf gekielt.

var. compactum (Host)

. Fr. kurz, dick. nicht zusammengedrückt, oben breit ahgestutzt.

var. turgidum ( $\mathrm{T}$. .)

(.), Fr. länglich, schmäler, etwas seitlich zusammengedrückt, etwas zugespitzt.

var. durum (Desf.)

S. (Gipfel-Ae. rerkimmert, oft kamm sichtbar. Vorsp. bei der Reife in 2 Stiicke zerfallmul. Sitenzahn der Hüllsp. spitz. Oestl. Mmgbt.

T. monococcum L.

Bt. Decksp. am frmule mit dentlichem, durch eine furche abgegrenzten Callus, hei der Reife mit je $1 \mathrm{Fl}$ abfallend. Lir. der Vorsp. angewachsen.

Agropyrum (32).

a. Aehre meist lang und schmal, mit tripfel-Ae. Hüllsp. ungekielt, 3- bis 7-nervig.

\%. Plattnerven ohersits mit vielen Reihen sehr kurzer Hate dicht besetzt.

I. Hüllsp. 9- bis 11-nervig, stumpf. A. junceum (L.) P. Beauv.

II. Hüllsp. 5-nervig, spitz.

A. strictum Rehb.

$\therefore$ Blattnerven oberseits mit einfacher Reihe sehr kleiner Stacheln oder Borsten besetzt und dadurch rauh.

I. Wurzelsteck nicht kriechend. B. auf heiden Seiten rauh. A. caninum (L.) P. Beauv.

II. Wurzelstock weit mmberkriechend. B. oberseits glatt, unterseits rauh.

1. Hüllspelzen lanzettlich, .ॅ-nervig, zugespitzt.

2. Hüllspelzen lïnglich. j- his 7 - A reprigens (L.) P. Beauv. sehr stumpt.

A. glancum $\mathrm{R}$, et Sch.

b. Aehren kurz. ohne (ripfel-Ae. Hiills\}. gekielt, 1-oder undeutlich 5-nervig. Orient. A. cristatum (Schreb.) P. Beauv.

B. Ae. 1- bis 2-blitis. in diunner Aehre, deren Glieder sich mit je einem anliegenden Ae bei der Reife ahlösen. Lepturus (4).

B. Ae. median zur Aehrenachse, d. h. die Sp. mit ihrem Rücken der Ausschnittsfläche zugewendet. 
a. Ae. lanzettlich. Pflanze ausdauernd, ausser blïhenden. aufsteigenden, $=$ zusammengedrückten Halmen nichtblïhende Blätterbüschel treibend.

๙. Halm glatt. Junge B. einfach zusammengefaltet. Ae. 6-bis 10-blïtig. Bl. grannenlos. L. perenne L.

¿. Halm oberwärts rauh. Junge B. zusammengerollt. Ae. 10. his 20-bliitig. B]. meist hegrannt. L. multitorum Lamk.

b. Ae. ellintisch. Pflanze $(\bullet)$ ohne sterile Blätterbischel. Halm aufrecht, stielrund. Junge B. zusammengerollt.

$\%$ Hüllsp. so lang oder länger als das Ae. Bl. meist mit langer Granue.

F. Hiillsp. kürzer als das Ae. Bl. meist grannenlos.

B. Aehre einseitswendig. $1 \mathrm{~N}$.

L. remotum Schrk. Nardus (1) stricta L.

A. Alle Ae. $\$$.

\section{Oryzeae.}

Ar. Ae. in Rispen.

A.2. Ae. mit - die Decksp. überragenden orler wenig kürzeren, begrannten Hüllsp. - Ostindien. Oryza (6) sativa L.

B. Ae ohne dentliche Hüllsp., diese nur durch Pulimente angedeutet.

Leersia (5) oryzoides (L.) Sw. B. Ae. zu 2-3 im Tinkel eines scheidenförmigen Tragh. verwachsen. Steppen des Mmght. Lygeum 1 Spritum L.

B. PHanze einhäusig. Ae eingeschlechtig, ohne Hüllsp.. linealisch. Ufer in N.-Am. u. N.-O.-Asien. Zizania (1) aquatica L.

\section{Paniceae.}

A. Ae. ohne hesondere, aus Borsten oder stacheln isterilen Zweiglein) bestehende Hüllen.

A. Ae. aus '2 Hüllsp., 1 und 1 : Bl. oder aus Höllsp. und $18 \mathrm{Bl}$. bestehend.

A.. 1. und 2. Hüllsp. umhegrannt, ohne teutlichen Callus.

Panicum (300).

a. Alle Ae ziemlich lang gestielt. in eine lockere Pispe gestellt.

$\%$ Rispe überhängend. Ae eifürmig. Pruchtsp. glatt, glänzend. Ostind.

P. miliacentm L.

$\because$ Rispe aufrecht. Ae lanzettlich. Fruchtsp. fein querrunzelig. 'Trop. Afr.

$P$. altissimum Jacq.

h. Ae. kurzgestielt. zunächst in Trauben scheinähren) und diese wieder traubig oler rispig oler fincerig gestellt.

\%. Scheinähren allseitswendig. 3 - bis t-zeilig. trauhig oder rispig gestellt. 2. und 3. . 1 . = hegrannt. Knoten kahl. B. ohne Ligula. P. Crus galli L.

¿. Scheinähren einseitswendig, einfach. fingeriggestelit. Hüllsp. grannenlos.

I. Halm $=$ aufrecht. Blattscheiden und B. behaart. Scheinähren meist zu 5 (4-6). Ae. länglich-lanzettlich.

$P$. sanguinale $\mathrm{L}$.

Il. Halm $=$ niederliegent. Blattscheiden und B. kahl. Scheinähren meist zu $3(2-4)$. Ae. eielliptisch. P. lincare Krock. 
B2. 1. Hüllsp. sehr klein, unbegrannt, 2. durch den konischen oder stielförmigen Callus von der 1. scheinbar weggerïckt, sowie die Decksp. der ơ Bl. aus dem Einschnitte der Spitze mit kurzer Stachelspitze oder \pm langer Granne.

Tricholaena (10).

Cะ. 1. und 2. Hüllsp. begrannt, 1. Hüllsp. ohne deutlichen Callus.

Oplismenus (4).

B1. Ae. aus 2 Hüllsp. und $1 \hat{\mathrm{B} l}$. bestehend, in einseitswendigen Trauben oder Aehren.

Paspalum (160).

B. Die einzelnen oder je 2 Ae. mit einer aus 1 bis vielen Borsten oder Stacheln (sterilen, zuweilen verwachsenen Zweiglein) bestehenden Hülle.

A1. Ae. zur Reifezeit aus der stehenbleibenden Hülle sich lösend.

Setaria (10).

a. Hüllborsten mit rückwärts gerichteten Zähnchen. Sp. der 8 Bl. ziemlich glatt. S. verticillata (L.) P. Beauv.

b. Hüllhorsten mit vorwärts gerichteten Zähnchen.

«. 2-3 Borsten unter jedem Ae. Sp. der Pflanze grasgriin.

I. Hüllborsten grün oder rötlich. Ae. bei der Reife bleibend. Scheinähren eiförmig bis walzlich, stets aufrecht. Halm oberwärts rauh.

$S$. viridis (L) P. Beauv.

II. Hüllborsten gelblich oder schwarz. Ac. bei der Reife abfallend. Scheinähren gelappt zur Fruchtzeit nickend. Halm oberseits meist zottig.

S. italica (L.) P. Beauv.

ア. Zahlreiche Borsten unter jedem Ae. Sp. der Bl. querrunzelig. Pflanze graugrün.

S. glauca (L.) P. Beauv.

Bi. Ae. zur Reifezeit samt der Hülle abfallend.

A2. Hüllborsten scheinquirlig, zart, am (irunde nicht verdickt. oft gewimpert.

๙. Hülle abfallend. Abyssinien.

3. Hülle nicht abfallend. 'Trop. Afrika. $P$. typhoideum Rich.

B. Hüllborsten steif oder stachelförmig, am (irrunde verdickt. oft verwachsen. - Südl. N.-Am. C'enchrus (12) tribuloides I.

\section{Andropogoneat.}

A. Alle Ae. gleichartig, §.

A1. Traubenachse vollkommen ungegliedert. Trauben in schmaler ährenförmiger Rispe. Ae. unbegrannt. - 'Trop. u. subtrop.

Imperata (5) arundinacea Cyr.

$B_{1}$. Traubenachse gegliedert. Trauben in reichästiger Rispe an verlängerter Hauptachse, die seitlichen ungestielt.

A2. Ae. umbegrannt. - Malay. Gbt. Saccharum (12) officinarum L.

B. Ae. begrannt. - Subtrop. Erianthus (17) Rarennce P. Beauv.

B. Ae. ungleichartig, die sitzenden (selten ), die gestielten $\bigcirc$, leer oder fehlend.

A1. Sitzende Ae. 2-blütig.

Ischaemum z. T.

B1. Sitzende Ae. 1-blütig.

Andropogon (180).

a. Trauben vielgliederig. Achsenglieder und Stiele mit einem medianen, durchscheinenden Längsstreifen. A. Ischaemum I. 
b. Trauben wenig- bis eingliederig. Achsenglieder olune durchscheinendenLängsstreifen. Trop.u.subtrop. A. arundinaceus Scop.

\section{Maydeae.}

\section{A. $\delta$ und $\bigcirc$ Ae. in demselben Hauptblütenstande.}

A. und $\mathrm{O}$ A . in derselben Aehre, die $\mathrm{C}$ mit erhärtender unterer Hüllspelze. Trop. u. subtrop. Amer. Tripsacum (3) dactyloides L.

$B_{1}$. Je 1 Aehre an der Spitze eines Zweigleins, unterhalb deren 1-2, auf ein einziges de. reduzierte 2 Aehren; die ? Ae. von dem eiförmigen oder kugeligen, elfenbeinharten Scheidenteil des Deckb. ganz umschlossen. Trop. Asien.

Coix (4) Lacryma L.

B. $\gamma$ und $\subseteq$ Ae. in verschiedenen Hauptblïtenstïnden. Aehren zahlreich in gipfelständiger Rispe. $\odot$ Aehren im Tinkel von Laubb., mit grossen, häutigen Vorb.

A. Aehren jedes Blattwinkels frei, in Glieder zerfallend.

Euchlaena (1) mexicana Schrad.

$B_{1}$. A Aehren jedes Blattwinkels zu einem Kiolben verwachsen. nicht zerfallend. Trop. Amer.

Zea (1) Mays L.

\section{Cyperaceae $(65 ; 2200)$.}

1. Bl. stets oder nur vereinzelte im Aehrchen hin und wieder eingeschlechtlich. A ehrchen immer zweigeschlechtlich. [Scirpeae.]

1. Schuppen des Ae. 2-zeilig. [Cyperinae.]

A. Ae. vielblütig, ohne Endbl.; meist sämtliche Decksp. mit Bl.

Cyperus (400).

a. Gir. 2-teilig mit linealischen Aesten. Aehrchenachse nicht geflügelt.

b. (ir. 3-teilig. Fr. 3-kantig.

э. Pflanze einjährig. Aehrchenachse schmal geflügelt.C. fuscus L.

5. Pflanze ausdauernd. Aehrchenachse deutlich geflïgelt. Aegypten.

B. Ae wenigblütig. Die 3 bis 6 untersten Decksp. kleiner und ohne Bl.

Sehoenus (60).

a. Ae. zu $5-10$. B. so lang oder halb so lang als der stengel.

S. nigricans $\mathrm{L}$.

b. Ae. zu 2 bis 3. B. mehrmals kiirzer als der Stengel.

2. Schuppen des Ae. spiralig. [Scirpinae.]

S. ferrugineus L.

A. Ae. mehrblütig, ohne Endbl. Die leeren, untersten Decksp. ebenso gross oder grösser als die übrigen.

A1. Gr. am Grunde nicht oder nur wenig verdickt.

A2. Blh. borstenförmig, nach der Blütezeit sehr verlängert.

a. Borsten der Blh. sehr zahlreich, gerade.

Eriophorum (13).

๙. Aehrchen zu mehreren, gestielt, zur Fruchtzeit über-

hängend.
E. Eolystachyum Lndständiges. gerades Aehrchen.
E. raginatum I.

b. Borsten der Blh. 4-6, gekräuselt. Aehrehen einzeln. 
B. Blh. fehlend odler nicht verlängert. Deckschuppen kahl.

a. Blh. vorhanden, meist borstenförmig. [Euscirpus.]

Seirpus (200).

a. Aehrchen eine endständige spirrenähnliche Rispe bildend.

I. Aehrchen länglich-rautenförmig, einzeln, langgestielt, nur die mittelständigen sitzend. Spelzen auf dem Rïcken abgerundet, ohne Stachelspitze.

$S$. radicans Schk.

II. A ehrchen eiförmig, zu 3-6 beisammen sitzend, nur wenige gestielt. Spelzen schwach-gekielt, stumpf, fein stachelspitzig.

S. silvaticus L.

₹. Aehrchen zu einer endständigen Aehre geordnet.

1. Aehrehen 6- bis 8-blütig. Borsten rückwärts-stachelig. S. compressus (L.) Pers.

II. Aehrchen 2- bis 5-blütig. Borsten aufrecht weichhaarig.

S. rufus (Huds.) Schrad.

$\because$. Aehrchen wenige, sitzend, koprig gedrängt oder kurz gestielt doldig.

I. 3 N. Nuss 3 -kantig.

1. Spelzen stumpf, stachelspitzig. Nuss querrunzelig. Halm 3 -kantig.

S. mucronatus L.

2. Spelzen ausgerandet, mit Stachelspitze in der Bucht. Nuss glatt. Halm stielrund.

S. lacustris L.

II. 2 N. Halm stielrund. Fr.planconvex.S'T'TabernaemontaniGmel.

¡. Ein einziges endständiges Aehrchen.

I. Oberste scheide in ein kurzes Blatt endigend. Spelzen mit sehr kurzem Kielfortsatz. Borsten länger als die Nuss.

II. Scheiden blattlos. Spelzen ohne Stachelspitze.

S. caespitosus L.

1. Borsten länger als die Nuss. Halm inwendig querwandig.

S. parvulus R. et Sch.

2. Borsten höchstens so lang" als die Nuss. Halm imnen ohne Querwände.

b. Blh. fehlend.

S. pauciflorus Lightf.

๑. $3 \mathrm{~N}$. Ae. trugseitenständig durch aufgerichtetes Hüllb.

1. de.klein, zurundlichen Köpf chen vereinigt. S.Holoschocnus L.

II. Ae. zu 1-3, genähert, sitzend.

ß. $2 \mathrm{~N}$. Ae. einzeln endständig.

S. setaceus L.

S. fluitans L.

B1. Gr. am Grunde rerdickt. Blh. vorhanden. Ein einziges endständiges Ae.

Heleocharis (80).

a. Nuss verkehrt-eifürmig, zusammengedrückt, glatt, am Rande abgerundet.

b. Nuss länglich, fein-vielrippig.

H. palustris (L.) R. Br.

H. acicularis (L.) R. Br.

B. Ae. wenig- (2- bis 3-) blütig, mit Lndbl. Die 3 bis 4 leeren untersten Decksp. kleiner als die oberen.

Ar. Blh. aus 5 oder mehr dünnen Borsten bestehend. 2 Griffeläste.

Rhynchospora (150).

a. Endständige Spirre nicht oder wenig küuzer als ihre Hüllb. Deckschuppen weisslich. 9-13 Hüllborsten, rückwärts rauh, höchstens so lang als die Nuss.

li. alba (L.) Vahl

b. Endständige Spirre von ihrem untersten Hüllb. weit überragt. 
Deckschuppen bräunlich. 5-6 Hüllborsten, rorwärts rauh. viel länger als die Nuss.

R. fusea (L.) R. et Sch.

B1. Blh. fehlend. 3 Griffeläste. Cladiun (30, Mariscus:L. R. Br.

II. Bl. stets eingeschlechtig, meist monücisch: und Bl. Achsen ungleicher Ordnung abschliessend. Scheinae. andrugyn oder eingeschlechtlich. [Cariceae.]

A. Scheinae. letzter Ordnung) 2-bliitig, androgyn. Arktisch-alpin.

Elyna (5) scirpina (WVilld.) Pax

B. Scheinae. (scheinbar Bl.) 1-bliitig, meist eingeschlechtlich.

A. Abstammungsachse der (an ihr seitlich stehenden $\subseteq$ Bl. rudimentair, aber doch stets wahrnehmbar. - Arktisch-alpin.

Kobresia (4) caricina IVilld.

B1. Abstammungsachse der $\subseteq$ Bl. nur in den allerersten Entwickelungsstadien wahrnehmbar, später verschwindevd.

Carex (500).

a. Hauptblïtenstand eine einzige endständige, androgyne oder eingeschlechtliche Aehre. [Monostachyae.]

๑. Aehre androgrn, oberwärts - . Pfanze monücisch. N. 3. Schläuche lanzettlich-pfriemelig, stielrund, zurückgebogeu. Sp. hinfällig.

९. Aehren eingeschlechtlich, diöcisch. N. 2.

I. Wrurzel faserig. Ausläufer fehlend. Stengel und Blattränder rauh. Schläuche länglich-lanzettlich, zuletzt abwärts gerichtet.

C. Davalliana Sm.

II. Wurzelstock kriechend, mit Ausläufern. Stengel und B. glatt. Schläuche eiförmig. abstehend oder = aufrecht. C. dioica L.

b. Auf demselben Stengel melnere traubig oder ïhrig gestellte, androgyne oder eingeschlechtliche Aehren.

a'. Aehren unter sich gleich, sämtlich androgyn, meist ährig gestellt. [Homostachyae.] Bei unseren Arten $2 \mathrm{~N}$.

a". Gesamtblütenstand nicht oder nur sehr unvollkommen von Bracteen umhüllt.

๑. Aehren am Grunde $O$, an der Spitze o ${ }^{\circ}$. [Acrarrhenae.]

I. Aehren rispig angeordnet. Schläuche beiderseits gewölbt.

1. Schläuche glanzlos, beiderseits nervig. kugelig-eifürmig.

C. paradoxa IVilld.

2. Sch]äuche gläuzend, nervenlos oder nur am Grunde des Rückens schwach nervig.

- Lockere Rispe. Stengel kräftig. Seitenflïchen eben. B. bis $3 \mathrm{mal}$ so breit als der Stengel. C.paniculata L. ++ Traubige Rispe. Stengel schwach, Seitenflächen schwach gewölbt. B. etwa so breit als der Stengel.

C. diandra Roth (C. teretiuscula Good.)

1I. Aehren sitzend. = durch deutliche Internodien von einander getrennt. Schläuche innenseitig flach,aussen gew ölbt.

1. Stengel nur oberwärts rauh, Seitenflächen eben. B. 2 bis $4 \mathrm{~mm}$ breit. Aehre gestreckt. Schläuche nervenlos oder undeutlich nervig.

C. muricata L.

2. Stengel scharf und rauh dreikantig mit vertieften Seitenflächen. B j-9 $\mathrm{mm}$ breit. Aehre dicht. Schläuche deutlich 5 - bis 7-nervig.

C. vulpina $\mathrm{L}$. 
3. Aehren am Grunde ơ, an der Spitze $\mathcal{O}_{\text {, }}$, in einfacher Aehre. [Hyparrhenae.]

I. Wurzelstock weit kriechend, mit Ausläufern.

1. Hauptähren meist etwas locker. Aehren gekrümmt, strohgelb. Schläuche abstehend, lanzettlich, länger als die Sp.

C. brizoides $\mathrm{L}$.

2. Hauptähren gedrängt. Aehren gerade, dunkelbraun. Schläuche aufrecht, eilänglich, so lang als die Sp. C. praccox Schreb.

II. Wurzelstock dichtrasig, olıne Auslïufer oder wenig kriechend.

1. Die untersten 2-4 Aehren weit von einander entfernt; Deckb. laubartig, das unterste den Gesamtblütenstand ïberragend.

C. remota $\mathrm{L}$.

2. Aehren \pm genähert. Deckb. kurz, meist schuppenförmig. + B. ziemlich derb und starr, kürzer als der Stengel. Schläuche mit ziemlich langem, deutlich zweizähnigem Schnabel.

- Achren meist 6 , genähert, eielliptisch. Schläuche aufrecht, flügelig gekielt.

C. leporina L.

-. Aehren meist 4, ziemlich entfernt, rundlich. Schläuche sparrig abstehend, flach gewölbt, mit ungeflügelten Kielen.

C. echinata Murr.

++ B. weich und schlaff, so lang oder lïnger als der Stengel. Schläuche aufrecht, mit kurzem Schnabel.

(•) Aehren zu $8-12$, genähert, länglich. Schliuche abstehend, lanzettlich. Schnabel sehr kurz 2-zähnig. C. clongata L.

$\odot \cdot$ Aehren zu 4-7. eirundlich, die unteren etwas entfernt. Schläuche eiförmig, Schnabel sehr kurz, schwach ausgerandet.

C. canescens $\mathrm{L}$.

b". Gesamtblütenstand meist kopfig, von Bracteen umhüllt. Aehren am Grunde 0 , oben 9 .

C. cyperoides $\mathrm{L}$.

$b^{\prime}$. Androgyne und eingeschlechtige Aehren in kopfig-ïhrigem Gesamtbluitenstande. Grundachse kriechend.

a. N. 2. [Holarrhenae.]

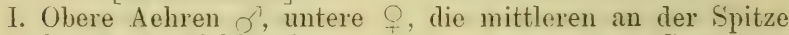
Schläuche kielflügelig.

C. arenaria L.

II. Obere und untere Aehren ?, die mittleren C.disticha Huds.

ア. N. 3. Endständige Aehre an der Spitze + , unten $\sigma$, die seitenständigen . . [Atratae.]

I. Blattscheiden ganz. Schlïuche eirundlich, zusammengedrïckt, am Rücken stumpf gekielt. Die Seitenähren gestielt, zuletzt hängend.

C. atrata L.

II. Blattscheiden netzig gespalten. Schlänche elliptisch, stumpf dreikantig. Unterste Seitenähre kurz gestielt.

C. Buxbaumii Whlbg.

$c^{\prime}$. Endständige Aelren or, seitenständige f, Gesamtblütenstand traubig oder ährig. [Heterostachyae.]

๙. N. 2. Schläuche meist \pm zusammengedrückt, schnabellos oder kurz geschnäbelt, kahl. [Limnonastes.]

I. Bliitenstengel am Grunde mit Scheiden, darüber Laubb.

1. Grosse, dichte Rasen bildend, ohne Ausläufer.

+ Stengel stark, steif aufrecht. Sämtliche Blattscheiden netzig gespalten. Schläuche flach, etwa 6-nervig. C. stricta Good. 
++ Stengel schlank, schlaff. Nur untere Blattscheiden netzig gespalten. Schlïuche beiderseits gewölbt, nervenlos.

2. Mit Ausläufern. Schläuche nervenlos, innen flach.

C. caespitosa $\mathrm{L}$.

C. Buekii Wimm.

II. Blütenstengel am Grunde nur mit Laubb. Mit Ausläufern.

1. - Aehren aufrecht, überneigend oder überhängend. Schläuche schwachnervig.

+ of Aehren meist 2-4, verlängert walzlich, zuletzt oft ïberhängend. Schläuche beiderseits stark gewölbt. Lnterstes Deckb. den Bliitenstand überragend. Stengel weit herab rauh. B. trucken meist zurückgerollt. C. acuta $\mathrm{L}$. ++ - Aehre meist 1 . kurz walzlich, aufrecht. Schläuche innenseitig flach. Unterstes Deckb. den Blütenstand nicht ïberragend. Stengel nur oberwärts rauh. B. trocken meist eingerollt.

C. Goodenoughii Gay

2. Aehren steif aufrecht. Schläuche nervenlos. Stengel fast glatt. steif. Lnterstes Deckb. sehr kurz. C. rigida Good.

F. N. 3. Schläuche \pm 3-kantig.

I. Schläuche schnabellos oder mit kurzem, gestutztem Śchnabel. [Cyrtostomae.]

1. O Aehren gestielt.

+ Schläuche kahl.

(-) Blïtenstengel am Grunde von zahlreichen Laubb. umgeben.

A Pflanze dicht rasig, ohne Ausläufer. C. pallescens Schreh.

î Mit Ausläufern. $\subsetneq$ und $;$ Ae. aufrecht. Schläuche kugel- oder eirund.

× Aehren wenigstens zuletzt ïberhängend. Schläuche elliptisch mit auswärts gekrümmter Spitze, etwas rauh. nervenlos.

C. flacca Schreb.

$X X \simeq$ Aehren aufrecht. Schläuche kugel- oder \pm eirund. 5 Aehre immer aufrecht.

C. panicea L.

C.) Blütenstengel am Grunde zunächst Niederb.. dann Laubb. tragend. Mit Ausläufern.

C. limosa L.

$+\nmid$ Schläuche kurzhaarig. Deckb. scheidenfürmig. ohne Spreite.

(-) Ohne Centralblattrosette. Blütenstengel mittelständig, zuletzt viel kürzer als die rimnigen, starren $\mathrm{B}$. = Aehren 2-3, entfernt, meist 3-bluitig. C. humilis Leyss.

$(-)$ Mit einer ausdanernden, mittelständigen Blattrosette. Bliitenstengel seitenständig, etwa so lang als die etwas schlaffen B.

$\hat{\imath}$ - Aehren etwas entfernt, $\bar{i}$ - bis 10-blütig, die oberste die $\gamma$ iberragend. Schläuche 3-kantig-verkehrt-eifürmig, wenig länger als die Sp.

C. digitata $\mathrm{L}$.

A 2 Aehren sehr genähert, 3-bis 4-blütig; alle Aehren fingerig neben einander gestellt. Schläuche elliptisch, fast doppelt so lang als die Sp.

2. Aehren sitzend. Schläuche kurzharig.

+ Wenigstens das unterste Tragb. laubartig. mehrmals länger als seine Aehre.

(- Rasen bildend. Stengel zur Fruchtzeit abwärts gekrümmt. 
Unterstes Deckb. aufrecht abstehend. O Aehren $3(-5)$, genähert.

C. pilulifera L.

$\odot(\bullet$ Ausläufer treibend. Stengel aufrecht. Unterstes Deckb. meist wagerecht abstehend. O Aehren 1-2, entfernt.

C. tomentosa L.

++ Tragb. trockenhäutia, zuweilen mit laubiger Spitze.

$\odot$ Dicht rasenformig. B. schlaff, weich, sehr schmal und lang.

C. montana L.

C. $\odot$ Mit Ausläufern. B. ziemlich breit, steif, meist oberseits auf den Nerven rauh.

A Sp. verkehrt eiförmig, stumpf, mit breitem, besonders vorn fransig geschlitztem, weissem Hautrande. C. ericctorum Poll.

१^ Sp. eiförmig-spitz bis lanzettlich, ohne oder mit schmalem, weissem Hautrande.

C. verna Vill.

II. Schläuche mit kürzerem oder längerem, an der Spitze 2-zähnigem, berandetem Schnabel. [Odontostomae]

1. Zähne des Schlauchschnabels gerade vorgestreckt, parallel. Meist nur 1 o Aehre. Heist olne Ausliufer. B. ohne deutliche Quernerven.

+ Schnahelzähne an den Rändern feinsägig-rauh. Schläuche wagerecht abstehend oder zurückgehogen. † Aehren kurz eiförmig bis kugelig, dichtbluitig.

+ + Schnabelzähne ganzrandig. Aehren sehr schlank, lockerblütig, lang gestielt, zuletzt überhängend. S'chläuche \pm aufrecht, nervenlos; Schnabel lang. dium. C. silvatica Huds.

2. Zähne des Schlauchschmabels auseinamdertretend. B. mit deutlichen Quernerven, daher fast gitterförmig geadert.

+ Rasen bildend. Meistnur 1 ; Aehre, 4-6 . C.Pseudo-Cyperus L.

++ Mit Ausläufern. Weist mehrere o und 2-4 tehren.

(.) Schläuche kahl. Deckh. blattartig, nicht oder kurz scheidenförmig. Untere $q$ Aehren \pm iiberhängend.

$\uparrow$ Schläuche nicht aufgeblasen, mässig lang geschnäbelt. Stengel scharfkantig. rauh. B. breit-lineal.

$\times$ Blattscheiden ohne deutliches Fasernetz. Sp. der $\sigma$ Aehren stachelspitzig. Schläuche grüı, zuletzt bräunlich.

C. riparia Curt.

$\therefore \times$ Blattscheiden in ein Fasernetz sich auflösend. Untero Sp. der ơ Aehren stumpf. Schläuche bläulichgrün.

C. acutiformis Ehrh.

$\uparrow \uparrow$ Schläuche aufgeblasen, reif grïnlichgelb, lang geschnäbelt.

$\times$ Stengel scharfkantig, an den kanten meist rauh. B. 6 bis $\diamond \mathrm{mm}$ breit, grasgrün, Schläuche schief aufrecht, allmählich in den Schnabel verschmälert. C. vesicaria $\mathrm{L}$. $\times \times$ Stengel stumpfkantig, glatt. B. $2-4 \mathrm{~mm}$ breit, graugrün. Schläuche fast wagerecht abstehend, plötzlich in den Schnabel verschmälert.

$\odot \odot$ Schläuche kurzhaarig.

C. rostrata With.

$\uparrow$ Grasgrün. Stengel stumpf 3-kantig, beblättert. B. breit, Hach, nebst den Blattscheiden behaart. Deckb. langscheidig: Untere Aehren gestielt. Sip. bleich. Schläuche langgeschnäbelt. 
¡^ Graugrün. Stengel rundlich, oberwärts blattlos. B. sehr schmal, rinnig oder gefaltet, kahl. Deckh, nicht oder sehr kurzscheidiy.

Aehren sitzend oder kurz gestielt. Sp. braun. Schläuche kurzgeschnäbelt.

C. filiformis $\mathrm{L}$.

Palmae (130; 1000).

I. Frkn. aus 3 freien oder locker verwachsenen Frb. gebildet. Blattstrahlen eingeschlagen, hohlrinnig. Coryphoideae.]

1. Diücisch mit dimorphen Bl. B. unpaarig gefiedert. [Phoeniceae.] - N.Afr., S.-W.-As.

2. Polygam. B. fächerförmig. [Sabaleae.]

A. 3 getrennte Frb. mit besonderen Gr. und $\mathrm{N}$.

A. Blattstrablen ganzrandig, regelmässig, einnervig. Westl. Mmgbt.

Chamaerops (2) humilis L.

$\mathrm{B}_{1}$. Blattstrahlen mit meist 2 Paar Hauptnerven und kleingezähntem Rand. - Japan. Rhapis (5) Ilabelliformis Ait.

b. :3 eng aneinander gepresste oder mit den Berührungsflichen

verwachsene Frb., von einem gemeinsamen, dreieckigen (tr. gekrönt.

A1. Blattfächer herzlänglich, mit lang vorgezogener Mittelrippe; Stiel stachellos. Venezuela bis südl. Ver. St. Sabal (7).

$B_{1}$. Blattfäeher kreisrund, mit radienartig gestellten Strahlen an kurzer Nittelrippe; Blattstiel mit 2 Reihen scharfer Stacheln. - Ndl. malay. Gbt. Livistona (12) chinensis Mart.

II. Frkn. aus 3 fest verwauhsenen F'rb. bestehend. B. gefiedert. Fiedern zurïckgeschlagen. T'rop. Amer.

A. Pflanzen niedrig. Stamm rohrartig. Fiedern wenig zahlreich. \pm vielnervig.

A1. Fiedern sehr breit flügelartig. B1. tief in Aushühlungen des fleischig verdickten liolbens eingesenkt.

Geonoma (8U).

$B_{1}$. Fiedern breit lanzettlich. Bl. frei auf der Obertläche der Spindel oder Blütenstandsüste.

Chamaedorea $(60)$.

B. Dicker, = hoher Stamm. Fiedern schmal, eimnervig. Cocos (30).

Cyclanthaceae $(6 ; 44)$.

$\checkmark$ Bl. in Gruppen zu 4, einzeln gestielt. langen. fadenförmigen Staminodien.

12. Bl. mit 4 sehr Carludevica 32.

\section{Araceate $(110 ; 840)$.}

I. Land- oder Sumpfpflanzen.

I’. Spicularzelien und Milchsaftschläuche fehlend. Bl. (bei Culcasia eingeschlechtlich, sonst) meist mit Blh. [Pothoideae.]

1. B. ohne Gliederung in Stiel und Spreite, linealisch. Sa. geradläufig.

2. B. in Stiel und Spreite gegliedert. Sa. ungewendet.
A. Bl. 2-gliederig.
S. mit Nährgewebe.
Anthurium 200 .
B. Bl. 3-gliederig.
S. ohne Nährgewebe.
Pothos (30).

II'. Whlchsaftschläuche fehlend; im Girund cewebe wenigstens dur' Stengel und B., bisweilen auch der Wurzeln spicularzellen. Bl. \&, meist nackt. [Monsteroideae.] 
1. Bl. mit Blh. Spatha nicht abfallend. Halbsträucher. SSpathiphylleae.]

Spathiphyllum (18).

2. Bl. ohne Blh. Spatha vor der Reife des Kolbens abfallend. Meist kletternd. [Monstereae.]

A. S. mit Nährgewebe und axilem E. Beere vielsamig. s. cylindrisch.

Rhaphidophora (20).

B. S. ohne Nährgewebe. Frkn. 2-fücherig, 2 herz- oder verkehrteiförmige $\mathrm{S}$. in jedem Fache.

Monstera (15).

III'. Spicularzellen fehlend. Leitbündel der Stengel und Blattstiele mit Milchsaftschläuchen.

I“. Milchsaftschläuche gerade, nicht verzweigt. B. ohne randständigen Kollektivnerv.

I"'. B. parallelnervig. Bl, ohne Blh.

I"*. Bl. \&. [Calloideae-Calleae.]

II'“. Bl. eingeschlechtlich. [Philodendroideae.

1. S. mit Nährgewebe. Stb. der o’ Bl. frei. Sa. geradläufig oder umgewendet.

1. Stamm \pm oberirdisch, strauchig oder kletternd. Sa. an langem Funiculus. [Philodendreac.]

A. Bl. mit 1-4 Staminodien.

A. Der sanze Blütenstand fertil. Placenten central. Sa. anatrop.

Homalomena (20).

B1. Oberer Teil des o Blütenstandes meist steril. Placenten parietal. Sa. \pm geradlïufig. Schismatoglottis (10).

B. B1. olnne Staminodien. Sa. geradlüufig. Kolben ohne Anhang.

Philodendron (100).

2'. Stamm unterirdisch. Sa anatrop, an kurzem Funiculus. [Zantedeschicae.] Zantedeschia (6) acthiopica (L.) Spreng.

2. S. olme Nährgewebe. Sa. ungewendet, an kurzem Funiculus. [Aglaonemeae.]

A. '- Bl. dicht bei einander stehend, olme Staminodien. of Bl. mit 2-3 getrennten Stb.

B. Bl. locker verteilt, mit staminodien. in ein Synandrium vereinigten Stb.

II“'B. verschieden gestaltet, netznervig.

I“". Bl. und mit Blh. oder eingeschlechtlich ohme Blh. Sa. anatrop. S. meist ohme Nährgewebe. B. im Umriss pfeilförmig, oft vielfach zerteilt. [Lasioideac.]

1. Bl. " mit Blh. Blattstiel warzig oder stachelig. Lasieae.] Sträucher mit kletterndem Stamm. Frkn. mit 1 Sa. am Scheitel des Faches.

Lasia (2).

2. Bl. eingeschlechtlich, ohne Blh. S. ohne Nährgewebe. [Amorphophalleae.]

A1. Sa. an längerem, dem Integument nicht angewachsenen Funiculus, vom Grunde aufsteigend. Amorphophallus (15).

B1. Sa. dick eiförmig, dem kurzen Funiculus seitlich angewachsen.

Hydrosme (13).

II“". Bl. eingeschlechtlich, ohne Blh. Sa. geradläufig oder anatrop. S. meist mit Nährgewebe. B. verschieden gestaltet. Meist Knollengewächse. [Aroideae.] 
1. Kolben ohne Anhang. Bl. mit Spuren der unterdrückten Geschlechtsorgane. Frkn. meist mehrfächerig. [Slaurostigmateac.] Sa.geradläufig. Frkn. 1-fächerig. B. herzförmig. Spathicarpa (4).

2. Kolben mit Anhang. Bl. ohne Spuren der unterdrückten Geschlechtsorgane. Frkn. 1-fächerig. Sa. geradläufig. [Areae.

A. Kolben walzlich, mit der Spatha nicht verwachsen.

A1. $\mathrm{Bl}$. direkt an die anschliessend oder Blütenrudimente zwischen beiden.

A2. Placenten parietal (an der der Achse zugekehrten Wand.

B. pfeil- oder spiessförmig.

Arum (15).

a. Pudimentiire Blïtenanlagen zwischen dem und Bl.

$\%$ Kolben schwarzpurpurn. A. maculatum L.

अ. Kolben gelb. Mmgbt. A. italicum Mill.

b. Der kurze Raum zwischen o und : Bl. olne Rudimente. Balear., Corsica, Sardin. A. pictum L. f.

B.. Placenten apical und basal. Mmgbt.

As. Der fertile Blütenstand an den = unmittelbar anschliessend. B. fussförmig. Dracunculus ? rulyaris schott

B3. Der fertile Blütenstand ron dem durch zahlreiche Blïtenrudimente getrennt.

Helicodiceros (1) muscivorus (L. f.) Engl.

$B_{1}$. Kolben ohne rudimentäre Blütenanlagen zwischen den von einander getrennten fruchtbaren und Bl. oder eingeschlechtlich.

A2. Frkn. mit mehreren Sa.

A3. Bl. aus 1 Stb. bestehend. B. ei- oder pfeilfürmig:

Arisarum (3).

B3. - Bl. aus 2-5 Stb. bestehend. B. 3-teilig oder mehrfach geteilt. Kolben meist eingeschlechtlich. Arisaema (50).

B.. Frkn. mit 1 Sa. J Bütenstand von dem durch eine ron der Spatha ausgehende Scheidewand getrennt. - Japan.

Pinellia (3) tuberifera Ten.

B. Kolbenachse nach 2 Seiten flügelförmig erweitert und so die rachenförmige Spatha in 2 Kammern teilend. deren vordere eine Bl., deren hintere einige = Bl, trägt. Unterital. Sardin., Sicil., Algier.

Ambrosinia (1) Bassii L.

II". Nilchsaftschlïuche verzweigt. B. netznervig, in der Regel die Seitemerven 2. Grades einen zwischen den Nerven 1. Grades verlaufenden Kollektivnerv bildend. Bl. eingeschlechtlich, ohne Blh. Stb. zu Synandrien verbunden. [Colocasioideac.

1. S. mit Nährgewebe. Srmpodium unterirdisch oder oberirdisch und dann gerade. [Colocasieae.]

A. Bl. mit Staminodien. Sa. umgewendet. Steudnera (2). B. $\mathrm{O}$ Bl. olne Staminodien.

A1. Placenten einfach parietal.

A. Kolben ohne Anhang. Oberer Teil der Spatha ganz zurückgeschlagen.

Remusatia (2).

B2. Kolben mit kurzem Anhang. Spatha aufrecht. Colocasia (6:

$\mathrm{B}_{1}$. Placenten weit in den Frkn. hinein rorspringend, fast centralwinkelständig. 
A2. Gr. fehlend.

B.. (Ar. scheihenförmig, üher den Frkn. hinausragend; die Gr. aller $O \mathrm{Bl}$. unter einander zusammenhängend.

$\mathrm{C}_{1}$. Placenten basal

Xanthosoma (20).

¿. S. ohne Nährgewebe. Sympodium kletternd. Sinnqonicae. Sa. grundständiæ, auf kurzem Funiculus. Syngonium (10).

II. Schwimmende Wasserptlanzen. Milchsaftschläuche und Spicularzellen fehlend. Bl. eingeschlechtlich, ohne Blh. o Bl. in einem Quirl; O Bl. nur eine. [Y'istioideae.] Tropen.

Pistia (1) Stratiotes L.

\section{Lemnaceae $(3 ; 19)$.}

I. Sprosse mit Wurzeln. Bliitenstand mit Spatha und 20 Bl. A. 4-fächerig, mit '2 Ritzen aufspringend. Muttersprosse aus 2 seitlichen 'l'aschen je 1 'T'ochterspross entwickelnd. [Lemnoidere].

A. Tochtersprosse mit 1 (irumih, beginnend. Sprosse mehrwurzelig.

Spirodela (2) polyrrhiza (L.) Schleid.

B. Tochtersprosse ohne (irmulh. Sprosse 1-wurzelig. Lemna (i) .

a. Frkn. mit 4-6 mmgewenteten Sia. Nihlrgewebe 1-schichtig. Sprosse dickbauchig

L. gibba L.

b. Frkn. mit $1 \pm$ geradläufigen Sa. Nährgewebe an den Seiten dreischichtig.

\%. Ohne hesondere Wintersprosse. Sprosse rundlich. I. minor I.

P. Sprosse liunglich; ausserem untergetauchte, spaltöffumngslose Wintersprosse.

L. trisulca L.

II. Surosse ohme Wurzeln. Bliitenstand ohne Spatha und mit

1 , Bl. A. o-fächerig mit einer quer ïber den Scheitel laulenden Spalte in "z sich zurickschlagente Klappen sich äfinend. Mutterspross ans einer Grube einen 'Tuchtersuross entwickelnd. [Wolffioideae.] Wolffia (12) arrhiza (L.) Wimm.

I. Fr. eine Kapsel.

\section{Bromeliaceate $(40 ; 450)$.}

1. Frkn. oberständig.

1'. B. ganzrandig, mit verbreitertor Basis. S. mit Haarkrone. [Tillandsieae.]

A. Blh, an der Basis ohne schiipluchen.

B. Blh. :tn der Basis mit '2 Schüpuchen.

Tillandsia (120).

Vriesea $(40)$.

2'. B. dornig gezähnt. [Puyeac.]

A. Bl. , in seitenstänliger, einfacher nder verzweigter Aehre.

B. Bl. durch Abort 2-häusig, klein, zahlreich, geknänelt.

Dyckia (6).

Hechtia (3).

2. Frkn. halb oder fast gamz oberständig. B. meist schlaff, lang, schmal, ganzrandig oder nur nach der Basis hin gezähnt. [Pitcainnieac.]

Pitcairnia (70).

II. Fr. eine Beere. Frkn. unterstandig. B. (ausser bei Ronnbergia) dornig gezähnt. [Bromelieae.]

1. Kelchb. meist stumpf, nicht stachelspitzig. Sa. längs des ganzen oder mitten am [nnenwinkel der Fïcher. [Billbergiinae.] 
A. Kelchb. und Blb. frei.

A1. 'Traubenrispe, Traube oder Aehre.

Billbergia (40).

B1. Blïtenstand dicht zapfenartig, oft mit Laubschopf an der Spitze. 'lrop. Amer.

Anamas (6) sativus Lindl.

B. Kelchb. ron der Spitze des Frkn. an frei. Blb. verwachsen.

Ar. Blb. nur an der Basis verwachsen. Bl. in Rispen. Bromelia ( 4 ).

Bi. Blb. hoch hinauf zu einer Pïhre verwachsen. Blütenstanel kopfig.

Nidularium (15).

2. Kelchb. und Deckb. starr, stachelspitzig, derb lederartig.

Aechmea (40).

\section{Commelinaceae $(25 ; 300)$.}

1. 6 fruchtbare Stb. Frkn. 3-fücherig. [Tradcscantieae.]

A. Blb. frei.

d1. Jedes Fach des Frkn. mit :) oder mehr Sa. Trop. Amer.

Tinantia (3) fugax Scheidw.

B1. Jedes Fach des Frkn. mit 2 Sa. - Ver. Staat, Mexiko.

Tradescantia (32) virginica $\mathrm{L}$.

$\mathrm{C}_{1}$. $1 \mathrm{Sa}$. in jedem Fache des Frkn. Centralamer.

Rhoeo (1) discolor Hance

B. Blb. \pm in eine Röhre verwachsen. Je $1-2$ Sa. Mexiko.

Zebrina (2) pendula Schnizl.

2. Sorler 2 fruchtbare Sth. und $0-t$ Staminodien. Commelineac.] A. Fruchtbare A. fast gerade.

A. Bluitenstände in den Achseln scheidenartiger Tragb. A. der Staminodien kreuztörmig. - Mexiko.

Commelina (88) coclestis Willd.

$B_{1}$. Bliitenstände ohne scheidenartige 'Tragh. Aneilema (60). B. Fruchtbare A. mit eng spiralig sewundenen Fächern. Ecuador.

Cochliostema (1) odoratissimum Lemaire

Pontederiaceae (6; 24). [Sympodialer Sprossbau!]

A. 6 Stb.

A1. Frkn. 3-fächerig mit vielen Sa. S.-Am.

Eichhornia (5) crassipes (Mart.) Solms

B1. Frkn. durch Abort 1-fächerig mit 1 Sa. Amer.

Pontederia (2) cordata L.

B. S (selten nur 1) Stb. und manchmal noch 1 Staminodium.

Heteranthera (9).

Juncaceae $(7 ; 236)$.

A. Kapsel 3-fücherig, seltener S-kammerig; in jedem Fache $\infty$ S.

a. Bl. mit Vorb.

Juneus (176).

๙. Blattspreite grasblattartig. S. ohne Anhängsel.

I. Fr. 3-kammerig.

1. Stengel beblättert.

+ Blhb. stumpf. Pflanzen ausdauernd, mit kriechendem Wurzelstock.

- Stengel fast stielrund. Blhb. fast so lang als die elliptische Kapsel. A. 3 mal so lang als die Stf. Gr. so lang als der Frkn. N. purpurn. J. Gerardi Lois. 
(.) Stengel zusammengedruickt. Blhb. halb so lang als die fast kugelige Kapsel. A. wenig länger als die Stf. Gr. halb so lang als der Frkn. N. fleischfarben.

J. compressus Jacq.

++ Blhb. spitz. Pflanzen 1 jührig, ohne Wurzelstock.

(.) Blattscheiden spitz auslaufend oder abgestumpft. Kapsel dreikantig.

$J$. bufonius L.

(.) Blattscheiden in 2 stumpfe Oehrchen verlängert. Kapsel rundlich, stumpf.

J. Tenageia Ehrh.

2. Stengel blattlos, am Grunde mit Scheiden umgeben.

J. tenuis Willd.

II. Kapsel dreifächerig. Steng. wie bei J.tenuis. J. squarrosus L. 3. Blattspreite cylindrisch oder von der Seite zusammengedrïckt.

+ Blïtenstand 3-bis 7-blütig. Kapsel 3-kammerig. J. filiformis L.

++ Blütenstand mehr- bis vielbluitig. Kapsel 3-fächerig.

$\odot$ Gr. deutlich. Stb. 6. Kapsel stumpf, stachelspitzig.

J. glaucus Ehrh.

(०) Gr. sehr kurz. Stb. 3. Kapsel am Scheitel eingedrückt.

$\uparrow$ Stengel im lebenden Zustand glatt. Gr. dem einfach eingedriickten Scheitel des Frkn. aufsitzend. J. effusus L.

$\uparrow \uparrow$ Stengel (bes. unter dem Bliitenstand) im lebenden Zustand gerieft. Gr. einer nabelförmigen Erhöhmug in dem eingedrückten Scheitel des Frkn. aufsitzend. J. Lecrsii Marsson

b. Bl. oline Vorb. Halm mit 2-3 rundlichen, knotig-gegliederten B.

I. 6 Stb. B. pfriemelig, nicht rinnig.

1. Kapsel 3-fächerig. Blhb. weisslich oder gelblich.

J. obtusiflorus Ehrh.

2. Kapsel 3-kammerig oder 1-fächerig. Blhb. braun oder schwarz. + Alle Blhb. gleichlang, kurzstachelspitzig. J. lampocarpus Ehrh. ++ Alle Blhb. zugespitzt, die inneren länger, an der Spitze auswärts gekrümmt.

• B. fast stielrund. Blhh. dunkelbraun, kürzer als die zugespitzt-geschnäbelte Kiapsel.

(.) B. kantig, trocken stark gerieft. Blhb. schwarz, so lang als die Kapsel.

J. atratus Krocker

II. 3 Stb. Halm fädlich; B. oberseits schmalrinnig, fast borstlich.

B. Kapsel 1-fächerig, 3-samig.

a. Blütenstand rispig oder trugdoldig.

\%. Blïtenstand länger als die Hüllb.

$\because$ Blïtenstand kiirzer als die Hïllb.

J. supinus Mönch

Luzula (51).

S. olme Anhängsel.

L. silvatica Gaud.

b. Blütenstand aus Aehren oder Köpfen zusammengesetzt.

$\because$ S. ohne Anhängsel. Blhb. gezähnt. L. spicata (L.) D.C.

S. S. mit kegelförmigem Anhängsel. Blhb. ganzrandig.

I. Innere und äussere Blhb. etwa gleichlang.

L. campestris (L.) D. C.

1. 5-10 + lïngliche Aehrchen, alle aufrecht oder etwas abstehend. A. etwa so lang als die Stf.

var. multiflora (Ehrh.) Celak.

2. 2-5 eirunde Aehrchen, die seitlichen zuletzt nickend. A. 2- bis 6 mal so lang als die Stf.

var. vulgaris Gaud. 
II. Innere Blhb. kïrzer als die äusseren.

1. Bis 20 Aehrchen. Blh. gelblich bis hellbram. A. halb so lang als Stf. var. pallescens (Whlbg.) Buch.

2. 5-10 Aehrchen. Blh. schwarzbraun. Stf. 4 mal so lang als A. var. sudetica (Willd.) Celak.

c. Blütenstand doldenähnlich. S. auf der Spitze ein \pm grosses, schwammiges, kammfürmiges Anhängsel tragend. L. pilosa Willd.

\section{Liliaceae (202; 2600).}

I. Fr. eine scheidewandspaltige Kapsel. A. meist extrors.

1. S. länglich, flach und geflügelt oder kantig.

1'. A. intrors, linealisch. Phizom kurz oder kriechend.

Tofieldia (14).

a. B1. nur mit einfachem Deckb. am Grunde des Stieles.

T. palustris Huds.

b. Ausser dem Deckb. am Grunde des Hï̈itenstieles noch mit einem kelchförmigen, 3-lappigen Involucrum.

T. calyculata (L.) Whlbg:

24. A. extrors. Dickes Rhizom oder Zwiebel.

1“. A. eiförmig. $3 \pm$ getrennte Gr. mit immenseitigen $\mathrm{X}$. Atl. N.-Am.

Helonias (1) bullata L.

2“. A. fast kugelig, mit sehr genäherten Füchern, zuletzt schildförmig. [Veratreae.]

A. Dickes Rhizom. B. eiförmig bis lineal-lanzettlich. Blütenstand behaart, unterwärts meist mit - Bl. S. flach, meist berandet.

Veratrum (9).

a. B. der Blh ganzrandis, dunkelpurpurn, so lang als die Stiele.

V. nigrum L.

b. B. der Blh, gezähnelt, grïnlich oder innen weisslich, viel länger als die Stiele.

V. album L.

B. Zriebel. B. linealisch. Blütenstand kahl. S. linealisch oder länglich, kantig, braun.

A1. Blh. frei, mit drïsenlosen B. und lang hervortretenden Stb. - Guatemala, Venezuela.

Schnenocaulon (5) officinale (Schlecht.) A. Gray

B. Blh. meist dem Frkn. angewachsen. ihre B. am Grunde meist drüsig und etwas verschmälert. - Pacif. N.Am.

Zygadenus (9) elegans Pursh

2. S. fast kugelig oder kreisförmig-flach.

1'. A. extrors. Rhizom Stengel verlïngert, beblïttert. - Japan. Tricyrtis (5) hirta Hook.

2‘. A. intrors. Zwiebelknolle. Schaft rerküzt. unterirdisch. mit 1-3 Bl. Nägel der Blhb. zusammenneigend oder verwachsen. [Colcliceae]

A. Nägel der Blhb. zusammenneigend.

A1. 3 von Grund aus getreunte Gr.

B. 1 oben in 3 Schenkel ausgehender Gr. Mingbt.

Meiendera (10).

Bulbocodium (1) vernum L

Niedenzu, Botanische Bestimmur.gsülungen. 
B. Blb.-Nägel vereinigt. 3 getrennte Gr. Colchicum (30) autumnale $\mathrm{L}$. II. Fr. eine fachspaltige Kiapsel oder Beere.

I'. A. extrors. Rhizom. [Melanthioideac-Uvularieae.]

A. B. nicht rankend. Rhizom kriechend. Atl. N.-Am.

Uvularia (4) grandiflora Smith

B. B. mit rankender Spitze. Rhizom knollig. Gloriosa 3).

II'. A intrors.

I“. Stf. dichtwollig; A. linealisch, zuletzt gedreht. Samenschale am Grunde und an der Spitze mit lineal-häutig-bentelförmigem Anhang. Narthecium (4) ossifragum (L.) Huds.

II". Stf. meist kahl; A. immer gerade. Samenschale ohme einseitigen Anhang.

I“". Rhizom mit \pm zahlreichen, grundständigen B., seltener aufrechter Stamm mit Blattschopf und dann die B. der Blh. lang röhrenförmig verwachsen.

I" Fr. eine vielsamige Kapsel (bei J ranclla eine Becre). [Asphodeloideae.]

1. Blh. getremntblättrig. [Asphodcleae.]

1'. Rhizom. B. zur Blütezeit vorhanden

1“. B. mehrreihig. Stf. meist in ein Grübchen der A. eingesenkt.

1“". Blh. radförmig. [Anthericinae.]

A. A. ohne Gribehen. Stf. etwa in der Mitte lang gebärtet.

Bulbine (23).

B. A. in einem am Grunde befindlichen Grïbchen den Stf. aufnehmend.

A1. Stf. lang behaart.

Bi. Stf. kahl.

Arthropodium (\$).

a. Kapsel kugelig. Bl, klein, in 'Traubenrispen.

A. ramosum L.

b. Kapsel eiförmig. Bl. grösser, in einfachen 'Trauben. A. Liliago L.

2“". B. der Blh. trichterig oder slockig zusammenneigend. [Asphodelinae.]

A. Stf. am Rücken der A. in ein Grübchen eingesenkt. A1. Bl. allseitswendig.

A.. Stengel oberwiirts nicht beblattert. Stf. fast gleich. Asphodelus (7).

a. B. B-kantig. Trauhen dichthluitig. Span. bis Albanien. 1. albus Mill.

b. B. rund, röhrig. Trauben lockerblütig. Mmgbt. A. fistulosus $\mathrm{L}$.

B2. Stengel his zum Blïtenstand heblättert. Stf. ungleich. Asphodeline (14).

$B_{1}$. Bl. einseitswendig. Pyrenäen bis Apenninen.

Paradisea (1) Liliastrum Bert.

B. Stf. am Grunde der A. in ein Grübchen eingesenkt.

Eremurus (18).

2". B. 2-reihig. Stf. verdickt. Beere. Dianella (11).

2'. Zwiebel. Windend. Laubb. kurz linealisch, bald ab fallend. Bl. polygam. Kapland. Bowiea (1) volubilis Harv. 
2. Bl. - zygomorph. B. der Blh. oben frei, unterwirts in eine Röhre vereinigt. [Hemerocallideae.]

A. B. gestielt, länglich-lanzettlich his herzförmig. Hosta 5 .

a. Blïtenstiel mit kleinem Torb. am Gruncle. Bl. Weiss. China, Japan. H. plantaginea (Lam.) Aschers.

b. Bliitenstiel ohne Vorb. Bl. lilafarben. China. Japan.

\%. B. breit, rundlich-oder herz-eiförmig. Traube mit $10-1.5 \mathrm{Bl}$.

I. B. mit 12-13 Seitemnerven jederseits rom Mittelnerr. H. Sieboldiana (Hook.) Fingl.

II. B. mit $5-6$ Seitennerven jederseits rom Mittelnerv. H. coerulea (Andrews) Tratt.

B. Banzettlich, mit je 3-4 Seitennerven. Trauhe mit 6-10 Bl. H. lancifolia (Thbg.) Engl.

B. B. grasartig. schmal, biegsam. Hemerocallis $(5)$.

a. Blh. rotgelb. Zipfel mit ästigen Rippen. S.-Frankr. bis Tolhỹn., Transkauk., Talyssch. Himal., Japan. H. julva L.

b. Bl. satt- oder hellgelb. Zipfel mit ungeteilten Rippen.

\%. Blhb. flach. hellgelb. S.-Frankr. bis Siebenbürs.. Sibir.. Japan.

3. Blhb. sattgelb, innere wellig. Sibir., Japan.

H. graminca Andr.

3. B. der Blh. fast in ihrer ganzen Länge zu einer cylindrischen Röhre vereinigt. [Aloineae.] Meist S-oder M-Afrika.

1'. Blätenstand endständig. dichtährig. [Kniphofinac.]

Kniphofia (16).

22. Bluitenstand axillär. meist lockerblütig. traubig oder rispig.

Nicht selten oberirdischer, einfacher oder rerzweigter

Stamm. [Aloinae.]

A. Fr. eine gewöhnliche, trockene Kapsel.

A1. Freie Abschnitte der Blh. gerade vorgestreckt.

A. Blh. eine cylindrische oder glockige, gerale oder nur wenig gekrümmte Riihre. Stb. ebenso lang als die Blh

Alö̈ (85)

B. Blb. eine unterwärts bauchige, oberwärts cylindrische, gekrümmte Pühre. Stb. kürzer als die Blh. (rasteria 3.).

B1. Freie Abschnitte der Blh. einen 2-lippigen saum bildend. die 3 oberen gerade, die 3 unteren sparris abstehend.

Haworthia (59).

B. Fr.fleischig, ziemlich spät aufs pringend. Lomatophyllum (3).

II"“. Fr. mit dümnem. sehr bald zerfliessendem oder aufbrechendem Perikarp und $1-3$ S. mit fleischiger Samenschale.

[Ophiopogonoideae.]

A. Frkn. frei oder etwas in die Heischige Blütenachse eingesenkt. Fächer des Frkn. mit je 1 Sa. Sanseviera (12).

B. Frkn. halb unterständig. Fächer des Frkn. mit je 2 Sa.

Ophiopogon (4).

II'“. Stamm aufrecht, bisweilen kurz, mit beblittertem Schopt oder ein Rhizom mit zahlreichen, grundständigen B. (Astelia.) B. nie fleischig, aber bisweilen lederartig. Blhb. getrennt oder am Grunde vereinigt. Beere oder Kapsel. [Dracaenoideae.]

1. B. der Blh. getrennt. 
1'. A. pfeilförmig. S. zahlreich, in 2 Reihen in jedem Fach, schwarz. [Yucceae.]

a. Stamm wenigstens ${ }^{1}: 2 \mathrm{~m}$ hoch. B. nicht fadentragend.

». B. von sehr kleinen Sägezähnen rauh. W.-Ind., Mexiko, N.-Carol.

B. B. ganzrandig, glatt. Südatl. N.-Am. $\quad Y$. gloriosa L.

b. Stamm kaum ïber den Boden heraustretend. B. am unteren Rande als Fiaden losgelöste Bastfasern tragend. Atl. N.-Am.

Y. filamentosa L.

2'. A. herzförmig. Wenige, kugelige, blasse \$. [Nolineae.]

A. Frkn. 3-fächerig, mit je 2 Sa.

Nolina $(10)$.

B. Frkn. 1-fächerig, mit 6 odex 3 Sa am Grunde. Dasylirion (10).

2. B. der Blh. am Grunde vereinigt. [Dracaeneae.]

A. Holziger, baumartiger oder niedriger Stanm.

A1. Fiacher des Frkn. mit zahlreichen Sa.

$B_{1}$. Fächer des Frkn. mit je einer Sa.

B. Kurzes Rhizom.

Corfyline (10).

Diacaena (36).

Astelia (9).

III" Sträucher oder Halbsträucher mit aufrechten oder kletternden Zweigen. Beere.

I"“". Gr. fadenförmig, mit kleiner N. [Luzuriagoideae.]

A. Frkn. 4-fächerig. Bl. unamsehnlich. B. parallehnervig. ().-Austr. Eustrephus (1) latifolius $\mathrm{R} . \mathrm{Br}$.

B. Frkn. 1-fächerig mit 3 wandständigen Placenten. Bl. schön und gross. B. 3- his j-nervig und netzaderig. Chile.

Lapageria (1) rosca Ruiz et Pav.

II"“. (tr. sehr kurz: N. 3-teilig. B. netzaderig und 3-his 7-nervig. [Smilacoideae.]

Smilax (200).

IV"u. Rhizom unterirdisch, in oherirdische, \pm heblitterte, blühende Zweige endigend und sich unter der Lrde weiter verzweigend oder unten fortwachsend und seitliche Blütenzweige entwickelnd. Beere. [Asparagoideac.]

1. Bl. homoiochlamydeisch.

1'. Rhizomzweige in oberirdische, beblatterte Stengel endigend.

1". Stengelb. klein, schuppenförmig, in ihren Achsehn nadeloder breitblatt artige Zweige tragend. [Asparageae.]

A. Bl. 8. Die $6 \mathrm{Stb}$. frei. Bl. einzeln oder zu mehreren am Grunde der meist nadelartigen Zweige stehend.

Asparagus (100) officinalis $L$.

b. Bl. 2-häusig. Die 3 Sth. in ein krugförmiges Gebilde vereinigt. Bl. einzeln oder in Büischeln auf der Fläche der blattartigen Zweige.

Ruseus (3).

a. Bl. zu 5-6 in einem Büschel. Cladodien lederartig, länglich. Südeur.

R. Hypoglossum L.

b. Bl. zu 1-2 in einem Büschel. Cladodien sehr starr, stachelspitzig. Mmgbt., W.-Hur. R. aculeatus L.

2". Stengelb. gross, laubig. [Polygonateae.]

A. 13. der Blh. getrennt oder an trunde ein wenig zusammenhängend.

A. Fndstandige Traubenrispe oder einfache Traube.

A. Bliitenstengel ron unten bis oben beblittert. 
a. Bl. in dichtbliitiger Rispe. Beeren blaurot. N.-Am.

S. racemosa Desf.

b. 10-20 Bl, in einer Traube. Beeren dunkelrot. N.-Am.

B2. Blütenstengel nur mit 2 Laubb. in der Mitte.

S. stellata Desf.

Majanthemum (1) bifolium (L.) D. C.

$B_{1}$. Oberirdischer Stengel der ganzen Lünge nach beblättert und meist verzweigt; Bl. achselständig.

Streptopus (4) amplexifolius (L.) D. C.

B. Blh. vereintblättrig, cylindrisch oder glockig. Trauben oder einzelne Bl. in den Achseln der am Stengel verteilten Laubb.

a. Stengelb. spiralig.

Polygonatum (23).

\%. Stengel kantig oder 2-schneidig.

I. B. \pm sitzend und stengelumfassend. Stengel kahl. Blh. oben fast bauchig, weiss. an der Spitze srün. P. officinale All.

II. B. kurzgestielt. Stengel behaart. Blh. glockig-röhrig. weiss mit grünen Rippen.

P. latifolium Desf.

$\therefore$ Stengel stielrund, kahl. B. kurzgestielt. Blh. röhrig, am Grunde bauchig, weiss, am Rande grïn. P.multiflorum (L.) All.

b. B. zu je 4-8 quirlständig, lineal-lanzettlich.

P. verticillatum (L.) All.

2'. Hhizom fortwachsend. Blitenzweig seitenständig.

[Convallarieae.]

1“. Gr. in $\doteq$ breite N.-Lappen endigend. [Aspidistrinat.

A. Blïtenschaft mit zahlreichen, in eine Aehre zusammengedrängten $\mathrm{Bl}$.

Tupistra (3).

B. Blütenschaft 1-blütig, sehr kurz, mit einigen schuppenförmigen Niederb. - Japan. Aspidistra (3) clatior Blume 2“". Gr. säulenförmig. mit kleiner N. Convallariinae.]

A. Blh. kugelig-glockig. Samenschale trocken.

B. Blh. cylindrisch. Samenschale saftig. O.-As.

Convallaria (1) majalis $\mathrm{L}$.

Reineckia (1) carnea Kth.

2. Bl. heterochlamydeisch. [Parideae.]

A. 4 oder mehr in einem Quirl stehende Laubb. 4- bis vielteilige, endständige Einzelb. Imnere B. der Blh. schmal, grüin.

Paris (6) quadrifolia. L.

B. 3े quirlständige Laubb. Bl. 3-gliedrig. Innere B. der Blh. farbig, blumenblattartig.

a. Blïtenstiel geneigt oder nickend.

Trillium (15).

\% Blb. schwarzrot, kaum länger als Kb. N.-Am. T.erectum L.

₹. Blb. glänzend weiss. ${ }^{1}{ }^{1}{ }_{t}$ ] ̈̈nger als die Kelchb. N.-Am.

T. grandiflorum Salisb.

b. Bl. sitzend, aufrecht. Blb. violett-purpurn, um $1 / 3-1 / 2$ länger als die Kelchb. N.-Am. T. sessile L.

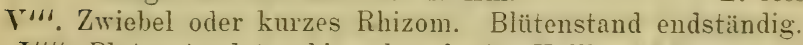

I“". Blütenstand traubiq. ohne breite Hüllb. [Lilioideae.]

1. Stengel mit einigen, seltener nur 1 Laubb. Bl. wenige in den Achseln von Laubb. oder einzeln endständig. ITulipeae. 
A. A. in der Mitte des Rückens angeheftet. Bl trichterig bis fast glockig.

Lilium (45).

a. B. der Blh. glockig zusammenneigend, ungenagelt. Bl. aufrecht. B. spiralig.

\%. Blh. weiss.

I. B nicht stachelspitzig.

1. Blh. röhrig-glockig, ihre B. bis über 1 dm lang. Japan.

2. Blh. glockig, ihre B. etwa $1 / 2 \mathrm{dm}$ lang.

L. longiflorum Thbg.

+ Stengel bis zur Mitte verdickt, sehr reichblütig. Gr. unterhalb der N. 3-seitig. Orient.

L. peregrinum Mill.

++ Stengel bis zur Mitte allnählich verdünnt, mässig reichbliitig. Gr. unterhalb der N. 3-furchig. S.-Eur. bis Persien.

L. candidum L.

Il. B. stachelspitzig. Japan, Nepal.

§. Blh. weiss oder hellrosa, innen rotpunktiert.

I. Innere B der Blh. ohne Mittelstreifen Japan. I.speciosum Thbg.

II. Innere B. der Blh. in der Mitte mit einem goldgelben Streifen. Japan.

L. auratum Lindl.

b. Blh. rot oder gelb, aufrecht, mit sichelförmig gekrümmten B.

o. B. spiralig. B. der Blh. nicht genagelt.

I. Stengel gekielt-kantig. Nectarien von Sternhaaren umgrenzt.

1. Kapsel stumpf 6-lappig. Mitt.-Lur. L Lulbiferum L.

2. Kapsel spitz 6-kantig. Mitt.-Eur.

L. croceum L.

II. Stengel geflügelt. Necturien von parallelen Kegelhaaren umgrenzt. Ostsibir.

L. spectabile Fisch.

9. B. quirlständig. B.der Blh. genagelt. N.-Am. L. philadelphicum L.

c. B. der Blh. ungenagelt, stark zurückgerollt.

0 . Laubb. spiralig.

1. Bl. aufrecht, orange. Stengel zottig, stielrund. China.

II. Bl. zurückgebogen oder nickend.

1. B. nicht gedreht.

+ B. eiförmig. Blh. rosenrot, am Grunde mit braunroten

Warzen, nach der Spitze weisslich. Japan. L. speciosum Thbg.

++ B. lineallanzettlich. Blh. ziegelrot bis zimmtbraun, innen mit dunklen Flecken und gelblichen Warzen. O.-Asien.

L. tigrinum Gawler

2. B. Jineal, gedreht. Blh. zimmtbraun mit gleichfarbigen Warzen. Kleinasien.

§. Laubb., wenigstens die unteren, quirlständig.

I. B. 5- und mehrrippig. Blh. hellviolett-fleischrot mit purpurbraunen Fleckchen. Eur. bis Japan. L. Martagon L.

II. B. 3-rippig.

1. B. entfernt quirlständig, unten an den Rippen \pm rauhhaarig. Bl. gelb bis rötlich, dunkel gefleckt. Atl. N.-Am. L. canadensc l.

2. Unterste B. quirlständig, die ïbrigen spiralig, alle ganz kahl. Blh. in der unteren Hälfte goldgelb mit dunklen Flecken, in der oberen feurig-scharlachrot. Atl. N.-Am.

B. A. basifix. 
A. Blh. glockig, ihre B. nicht zurückgebogen.

A. Bl. nickend; Blhb. mit Honiggrube.

Fritillaria 40 (i).

a. Stengel 1-bliitig. Blhb. schachbrettartig gezeichnet. Wi.-u. S.-Eur.

F. Meleagris L.

h. Stengel mehrblütig; die Tragb. der Bl. in einen Schopf vereinigt. Pers. bis Kaschmir.

$F$. imperialis $\mathrm{L}$.

B. BI. allermeist aufrecht; Blhb. ohne Honiggrube, aber oft mit einem Fleck am Grunde.

a. Stf. kahl.

Tulipa (50).

Zwiebelschuppen innen dicht wollig.

I. Blh. weiss. Sïdeuropa.

T. Clusiana D. C.

II. Blh. rot. ibre B. innen am Girunde mit einem dunklen Fleck.

1. Aeussere Blhb. stumpf. Mittl. S.-Eur. T. Oculus solis. St.Amans

2. Aeussere B. der Blh. lanzettlich. spitz. Tie vor. u. Kleinas.

T. praccox Tenore

$\because$ Zwiehelschupnen innen angedruckt behaart oder kahl.

I. B. und Stengel kahl. Lrim bis Songarei. T. GesnerianaL.

II. Hlattoberseite und Stengel flaumharig. Don bis kasp. Meer.

T. suaveolens Roth

b. Stf. am Grunde behaart.

\%. Bl. weiss, klein. Kaukasus bis Altai.

B. rosafarben. Kreta.

$\because$ Bl. gelb.

I. Bl. aufrecht. S.-Eur.

II. Bl. nickend. MI.- u. S.-Eur.

B. B. der Blh. zurükgebogen. - S.-Eur., Altai, Japan.

T. biflora L.

T. saxatilis Sieb.

T. Celsiana Red. T. silvestris L.

Erythronium (7) Dens canis L.

2. Stengel ohne Laubb. Bl. in den Achseln von Hochb. [Scilleae.]

A. S. zusammengedrüickt oder kantig.

A1. Blh. getrenntblättrig.

A2. Hih. bleibend.

Albuca (30).

B2. Blh. abfällig. - Mmgbt. Lrginea 24) maritima (L. Baker $B_{1}$. Blh. vereintblättrig.

A2. Rühre der Blh. breit und kurz. Abschnitte abstehend. S.-Afr. Galtonia (2) candicans (Baker) Dcne.

B2. Rïhre der Blh. cylindrisch, äussere Abschnitte abstehend, innere aufrecht. - Westl. IImgbt. Dipeadi $(20$; scrotinum Med.

B. S. kugelig oder verkehrt-eiförmig.

A. B. der Blh. getrennt oder nur ganz am Grunde vereinigt.

A. Stf. fädlich oder nur am Grunde verbreitert.

A3. Blütenstand ohne Blattschopf.

At. Abschnitte der Blh. 1-nervig.

a. B. der Blh. von Grund aus abstehend. Sämtliche Stb. in gleicher Höhe.

a. Fächer des Frkn. mit mehreren Sa.

I. Mehrere Laubb.

1. Blïtenstiele aufrecht abstehend.

+ B. stumpflinealisch. $6-12 \mathrm{Bl}$. in den Achseln linealischer Hochb. W.-Eur.

S. verna Huds. ++ B. breitlinealisch. $3-6 \mathrm{Bl}$. Deutschl., Oberital.

$S$. amoena $\mathrm{L}$. 
2. 1-3 nickende, stahlblaue Bl. Mittl. Russl. bis Kleinas. S. sibirica Andr.

II. 2 schmale Laubb. $3-8 \mathrm{kleine} \mathrm{Bl}$. auf ziemlich langen, aufsteigenden Stielen. M.- u. S.-Eur., Kleinas. S. bifolia L.

९. Fächer des Frkn. mit $2 \mathrm{Sa}$. 'Traube reichblütig.

I. B. linealisch, gleichzeitig mit den Bl. auftretend. Adriat. Gbt.

$S$. pratensis $W$. et $K$.

II. B. fast stielrund, nach den Trauben entwickelt. W.- и. S.-Eur.

S. autumnalis $\mathrm{L}$

b. B. der Blh. am Grunde zu einem Becher zusammenneigend. Stb. der beiden Kreise ungleich und in ungleicher Höhe der Blh. eingefügt.

๙. Blh. kurzglockig. Traube allseitswendig. Iber. Halbins.

S. hispanica Mill.

ק. Blh. langglockig. Traube einseitswendig. W.- u. S-Eur. S. nonscripta (L.) Hoffm. et Link Bt. Abschnitte der Blh. mehrnervig. Camassia (2). $B_{3}$. Blïteristand mit einem Schopf von Hochb. über den Bl.

Eucomis (5).

B2. Stf. flach, verbreitert. Bl, gestielt. () rnithogalum (70).

a. Traube locker, trugdoldig. B. der Blh. gestreift, nur am Rande weiss. Gr. fadenförmig.

O. umbellatum $\mathrm{L}$.

b. Traube lang.

a. B. der Blh. gestreift, am Rande weiss oder bräunlich.

I. Stf. oben mit 2 seitlichen Zäbnen. (ir. fadenförmig.

1. Innenseite des Stf. zahnlos. Frkn. kïrzer als Gr. O. nutans L

2. Inmenseite des Stf. mit einem spitzen Zahn. Frkn. so lang als der Gr.

O. Bouchéanum (Kth.) Aschers.

II. Stf. ohne Zahn. Gr. kurz.

1. B. vor dem Aufbliihen verwelkend. Bl. weisslich, auf dem Rücken grün gekielt. IV.- u. S.-Wur. O. pyrenaicum T.

2. B. zur Blütezeit noch griin. Blhb. weisslich. grün gestreift. S.- Hinr.

O. narbonense L.

F. B. der Blh. weiss, nicht gestreift. Kapl. O. lacteum Jacq. $B_{1}$. Blh. vereinthlättrig.

A2. Mehrere Giundb.

A3. Freie Absehnitte der Blh. länger als die glockige Rühre.

At. Stb. frei. Kreta, Kleinas. Chionorloxa (4) Luciliac Boiss.

B. Stb. vereinigt. - Kaukas., Kleinas.

Puschkinia (2) scilloides Adams

B3. Freie Abschnitte der Blh. kürzer als die Röhre.

At. Blh. trichterförmig, am Schlunde nicht zusammengezogen.

Hyacinthus (30).

a. Rühre der Blh. einfach trichterig, Abschnitte zurüickgebogen. Oestl. Mmgbt.

$H$. orientalis $\mathrm{L}$.

b. Röhre der Blh. glockig-trichterig, Abschnitte fast aufrecht, sehr kurz. Span. bis Bosnien.

B. Blh. kugelig oder krugförmig.

$H$. amethystinus $\mathrm{I}$.

Muscari (40).

a. Abschnitte der Blh. abstehend, zahnartig, sehr klein, auf der Rückseite verdickt. Vord.-As. II. moschatum Willd.

b. Abschnitte der Blh. \pm zurückgebogen, dreieckig. 
๑. Ein deutlicher Schopf steriler B. entwickelt. M. comosum (L.) Mill.

3. Schopf steriler B. schwach oder gar nicht entwickelt.
I. Blh. oberwärts gefurcht.
M. racemosum (L.) Mill.
II. Blh. oberwärts nicht gefurcht.
1I. botryoides (L.) D. C.

B. Nur 2, selten bis.弓 Grundb. S.-Afr. Lachenalia (30) tricolor Thbe.

II. "." Blütenstand eine von 2 breiten, bisweilen vereinigten Hüllb. \pm eingeschlossene Scheindolde, aus verkürzten Schraubeln zusammengesetzt. seltener (Gagea) eine von 2 schmalen B. gestützte Scheindolde oder Einzelbl. [Allioideac.]

1. Rhizom. Blh. vereintblätrig. [Agapantheae.] - S.-Afr.

Agapanthus (9) umbellatus L'Hér.

2. Zwiebel oder von häutigen Niederb. umschlossene Grundachse.

1'. Andröceum strahlig. [Allieae.]

A. Eine aus wenigbluitigen Schraubeln zusammengesetzte Scheindolde oder Linzelbl., mit 2 schmalen Hochb. Gagea (25).

a. 3 wagerechte, nackte ' wiebeln bei einander.

G. pratensis (Pers.) Schult.

b. 2 aufrechte, ron einer gemeinsamen Haut umschlossene Zwiebeln bei einander.

๙. 2 grundständige $B$.

I. Hüllb. lineal-lanzettlich; Blütenstiele zottig.

1. Grundb. lineal. rinnig. Hüllb. zugespitzt. Blïtenstand meist 5- bis 10-blütig. $\quad G$. arvensis (Pers.) Schult.

2. Grundb. fadenförmig. Hüllb. stumpt. Blïtenstand 1bis 3-blütig.

G. saxatilis Koch

II. Unterstes Hïllb. mit breitem Grunde, die übrigen schmall. Blütenstiele \pm kahl.

३. 1 grundständiges $B$.

c. 1 einzige Knollenzwiebel.

G. spathacea (Hayne) Salisb.

G. minima (L.) Schult.

G. Iutea (L.) Schult.

B. Scheindolde von 2 breiten, häutigen Hochb. umschlossen.

A1. B. der Blh. frei.

Allium (250).

a. Alle Stf. ungezähnt oder die inneren seitlich mit je 1 Zahn.

\%. Zwiebeln einem Rhizom aufsitzend. Stf. einfach.

I. B. länglich, in einen Stiel verschmälert. A. Victorialis L.

Il. B linealisch. Centr.- $\mathrm{u}$. O.-As.

ß. Zwiebel ohne längeres Rhizom.

I. Hüllb. geschnäbelt, oft von Grund aus schmal, die BI. erreichend oder ïberragend, getrennt.

1. Dolde ohne Brutzwiebelchen. Bl. gelb. Nmgbt. A. flarum L.

2. Dolde mit Brutzwiebelchen. Bl. meist rötlich.

+ Stf. etwa so lang als die stumpfen Blhb. A. oleraceum L.

+ + Stf. zuletzt doppelt so lang als die länglich-verkehrt-eiförmigen Blhb.

A. carinatum L.

II. Hüllb. vereinigt, kurz, die Bl. nicht überragend.

1. B. linealisch, flach, nicht hohl.

+ Dolde ohne Brutzwiebelchen.

(-) Blh. gelb. B. glatt, kahl. Mimgbt. A. Moly L.

$\odot \cdot$ Blh, weiss oder weisslich.

$\uparrow$ B. am Rande behaart, breit linealisch. Mmgbt. A. Chamaemoly L.

$\uparrow \uparrow$ B. kahl, flach. Stengel dreikantig. A. ursinum I. 
+ Dolde mit Brutzwiebelchen und nur 1-2, selten mehreren weissen, langgestielten $\mathrm{Bl} . \quad 1-2$ dreikantige $\mathrm{B}$.

2. B. halbstielrund oder stielrund, hohl. A. paradoxum Don

+ Stb. kürzer als die rote Blh.

A. Schoenoprasum L. + + Stb. ungefähr so lang als die lilafarbene Blh. Kleinasien.

+++ Stb. länger als die grünlichweisse Blĭ.

A. ascalonicum $\mathrm{L}$.

(.) Blütenstiel etwa $4 \mathrm{mal}$ so lang als die Blh. Stf. ohme Zähne. Sibirien.

A. fistulosum L.

$\odot$ Blitenstiel etwa $8 \mathrm{mal}$ so lang als die Blh. Stf. am Grunde mit 2 seitlichen Zähnen.

A. Cepa L.

b. Die 3 inneren Stf. verbreitert, zu beiden Seiten der A. mit einer Spitze. Zwiebel ohme Rhizom. B. flach oder gekielt, oft mit langen Scheiden. Huillb. \pm mit cinander vereinigt.

c. Bliitenstand ohne Brutzwiebelchen.

I. B. flach. Mingbt.

II. B. halbstielrund.

A. Ampeloprasum L. A. sphaerocephalum I.

$\beta$. Blïtenstand mit zahlreichen Brutzwiebelchen.

I. B. flach.

1. Bl. rötlich. Hülle kurzgeschuäbelt. A. Scorodoprasum Is.

2. Bl. weisslich. Hülle langgeschnäbelt, in einem Stück abfallend. Songarei.

II. B. halbstielrund oder stielrund.

Bı. B. der Blh. am Grunde oder bis zur Mitte vereinigt.

$\mathrm{C}_{1}$. Blh. hoch vereintblättrig.

Nothoseordum (10).

A2. Blh. trichterig-glockig. (; Stt., von denen zuweilen 3 steril.

Brodiaea (30).

B. Röhre der Bih. cylindrisch odter ïber den Frkn. zusammengezogen. Die 3 immeren Sth. staminodial. Lencocoryne (4).

2`. Andröceum zygomorph, einscitswendig, meist nur teilweis fruchtbar. [Gilliesicae.] Die 3 oberen stb. in staminodiale, kurze Zähne verwandelt.

Gilliesia (3).

\section{Amaryllidaceae $(71 ; 760)$.}

I. Unterirdische Achse ein Rhizom. Schaft beblättert. Involucralb. meist fehlend.

I'. B. von gewöhnlicher Consistenz. [Hypoxidoideae.]

1. B. linealisch. Blütenstand nicht doldig.

1'. Stengel beblaitert. Bl. in Wickelrispen oder -köpfchen. [Conostylideae.]

Anigosanthus (8).

2'. Blïtenstiel nicht bebliittert. Bliitenstand ährig oder traubiy. [Hypoxideae.]

A. Fr. eine an der Spitze aufspringende, dünnwandige Kapsel. Frkn. ungeschnäbelt.

Hypoxis (50).

B. Fr. fleischig, nicht aufspringend. Frkn. oberwärts oft in einen Sehnabel verlängert.

Cureuligo (12).

2. B. meist um $180^{\circ}$ gedreht. Blütenstand scheindoldig, meist mit Involucralb. [Alstrocmerieae.] 
A. Bl. strahlig. äussere Blhb. kleiner. Stengel meist windend. Bomarea (50).

B. Bl. melian zrgomorph, sonst die B. beider Kreise sleich. Stengel nicht windend.

Alstroemeria (50).

II'. B. dickfleischig. meist gross und dicht rosettenfürmig anceordnet. [Agaroideae.]

A. Bl. strahlig. Blütenstand sehr reichblütig.

A. Stf. länger als die Blh. - Mexiko. Agave sili americana L.

B:. Stf. kürzer als die Blh.. deren Rühre sehr kurz.

Fonrerosa (15).

B. Bl. durch Abwärtskrümmung = zrgomorph. Bl. zu je 2 in den Achseln an einfacher Traube. Rihizom linollig. Centr.-Am.

Polianthes (3) tuberosa L.

II. Zwiebel. Schaft hlattlos, mit einem ron Involucralb. umhiillten. doldenartigen Blütenstande oder Einzelbl. [Amaryllidoirlece.]

1. Nebenkrone fehlend. [Amaryllideae.]

1'. In jedem Fach des Frkn. zahlreiche Sa.

1“. Piihre der Blh. fehlend vder nur sehr kurz; stb. daher = epigyn.

1“. Bl. strahlig. einzeln oler nur wenige. Galanthinac.]

A. Alle $6 \mathrm{~B}$. der Blh. einander gleich.

Leucojum i9.

i. Bl. zu mehreren in Scheindolden. S. glänzend schwarz. L. restivum $\mathrm{L}$.

b. Bl. einzeln. selten zu ‥ \$. blass, mit schnabelfürmiger Caruncula.

L. vernum L.

B. Die inneren B, der Blh, von den änsseren verschieden.

Galanthus (כ) nivalis L.

2.". Bl. = zysomorph. in reichblütigen scheindolden. Amaryllidinae.]

A. Stf. frei, fadenförmig.

A. Bl. wenig zrgomorph. S. stark zusammengedrücht. Kapld. Tallota (1) purpurea (Ait) Herb.

B1. Bl. stark zygomorph. S. rundlich.

A2. Kapsel kreiselfürmig, כ̈-kantig. Sa. in die Placenta eingesenkt. Lap. C'anaren. Amaryllis 1 , Belladonne L.

B2. Tapsel3 schneilig. Sa.nicht eingesenkt. Brunswigia!9!

B. Stf. am Grunde angeschwollen und = mit einander rereinigt.

Nerine (9).

2“. Rübre der Blh. verlüngert: Stb. daher perigyn. S. platt zusammengedrückt.

1“.. Bl in reichblütigen Scheindolden. Crininac. Crinum(60). 2" B1. einzeln. [Zephyranthinae.]

A. Abschnitte der Blh. elliptisch. S. flach. zusammengedrückt

Zephyranthes (30).

B. Abschnitte der Blh. linealisch bis lanzettlich. S. runilich.

Sternbergia (12).

2'. In jedem Fach des Frkn. wenige sa.

A. A. basifix. N. deutlich dreiteilig.

Haemanthinae.]

B. A. dorsifix.

Hessea (10!

A. 3-6 Sa. in jedem Fach. Kapland.

Clivia (3). 
a. Bl. strahlig; Blh. trichterig; ihre Abschnitte und Stb. abstehend.

C. miniata (Hook.) Bth.

b. Bl.zygomorph; Blh. glockenförmig, abwärts gekrümmt, schmal; ihre Abschnitte und Stb. \pm aufrecht.

\%. Bl. mässig gekrümmt; Abschnitte aufrecht. C. nobilis Lindl.

₹. Bl. stärker gekrümmt; Abschnitte etwas abstehend.

B1. 2 Sa. in jedem Fach des Frkn.

C. Gardeni Hook.

2. Nebenkrone vorhanden, wenn auch bisweilen auf einzelne Schuppen oder einen Ring reduziert. [Narcisseae.]

1'. Sehr viele Sa. in jedem Fach. B. nie herzförmig.

1“. Stf. aus dem Rande der becherförmigen, nicht am Schlunde aufsitzenden, bisweilen zu einzelnen Schuppen reduzierten Nebenkrone entspringend. [Pancratiinac.]

A. Stf. \pm frei. N. 3-teilig.

Hippeastrum (50).

B. Stf. aus dem Rande der Nebenkrone entspringend. N. kopfig. - Mmgbt.

Pancratium (12) maritimum $\mathrm{L}$.

2“. Stf. innerhalb der becherförmigen, am Schlunde der verlängerten Röhre aufsitzenden Neisenkrone eingefïgt. [Narcissinae.]

Narcissus (35).

a. Blh. strahlig; ihre Abschnitte elliptisch.

\%. Stf. am Grunde der Nebenkrone eingefügt.

I. Blütenhiullabschnitte abstehend.

1. Blh. und Nebenkrone gelb.

2. Blh. weiss, Nebenkrone gelb.

N. Pseudonarcissus L. N. bicolor L.

II. Blütenhüllabschnitte riickwärts gebogen. N. cernuıs Salisb.

3. Stf. in der Mitte der Nebenkrone eingefügt.

I. Nebenkrone halb bis ebenso lang als die Blütenhüllabschnitte.

1. A. kurz. B. schmal, gerundet, oberseits mit Rinne. Blh. gelb. Japan.

2. A. lang. B. ziemlich flach. Blh. hellgelb. W.-Eur.

N. incomparabilis Curt.

11. Nebenkrone flach, schüsselförmig, viel kïrzer als die Blütenhüllabschnitte.

1. Blütenhüllabschnitte lang.

+ Schaft gerillt, "2-blütig. Nebenkrone mit weisslichem Rande. Engl., Schweiz, Ital. N. biflorus Curt.

++ Schaft gefurcht, 1-bluitig. Nebenkrone mit scharlachrotem Rande. Engl, S.-Eur. N. poëticus L

2. Blh. napf- oder becherförmig. Japan. N. Tazetta L.

b. Blh. zygomorph, Abschnitte schmallanzettlich. Nebenkrone sehr gross, glockig: Westl. Mmgbt. N. Bulbocadium I.

2'. Wenige Sa in jedem Fach, bisweilen nur 1 Fach sich entwickelnd. B. meist gestielt, ]änglich oder herzförmig. [Eucharidinae.]

Eucharis (4).

\section{Dioscoreaceae $(9 ; 170)$.}

A. Fr. eine 3-kantige oder 3-schneidige Kapsel. S. Hach, geflügelt. A. Rhizom ober- oder unterirdisch, knollig. S. oberwirts oder ringsum geflïgelt.

Dioscorea (150). 
B1. Rhizom oberirdisch. sehr gross, dessen Rinde mit eckigen, harten Feldern versehen. S. unterwärts geflïgelt. Kapl.

Testudinaria (2) Elephantipes (L'Hér.) Burch.

B. Fr. eine runde, bei der Reife rote Beere. s. ungeflügelt. - M.-Eur., Mmgbt.

Tamus (2) communis L.

\section{Iridaceae $(57 ; 780)$.}

I. Oberirdischer Stengel kurz oder fehlend. B. nicht genau nach 1.2-Divergenz. Bl. einzeln oder in einem einfachen, wenigblütigen Blütenstand. [Crocoideac.]

A. Oberirdischer Stengel kurz. Blh. mässig lang trichterförmig. - S.-Eur.

Romulea (50) Bulbocodium Seb. Maur.

B. Oberirdischer Stengel fehlend. Röhre der Blh. sehr lang:

a. Bl. ohne grundständige Spatha.

Crocus $(60)^{\circ}$.

๗. Hülle der Kinolle paralleltaserig, hïntig. Frühlingshl., goldgelb. Griechenl.

C. aureus Sibth. et Sm.

ऽ. Hülle der Knolle aus deutlich netzartigen Fasern bestehend. Frühlingsblütler.

I. Bl. weiss bis lila. Griechenl. $\quad C$ reticulatus M. Bieb.

II. Bl. orange. Vorderasien.

C, susianus Ker

$\because$. Hïlle der Knolle in einzelne Ringe sich trennend.

.1. Früblingsblütler. Bl. weiss, violett gestreift. T'aurus.

C. biflorus Mill.

II. Herbstblütler. Bl. blau. Taurus. C. speciosus M. Bieh.

b. Bl. mit Spatha am Grunde des Schaftes.

э. Hülle der Kinolle parallelfaserig, häutig. Herbstblütler. Bl. blass lila Vorderas. C. iridiflorus Heuff.

F. Hülle der Knolle deutlich netzfaserig.

I. Frühlingsbliitler. Bl. weiss oder violett. Mitt.- u. Süd-Eur.

C. vernus All.

II. Herbstblütler. Bl. blass violett, dunkler gestrelft. Oestl. Mittmgbt.

C. sativus $\mathrm{L}$.

II. Oberirdischer Stengel deutlich entwickelt. B. reitend. BI. ron Spathen umschlossen, in zusammengesetzten Blütenständen.

I'. Spathen mehrblïtig. B1. meist strahlig. [Iridoideac.]

1. Röhre der lilh. kurz oder fehlend. Kapsel nicht von der Spatha eingeschlossen.

1'. Griffeläste ungeteilt, rundlich oder nur wenig verbreitert. 1". Stf. frei.

A. B. der Blh, alle gleich. Bl. rot oder gelb. Ostas.

Belameanda (1) chinensis (L.) Leman

B. Innere B. der Blh grösser als die äusseren. Bl. weiss oder blau.

Libertia (8).

2“. Stf. am Grunde zu einer Röhre vereinigt. Sisyrinchium (50).

2'. Griffeläste verbreitert oder mehrfach geteilt, immer über die Stb: fallend.

1“. N. an der Spitze der schmalen, tief gegabelten Griffeläste. Innere Blhb. kleiner. - Mexiko.

Tigridia (7) Pavonia (L.) Ker 
2". N. auf der Unterseite der verbreiterten und die Stb. überragenden Griffeläste.

A. Griffeläste nicht blattartig.

A1. Rhizom.

B. Zwiebelknolle.

B. Griffeläste blattartig.

Marica $(9)$.

Cypella (5).

A1. B. der Blh. bis zum Grunde frei. Stb. am Grunde \pm verbreitert und verwachsen.

Moraea (40).

$B_{1}$. B. der Blh. am Grunde \pm vereinigt. Stb. frei. Iris (100).

a. Rhizom bald gedrungen knotig, bald verlängert, niemals von Scheiden bedeckt.

o. Alle B. der Blh. kahl.

I. Stengel zweischneidig. Frkn. 6-seitig. I. graminea L. II. Stengel \pm stielrund.

1. Frkn 6-seitig. Kankas, Sibir. I. Giildenstaedtiana Lepech.

2. Frkn. 3-seitig oder 3-schneidig.

A. Stengel hohl.

I. sibirica I.

B. Stengel voll.

a. Blhb. citrongelb.

b. Blhb. blau oder tiefviolett und weiss gefleckt.

u. Innere Blhb. kaum breiter als die Griffeläste. B. steif, \pm meergriin. N.-Am.

I. virginica $\mathrm{l}$.

G. Innere Blhb. un die Hiilfte breiter als die Griffeläste. B. schlaff, grasgrün. N.-Am.

I. versicolor $\mathrm{L}$.

ア. Aeussere Blhb. längss des Mittelnerven gebärtet.

I. Stengel niedriger oder nur wenig höher als die B. S.-O.-Lur.

II. Stengel höher als die B.

I. pumila 1 .

1. Deckb. krautig, bez. nur am Rande etwas trockenhäutig. Mähren bis Südrussl.

2. Deckb. halb trockenhäutig, halb krautartig

+ Blhb. beiderseits gleichfarbig. N. einfarbig.

- Blhb. gelb, innere ziemlich eben. O.-Eur. I. tlavescens Red.

(•) Blhb. weisslich-bläulich, innere am Rande kraus. Ital. Cyperu.

I. florentina L.

++ Die beiden Seiten der äusseren Blhb. nicht ganz gleichfarbig. N. bunt.

(o) A. so lang als die Stf. Alle Blhb. violett. I. germanica $\mathrm{I}$.

(•) A. um die Hälfte länger als die Stf. Innere Blhb. gelb-violett, äussere violett, hinten weisslich, mit dunkleren Adern. S.- u. O.-Wur.

I. squalens L.

3. Deckb. ganz trockenhäutig. Blhb. blassblau. Ital.,Griechenl.

I. pallida Lam.

b. Knolle oder Zwiebel. B. der Blh. nicht gebärtet.

a. Stb. vom Gr. frei. Westl. Mmgbt.

F. Stb. dem Gr. anhaftend. Mmgbt.

I. Xiphium L. I. Sisyrinchium L.

2. Röhre der Blh. \pm lang. Kapsel stets von der Spatha eingehüllt.

Aristea (13).

II'. Spathen immer einblütig. Bl. öfters zygomorph. [Ixioideae.]

1. Griffeläste ungeteilt. 
l'. Bl. nicht oder nur wenig zrgomorph. Stf. und Gr. gerade.

ㄴ. Bl. stark zygomorph.

A. Blh. gerade, aufrecht.

B. Blh. gekrümmt.

Schizostylis (2).

a. Aeussere Blhb. nicht oder kaum stachelspitzig.

\%. B. nicht berandet.
I. Bl. zweizeilig. Ost-Eur.
G. byzantinus Mill.

II. Bl. einseitswendig.

1. Kapselkanten überall abgerundet. B. sehr stumpf. O -Eur. G. imbricatus L.

2. Kapselkanten nach oben in einen Kiel herrortretend. B. spitz. G. communis L.

3. B. berandet, vielrippig. Bl. einseitswendig, scharlachrot. S.-Afr.

G. cardinalis Curt.

b. Aeussere Blhb. mit Stachelspitzchen. S.-Afr.G. psittacinus Hook.

உ. Griffeläste 2-teilig.

A. Röhre der 13lh. gerade oder wenig sekrïmmt. Stf. kurz.

Lapeyrousia (22).

B. Röhre der Blh. gekrümmt. Stf. rerlängert. Whtsonia (25).

\section{Musaceae $(4 ; 60)$. (Fig. 3 E.)}

A. Unpares Kelchb, nach rorn. Hinteres Stb. fehlend ibei Musa Ensete vorhanden). $\infty$ Sa. in jedem Fache des Frkn.

A. Kelchb. frei, die -2 seitlichen Blb. verwachsen. Laubh, zweizeilig.

Strelitzia (5).

B1. Kelchb. unter sich und zum Teil mit den Blb. rereinigt. Laubb. spiralig.

Musa (23).

B. Lnpaares Kelchb. nach hinten. Hinteres Stb. staminodial. 1 Sa. in jedem Fach des Frkn. Laubb. zweizeilig. Bliitenstände wickelförmig, in den Achseln zweizeiliger Sirathen. Heliconia (30).

\section{Zingiberaceae (24; 300.) (Fig. 3 D.)}

1. Frkn. 3ffächerig; Placenten centralwinkelständig.

1'. Seitenstaminodien blattartig, etwa wie das Lahellum.

A. Comnectiv ohne spornförmigen Fortsatz nach unten.

[Hedychieae.]

A1. Connectiv ohne Fortsatz nach oben.

$B_{1}$. Connectiv mit Fortsatz nach ob:n.

Hedychium (2 7 .

Kaempferia (18).

B. Connectiv nach unten zu zwei Sporen verlängert. Curcuma (30).

2'. Seitenstaminodien linien- oder zahnförmig oder fehlend. [Zingibereae.]

A. Connectivfortsatz klein oder fehlend.

A. Connectiv sehr schmal, ohne Fortsatz.

A. Labellum etwas ausgehöhlt, abgestutzt. Renealmia (25).

B. Labellum flach ausgebreitet, schwach 3-lappig. Ostind.

Elettaria (1) Cardamomum White et Maton

$B_{1}$. Connectiv (wenigstens oben) verbreitert, zuweilen kurz vorgezogen. 
112 Musaceae. - Ziugiberaceae. - Cannaceae. - Marantaceae.
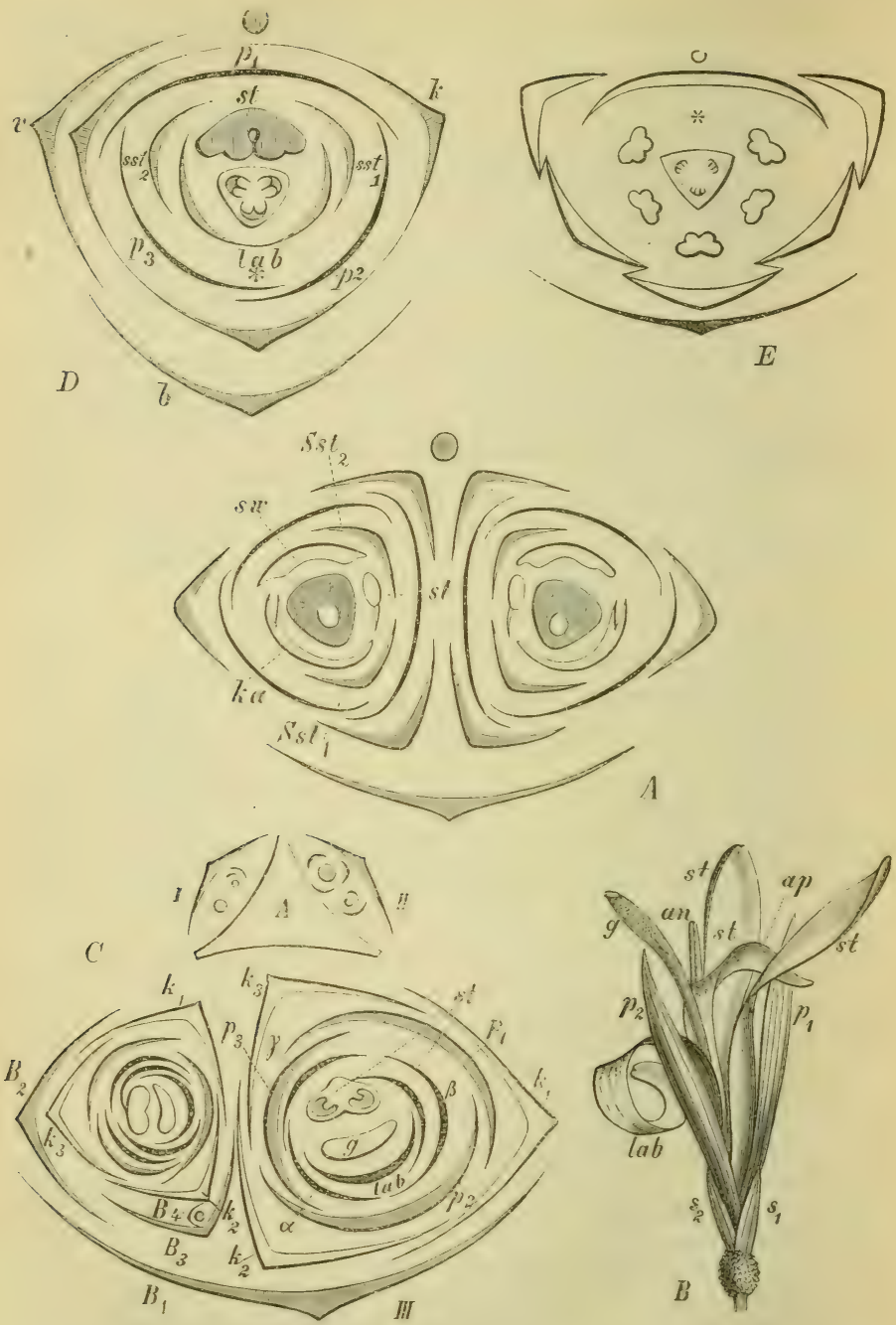

Fig. 3.

I Diagramm dos Bl.paares von Mlaranta bicolor Kier; ka Kapuzenb, st Stb., Sst Seitenstaminodien, sw Schwielenb. - L Bl. von Canna indica L ; $s_{1}$ u. $s_{2}$ Kib.; $r_{1}$ u. $\nu_{2} \mathrm{Blb}$; lab Labellum; st blb.artige Staminodien; an fruchtbare, $n p$ blb.artige llälite d. Stb. ; / Gr. - C Bl.standsliagramm ron Cunna Sellowii Bouché ; i. $_{2} 3$ Kíb. ;

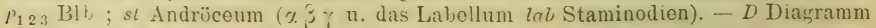

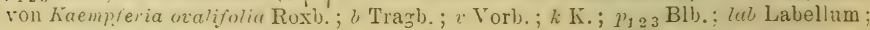
sst $_{12}$ Seitenstaminodien; si Stb. - E Diagramm von MIusa ornata Roxb. 
A2. Bl. am Ende eines Laubb. tragenden Stengels. Alpinia (40).

B. Blütenstand und Laubb. an verschiedenen Achsen.

B. Connectivfortsatz gross, breit blattartig.

C. Connectivfortsatz hornartig.

Amomum (50). Costus (25).

2. Frkn. 1-fächerig; 3 wandständige Placenten.

Zingiber (20).

[Globbeae.]

Globba (24).

\section{Cannaceae (Camna, 25). (Fig. 3 B, C.)}

a. Die 3 äusseren Staminodien getrennt, nur wenig ungleich.

๘. Blkr. gelb.

I. B. der Blkr. und Staminodien lineal-lanzettlich, letztere \pm rot, zuweilen am Grunde oder auch Rande gelblich. Kapsel aufspringend.

1. Pflanze grasgrün. Staminodien scharlachrot oder unten = gelb gefleckt. Gr. gerade. W.-Ind.

C. indica $\overline{\mathrm{L}}$.

2. Pflanze meergrün. Staminodien gelb mit dunkelrotem Längsstreifen. Gr. sichelförmig. Caracas. C. glauca L.

II. B. der Blkr. und Staminodien spatelig. Kapsel nicht aufspringend. Südl. N.-Am.

¿. Blkr. rosenrot, Labellum gelb gefleckt. Peru.

C. iridiflora Ruiz et Pav.

b. Zwei äussere Staminodien vereinigt. das dritte frei. Blkr. orange, Staminodien gelb und rot gefärbt. Centr.-Am.

C. speciosa Rosc.

\section{Marantaceae $(12 ; 150)$. (Fig. 3 A.)}

1. Frkn. 3-fächerig, in jedem Fache $1 \mathrm{Sa}$. [Phrynieae.] Calathea (60).

2. Frkn. 1-fächerig, mit 1 Sa. [Maranteae.]

A. 2 (selten 0) Seitenstaminodien.

A. Kronemröhre verlängert. Deckb. 2-zeilig gegenüberstehend. Maranta (15).

B. Kronenröhre sehr kurz, weit. Deckb, einander einseitig genähert.

A2. B. antitrop.

A3. Deckb. häutig, abfallend. Seitenstaminodien klein oder fehlend.

Stromanthe (5).

$\mathrm{B}_{3}$. Deckb. pergamentartig, bleibend. Seitenstaminodien kronblattartig.

Ctenanthe (7).

B2. B. homotrop. Seitenstaminodien kronblattartig. Saranthe $(7$.

B. 1 Seitenstaminodium. B. homotrop. Deckb. abfällig. Kronröhre kurz.

Thalia (7).

\section{Orchidaceae $(410 ; 7000)$.}

I. Die beiden paarigen Stb. des inneren Kreises fruchtbar, das unpaare des äusseren staminodial, die übrigen fehlend. [Diandrae.] (Fig. $4 B$ u. Fig. $6 A-D$.)

A. Knospenlage der Laubb. convolutiv.

A. Frkn. 1-fächerig mit 3 wandständigen Placenten.

Cypripedilnm (20).

Niedenzu, Botanische Bestimmungsübungen. 

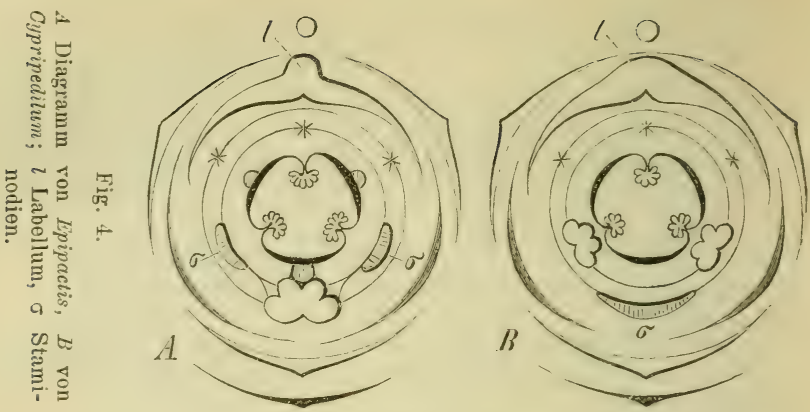

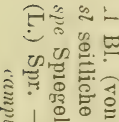
$\approx-1$ है

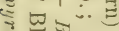

है 2

ミ $\approx * 1-$

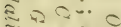
क $2 \stackrel{8}{8}$ อे

트율 के

ఐ 10 .

의유 을

$\therefore$ ๘。응 ล

त

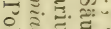

을 छ छ

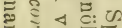

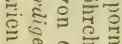

- 0 .

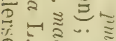

유

$\cong \approx 1$ 挋

छ. $\approx \Delta \overrightarrow{0}$

+

哈

․ㅗㅇ. 융 $\approx$

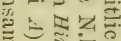

इ) ะ

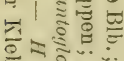
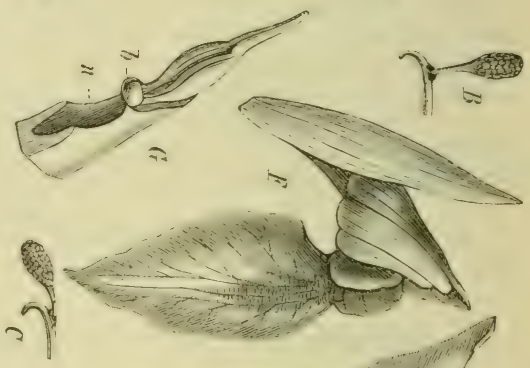

象

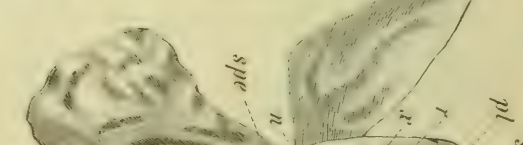

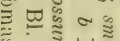

实

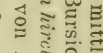

స
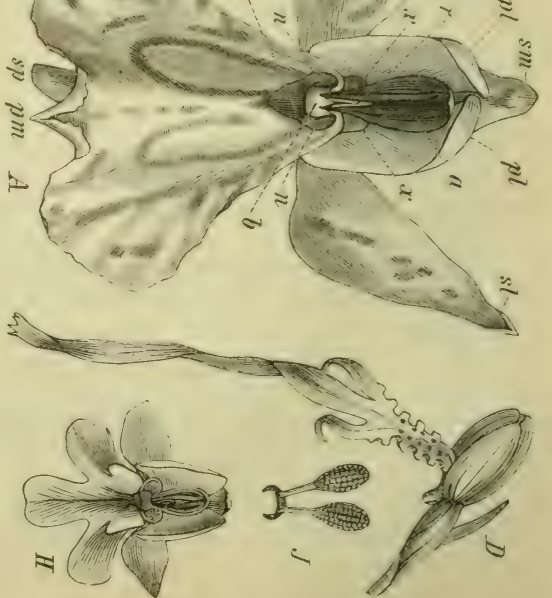

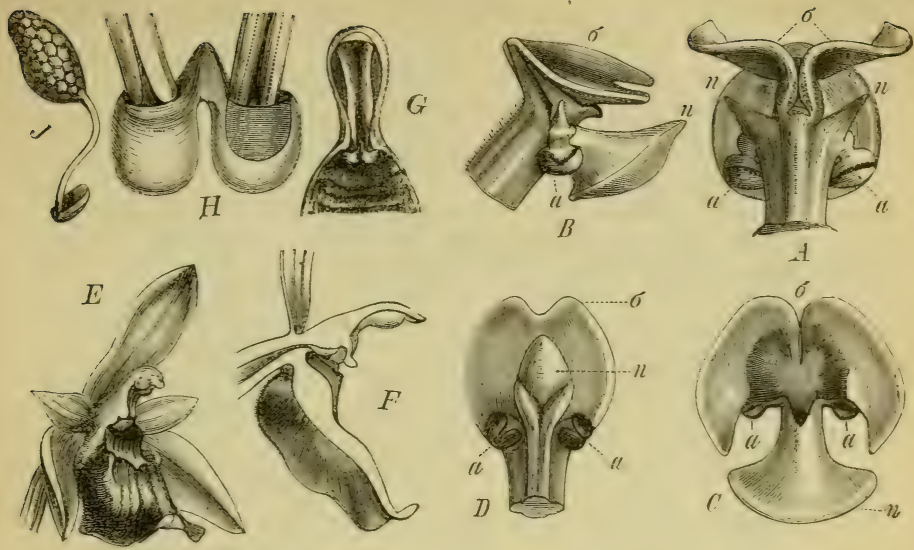

Fig. 6 .

1-C Säule von Papliopedilum larbatum (Lindl.) Pfitz.: A von aussen, $L$ ron der Seite, $C$ ron oben. - $D$ Säule ron I'aphiopedilum insigne (Wall.) Pfitz. ron innen her gesehen (a A., $\sigma$ Staminodien, $n$ N.flächo). $-E \mathrm{Bl}$, von Ophrys Arachuites Rchb.; $F$ dieselbe im Längsschniti. - $G-J$ uphrys aranifera Huds.: $G$ Stl., Rostellum u. N.fläche; $H$ Rostellum u. Spitzen der A.fächer (rechts mit durchscheinender Klebmasse); $J$ Pollinarium.

a. B. kahl. Lipne gelb, kürzer als die bramen übrigen Blhb. C. Calceolus L.

b. B. zottig. Lippe rosenrot, länger als die weisslichen Blhb. Atl. N.-Am.

B1. Frkn. 3-fächerig, tief gefurcht.

C. spectabile $\mathrm{Sw}$.

B. Knospenlage der Laubb. duplicativ. Frkn. vollkommen oder nur an der Spitze 3-fächerig. (Fig. 6 A-D.) Paphiopedilum (30).

a. Wenige, kurze, meist stumpfe Laubb. Traube einblütig. Innere Blhb. flach, ziemlich gleich lang wie die äusseren. Java.

P. barbatum (Wall.) Pfitz.

b. Zahlreiche, ziemlich lange, meist spitze Laubb. Innere Blhb. gedreht, schmal, viel länger als die äusseren, bis ïber ${ }^{1}$. $\mathrm{m}$ lang. Chiriqui.

P. caudatum (Lindl.) Pfitz.

II. Die beiden paarigen Stb. des inneren Kireises staminodial (oder auch fehlend), das unpaare des äusseren fruchthar, die ïbrigen fehlend. [Monandrae.] (Fig. 4 A.)

I'. Die Pollinien entwickeln nach der Basis der A. hin Caudiculae. welche mit den Klebmassen des Rostellums in Terbindung treten. (Fig. 5, $6 G-J$.) Stf. sehr kurz und breit; A. niemals abfallend. [Basitonae-Ophrydinae.]

1. Klebmassen von den Fortsätzen der A. umschlossen oder nackt. [Gymnadenieae.] 
A. Klebmassen von einem dünnen Häutchen umgeben, welches mit ihnen entfernt wird.

A1. Caudicula äusserst kurz. Klebmassen sehr gross, platt.

Herminium (4) Monorchis L.

B1. Caudicula ziemlich lang. Klebmassen klein, kaum breiter als die Caudicula. Coeloglossum (2) viride (L.) Hartm.

B. Klebmassen ganz nackt.

A1. Rostellarfortsatz eine schmale Falte zwischen den Fächern der A. bildend. Klebflächen der Lippe zugekehrt.

A2. Lippe ungeteilt, aufwärts gerichtet, kurz gespornt. Alp., Apenn., Balk., Skand. Nigritella (1) angustifolia L. C. Rich.

$B_{2}$. Lippe 3-lappig, abwärts (seltener seitwärts) gekehrt, deutlich gespornt.

Gymmadenia (10).

a. Auch die seitlichen Kelchb. dem Helm anliegend. Sporn walzlich, $1 / 3$ so lang als der Frkn. G. albida (L.) Rich.

b. Seitliche Kelchb. weit abstehend. Sporn fadenförmig.

a. Sporn kaum so lang als der Frkn. Lippe seicht 3-spaltig.

G. odoratissima (L.) Rich.

3 . Sporn fast doppelt so lang als der Frkn. Lippe 3-spaltig.

G. conopea (L.) R. Br.

B1. Rostellum ganz breit und niedrig, ohne Rostellarfortsatz. Klebflächen senkrecht, im rechten Winkel mit den Caudiculis.

Platanthera (70).

a. Fächer $\operatorname{der} \mathrm{A}$, einander parallel, genähert. Bl. sehr wohlriechend.

b. Fächer der A. nach unten divergierend.

P. montana (Schmidt) Rehb. f.

2. Klebmassen in Beutelchen ('Teilen des Rostellums) eingeschlossen. [Serapiadeae.]

A. 2 getrennte Beutelchen. Lippe meist convex und behaart. (Fig. $6 E-J$.)

a. Kelchb. grünlich. Lippe ohne Anhängsel.

๙. Lippe ungeteilt, gewölbt, mit umgefalteten Rändern.

[^. Lippe langgestreckt, 3-lappig.

O. aranifera Huds.

O. muscifera Huds.

b. Kelchb. weiss oder rötlich. Lippe gewölbt, mit einem kahlen, grünen oder gelblichen Spitzchen.

a. Lippe ungeteilt, am Rande flach.

O. Arachnites Murr.

ק. Lippe 5-spaltig, am Rande umgebogen.

B. 1 gemeinsames Beutelchen.

A1. 2 getrennte Klebmassen. (Fig. $5 A-C$.) Orchis (70).

a. Kelchb. und Blb. helmartig zusammenneigend. Knollen ungeteilt. Deckb. 1-, die untersten zuweilen 3-nervig.

a. Lippe 3-lappig, Lappen breit, kurz. Stengel bis oben beblättert.

O. Morio L.

§. Lippe tief 3-spaltig, Mittelzipfel 2-teilig, meist mit einem Zwischenzähnchen in der Bucht. Stengel oberwärts blattlos.

I. Deckb. wenigstens halb so lang als der Frkn.

1. Helm halbkugelig, stumpf, aussen schwarzpurpurn; Lippe weiss, rot punktiert. Sporn ${ }^{1 / 4}$ so lang als Frkn. 
2. Helm länglich, spitz; Lippe blasslila, rot punktiert. Sporn halb so lang als der Frkn.

II. Deckb. höchstens $1 / 3$ so lang als der Frkn.

1. Helm kurz eiförmig, aussen grünlich, dunkelpurpurn gefleckt oder braunrot. Lippe hell.

O. purpurea Huds.

2. Helm eilanzettlich, aussen rötlichgrau oder lila; Lippe mit dunklen Haarbüscheln.

O. militaris $\mathrm{L}$.

b. Seitliche Kelchb. abstehend.

ฯ. Tragb. häutig. Knolle ungeteilt.

I. Lippe am Grunde am breitesten, tief 3-spaltig; Mittelzipfel länglich.

1. Aehre fast kugelig oder kurz pyramidal. Bl. blass fleischfarben. Lippe mit 3-eckigen Seitenzipfeln. O. globosa L.

2. Aehre walzlich. Bl. schmutzig braunrot, übelriechend. Lippe mit $\doteqdot$ rankenförmigen Seitenzipfeln. O.coriophora $\mathrm{L}$.

II. Lippe aus keilförmigem Grunde verbreitert; Lappen breit, kurz.

1. Obere Deckb. mehrnervig. Sporn kürzer als der Frkn. B. vom Grunde an verschmälert. O. palustris Jacq.

2. Obere Deckb. 1-nervig. Sporn so lang als der Frkn. B. aus schmälerem Grunde bis zur Mitte verbreitert.

+ Aehre kurz eifürmig. Bl. blassgelb (selten purpurn), ihre B. eiförmig, Kelchb. stumpf. Lippe seicht 3-lappig.

O. pallens L. ++ Aehre verlängert. Bl. purpurn, ihre B. länglich, spitz. Lippe tief 3-lappig.

O. mascula L.

₹. Tragb. krautig. Knolle 2-lappig bis handförmig geteilt.

I. Stengel markig, 6- bis 10-blättrig. Deckb. so lang oder kürzer als die Bl. Blh. hellpurpurn oder weisslich. O. maculata L.

II. Stengel hohl, 3- bis 6 blättrig. Deckb. länger als die Bl.

1. Knollen tief (oft handförmig) geteilt. Sporn meist kürzer als der Frkn.

+ Lippe ungeteilt oder undeutlich 3-lappig. Bl. hellpurpurn oder fleischfarben.

O. incarnata L.

t+ Lippe 3-lappig. Bl. lilapurpurn, selten rötlich oder weisslich.

2. Knollen an der Spitze kurz 2 oder 3-lappig. Sporn lang oder länger als der Frkn. Bl.weisslichgelb. O. sambucina L.

B1. 1 gemeinsame Klebmasse.

A. Connectiv nicht verlängert. Rostellarspitze kegelig.

A3. Lippe gleichmässig 3-lappig, mit 2 Längsschwielen, in der Knospe flach. (Fig. $5 \mathrm{H}, J_{\text {.) }}$

Anacamptis (1) pyramidalis (L.) Rich.

B3. Mittellappen der Lippe grösser und länger als die seitlichen.

At. Lippe nicht oder nur kurz gespornt; Seitenlappen länglich, Wittellappen \pm tief eingeschnitten, in der Knospe über die A. gebogen. Aceras (2) anthropophora (L.) R. Br.

B. Lippe kurz gespornt; Seitenlappen kurz, Mittellappen riemenartig, in der Knospe uhrfederartig eingerollt. (Fig. 5 D).

Himantoglossum (2) hircinum (L.) Spr.

$B_{2}$. Connectiv verlängert. Rostellarfortsatz seitlich zusammengedrückt. Nmgbt. (Fig. $5 F^{*}, G$.) Serapias (5) cordigera L. 
II'. Die Pollinien bleiben ohne Anhängsel oder entwickeln dieselben nach der Spitze der A. hin. Stf. meist dünn und zart, A. daher in der Regel leicht abfallend. [Acrotonae.] (Fig. 7, 8, 9.)

I". Blütenstände an der Spitze der einzelnen sympodial verbundenen Sprosse terminal. [Acranthae.]

1. Knospenlage der B. convolutiv.

1'. Blattfläche und Blattscheide nicht von einander abgegliedert.

A. meist welkend an ihrem Platze bleibend; Pollenmassen nur selten fest und wachsartig, meist weich, körnig. [Neottiinae.] 1". A. das Rostellum \pm weit überragend, stumpf endigend; bei Entfernung der Klebmassen kein scharf begrenzter Einschnitt im Rostellum.

1". Lippe ohne Hypochil. [Vanilleae.] - Mexiko.

Vanilla (20) planifolia Andr.

2“. Lippe mit deutlichem, oft gesporntem Hypochil. (Fig. 7 $F-J$.$) \quad [Cephalanthereae.]$

A. Blütenschaft mit Laubb. Lippe ohne eigentlichen Sporn. A1. Lippenplatte rundlich, aus der weit geöffneten Blh. frei vortretend. Hypochil concav, olme abgesetztes Kinn. (Fig. $4 A, 7$ F.)

Epipactis (10).

a. Hypochil ziemlich flach, beiderseits geöhrt. Lippenplatte rundlich, stumpf, flach, wellig gekerbt.

E. palustris (L.) Crantz

b. Hypochil halbkugelig; Lippenplatte zugespitzt vertieft, an der Spitze zurückgebogen.

a. B. ziemlich gross, meist länger als die Internodien, auf den Nerven flaumig-rauh.

I. B. eilänglich. Bl. grünlich, rotbraun überlaufen oder grünlich-gelb. $E$. latifolia (L.) All.

II. B. \pm lanzettlich. Bl. dunkelrotbraun.

E. atrorubens Schult.

ß. B. klein, meist kürzer als die Internodien, auch auf den Nerven fast kahl. Bl. grünlich, am Rande rötlich, Lippe weissberandet. $E$. microphylla Sw.

B1. Lippenplatte länglich, von den Kelchb. fast ganz umschlossen. Hypochil mit deutlichem Kinn. (Fig. $7 E, H, J$.)

Cephalanthera (10).

a. Bl. weiss oder gelblichweiss. Ganze Pflanze kahl.

๔. B. eilänglich. Deckb. länger als der Frkn. Blhb. stumpflich.

C. grandiflora Babgt.

ß. B. lanzettlich. Deckb. viel kürzer als der Frkn. Aeussere Blhb. spitz. C. Xiphophyllum (L. f.) Rchb. f.

b. Bl. hellpurpurn oder rosa. Stengel oberwärts nebst Frkn. kurzhaarig.

B. Blïtenschaft schuppig, ohne Laubb. Lippe gespornt.

A1. Såule kurz. Lippe aufwärts gewandt.

Epipogon (1) aphyllus (Schmidt) Sw.

B1. Säule lang. Lippe abwärts gewandt. (F'ig. $7 \mathrm{G}$.)

Limodorum (1) abortivum (L.) Sw.

2". A. in der Regel ebenso lang wie das Rostellum und demselben dicht anliegend. Durch Entfernung der Klebmassen entsteht ein \pm scharf begrenzter Einschnitt im Rostellum. 

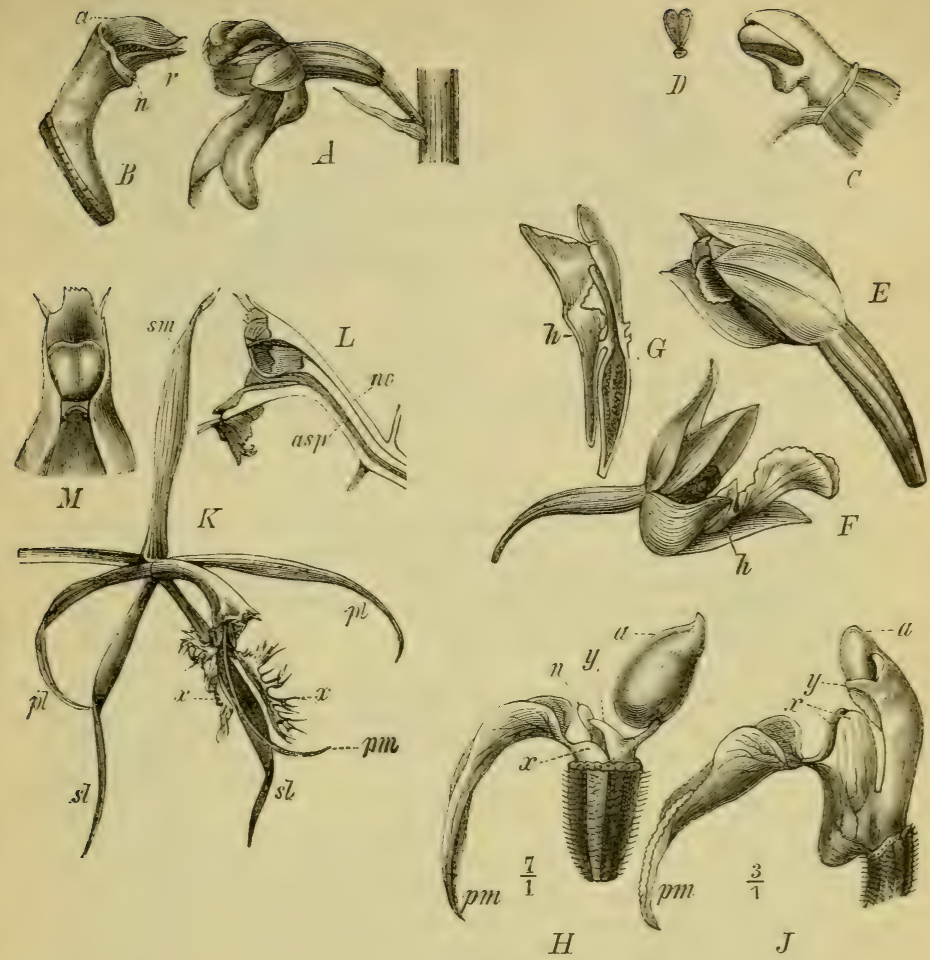

Fig. 7.

$A$ Bl., $E$ Säule ron Neottia Nidus avis L. (a A., $r$ Rostellum, $n$ N.). $-C$ Säule, $D$ Polliniam von Listera ovata R. Br. - E Bl. von Cephalanthera grandiflora Babgt. - F Bl, von Epipactis palustris (L.) Crtz. ( $h$ Hypochil). - G Bl.längsschnitt ron Limodorum abortium (L.) Sw. - H Säule n. Lippe aus einer $4 \mathrm{~mm}$ langen Knospe, $J$ aus einer fertigen Bl. von Cephalanthera mbra (L.) Rich. ( $p m$ Endlappen der Lippe, $x$ Seitenlappen des Hypochiles, $y$ Staminodien auf d. Säule, $a$ A.). - $K-L$ Epidendrum ciliare L. $K$ Bl.; L Säulenlängsschnitt; II Säulenspitze von vorn $(s l, s m, p l, p m$ wie in Fig. $5 A, x$ wie bei $H$ u. $J$; asp Achsensporn, nc Narbenkanal.)

1“". Pollinien wachsartig oder pulverig, nicht in $\propto$ bestimmte Massen abgeteilt. [Spirantheae.]

A. Kelchb. und Blb. gleichmässig abstehend, frei. A. 2 gegenüberstehende, breite Laubb. am Blütenschaft. (Fig. $7 C, D$.)

a. Pflanze kräftig. B. eielliptisch. Traube vielblütig. Lippe einfach 2-spaltig, fast gelblich. sonst Blïte grim. Is. orata (L.) R. Br. 
b. Pflanze zart. B. herzförmig. Traube bis 9-blütig. Lippe am Grunde mit jederseits einem Zähnchen. Bl. grünlich, innen purpurn.

L. cordata (L.) R. Br.

B1. Blïtenschaft blass, ohne Laubb. (Fig. $7 A, B$.)

Neottia (3) Nidus avis L.

B. Medianes Kelchb. und die angrenzenden Blb. helmförmig zusammengeneigt, aber nicht verwachsen. Spiranthes $(40)$.

a. Stengel mit lineallanzettlichen B. Lippe eilänglich.

S. aestivalis (DC.) Rich.

b. Stengel blattlos, nur mit Blattscheiden. Lippe verkehrteiförmig, ausgerandet.

S. spiralis (L.) C. Koch

2'“. Pollinien in viele bestimmte Massen geteilt. [Physureae.]

Goodyera (25) repens (L.) R. Br.

2. Blattfläche von der Blattscheide mit scharfem Riss sich trennend. Ein Internodium knollig verdickt. A. meist bei Entfernung der gewöhnlich wachsartigen 4 Pollinien abfallend. [Coelogyninae.]

2. Knospenlage der B. duplicativ.

Coelogyne (50).

1. Aeussere Blhb. höchstens gleich umfangreich wie die inneren;

Lippe am meisten in die Augen fallend.

1“. Laubb. ungegliedert oder fehlend. [Liparidinac.]

A. Laubb. vorhanden. Säule ohne Fuss.

$A_{1}$. Lippe nicht schuhförmig.

A2. A. aufrecht.

A3. A. durch Schrumpfen ihrer Wandungen die Pollinien frei legend, nie abfallend. Malaxis (1) paludosa (L.) Sw.

B3. A. nicht schrumpfend, einwärts aufspringend, abfallend.

Microstylis (70).

$B_{2}$. A. übergeneigt, abfallend.

B. Lippe schuhförmig.

Liparis $(70)$.

B. Ohne Laubb. Säulenfuss mit den seitlichen Sepalen ein schwaches Kimm bildend. Corallior rhiza (12) innata(L.) R. Br.

2". Laubb. gegliedert. Lippe bedeutend grösser als äussere Blhb. [Laeliinae.] Säule fusslos.

A. 8 Pollinien, parweise durch parallele Caudiculae verbunden.

A1. Lippengrund allmählich in die Platte übergehend.

Laelia (20).

$B_{1}$ Lippengrund fest um die Säule gerollt, plötzlich in die abstehende, breite Platte verbreitert. Brassavola (20).

B. 4 Pollinien, in der A. den 4 schmalen Caudiculis aufliegend.

Ar. Lippe frei, die Säule umfassend.

$B_{1}$. Tippe der Säule \pm angewachsen, Platte meist abstehend. (Fig. $7 K-M$.)

Epidendrum (400).

2'. Aeussere Blhb. stärker entwickelt als die inneren, diese oft verdeckend. Säulenfuss deutlich. 2 oder 4 Pollinien; Caudiculae fehlend oder schwach. [Pleurothallidinae.]

A. Seitliche Aussenblhb. frei oder zu einem fiachen oder schwach concaven Gebilde verwachsen

Pleurothallis (400).

B. Aussenblhb. am Grunde röhren- oder schalenförmig verwachsen, oberwärts einzeln in meist lange Fortsätze ausgezogen.

Masdevallia (100). 

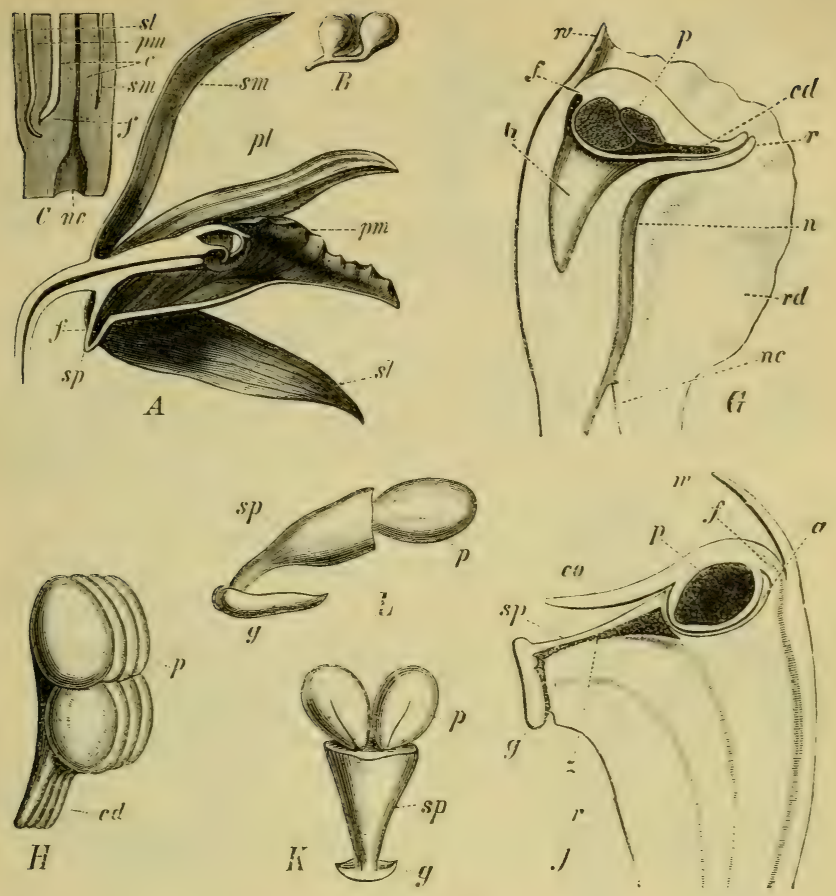

Fig. 8 .

A Bl.längsschnitt, $L$ Pollinarium von Ihujus Llumei lindl. ( $* m, s l, p^{\prime}, p m$, sp wie früher; $f$ Säulenfuss). - $C, G, H$ Ihajus cupreus Rchb. f. $C$ Knospenlängsschnitt $(s l, s m, p m, f, n c$ wie vorher, $c$ Säule); $G$ Längsschnitt durch die Săulenspitze $(f$ Fila• ment, $w$ Verlängerung des Androcliniums, $h$ Höhlung unter der A.. $p$ Pollinien. cd Caudiculae, $r$ Rostellum, $n$ x.fläche, $r d$ Säulenflügel, $n c$ Vorderfläche der Säule ; $H$ Pollinarium. - I, $K, I$, Cochlioda sanguinea Benth. $J$ Längsschnitt durch die Säulenspitze ( $a$ Aushöhlung, in der die A. liegt, $f, p, w$ u. $r$ wie bei $G$, co Connectirfortsatz, g Klebmasse, $s p$ der sich rom Rostellum durch Desorganisierung der mit $\approx$ bezeichneten Gewebe loslösende Stipes); $K$ Pollinarium elien abgelöst, ron rorn: $L$ dasselbe nach Ueberbeugung der Pollinien, ron der Seito gesehen.

II". Blütenstände auf Seitensprossen, nicht Sympodialgliedern. [Pleuranthae.]

1. Knospenlage der Laubb. convolutiv.

1'. Stammglieder schlank oder gleichmässig angeschwollen.

1“. 4-8 wachsartige Pollinien mit Caudiculis, ohne Stipes. Lippe ohne Hypochil. [Phajinae.] (Fig. \& $A-H$.)

A. Laubb. nicht gegliedert.

A1. Lippe frei, die Säule umfassend.

Phajus (12). 
B1. Lippengrund der Säule angewachsen, Platte abstehend

B. Laubb. gegliedert.

Calanthe (40)

$2^{\prime \prime}$. 2-4 wachsartige Pollinien olne Caudicula, mit \pm langem Stipes. Lippe mit deutlichem Hypochil. Laubb. gegliedert. [Catasetinae.]

Bl. trimorph.

Catasetum (30).

2'. Ein einzelnes Stammglied zur Luftknolle entwickelt. 2 oder 4 Pollinien mit deutlichem Stipes.

1“. Lippe häutig, ohne Hypochil, mit dem Säulenfuss gegliedert. 1“'. Lippe meist mit Längsschwielen. Blütenstand unterhalb des neuen Laubsprosses entspringend. [Lycastinac.]

A. Blhb., namentlich die äusseren, ausgebreitet. Lyeaste (30).

B. Blhb. fast kugelig zusammengeneigt.

Anguloa (3).

2“". Lippe mit quer verlaufendem Schwielenbogen. Blütenstand oberhalb des neuen Laubsprosses entspringend. [Zygopetalinae.] (Fig. $9 A-D$.)

Zygopetalum (10).

2". Lippe knorpelfleischig, durch ein deutliches Hypochil mit dem Säulenfuss verbunden. Blütenstand unterhalb des neuen Laubsprosses entspringend. [Gongorinac.] (Fig. $9 \mathrm{E}-H_{\text {.) }}$

Stanhopea (20).

2. Knospenlage der Laubb. duplicativ.

1'. Laubtriebe mit begrenztem Spitzenwachstum, die einzelnen Jahrestriebe sympodial verbunden. Lippe ohne Hypochil, häutiø. 1". Lippe dem Säulenfuss \pm beweglich angegliedert.

1““. Pollinien anhangslos oder mit Caudicula oder Śtipes.

A. Lippe ohne Schwielen. Pollinien anhangslos oder mit kleiner Caudicula.

A1. Blütenstände an der Spitze der schlanken Stämme oder auf der Luftknolle entspringend. [Dendrobiinae.]

Dendrobium (300).

$B_{1}$. Blütenstände unter der Luftknolle entspringend. [Bolbophyllinae.]

A2. Seitliche Aussenblhb. am Grunde getrennt, sonst mit ihren Aussenrändern verklebt. Cirrhopetalum (30).

B. Seitliche Aussenblhb. frei oder mit den in der Knospe benachbarten Rïndern etwas verklebt.

Bolbophyllum (100).

B. Lippe mit Längsschwielen. Pollinien mit deutlichem Stipes. [Maxillariinae.]

Maxillaria (100).

2“". Pollinien mit quergestreckter Caudicula und breitem Stipes. B. riemenartig. [Cymbidiinae.] Cymbidium (30).

2". Lippe mit dem Säulenfuss fest verbunden, mit Längsschwielen oder Warzen u. dgl. besetzt. Pollinien mit deutlichem Stipes. [Oncidiinae.] (Fig. $8 J-L$.)

A. Lippe höchstens am Grunde der Süule etwas angewachsen, frei ausgebreitet.

A1. Lippe vom Grunde an von der kurzen Säule unter einem deutlichen Winkel abstehend, nicht genagelt. Oncidium(300).

Bi. Lippengrund (Nagel) der schlanken Säule parallel, ihr bisweilen etwas angewachsen; Lippenplatte abstehend.

Odontoglossum (100). 

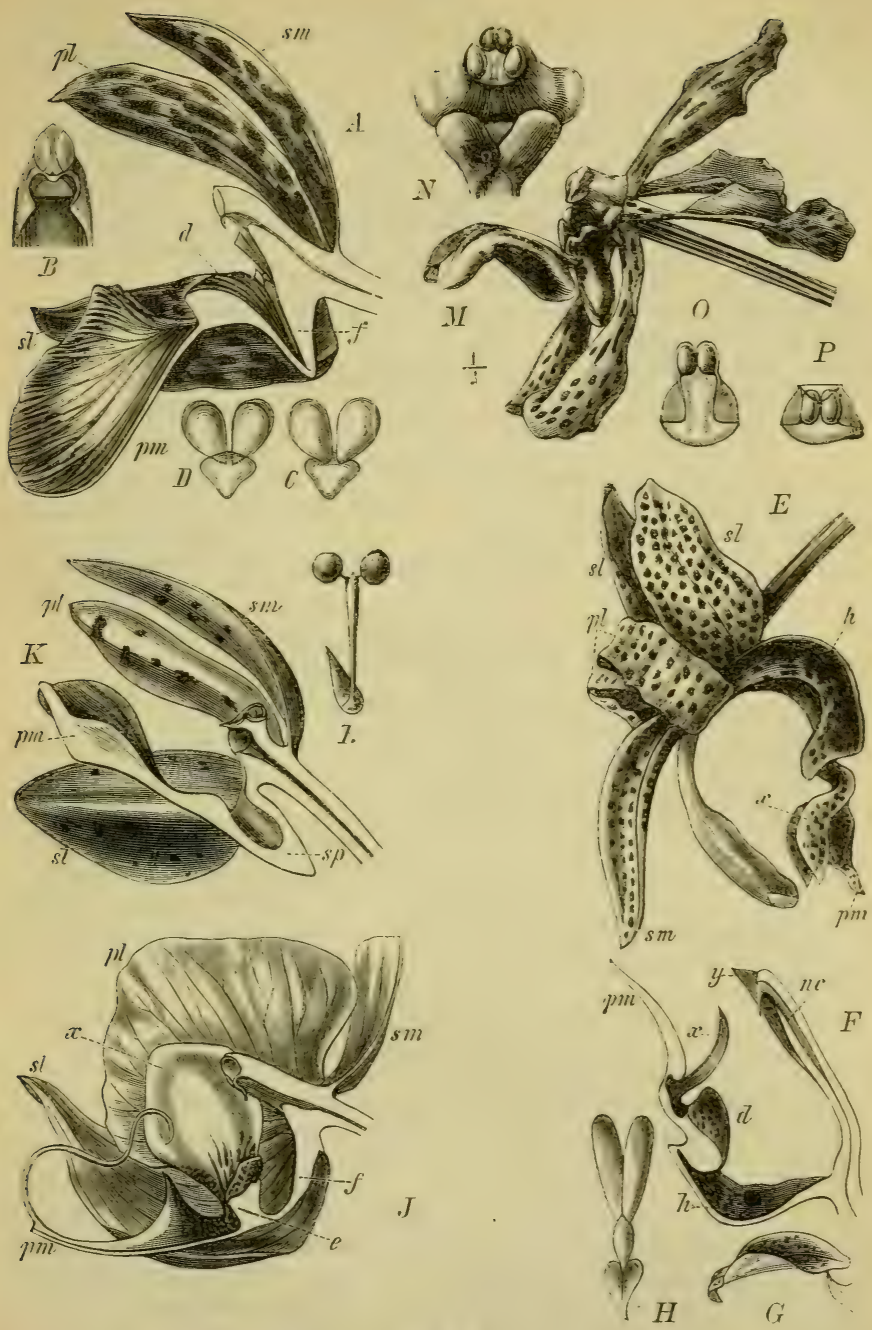

Fig. 9.

$A-D$ Zygopetalum Mackaii Hook. A Bl.längsschnitt; $D$ Säule ron vorn: $C$ u. $D$ Pollinarium ron hinten u. von vorn. $-E$ Bl. von Stuntıpea platyceras Rchl,. f. $F-H$ Stantiopea oculatu Lindl. F Längsschnitt der Lippe u. Säule, G Lippenepichil, It Pollinarinm. - J Phalaenopsis Aphrodite Rehb. f. $-K$ Bl.längsschnitt, I Pollinarium ron Saccolabium giganteum Lindl. - I-P Tanda tricolor Lindl. II Bl. ; N Siale von rorn; O Pollinarium mit geradem, $P$ mit eingeschlagenem

Stielchen, $-d$ in $A$ u. $F$ n. $e$ in $J$ Schwiele; das ubrige wie früher. 
B. Lippe dem Säulengrund angewachsen. [Trichopilicae.] Lippe um die Säule gerollt.

Trichopilia (18).

C. Lippe erst von der Säulenmitte frei abstehend. [Aspasicae.] (Fig. $8 J-L$.)

2. Laubtriebe mit unbegrenztem Spitzenwachstum. Laubb. gegliedert. Lippe compliciert gebaut, oft in Hypo-, Meso- und Epichil gegliedert oder gespornt. [Sarcanthinae.] (Fig. $9 \mathrm{~J}-\mathrm{P}$.)

A. Lippe dem Säulengrunde berveglich angegliedert: Siulenfuss fehlend.

B. Lippe mit dem Säulengrunde fest verbunden.

A. Lippe spornlos. Mit Säulenfuss. (Fig. () J.) Phalaenopsis (35)). $B_{1}$. Lippe gespornt.

A2. Säulenfuss fehlend. Seitliche Aussenblhb. nur am Rande des Frkn. inseriert.

A3. Stielchen der Pollinien fadenförmig. (Fig. $9 K, L$.)

Saccolabium (20).

B3. Stielchen durchweg breit oder uberwärts verbreitert.

At. Sporn kurz und breit. (Fig. $9 M-P$.) Vanda (20).

$B_{4}$. Sporn lang und dünn. Angreeum (15).

B:. Seitliche Aussenblhb. am Säulenfuss herablaufend, kinnbildend.

Aerides (15).

\section{Dicotyledoneae.}

I. B1. achlamydeisch, homoiochlamydeisch oder apetal.

1. Sa. ohne Integument. Halbparasiten mit mattgrinen B. [Santalales.]

A. Freie fädliche (oft gewundene) Centralplacenta, von deren Spitze die Sa. deutlich abgegliedert hermnterhängen. B. spiralig.

Santalaceae (S. 149).

B. Centrale Placenta mit der Frkn.wandung zusammenhängend oder überhaupt nur undentlich; Sa. dem Placentargewebe eingebettet. $\mathrm{B}$. gegenständig.

2. Sa. mit 1 oder 2 Integumenten. Autophyten.

A. Nit Oelzellen.

a. Sa. orthotrop. S. ohne Arillus. Nährgewebe aus Endosperm und Perisperm bestehend, nicht zerkliiftet. [Piperalcs.]

a. Gefässbündel in 1 Kreis. B. mit Nebenb.

I. 3-4 Frb., frei oder zu einem Frkn. mit wandständigen Placenten vereinigt, mit je mehr Sa. Saururaceae (S. 137).

II. $1 \mathrm{Frb}$. mit 1 von der Spitze herabhängenden Sa.

Chloranthaceae $(3 ; 33)$.

Bl. \&, achlamydersch. Stb. mit einander und dem Frkn. verwachsen. - O.-As. Chloranthus (10) inconspicuus Sw.

ß. Gefässbündel in mehreren Kreisen. Bl. achlamydeisch, mit einer grundständigen Sa.

b. Sa. anatrop. Holzgewächse. [Ranales p. p.]

a. Bl. 3 . Blh. petaloid. $\infty$ Frb. mit $2-\infty$ Sa. in 2 Längsreihen an der Bauchnaht. S. ohne Arillus, Nährgewebe nicht zerklüftet. cf. $1^{\prime}$ A auf S. 128.

Magnoliaceate p. p. und Calycanthaceac. 
. Bl. diöcisch. Blh. prophylloid. 1 Frb. mit 1 fast grundständigen Sa. S. mit Arillus und zerklüftetem Endosperm.

Myristicaceae (Myristica, 80).

B. Ohne Oelzellen. Nährgewebe fehlend oder allermeist nur aus Endosperm bestehend.

A1. Placenta basilär.

a. Mehrere freie oder \pm mit einander zu einem mehrfächerigen Frkn. verwachsene $\overline{\mathrm{F}} \mathrm{rb}$.

b. Frkn. 1-fächerig; Placenta centralgrundständig.

a. $2-\infty$ Sa. Kräuter.

I. B. gegenständig, etwas fleischig. Primulaceae p. p. (S. 269).

II. B. spiralig, laubig.

¡. 1 grundständige, aufrechte (selten an langem Funiculus hängende) Sa.

I. Sa. geradläufig.

1. Holzpflanzen. (Juglandales.)

+ B. einfach.

++ B. gefiedert.

2. Kräuter.

+ B. mit Ochrea.3 (2-4) getrennte Gr. Polygonaceae (S.150).

++ B. ohne Ochrea. $1 \mathrm{Gr}$. Urticaceae (S. 148).

II. Sa. anatrop oder campylotrop.

1. Holzpflanzen mit Sternhaaren. Elaeagnaceae (S. 248).

2. Kräuter ohne Sternhaare. (Centrospermae p. p.)

+ Unterer Teil der trichterig-röhrigen Blh. nach der Bl. bleibend und als "Anthocarp " die Fr. umhüllend. Bl.stand von kelchblattartigen oder farbigen Hochb. umhüllt.

Nyctaginaceae (S. 157).

++ Blh. kein Anthocarp abgliedernd. Bl.stand nicht von Hochb. umhïillt.

$\odot$ B. gegenständig.

$\times$ Stb. unter sich frei. Caryophyllaceae p. p. (S. 159).

$\times \times$ Stf. unterwärts zu einer (oft "Pseudostaminodien" entwickelnden) Röhre verwachsen.

$\odot \odot$ B. spiralig.

Amarantaceae p. p. (S. 156).

$\times$ Blhb. trockenhäutig, meist gefärbt, unter sich frei. Stb. der Bl.achse eingefügt. Amarantaceae p. p. (S. 156).

$\times \times$ Blhb. krautig, meist grün, \pm verwachsen. Stb. der Blh. angewachsen.

B1. 2 (bei Berberidopsis 3) parietale Placenten.

a. Holzpflanzen. Bl. mit Discus.

a. Bl. achlamyd., in eingeschlecht. Kätzchen. Salicaceae (S.138).

F. Bl. homoiochlam. od. apetal, gestielt in traub. Bl.ständ.

I. Ohne Ranken u. Gynophor. co.Sa. Flacourtiaceae p. p. (S. 244).

II. Mit Ranken u. Gynophor. 5 Stb. Passifloraceae p. p. (S. 244).

b. Kräuter. Bl. apetal.

u. Bl. 8 .

I. Ohne Milchsaft. $2 \mathrm{Gr}$. Andröceum obdiplostemon.

Saxifragaceae p. p. (S. 186).

II. Mit Milchsaft. 1 Gr.u. N. $\infty$ Stb. Papaveraceae p. p. (S. 174). ¡. Bl. diöcisch, selten polygam.

Datiscaceae $(3 ; 5)$. 
Hanfähnl., diöcischeStaud. - IVstl. As. Datisca (2) cannabinaL. C1. Sa. an der Bauchnaht der Frb. oder an der Mittelwand des 2 -fächerigen oder an centralwinkelständigen Placenten des mehrfächerigen Frkn. sitzend.

a. Bl. achlamydeisch.

a. 7 und $\bigcirc \mathrm{Bl}$. in getrennten Kätzchen. Betulaceae (S. 142). ß. Bl. nicht in Kätzchen.

I. Bl. 8. [Fraxinus excelsior.] Oleaceae p. p. (S. 272).

II. Bl. eingeschlechtig.

1. Frkn. 3-fächerig.

Euphorbiaceae p. p. (S. 225).

2. 2 Frb.; Frkn. durch falsche Scheidewände in 4 Nüsschen zerfallend.

b. Bl. homoiochlamydeisch bez. apetal.

a. Bl. hypogyn.

I. Sa. orthotrop.

II. Sa. amphi- oder anatrop.

1. $\infty$ unter sich freie Frb. (Ranales p. p.)

+ Bl.achse verkehrtkegelig, auf der flachen Oberseite die 1-samigen Frb. eingesenkt. (Nelumbo.)

Nymphaeaceae p. p. (S. 164).

++ Bl.achse kurzconvex oder kegelig.

Ceratophyllaceae (S. 165).

$\odot$ Bl. spiralig oder, wenn hemicyclisch oder cyclisch, dann mehr als 3-zählig. Teilfr. Balgkapseln oder Nüsschen.

Ranumculaceae p. p. (S. 166).

$\odot$ Bl. 3-zählig-quirlig. Teilfr. beerenartig.

Laxdizabalaceae $(7 ; 11)$.

Schlingstrauch mit 3- bis 5-fingerigen B. - Japan.

Akebia (2) quinata (Thbg.) Dene.

2. Frb. im Frkn. verwachsen oder nur 1 Frb.

+ Frkn. 1-fächerig.

- Mit Nebenb. Blh. kelchartig. Meist 2-(selten 1-) schenkelige N. und 1 vom Gipfel herabhängende Sa. Oft Cystolithen.

$\uparrow \mathrm{Bl}$. in Büscheln oder einzeln. Ohne Milchsaft.

Ulmaceae (S. 146).

$\uparrow \uparrow$ Bl. in trugdoldigen Bl.ständen mit oft fleischiger erweiterter Rhachis. Mit Milchsaft. Moraceae (S. 147).

$\odot \odot$ Ohne Nebenb. Sa. an der Bauchnaht.

$\uparrow$ Blh. blumenblattartig. N. einfach. Proteaceae (S. 149).

$\uparrow \uparrow$ Blh. apetal. N. 3-schenkelig. Anacardiaceae p. p. (S.228). + + Frkn.2-bis 4-fäch. Sa. hängend, je 1-2. N. meist getrennt. - Geflüg. Nuss. B. gefiedert.[Frax. amer.] Oleaceae p.p. (S.272). $\odot \odot$ Spaltfr. oder Kapsel. B. einfach oder gelappt.

Rhaphe ventral. Coccenfr. Euphorbiaceae p.p. (S. 225). $\uparrow \uparrow$ Rhaphe dorsal. Fr. kapselartig. Buxaceae (S. 228). $\uparrow \uparrow \uparrow$ Rh. dors. 2 'Teilfr., geflüg. Nüssch. Aceraceae p.p.(S.231).

ß. Bl. perigyn.

I. B. gefiedert oder gelappt.

II. B. ungeteilt, ganzrandig.

Rosaceae p. p. (S. 192).

1. Kräuter mit kleinen Nebenb. Mehrere Frb. mit je $\infty$ Sa.

Lythraceae p. p. (S. 248).

2. Neist Holzgewächse. Nebenb. 0. 1 Frb. mit 1 hängenden Sa.

Thymelaeaceae p. p. (S. 247). 
$\gamma$. Bl. halb oder ganz epigyn.

I. Frkn. mehrfächerig.

1. In jedem Fach des Frkn. $\infty$ Sa.

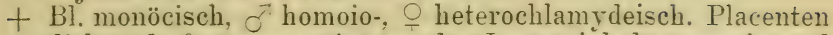
dick und oft \pm verzweigt aus den Innenwinkeln rorspringend oder teilweise wandständig.

++ Bl. \&. Placenten einfach centralwinkelständig.

C Stb. u. Gr. Gynostemium bildend. Aristolochiaceae (S.150).

- Stb. unter sich u. rom Gr. frei. Onagraceae p. p. (S. 253).

2. In jedem Fach des Frkn. 1-2 Sa.

+ Kräuter ohne Nebenb.

(-) B. einfach. Aizoaceae p. p. (Tetragonia) (S. 157).

$\odot$ B. doppelt zusammengesetzt. Adoxaceae $(1 ; 1)$.

Rhizom mit Niederb. Oberirdischer Stengel mit 2 gegenständ. Laubb. u. endständ., 5-(-7-) blüt. Bl.knäuel. Tragb. u. Torb. einen Scheink. bildend. Adoxa Moschatellina L. ++ Holzgewächse mit Nebenb.

(C) Blhb. meist frei. Fr. 2-fächerig, loculicid und septicid aufspringend.

$\odot \odot$ Blh. vereintblattrig. Fr. eine 1 -samige Nuss.

II. Frkn. 1-fächerig, mit 1 hängenden, anatropen Sa.

Fagaceae (S. 144).

Halor'rhagidaceae p. p. (S. 257).

II. Bl. heterochlamydeisch (wobei petaloide Aussenstaminodien bez. Honigb. als Blb. gerechnet werden und manchmal die Kih. ganz allmählich in die Blb. übergehen).

I'. Blkr. freiblättrig.

1. Sa. auf der Fläche der Frb. stehend.

A. Placenten wirklich auf der ganzen Blattfläche (ausser Mittelrippe). Tasserpflanzen mit $\doteq$ schildfürmigen, allermeist schwimmenden B.

Nymphaeaceae p. p. (S. 164).

B. Placenten der Anlage nach centralwinkelständig, durch nachträgliche Verschiebung scheinbar $\doteq$ an die Rüickenseite der Frb. gerückt. Landpflanzen mit nicht schildförmigen B.

a. Kräuter oder Halbsträucher mit fleischigen B. (ILsembrianthemum.)

b. Bäume mit laubigen $B$.

2. Placentation centralgrundständig.

A. $2 \mathrm{~Kb}$.

a. $2-\infty \mathrm{Sa}$.

b. $1 \mathrm{Sa}$.

Aizoaceae p. p. (S. 157, 158).

B. $4-5 \mathrm{~Kb}$.

a. Kräuter mit meist gegenständ. B. Caryophyllaceae (S. 159).

b. Kräuter mit quirlständigen B. oder Grundrosette.

Punicaceae ${ }^{1}$.

Droseraceae (S. 183).

c. Holzgewächse mit kleinen, oft ericoiden oder schuppenfürmigen, spiraligen $B$.

Tamaricaceae ${ }^{2}$ ) (S. 242).

3. Placenten die Ränder der Frb. einnehmend, wandständig. \pm vorspringend oder centralwinkelständig.

1) Weil in Knospen die Placenten noch $=$ centralminkelstindig sind, so finden sich die Prinicaceae später wieder erwähnt. (S. 133.

2) In Wirklichkeit sind hier die Placenten nur parietal-grundstiindig. (Vgl. S. 129, Zeile 1 von unten.) 
1'. Gynaeceum freiblättrig oder auf ein einziges Frb. reduziert.

A. Ganze Bl. spiralig; Blh. vielblättrig, meist ohne scharfe Grenze von K. und Blkr. Mit Oelzellen.

a. B. spiralig. Stamm ohne stammeigene Bündel. Bl.achse walzlich. Magnoliaceae p. p. (S. 165).

b. B. gegenständig. Stammeigene Bündel in der Stammrinde. Bl.achse becherförmig-ausgehöhlt. Calycanthaceae (S. 173).

B. Bl. hemicyclisch oder cyclisch; Blh. aus 2 (selten mehr) meist gleichzähligen, deutlich verschiedenen Kreisen gebildet.

a. Mit Oelzellen.

\%. $\infty$ Frb., meist spiralig. Stb. meist mit Längsspalten.

I. Bl.achse \pm walzlich-verlängert.

1. Nicht fleischige Sammelfr. Nährgewebe nicht zerklüftet. Magnoliaceae p. p. (S. 165).

2. Beerenartige Sammelfr. Nährgewebe zerklüftet. Anonaceae (46;700) (Anona).

II. Bl.achse \pm ausgehöhlt.

Monimiaceae (S. 174). 5. Ein einziges Frb. Sth. mit Klappen. Lauraceae (S. 174). b. Ohne Oelzellen.

a. Ohne Nebenb.

I. $\infty-2$ Frb.

1. Bl.achse \pm gestreckt. Frb. meist spiralig. Bl. deutlich hypogyn.

+ Oft mit Honigb. S. ohne Arillus.

Ranunculaceae p. p. (S. 166). ++ Honigb. fehlend. S. mit Arillus. Dilleniaceae p. p. (S. 240).

2. Bl.achse flach oder \pm ausgehöhlt. Frb. quirlig. Bl. \pm perigyn. Honigb. 0. $+\infty-3$ Frb.

(.) B. \pm dickfleischig, allermeist ganzrandig.

$\odot$ B. laubig, meist \pm gezähnt bis geteilt.

Crassulaceae (S. 184).

$\times$ Stauden oder aufrechte Sträucher. N. einfach, auf \pm langem $\mathrm{Gr}$.

$\times \times$ Schlingpflanzen. N. zerschlitzt, sitzend.

Rosaceae p. p. (S. 192).

Menispermaceae (S. 173).

$++2 \mathrm{Frb}$

II. 1 Frb.

1. $\infty$ spiralige Stb.

2. Stb. in 1-2 Quirlen.

+ Bl. hypogyn.

(- Bl. '2- bis 3-gliederig. Andröceum strahlig, alle Stb. fruchtbar.

$\odot \odot$ Bl. 5-gliederig. Andröceum zygomorph, \pm Stb. staminodial.

++ Bl. perigyn mit langröhriger Bl.achse.

Saxifragaceae p. p. (S. 186).

Ranunculaceae p. p. (S. 166).

Thymelaeaceae p. p. (S. 247).

3. Mit Nebenb.

I. Mit Honigb.

1. $\infty$ spiralige Stb. und Frb. Rammuculaceae p. p. (S. 166).

2. Stb. quirlig. 1 Frb.

Berberidaceae p. p. (S. 172). 
II. Ohne Honigb.

1. Bl. dichtgedrängt in langhängenden, kugeligen Köpfchen mit starkverdickter Rhachis.

Platanaceae (S. 192).

2. Bl. einzeln oder in mehr Jockeren Blütenständen, oder, wenn in Köpfchen, dann nicht mit stark verdickter Rhachis.

$+2-\infty$ Frb.

++1 Frb.

$\odot$ Blh. strahlig.

$\times$ Schliessfr.

Rosaceae p. p. (S. 192).

$\times \times$ Fr. eine Hülse. Meguminosa p. p. (S. 206).
$\odot \odot$ Blh. zygomorph. Meist Hülse. Leguminosae p. p. (S. 206).

Rosaceae p. p. (S. 192).

2'. Die $2-\infty$ quirlig stehenden Frb. werigstens im Frkn. \pm hoch oder vollständig verwachsen.

A. Bl. hypogyn.

A1. Blb. tief zerschlitzt. Frb. wenigstens nach der Bl. nicht ganz geschlossen.

B1. Blb. allermeist ungeteilt. Frb. ganz geschlossen.

a. Kb. in 1 oder 2 zwei- (selten im ersteren Falle auch drei-) zähligen Quirlen, Blb. in 1 vierzähligen Quirl. [Rhoeadales.]

a. 2 (selten 3) Kb.

ア. $4 \mathrm{~Kb}$. in 2 zweizähligen Quirlen.

Papaveraceae (S. 174).

I. Bl. streng strahlig. Discus fehlend oder in Form getrennter Drüsen. Gynophor fehlend. Cruciferae (S.177).

II. Bl. \pm zygomorph. Discus einen zusammenhängenden Ring bis Röhre bildend. Gynophor \pm deutlich.

Capparidaceae (S. 183).

b. Kb. quincuncial oder genau in einem 4-oder 5- (bei Elatine, Cneorum und Empetrum auch 3-) zähligen Quirl, Blb. in einem den $\mathrm{Kb}$. typisch gleichzähligen Quirl.

\%. Placenten parietal, wenn auch (bei den Guttiferae) oft weit bis zur Achse vorspringend. Knospendeckung des K. bei den Frankeniaceae klappig, sonst dachig. [Parietales.]

I. $\infty$ Stb. B. (wenigstens die untersten) gegenständig.

1. Ohne Discusdrüsen.

+ Keine inneren Drüsen. Drüsenhaare mit ätherischem Oel.

Cistaceae (S. 242). ++ Schizogene Secretbehälter bes. in Zweigen und B.

2. Mit Discusdrüisen.

Guttiferae (S. 240).

II. Androeceum diplo- oder haplostemon.

1. Gr. wenigstens oberwärts und N. frei. Mit kleinen B.

+ Sträucher oder Bäume mit spiraligen, oft schuppigen B. Placenten sehr tief parietal. Bl. in Trauben; Vorb. 0. Blb. ohne Ligulargebilde. Tamaricaceae ${ }^{1}$ ) (S. 242).

++ Stauden od. Halbsträucher mit gegenständigen Nadelb. Placenten an der Frkn.wand höher hinaufreichend; Sa. an langem Funiculus. Bl. in Dichasien; 4 Vorb. Blb. mit zungenförm. Spreitenverdoppelung innen am Scheinnagel. Frankeniaceae $(4 ; 34)$ (Frankenia, 31).

2. Gr. und N. verwachsen. B. laubig, spiralig.

1) Vgl. Seite 127, Zeile 3 von unten.

Niedenzu, Botanische Bestimmungsübungen. 
+ Bl. strahlig. Holzpflanzen mit rindenständigen, schizogenen Harzgängen, ohne Nebenb.

Pittosporaceae (S. 244). $++\mathrm{Bl}$. zygomorph. Kräuter ohne Harzgänge, mit Nebenb.

ß. Placenten centralwinkelständig.

Violaceae (S. 243).

I. Knospendeckung des K. klappig, die der Kr. oft gedreht. Häufig mit Sternhaaren bekleidet. [Malvales.]

1. Gr. getrennt. A. monothecisch. $\infty$ Stb. Malvaceae (S. 237).

2. Gr. und N. verwachsen. A. dithecisch.

$+\infty$ Stb. Knospendeckung d. Kr. verschieden. Tiliaceae (S. 236).

++ Andröceum diplostemon mit staminodialen Kelchstb. oder haplostemon. Blb. gedreht. Sterculiaceae (S. 239).

II. Knospendeckung von K. und Kr. dachig oder offen.

1. Androeceum $\infty$-gliederig.

+ Holzpflanzen.

$\odot$ S. mit Arillus.

T.) S. ohne Arillus.

Dilleniaceae p. p. (S. 240). Theaceae (S. 240). + Kräuter.

$\odot$ B. fiederig-zerteilt

Ranunculaceae p. p. (S. 166).

(•) B. kannenförmig, mit Deckel. Sarraceniaceae (S. 183).

2. Androeceum diplo-, obdiplo- oder haplostemon (einzelne Glieder manchinal staminodial oder abortiert).

+ A. mit \pm gipfelständigen Poren aufspringend; Androeceum obdiplostemon.

(•) Bl. strahlig. Kr. und Androeceum dem $\mathrm{K}$ isomer. Frb. mit sehr zahlreichen Sa. [Ericales p. p.]

$\times 3 \mathrm{Frb}$.

$\times \times 4-5$ Frb.

Clethraceae (S. 264).

$\uparrow$ Kräuter. Placenten im unteren 'Teile des Frkn. dickfleischigcentralwinkelständig, im oberen nur weitvorspringend wandständig.

$\uparrow \uparrow$ Holzpflanzen. Placenten einfach centralwinkelständig. Ericaceae p. p. (S. 265).

(-) Bl. zygomorph. Kr. und Androeceum oligomer. Frb. mit 1, sehr selten bis $4 \mathrm{Sa}$ Polygalaceae (S. 225). ++ A. mit Längsspalten aufspringend.

(-) Bl. rein strahlig. K. und Kr. 4-blättrig. Stb. typisch nur 2. Oleaceae p. p. (S. 272).

- - Androeceum isomer oder durch Abort oligomer.

$\times$ Sa. lyco-od. hemianatrop, hängend. Funiculus seitlich. Malpighiaceenhaare. Meist K.drüsen. Malpighiaceae (S. 224).

$X \times$ Sa. anatrop mit meist medianem Funiculus. Die übrigen Charaktere von $\times$ fehlend.

$\uparrow$ Septifrage Kapsel. Sa. etwa horizontal oder schwach aufsteigend mit seitlichem oder fast oberem Funiculus. Bl. durchgehends isomer 3-oder 4-zählig. Elatinaceae (S. 242).

$\uparrow \uparrow$ Nicht septifrage Kapsel. Sa. hängend oder aufsteigend mit medianem Funiculus. Bl. meist 5-zählig.

$\square$ Sa. meist hängend mit ventraler, selten aufsteigend mit dorsaler Rhaphe. [Geraniales.]

$\triangle$ Ohne Secretbehälter und allermeist ohne Discus.

$\sim$ Wenigstens die N. frei. Stf. ohne innenseitige Anhängsel. 
* Gr. vőllig oder zur Hälfte frei.

* Stb. frei.

¥ Androeceum obdiplostemon. Frkn. ohne falsche Scheide. wände. B. zusammengesetzt. Oxalidaceae (S. 221).

$\Varangle \Varangle$ Androeceum haplostemon. Frkn.fächer durch falsche Längsscheidewände halbiert. B. ‡l lineal. Linaceae (S. 222).

* * Stf. am Grunde zu einer kurzen Röhre verwachsen.

Erythroxylaceae $(2 ; 93)$.

Strauch mit spiraligen, ganzrandigen B. mit Intrapetiolarstipeln und unansehnlichen, griunlichweissen, einzeln- oder gebüschelt-achselständigen $\mathrm{Bl}$. Blb. mit 2spaltiger Schuppe. - Peru. Erythroxylon (92) Coca Lam. $\neq \neq$ Gr. verwachsen; N. frei.

* Bl. nicht gespornt. Fr. in nüsschenartige, grannenschnäbelige Teilfr. zerfallend.

Geraniaceae (S. 219).

* * Bl. durch eine Achsenaussackung gespornt. Teilfr. ungeschnäbelt.

Tropaeolaceae (S. 221).

舟 Gr. und N. verwachsen. Stf. mit innenseitigen Anbängseln.

Zygophyllaceae (S. 222).

Mit Secretbehältern und allermeist mit Discus.

B. ungeteilt.

+ Oelzellen im Schwamm-u.Rindenparenchym. Cneoraceae (12).

Sträucher mit spiraligen, lederartigen, ganzrandigen B. ohne Nebenb. und einzeln od. in T'rugdolden achselständigen, tetracyclischen (bei C. tricoccum 3·zähligen) Bl. - S.-WT.-Eur.

Cneorum (12) tricoccum L. $\neq \neq$ Lysigene Oeldrüsen im B.- und Rindenparenchym.

B. gefiedert oder 3-zählig.

Rutaceae p. p. (S. 222).

* Lysigene Oeldrüsen im B.- und Rindenparenchym.

Rutaceae p. p. (S. 222).

+ + Lysigene Oeldrüsen fehlend. Bisweilen schizogene Oelgänge im Mark. Rinde bitter. Simarubaceae $(30 ; 120)$. B. gefiedert, B.chen am Grunde jederseits mit 1-3

kleinen, drüsentragenden Läppchen. Bl. in endständiger Rispe. Flügelfr. - O.-As. Ailanthus (3) glandulosa Desf. $\neq \neq \neq$ Keine Drüsen, aber meist Secretzellen vorhanden. Stf. in eine Röhre verwachsen.

Sa. hängend mit dorsaler oder aufsteigend mit ventraler Rhaphe. [Sapindales.]

Gynaeceum isomer oder pleiomer.

Bl. strahlig. Frb. mit je 1 Sa.

$\neq$ Bl. 5̃-zählig. Androeceum diplostemon. Fr. in Nüsschen zerfallend.

* Sa. hängend.

Coriariaceae (Coriaria, 8). Kahle Sträucher; Zweige kantig; B. gegen- oder quirlständig, ganzrandig. Bl. klein, grünlich. - Westl. Mmght. C. myrtifolia L.

* * Sa. aufsteigend. Limnanthaceae $(2 ; 5)$. Saftige Kräuter mit fiederig eingeschnittenen B. und 5-zähligen Bl. Pac. N.-Am. Limnanthes (4) Douglasii R. Br. 
$\neq \neq$ Bl. 3-zählig. Androeceum haplostemon. Steinbeere.

Empetraceae $(3 ; 4)$.

Niederliegender, ericoider Strauch mit spiraligen B.; Bl. klein, zu 1-3 an schuppentragenden Kurztrieben, mit 6-9 Frb.

Empetrum (1) nigrum L.

$\sim \sim$ Bl. zygomorph. Frb. mit $\infty$ Sa. Kapselartige Fr. Androeceum haplostemon. Balsaminaceae (S. 233).

$\triangle \triangle$ Gynaeceum oligomer.

Androeceum isomer.

+ Meist Steinfr. mit harzreichem Mesocarp. Schizogene Harzgänge.

$\neq \neq$ Ohne Harzgänge.

Anacardiaceae p. p. (S. 228).

* Kapsel od.Beere. Celastraceae $\left.{ }^{1}\right)$ u. Staphyleaceae ${ }^{1}$ ), cf.S.133. * * 4- bis 8-kernige Steinfr. Blb. unter sich und mit den Stb. am Grunde etwas verwachsen. Aquifoliaceae ${ }^{2}$ ) (S. 229).

N Androeceum durch Abort weniger als diplostemon.

+ B. gegenständig.

* Bl. strahlig.

Aceraceae (S. 231).

* * Bl. schräg zygomorph. Hippocastanaceae (S. 232). $\neq \neq$ B. spiralig, unpaarig gefiedert. Sapindaceae (S. 233). B. Bl. peri- oder \pm epigyn.

a. Placenten parietal, manchmal sehr weit vorspringend.

a. Bl. spiralig. N. verwachsen. Cactaceae (S. 246).

ß. Bl. cyclisch.

I. 2 Frb.

1. Ohne Oeldrüsen. B. spiralig. Saxifragaceae p. p. (S. 186).

2. Mit Oeldrüsen. B. gegenständig. Myrtaceae p. p. (S. 249). II. $3-5$ Frb.

1. Bl. perigyn, mit Discus. Androeceum haplostemon. Gr. nur unterwärts verwachsen. Passifloraceae (S. 244).

2. Bl. epigyn, ohne Discus. $10-\infty$ Stb.

+ B1.8, mit Staminodien. N. verwachsen. Loasaceae (S. 245).

++ Bl. monöcisch. Gr. getrennt, meist gespalten; N. ein Schraubenband bildend.

Begoniaceae p. p. (S. 245).

b. Placenten centralwinkel-, bez. scheidewandständig.

a. Bl. ohne Discus.

I. Gr. \pm unter sich frei.

1. Ohne Nebenb.

$+\infty$ Sa. in jedem Fach an dicker, centralwinkel- oder scheidewandständiger Placenta. Saxifragaceae p. p. (S. 186).

$++1 \mathrm{Sa}$. in jedem Fach, von der Spitze des Innenwinkels herabhängend. Halorrhagidaceae p. p. (S. 257).

2. Mit Nebenb.

$+\infty$ Sa. an blattartigen Placenten. Begoniaceae p. p. (S. 245).

$++1-2$ einfach in den Centralwinkeln sitzende Sa. (selten $\infty$ in 2 einfachen Längsreihen).

○) 2 Frb., bei d. Reife loculicid u. zugleich septicid aufspringend.

1 (-2) hängende Sa. Hamamelidaceae p. p. (S. 191),

(-) Meist 5 (2-5) Frb., mit der Blitenachse eine saftige.

1) Diese Bl. sind eigentlich perigyn; vgl. unter B b f I S. 133.

2) Diess Familio ist wieder erwähnt unter den Sympelalae S. 134. 
geschlossene Halbfr. („Apfelfr. ${ }^{*}$ ) bildend. 2 aufrechte Sa. od. $\infty$ in 2 einfachen Längsreihen. Rosaceae p. p. (S. 192). II. Frb. in $1 \mathrm{Gr}$. und meist $1 \mathrm{~N}$. verwachsen.

1. Androeceum obdiplostemon (Vacc.Oxyc.). Ericaceae p.p.(S.268).

2. Androeceum nicht obdiplostemon.

+ 8 Stb., 5 Kb. Kein markständiges Leptom. Spaltfr.

Aceraceae p. p. (S. 231). ++ Stb. $\propto$ oder isomer. Markständiges Leptom. [IIyrtiflorae.] $\odot \infty$ Stb.

$\times$ Ohne Oeldrüsen. Placenten meist in $2-3$ Kreisen, später Etagen.

Punicaceae ${ }^{1}$.

$x \times$ Mit Oeldrüsen. Placenten in gewöhnlicher. Weise in 1 Kreise.

Myrtaceae (S. 249).

$\odot \odot$ Androeceum diplo- oder haplostemon oder oligomer.

$\times$ A. mit Längsspalten aufspringend.

$\uparrow$ Bl. perigyn. : Lythraceae (S. 248).

$\uparrow \uparrow$ Bl. epigyn. Onagraceae (S. 253).

$\times X$ A.mit Gipfelporen sich öffnend. Melastomataceae (S. 252).

3. Bl. mit Discus.

I. Discus hypo-, bez. peri- oder halbepigyn.

1. Androeceum diplostemon oder obdiplostemon.

$+\infty$ Sa. an dicker Placenta in jedem Fach. Stb. in 2 dem

K. (bez. Kr.) isomeren Quirlen. Saxifragaceae p.p. (S. 186). ++ Je 2 Sa. in jed. Fach. 5 Kb. ; 5 Blb.; 8 Stb. Aceraceae (S. 231).

2. Androeceum haplostemon.

+ Stb. vor den Kb.

○ Gr. unten getrennt. B. gefiedert. Staphyleaceae ${ }^{2}$ ) (S.231).

$\odot \odot$ Gr. verwachsen. B. einfach. Celastraceae ${ }^{2}$ ) (S. 230). ++ Stb. vor den Blb. [Rhamnales.]

(.) Steinfr. mit 1-5 einsamigen Kernen. Rhamnaceae (S. 233).

$\odot \odot$ Beerenfr.

Vitaceae (S. 234).

II. Discus epi-od.halbepigyn u. dann im Stengel markständ. Leptom.

1. Discus \pm ringförmig. [Myrtiflorae p. p.]

+ Bäume. $\infty$ Stb. Discus schlicht kreisringförmig.

- Placenten meist in 2-3 Kreisen, später Etagen. Mit markständigem Leptom, ohne stammeigene, rindenständige Bündel. B. gegenständig. Granatrote Bl. - Oestl. Mmgbt., Himal. Punicaceae $\left.{ }^{3}\right)(1 ; 2)$ [Punica (2) Granatum L.]

$\odot$ Placenten in gewöhnlicher Weise in 1 Kreise. Ohne markständiges Leptom, mit stammeigenen rindenständigen Bündeln. B. spiralig. Lecythidaceae $(18 ; 200)$. $\mathrm{Bl}$. in langen, überhängenden Trauben. $4 \mathrm{~Kb}$; $4 \mathrm{Blb}$.; Frkn. 2- oder 4-fächerig mit je 2-9 hängenden Sa. Fr. 1-samig. - Sundainseln. Barringtonia(30) insignis (Bl.) Miq. + + Schwimmendes Kraut. 4 Stb. Discus ein wellig-faltiger, gezähnelter, in der $\mathrm{Bl}$. halbepigyner Drüsenring.

Hydrocaryaceae $(1 ; 3)$ [Trapa (3) natans L.]

2. Discus \pm polsterförmig. 4 oder $5(-6) \mathrm{Stb}$. [Umbelliflorae.]

1) Da der Discus nicht immer doutlich herrortritt. sind dio Punicaceae auch hier aufgeführt. Vgl. unten, Zeile $35-38$ und S. 127, Zoile 13 von unten.

2) Vgl. S. 132 , Zeile 13.

3) V gl. oben, Zeile $10-11$ und S. 127, Zeile 11 von unten. 
+ Halbfr. eine gerippte Spaltfr. (selten Nuss). Gr. getrennt. Kräuter; B. gelappt oder \pm geteilt. Umbelliferae (S. 257). ++ Halbfr. beeren- oder steinfruchtartig.

$\odot$ Kräuter oder Klettersträucher. B. gelappt oder geteilt. Bl. 5-gliederig.

Araliaceae (S. 257).

$\odot \odot$ Aufrechte Sträucher. B. ganzrandig. Bl. 4-gliederig. Gr. verwachsen.

II'. Blb. \pm mit einander verwachsen.

1. Frkn. oberständig.

A. Frb. fast völlig frei, balgfruchtartig. Crassulaceae p. p. (S.184).

B. Frkn., meist auch Gr. und N. völlig verwachsen.

A1. 3-5 $(-\infty)$ Frb. Bl. allermeist strahlig.

A2. Androeceum obdiplostemon. [Ericales p. p.]

a. Alle Stb. fruchtbar, sehr selten einzelne abortiert. Hypogyner Discus. Gynaeceum isomer. Ericacene p. p. (S. 265).

b. Die 5 epipetalen Stb. staminodial. Discus 0. Gynaeceum oligomer.

Diapensiaceae p. p. (S. 269).

$B_{2}$. Androeceum haplo-, diplo- oder triplostemon.

A3. So viele Frkn.fächer als Frb. (bei einzelnen Solanaceae Frkn. durch falsche Scheidewände mehrfächerig).

A4. Knospendeckung der Blb. dachziegelig (oft quincuncial). A5. $\infty$ Sa. in den einzelnen Fächern. [Ericales p. p.]

a. Gynaeceum isomer. Hypogyner Discus.

b. Gynaeceum oligomer, 3-fächerig. Discus 0 .

Epacridaceae (S. 269). Diapensiaceae p. p. (S. 269).

B5. 1-2 (seltener einige) Sa. in jedem Fach.

A6. Androeceum diplostemon. Gr. lang. Einige Sa. in jedem Fach. Styracaceae p. p. (S. 272).

B6. Androeceum haplostemon. Gr. kurz oder fehlend. 1-2 Sa. in jedem Fach.

Aquifoliaceae ${ }^{1}$ ) (S. 229).

B. Knospendeckung d. Blb. gedreht od.gefaltet. [T'ubiflorae p. p.]

a. Knospendeckung der Blb. gefaltet.

u. Fr. coccenartig in die einzelnen Frb. zerfallend.

ß. Kapsel, nicht in Coccen zerfallend.

Nolanaceae (S. 289).

1. $\infty$ Sa. in jedem Fach. Solanaceae p. p. (S. 289).

II. 2 Sa. in jedem Fach. Convolvulaceae p. p. (S. 277).

b. Knospendeckung der Blb. gedreht. Polemoniaceae (S 278). B3. Frkn. 1-fächerig mit $\infty-1$ Sa. an der basilären oder freien Centralplacenta. [Primulales.]

a. Holzpflanzen mit steinfruchtartigen, 1-od. wenigsamigen Fr.

b. Stauden oder einjährige Sträucher mit Trockenfr.

Myrsinaceae (S. 269).

๘. $\infty$ Sa. an einem centralen Säulchen. Kapsel.

ß. 1 basiläre Sa. Kapsel oder Nüsschen.

Primulaceae (S. 269).

Plumbaginaceae (S. 271).

B1. 1 Frb. Androeceum diplostemon. Schmetterlingsbl. [Trifolium.]

Leguminosae p. p. (S. 206, 212).

$\mathrm{C}_{1} .2$ (selten 1) Frb. Androeceum haplostemon oder oligomer. 
A2. B. gegenständig. K., Blkr. und Androeceum strahlig. Knospendeckung der Blb. gedreht oder klappig (bei manchen Oleaceac und Loganiaceae dachig). ' [Contortae.]

a. 2 Stb.

b. Androeceum isomer.

Oleaceae (S. 272).

๑. Ohne Milchsaftschläuche, oft auch ohne inneres Phloëm.

I. Frkn. 2-fächerig; Placenten scheidewandständig.

Loganiaceae (S. 273).

II. Frkn. 1-fächerig; Placenten parietal. Gentianaceae (S. 273).

ß. Mit ungegliederten Milchröhren und innerem Phloëm.

I. A. lineal-länglich oder pfeilförmig, ohne äussere Anhängsel. Gr. verwachsen, unterhalb der glatten Spitze oder um sie herum mit ringförmiger N. Apocynaceae (S. 275).

II. A. mit Rüickenanhängseln (sterilen Hälften), die eine Nebenkr. bilden. Frb. nur durch den schildförmigen Gr.kopf zusarnmengehalten; N. am Scheitel. Asclepiadaceae (S. 275).

$\mathrm{B}_{2}$. B. spiralig; wenn B. gegenständig, danu Bl. (wenigstens im Androeceum) zygomorph. [Tubiflorae.]

a. Ohne Oelzellen.

๙. Kapsel, Beere oder Nüsschen.

I. Frb. diagonal. Gefässbündel bicollateral.

II. Frb. median. Gefässbündel collateral

Solanaceae p. p. (S.289).

1. Gewöhnl. Klappenkapsel, Beere od. Fr. in Nïssch. zerfallend. + Bl. 5-zählig-strahlig. B. spiralig.

- Bl. einzeln oder Bl.stand nicht wickelartig. Sa. in jedem Frb. 2 mit abwärts gekehrter Mikropyle.

Convolvulaceae p. p. (S. 277).

$\odot \odot$ Bl.stand wickelartig. Sa. je $\infty-2$ mit aufwärtsgerichteter Mikropyle. Hydrophyllaceae (S. 279).

$++\mathrm{Bl}$. (wenigstens im Androeceum) \pm zygomorph. Knospendeckung der Blb. dachig, meist cochlear ab-od. aufsteigend. B. oft gegenständig.

$\uparrow$ Frkn. 2- (bisweilen falsch 4-) fächerig mit scheidewandständigen Placenten.

$\odot$ Knospendeckung der Blb. aufsteigend.

Scrophulariaceae-Rhinanthoideae (S. 291, 294).

$\odot \odot$ Knospendeckung der Blb. absteigend.

S. mit Nährgewebe, meist ungeflügelt.

Scrophulariaceae p. p. (S. 291).

S. ohne Nährgewebe. 4 didynamische Stb.

* Ohne Staminodium. Holzgewächse mit häufig anomalem

Dickenwachstum des Stammes. Bignoniaceae (S. 300).

* * Fünftes Stb. ein kleines, pfriemeliges Staminodium.

( oder ausdauernde Kräuter. Pedaliaceae $(14 ; 45)$.

Bl. einzeln achselständig. Frkn. fast durchaus falsch

4-fächerig. - Palaeotrop. Sesamum (12) indicum I.

$\uparrow \uparrow$ Frkn. 1-fächerig nit $2 \pm z$ weispaltigen, \pm weit vorspringenden, wandständigen Placenten.

Knospendeckung der Blb. absteigend.

* Fr. durch die später vorwachsenden Placenten 4 - bez. 5 -kammerig. 
** Fr. rein einfächerig.

Gesneriaceae p. p. (S. 299). Knospendeckung der Blb. aufsteigend.

* Autobiotische, chlorophyllgrüne Gewächse.

Gesneriaceae p. p. (S. 299).

* Wurzelparasiten ohne Chlorophyll, mit Schuppenb.

Orobanchaceae (S. 298).

$\uparrow \uparrow \uparrow$ Frkn. 1-fächerig mit $\infty$ Sa. an freier Centralplacenta.

Utriculariaceae (= Lentibulariaceae) (S. 298).

$\uparrow \uparrow \uparrow \uparrow$ Frkn. mit 1 Sa. Fr. ein schiefes Nüsschen.

Globulariaceae (S. 300).

2. Fr. eine von der Spitze bis zum Grunde fachspaltige Kapsel mit zurückgekrümmten, in der Mitte die halben Scheidewände tragenden Klappen. In B. u.Stengel grosse, äusserlich als Striche od. Erhöhungen sichtbare Cystolithen. Acanthaceae (S. 300).

3. Fr. eine Deckelkapsel, selten Nüsschen. Bl. strahlig, 4-zählig. B. spiralig.

३. Fr. in (4) Klausen zerfallend oder Steinfr.

I. 5 fruchtbare Stb. Bl. allermeist strahlig. Klausen nüsschenartig.

II. 4 oder 2 Stb. fruchtbar.

1. Nüsschenartige Klausen.

Borraginaceae (S. 279).

2. Steinfruchtartige Klausen od. Steinfr. Verbenaceae (S, 282).

b. Mit Oelzellen. Steinfr. mit einem in einsamige Fächer geteilten Steinkern. Myoporaceae (5; 80) (Myoporum, 20).

2. Frkn. unterständig oder halbunterständig, völlig verwachsen.

A. Androeceum obdiplostemon. Ericaceae p. p. (S. 265).

B. Androeceum diplo- bis tetraplostemon.

A1. Placenten parietal oder \pm centralwinkelständig.

Styracaceae p. p. (S. 272).

B1. Freie Centralplacenta. [Samolus.] Primulaceae p. p. (S. 269).

C. Androeceum haplostemon iso- oder oligomer.

A1. Stb. unter sich frei, parallel oder oberwärts \pm divergent.

A2. Androeceum isomer. Bl. meist strahlig. [Rubiales.]

a. Nebenb. vorhanden (manchmal nur klein). Rubiaceae (S.301).

b. Nebenb. 0 .

Caprifoliaceae (S. 303).

B. Androeceum oligomer. Bl. zygomorph oder unregelmässig. [Aggregatae.]

a. Bl. meist zygomorph mit gewöhnlichem K. und einzeln mit Aussenkelch.

Dipsacaceae (S. 305).

b. Bl. unregelmässig, ohne Aussenkelch. K. zur Bl.zeit wenig deutlich, später vergrössert, als Haarkrone entwickelt.

Valerianaceae (S. 304).

$B_{1}$. Stb. unter sich (bes. in den A.) \pm verwachsen od. wenigstens mit den A. zusammenneigend. [Campanulatae + Gesneriaceae p.p.]

a. Bl. allermeist diklin. Stb. vom Grunde her \pm weit tri- bis monadelphisch verwachsen. Beere. Placenten von den Centralwinkeln weit in die Fächer zurückspringend.

Cucurbitaceae (S. 306).

b. Bl. allermeist $\xi$. Stf. frei ; A. zusammenneigend, verklebend oder verwachsend.

a. Frkn. 5- bis 2-fächerig, zuweilen durch Abort des 2. Frb. 1-fächerig. $\infty$ Sa 
I. Mit gegliederten Milchsaftschläuchen. Campanulaceae (S. 308).

II. Ohne Milchsaft.

1. Stb. nicht mit dem Gynaeceum verwachsen.

+5 gleichlange Stb. Gr. mit Pollenbecher unterhalb der N. ++4 didynamische Stb. Gr. ohne Pollenbecher.

Goodeniaceae (S. 310).

Gesneriaceae p. p. (S. 299).

2. 2 mit dem Gynaeceum verwachsene Stb. Candolleaceae (S.311).

3. $2 \mathrm{Frb}$. nur durch die beiden Gr.schenkel angedeutet. Frkn. 1-fächerig mit 1 grundständigen Sa. A. zu einer Röhre verwachsen. Bl. in Körbchen.

Compositae (S. 311).

\section{Saururaceae $(3 ; 4)$.}

A. Stb. 6 oder mehr. Frb. fast oder ganz frei mit je 2-4 Sa. Atl. N.Am.

Saururus (2) cernuus L.

B. Stb. 3. Frkn. 1-fächerig. 3-4 getrennte N. Placenten parietal. Unter der Aehre blumenblattartige Hochb. Japan.

Houttuynia (1) cordata Thbg.

\section{Piperaceae $(9 ; 1020)$.}

A. 2-5 getrennte N. Die äusseren Gefässbündel zu einem Ring vereinigt, die inneren frei in 1 oder 2 Kreisen. Nebenb. \pm entwickelt.

B. N. einfach. Alle Gefässbündel frei. Nebenb. fehlend.

Piper (600).

Peperomia (400).

\section{Juglandaceae $(6 ; 33)$.}

A. $\sigma^{7}$ und $\bigcirc \mathrm{Bl}$. ohne Blh. oder höchstens das hintere Blättchen der Blh. angedeutet. Frb. quer, N. median. ơ Kätzchen zu 3-9 auf gemeinsamem Hauptstiel. Mark der Zweige ungefächert. - Südöstl. Verein. Staaten. Hicoria [Carya] (10).

a. Knospenschuppen zahlreich, reitend, die inneren meist beim Aufbrechen stark vergrössert. Fr. am Grunde stets 4-, oben 2-fächerig.

๑. Tragb. der $\mathrm{Bl}$. etwa um die Hälfte bis dreimal länger als die Vorb. Aeussere Fruchtschale sehr dick, innere kantig oder mit Längsleisten.

I. Blättchen 5, ohne Sternhaare (Carya alba Nutt.)

II. Blättchen $7-9$.

H. ovata (Mill.) Britton

1. Triebe, Blattstiel und Spindel anfangs drüsig, später kahl; auch Unterseite der Blättchen ohne Sternhaare. (Carya sulcata Nutt.)

$H$. acuminata Dippel

2. Triebe, Blattstiel, Spindel und Unterseite der Blättchen sternhaarig-filzig. (Carya tomentosa Nutt.) H. alba (L.) Britton

$\beta$. Tragb. der $\sigma$ Bl. so lang als die Vorb. Aeussere Fruchtschale dünn, innere ohne Längsleisten. Blättchen 5-7, unterseits \pm zerstreut-drüsig und in den Aderwinkeln gebärtet, sonst kahl. (Carya porcina Nutt.) H. glabra (Mill.) Britton

b. Knospenschuppen höchstens 6 , in gekreuzten Paaren. Fr. am Grunde 2- oder 4-fächerig. 
$\because$ Blättchen 7-11 (5-13). Fr. am Grunde 4-fächerig.

1. Blattstiele kahl. Fr. am Grunde rundlich, Aussenschale nur bis zur Mitte 4-teilig, Innenschale ohne Längsleisten. (Carya amara Nutt.)

H. minima (March.) Britton

II. Blattstiele anfangs behaart. Fr. auch am Grunde plötzlich zugespitzt, Aussenschale bis zum G'runde 4-klappig, Innenschale mit starken Längsleisten. (Carya aquatica Nutt.)

H. aquatica (Mchx.) Britton

९. Blättchen 13-17. Blattstiel sternhaarig. Fr. 2 mal so lang als breit, Aussenschale bis zum Grunde 4-klappig, Innenschale glatt. (Carya olivaeformis Nutt.) H. Pecan (Marsh.) Britton

B. of und ㅇ Bl. mit Blh. Die beiden Frb. median. o' Kätzchen einzeln. Mark der Zweige quer gefächert.

A1. Die beiden Vorb. zur Blütezeit vom Frkn. frei, bei der Reife zu Flügeln auswachsend.

Pterocarya (4). † Kätzchen sehr lang, vielfrüchtig. Kaukas., Armen., W.-Pers.

$P$. fraxinifolia (Lam.) Spach

B1. Die beiden Vorb. bis oben hinauf mit dem Frkn. vereinigt, bei der Reife verkümmernd.

Juglans (8).

a. Aeussere Fruchtwand drüsenhaarig-klebrig, innere mit 2 seitlichen Scheidewänden, beide dick. S. am Grunde 2-lappig. Wenigstens 13 Blättchen, scharf gesägt, oberseits kurzhaarig. Nördl. atl. N.-Am.

$J$. cinerea $\mathrm{L}$.

b. Aeussere Fruchtwand kahl, innere am Grunde mit 4, oberseits 2 Scheidewänden. S. am Grunde 4-lappig.

๙. Blättchen meist mehr als 13, gesägt, unterseits weichhaarig. Stb. 20 - 30. Scheidewände der Fr. dick. Atl. N.-Am. J. nigra L.

$\beta$. Blättchen meist $7(5-13)$, unterseits in den Aderwinkeln bärtig, sonst kahl. 12-20 Stb. Scheidewände der Fr. dünn. Oestl. Mmgbt., Himal., Japan.

J. regia L.

\section{Myricaceae (Myrica, 32).}

a. B. tief fiederteilig, mit Nebenb. Vorb. in der $\mathrm{Bl}$. länger als der Frk., mit Knospen in ihren Achseln. N.-Am.

M. asplenifolia (L.) Baill.

b. B. ungeteilt, meist oberwärts gesägt, ohne Nebenb. Vorb. der o Bl. schuppenartig, ohne Achselknospen.

๙. Vorb. mit der Fr. verwachsen, an ihr Flügel bildend. M. Gale L.

$\beta$. Vorb. klein bieibend, nicht der Fr. anwachsend. Atl. N.-Am. M. cerifera L.

\section{Salicaceae $(2 ; 178)$.}

A. Discus becher- oder krugförmig. Stb. zahlreich. Tragb. der Bl. zerschlitzt.

Populus (18).

a. Schuppen und junge Triebe kahl und klebrig. Tragb. der Bl. durchscheinend berandet, kahl, selten sparsam gewimpert. Stb. $12-30$. N. meist sehr breit und kraus. Rinde rissig.

๙. Blattstiele seitlich zusammengedrückt. B unterseits grün. Aeste schlank, ledergelb, glänzend. 
1. Jüngere Aeste ohne Korkrippen, \pm rundlich. Frkn. meist 2-teilig.

II. Jüngere Aeste oft durch Korkrippen \pm kantig. Frkn. 3-bis 4-teilig.

1. Untere oder alle B. der Aeste am Grunde in einen rechten oder stumpf $\in \mathrm{n}$ Winkel vorgezogen. Nordöstl. N.-Am.

I?. canadensis Mönch

2. B. am Grunde gestutzt oder etwas herzförmig. Atl. N.-Am. P. monilifera Ait.

3. Blattstiele rundlich, oberseits rimnig. B. meist unterseits weisslich. Aeste kurz und dick. Atl. N.Am., Sibir

$P$. balsamifera $\mathrm{L}$.

b. Junge Triebe kurzhaarig. Blattstiele seitlich zusammengedrückt. 'Tragb. der Bl. zottig gewimpert. Stb. 4-8. Narbenäste kurz fädlich. Rinde lange glatt bleibend.

๑. Knospen grau oder weiss behaart, nicht klebrig. B grob und ungleich buchtig-stumpfzähnig, unterseits weissfilzig.

P. alba L.

Jnospen glänzend kastanienbraun, \pm klebrig. B. grob und ausgeschweift-stumpfgezähnt, meist bald völlig kahl.

P. tremula L.

B. Discus auf einzelne Zähne reduziert. Stb. meist wenige. Tragb. der Bl. ganzrandig.

Salix (160).

a. Tragb. der $\mathrm{Bl}$. fast stets einfarbig. In der $\mathrm{o}^{-3} \mathrm{Bl} \cdot 2(-6)$ Discuszähne. Stb. 2-5. Griffeläste transversal, Kätzchen mit den B. erscheinend, auf beblätterten Stielen.

ø. Grössere Sträucher oder Bäume. Blattstiele oberwärts meist mit Drüsenhöckerchen; B. elliptisch bis schmal-lanzettlich, zugespitzt, scharf oder drüsig gesägt; Nebenb. meist sehr deutlich. Gr. an der Spitze kaum oder bis zur Mitte gespalten. I. Tragb. der of Bl. hinfillig, meist auch in den $9 \mathrm{Bl} .2$ Discuszähne und dann junge $B$. meist klebrig.

1. Stb. $5(-3)$.

+ Blattstiel olıne deutliche Drüsenhöckerchen. B nichtklebrig.

B. der Laubzweige schmal, mehr als 5 mal so lang wie breit, B. der Blütenzweige ganzrandig. Stb. 5-3. In der q Bl. 1 Discuszahn. Atl. N.-Am. S. nigra Marsh. ++ Blattstiel mit sehr deutlichen Drüsenhöckern. B. höchstens 5 mal so lang als breit, auch die der Blütenzweige drüsig gesägt.

2. Stb. 2 .

S. pentandra L.

+ Zweige am Grunde leicht abbrechend. Blattstiel deutlich drüsenhöckerig. B. kahl, anfangs klebrig. In der $\mathrm{O} \mathrm{Bl}$. 2 Drüsen; Stiel des Frkn. 2- bis 3 mal so lang als die hintere Drüse.

$S$. fragilis $\mathrm{L}$. $++\mathrm{Zweige}$ nicht leicht abbrechend. Blattstiele ohne deutliche Drüsenhöcker. B. wenigstens anfangs seidenhaarig und nicht klebrig. In den $q \mathrm{Bl}$. 1 Drüse. Stiel des Frkn. kürzer als die Drüse oder fehlend. S. alba L. II. Tragb. der $\bigcirc \mathrm{Bl}$. bis zur Fruchtreife bleibend. In der $\bigcirc$ Bl. nur 1 Discuszahn. B. nicht klebrig. 
1. Stb. 3. Frkn. kahl, sein Stiel $3-5$ mal so lang als die Drüse. Aeste und Zweige aufrecht. S. amygdalina L

2. Sth. 2. Fruchtknotenstıel höchstens doppelt so lang als die Driise. Aeste und 'Zweige stark hängend. S. babylonica L. F. Kriechend oder niederliegend oder höchstens $1 \mathrm{~m}$ hoch. Blattstiele drüsenlos; B. rundlich bis verkehrt-eifürmig oder ellip. tisch, nicht oder kaum zugespitzt, ganzrandig oder gekerktgesägt. Nebenb. meist fehlend. Tragb. bleibend. Stb. '2. Gr. tief 2-ästig.

I. Niederliegend oder unterirdisch kriechend.

1. In den $q \mathrm{Bl} .1$ grosse hintere Drüse.

+ Kätzchenstiele end- und seitenständig. B. rundlich, ringsum gekerbt-gezähnt.

S. herbacea L.

++ Kätzchenstiele nur seitenständig. B. keilförmig, verkehrteiförmig, unterwärts undeutlich gekerbt-gesägt. S. retusa L.

2. In den $q \mathrm{Bl}$. die Drüse in 2 spreizende Abschnitte tief geteilt.

S. reticulata L.

II. Sträucher von ${ }^{1 / 2}$ bis $1 \mathrm{~m}$ Höhe. B. ganzrandig, beiderseits mit langen, feinen Zotten besetzt. Kätzchen seitenständig. Frkn. filzig.

1. Tragb. rotfarbig. Stielchen des Frkn. länger als die Drüse.

S. pyrenaica Gouan

2. Tragb. gelblich, mit rotbrauner Spitze. Stielchen des Frkn. kürzer als die Drüse.

S. glauca L.

b. Tragb. der Bl. meist am Grunde hell, an der Spitze rotfarbig bis schwärzlich, stets bleibend. In den of und $\mathrm{Bl}$. nur eine hintere Drüse. Stb. 2. Blattstiele ohne Drüsenhöckerchen.

o. Gr. verlängert, dünn. (Ausser bei S. Elacagnos) Stb. frei und Stf. kahl.

I. Gr.- (bez. N.-Aeste) quer (rechts und links).

1. Zweige nie bereift. B. nie besonders lang und schmal.

+ Niedrig, sparrig, oft dickzweigig. Stielchen des Frkn. fehlend oder sehr kurz, selten etwas länger als die Drüse.

$\odot$ A. nach dem Verblühen braun. Kätzchen zu mehreren gebäuft am Ende der Zweige auf langen, beblätterten Stielen. Junge Zweige kurz- oder mässig-behaart. B. später meist kahl.

S. Myrsinites L.

$\odot \odot$ A. nach dem Verblühen gelb. Kätzchen sehr kurz gestielt oder sitzend. Junge Zweige meist weisszottig. B. wenigstens unterseits bleibend filzig-zottig. S. Lapponum L.

++ Zweige schlank, kahl. B. später kahl. A. nach dem Verblühen gelb. Frkn. behaart.

- Stielchen 2-3 mal länger als die Drüse. S. bicolor Ehrh. $\odot \odot$ Stielchen kürzer als die Drüse. S. Arbuscula L.

2. Zweige lang, aufrecht, bereift; junge Zweige, Stiele und Unterseite der schmalen B. kreideweissfilzig.

+- Nebenb. ei- bis lineallanzettlich. Kätzchen gerade. Frkn. filzig. Nordöstl. N.-Am.

S. candida Flïgge

++ Nebenb. fehlend. Kätzchen gekrümmt. Stf. \pm verwachsen, bis zur Mitte zottig. Frkn. kahl. (S. incana Schrank). 
II. Gr.- (bez. N.-) Aeste median. Zweige schlank.

1. Zweige kahl, nie bereift. B. elliptisch bis lanzettlich, wenigstens später kahl. Stielchen $1 \frac{1}{2}-8$ mal so lang als die Drüse. Frkn. kahl. Kätzchen mit den B. erscheinend.

+ Stf.kahl. B. oberseits \pm matt; Nebenb.halbherzfg. S. hastata T. + + Stf. unterwärts zottig. B. oberseits glänzend; Nebenb. klein und nierenförmig oder fehlend. S. glabra Scop.

2. Zweige bereift oder die jungen filzig. Blattstiele \pm rötlich, Mittelrippe unterseits ockerfarbig bis gelblich. B. längiichbis lineal-lanzettlich. Stielchen kürzer als die Drüse oder fehlend. Kätzchen vor den B. erscheinend.

+ Zweige bereift, kahl oder doch zeitig kahl werdend. B. zeitig kahl werdend oder kahl, länglich-lanzettlich bis lanzettlich. Frkn. kahl. Innere Rinde im Sommer citrongelb.

$\odot$ Nebenb. halbherzförmig. B. länglich-lanzettlich. Zweige dick. $\odot \odot$ Nebenb. lanzettlich oder fehlend.

$S$. daphnoides Vill.

B. schmal-lanzettlich.

S. acutifolia Willd.

++ Zweige sammetartig-graufilzig. B. unterseits schimmernd seidenfilzig. Frkn. filzig, Innere Rinde grün, S. viminalis L.

3. Gr. kurz oder sehr kurz. N. ziemlich - sehr kurz, median.

I. Stielchen mindestens $2 \mathrm{mal}$ so lang als die Drüse. Stf. frei, (nur bei $S$. repens bisweilen bis $\mathrm{zu}^{1 / 3}$ verwachsen).

1. Kätzchen auf ansehnlichen, beblätterten Stielen. Frkn. und Stf. kahl.

S. myrtilloides L.

2. Kätzchen sitzend oder fast sitzend. Frkn. meist behaart.

+ Aufrechte Sträucher oder Bäume. Aeste nicht rutenförmig. B. ziemlich gross, meist gesägt oder gezähnt, unterseits grau, behart, oft filzig, (ausser bei $S$. Caprea) \pm verkehrteiförmig; Adern oben vertieft, unten vorspringend; Nebenb. gross. Kätzchen vor den B. am Grunde von 4-7 schuppenförmigen (bei $S$. livida grösseren, laubigen) Blättchen umgeben. Stf. am Grunde zottig; A. nach dem Verstäuben und N. gelb. Frkn. filzig.

$\odot$ B. von Anfang an oder doch zuletzt kahl. S. livida Whlbg. haart und grau.

$\uparrow$ 2-jährige Zweige und Knospen kahl oder nur schwach kurzhaarig, 1-jährige \pm kurzfilzig, meist bald kahl werdend. B. anfangs seidenglänzend-tilzig.

$\times$ B. verkehrt-eiförmig, zuletzt oberseits trübgrün, kurzhaarig, glanzlos.

$S$. aurita L.

$X \times B$. rundlich bis elliptisch, zuletzt oberseits, kahl, rein grün, etwas glänzend.

S. Caprea L.

$\uparrow \uparrow$ 1- und 2-jährige Zweige und Knospen filzig. B. anfangs glanzlos weisslich-filzig.

S. cinerea L.

++ Sträucher mit unterirdisch kriechendem Hauptstamm;

Aeste rutenförmig. B. klein, breit-oval bis lineal-lanzettlich: Nerven wenig deutlich; Nebenb. oft klein. Kätzchen mit oder kurz vor den B. erscheinend. Stf. kahl od. am Grunde sehr sparsam zottig, frei oder bis $1 / 3$ verwachsen. A. nach dem Verstäuben bräunlich. N. meist purpurn.

$S$. repens $\mathrm{L}$. 
II. Stielchen fehlend oder höchstens halb so lang wie die Drüse. Stf. bis zur Spitze, zuweilen auch die A. verwachsen. A. purpurn, nach dem Verstäuben schwärzlich. Frkn. filzig; N. purpurn. B. wenigstens unterwärts ganzrandig: Nebenb. fehlend oder sehr klein. B. lang und schmal verkehrt-eilanzettlich. 'Tragb. zottig.

S. purpurca L.

\section{Betulaceae $(6 ; 70)$.}

1. Bl. in Dichasien auf dem Deckb., mit Blh.; q Bl. ohne Blh., ihre Vorb. dem Deckb. angewachsen.

A. A. ungeteilt. Schuppen der Fruchtkätzchen 5-lappig. Alnus (14).

a. + Kätzchen in der Achsel von Laubb., nackt (wie das o) überwinternd. of Bl. mit deutlicher, 4-teiliger Blh. Seitenknospen gestielt, nur von den Nebenb. des 1. B. umschlossen.

a. Kätzchen fast stets einzeln. B. in der Knospe nicht gefaltet. Mmgbt.

ß. $q$ Kätzchen in achselständigen Trauben. B. in der Knospe längs der Seitennerven gefaltet.

I. B. stumpf, unterseits nur in den Nervenwinkeln gebärtet, sonst kahl. Zweige und Knospen klebrig. A. glutinosa Grtn.

II. B. spitz, unterseits grau, völlig oder nur an den Nerven kurzhaarig. Die sammetharigen jungen Zweige und Knospen nicht klebrig.

A. incana Willd.

b. O Kätzchen auf einem erst im Frühjahr sich entfaltenden, beblätterten Zweige; Kützchen nackt iiberwinternd. o Bl. mit freiblättriger, undeutlicher, oft unvollständiger Blh. Seitenknospen mit 1 ungeteilten Schuppe. Sitzend. A. viridis D. C. B. A. 2-teilig Schuppen der Fruchtkittzchen 3-lappig. Betula (35).

a. B. mit 10-14 fiederigen Paaren uberseits vertiefter Hauptseitennerven.

a. B. herzeiförmig, zugespitzt. Mittellappen der Fr.schuppen kaum länger. Junge Zwerge weichhaarig. Atl. N.-Am. B. lenta L.

$\beta$. B. aus abgestutztem bis stark herzförmigem Grunde breit 3-eckig mit abgerundeten Leken, zugespitzt. Junge Zweige kahl oder sparsam behaart. Mittellappen der Fruchtschuppen viel länger als seitliche. O.-As. B. ulmifolia Sieb. et Zucc.

b. B. mit höchstens $6-7$, oberseits nicht vertieften Hauptnervenpaaren.

a. Kätzchen an der Spitze von Langtrieben, frei überwinternd, hängend; o zuletzt meist hängend. B. spitz; ihr Adernetz mässig stark vortretend.

I. Junge Triebe drüsenlos oder nur mit ganz vereinzelten Drüsen, besonders die Langtriebe sammethaarig oder dicht kurzzottig, ältere oft ganz kahl. Alte B. dicklich, fast lederartig. B. pubescens Ehrh.

II. Junge Zweige mit reichlichen, warzigen Drüsen. Aeltere B. duinn.

1. Seitenlappen der Fruchtschuppen wagerecht oder zurückgebogen, Mittellappen kurz 3-eckig, höchstens so lang. wie breit, kürzer als die wagerecht gemessenen Seitenlappen. 


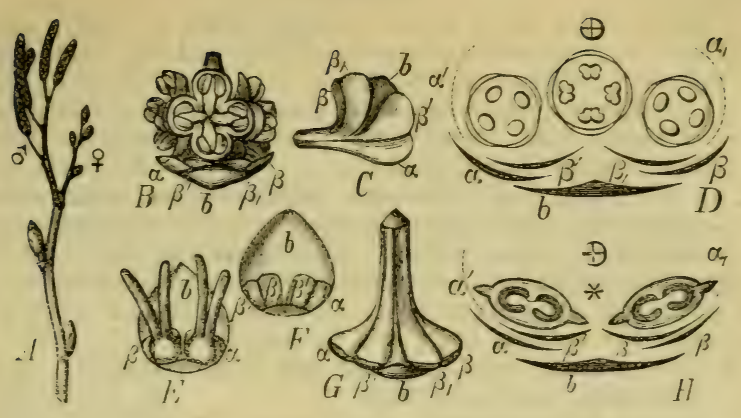

Fig. 10.

Alnus glutinosa L. A Winterzweig mit $\sigma^{-}$u. F Fätzchen: $B$ Grappo $\sigma^{7}$ Bl, ron oben, mit Deckl). $z$ u. Torb. der Jittelbl. ( $x$ u. 3 , die zugleich Deckb. der Seitenbl. sind) somie Vorb. der Seitenbl. ( $\xi^{\prime}$ u. $\left.\bar{\gamma}_{1}\right)$; $C$ Deckb. u. Vorb. von der Seite gesehen; $D$ Diagramm der Blütengruppe $B ; E \bigcirc$ Blïtengruppe ron innen (hinten) gesehen; $F$ dieselbe nach Wegnahme der Bl.; $G$ Terwachsungsprodukt der Schuppen (wie in $F$ ) bei der Frachtreife, ron oben gesehen; $H$ Diagramm ron $E$.

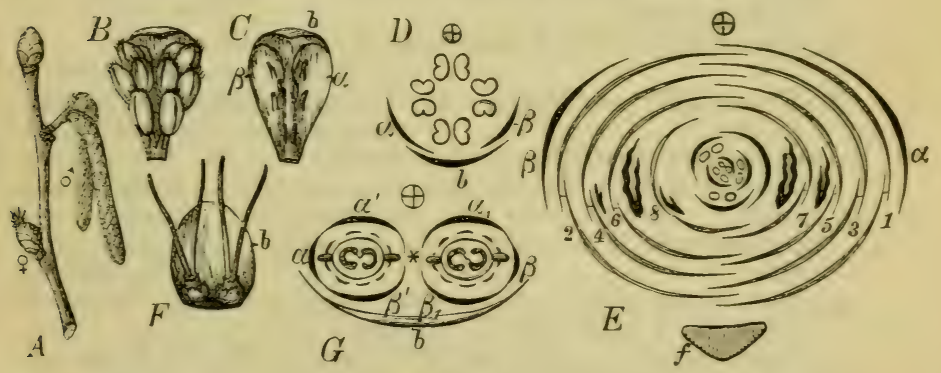

Fig. 11.

Corylus Avellana L. A Blütenzweig mit $=$ u. Fätzchen; $B$; Bl. mit Deckschuppe, ron oben (innen); $C$ dieselbe nach Wegnahme der A.; D Diagramm derseilen; $E$ Diagramm des $\bigcirc$ Gesamtblütenstandes; $F \bigcirc$ Blütengruppe mit Deckb., ron innen, etwas nach der Bestäubung; $G$ Diagramm ron $F$. [Bedeutung der Buchstaben wie in Fig. 10.]

+ Schuppen 5-7 mm lang. Flïgel 2-3 mal so breit wie die Fr. B. zugespitzt. B. pendula Roth (B. verrucosa Ehrh.). ++ Schuppen 2-3 mm lang. Flügel $1-1^{\prime \prime} 3$ mal so breit wie die Fr. B. sehr lang und fein zugespitzt. Atl. N.-Am.

B. populifolia Ait.

2. Seitenlappen der Fruchtschuppen schräg aufwärts bis aufrecht, kürzer als der Mittellappen, der länger als breit ist. B. eiförmig, spitz. 
+ Bäume, bis $25 \mathrm{~m}$ hoch. Zweige kahl. B. später unterseits in den Aderwinkeln meist gebärtet und oft auch längs der Nerven kurzhaarig. N.-Am. B. papyracea Ait. ++ Sträucher, bis $3 \mathrm{~m}$ hoch. Junge Zweige zerstreut behaart. B. später kahl, meist drüsig punktiert. Blattstiele meist über $1 \mathrm{~cm}$ lang. Nördl. O.-As. B. fruticosa Pallas

$\beta . \sigma^{\gamma}$ Kätzchen auf blattlosen Seitenzweigen (oder ausserdem endständig), von Knospenschuppen umgeben oder eingeschlossen, aufrecht; o kurz, aufrecht. B. meist stumpf, mit 2-4 Nervenpaaren und unterseits deutlich vortretendem Adernetz. Fruchtschuppen etwa gleichlang, seitliche aufrecht. Flügel selten mehr als halb so breit wie die Fr.

I. Zweige zeitig kahl, reichlich mit Drüsen besetzt. B. eirundlich, spitz oder stumpflich.

B. humilis Schrank

II. Zweige dicht sammet- oder kurzhaarig, mit lange bleibender Bekleidung, drüsenlos. B. fast sitzend, kreisrund oder quer breiter. Flügel mehrmals schmäler als die Fr. B. nana L.

2. $\sigma^{3}$. einzeln auf dem Deckb., ohne Blh.; 을. mit Blh., ihre Vorb. der Fr. als Hülle angewachsen. A. nebst Stf. 2-teilig, mit Haarschopf.

A. Frb. quer zum Deckb. gestellt. $\sigma^{\lambda} \mathrm{Bl}$. ohne Vorb. B. in der Knospe kahnförmig, nicht längs der Mittelrippe, sondern nur an den Seitenrippen gefaltet. Keimb. entfaltet. Blütezeit mit der Belaubung.

$A_{1}$. Fruchthïlle offen, 3-teilig oder tief gezähnt.

B1. Fruchthülle sackförmig, die Fr. einschliessend. Mmgbt. N.-Am.

Ostrya (1) virginiana Willd.

B. Frb. median zum Blütendeckb. gestellt. $\mathrm{Bl}$. mit 2 Vorb. B. in der Knospe an der Nittelrippe gefaltet. Keimb. nicht entfaltet. Blütezeit vor der Belaubung. of Kätzchen frei überwinternd, $q$ knospenförmig mit allein vorragenden, purpurnen N.

Corylus (7).

a. Becherhülle oben weit klaffend oder 2-klappig verengert, meist aus 2 getrennten $B$. gebildet.

a. Teile der Becherhülle in viele lange, schmale Zipfel zerschlitzt. Mmgbt.

C. Colurna L.

$\beta$. Teile der Becherhülle in kurze, breite, gezähnt-gesägte Zipfel zerschlitzt.

I. Schuppen der ơ Kätzchen grannenartig zugespitzt. Die 2-klappige Becherhülle doppelt so lang als die Fr. Atl. N.-Am.

C. americana Mill.

II. Schuppen der $\sigma^{\top}$ Kätzchen mit sehr kurzem Spitzchen. Becherhülle etwa so lang als die Fr. C. Avellana L.

b. Becherhülle besonders unterwärts dicht rostgelb steithaarig, unterwärts der Fr. dicht anliegend, dariiber in eine lange, enge Röhre ausgezogen. N.-Am. C. rostrata Ait.

\section{Fagaceae (j; 350).}

A. $\sigma^{\top}$ Kätzchen fast kugelig. $\quad \mathrm{Bl}$. in Dichasien in Laubblattachseln, zu 2 in vierteiligem Fruchtbecher. Seitliche (und einzelne) Fr. 3-kantig. Keimb. entfaltet.

Fagus (4). 
a. B. entfernt stark-gezähnt, jederseits mit 9-1t in die Zähne laufenden Nerven. Atl. N.-Am.

F. ferruginea Ait.

b. B. entfernt klein-gezähnelt, mit 5-9 Nervenpaaren. $F$. silvatica $L$.

B. Kätzchen verlängert, \pm unterbrochen. Bl. in Dichasier oder einzeln in den Achseln von Kätzchenschuppen. Fr. an den Seiten abgerundet. Keimb. nicht entfaltet.

A1. Kätzchen aufrecht. Bl. meist 3 in einer Hülle, mit meist je $6(3-8)$ Gr. Fruchthülle stachelig oder harthöckerig, schon zur Blütezeit deutlich, 3- bis t-klappig aufspringend.

- Nmgbt., China. Castanea (30) sativa Mill.

B1. Kätzchen hängend. Bl. stets nur 1 in einer Hülle. Gr. 3. Fruchthiille nipfchenförmig, abgestutzt. Fr. meist vorragend.

Quereus (200).

a. Abortierte Sa. in oberen 'T'eile der Fr. Gr. verlängert, vorn kopfig. Schuppen des Fruchtbechers angedrückt. Eicheln im 2. Jahre reifend, ihre Schale oft dickwandig, innen tilzig. B. an der Spitze und den Abschnitten mit feiner Borste. Atl. N.-Am. [Erythrobalanus, Black Oaks.]

๙. B. länglich bis lanzettlich, an älteren Bäumen ganzrandig (an ïppigen Trieben öfters mit einzelnen Zähmen), an der Spitze begramnt, mit lebhafter Herbstfärbung. [Phellos.]

I. B. länglich $(1: 3-5)$. Z anfangs sternhatrig. Q. imbricaria Mchx.

II. B. schmal (1:6). Zweige bald kahl. (?. Phellos L.

3. B. buchtig gelappt, mit \pm buchtig gezïhnten Abschnitten. im Herbst scharlachrot. [Rubrae.]

1. B. unterseits bis zum Spätsommer rostgelblich Hockig-sternhaarig, zuweilen zuletzt mit Ausnahme der Mittelrippe kahl. Knospen meist filzig.

Q. velutina Lam.

2. B. unterseits an den Nerrenwinkeln bärtig. sonst kahl. Knospen kahl.

+ Becher halbkugetig bis = Hach, am Grunde abgerundet. mehr allmählich in den Stiel verlaufend.

(.) B. seicht (höchstens bis zur Mitte) fiederspaltig. Q. rubra L. $\odot \odot$ B. tief fiederteilig. $\quad$ Q. coccinea Wgh. ++ Becher sehr flach, am breit abgestutzten Grunde schart gegen den beschuppten Stiel abgesetzt. B. tief fiederteilig.

Q. palustris Duroi

b. Aburtierte sia. im unteren Teile der Fr. Lichel dünnwandic, innen kahl. [Lepidobalanus.]

ฯ. Gx. pfriemelig, spitz. Becherschuppen gross, abstehend bis zurückgekrümmt, wenigstens die oberen linealisch und verlängert. Fruchtreife 2-jährig. Nimgbt. [Cerris.]

B. fiederlappig bis fiederteilig. Q. Cerris L.

F. Gr. kurz, abgerundet. Becherschuppen mässig gross oder klein, meist angedrückt, selten etwas locker.

L. B. I dick, lederartig, immergrün oder doch lange bleibend, ganzrandig oder stachelspitzig-gesägt oder -gezähnt. Mmght.

Q. Ilex L.

II. B. summergrïn, buchtig-gelappt oder lappig-gesägt mit spitzlichen bis stumpfen Abschnitten. 
1. Rinde hell, in dicken B. abschälend. B. hellgrün, oft bläulich, im Herbst orange, purpurn oder braun. Atl. N-Am. [Prinos, White Oaks.]

+ + B. aus meist keilförmigem Grunde \pm länglichverkehrteiförmig, grob stumpflich- und stachelspitzig-gezähnt, ohne Seitennerven nach den Buchten zu.

Q. Prinos L. ++ B. \pm tief-buchtig-gelappt, meist mit Seitennerven nach den Buchten.

(-) Becher zu $1-2$ auf $2^{1 / 2}-6 \mathrm{~cm}$ langem Stiel. B. unterseits weissfilzig mit ockergelben Nerven.

Q. bicolor Willd.

(.) Becher zu 1-3 sitzend oder auf höchstens $2^{1 / 2} \mathrm{~cm}$ langen Stielen.

$\uparrow$ B. unterseits mässig graufilzig.

Q. macrocarpa Mchx.

$\uparrow \uparrow$ B. unterseits zuletzt kahl, weisslichgrün mit gelblichen Nerven.

Q. alba L.

2. Rinde dunkel, tief rissig. B. oberseits meist dunkelgrün. [Robur.]

+ B. unterseits deutlich sternhaarig bis sternfilzig. Becher sitzend oder kurz gestielt.

(-) Becherschuppen ziemlich gross, länglich his lanzettlich, locker anliegend.

$\uparrow$ Blattbuchten höchstens bis ${ }^{1 / 3}$ der Spreitenhälfte eindringend, Lappen vom Grunde an verschmälert, länglich-dreieckig, in der Mitte am grössten, jederseits $(5-) 8-11$. Kauk., N.-Pers.

Q. macranthera Fisch. et Mey.

$\uparrow \uparrow$ Blattbuchten bis zur Mitte oder tiefer gehend; mittlere Lappen parallel-randig. stumpf, jederseits 5-9.

$\times$ Zweige etwas rauh, nicht dicht behaart. Blattstiele bis $3 \mathrm{~mm}$ lang. B. jederseits mit 7-9 Lappen. Ital., S.-O.-Eur.

Q. conferta Kitaibel

$\times X$ Zweige ziemlich dicht rostgelblich sternhaarig. Blattstiele $5-8(-15) \mathrm{mm}$ lang. B. jederseits mit 5-7 Lappen. S.-W.-Eur.

Q. Toza Bose.

$(\bullet)$ Becherschuppen klein, eilänglich, fest angedruickt. Zweige dicht filzig. B. jederseits mit $4-8$ abgerundeten Lappen.

(Q. pubescens Willd.) Q. lanuginosa Thuill.

++ B. zeitig ganz kahl (oder nur am Mittelnerv unterseits noch schwach behaart) oder unterseits sehr fein behaart.

( ) Becher einzeln oder zu wenigen auf sehr kurzem Stiel. Blattstiele (8-) $10-20 \mathrm{~mm}$ lang.

Q. sessiliflora Salisb.

(-) Becher auf langem Stiel einzeln oder zu 2-7 lockertraubig. Blattstiele selten bis $10 \mathrm{~mm}$ lang.

Q. Robur L.

\section{Ulmaceae (13; 130).}

A. Bl. meist in Büscheln in den Achseln ron Niederb. Frkn. flach. H'r. ein ringsum breit geflïgeltes Nüsschen. E. gerade, Keimb. der Länge nach zusammengefaltet. B. gesägt, fiedernervig. B. sommergrïn. Blh. verwachsenblättrig. Ulmus (16).

a. Bl.stiele höchstens $1^{t, 2}$ mal so lang als die Blh. Frkn. und Fr. am Rande kahl. [\$ Dryoptelea.] 
๘. Frkn. und Fr. auf der Fläche kahl. S.fach dem oberen Flügelrande genähert, mindestens $3 \mathrm{mal}$ so lang wie seine Entfernung: vom oberen Flïgeleinschnitt. Nerven auf der breiteren B.hälfte meist $9-11$.

$U$. campestris L.

¿. Frkn. und Fr. auf der Flächenmitte weichhaarig. S.fach in der Flügelmitte. Nerven $12-14(-16)$. Knospen mit fuchsrotem Filz aufbrechend. Nördl. atl. N.-Am.

$\tau$. fulva Michx.

b. Bl.stiele mehrmals länger als die Blh. Frkn. und Fr. dicht zottig. gewimpert. B. sehr ungleichseitig, meist scharf doppeltgesägt und zugespitzt. [§ Oreoptelea.]

๘. Einjährige Zweige dicht weichhaarig. A. purpurn. S.fach 2-3mal so lang wie seine Entfernung vom oberen Flïgelausschnitt.

j. Einjährige Zweige kahl oder zerstreut-behaart. A violett. S.fach den Flügelausschnitt fast berïhrend. N.-Am.

$U$. americana Mill.

B. Bl.stiele oder -zweige in den Achseln von diesjährigen B., wenigstens die $\delta$ einzeln in Laubblattachseln. Frkn. \pm kugelig. Fr. steinfruchtartig. E. gekrümmt mit quer gefalteten Keimb. A1. Blhb. getrennt oder nur wenig vereinigt. Gr. central. Fr. kugelig; Aussenschicht fleischig; Stein 士 grubig. B. am Grunde 3-, oberwärts fiedernervig, meist ungleichseitig.

Celtis (60).

a. B. unterseits auf der ganzen Fläche kurzhaarig. Bl. meist )-zählig; Abschnitte der Blh. breit. Gr. feinspitzig. Fr. kirschgross, bei Vollreife schwarz, mit süssem Fleisch. Mmgbt.

C. australis $\mathrm{L}$.

b. B. unterseits nur auf den Nerven kurzhaarig. Bl. meist 6-zählig; Abschnitte der Blh. schmal. Gr. stumpflich. Fr. erbsengross, bei Vollreife orange- bis rötlichbraun, nicht wohlschmeckend. N.-Am.

C. occidentalis $\mathrm{L}$.

B1. Blhb. fast ihrer ganzen Länge nach vereinigt. Gr. excentrisch. Fr. schief; Aussenschicht \pm häutig; Stein runzelig. B. gleichmässig fiedernervig, gleichseitig.

Zelkowa (4).

\section{Moraceae ( $\check{5} ;$; 900).}

1. Holzpflanzen. Cystolithen eiförmig oder kugelig oder (Dorstenia) fehlend.

I'. Stb. in der Knospe einwärts, in der Bl. zurückgebogen. B. in der Knospenlage gefaltet, mit meist kleinen Nebenb., die keine stengelumfassende N. zurücklassen. [Moroideae.]

1. Bl. in Scheinähren. -trauben oder -köpfchen; Bl.stände eingeschlechtlich.

A. Bl.stand eine kätzchenähnliche, o eine aufrechte Scheinähre. Fr.stand eine beerenartige Scheinfr. Morus (10).

a. N. rauhhaarig. B. am Grunde meist gleichseitig, derb, oberseits sehr, unterseits kurzhaarig rauh. Aeste hellrotbraun. Scheinbeere schwarzviolett. Vord.-As. M. nigra I.

b. N. nur mit kleinen Wärzchen besetzt. B. am Grunde oft ungleichseitig, hautartig. oberseits glatt oder etwas rauh. Aeste \pm grau. 
ฯ. B. unterseits meist sparsam kurzhaarig, bei der Entfaltung nicht weissfilzig. Scheinbeere rundlich oder eiförmig. weiss bis rötlich. A este graubraun. Mittl.u. O.-As. M. alba I. F. B. unterseits bei der Entfaltung weissfilzig, später weichhaarig. Scheinbeere walzlich, schwärzlichrot. N.-Am.

M. rubra L.

B. Bl.stände kugelige Scheinköpfchen, - O.-As.

Broussonetia (3) papyrifera (L.) Vent.

‥ Bl. beiderlei Geschlechts auf einem flachen Receptaculum.

Dorstenia $(50)$.

II'. Stb. stets gerade. B. in der Knospenlage eingerollt. Nebenb. meist eine stengelumfassende N. zurüicklassend.[Artocarpoideae.]

Receptacula kugelig oder verkehrt-eiförmig, hohl und auf der Imnenseite die Bl. tragend. - Mmgbt. Ficus (600) Carica L.

I1. Krïuter. Cystolithen spindelförmig. Stb. kurz, gerade. [Cannaboideae.]

A. Einjährig. Stengel aufrecht. B. gefingert. (. Bl. in ährigen Knäueln. Centr.-As.

Cannabis (1) sativa $\mathrm{I}$.

B. Mehrjährig. Stengel windend. B. 5- bis 7-nervig, herzförmig oder 3- bis 7-lappig.

Humulus (2).

a. Vorb. des Blïtenstandes mit Iaunulin-Drüsen reichlich besetzt. H. Lupulus L.

h. Torh. des Blütenstandes whe Iupulin-Drüsen. O.As. H. japonicus Sieb. et Zuce.

Urticaceac $(41 ; 460)$.

1. Mit Brennharen. [Urereae.]

A. B. gegenständig; Nebenb. frei (selten zwischen den Blattstielen vereinigt). N. pinselförmig. Schliessfr. gerade. Lrtiea $(30)$.

a. Blütenstände androgyn. Nebenb. zwischen den Blattstielen frei oder am Grunde vereinigt.

b. Blütenstände eingeschlechtlich.

a. Nebenb. getremnt oder nur etwas vereinigt.

1. Knïuel der Bl. Scheinküpfchen bildend, oft einzeln.

1. B. breit herzförmig, eingeschnitten gezähnt. Engld., Mmgbt. S.-As.

$U$. pilulifera $\mathrm{L}$.

2. B. ganzrandig, hier und da ausgebuchtet oder gezähnt. W. Eur.

II. Blütenknäuel in Aehren oder Rippen.

1. B. 3-teilig. Abschnitte fiederteilig oder doppelt-fiederteilig. Pers. Sibir.

$U$. cannabina $\mathrm{L}$.

2. B. eiförmig oder eilanzettlich, am Grunde herzförmig, verschieden gezälınt. Diöcisch.

$U$. diveca $\mathrm{L}$.

5. Nebenb. zwischen den Blattstielen vereinigt. B. eielliptisch, grobgezähnt. Cymen ährenähnlich. $T$. membranacea Poir.

B. B. spiralig; Nebenb. I vereinigt. N. linealisch, nur einseitig mit Papillen besetzi. Schliessfr. schief, glatt. - N.-Am.

2. Ohne Brennhaare.

Laportea (25) canadensis L.

1'. N. pinselförmig. Blh. der $\bigcup$ Bl. meist 3-teilig. B. gegenständig. die eines Pares meist ungleich und oft verschieden gestaltet.

Pilea (100). 
Proteaceae. - Loranthaceae. -- Santailaceae.

2’. \. nicht pinselförmig. Blh. der Bl. meist röhrig, seltener fehlend.

1". Vorb. niemals zu einem Involucrum vereinigt. [Bochmerieae.] - Staude; B. herzfürmig, zugespitzt, gezähnt, unterseits weisslich, mit Nebenb. O-As.

Boehmeria (45) nivea (L.) Hook, et Arn. 2". U' 'eilbliitenstände von Hochb. umschlossen. Blh. der $\mathrm{BI}$. frei. B. spiralig. |l'arietarieac.| - Staude: B. eilänglich, ganzrandig, ohne Nebenh. Parietaria (7) nfricinalis l.

\section{Proteaceae $(\check{0}) ; 960)$.}

I. Bl. meist paarweise in den tchseln der Tragh., welche auch bisweilen fehlen. Frkn. mit mehreren oder 2 umgewendeten Sa. Fr. mehr-bis 1-samig. meist anfspringend. [Grcrillcoirleae.]

1. Bl.stand ohne Involucrum oder dasselbe undeutlich. Frkn. meist mit 2 Sa. Fr. ohne Scheidewände zwischen den Sa. [Grevillecae.]

A. S. ungeflïgelt oder schmal gefliigelt. (ir. gewöhnlich lang und durch einen Spalt der Pühre der Blh. knieförmig hervortretend, mit dem scheiben-oder schiefkegelförmigen Ende fest geklemmt.

Grevillea (170).

B. S. mit langem, endständigem Flügel, (ir. nicht eingeklemmt. - W.-Austr.

Hakea (100) suaveolens R. Br.

‥ Bl.stand meist mit Involucrum. Fr. meist mit Scheidewänden zwischen den S. Frkn. mit 2 Sa. Tragh. der Bl. bleibend. [Banksieae.]

A. Aehre von Grund aus Bl. tracend, mit verlängerter oder stark gewölbter Achse.

Banksia (46).

a. Fr.ende nicht gestreift, N. klein. S.-O.-Austr. B. marginata Car.

b. (rr.ende kantig und gefurcht oder gestreift.

\%. Aehren scharlachrot. W.-Austr. $B$. coccinca R. Br.

P. Aehren gelb. O.-Austr.

B. Bl.stand ein Körbchen.

B. serrata L. f.

Dryandra (48).

II. Bl. einzeln in den Achseln der Tragh. Frkn. nur selten mit einigen oder 2 Sa. Fr. stets 1-samigr. Nuss oder Steinfi: [Persoonioideae.

Protea (60).

\section{Loranthaceae $(20 ; 500)$.}

I. Unterhalb der Blh. keine deutliche Calyculuswucherung. [Viscoideae.]

Viseum (50) album $\mathrm{I}_{\text {. }}$.

II. Unterhalb der Blh. ein Calyculus, d. i. eine \pm deutliche, ganzrandige oder gelappte oder gezähnte Wucherung der Bl.achse. [Loranthoideae.]

Lolanthus (200) europaeus L.

Santalaceae $(26 ; 250)$.

Liräuter, am Grunde oft holzig; B. spiralig. Bl. epigyn. Thesium 115 .

a. Unter jeder Bl, ein einziges Deckb. Zipfel der Blh. ohne seitliche Oehrchen. Fruchttragender Stengel mit einem Schopf unfruchtbarer Deckb. an der Spitze. 
\%. Wurzel kriechend.

T. ebracteatum Hayne

§. Wurzel abgebissen, vielköpfig. T. rostratum Mert. et Koch

b. Unter jeder Bl. 3 Deckb. Zipfel der Blh. jederseits mit einem Oehrchen.

\%. Blh. zur Fr.zeit röhrig, nur an der Spitze eingerollt, so lang oder etwas länger als die Fr.

I. B. schwach 3-nervig. Blh. 5-zipfelig. Fr.ästchen wagerecht abstehend, allseitswendig.

T. pratense Ehrh.

II. B. 1-nervig. Blh. meist 4-zipfelig. Fr.ästchen aufrecht abstehend, einseitswendig.

$T$. alpinum $\mathrm{L}$.

3. Blh. zur Fr.zeit bis auf den Grund eingerollt, viel kürzer als die Fr.

I. Wurzelstock kurz, nicht kriechend, ohne Ausläufer. B. lanzettlich, lang zugespitzt, meist 5-nervig. Pflanze dunkelgrün.

T. montanum Ehhrh.

II. Wurzelstock kriechend, mit Ausläufern. B. lineal, spitz, undeutlich 3-nervig. Pflanze gelblich grün. T' intermedium Schrad.

\section{Aristolochiaceae $(5 ; 200)$.}

A. Blh. regelmässig, glockig 3-spaltig. 12 Sth., auf dem Frkn. stehend, frei.

Asarum (13).

a. Blh. nur mit dem Basalteil des Frkn. vereinigt, mit starker Ringleiste am Schlunde ihrer Röhre. Japan. A. Thunbergii A. Br.

b. Blh. fast dem ganzen Frkn. angewachsen, ohne Ringleiste.

\%. B. glänzend, bis zum nächsten Frühjahr frisch bleibend.

A. europacum L.

F. B. unterseits weichlaarig, nicht ausdauernd. Atl. N.Am. A. canadense L.

B. Blh. unregelmässig, röhrig, am Grunde bauchig, 3-lappig oder 1-lippig. A. 6, dem Gir. unterhalb der N. angewachsen.

Aristolochia (180).

a. Saum der Blh. 3-lappig. Gr.säule an der Spitze 3-lappig. A. 6, paarweise genähert.

u. Klettersträucher.

I. B. kahl. Bl.stiele mit eiförm. Deckb. Atl. N.-Am. A. Sipho L'Hér.

II. B. unterseits filzig. Bl.stiele ohne Deckb. Südatl. N.-Am.

A. tomentosa Sims

j. Stauden mit aromatischer, faseriger Wurzel. Südatl. N.-Am. A. Serpentaria L.

b. Gr.säule an der Spitze 6-lappig. A. 6, gleichweit von einander abstehend. Saum der Blh. 1- (bez. 2-) lippig.

\% Fortsätze der N.lappen oberhalb der $\mathrm{A}$. eine ringartige, gekerbte Umwallung bildend. Mmgbt.

A. Clematitis L.

F. Ohne Ringwall oberhalb der A. Lippe in einen langen, linealischen Schwanz verlängert. Antillen bis Bahia. A. trilobata I.

\section{Polygonaceae $(30 ; 660)$.}

I. Bl. eucyclisch. Nährgewebe nicht zerklüftet. [Rumicoideae.]

1. Laubb. meist ohne Ochrea. [Eriogoneae.] Eriogonum (120).

2. Laubb. mit Ochrea. [Rumiceae.] 
A. Bl. 3-zählig.

A1. Fr. nicht gefliigelt.

A2. Blh. bei Frreife \pm häutig, weder röhrig verwachsen, noch die Fr. fest umschliessend. Rumex (100).

a. Bl.

a. Innere Blh.zipfel ohne Schwielen.

I. Blh.zipfel spitz.

II. Blh.zipfel stumpf.

R. alpinus L.

$R$. aquaticus $\mathrm{L}$.

$\therefore$ Einzelne oder sämtliche immere Blh.zipfel mit \pm grosser Schwiele.

I. Innere Blh.zipfel ganzrandig oder schwach gezähnt.

1. Innere Blh.zipfel lineal-länglich (fast doppelt so lang als breit), stumpf, 1 oder 2 mit Schwielen.

+ B. lanzettlich. Atl. N.-Am.

++ B. am Grunde herzförmig.

R. Brittanica L.

2. Innere Blh.zipfel eirundlich oder fast 3-eckig (so breit als lang), 2 oder 3 (selten nu 1) mit Schwielen.

+ Bl.stand beblättert. $R$. conglomeratus Murr. ++ Bl.stand blattlos.

- Innere Blh.zipfel an der Spitze breit gerundet, am Grunde \pm herzförmig-rundlich.

A B. flach, eilanzettlich, dümn.

R. Patientia L.

is B. am Rande kraus, länglich-lanzettlich, etwas dicklich.

$R$. crispus L.

- Innere Blh.zipfel vor der Spitze plötzlich verschmälert.

$R$. Hydrolapathum Huds.

II. Innere Blh.zipfel zur Fruchtzeit stark gezähnt.

1. 1 innerer Blh.zipfel mit grosser Schwiele.

$R$. pratensis Mert. et Koch

2. Alle 3 inneren Blh.zipfel mit Schwiele.

+ Bl.stand durchaus beblättert.

(๖) Innere Blh.zipfel länglich-eifürmig, länger als ihre Zähne. Bl.trauben unterbrochen. $R$. palustris Sm.

$\odot(\bullet)$ Innere Blh.zipfel länglich-rautenförmig, höchstens so lang als jhre Zähne. Bl.trauben dicht, unterwärts unterbrochen.

$R$. maritimus L.

++ Bl.stand oben blattlos.

$R$. obtusifolius L.

b. Bl. diöcisch oder polygam.

\%. Innere Blh.zipfel ohne Schwielen und Schuppen am Grunde.

I. B. schmal, lanzettlich oder spiessförmig-3-lappig.

R. Acetosella L.

II. B. breit, ei- oder spiessförmig-dreieckig. $R$. scutatus L.

F. Innere Blh.zipfel mit Schwielen oder Schuppen am Grunde.

I. Innere Blh.zipfel mit Schwielen.

$R$. vesicarius L.

II. Innere Blh zipfel mit Schuppen am Grunde. R. Acetosa L.

B.. Blh. bei Fr.reife derb, röhrig verwachsen, die Fr, einschliessend. Imgbt., S.-Afr., Austr. Emex (1) spinosa Campd. B1. Fr. 3-flügelig.

Rheum (20).

a. Bl.stände olnne laubige Bracteen.

\%. B. 3-nervig. S. Russld. bis Altai.

$R$. tataricum L.

3. B. 5- bis 9-nervig. Nepal.

$R$. australe Don 
b. Bl.stände mit laubigen Bracteen.

\%. B. ganzrandig

I. Bl. und Aeste purpurrot. B. eiförmig mit herzförm. Grunde. Himal.

II. Bl. gelb oder gelblich-weiss.

1. B. eiförmig mit herzfö:m. (rounde und starkwelligem Rande. O.-Sibir.

R. undulatum $\mathrm{L}$.

2. B. rundlich, am Grunde tief herzförmig. Rand gewellt. O.-Sibir.

R. Rhaponticum L

3. B. eingeschnitten oder gelappt.

I. B. eingeschnitten. Himal., W.-China. $R$. officinale Baill.

II. B. handförmig gelappt. IV.-China.

B. Bl. 2-zählig. Fr. flach, 2-flügelig. Arkt.-alpin.

11. Bl. acyclisch

Oxyria (1) digyna Campd.

I'. Nährgewebe nicht zerklüftet. [Polygonoideac.]

1. Sträucher oder Bäume. [Atraphaxideac.] Atraphaxis (17).

2. Kräuter, selten Halbsträucher. [Polygoneae.]

A. Keimb. nicht gefaltet, meist schmal. Polyæomum (150).

a. 2-3 (ir. Aeussere Blhb. nicht gekiclt. B. eiförmig. lanzettlich oder lineal.

a. Bl. blattwinkelständig. E. notorhiz. B. am B.stiel gegliedert; Ochrea trockenhäutig, 2-spaltig. P. avicularc I.

F. Bl. in endständigen Blütenständen. B.stiel nicht segliedert.

I. Keimb. schmal.

1. Bl. in einzelnen oder zu rispigen fiesamthl.ständen vereinigten Aehren.

+ E. notorrhiz. O.-Ind., Austr.. S.-Afrika. P. orientale I. ++ E. pleurorrhiz.

- Stengel ästig, jeder Ast mit 1 Aehre endigend.

Frkn. 3-teilig. China. P. tinctorium Lour.

$\hat{\uparrow}$ Frkn. 2-teilig.

Aehren fadenförmig oder dium linear. lockerhlütis oder unterbrochen.

Bl.stiele drüsig

P. Hydropiper L

Bl.stiele ohme Drüsen. Tuten lang gewimpert. * B. an der Basis verschmälert. P. mite Schrank * * B. an der Basis abgerundet. Aehren aufrecht.

P. minus Huds.

Aehren eiförmig, länglich. cylindrisch, nie farlenförmig, dichtblütig.

$\square$ Bl.stiele drüsig behaart.

Bl.stiele ohne Drüsen.

* Ochrea ohne Wimpern. 2 $\quad P$. amphibium L. * * Ochrea mit Winpern. (.)

P. lapathifolium Ait.

$\neq$ B. kahl. Ochrea langgewimpert. eng anliegend. P. Persicaria L.

$\neq \neq B$. unterseits drüsig punktiert. Knoten besonders stark angeschwollen. Scheiden locker, kurzgewimpert. $P$. nodosum Pers.

(C) Stengel meist einfach. Aehren dichtblütig. 21. 
A Aehre lang linear. am Grunde oft mit Brutknospen. B.stiele ungeflügelt.

$P$. viviparum $\mathrm{I}$.

^^ Aehre länglich, stumpf. B.stiele geflügelt. P. Bistorta L.

2. Teilbl.stände köpfchenförmig, länglich oder kugelig. Stengel mit rïckwärts gerichteten Stachelborsten. Japan.

P. Sicboldi Meissn.

II. Keimb, breit, Hach.

1. B. rauh oder glatt. Sibirien. P. Laxmanni Lepech.

2. B. kahl. Sibirien.

$P$. divaricatum $\mathrm{L}$.

b. 1 (tr. Aeussere Blhb. auf dem Rücken gekielt oder geflïgelt. B. 3-eckig, herz- oder pfeilförmig.

\% Neussere Blhh. anf dem Rücken bloss gekielt. B. herzpfeilförmig.

P. Convolvulus L.

F. Aeussere Blhb. auf dem Rücken geflügelt.

I. Windendes Kraut mit 3-eckig-herzförmigen B. P.dumetorum I,

II. Aufrechte Stande.

1. B. zugespitzt, nicht herzförmig. Japan.

P. cuspidatum Sieb. et Zucc.

2. B. herzförmig. Sacchalin. P. sacchalinensc F. Schmialt B. Keimb. breit, gefaltet. B. dreieckig nder herzförmig, 3- bis う-nervig.

Fagopyrum (2).

a. B. wenigstens so lang als hreit, mit stumpfen oder rundlichen Lappen. Stengel zuletzt meist rot. Fr. mit scharfen, ganzrandigen Kanten. Blh. weiss oder rötlich. Centralasien.

F. esculentum Mnch.

h. B. meist breiter als lang. Stengel grün bleibend. Fr. mit stumpflichen, ausgeschweiften Kianten. Blh. meist grïn. Centralasien.

F. tataricum (L.) Gärtn.

II'. Nährgewebe zerkliiftet. [Coccoloboideae.]

A. Blh. tief 5 -spaltig.

B. Blh. \pm hoch verwachsen.

Mnehlenbeckia (15)

Coccoloba (125).

\section{Chenopodiaceae $(73 ; 540)$.}

I. E. ring- oder hufeisenförmig, das Nährgewebe ganz oder teil. weise umfassend. [Cyclolobeae.]

1. Wurzeln und Stamm normal gebant. Bl. 2 , einzeln. Stb. 1-i) unten rereinigt. B. lineal oder pfriemelig. [Polycnemeae.]

Polyenemum (5).

a. Aeste dïnn, $\doteq$ niederliegend. Deckb. so lang als Blh.

b. Aeste dick, steif. Deckb. länger als Blh. $\quad P$. majus 1 .

2. Wurzeln und bei ausgiebigerem Dickenwachstum auch der Stamm anormal gebaut.

1'. Fr. bei der Reife oder Keimung mit einem Deckel sich öffnend. Bl. \&, proterandrisch, cymös. Stl, 1-i, unten vereinigt: N. kurz, meist breitlappig, innen papillös. [Beteae.]

A. Blh. mittelständig, bei der Fr.bildung am Grunde verhärtend.

Beta (6) vulgaris L.

B. Blh. unterständig, bei der Fr.bildung nicht verhärtend. Zweige kletternd. Kaukasus. Hablitzia (1) trmnoides M. Bieh. 
2. Fr. geschlossen bleibend, selten zerbröckelnd.

1“. Bl.stand knäuelig oder ährig. Stengel beblattert, nicht gegliedert.

1“'. Reife Fr. von Vorb. oder der Blh. eingehüllt. $1^{\prime \prime \prime}$. Bl. 8.

1“\%". Blhb. krautig und mindestens bis zur Mitte frei. B. breit, häufig spiesstörmig, mit Drüsen- oder Blasenhaaren. [Chenopodieac.] Chenopodium (60).

a. B. und \pm die Bl. mit Drüsenhaaren (einreihigen Köpfchenhaaren) bedeckt. S. horizontal.

\%. Köpfehen der Drüsenhaare keulig. Frkn. mit, Blhb. ohne Drüsenhaare. Blh. die Fr. einschliessend. Bl, in Knäueln. B. lanzettlich, entfernt gezähnelt. C. ambrosioides L.

\%. Köpfchen der Drüsenhaare kugelig. Blhb. mit, Frkn. ohne Driisenhaare. Blh. nach dem Abfall der Fr. meist an der Mutterpflanze stehen bleibend. Bl. in lockeren. am Ende wickeligen Dichasien. B. fast fiederspaltigbuchtig.

C. Botrys L.

b. Drüsenhaare fehlend, häufig sog. Blasenhaare (mit sehr kurzem Stiel und grossem, kugeligem Köpfchen) vorhanden.

\%. S. horizontal. E. ringförmig. Blh. an der Fr. krautig, grün oder vertrocknet.

I. B. ganzrandig.

1. Pflanze unbestäubt (d. h. ohne Blasenhaare), dunkeloder hellgriin, oft rot überlaufen. Untere B. \pm länglicheiförmig. Fr.hülle offen.

C. polyspermum L.

2. Pflanze mehlig bestaubt (d. h. mit Blasenhaaren), graugï̈n. B. breit-rauten-eiförmig. Fr.hiille geschlossen.

II. B. gezähnt.

C. Vulvaria L.

1. B. am Grunde gestutzt oder verschmälert.

+ B. glänzend, nicht oder nur anfangs mehlig-bestäubt.

( B Blstände ziemlich locker, in abstehenden kleinen Rispen.

C. murale L.

(•) Bl.stände geknäuelt, in aufrechten Scheinähren.

++ B. glanzlos, mehlig bestäubt.

C. urbicum $\mathrm{L}$.

(-) B. schwach gezähnt, eirautenförmig oder eilanzettlich.

$\odot$ B. breit-gänsefuss- bis spiessförmig. Peru. C. album L.

C. Quinoa Willd.

$(\odot \bullet$ B. tief eingeschnitten, \pm deutlich 3-lappig.

C. opulifolium Schrad.

2. B. eiförmig-3-eckig, am Grunde herzförmig, grob-buchtiggezähnt, nicht mehlig-bestäubt.

C. hybridum L

$\because$ S. vertikal, in den Endverzweigungen auch horizontal. E. unvollkommen ringförmig.

I. Blhb. krautig oder häutig bei der Fr.reife.

1. N. mässig gross, \pm aufsteigend. B. gezähnt.

+ B. glänzend, nicht oder nur anfangs mehlig-bestäubt. Stengel meist rot angelaufen. 
++ B. glanzlos, unterseits blaugrün und mehlig-bestäubt. C. glaucum $\mathrm{L}$.

2. N. sehr gross, wagerecht abstehend. B. ganzrandig, 3-eckig, am Grunde spiessförmig. Pflanze mehlig-bestäubt oder etwas klebrig.

C. Bonus Henricus L.

II. Blhb. an der Fr. saftig-Heischig werdend.

1. Stengel bis zur Spitze beblättert. B. \pm länglich-rautenförmig, eingeschnitten-gezähnt. Bl stände sämtlich in den Bl.winkeln, entfernt. S.-Eur. ('. foliosum March.) Aschs.

2. Stengel oberwärts nicht beblättert. B. 3-eckig, am Grunde gestutzt oder fast spiessförmig, meist schwach gezähnt. Ohere Bl.stände zu einer Aehre verbunden. S.-Hur. C. capitatum I.

¿“w" Blhb. membranös, gewöhnlich bis höchstens zur Mitte frei. B. meist schmal und durch lange Fadenhaare seidig. [Camphorosmeae.]

A. S. aufrecht; E. hufeisenförmig. Blh. bei der Fr.reife häutig bleibend.

Camphorosma (7).

B. S. meist horizontal; E. ringförmig. Blh. bei der Fr.reife = spongiös mit horizontalem Flïgel. S.-Eur., Asien. Kochia (30).

a. B. lineal-lanzettlich, gewimpert. Anhängsel der Fr.hülle sehr kurz, dreieckig.

b. B. pfriemelig-fädlich. Anhängsel der Fr.hülle fast rautenförmig, ungleich. $K$. arenaria Roth

$K$. scoparia Schrad.

2“". Bl. eingeschlechtlich. Bl. ohne Vorb., mit Blh., mit Vorb. und meist ohne Blh.. B. gewöhnlich spiessförmig, mit Blasen- oder Sternhaaren. [Atripliceae.].

A. B. kahl oder mit Blasenhaaren bedeckt. S. vertikal oder horizontal.

A. Vorb. an der Fr. kaum oder doch nie völlig verwachsend und verhärtend. N. 2 (selten 3). B. und Stengel in der Jugend mit Blasenharen, später durch deren Zusammenfalten oft mit einem grauen, scheinbar gleichmässigen Ueberzuge bekleidet.

Atriplex (120).

a. Stämmchen des E. unten, etwas nach oben oder nach der Seite umgebogen. Vorb. der O Bl. ei-rautenförmig oder 3-eckig. N. mässig lang. S. mit krustiger Schale.

a. 2 Arten von $\mathrm{Bl}$., solche mit $2 \mathrm{Vorb}$. ohne Blh. (S. vertikal) und solche mit Blh. ohne Torb. (S. horizontal). B. der Fr.hülle krautig, bis auf den Grund geteilt. am Blütenstielchen angewachsen.

I. B. oberseits glänzend, unterseits grau- od. weissschülferig. 3-eckig-eiförmig oder länglich. zugespitzt. Deckb. rauteneiförmig.

A. nitens Schkr.

II. B. glanzlos, beiderseits fast gleichfarbig, die unteren herz3-eckig, spitzlich, die mittleren lïnglich aus spiessförm Grunde. Deckb. eirundlich.

A. hortense $\mathrm{L}$

3. Sämtliche $9 \mathrm{Bl}$. ohne Blh., mit 2 nicht herablaufenden Vorb., die unterwärts mit den Rändern unter sich verwachsen und eine oberwärts gespaltene Tasche bilden. in deren Grunde die Fr. sitzt. (S. vertikal.) 
I. Vorb. nur am Grunde mit einander verwachsen, krantig, häutig oder schliesslich nur am frunde knorpelig.

1. Vorb. rhombisch-eiförmig. B. ahwechselnd. Obere B. einfach \pm lineal-lanzettlich, meist ganzrandig. A. patuhum L.

2. Vorb. \pm 3 -eckig. Untere B. oft gegenständig. Auch obere B. mit spiessförmigem Grunde.

+ B. und Vorb. ganzrandig oder kleingezähnt. A. hastatum I. ++ B. und Vorb. tief und pfriemelig zugespitzt-gezähnt. A. Calotheca (Schum.) Rfin. et Fr.

II. Vorb. bis über die Hälfte zusammengewachsen, bei der Reife bis zur Mitte knorpelig, weiss. Pflanze weissschülferig. A. roseum $\mathrm{I}$.

b. Stämmchen des E. weit nach oben emporgezogen. Vorh. der Bl. verkehrt-3-eckig. N. ziemlich kurz. Samenschale dïnn.

a. Vorb. an der Fr. nur unten verwachsen. A. sibiricum L.

3. Vorb. an der Fr. fast bis oben verwachsen. A.pedunculatum I,

Bi. Vorh, an der $\mathrm{Fr}$. bis zur Spitze verwachsen und verhärtet. N. 4-5. B. und Stengel kahl. - Or. Spinacia (2) oleracea I.

B. B. mit Sternhaaren. S. vertikal. - Span., Mähr., Russl. Himal. Eurotia (2) ceratoides (L.) C. A. Mey. 2"“. Reife Fr. nackt. [Corispermeac.] Corispermum (12). Blh. 2-blittrig. S.-Eur., Ctr. u O.-As., N.-Am. C. hyssopifolium L.

2“. B1. zu keuligen, zapfenähnlichen Bl.ständen angeordnet oder in Höhlungen scheinbar blattloser Zweige eingesenkt, proterandrisch. Vorb. fehlend. Blh. verwachsen. Stb. 1-2 B. kahl. hänfig gegenständig, paarweise verwachsen und den kurzen Internodien angewachsen. Zweige vielfach gegliedert. [Salicornicae.]

Salicornia (9) herbacea I.

II. E. spiralig gerollt: Nährgewehe durch den E. in 2 gesonderte Massen geschieden oder fehlend. [Spirolobeae.]

1. Vorb. klein, schiippchenartig. N. ringsum papillös. E. planspiral. B. kahl; keine Scheide von Sammelzellen um die Gefässbïndel. [Suaedeae.] Suacla (40) maritima (L.) Dum.

2. Vorb. so gross oder grösser als die Blhb. N. innen papillös. k. plan oder konisch-spiral. B. meist von Fadenhaaren bedeckt: um die Nerven eine Scheide von Sammelzellen. [Salsoleae.

Salsola (40) Kali I.

Amarantaceae $(40 ; 460)$.

I. Stb. 4-fächerig. [Amarantoideae.]

1. Frkn. mehrsamig. [Celosiene.] - Tropen. Celosia (35) argentea I.

2. Frkn. 1-samig. [Amaranteae.]

1. Sa. aufrecht, mit abwärts gerichtetem Stämmchen. $\mid A m r-$ rantznae.]

Amarantus (45).

a. Stengel aufsteigend oder niederliegend. Fr. nicht aufspringend. Bl. 3-zählig.

b. Stengel aufrecht. Fr. eine Deckelkapsel.

\% Blhb. so lang als die Deckb.

1. Hndständige Aehre hängend, vielmal länger als die seitlichen, alle stumpf. Blhb. länglich-eiförmig. stachelspitzig. A. candatus $\mathrm{I}$. 
Basellaceae. - Phytolaceaceae. - Nyetaginaceae. - Aizoaceae. 15T

II. Endständige Aehre aufrecht, nur etwa doppelt so lang als die seitlichen, alle spitzlich. Blhb. lanzettlich. A. paniculatus L.

$\therefore$ Blhb. halb so lang als die Deckb. Aehren kurz, die oberen zu einer sehr dichten, endständigen Rispe zusammengedrängt.

A. retroflexus $\mathrm{L}$.

2`. Sa. hängend; Spitze des Stämmchens aufwärts gerichtet. [Achyranthinae.]

A. Blhb hyalin-häutig, nicht dornspitzig.

B. Blhb. starr-lederig, dornspitzig.

II. Stb. 2-fächerig. Frkn. 1-samig. [Gomphrenoideae.]

A. 2 pfriemelige Gr. oder 1 Gr. mit $2-4$ pfriemeligen $\mathrm{N}$.

A. Freier Teil der Stf. pfriemelig, ganzrandig. Iresine (20).

B. Freier Teil der Stf. breit, gefranst, gezähnt oder 3-schnittig.

B. 1 Gr. mit kopfförmiger $\mathrm{N}$.

Gomphrena $(90)$. Alternanthera $(70)$.

Basellaceae $(5 ; 14)$.

A. Stf. unten stark verbreitert, in der hnospe gerade. L. spiraliy. Trop. Asien.

Basella (1) alba L.

B. Stf. fädlich-pfriemelig, in der Knospe gekrïmmt. E. halbkreisoder hufeisenförmig. Trop. Amerika.

Bonssingaultia (10) baselloides H. B. K.

\section{Phytolaceaceae $(22 ; 82)$.}

Bl. oder, wenn eingeschlechtlich, nit deutlichen Rudimenten von Stb. oder Frb. Blh. 4- bis 5-blisttrig.

Phytolacca (11).

a. Bl. diöcisch. K. derb. $\quad: 20-30 \mathrm{Stb}$; : $10-12$ freie oder nur am (irunde verwachsene Frb. Baumartig. S.-Am. $P$. divica I.

b. Bl. . K: zart, grün oder petaloid; 10 Stb., 10 zu 1 Frkn. verwachsene Frb. Krautartig, $\odot$ oder $\odot$. N.-Am. P. decandia I.

\section{Nyctaginaceate $(18 ; 160)$.}

A. Bl. doldenähnlich zusammengestellt, von 2-3 freien, lanzettlichen bis spateligen Hochb. umgeben.

Boerhavia ( 20 .

B. 1-3 (selten 5-10) Bl. dichtgenähert und von einer gememschaftlichen. kelchähnlichen, verwachsenblättrigen, 5- (selten 4 spaltigen, glockigen Hülle umgeben.

Mirabilis $(24$.

a. Blh. glockig, ohne Röhre. Hülle 2- bis 5-blütig. Anthocarp keulen- oder verkehrt-eiförmig, 5-rippig. grobhöckerig, verschleimt. Amerika. M. viscosa Cav.

b. Blh. trichterig, oft mit sehr langer Röhre. Hülle 1-blütig. Anthocarp nicht verschleimt. ellipsoidisch.

\% Bl. sitzend. Röhre sehr lang, zottig. B. fast sitzend, zottigklebrig. Mexiko.

M. longiflora L.

3. Bl. etwas gestielt, Röhre doppelt so lang als die Zipfel. B. gestielt. Mexiko.

M. Jalapa L.

Aizoaceae $(18 ; 420)$.

A. Blb.artige Staminodien 0. Fr. nuss- oder steinfruchtartig. Japan, Austr., Polynes.. S.-Am. Tetragonia (26) expansa Murr. 
B. Blb.artige Staminodien $\infty$. Fr. kapselartig, 5- bis $\propto$-klappig aufspringend. S.-Afr.

Mesembrianthemum $(300)$.

a. B. nicht mit Papillen besetzt.

a. B. \pm 3 schneidig, am Grunde nicht oder nur wenig mit einander vereinigt.

I. Gr. und N. 10-12. Bl. \pm gelb.

1. B. wenig verlängert, nach innen oder aussen gekrümmt, punktiert. Bl. gelb, am Grunde blutrot. M. tricolorum Haw.

2. B. sehr lang, unpunktiert. Bl. einfach gelb. M.pugioniforme L. II. Gr. und N. meist 5 (selten - 10). Bl. weiss oder rötlich, gross. B. \pm sichel- oder säbelförmig.

1. Bl. einzeln. Stengel aufrecht oder niederliegend.

+ B. mit glatten Kanten.

M. acinaciforme $\mathrm{L}$.

++ B. mit gesägten Kanten.

2. Bl. zu 2 oder 3. Aeste aufrecht.

(.) B. verlängert, spitz. Bl. hell rosarot. M. blandum Haw.

(.) B. etwas vereinigt, allmählich verschmälert. Bl. purpurrot. M. spectabile Haw.

¡. B. linealisch, rund oder halbrund. Bl. scharlachrot.

I. Stengel aufrecht.

II. Stengel ausgebreitet niederliegrend.

M. coccineum Haw.

b. B. mit Papillen besetzt.

\%. B. rund, halbrund oder zusammengedrückt.

I. 1-jähriges Kraut. Bl. sitzend, axillär. Auch Canaren, Mmgbt. u. arab.-ägypt. Wüste.

II. Ausdauernde Kräuter oder Halbsträucher.

1. Aeste mit Borsten bekleidet. Bl. rosa. Stb. spreizend.

2. Aeste glatt

M. floribundum Haw.

+ B. stachelig oder rauhhaarig.

II. echinatum Ait.

+- B. rauh punktiert. Bl. violett, gestielt; Blütenstiel mit Bracteen.

M. violaceum D.C.

ß. B. flach.

I. Gr. und N. 5.

1. B. herzförmig. Blb. purpurn.

M. cordifolium L.

2. B. spatelförmig oder ei rhombisch. Blb. weiss. Auch Canar., Mmgbt., Austr., Kaliforn.

M. crystallinum L.

3. B. lineal, stumpf. Blb. glänzend grünpurpurn, am Grunde weiss

4. B. leierförmig-fiederspaltig.

M. pyropaeum Haw.

M. pinnatifidum L.

II. Gr. und N. 10-20. Auch Austral. Bl. gelb. M. pomeridianum L.

\section{Portulacaceae $(17 ; 145)$.}

A. Frkn. oberständig.

A1. Frkn. mit sehr zahlreichen Sa. a. Stengel fast blattlos, einfach. B. stumpf, in eine Rosette ge-
stellt. Blkr. rot. Vancouver.

b. Stengel beblättert, halbstrauchig, verzweigt. B. spitz oder spitzlich.

๘. B. spatelig-lanzettlich, oben meergrün, unten purpurrot. Blkr. hellpurpurn. Chile.

C. discolor Schrad. 
¿. B.rautenförmig. meergrün. Blkr. rosa. Chile. C'.grandiflora Lindl. $B_{1}$. Frkn. mit wenigen, nicht mehr als 5 Sa.

A2. 5 Stb. Blb. frei oder nur am äussersten Grunde vereinthlättrigr. -- Pacif. N.-Am. bis Kuba. Claytonia (20) perfoliata Don B2. 3 Stb. Blkr. vereintblättrig.

Iontia (2).

B. Frkn. halbunterständig oder unterständig. Stb. und Sa. zahlreich.

Portulaca (20).

a. B. länglich-keilig orler verkehrt-eiförmig, beiderseits flach. fleischig. Bl. gabel- oder zu $1-3$ blattwinkelständig. Blh. kïrzer als die $\mathrm{Kb}$. $P$. oleracea $\mathrm{L}$.

b. B. lineallanzettlich, spitz. oberseits flach, unterseits gewölbt. $B l$. in endständigen Knäulen. Blb. vielmals länger als die Kl. Brasil. $P$. grandiflora Hook.

\section{Caryophyllaceae $(70 ; 1300)$.}

I. K. vereintblättrig. Blb. und Stb. hypogyn, häufig einem stielförmigen Internodium aufsitzend. Gr. frei. [Silenoideae.]

1. K. fast immer mit Commissuralrippen. Blb. in der Kinospenlage wechselwendig. [Lychnideae.]

A. Fr. eine mit Zähnen aufspringende Kapsel.

A1. Gynaecum isomer; Frb. mit den Krb. abwechselnd; N. ringsum behaart. Nagel der Blb. 2-flügelig. Ag'rostemma (2) Githago L.

$\mathrm{B}_{1}$. Frb., wenn isomer, vor den $\mathrm{Kb}$. stehend; sonst Gynaeceum oligomer.

A2. Kapsel am Grunde mehrfächerig.

A3. Kapselzähne so viel als N. Stengel unter den Knoten klebrig. K. mit deutlichen Commissuralnerven.

Viscaria (5) viscosa (Gilib.) Aschers.

B3. Kapselzähne doppelt so viele als $\mathrm{N}$.

Silene $(300)$.

a. Knospenlage der Blb. imbricat. K. zur Bl.zeit aufgeblasen. rerbreitert, 10-bis 20-nervig. [Behen.] S. renosa (Gilib.) Asch.

b. Knospenlage der Blb. abwechselnd gedreht. K. zur Bl.zeit nicht aufgeblasen.

». K. zur Fruchtzeit aus verbreitertem Grunde kegelig, 20- bis 60-nervig. [Conosilene.] - Mmgbt. S. conica L

3. K. 10-nervig. [Eusilene.]

1. Bl. in \pm zusammengesetzten Dichasien, deren Zweige gleich oder ungleich, der eine bisweilen auf 1 Einzelb]. reduciert. Pflanze bisweilen 1- bis wenigblütig. [\$ Dichasiosilene.]

1. Stengel reichblütig.

$+5 \mathrm{~N}$.

(-) Frk. oben nicht zusammengezogen S.-W.-Eur.,Algier.

S. laeta (Ait.) A. Br.

K. oben zusammengezogen, zwischen den Nerven tief gefurcht. Westl. Mmgbt. S. Coelirosa (L.) A. Br. $++3 \mathrm{~N}$.

$\odot$ Pflanze kahl. Stengel oberwärts unter den Knoten klebrig. B. eiförmig. bläulichgrün. K röhrig-keulig. Blb. blasspurpurn.

S. Armeria L. 
(-) Stengel und Bl.stiele kurzrauhharig. Untere B. spatelig, obere lineal. Frk. oben zusammengezogen. S. linicola Gmel.

2. Stengel 1-bis 3-blütig. K. glockig. 3 N. S. acaulis L.

II. Bl. in einfachen Wickeln. [S Cincinnosilenc.] - Blb. ungeteilt, verkehrt-eiförmig. s. nierenfürmig, nicht geflïgelt. Mmgbt.

$S$. gallica I.

111. Bl. in einfachen oder verzweigten 'T'rauben, mit kurzen oder verlängerten Aesten; bisweilen Bl.stand quirlig oder küpfchenförmig. [\$ Botryosilene.]

1. Bl.stiele am Grunde mit 2 Vorb. Blb. olıne Schlundschuppen. - Blb ungeteilt, linealisch, grünlich. Diöcisch. S. Otites(L.) Sm. + + Blb.2-spaltig, weisslich. Sibir., östl. Eur. S. tatarica (L.) Per's.

2. Bl.stiele sehr lang, mitten oder oben mit 2 Vorb.

+ Bl. aufrecht. Blb. ohne Schlundschuppen. Mmgbt.

S. italica (L.) Pex's.

++ Bl. nickend. Blh. mit Schlundschuppen. S. mutans L. B\%. Kapsel völlig einfächerig.

A3. Kapselzähne so riel als $\mathrm{N}$. Blb. gedreht. S'. nicht gebiirtet. Lychnis (10).

a. Blb. mit flach aufitzendem Krönchen, \pm rosenrot. Fr. etwas gedreht.

$\%$ K. mit ungleichstarken Rippen und gedrehten Zähnen. Blb. ungeteilt. Habitus wie bei L. Flos Jovis. S. u. S.-O.-Eur.

L. Coronaria (L.) Lam.

\%. K. mit gleichstarken Rippen und ungedrehten Zähnen. Blb. geteilt.

1. Pflanze dicht seidenartig-weisstilzig und zottig. K. lederig. Blb. 2-spaltig. Centr.-Alpen. L. Flos Jovis (L.) Desr.

11. Stengel von ruickwïrts angedruickten Haaren rauh. K. krautig. Blb. 4-spaltig.

L. Flos cuculi L.

h. Blb. geteilt mit einem auf einer hohlen Wölbung stehenden Krönchen, meist scharlachrot. Fr'. nicht gedreht.

\% Blb. 2-teilig, oft noch mit einem weiteren Zahn auf jeder Seite. Pflanze ziemlich kahl. Bl. zu vielen in Büschelı. Sibir., M.- u. S.-Russl.

L. chalcedonica L.

ऽ. Blb. dentlich t.teilig. P'flanze filzig. Bl. zu 2-3. Sibir

B3. Kapselzïhne doppelt so viel als $\mathrm{N}$.

L. fulgens Fisch.

At. S. an Ruicken 2-reihig höckerig. Gbg. v. S.- u. M.Eu.

B. S. höckerig.

Heliosperma (5) quadrifidum (L.) Rehb.

a. Bl. \&. Fr. 3-zählig.

b. Bl. diöcisch. Fr. 5-zählig.

\%. BI. weiss (selten hellrosa). Stengel oherwärts und Bl. stiele drüsig-weichhaarig. M. album (Mill.) Geke.

\%. Bl. hellpurpurn. PHanze drüsenlos. M. rubrum (Weig.) Geke. B. Fr, eine Beere.

Melandeyum (60).

M. noctiflorum (L.) Fr.

Cncubalus (1) baccifer L.

‥ K. ohne Commissuralrippen. Blb. in der Knospenlage gedreht. [Diantheac.]

A. Kb. nicht durch trockenhäutige Streifen verłunden.

A1. Blkr. ohne Ligularkrönchen. 
A2. Ohne Hochb. unterhalb der Bl. K. 15- bis 25-rippig. E. gekrümmt. Vaccaria (3) segetalis (Neck.) Geke.

B.. Enterhalh der Bl. meist begrannte Hochb. K. vielrippig. E. gerade.

Dianthus ( 230 ).

a. Bl. einzeln oder zu 2 (selten mehr). Blb. gezähnt oder fransig-gewimpert. Gynophor etwas verlängert.

๙. Blb. gezühnt, unbebärtet. W.-Frankr., Ital., Dalmatien.

3. Blb. gezähnt, schwach gebärtet. D. Caryophyllus L.

I. 4-6 kurzgestielte, stumpfe Hüllb., nur ${ }^{1}$ \& so lang als die K.röhre.

D. caesius $\mathrm{Sm}$.

II. - langbegrannte Hüllschuppen. mit der Granne halh so lang als die K.röhre.

D. deltoides L.

\%. Blh. bis zur Mitte oder tiefer fransig-gewimpert. 4-16 Hüllb.

I. Blb. fiederig-eingeschnitten mit länglichem Mittelfeld. B. grasgrün.

1. Stengel 2- bis melırblïtig. B. lineal-lanzettlich, untere stumpflich.

2. Stengel meist 1-blütig. B. lineal. spitz. D. arenarius L.

II. Blb fingerig-eingeschnitten mit verkehrt-eiförm. Mittelfeld. B. graugrün, lineal-pfriemelig. S. O.-Eur. D. plumarius L.

b. Bl. dichtbüschelig oder kopfig gehäuft. Blł. gezähnt. Gynophor kurz.

a. Ausdauernd.

I. B.scheiden so lang als die Breite des B.

1. Hüllschuppen ganz krautig. Deckb. lineal, zurückgebogen.

D. barbatus L.

2. Hüllschuppen am Rande trockenhäutig. Deckb. lanzettlich-pfriemelig, aufrecht.

D. Seguierii $\nabla$ ill.

II. B.scheiden etwa $4 \mathrm{mal}$ so lang als die Breite des B.

D. Carthusianorum L.

3. 1-oder 2-jährig. B.scheiden so lang als die Breite des

B. 2 Hochb. Kb. 9- bis 11-nervig. Blb. schwach bebärtet.

D. Armeria L

B1. Blkr. mit Ligularkrönchen. E. gekrümmt.

Saponaria (20) officinalis L.

B. Kb. durch trockenhäutige Streifen verbunden. $\bar{K}$. 5 - bis 15-rippig.

A. S. nierenförmig mit gerundetem Rücken. E. gekrümmt.

Gypsophila (50).

a. K. kurz, kreisel- oder glockenfürmig. Stämmchen des E. nicht verlängert.

๘. Kb. hoch hinauf verwachsen. Placenta verlängert.

I. Stengel aufrecht. Bl.stand sehr locker, ausgebreitet, kahl. O.-Eur. Sib.

G. paniculata L.

II. Stengel aus niedergestrecktem oder aufsteigendem Grunde aufrecht. oberwärts gedrungen-doldentraubig und nebst den Aesten drüsig-weichhaarig. Stb. und Gr. länger als die Blkr.

G. fastigiata L.

J. K. tief gespalten. Placenta kugelig. Kapsel rund. Tord.-As. G. elegans M. Bieb. 
b. K. verkehrt-kegelig-röhrig. Kapsel eiförmiøg oder ] länglichcylindrisch. Placenta $\perp$ verlängert. H. nit verlängertem Stämmchen. $G$. muralis $L$.

B1. S. schildförmig, ohen gewällot, unten vertieft. Hi. fast gerade.

Tunica (20).

a. Stengel niederliegend, ästig. Bl. in rispenförmigen Trugdolden. je 1 von Hüllschuppen umschlossen. T'. Saxifraga (L.) Scou,.

b. Stengel aufrecht, meist einfach. Pl. kopfig, meist je mehrere von Hüllschuppen umschlossen. T. prolifera (L.) Scop.

II. K. freiblättrig. Stb. häufig perigyn. [Alsinoideae.]

1. Fr. eine mit Zähnen sich öffnende Kapsel.

1'. Gr. vom Grunde aus frei.

1“. Nebenb. fehlend. [Alsineae.

A. Blb. ganzrandig oder gezähnelt orler fransig zerschlitzt oder schwach ausgerandet oder fehlend.

A1. Bl.stand doldig. Gr. 3. S. zusammengedrückt-schildförmig

Holostemm (6) imbellatum L.

B1. Bl.stand nicht doldig.

A2. Gynaeceum isomer.

A3. Gr. episepal.

a. 4 Stb.

b. 8 Stb. Nmgbt.

B3. Gr. alternisepal.

Moenchia (5).

a. Bl. 5-zählig. Blb. doppelt so lang als $\mathrm{Kb}$.

b. Bl. 4-zählig. Blb. kürzer als Kb.

S. nodosa (L.) Bartl.

c. Stengel am firunde wurzelnd, Iniederliegend. B. kahl. Bl.stiele nach dem Verhlïhen hakig zurückgekrïmmt, dann wieder aufrecht. S. procumbens L.

3. Stengel nicht wurzelnd, \pm aufrecht. B. am Grunde gewimpert, stachelspitzig. Bl.stiele nach dem Verblühen stets aufrecht. Blkr. sehr klein, bald verschwindend. Die beiden äusseren Kh. stachelspitzig.

S. apctala L.

B2. Gynaeceum oligomer.

A3. Fr.klappen ungeteilt, daher so viel Kapselzähne als Gr.

Alsine (60)

a. Rasen bildend. Blb. Jänger als die am Rande häutigen Kib.

๘. B. pfriemelig, die untersten dachziegrelig. Kb. eilanzettlich. Blh. eiförmig, am Grunde fast herzförmig

A. verna (L.) Bartl.

j. B. pfriemelig-fädlich. Kib. breit. stumpt. Blb. verkehrt. eiförmig, ausgerandet.

A. laricifolia Crantz

b. Stengel einzeln. Blb. kürzer als die $\mathrm{Kb}$.

\%. Frk. nicht erhärtend. Abschnitte gleich. A. viscosa schreb.

₹. Frk. am Grunde erhärtend: Abschnitte ungleich, weisslich.

A. Jacquini Koch

B3. Fr.klappen 2-zähnig oder 2-teilig. daher doppelt so riel Kapselzähne als $\mathrm{Gr}$.

A4. S. ohne Anhängsel (Strophiola), glatt. Arenaria 1711 . 
a. Kb. nicht erhärtend, lanzettlich, 3-nervig, länger als die Blb. B. eiförmig, zugespitzt, sitzend. Li. serpyllifolia L.

b. Kb. am Grunde erhärtend, abgerundet-stumpf, 1-nervig; viel kiirzer als die Blb. B. rinnig. am Rande rauh, untere rerlängert.

A. graminifolia Schrad.

B. S. mit Anhängsel (Strophiola), etwas rauh.

B. Blb. ausgerandet-2-teilig.

Moehringia (20) trinervis (L.) Clairv.

A1. Gr., wenn isomer, episepal. Kapsel cylindrisch. Cerastium (80).

a. 3 Gr. (Untg. Dichodon.) C. trigynum Vill.

b. 5 Gr. (Untg. Eucerastium.)

Kapselzähne gerade oder abstehend, flach oder am Rande zuriickgerollt. [\$ Orthodon.]

1. Blb. kürzer oder so lang als Kb.

1. Alle Deckb. bis zur Spitze krautig und behaart. Blb. und Stf. gewimpert. C. vulgatum L.

2. Mittlere und obere oder alle Deckb. nebst den Kib. an Rande trockenhäutig, an der Spitze kahl. Blb. und Stf. kahl.

+ Stengel nicht wurzelnd, meist drüsig-klebrig. Fr.stiele \pm zurückgeschlagen.

C. semiderandrum $\mathrm{L}$.

++ Stengel meist drüsenlos. seitenständige an den unteren Gelenken wurzelnd.

C. triviale Lk.

II. Blb. dopjelt so lang als Kh. Deckb. hreit trockenhüutig. + Bl.stiele kurz-weichharig. C. arvense L.

+ + Stengel. B. und Bl.stiele wollig-filzig. Ital., Balkanhalbinsel.

C. tomentosum L.

$B_{1}$. Gr, wenn isomer, alternisepal. Kapsel kugelig. Stellaria (80).

a. 5 Frb. (Untg. Myosoton.) S. aquatica (L.) Scop.

b. Gewöhnlich nur 3-2 Frb. (Untg. Eustellaria.)

a. B. gestielt. eiförmig, elliptisch oder länglich. Stengel stielrund.

I. 10 Stb. Stengel drüsig-weichhaarig. Kih. viel kürzer als Blb.

II. 3-5 Sth. Stengel einzeilig behart. Ḱb. so lang als Blb.

¡. B. sitzend, lineal. Stengel 4-kantig.

S. media (L.) Cyr.

1. Die zusammengehörigen B.paare am Grunde scheidig verwachsen. Stb. fast hypogyn. Blb. bis zur Mitte 2-spaltig.

S. Holostea L.

II. B. nicht rerwachsen. stb. deutlich perigyn. Blb. \pm bis zum Grunde 2-teilig.

1. K. am Grumde abgerundet.

+ Stengel aufrecht, meist einfach. B. graugrün, kahl. Deckb. am Rande kahl. Blkr. meist doppelt so lang als $K$.

S. glauca With.

+ Stengel schlaff, aufsteigend, meist ästig. B. grasgrün, am Grunde (wie die Deckb.) gewimpert. Blkr. meist so lang als $K$.

2. K. am Grunde trichterig.

+ Stengel meist niederliegend. B. am Grumde gewimpert. Deckb. trockenhäutig. Blkr. kürzer als K.

S. uliginosa Murr. 
++ Stengel \pm aufrecht. B. kahl, etwas fleischig. Deckb. krautig. Blkr. länger als K. S. crassifolia Ehrh. 2". Nebenb. vorhanden, klein, trockenhäutig. [Sperguleae.]

A. Frb. und Gr. 5. Spergula (3) arvensis L.

B. Frb. und Gr. 3.

A1. Frkn. unvollkommen 3-fächerig. Mmgbt.

Telephium (4) Imperati L.

B1. Frkn. 1-fächerig. - Bl.rosa. Tissa (20) campestris (L.) Pax 2'. Gr. unterwärts vereinigt. [Polycarpeae.]

A. Blb. ganzrandig oder 2-zähnig. K. ganzrandig.

A1. Ḱb. gekielt. - Mmgbt. Polycarpon (7) tetraphyllum L.

B1. Kb. ungekielt.

B. Blb. 2-teilig. - Trop. As., Afr. u. Amer.

Polycarpaea (30)

Drymaria (30) cordata Willd.

2. Trockene Schliessfr., selten am Grunde zerreissend. 1-4 Sa. 1. B. mit Nebenb. [Paronychicae.]

A. E. gekrümmt.

A1. 3 Frb. B. anch spiralig.

B1. $2 \mathrm{Frb}$. B. stets gegenständig.

A. Kb. stumpf.

a. B. und Kb. kahl.

b. Stengel, B. und Bl. kurzhaarig.

Corrigiola (6) litoralis L.

B.. Kb. oben kapuzenförmig, am Rücken mit aufgesetzter
Spitze. Meist 5 kleine haarförmige Blb. Parouychia (40).
B. E. gerade. Kb. dick, seitlich zusammengedrückt, zugespitzt.
Illecebrum (1) verticillatum L.

B.. Kb. oben kapuzenförmig, am Rücken mit aufgesetzter
Spitze. Meist 5 kleine haarförmige Blb. Paronychia (40).
B. E. gerade. Kb. dick, seitlich zusammengedrückt, zugespitzt.
Illecebrum (1) verticillatum L.

B.. Kb. oben kapuzenförmig, am Rücken mit aufgesetzter
Spitze. Meist 5 kleine haarförmige Blb. Paronychia (40).
B. E. gerade. Kb. dick, seitlich zusammengedrückt, zugespitzt.
Illecebrum (1) verticillatum L.

Herniaria (15). H. glabra L. $H$. hirsuta $\mathrm{L}$.

2'. B. olne Nebenb. [Sclerantheac.] Scleranthus (12).

a. Kb. mit schmalem Hautrand, ziemlich spitz.

b. Kb. breit häutig-berandet, stumpf.

S. annuus L.

S. perennis L.

\section{Nymphaeaceae (8; 5 5).}

I. S. ohne Nährgewebe. Frb. einzeln in d. breiten, ebenen EndHäche d. verkehrt-kegelig. Bl.bodens, 1-sam. [Nehmbonoideae.|Nelumbo(2).

a. Bl. \pm gelblich. Atl. N.-Am. bis Columbien. N. Lutea Pers.

b. Bl. rosentot. Trop. Asien bis N.-Austr. N. nucifera Grtn.

II. S. mit Perisperm und Endosperm.

I'. Frb. getrennt, 1- bis 4-samig. - [Cabomboideae.]

A. Stb. $3-6$; 1. extrors. Frb. meist 3.

Cabomba (4)

B. Stb. 12-29; A, seitlich nach innen aufspringend. Frb. 6-18. Tropen. Brasenia (1) purpurea (Mchx.) Casp.

II'. Frb. wenigstens an der Achse und dem Rïcken vereinigt (in der Mitte frei) oder ganz verbunden-aufgewachsen, os-samig. [Nymphaeoideae.]

1. K. 4-blättrig. S. mit Arillus. [Tetrasepaleae.]

A. Kb. unterständig. Blb. und Stb. mit dem Frkn. vereinigt. Pflanze stachellos.

Nymphaea (32).

a. Frb. blos an der Achse und dem Rücken verbunden-aufgewachsen, sonst frei, mit kurzdreieckigem Fortsatz. Stb. mit langem, spitzlichem Fortsatz. S. behaart. Bl. blau. N.-O.-Afr.

N. coerulea Sav.

b. Frb. völlig verbunden-aufgewachsen. Stb. fast ohne Anhang oder nur die äusseren mit Fortsatz. 
a. Pollen in der grüsseren Hälfte oder ganz warzig oder stachelig. Fortsätze der Frb. eiförmig- od. lineal-länglich. S. \pm gross u. glatt.

1. Alle Stf. breiter als die A. 6-14 Frb., oberwärts verschmïlert u. ohne Stb.; Y.strahlen breit, rimnig, meist hochrot. Fr. eiförmig.

N. candida Presl

2. Innerste Stf. kaum so breit als die A. 10-20 Frb., oberwärts nicht verschmälert, bis oben mit Stb. besetzt. N.strahlen schmal, nicht rimnig. meist hellgelb. Fr. \pm kugelig. V. alba L.

3. Pollen glatt. S. behaart.

I. Nerven der Kb. undeutlich. Blb. grüngelblich. Fortsätze der Frb. walzlich-keulig, sehr lang. Wr.-Ind., nördl. S.-Am.

N. Amazonum Mart. et Zuce.

II. Nerven der Kh. erhaben. Fortsätze der Frb. abgeplattetwalzlich, lineal. B. buchtig-zähnig.

1. Bl. rot. S.-O.-dsien.

N. rubra Roxb.

2. Bl. weiss. Afrika.

N. Lotus L.

B. Frkn. unterständig. Pflanze stachelig.

A1. Pollenkörner einzeln, zart gestachelt. Stb. und Frb. ohme Anhang. Keine Lebergangsh. zwischen Blb., Stb. und Frb. vorhanden. O.-Asien.

Euryale (1) ferox Salisb.

B1. Pollenkörner in Tetraden, glatt. Stb. mit Spitzenanhang. Uebergangsb. zwischen Blb.. Stb. und Frb, vorhanden. Trop. Amerika.

Victoria (3) regia Lindl.

2. Kb. 5 (selten bis 12), unterständig und frei wie Blb. und Stb. S. ohne Arillus.

Nuphar (7) luteum (L.) Sm.

\section{Ceratophyllaceae (C'eratophyllum. 3).}

a. B. 3-fach gabelteilig, mit $5-3$ borstlichen Zipfeln. Fr. flügellos, am Grunde ohne Stacheln. mit 1 kurzen Stachel an der Spitze.

C. submersum $\mathrm{L}$.

๖. B. gabelspaltig, mit 2-4 linealischen Zipfeln. Fx. mit einem langen, geraden Stachel an der Spitze und 2 zurückgekrümmten am Grunde, aber ohne Flïgel.

C. demersum $\mathrm{L}$.

\section{Magnoliaceae $(9 ; 70)$.}

1. B. mit Scheiden, welche in der Knospe rimgsum geschlossen sind. Bl. 8, mit verlängerter Achse. [Magnolieae.]

A. B. Ganzrandig. A. intrors oder mit seitlichen Fächern. S. durch Aufspringen oder Verwesen der Fr.wand frei werdend.

Magnolia (21).

a. Meist 2 der Bl. vorhergehende ścheidenb. Meist vor der Belaubung blühend. Japan.

๙. Alle Blhb. etwa gleichgestaltet, kronenartig. weiss, schmal, sehr zahlreich.

II. stellata Maxim.

अ. Aeussere Blhb. kürzer, innere aussen violett. M. oborata Thlog.

b. Nur 1 Scheidenb. Nach der Belaubung blühend. N.-Am.

\%. Nebenl, dem B.stiel nicht angewachsen, kahl. A. intrors.

ア. Nebenb. dem B.stiel angewachsen. 
1. Nebenb. kahl; B. gegen die Spitze der Jahrestriebe zusammengedrängt. A. intrors.

II. Nebenb. behaart.

1. Blhb. gelb, bereift. A. seitlich aufspringend. B. oval, zugespitzt.

2. Blhb. weiss. A. intrors. B. länglich-verkehrt-eiförmien. 6-9 Blhb.

M. macrophylla Michx.

B. B. gelappt. A. extrors. Hinsamige Schliessfr. Atl. N.-Am. Liriodendron (1) Tulipifera L.

2. B. ohne Scheiden oder Nebenb. Bl. ? oder eingeschlechtlich. mit kurzer Achse und in einen Kreis gestellten Frb. [Iilicieae. A. Blhb. zahlreich, frei, allmählich kronenartig werdend. A.intrors. Illicium (7).

B. K. einen anfangs geschlossenen Sack oder Becher bildend. A. extrors.

Drimys (10).

\section{Ranuneulaceae $(27 ; 1200)$.}

1. Sa, zu beiden Seiten der Bauchuaht von den beiden Banchnerven entspringend, gewöhnlich in je einer Reihe. selten einzeln. Meist mehr- (oder 1-) samige Balgfr., selten Beere oder Kapsel.

1'. Aeusseres Integument der Sa. länger als das innere, mächtig. Bl. fast stets einzeln, olnne Honigb. Frkn.wand fleischig. N. verbreitert. [Paconieae.]

A. Blh. einfach. Stengel mit einzelnen, auch im Mark zerstreuten Gefässhündeln. B. handförmig gelappt. - N.-Am.

Hydrastis (2) canadensis L.

B. K. und Blkr. Stengel mit Holzring. B. doppelt 3-zählig oder fiederig zusammengesetzt.

a. Stauden. Discus nur den Grund der Frb. umgebend.

a. Spreiten der B.chen 2. Ordnumg kaum am Grunde zusammenhängend, gewöhnlich ganzrandig-lanzettlich. S.-Eur.

P. corallina Retz.

¿. Spreiten der b.chen 2. Ordnung am Grunde zusammenhïngend, \pm tief weitergeteilt.

I. B.chen tief 3-teilig. Ahschnitte länglich, etwa $10 \mathrm{~mm}$ hreit. S.-Lur., W.-As.

P. peregrina Mill.

II. B.chen fiederig zerteilt, Abschnitte linear-pfriemelig, 1-2 mm breit. S-O.-Eur. P. tenuifolia L.

b. Stranchig. Discus die Frb. höher hinauf (oft ganz) umgebend. Japan, China. P. Moutan Sims

$2^{\prime}$. A Ausseres Integument der Sa. nicht länger als das innere. zuweilen nur 1 vorhanden. Fruchtknotenwand nur selten fleischig und dann Bl. in Trauben. [Helleboreae.]

A. Honigb. ohne Sporn, zuweilen fehlend.

A1. Stengel ohne Sklerenchymring. Frb. mit Queradern. B. ungeteilt-herzförmig-rundlich, hand- oder fussförmig gelappt bis geteilt.

A2. Honigb. flach, oberseits mit nackter Grube, zuweilen fehlend. A3. B. ungeteilt oder nur gelappt. Honigb. stets fehlend. 
B3. B. handförmm gespalten bis geteilt. Honigb. selten fehlend. Trollius (12) europaeus L.

B.. Honigb. Aurchaus oder wenigstens am Grunde röhrig.

A3. Sa. mit nur 1 Integument. Blh. derb, bleibend. B. meist fussförmig geteilt.

Helleborus (15).

a. Mehrere Laubb, am oberirdischen, meist holzigen Stengel. S.- u. W.-Eur. H. foetidus L.

h. Laubb. wenige oder einzeln vom Rhizom entspringend.

э. Stengel fast gabelig, nur an den Terästelungen beblättert. Blättchen krautig, rom Grunde bis zur Spitze scharf gesägt. Blhb. grün.

$H$. viridis $\mathrm{L}$.

¡. Blättchen lederig, nur an der Spitze gesägt. Blhb. weiss. H. niger L.

B3. Sa. mit 2 Integumenten. Blh. zart, abfallend. B. handförmig geteilt, mehrfach eingeschnitten. - S.-Eur.

Eranthis (7) hiemalis Salisb.

B. Stengel mit Sklerenchymring. B. 3-zählig- oder fiederig-zusammengesetzt (nur selten einfach 3 - oder 5-zählig und daun Frb. ohne Adern).

A2. Frb. frei.

A3. B. zusammengesetzt mit ganzrandigen oder nur rorn eingeschnittenen bis gelappten Abschnitien.

At. 20 Frb. Sa. mit nur 1 Integument. Cent.-As.

Leptopyrum (1) fumarioides (L.) Rehb.

B. 2-8 Frb. Sa. mit 2 Integumenten.

Isopyrum (17) thalictroides L.

$B_{3}$. B. zusammengesetzt mit gesägten Abschnitten.

At. Frb. mit Queradern. Balgfr. oder Beere. Actaea (13).

a. Staminodien ohne Honiggrube. 1 Frb.

\%. Beere. Staninodien mit einfachem Mittelnerv, höchstens kurz 2-spaltig. M.-Eur., Japan.

A. spicata $\mathrm{L}$.

3. Balgfr. Staminodien -2-spaltig. mit gegabeltem Nerr. Atl. N.-Am.

A. racemosa $\mathrm{L}$.

b. Honıb. mit Honiggrube, 1 oiler mehr Frb. Balgfr. O.-Eur. pacif. N.-Am.

B. Frb. ohne Adern oder mit Längsadern. Balgfr.

A.s. Pflanze krautig. Bl. spiralig gebaut. Teilfr. mehrsamig. Circumpolar.

Coptis (8) trifolia (L.) Salisb.

B. Pflanze holzig. Bl. quirlig gebaut. Teilfr. meist 1-samig. Atl. N.-Am.

Xanthorrhiza (1) apiifolia L'Hér.

B.2. Frb. am Grunde oder durchaus verwachsen. Nigella (16).

a. Blh. kelchartig. 5 Honigh. mit Grube. Frb. mit 1 Rückennerv. Mmgbt.

N. Garidella Spenn.

b. Blhb. gelhlich. 5-8 Honigb. mit Grube. Frb. mit 3 Rüickennerven. Orient.

$N$. orientalis $\mathrm{L}$.

c. Blhb. blau oder bläulich. 8 Honigb. mit Grube und drüsigen Höckern und śpitzen. Frb. mit 1 oder 3 Rückennerven.

x. Bl. ohne Involucrum.

I. A. stachelspitzig. Kapsel glatt.

N. arvensis $\mathrm{L}$.

II. A. ohne Stachelspitze. Kapsel drüsig rauh. Imgbt. 
ア. Bl. von einem vielteiligen Involucrum umgeben. A. olne Stachelspitze. Kapsel glatt. Mingbt. N. damascena L. B. Honigb. gespornt.

A1. Bl. strahlig, mit 5 Honigb.

a. Sporn der Honigb. nicht länger als die Platte.

a. Bl. gross, hell violettblau, rosa oder weisslich. Stb. mässign weit vorragend.

A. vulgaris $\mathrm{L}$.

3. Bl. etwa halb so gross wie bei $\alpha$, sehwarzviolett. Stb. weit vorragend.

A. atrata Koch

b. Sporn der Honigb. beträchtlich länger als die Platte.

๙. Bl. scharlachrot, am Saume gelb. Atl. N.Am. A. canadensis L.

$\beta$. Bl. goldgelb. Kalifornien.

A. chrysantha Hook.

Bi. Bl. zygomorph, mit 2 (zuweilen in 1 verwachsenen) Honigb.

A2. Honigb. sitzend. Unpares B. der Blh. abstehend, schlank, spornförmig.

Delphinium (120).

a. 2 getrennte Honigb. ohne nervenlose Seitenflügel. 2 seitliche Staminodien. Frb. 3 (selten 5).

a. Kräuter. Staminodien kahl. Mmgbt. D. Staphisagria I.

ß. Stauden. Staminodien bebärtet.

I. Honigh. und Blh. blau bis violett. Hochb. schmal. Sibir.

II. Honigb. und Staminodien \pm dunkelbraun.

1. Hochb. schmal.

D. grandiflorum $\mathrm{h}$.

2. Hochb. län mit Moschusgeruch. W.-Himalaya. D. cashmirianum Royle

b. 2 in eines verwachsene Honigb. mit nervenlosen Seitenflügeln. Seitliche Staminodien fehlend. $1 \mathrm{Frb}$.

a. 'Teilfr, behaart. 'Traube reichbliitig, gestreckt. D. Ajacis T.

3. Teilfr. kahl. Traube armblütig. sparrig. D. Consolida T.

B2. Honigb. gestielt. Unpares B. der Blh. aufrecht, helmförmigr.

Aconitum (60).

a. Wurzeln nicht knollig verdickt. Helm der (meist blassgelben) Blh. hoch und schmal.

A. Lycoctonum L.

b. Wurzel mit der Basis des Erneuerungssprosses zu einer rübenförmigen Knolle verdickt. Helm der Blh. niedriger und breiter.

a. Blh. blassgelb, bleibend. südl. Alpen. A. Anthora L.

ア. Blh. blau (selten weiss), abfallend.

I. Jüngere Teilfr. spreizend. Honigb. auf gekrümmtem Nagel wagerecht-nickend. A. Napellus L.

I1. Jüngere Teilfr. einwärts gekrümmt. Honigb, auf schwach gekrïmmtem Nagel schief geneigt A. Stocrkcanum Rchb.

III. Jüngere T'eilfr. gleichlaufend. Honigb. auf geradem Nagel aufrecht oder schief-geneigt.

A. variegatum $\mathrm{L}$.

2. Sa. einzeln am Grunde der Bauchnaht vom einzigen (oft oberwärts geteilten) Bauchnerv entspringend (oft noch rudimentäre an den Seiten der Bauchnaht). 1-samige Schliessfr. [Anemoneac.]

A. Sa. mit nur 1 Integument.

A1. Sa. aufrecht, grundständig (selten hängend). Frkn. ohne oder mit Längs- oder Queradern. Honigb. mit Grube oherseits über dem Grunde (selten fehlend). 
A2. Teilfr. ohne Hartschicht. B. eine Grundrosette bildend.

Myosurus (5) minimus L.

B2. Teilfr.mit Hartschicht. B. am Stengel spiralig. Ranunculus (250).

a. Teilfr. ohne Krystalle.

ж. Nectarium der Honigb. in einer seichteren Grube oder tieferen Tasche.

I. Stengel im Schlamm kriechend oder im Wasser flutend; Wasserb. vielfach zerteilt, mit fädlichen, 1-nervigen $A$ bschnitten. Honigb. weiss. Fr. runzelig.

1. Stengel kriechend; keine Wasserb.

R. hederaceus $\mathrm{L}$.

2. Stengel flutend, mit Wasserb.

+ Stb. kürzer als das Gynaeceum.

R. fluitans Lmk.

++ Stb. Jänger als das Gynaeceum.

- Untergeiauchte B. mit schlaffen, ausserhalb des Wassers zusammenfallenden Zipfeln.

$R$. aquatilis $\mathrm{L}$.

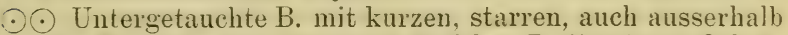
des Wassers ausgebreiteten Zipfeln. $R$. divaricatus Schrk.

II. Stengel aufrecht, mit Grundb. Fr. glatt.

1. Honigb. hellgelb.

2. Honigb. weiss. Bair. Alpen.

R. sceleratus L.

$R$. alpestris $\mathrm{L}$.

3. Honigb. mit freier, das Nectarium bedeckender Schuppe, gelb. meist 8 . Blhb. meist 3 . B. herzförmig, ungeteilt. R. Ficaria L.

b. Teilfr. mit Krystallen. Honigb. meist gelb.

๘. Wurzel fleischig-knollig. Honigb. mit Tasche. Fr. mit Adern. gewölbt. Frundb. fehlend. Unterstes Stengelb. nierenförmig, gekerbt. Pyren. bis Siebenbürg.

R. Thora L.

¡. IV urzel faserig. Honigb. meist mit freier Schuppe. Fr. meist zusammengedrückt. Fast stets 2 Vorb.

I. Teilfr. mit 1 Rückennerv. Stengelb. verlängert, ungeteilt. Nectarium in einer Tasche oder mit kurzer Schuppe.

+ Stengel aufsteigend. Teilfr. mit einem kurzen Spitzchen. Honigb. hellgelb, mittelgross.

R. Flammula L.

$+\div$ Stengel aufrecht. Teilfr. mit breitem, sichelförmigem Schnabel. Honigb. goldgelb, gross.

R. Lingua L.

II. Teilfr. mit 3 Rückennerven. B. handförmig gespalten bis geteilt.

1. Teilfr. ohne Knötchen.

+ Blütenstiele rund, nicht gefurcht.

.) Grundständige B nierenförmig, gekerbt, obere handförmig geteilt mit \pm lineallanzettlichen Zipfeln. 'Teilfr. sammethaarig.

A Mehrere der unteren B. nierenförmig. $R$. auricomus L.

$\hat{\uparrow} \uparrow$ Lin einzelnes nierenförmiges Grundb. $R$. cassubicus L.

○) Sämtliche B. handförmig geteilt. Teilfr. kahl.

$\uparrow$ Blütenachse kahl.

$\times$ Stengel und $B$. angedrüickt-behaart.

$\square$ Wurzelstock kurz, abgebissen. Untere B. j-teilig, spitzzahnig. Teilfruchtschnabel fast gerade, vielmal kürzer als die Teilfr.

R. acer $\mathrm{I}$

- $3 \square$ Turzelstock kriechend. Untere B. 3-teilig, Zipfel 
grobgezähnt, sehr hreit, verkehrt-ei- oder rautenförmig. Schmabel breit, an der Spitze hakenförmig. R. Stcveni Andrz. Stengel. B.- und Bl.stiele abstehend-rauhharig. Schmahel der 'Teilfr. lang, hakenförmig.

$R$. lanuginosus $\mathrm{L}$.

$\leadsto$ Bl.achse behaart. Teilfr. mit kurzem, gekrümmtem S'chmabel. B.zipfel länglich-lineal.

++ Bl.stiele gefurcht.

- Blhb. nicht zurückgeschlagen.

A Ohne kriechende Auslänfer. Stengel aufrecht. Lintere b. handfö̀mig-geteilt.

B.zipfel 3- bis 5-teilig, eingeschnitten, mit lineal-lanzettlichen Zipfelchen. Schnabel der 'T'eilfr. kurz, gekrümmt.

R. polyanthemus L.

$\times$ B.zipfel breit verkehrt-eiförm., 3-spaltig. gezähnt. Schnabel der T'eilfr. lang, an der Spitze eingerollt. R. ncmorosus D.C'.

A^ Mit kriechenden Ausläufern. Stengel aufistejgend. B. 3-teilig. untere mit gestielten, B-teiligen. obere mit länglichen, ungeteilten B.chen.

$\odot \odot$ Blhb, zurückgeschlagen.

A Stengel am crimole knollig verilickt. subnabel der T'eilfr. gekriimmt.

A Stengel am cirunde nicht verdiekt. S'chnabel der Teilfr. gerade.

R. sardous Crtz.

2. Trilfi. mit stumpfen oler dornig-spitzigen Höckern.

+ 'T'eilfr, zahlreich, mässig gross, ein fast kugeliges Küpfichen bildend, wenig hörkerig. S.hmabel gorade. Honigb. goldgelh. gross.

R. sardous Crtz.

++ T'eilfi. 4-s, sehr gross. = stark stachelien. Schnabel lang. etwas gekrümmt. Honigb. blassgelb, klein. R. arensis 1 .

Br. Sa. hängend. Frh. ohne Adern. Honigb, ohne Grube oder fehlend.

A2. B. spiralig, nur die 3 der Bl. vorhergehenden eine quirlige Aussenhiille bildend.

Anemone $(90)$

a. (tr. an der Fr. nicht verlängert. Honigh. fehlend. Pfahl. wurzel früh absterbend.

๘. 1-achsige Stauden.

I. Fr. kahl oder steifhaarig.

1. Blhb. gelb, aussen flaumharig. A. ranunculoides $\mathrm{L}$.

$\stackrel{\text {. }}{ }$ Blhb. weiss (oder rötlich oder bläulich, wanz kahl.

II. Fr. wollig behaart.

A. nemorosa L.

1. Rhizom nicht knollig.

+ Blachse walzenförmig.

-) Stockh. 5-teilig. Blhb.5, weiss, aussen zottig A. silvestris L.

$\odot$ Stockb. 3-zählig-geteilt. B]hb. 5-8, weiss, gelb od. purpurn, aussen seidenhaarig. N.-Am., Chile. A. multifida D.C. ++ Bl.achse halbkugelig.

Blhb.5-8, gelblich-grïn,fastlederig. N. Am. A. rirginiana L.

-P Blhb, zahlreich (bis 21), purpurrot, seidenhaarig. Japan.

2. Rhizom knollig. A. japonica Sieb. et Zuec. 
$\div$ Blhb. 5-s, oval oder verkehrt-eifürmig. Stockb. 3-zählig zusammengesetzt, Zipfel stachelspitzig. Nimgbt. A. coronaria I. ++ Blhb. 8-15, länglich-lanzettlich, stumptlich.

( Stockb. = tief 3-teilig. Frankreich. A. fulgens Gay $\odot \odot$ Erste Stockb. herzförmig. S.- u. O.-Eur. A. hortensis L. 3. 2-achsige Stauden.

I. Stockb. handförmig 3- his 5-teilig Abschnitte tief 2- bis 3spaltig. Bl. in einer Dolde. Aussenhüllb. 3-teilig, laubartig. Blhb. weiss.

A. narcissiftora L.

II. Stockb. 3-lappig, Abschnitte ganzrandiæ. Bl. cinzeln. Aussenhüllb. einfach, einen K. bildend. Blhb. blau. A. Hepatica L.

b. Gr der Fr, verlängert, behaart 1-achsige Stauden mit hleibender Pfahlwurzel.

a. Aussenhiillb. laubig. Honigb. fehlend. Blh. weisslich. A. alpina $\mathrm{I}_{\text {. }}$.

3. Aussenhüllh. hochblattartig, tief eingeschnitten. Aeussersto Stb. in kopfige Honigb. ungebildet.

I. Grundb. überwinternd. Blhb. rosenrot. mit gelben Haaren. B. einfach gefiedert, Fiederchen \pm 3 -zählig. Bl. $\doteq$ aufrecht.

II. Grundh. nicht ïberwinternd. Blhb. violett bis blan. mit weissen Haaren.

1. Grundb. 3-zählig, B. fingerig-geteilt. Bl. aufrecht. A.patens $\mathrm{I}_{\text {. }}$.

2. Grundb. doppelt gefiedert, B.chen fiederteilig.

+ Blhb. an der Spitze gerade, doppelt so lang als die Sth., hellviolett. Bl. wenig nickend, etwas ausgebreitet.

A. Pulsatilla L.

$+\div$ Blhb. an der Spitze nach anssen gebogen, wenig längor als die Stb., dunkelviolett. Bl. nickend, geschlossenglockig.

A. pratensis Mill.

B2. B. gegenständig.

(Gematis $(170)$.

a. Sth. lose abstehend, ohne Nectarien, meist kahl.

\%. Blhb, nicht oder nur rorn mit Saum. Stb. zuweilen am Grunde behaart.

I. Stengel aufrecht. Blhb. weiss. C. recta All.

II. Stengel kletternd.

1. Blhb. grünlich-gelb. Mmgbt. Cent.-As. C'. orientalis L.

2. Blhb. weiss.

$\div$ B. gefiedert. Blhb. beiderseits filzig. Frb. viele. S.-Lur.

C. Vitalba L. ++ B. doppelt gefiedert. Blhb. nur am Rande filzig. Frh. 6-8. S.Eur.

C. Flammula I.

३. Blhb. vom Grunde an mit breitem Saum. Stb. zuweilen oben mit einzelnen Haaren. Bl. dunkelviolett oder rot. IImgbt.

C. Viticella L.

b. Stb. aufrecht zusammenschliessend, mit Nectarien. von oben herab behaart (selten kahl).

๘. Keine Petaloidstaminodien.

I. Bl. \&.

1. B. einfach, ungeteilt, ganzrandig, nicht rankend. S.-Eur. bis Sibir.

C. integrifolia L.

2 B. fiederig geteilt oder zusammengesetzt. rankend. 
+ Blhb. violett. N.-Am.

++ Blhb. purpurrot. 'Texas.

C. Viorna $\mathrm{L}$.

C. coccinea kingelm.

II. Bl. 2-häusig. B. 3-schnittig. Blhb. blau, bis zur Mitte röhrig verwachsen. Oestl. Cent.-As.

C. tubulosa Turez.

F. $\infty$ äussere Stb. in Petaloidstaminodien verwandelt.

B. Sa. mit 2 Integumenten. Keine Honigb.

C. alpina (L.) Mill.

A1. Blh, einfach, meist unscheinbar. Frb. mit Längsadern. 'Teilfr. ohne Hartschicht.

Thalictrum (76).

a. Teilfr. längsfurchig, sitzend, ihr Bauch stärker gewölbt als der Rücken.

o. B.chen etwa so breit als lang, rundlich bis verkehrt-eirund. T. minus L.

3. B.chen mehrmal länger als breit, \pm länglich-keilförmig.

I. Bl. in lockerer, pyramidenförmiger Rispe, nebst den Stb. ïberhängend.

T. simplex L.

II. Rispe fast ebensträussig. Bl. an der Spitze der Aeste und Aestchen dicht büschelig gehäuft, nebst den Stb. aufrecht.

1. Wurzelstock kurz. B.chen meist ungeteilt, unterseits granwrün. Verzweigungen des B.stiels ohne Nebenb.chen.

$T$ '. angustifolium Jacq.

2. Wurzelstock kriechend. B.chen meist 3-spaltig, unterseits grasgrün. Verzweigungen des B.stiels meist mit häutigen Nebenb.chen. $\quad T$. flavum L.

b. 'Teilfr. glatt, ungerieft, gestielt, 3-kantig-geflügelt, ibr Rücken stärker gewölbt als der Bauch.

T. aquilegiifolium $\mathrm{L}$.

Bı. K. und Blkx. vorhanden. Frb. mit Queradern Teilfr. mit Hartschicht.

Atonis (20).

a. Fräuter. 5-S rote Blb. Teilfr. kahl; Fruchtgr. gerade. Sa. hängend.

๙. K. kahl. Blb, verkehrt-eiförmig.

I. K. von den halbkugelig zusammenneigenden Blb. abstehend. Teilfr. ungezähnt.

A. autumnalis $\mathrm{L}$.

II. K. den ausgebreiteten (zuweilen hellgelben) Blb. angedrückt. Teilfr. unten mit einem spitzen Zahn, an der oberen Kante mit spitzem Höcker.

A. aestivalis $\mathrm{L}$.

3. K. angedriickt rauhhaarig. Blb. länglich. Teilfr. oben mit Höcker.

A. flammea Jacq.

b. Ausdauernd. 12-20 hellgelhe Blb. Teilfr. behaart; Fr.gr. zurückgekrümmt. Sa. schief oder aufrecht. A. v'ernalis $\mathrm{L}$.

\section{Berberidaceate $(8 ; 135)$.}

A. Ohne Honigb. Stauden. Bl. einzeln.

A1. A. mit Längsspalten. Beere.

a. Mehr als 6 (bis 12) Stb. Atl. N.-Am.

b. 6 Sth. Himal.

B1. A. mit Klappen. Fr. quer aufspringend. - Atl. N.-Am.

Jeffersonia (2) diphylla (L.) Pers

B. Mit Honigb. Bl. in einfachen oder zusammengesetzten Trauben.

Ar. A. mit Längsspalten. Beere. Strauch. O.-As.

Nandina (1) domestica Thbg. 
B1. A. mit Klappen.

A.2. Zahlreiche Sa an der Bauchnaht. 2-klappige Krapsel. Stauden.

a. Bl.quirle 2-zählig.

Epimedium (11).

\%. Honiggrube oder Sporn kürzer als die braunen Blb. Gibg. von S.-Eur. $\quad E$. alpinum L.

5. Sporn lïnger als die weissen oder violetten Blb. Japan.

E. macranthum Morr. et Dene.

b. Bl.quirle 3-zählig. Pac. N.-Am. E. hcrandrum Hook.

B2. Wenige oder einzelne grundständige Sa.

A3. Stauden. Fr. trocken. S.schale um den E. einwärts gefaltet. - O.-As., atl. N.-Am. Leontice (12) thalictroides L.

$B_{3}$. Strüucher. Beere. S.schale nicht gefaltet. Berberis (100).

a. B. gefiedert, lederig, immergrün; B]ättchen meist dornig geziihnt. Trauben in den Achseln der Kinospenschuppen.

\%. Blättchen 7-9, dunkelgrün, oberseits stark glänzend, buchtigdornzähnig. Ohne Auslïufer. Pacif. N.-Am. B. Aquifolium I..

¡. Blattchen $3-7$, hell, durchaus glanzlos, feindornig-kleingezälnelt. Mit Ausläufern. Pacif. N.-Am. B. repens Lindl.

b. B. der Langtriebe meist in 1- bis jo-teilige Dornen umgebildet, in deren Achseln Kurztriebe mit einfachen Laubb. und endständigen Trauben (selten Einzelbl.).

a. B. immergriin.

I. Zweige kurzhaarig. B. verkehrt-eiförmig, buchtig-dornzähnig. (restielte Doldentrauhen. Antarkt. Gebiet.

B. Darwini Hook.

II. Zweige kahl. B. nadelartig, ganzrandig, am Rande zurückgerollt. Bl. zu 1-2. Antarkt. Gbt. B. empetrifolia Poir.

३. B. sommergrün.

I. Vielblütige Trauben. B. borstiggezähnt.

1. $2-5 \mathrm{~m}$ hoch. Trauben reichblütig.

2. $1 \mathrm{~m}$ hoch. Trauben 5- bis 8-blütig. Atl. N.-Am.

B. vulgaris $\mathrm{L}$.

B. canadensis Mill.

II. Bl. einzeln vder in 2- bis 4- (selten bis 10-) blütigen Doldentrauben od. Dolden. B. ganzrandig. Japan. B. Thunbergii D.C.

\section{Мenispermaceac (56; 250, Menispermum [3]).}

a. B. unterseits auf den Nerven nahe dem Grunde weichharig. o Rispen etwa $3-11 \mathrm{~cm}$ lang. Atl. N.-Am. M. canadense L.

b. B. kahl. z Rispen 1-2 $2^{1} \mathrm{~cm}$ lang. Oestl. C.-As. u. O.-As. II. dahuricum D.C.

\section{Calycanthaceae (Calycanthus, 5).}

a. Keine Kinospenschuppen. Bl. an Laubzweigen endständig. Blhb. gleichfarbig, braunrot. Fertile Stb. 13-23.

\%. B. unterseits weichfilzig. Bl. stark duftend. Südatl. N.-Am. C. floridus $\mathrm{L}$.

. B. unterseits sehr schwach behaart oder kahl. Bl. fast geruch los. Kaliforn.

C. occidentalis Hook: et Arn. 
h. Mit Knospenschuppen. B1. an beschuppten Zweigen, vor der Belanbung blühend. Aeussere Blhh. gelblichweiss, innere purpum. Fertile Stb. etwa 5. Japan.

C. praecox L.

\section{Monimiaceae $(23 ; 170)$.}

A. A. mit Längsspalten. Sa. hängend. Chile. Peumus (1:Boldus Mol. B. A. mit Klappen. Sa. aufrecht. - Chile.

Lamelia (2) sempervirens (Rz. et Pav.) Tul.

\section{Lauraceae $(39 ; 1000)$.}

I. A. 4 fächerig, mit 4 Klappen aufspringend. [1'erseoideac.]

1. Stb. des 3. Kreises mit extrorsen 4. 9 fertile Stl). [Cinnamomere.] Staminodien des 4 . Krreises an der Spitze verschieden verdickt.

A. Blhb. nach der Bl.zeit einzeln abfallend. Laubb. Ӟ-nervig. Cinnamomum (40).

B. Blh. nach der Bl.zeit als tianzes abfallend. Laubb. fiedernervig.

2. Alle Stb. mit introrsen A. Bl. diöcisch. [Litsceac.]

9 fertile Stb. Keine Staminodien. N.-Am.

Sassafras (1) officinale Nees

II. A. 2-fächerig, mit 2 Klappen $\mid$ Lauroideae , stets intrors. [Laureae.]

A. Androeceum in 3 Kreisen (6-9 Stb.).

Lindera $(60)$.

a. B. fiedernervig, diim. Knospenschuppen dachziegelig. Japan.

L. praecox Bl.

Ђ. B. :'-nervig, lederig. Kospenschuppen wenige. - Japan (?).

$L$. gracilis (Nees et Otto) Bth.

B. Androeceum in 4 orter mehr Kreisen. (12 oder mehr Stb.) - Mmgbt.

Lamus (2) nobilis L.

\section{Papaveraceate $(28 ; 80)$.}

1. Blb. ohne Sporn. Sämtliche Stb. mit dithecischen 1., in 2 bis vielen 2- bis mehrzähligen Quirlen.

I'. Stb. 4, in 2 2-gliedrigen (umlen. Frkn. dimer. [Hypecoideac.] - Mmgbt. (Fig. 12 C.) Hypecoum (12) procumbens L.

II'. Stb. in mehr' als 2 (Quirlen. Frkn. di-lis polymer. [Papaveroideac.]

1. (ir. so viele als E'rh., mit den I'lacenten alternierend, frei oder am Grunde kurz vereinigt. [Eschscholtzicae.]

A. :) oder mehr Fib. Bl. meist 3-zialhlig. Kalifornien bis Utah.

B. 2 Frb. Bl. 2-zählig.

Platystemon (1) californicus Bth.

A1. Kib. frei. Mexiko. Humemannia (1) fumariffolia Sweet

$B_{1}$. Kb. mützenförmig verwachsen. Kalifornien bis Neumexiko und Utah.

Eschscholtzia (10) californica Cham.

2. Gr. in 2 (selten 3-4) mit den Placenten alternierende ungreteilte Aeste endigend, welche innen und am Rande die N.fläche tragen. [Chelidonieae.]

A. S-12 weisse Blb. Atl. N.-Am. Sanguinaria (1) canadensis I.

B. 4 gelbe Blb.

C. Bih. fehlend. ().-.Is. Marleya (1) cordata (Willd.) R. Br. 

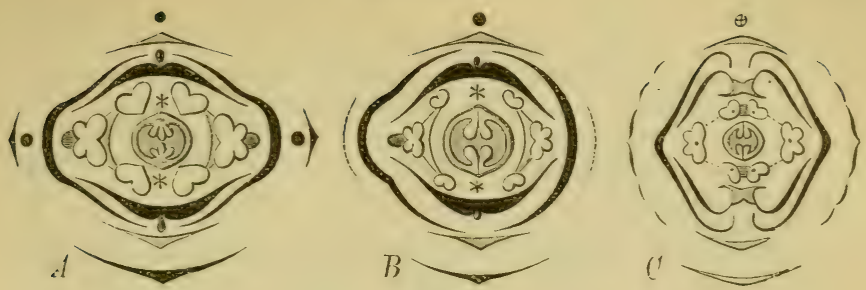

Fig. 12.

Diarramme von: I licentice jormose (Andr.) D.C., L Cor! dulis cauc Schweigg. et lïnte, C IIypecoum procumbens L.

3. N. über den Placenten liegend, bald auf lappigen Vorsprüngen zwischen den (ir.ästen, bald auf den Strahlen einer scheibe. [Papavereae.]

A. Fr. linealisch oder cylindrisch, his zum tirunde aufspringend. Frb. 2-4.

A1. Fr. mit falscher Scheidewand.

Glaucium (11).

a. Stengel und B. behart. B. im Lmiss eiförmig. am Girunde abgestutzt. Blb, rot. Kapsel steifhaarig, nicht warzig.

G. corniculatum (L.) Curt.

b. Stengel kahl. B. im Cmriss fast kreistörmig, am (irunde tief herzfürmi心. Blh. gelb. Kapsel warzig-rauh, kahl.

B. Fr. ohne falsche Scheidewand. - S.-Eur.

G. flavum Crantz

Roemeria (3) hybrida (L.) D.C.

B. Fr. länglich, eifürmig viler kugelig. nur oberwiirts aufspringend. Frb. 4-16.

A. Gr. dentlich. - W.-Eur. Meconopsis (10, cambrica (L.) Vigu. B1. Gr. sehr kurz oder fehlend.

A2. N. in den Einsattelungen zwischen den zusammenmeigenden Griffelästen. - Trop. Amer. Argemone (6) mexicana I.

Bะ. N. auf einer scheihenförmigen Ausbreitung. Paparer (41)).

a. 1-jährig.

\%. Stengelb. sitzend, ein- bis mehrfach fiederteilig.

I. Stf. oberwïrts verbreitert. Kapsel meist steifhitarig.

1. Kapsel verlängert-keulenförmig. mit zerstreuten, aufrechten Borsten besetzt, selten kahl. N. 4-bis 5-strahlig.

P. Argemone L.

2. Kinpsel kurz kreiselförmig. mit abstehenden, gekrümmten Borsten besetzt. N. 6- bis 8-strahlig. 1'. hybridum L.

II. Stf. pfriemelig. Kapsel kahl.

1. Bl.stiele mit anliegenden Borsten. N.strahlen $6-8$, braun, sich nicht deckend.

P. dubium L.

2. Bl.stiele mit abstehenden Borsten. N.strahlen $8-12$. schwarz-violett, sich teilweise deckend. $P$. Rhocas L.

3. Stengelb. umfassend, höchstens gelappt. Oestl. Mmgbt.

b. Ausdauernd.

P. somniferum L. 
a. Stengel beblättert.

I. Stengel 1-blütig. B. fiederteilig.

1. Unter den Bl. keine laubige Aussenhülle. Kauk. I'. orientale I.

2. Unter den Bl. eine laubige Aussenhülle. Kauk.

$P$. bracteatum Lindl.

II. Stengel mehrblütig, oft traubig. B. meist umfassend, wenig geteilt. Vord.-As.

$P$. pilosum Sibth.

ß. Stengel blattlos, 1-blütig.

I. B. einfach fiederspaltig oder fiederteilig, Lappen fast ganzrandig. Blb. weiss oder gelb. Arkt. G blbt. $P$. nudicaule L.

II. B. \pm doppelt fiederteilig oder einfach fiederspaltig mit 3spaltigen Lappen.

1. Bl. weiss. Alpen.

2. Bl. gelb. Hochgbg. von Eur.

$P$. alpinum $\mathrm{L}$.

P. pyrenaicum (L.) D.C.

II. 1 oder beide äussere Blb. mit Aussackung oder Sporn; vor diesen vereinigt 1 Stb. mit dithecischer A. und $\mathrm{zu}$ dessen Seiten je 1 Stb. mit monothecischen A. [Fumarioideae.]

A. Beide äussere Blb. ausgesackt oder gespornt. Frkn. in der Mediane der Frb. breiter. Bl. mit Vorb.

A. Stf. frei oder die je einer Seite \pm verbunden. Dicentra (15).

a. Phizom nicht zwiebelig. Stengel heblattert. Blb. frei, abfallend. S. mit concavem Anhang. O.-As. D. spectabilis (L.) D.C.

b. Rhizom nicht zwiebelig. Stengel hlattlos. Blb. vereinigt, bleibend. S. mit abstehendem Anhang. Pacif. N.-Am. (Fig. 12 A.)

D. formosa (Andr.) D.C.

$B_{1}$. Stf. sämtlich in eine der Blkr. angewachsene Röhre vereinigt. Atl. N.-Am.

Adlumia (1) fungosa (Gmel.) Irmisch

B. Nur eines der äusseren Blb. gespornt. lirkn. in der Mediane der Frb. schmäler. Bl. fast stets ohne entwickelte Vorb.

A. Fr. mehrsamig, aufspringend. (Fig. 12 B.) Corydalis (90).

a. Wurzelstock nicht knollig. S. mit concavem Anhang.

a. Stengel endständig. Bl. rosenrot. N.-Am.

C. sempervirens (L.) Pers.

:Stengel seitlich von der unbegrenzten Hauptachse entspringend. Bl. hellgelb. Altai.

C. nobilis Pers.

b. Wurzelstock knollig. (ir.bleibend. S. mit abstehendem Anhang.

a. Stengel endständig, unter den Laubb. mit einer Schuppe. C. solida Sw.

(2. Stengel seitlich an der unbegrenzten Hauptachse; keine Schuppe unter den Laubb. (Fig.12 B.) C. cava Schweigg. et Körte

B1. Fr. eine 1-oder 2 -samige, \pm kugelige Schliessfr. Fumaria (40).

a. N. 3-spaltig mit verlängertem 2-spaltigem Mittellappen. Fr. zusammengedrückt, jederscits 1 -nervig. $\quad F$. spicata L.

b. N. 2-hörnig. Fr. fast kugelig, nervenlos.

a. Reife Fr. höckerig-runzelig.

I. Kb. eirundlich, zugespitzt, halh so lang als die Blkr. $F$. rostellata Knaf

II. Kib. eilanzettlich, 3 mal kürzer als die Blkr. F.officinalis L.

III. Kb. eiförmig-spitz, 5-6 mal kürzer als die Blkr. $F$. parviflora Lam.

IV. Kíb. kaum mit blossem Auge zu sehen. F. Vaillantii Loisl. ß. Reife Fr. glatt. 


\section{Cruciferae (208; 1200).}

I. Haare unverzweigt oder fehlend. Keine Drüsenhaare oder -hücker.

I'. N. ringsum gleich entwickelt, oft kopfig. [Thelypodieac.]

Keimb. doppelt quergefaltet. S-Afr. Heliophila (60) pilosa Lam.

II'. N. über den Placenten stärker entwickelt, auf gestutztem oder seicht bis tief 2-lappigem, vorn zuweilen eingezogenem Gr. [Sinapeae.]

1. Krümmung des E. in den Keimb. liegend. Bl. perigyn oder mit seitlichen und medianen Honigdrïsen. [Lepidiinae.]

A. Fr.fächer mit mehreren über einander stehenden S. Bl. perigyn; nur seitliche Honigdrüsen. E. pleurorrhiz. Winziges Kraut. Teesdalea (2) nudicaulis (L.) R. Br.

B. Fr.fächer 1-samig (selten 2S. neben einander). Bl. hüchstens ganz schwach perigyn; meist auch mediane Honigdrüsen. A. S. von der Spitze des Faches herabhängend.

A. Scheidewand der Fr. lanzettlich bis elliptisch.

Lepidium (100).

a. Fr. herz-eiförmig, gedunsen, spitzlich, mit fädlichem Gr. L. Draba L.

b. Fr. vorn rundlich, = stark ausgerandet; Gr. kurz.

a. Keimb. ungeteilt. Fr.stiele abstehend.

I. Gr. frei.

1. Fr. vorn schwach ausgerandet, ungeflügelt.

2. Fr. vorn stark ausgerandet, geflügelt.

L. latifolium L.

+ Oberste B. linealisch.

L. ruderale $\mathrm{L}$.

++ Oberste B. herz-eiförmig, stengelumfassend S.-Eur., Orient.

L. perfoliatum L.

II. Flügel d. Fr. dem Gr. angewachsen. L. campestic (L.) R. Br.

3. Keimb. 3-teilig. Fr.stiele aufrecht. Oestl. Mingbt.

L. sativum L.

B2. Fr. nierenförmig, mit ganz schmaler, linealischer Scheidewand, nicht aufspringend, oder die S. von den Klappen eng umschlossen.

Coronopus (12) Rucllii All.

B1. S. von der Mitte entspringend, wagerecht: Fr. angustisept, von der Seite ganz flach gedrückt. - Westl. Mmght.

Biscutella (12) auriculata L.

2. E. an der Grenze von Keimb. und Stämmchen gekrümmt.

1'. Nur seitliche Honigdrüsen. Gr. fast stets gestutzt. Fr. fast stets ein Schötchen oder 1- bis 2-samige Schliessfr. Keimb. nicht gefaltet. [Cochleariinae.]

A. Rahmen seitlich und besonders am Grunde verbreitert.

A1. Fächer mehrsamig. E. notorrhiz. Portugal.

Jonopsidium (1) acaule (Desf.) Rchb.

B. Je 1 hängender S. im Fach. E. pleurorrhiz. Iberis (30).

a. Pflanze einjährig, krautig. S.- u. W.-Eur. I. amara L.

b. Pflanze andauernd, halbstrauchig. Fr. in gewöhnlichen Trauben.

I. sempervirens $\mathrm{L}$.

B. Schötchen mit schmalem Rahmen oder Schliessfr. 
A1. Kb. nicht gesackt.

A2. Klappen ganz flach. 1-samige Schliessfr. ohme Scheidewand. - Oestl. Mmgbt.

Peltaria (3) alliacea L.

B2. Klappen \pm gewölbt. Fr. elliptisch bis kugelig.

A3. Stf. gerade.

Cochlearia (15) officinalis L.

B3. Stf. einwärts gebogen. - Pyrenäen bis Balkan u. Karpathen.

Kernera (5) saxatilis (L.) Rehb.

C.. Kilappen gekielt, oft gefliigelt. E. pleurorrhiz.

Thlaspi (60) arvense L.

B1. Kb. \pm gesackt. Klappen gekielt, meist geflügelt. - Span. bis Montenegro.

Aethionema (50) saxatile (J.) R. Br.

$2^{\prime}$. Meist seitliche und mediane Honigdrüsen. Schote, seltener Schötchen, Gliederfr. oder 1- bis 2-samige Schliessfrucht.

1“. Gr. gestutzt, nicht eingezogen. Schote. Alliaria (5) officinalis D.C. 2". Gr. seicht- oder tief-2-lappig oder eingezogen.

1“. E. pleurorrhiz. Fr. stets 2-klappig. [Cardamininae.]

A. Klappen mit deutlichem, bis zur Śpitze auslanfendem Mittelnerv.

Barbarea (14).

a. Blkr. goldgelb, fast doppelt so lang als die Kb. Seitenlappen der unteren B. etwa so gross als der Endlappen. B. vulgaris $\mathrm{R}$. Br.

b. Blkr. hellgelb, wenig lïnger als der $K$. Seitenlappen der unteren B. sehr klein.

B. stricta Andr.

B. Mittelnerv der Klappen vor der Spitze verschwindend oder mit der Lupe überhaupt nicht wahrnehmbar.

A1. Klappen gew ölht. Fr. kugelig bis linealisch. Nasturtium (50).

a. Mediane Honigdrüsen fehlend. Blb. weiss. N. officinale R. Br.

b. Mit medianen Honigdrüsen.

o. Fr. kugelig bis kurz elliptisch, nicht halb so lang als der Stiel. B. teilweise ungeteilt.

I. Blb. weiss.

II. Blb. hochgelb, länger als der $\mathrm{K}$.

1. Stengel meist hohl. B. länglich bis lanzettlich, gezähnt oder gesägt, untere gestielt u. oft kamm- oder leierförmig fiederspaltig.

N. amphibium (L.) R. Br.

2. Stengel derb. B. länglich-spatelig, mit tief herzförmigem Grunde sitzend, unterste in den geöhrten Blattstiel verschmälert. $\quad N$. austriacum (Rehb.) Crantz

ß. Fr. langelliptisch bis linealisch.

I. Fr. etwa halb so lang als ihr abstehender Stiel; Gr. meist ziemlich lang. Obere B. oft nur \pm keilförmig-länglich, unterwärts eingeschnitten. $N$. anceps (Whlbg.) D. C.

II. Fr. etwa so lang als ihr \pm aufrechter Stiel, viel länger als der sehr kurze Gr. B. sämtlich fiederteilig.

1. Blb. hochgelb, länger als die Kb. N. silvestre (L.) R. Br.

2. Blb. blassgelb, kaum länger als Kb. N. palustre(Leyss.)D.C.

B1. Klappen flach oder höchstens durch die S. etwas aufgetrieben.

A2. S. 1-reihig, hängend, meist ungeflügelt.

A3. Klappen sehr zart netzaderig (kaum mit der Lupe wahrnehmbar). Rhizom ohne Niederb.

Cardamine $(50)$. 
a. Nur seitliche, keine medianen Honigdrüsen vorhanden. Untere Stengelb. 3-teilig oder nehst den oberen gefiedert 2- bis 3paarig.

b. Auch mediane Honigdrüsen vorhanden.

э. 1- und 2-jährig. Blb. länger als die Kb., zuweilen fehlend.

I. B.stiel am Grunde pfeilförmig-geöhrelt. C. impatiens L.

II. B.stiel ohne Oehrchen.

1. Stengel kahl, hin- und hergebogen. B.chen meist sitzend. die der unteren B. länglicb, die der oberen lineal.

C. parviflora L.

2. Stengel \pm behaart, gerade. B.chen der unteren B. rundlich, gestielt.

+ Stengel meist mehrere, 1 - bis 3-blättrig; grundständige B.rosette. Stb. meist 4. Fr.stiele aufrecht. Fr. die Bl. weit überragend. C. hirsuta L. +- + Stengel meist einzeln, reichbeblättert. Stb. meist 6 . Fr. auf abstehenden Stielen aufrecht, die Bl. wenig überragend.

C. silvatica Lam.

P. Blb. ausgebreitet, fast 3 mal so lang als die Kb.

I. Stengel hohl. stielrund. B.chen der Stengelb, lineal oder länglich, ganzrandig. A. gelb. (ir. kurz, stumpf. C. pratensis L.

II. Stengel derb, kantig. B.chen der Stengelb. lünglich bis rundlich, eckig-gezähnt. A. violett. Gr. lang, spitz. C. amara L.

$B_{3}$. Klappen höchstens mit ganz zartem Mittelnerv. Rhizom meist mit Niederb.

Dentaria (15).

Stengel quirlig-3-l,lättrig. B. 3-zählig.

B.. S. 2-reihig, wagerecht. mit Flïgelsaum.

D. cineaphyllos L. Klappen netzaderig.

Lunaria (2).

a. Fr. beiderseits abgerundet. S.-O.-Eur.

b. Fr. beiderseits verschmälert.

L. biennis Mïnch L. rediviva $\mathrm{L}$.

2"“. E. notorrhiz (bei Cakile pleurorrhiz, hier aber Fr. quergegliedert). [Sisymbriinae.]

A. Fr. 2-klappig, mit mehreren S. in jedem Fache. Sisymbrium (50). a. Blb. weiss. Kilappen 1-nervig. WV.Eur. S. supinum L.

b. Blb. gelb. Klappen 3-nervig.

a. Schoten an den Stengel angedruickt, pfriemelig zugespitzt. Bl. fast sitzend.

3. Schoten abstehend, länger gestielt.

I. Schoten stielrund. S. länglich oder fast eiförmig.

1. Fr.stiele dünner als die Fr. Scheidewand zart, ihre Zellen langgestreckt, mit dünnen, geraden Wänden. S. Irio L.

2. Fr.stiele so dick als die Fr., kurz. Scheidewandzellen mit verdickten Wänden.

S. austriacum Jacq.

II. Schoten kantig. S. linealisch, verlängert. B. ungeteilt. Aeussere Kb. an der Spitze gehörnt. S. strictissimum L.

B. Fr. quergegliedert, im vorderen, nicht aufspringenden Glied 1 aufrechter $\mathrm{S}$.

A1. Hinteres Glied 2-klappig. E. notorrhiz.

$B_{1}$. Hinteres Glied nicht aufspringend. E. pleurorrhiz.

Cakile (4) maritima Scop. 
C. Nicht quergegliederte Schliessfr., mit dünner oder olıne Scheidewand, mit 1 bis mehreren $\mathrm{S}$.

A1. Klappen ohne Fortsatz oder Auftreibung.

A2. Fr. mit ziemlich kreisrundem Querschnitt, kurz bespitzt. S. nicht geschnäbelt. Verkümmerte Sa., wenn vorhanden, unter der entwickelten. Calepina (1) Corvini (All.) D.C.

B2. Fr. seitlich flachgedrückt, häutig geflügelt, jederseits des Mittelnerven mit 1 Längsnerven. S. geschnäbelt, darüiber eine verkümmerte Sa.

Isatis (50) tinctoria $\mathrm{L}$.

B. Klappenspitze aufgetrieben-hohl. Myagrum (1) pcrfoliatum L. $3^{\text {"u. }}$. E. orthoploc.

1“". Schötchen oder 2-fächerige Schliessfr. mit wagerechten S. und derber Scheidewand im vorderen Gliede. [Vcllinac.]

$2^{\prime \prime \prime}$. Schote, zuweilen quergegliedert, mit meist aufrechten (selten vom aufrechten Funiculus hängenden) S. und höchstens zarter Scheidewand im vorderen Gliede. [Brassicinae.]

A. Vordere S. nicht in einem besonderen, breiteren Gliede. A1. Fr. mit flachem, zweischneidigem Schnabel, 2-klappig.

A2. Klappen mit nur 1 starken Hittelnerv. Mmgbt.

B. Kllappen mit 3 Längsuerven. Eruca (10) sativa Lam. Sinapis (j) alba L. B1. Fr. mit cylindrischem oder conischem, höchstens schwach abgeplattetem Schnabel.

A2. Fr, 2-klappig.

A3. S. oval bis länglich.

At. Klappen flach. S. 2-reihig.

a. Blb. gelb. Fr. plötzlich in ien Gr. verschmälert. D. muralis (L.) D.C.

b. Blb. violett oder weiss mit violetten Adern. Fr. vorn allmählich in einen sichnabel verschmälert. Mmgbt.

D. erucoides (L.) D.C.

Bt. Klappen gewölbt, mit starkem Nittelnerv. S. 1-reihig.

Erucastrum (15).

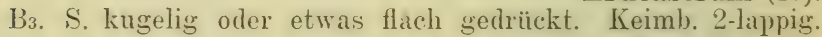

a. Klappen mit Mittelnerv und Adernetz.

Brassica $(50)$.

o. Gr. cylindrisch oder schwach conisch. Alle B. gestielt. Fr. aufrecht angedrückt.

B. nigra (L.) Koch

G. Gr. allmählich in einen conischen Schnabel verschmälert. Obere B. sitzend.

I. Kib. aufrecht, anliegend. Alle Stb. aufrecht. B. oleracea L.

II. Kb. abstehend. Kürzere Stb. abstehend.

1. Untere B. grasgrün. Bl.trauben flach (die Bl. die gedrängten Knospen überragend). „Rübsen. "B).campestris L.

2. Alle B. blaugrün. Bl.trauben locker (Knospen über den geöffneten Bl. stehend). "Raps."

B. Napus L.

b. Klappen mit 3 ziemlich gleichstarken Längsmerven. Kb. wagerecht-abstehend.

B. Sinapistrum Boiss.

B. Fr. nicht aufspringend. Kb. aufrecht. Rhaphanus (10).

a. Fr. nicht quergegliedert. S. 2-reihig in der Fr. $R$. sativus L.

b. Fr. quergegliedert. S. 1-reihig in der Fr. R. Rhaphanistrum L. 
B. In einem besonderen, schon bald nach der Bl. breiteren, vorderen (oberen) Gliede der Fr. 1 oder mehrere aufrechte oder vom langen, aufrechten Funiculus hängende S.

A1. Vorderes Glied ohne Scheidewand, hinteres (unteres) leer. S. vom anfrechten Funiculus hängend. Crambe (20) maritima L.

B1. Torderes Glied mit Scheidewand und aufrechten S.. hinteres gewöhnlich mit mehreren S.

Rapistrum (10).

II. Haare sämtlich oder teilweise verzweigt (wenn verzweigte Haare fehlend, dann keine medianen Hovigdrüsen vorhanden [Moricandiinae S.: 82]) ; zuweilen ausserdem Drüisenhaare oder Drüsenhöcker. $N$. über den Placenten stärker entwickelt auf ungeteiltem oder über den Placenten in kürzere oder längere Lappen verlängertem Gr. [Hesperideae.]

1. Oberhautzellen der Scheidewand nicht der Quere nach geteilt.

1'. Oberhautzellen der Scheidewand ohne zahlreiche parallele Teilungswände.

1". Nur seitliche Honigdrïsen. Fr. meist kurz. S. nie 1-reihig. [Capsellinae.]

A. Klappen gekielt.

A1. Fr. vorn abgerundet oder spitz. - Pyr., Alp., Karp.

Hutchinsia (8) alpina (L.) R. Br.

$\mathrm{B}_{1}$. Fr. vorn verbreitert bis ausgerandet.

Capsella (4) Bursa pastoris (L.) Mönch

B. Klappen gewölbt oder flach, nicht gekielt; zuweilen Schliessfr.

A1. Fr. birnförmig bis kugelig. E. notorrhiz.

A. Klappen über den Grund des Gir. sich hinauf erstreckend.

Camelina (8) sativa (L.) Crtz.

B2. Schliessfr. Gr. über dem Grunde gegliedert, abfallend.

Neslia (1) paniculata (L.) Desv.

B1. Fr. kreisscheibenförmig bis lineal-länglich. E. pleurorrhiz. A2. Stf. weder geflïgelt, noch gezähnt. K. offen.

Draba (150) verna $L$.

B:. Stf. geflügelt. kürzere oft mit Zahn. K. geschlossen. Griechl.. Kleinas. Aubrietia (12) deltoidea (L.) D.C.

2". Mediane Honigdrüsen (ausser bei einzelnen Aiabi-Arten) nie fehlend. Fr, meist lang.

1“". Honigdrüsen meist zu einem Ringe vereinigt. je 1 mediane. [Turritinae.

A. Fr. mit Fasern in der Scheidewand.

Descurainia (12) Sophia (L.) Webb

B. Fr. ohne Fasern in der Scheidewand.

A. Klappen Hach, mit schwachem Mittelnerv. Arabis (100).

a. Blb. aufrecht. Stengelb. sitzend oder umfassend.

b. Blb. abstehend.

A. hirsuta (L.) Scop.

a. Kb. nicht gesackt. Grundb. meist fiederteilig. Stengelb. \pm kurz gestielt. S. nicht breithautflügelig.

I. Stengel kahl. Schoten gedunsen. A. Halleri L.

II. Stengel ron einfachen Haaren rauh. A. arenosa (L.) Scop.

j. Kb. gesackt. B. kahl oder spärlich gewimpert, glänzend. Stengel kahl, reichblättrig. S. breitflügelig. 
B1. Klappen gewölbt bis gekielt, mit starkem Mittelnerv.

A2. F. notorrhiz. Stemophragma (10) Thalianum (L.) Cel.

B2. E. pleurorrhiz.

2“" Je 2 mediane Honigdrüsen. [Erysiminae.]

A. E. pleurorrhiz. - S.- u. W.-Eur. Cheiranthus (10) Cheiri L.

B. E. notorrhiz.

Erysimum (80).

a. Stengelb. am Grunde verschmälert. Blb. ausgebreitet, gelb.

o. Bl.stiele 2-3 mal so lang als der Kelch. Fr. aufrecht abstehend, fast kahl.

E. cheiranthoides L.

ङ. Bl.stiele so lang als der Kelch. Fr. aufrecht angedrückt, weichhaarig.

$E$. hieraciifolium L.

b. Stengelb. am Grunde tief-herzförmig, umfassend. Blb. weissgelb oder weiss, aufrecht.

E. orientale (L.) R. Br.

2`. Oberhautzellen der Scheidewand mit zahlreichen, parallelen, aber in den verschiedenen Zellen verschieden gerichteten Teilungswänden. [Alyssinae.]

A. Kb. offen bis aufrecht, nicht gesackt.

A1. Blb. ungeteilt, gelb oder blassgelb.

A2. Fr. 2-klappig, mit 1- bis mehrsamig. Fächern. Alyssum (100).

a. Ausdauernd, mit enistindiger Blattrosette. 2-6 S. in einem Fach.

A. saxatile L.

b. 1-jährig. $2 \mathrm{~S}$. in jedem Fach.

a. Stf. ohne Zähne.

ß. Stf. fast stets mit Zähnen.

A. calycinum $\mathrm{L}$.

A. montanum $\mathrm{L}$.

B.. 1-samige Schliessfr. ohne Scheidewand. Mmgbt.

Clypeola (12) Jonthlaspi L.

B1. Blb. 2-spaltig, weiss.

Berteroa (5) incana (L.) D.C.

B. I. geschlussen, Kib. gesackt. F'r. kugelig. Südl. M.-Hur.

Vesicaria (2) utriculata (L.) Lam.

2. Oberhautzellen der Scheidewand der ()uere nach geteilt.

1.. Behaarung vorhanden.

1“. Keine Drüsenhaare od. Drüsenhöcker. [Mitcolmiinae.] Scheidewand der Fr. mit Faserschicht.

A. Klappen ohne Auswuchs.

A1. S. gedunsen. E. notorrhiz. Mngbt.

Malcolmia (30) africana (L.) R. Br.

B. S. flach, geffligelt. H. plemrorhiz. Oestl. Umgbt. Farsetia(7).

B. Klappen vorn mit Auswiichsen. (-) A Aste hygroskop., trocken eingebogen. Orient, Aegypt. Anastatica (1) hierochuntica L. 2". Drüsenhare oder Drüsenhöcker vorhanden. [Hesperidinae.]

A. Haare vorherrschend oder sämtlich verzweigt.

A1. Nur seitliche Honigdrüsen. Keimb. gerade.

A2. E. notorrhiz. Gr. olne Auswuchs. Hesperis (24) matronalis L.

B2. E. pleurorrhiz. (ir. auf dem Rücken der Lappen mit Hücker oder Auswuchs. - Mmght. Matthiola (50) incana (L.) R. Br.

B1. Auch mediane Honigdrüsen. E. spiralig gerollt. - Orient, Sibir.

Bumias (5) orientalis L.

B. Haare vorherrschend oder sämtlich einfach. Chorispora (12).

2`. Behaarung vollständig fehlend. Mittlere Honigdrüsen 0 , seitliche herabgezogen. Keimb. gewölbt bis gefaltet. [Moricandiinac.]

A. Gr. mit kurzen od. kaum erkembaren Lappen. Keimb. gewölbt.

- Oestl. Mmgbt., M.-Eur. Conringia (6) orientalis (L.) Andrz. 
Capparidaceae. - Resedaceae. — Sarraceniaceae. - Droseraceae. 183

B. Gr. mit verlängerten, aufrechten Lappen. Keimb. gefaltet. Mmgbt.

Moricandia (10) arcensis (L.) D.C.

\section{Capparidaceae $(34 ; 300)$.}

I. Meist einjährige, häufig drüsige, niemals mit Schuppen bekleidete Krräuter. Fr. eine schotenförmig mit bleibendem Replum aufspringende Kapsel. Keimb. cylindrisch, gekrümmt. [Cleomoideae.] A. Stb. 6, selten nur 4, alle fertil und gleich.

A1. Androphor fehlend.

Cleome (70).

a. Fr.kahl oder schwach behaart. Trop.Am., W.-Afr. C. spinosa L.

b. Fr. drüsig oder stachelig. Spanien. C. violacea L.

B. Androphor deutlich. - Würmere Gebiete von As., Afr.

Pedicellaria (15) pentaphylla (L.) Schrank B. Stb. $4-\infty$, ungleich, nur wenige fertil.

A. Stb. $4-\infty$, davon etwa die Hälfte fertil. Polanisia (30).

B. Stb. 5, nur 1 fertil. Brasil. Dactylaena (3) micrantha Schrad.

II. Meist mit Sternhaaren, Schuppen oder einfachen Haaren bekleidete Sträucher. Fr. beerenartig. Keimb. gerollt. [Capparidoideae.] - Mmgbt.

Capparis (50) spinosa L.

\section{Resedaceae $(6 ; 60)$.}

Jrb. verwachsen, oben offen. Placenten wandständig, mit so Sa. Reseda (53).

a. Placenten einfach. Sa. 2- bis 4-reihig.

a. Gynaeceun 4-zählig. B. fiederteilig. Blb. weiss oder weisslich. W.-Eur., Mmgbt.

R. alba L.

3. Gynaeceum 3-zihlig. B. lanzettlich bis doppelt fiederspaltig. Bib. gelb oder weisslich-gelb.

I. Kapsel verkehrt-eiförmig, hängend. $\quad R$. odorata $L$.

II. Kapsel länglich-walzlich, aufrecht abstehend. R. lutea L.

III. Kapsel länglich-kenlig. stumpf kantig. $\quad R$. Phyteuma L.

b. Placenten 2-teilig. 3 Frb. B1. gelb. B. lanzettlich. R. Luteola L.

\section{Sarraceniaceae $(3 ; 8)$.}

A. Frkn.scheitel convex; (rr. schirmartig erweitert, ‘) N.zäpfchen auf der Unterseite. Kamnendeckel ohne Anhang. Atl. N.-Am.

Sarracenia (6).

a. Bl. purpurrot oder violett.

๘. B. aufrecht, oberwärts purpurn, an Mündung und Deckel weissgefleckt. Deckel aufrecht. S. Drummondii Croom. ¡. B. auf liegend oder anfsteigend-zurückgeneigt, blutrot gerippt, mit einem breiten, nach oben und unten versebmälerten Flügel. Deckel die MIündung der Piöhre fast verschliessend. S.purpurea L.

b. Bl. blaugelb oder hellgrün. Deckel aufrecht. S. flarc L.

B. Frkn.scheitel concav; Gr. 5-ästig, geteilt. Kannendeckel der B. mit fischschwanz-ähnlichem Anhang. Sierra Nevada im pacif. N.-Am. Darlingtonia (1) californica Torr. et G'r.

\section{Droseraceae $(6 ; 100)$.}

A. B. im Mittehnerv zusammenklappend. Stiel flïgelig; Reizborsten auf jeder Spreitenhälfte; Rä̈nder frei von Digestionsdrüisen. 
A1. 15-20 Stb. Scheindolde aus Wickeln. B. in Grundrosette, Stiel verkehrt-eilanzettlich, Spreite mit Randborsten. Südatl. N.-Am. Dionaea (1) muscipula Ell. B1. 5 Stb. Bl. einzeln achselständig. B. in Quirlen, Stiel linealisch, oben mit Borsten.

Aldrovanda (1) vesiculosa L.

B. B. mit flachrundlicher oder linealer Spreite, auch am Rande mit langgestielten, einkrümmungsfähigen Digestionsdrüsen.

A1. 10-20 Stb. Marokko, iberische Halbinsel.

B1. Stb. den Blb. gleichzählig.

Drosophyllum (1) lusitanicum Lam.

a. Kapsel nicht gefurcht. S. spindelförmig. Stengel aufrecht, 2-4 mal so lang als die B.

๘. B. ausgebreitet, Spreite fast kreisrund. D. rotundifolia L.

ア. B. aufrecht, lineal-lïnglich, am Grunde \pm keilförmig, 3-4 mal so lang als breit.

D. anglica Huds.

b. Kapsel gefurcht. S. walzlich-eiförmig. B. rerkehrt-ei-keilförmig, aufrecht. Stengel aufsteigend, wenig länger als die B. D. intermedia Hayne

\section{Crassulaceae $(13 ; 450)$.}

A. Androeceum obdiplostemon (selten haplostemon).

A1. Blb. frei oder fast frei.

A2. Bl. 4-bis 5-zählig. B. spiralig oder in 2- bis 3-gliedrigen Quirlen.

a. Bl. diöcisch oder polygam, 4-zählig. Serlum (140).

b. Bl. 8, 5-zählig.

๙. Ohne sterile Sprosse. Alle oberirdischen Teile jührlich absterbend. B. Hach.

I. Rhizom schwach entwickelt. Wrurzel rübenförmig. [sTclephium.]

1. B. nach der Spitze hin gesägt oder gezähnt.

+ Blb. lila-purpurn. B. sämtlich am Grunde keilförmig.

S. Fabaria Koch

++ Blb. grïn-gelblichweiss. B. eilänglich, obere mit herzförmigem Grunde halbstengelumfassend. S. maximum Sut.

2. B. ganzrandig. Blh. purpurrot. S. Anacampseros L.

II. Rhizom bis $2 \mathrm{~cm}$ dick. WVurzeln unbedeutend. [S Aizoon.] B. lanzettlich, gesägt. Sib., O.-As. S. Aizoon I.

5. Nit ausdauernden sterilen Sprossen. Rasenbildend. Quantitativ der kriechende Stammapparat in den Tordergrund tretend. [\$ Seda genuina.]

I. B. flach, verkehrt-eiförmig, vorn kerbiggezähnt. Bl. rötlich. Pflanze ausdauernd. S. spurium M. Bieb.

II. B. dick, kurz elliptisch, eiförmig oder pfriemelig. Pflanzen ausdauernd.

1. Bl. weiss, rosa oder purpurn.

+ B. kurz elliptisch.

○. K. und Bl.stiele drüsig-weichhaarig. S. dasyphyllum L. $\odot \odot$ Ganze Pflanze kahl. IV.-Eur. ++ B. walzenförmig, stumpf.

S. anglicum Huds. S. album L. 
2. Bl. gelb.

+ B. stumpf, klein, eiförmig, mit stumpfem Grunde sitzend.

++ B. spitz oder zugespitzt.

S. acre $\mathrm{L}$.

S. reflexum L.

III. B. halbstielrund oder cylindrisch. B. und Trugdolden drüsigweichhaarig. Bl. weiss. Pflanzen 1- oder 2-jährig. S. villosum L. B2. Bl. 6- bis os zählig. B. rosettenförmig gehäuft.

A3. Schüppchen aussen am Grunde der Frb. klein oder fehlend. Blb. \pm lanzettlich, hervorstechend gefärbt. Sempervivum (50).

a. Bl. 28--32-zählig. Schüppchen fehlend. Stamm kurz. Blb. gelb. [\$ Greenovia.]

b. Rl. 6- (5-) - 12- bez. - 20-zählig.

\% Bl. 6- bis 20-zühlig. Frb. auf \pm convexem Blütenboden.

I. Bl. meist 12-zählig. Blb. unter sich und mit den Stb. am Grunde vereinigt, samt den Kb. sternförmig ausgebreitet. Schüppchen bisweilen verkümmert. Balgfruchtartige Teilfr. divergierend. [\$ Eusempervivum.]

1. Blb. rosenrot oder lila.

+ B. nicht drüsig behaart, nur am Rande mässig lang gewimpert.

S. tectorum l.

++ B. gewimpert und zugleich drüsig behaart. Pyr.-Siebbg.

$\odot$ B. kurz gewimpert.

S. montanum L.

๑) B. lang gewimpert, aber nicht verfilzt. S. Funckii A. Br.

$\odot \odot \odot$ Wimperhaare der B. spinnwebenartig rerfilzt.

2. Blb. gelblich. Ostalpen.

$S$. arachnoideum $\mathrm{L}$.

+ B. nichtdrüsig, nur am Rande kurz gewimpert. Bis Savoyen.

S. Wulfeni Hoppe

++ B. mit Wimper- und Drüsenhaaren. S. Braunii Funck

II. Bl. meist 6-zählig. Blb. und Kỉ, aufrecht, glockig zusammenneigend. [\$ Jovisbarba.

1. B. und Kb. nur am Rande gewimpert, beiderseits kahl.

+ Rosettenb. schmal-lanzettlich. Ostalp. S. arenarium Koch

+ + Rosettenb. länglich-keilförmig. S. soboliferum Sims

2. B. und Kb. am Rande gewimpert, unterseits kurzhaarig. Alpen bis Siebenbürgen.

S. hirtum L.

3. BI. j-bis 12-zählig. Frb. in den \pm concaven Bl.boden eingesenkt.

I. Schüppchen fehlend. Pflanzen mehrjährig. mit am Grunde dicht beblätterten Aesten und kleinen Bl. [\$ Goochia.] Canaren. S. barbatum Chr. Sm.

II. Schüppchen keulenförmig, quadratisch oder verkehrt-herzförmig. Stamm kräftig, dick und fleischig, mit dichten Grundb.rosetten. [s Aconium.] - Mmgbt. S. arboreum I.

B3. Frb.schüppchen breit, blumenblattartig. Blb. linealisch, unansehnlich. - Canaren.

Monanthes (4) polyphyl!a Haw. $\mathrm{B}_{1}$. Blb. meist bis zur Mitte oder darüber hinaus verwachsen.

A2. Bl. 5-zählig.

a. Kb. fast frei, viel kürzer wie die Blkr. Rühre der Blkr, cylindrisch od. krugförmg. [\$Eucotyledon.] - S.-Afr. C. orbiculata L.

b. Kb. fast frei, oft fast so lang wie die Blkr., meist sehr breit. Abschnitte der Blkr. breit, meist viel länger als die Röhre. 
Blkr. krugförmig, oft 5-kantig. [క Echercria.] - Mexiko. C. gibbiflora (D.C.) Schönl.

c. K. so gross oder wenig kürzer als die cylindrische oder glockige Rühre der Blkr. [\$ Umbilicus.] - Trop. Afr. bis England. C. Umbilicus L.

B2. Bl. 4-zählig. B. stets gegenständig.

A3. Kb. fast frei, selten bis zur Mitte verwachsen. Kalanchoë (55).

a. B. breit verkehrt-eiförmig, gebuchtet. Bl. grünlich-gelb. O -Ind.

$K$. grandiflora W. et A.

h. Untere B. unpaarig gefiedert. Bl. gelb. 'Trop. d. alt. IVelt. $K$. laciniata D.C.

B3. K. bauchig angeschwollen, kurz 4-zipfelig. Bryophyllum (4).

a. B. einfach, selten gefiedert mit eiförmigen Fiederb.chen. Trop. B. calycinum Salisb.

b. B. meist gefiedert mit länglich-lanzettlichen Fiedern. Madagaskar.

B. Androeceum haplostemon. B. stets gegenständig:

A1. Blb. frei oder fast frei. Halbsträucher. Crassula (120).

a. B. gestielt, nicht rosettenförmig gehüuft, breit herzförmig.

a. B. ganzrandig. S.-Afr.

3. B. gekerbt. S.-Afr.

C. cordata Ait.

h. B. sitzend, am Grunde meist \pm mit einander verwachsen. nicht rosettenförmig gehäuft. S.-Afr.

C. lactea Ait.

B1. Blb. meist bis zur Mitte oder darüber hinaus verwachsen. Kräuter.

Aュ. Derbe, fleischige Kräuter. K. kleiner wie die Röhre der Blkr. S.-Afrika. - Bl. scharlachrot. Rochea (4) coccinea D.C.

Bะ. Kleines Kraut von enzianartiger 'Tracht. K. glockenförmig, so gross, wie die Rühre der gelhen oder orangefarbigen Blkr. Kapland.

Grammanthes (1) dichotoma (L.) D.C.

\section{Saxifragaceae $(69 ; 600)$.}

I. Kräuter, meist 2 .

I'. Bl. meist 5-zählig. Frkn. 1-oder '-fächerig. [Saxifragoideae.]

1. Frb. meist 2, zuweilen frei, meist $=$ rereinigt. Gr. getrennt. [Saxifrageae.]

1'. B. doppelt oder 3-fach gedreit, mit häutigen Stipularscheiden. - Japan.

Astilbe (7) japonica (Morr. et Dene.) Miq.

2'. B. ungeteilt oder gelappt oder handförmig gespalten, zuweilen mit nebenblattartiger Auszweigung der Scheide. [Saxifraginae.]

A. B. mit eingesenkten, mehrzelligen Drüsenharen, dick, gross.

Bergenia (7).

a. B. rundlich herzförmig. Altai. $B$ cordifolia (Haw.) A. Br.

b. B. länglich, gekerbt, \pm keilförmig in den Stiel verlaufend. Altai.

B. B. ohne eingesenkte Drüsenhare.

A. Placenten central, dick. Meist \%, selten $\odot$ oder $\odot$ (meist Gebirgs-) Kräuter.

a. Haare vielzellig, einreihig. 
๙. S. kugelig. Blb. gelb, mit 2 kleinen, drüsenfürmigen tnhängseln am Grunde. B. fleischig, 5- bis 9-lappig, von epidermoidalen Gerbstoffschläuchen braun gestrichelt. [\$ Cymbalaria.] - Oestl. Mmgbt.

S. Cymbalaria L.

S. spindelförmig oder länglich. Blb. gewöhnlich weiss.

I. Bl.achse schüssel- oder becherförmig; Nektar ausscheidender Discus, wenn vorhanden, hypo- oder perigyn.

1. Stf. pfriemelig. Gr. kurz. Kapsel länglich-eifürmig.

+ Kb. an der Fr. abstehend oder zurüickgeschlagen. Blb. längiich. B. meist nierenförmig, klein gelappt oder gekerbt.

A Wurzelstock \%. Bulbillen fehlend. [\$ Iri*copetalum.] Pyren. bis Karp. u. Kauk.

^^ iVurzelstock $\odot$ oder $(.$. . Häufig Bulbillen in den Achseln der Grundb. [\$ Nephrophyllum.] S. granulata L. ++ Kb. aufrecht. Blb. verkehrt-eiförmig, ausgerandet. Hapaxanth, meist $\ldots$, mit Rosette spateliger oder keiliger, 3bis 7-lappiger Grundh. [\$ Tridactylites.] S. tridactylites L.

2. Stf. fädlich oder keulig. Frkn. kurz eiförmig oder kugelig. $\mathrm{Kb}$. an der Fr. meist abstehend oder zurüickgeschlagen. Blb. elliptisch oder lanzettlich. ?. meist mit (irundhlattrosette. [\$Boraphila.] - Circumpolare Glacialpflanze. S. stellari: L. II. Bl.achse kreiselförmig oder glockig, mit dem Frkn. vereinigt. Discus epigynisch. Kapsel kugelig oder eiförmig. [\$ Dactyloides.] S. decipiens Ehrh.

b. Haare vielzellig, mehrreihig.

๔. B. ohne kalkausscheidende Grübchen am Rande.

I. B. gelappt, Grundb. auch doppelt gekerbt mit hreiter, gefianster Scheide. Blïtenachse schüsselförmig. Stf. keulig. 2 Blb. sind grösser, rein weiss. 3 kleiner u. bunt gefleckt. [\$ Diptera.] - China, Japan.

S. sarmentosa L.

II. B. linealisch oder lanzettlich, seltener breit spatelig. ganzrandig oder gezähnt oder gewimpert. Stf. fädlich.

1. Blachse flach. Kapsel eilänglich. B. ganzrandig. gefranst. Blb. gelb, am Grunde mit 2 oder 4 Drüsen. [s Hirculus.] Circumpolare Glacialpflanze (bis Alp.. Kauk., Himalaya:

S. Hirculus L.

2. Bl achse $\doteq$ becher- oder schüsselfürmig. Lapsel eikugelig: B. fleischig oder lederig, starr, ganzrandig oder borstig sewimpert. [\$ Trachyphyllum.] - Circumpolare Glacialpflanze.

S. aizoides $\mathrm{L}$.

III. B. keilförmign, spatelig oder rundlich-eiförmig, am Rande gekerbt oder gezïhnt und mit (rrïbchen, aber ohne Kalkausscheidung. Bl.achse flach. Kib. schon in der Bl. zurïckgeschlagen. Stf. keulig. Kapsel eilänglich. \$ Robertsoniaj.

1. Grundb. - verkehrt-eilänglich, in einen flachen Stiel ïbergehend. $\bar{B}$ lb. weiss, am Grunde punktiert. $1-2$ dm. Pyrenäen bis Apenninen u. Siebenbürgen. S. cuncifolia L.

2. Grundb. ei- oder kreisrund, Stiel halbrund oder cylindrisch. Blb. wie bei ror. 2-3 dm. Pyrenäen u. Irland. S. Geum L. P. B. mit kalkausscheidenden Grübchen am Rande. Bl.achse becherförmig. Kb. aufrecht. Kapsel eikugelig. 
I. B. spiralig. Blb. meist weiss.

1. Secundäre Sprosse von den primären frühzeitig sich loslösend. [\$ Euaizoonia.]

+ Stengel von unten an rispig verzweigt, bis ${ }^{1}{ }_{2} \mathrm{~m}$. Blb. keilförmig. Pyrenïen bis Kärnthen u. Island. S. Cotyledon L. ++ Rasig. Stengel nur oberwärts rispig. Blb. verkehrteirundlich. Gbge. von Kuropa.

S. Aizoon Jacq.

2. Secundäre Sprosse durch stärker verholzende Stengel mit den primären inniger verbunden. [\$ Kabschia.] - Pyrenäen bis Apenninen und Karpathen, kalkliebend. S. caesia L.

II. B. gegenständig, dick, ganzrandig, am Grunde gewimpert. Blb. gewöhnlich purpurn oder violett. [\$ Porphyrion.] _ Pyrenäen - Skandinavien - Altai - Tibet-Rocky Mountains.

S. oppositifolia L.

B1. Placenten wandständig. Frb. zu einem 1-fächerigen Frkn. vereinigt, aber Gr. getrennt.

A. Bl.achse glockig bis röhrig; Frkn. ganz oder oberwärts von ihr frei. Blb. vorhanden.

A3. Blb. ungeteilt.

At. Bl.achse glockig. Sth. 5. Trugtolden, eine Rispe oder Scheinähre bildend. Stauden mit langgestielten, handnervigen, gelappten Grundb. und bis ${ }^{1 / 2} \mathrm{~m}$ hohem, blatt. armem Blütenstengel. N.-Am. Heuchera (24).

a. K. klein (bis $5 \mathrm{~mm}$ lang).

a. Cymen armblütig, gedrängt. Bl. klein. Stb. höchstens so lang als die Kb. Rocky Mountains des Oregongbt.

$H$. parvifolia Nutt.

3. Cymen - reichbliitig und locker. Stb. 2-4 mal länger als die $\bar{K} b$.

I. Blb. grïnlich oder weisslich, 1 bis $1^{1 / 2}$ mal so lang als die Kb. Atl. N.-Amerika.

II. Blb. weiss, $2-3 \mathrm{mal}$ so lang als die $\mathrm{Kb}$.

1. K. grünlich. Nordkaliforn. H. pilosissima Fisch. et Mey.

2. K. bei der Fruchtreife vergrössert und rötlich. Pacif. N.Amer.

b. K. gross (7-9 $\mathrm{mm}$ lang).

a. Cymen locker. Nördl atl. N.-Am. H. hispida Pursh

ア. Cymen knäuelartig. K. prachtvoll rot. Nordmexiko.

H. sanguinea Engelm.

Bt. Bl.achse schief-röhrig. Blb.haarförmig. Stb.3. Bl. in'Trauben. Pac. N.-Am. Tolmiea (1) Menzicsii (Hook.) Torr. et Gray

B3. Blb. meist geteilt. Bl. in Trauben. $10 \mathrm{Stb}$. Tellima (7). Blb. fiederspaltig. ${ }^{1 / 2} \mathrm{~m}$ hohe Staude mit rundlich-herzfürmig., gelappten B. Pac. N. Am. T. grandiflora (Pursh) R. Br.

B2. Bl.achse kreiselförmig, mit dem Frkn. vereint. Blb. fehlend.

Chrysosplenium (40).

a. $: 2-1^{1 / 2} \mathrm{dm}$ hohes, hygrophiles Pflänzchen mit goldgelben Bl. und Deckb., 3-kantigem Stengel und wechselstïndigen, rundlichnierenfg., gekerbten B.

C. alternifolium $\mathrm{L}$.

b. B. gegenständig, kurzgestielt. Stengel 4-kantig. Sonst wie vorige. 
2. Frkn. 1-fächerig, Placenten wandständig. 3-4 Frb., N. u. Fruchtklappen. Gr. kurz oder fehlend. [Parnassieae.]

Parnassia (19) palustris L. II'. Bl.4-zählig. Frkn. 4-fächerig. [Francoideae.] - Chile. B. leierförmig-fiederspaltig. Trauben. Francoa (2) appendiculata Cav.

II. Holzpflanzen, allermeist Sträucher:

I'. Frkn. ober- bis unterständig, 2- bis 7-fächerig.

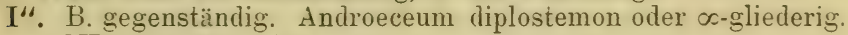
[Hydrangeoideae.]

1. Bl. alle gleichartig. Stf. meist flach. Fr. scheidewandspaltig, die einzelnen Frb. häufig nach innen fachspaltig. [Philadelpheae.]

A. Knospendeckung der Blb. gedreht. Stb. $x$. Bis 5 m hohe Sträucher. Haare einfach kegelig. Philadelphus (22).

a. Gr.enden so lang und breit wie die A. O.-Alp., Siebbürg., Kauk., O.-As.

$P$. coronarius L.

b. Gr.enden 2-3 mal so lang und breit wie die A. Tirginia, Georgia.

$P$. grandiflorus Willd.

B. Kinospendeckung der Blb. (quincuncial oder) klappig. Stb. 10 (selten bis 15). B. mit Sternhaaren. Deutzia 10).

a. Aeussere (längere) Stf. zahnlos, kürzere mit 2 kleinen Zähnen. B. scharf gesägt. S.-Japan. D. scabra Thbg.

b. Alle Stf. mit 2 grossen Zähnen unter den A.

๑. Aeussere Stb. wenig kürzer wie Blb. B. eifürmig, gekerbt, rauh. Japan.

D. crenata Sieb. et Zucc.

F. Stb. etwa halb so lang wie Blb. B. lanzettlich, gesägt, kahl. S.-Japan.

D. gracilis Sieb. et Zucc.

2. Peripherische Bl. des Bl.standes häufig steril, mit grüsseren K̉b. Stf. meist fädlich. Knospendeckung der Blb. meist klappig. [Hydrangeeae.] Hydrangea (30).

a. Blb. bis nach dem Ausstäuben der A. stehen bleibend. S. ungeflügelt. Atl. N.-Am.

a. Straussartige, ei- oder pyramidenförmige Rispe. B. buchtig3- bis 5-lappig.

H. quercifolia Bertr.

3. Flache Schirmrispe. B. ei-herzförmig, zugespitzt, gesägt. gezähnt.

$H$. arborescens $\mathrm{L}$.

b. Blb. frühzeitig abfallend. S. an beiden Enden geflügelt. O.-As.

o. Nur die Randbl. unfruchtbar. Frkn. vollständig gefächert. B. nicht tief gesägt.

H. paniculata Sieb.

f. Meist fast alle Bl. unfruchtbar. Frkn. eigentlich nur gekammert. B. mit grossen, scharfen Sägezähnen.

H. Hortensia D.C.

II". B. spiralig, oft lederig und drüsig-gesägt. Androeceum haplostemon. [Escallonioideae.

Frkn. halbunterständig oder unterständig. - Andin. S-Am.

Escallonia (50) rubra (Rz. et Pav.) Pers.

II‘. Frkn. halb unterständig oder unterständig, 1-fächerig mit zwei wandständigen Placenten.

I“. B. gegenständig, 3-teilig. Bl. einzeln achselständig. Frkn. halbunterständig. Fr. eine fachspaltige Kapsel. [Baueroideae.]

Bauera (3).

Bl. gestielt. $\propto$ Sa. B.chen gesägt. S.-O.-Austr. B.rubioides Andr. II". B. spiralig, einfach. Bl. in (zuweilen 1-blütigen) Trauben. 
Frkn. unterständig, 1-fächerig mit 2 wandständigen Placenten. Fr. eine Beere. [Ribesioideae.]

Ribes (50).

a. B. in der Knospenlage gefaltet. Bl.achse schüsselförmig oder meist glockig (selten cylindrisch).

๙. Meist stachellos. 'Trauben vielblütig. Bl.stiele verkürzt, gegliedert. Vorb. selten fellend, zuweilen an der Fr. bleibend. Stb. oft kürzer als Kb. Beeren meist kugelig. [\$ Ribesia.] I. A. mit getrennten Thecis an kurzem Connectiv; Stb. kurz. Traube meist vielblütig. [\$§ Rubra.]

1. Stachellos. B. nicht borstig.

$+\mathrm{Kb}$. abstehend. Gr. bis zur Hälfte verwachsen.

- Bl.achse schüsselförmig. Bl. grünlich. R. rubrum L. (-) Bl.achse glockenförm. Bl. bräunlichrot. R petraeum Wulf. + + Kb. zurückgebogen. Stb. und Gr. hervorragend. BI. grünlich. Sardin. bis China. R. multiflorum Kit.

2. Sehr stachelig. B. borstig. Bl. gelblich od. rötlich. N.-Am. $R$. lacustre Poir.

II. A. breiter als lang, 2-lappig, aber die Thecae fast ihrer ganzen Länge nach verbunden. Bl. grünlich oder trübgelb, klein. polygam oder diöcisch; Frkn. in den $\sigma^{7}$ Bl. fadenförm. Bl.achse schüsselförmig. 'Tragb. u. Vorb. gross. [\$\$ Alpina.]

1. Ohne oder mit nur sparsamen Drüsenhaaren.

+ Normale Trauben.

$\odot$ Stachellos.

R. alpinum L.

$\odot$. Zweige mit kleinen Stacheln. NördI. As. R. Diacantha Pall. + Traubenachse verkürzt; Bl. daher in Büscheln. O.-As.

R. fasciculatum Sieb. et Zucc.

2. Zahlreiche klebrige Drüsenhaare an B.stielen, B.flächen, Trauben uud Fr. Griechld.-W.-Himal. $R$. orientale Desf.

III. Stf. zungenförmig; Thecae der A. am Rücken der ganzen Länge nach zusammenhängend; Connectiv an der Spitze mit Grübchen. Bl.achse meist glockig. Bl. meist grünlichgelb. B. an der Spitze besonderer 'Triebe, unterseits oft mit Harzkügelchen, stark riechend. 'Trauben reichblütig an besonderen, meist unbeblätterten Seitensprossen. [\$S Nigra.]

1. Bl.achse oberhalb des Frkn. schüsselförmig erweitert. Pac. N.-Am.

$R$. bracteosum . Dougl.

2. Bl.achse oberhalb der Frkn. plötzlich glockenförmig erweitert. Gr. ungeteilt. B. unterseits \pm behaart. O-Eur. bis Amur. R. nigrum $\mathrm{L}$.

3. Bl.achse oberhalb des Frkn. allmählich glockig oder cylindrisch erweitert.

+ 'Tragb. der Bl. verkehrt-eiförmig oder breit-lanzettlich.

$\odot$ Stb. in gleicher Höhe mit den Blb. eingefügt. Bl. purpurrot, deutlich gestielt. Frkn. über die Tragb. hinwegragend. Pac. N.-Am. R. sanguineum Pursh

$\odot \odot$ Stb. tiefer als die Blb. eingefügt. Bl. wachsweiss, kurzgestielt oder sitzend. Frkn. von den Tragb. bedeckt. Pac. N.-Am.

$R$. cereum Dougl.

+ + Tragb. der Bl. schmal, lanzettlich oder linealisch. Atl. N.-Am., Quito. $R$. floridum L'Hér. 
F. Meist 1, 3 oder 5 Stacheln unter der B.basis und ausserdem am Stengel zahłreiche dünnere Stacheln zerstreut. Trauben 1- bis 3.bluitig. Torb. selten vorhanden. Bl.achse meist $\doteq$ glockig. Thecae der A. ganz zusammenhängend. Beeren gross, eiförmig, oft borstig. [\$ Grossularia.]

I. Stb. selten etwas länger als die $K b$. Sa. $\infty$ in mehreren Reihen. [\$S Eugrossularia.]

1. A. eiförmig oder rundlich, stumpf.

+ Bl.achse innen und Gr. zottig.

$\odot$ Stb. so lang wie die Blb. Bl. grünlich-rütlich. Brit. N.-Am.

○ Stb. 2-5 mal so lang als die Blb.

$R$. oxyacanthoides L.

A Stf. kahl oder schwach behaart, A. kahl. Bl. grünlichrötlich.

R. Grossularia L.

^^ Stf. und A.zottig. Bl. weiss. Pac. N.-Am. R. nireum Lindl.

++ Blachse immen und Gr. kahl. Frkn. und Fr. in der Mitte mit einem Kranze weniger, platter, drïsenloser Stachelborsten. Bl.grünlichweiss. Nördl. atl. N.-Am. R. Cynosbati I,

2. A. pfeilförmig, stachelspitzig. Bl. rot. Frkn. und Fr. allseitig dicht und lang igelstachelig. Kalif. R. Menziesii Pursh

II. Stb. mehr wie doppelt so lang als die linealischen $\mathrm{Kb}$. Blb. purpurn. Sa. wenige, 2-reihig. Kalif. $R$. speciosum Pursh

b. B. in der Kinospenlage eingerollt. Trauben mehrblütig. Bl. gelb. Bl.achse lang cylindrisch; Kib. 3-4 mal kürzer. Beere kahl, vielsamig. Ohne Stacheln. [\$ Siphocalyx.] Pacif. N.-Am. R. aureum Pursh

\section{Hamamelidaceae $(18 ; 50)$.}

I. $\infty$ Sa. in jedem Fach des Frkn. Drusen im B.parenchym; das Biindelstereom der Laubb. fehlend oder nur schwach entwickelt. [Bucklandioideae.] Blb. fehlend. Leitbündel mit centralem Balsamgang. [Altingieae.]

Liquidambar (4).

a. B. derb, handförmig 3- oder 5-schnittig; Abschnitte eilanzettlich, meist lang zugespitzt, reichlich und tief gesägt, nicht weiter geteilt. Atl. N.Am.

L. styraciflua L.

๖. B. zart, handförmig 5-oder 7 -schnittig; Abschnitte am Grunde parallelrandig oder eingezogen, wenig und klein gekerbt, oben einfach spitz oder stumpf, oft nochmals gelappt. Kleinas.

L. orientalis Mill.

II. $1 \mathrm{Sa}$. in jedem Fach des Frkn. Einzelkrystalle im B.parenchym; das Bündelstereom der Laubb. mächtig entwickelt [Hamamelidoideae.]

1. Stf. lang, fädlich; Connectiv meist dünn. Bl. in Aehren, die meist von häutigen, schwach gefärbten Hochb. umbüllt werden. [Parrotieae.]

A. Bl. apetal. Zahl der Kb. und Stb. wechselnd. Gr. spitz; N. schmal, an der Innenseite herablaufend.

A1. A. lang oval, in ein Spitzchen auslaufend, mit seitlichen Längsspalten aufspringend. Parrotia (1) persica (D.C.) C. A. Mey.

B1. A. kurz, abgestutzt, mit 2-flügeligen, seitlichen Klappen aufspringend. - Atl. N.-Am. Fothergilla (2) Gardeni L. 
B. Blb. vorhanden. Bl. 5-zählig. N. schwach kopfig. Corylopsis (6).
A. mit Längsspalten. Japan.
C. spicata Sieb. et Zucc.

2. Stf. kurz, dick oder breit; Comnectiv dick. Bl. in Köpfchen; die sterilen Hochb. der Bl.standsachse meist schuppenförmig: [Hamamelideae.]

A. Köpfchen höchstens 5-blütig. Kronstb. in schuppenförmige Staminodien umgewandelt. A. mit Klappen. - Atl. N.-Am.

Hamamelis (3) virginiana $\mathrm{L}$.

B. Köpfchen vielblütig. Kronstb. völlig geschwunden. A. mit Klappen. - S.-Afr. Trichocladus (2) crinitus Pers.

\section{Platanaceae (Platanus, 2).}

a. B. meist mit $5(3-7)$ Hauptnerven und Lappen, die lanzettlich oder unterwärts parallelrandig sind. Nmgbt. $P$. orientalis L.

b. B. meist mit $3(-5)$ Hauptnerven und Lappen, die eiförmig und öfters ziemlich lang zugespitzt. N.-Am. P. occidentalis L.

\section{Rosaceae (90; 2000).}

I. Teilfr. (meist an der Bauchnaht balgfruchtartig) aufspringend, nicht mit der Bl.achse verwachsen. Stf. aus breiter Basis nach oben verschmälert. [Spiraeoideae.]

1. Bl. höchstens $1^{1,}$ em im Durchmesser. Teilfr. frei oder nur am Grunde verwachsen, 2- bis oc-samig. S. ungeflügelt. Nebenb. zuweilen fehlend. [Spiraeeae.]

A. S.schale glänzend, steinhart. Frb., wenn isomer (5), mit den Kíb. abwechselnd. B. ganz oder nur gelappt; Nebenb. ziemlich gross.

A1. Teilfr. aufgeblasen, 2-klappig aufspringend. Physocarpus (4).

a. Frkn. u.'T'eilfr. grauweiss, sternfilzig, letztere schmal-länglich, kaum länger als die Ḱb. Amurgebiet. $P$. amurcnsis Maxim.

b. Frkn. und Teilfr. kahl, letztere eiförmig, viel länger als die Kb. N.Am. $P$. opulifolia (L.) Maxim. B1. 'Teilfr. nicht aufgeblasen, nur an d. Bauchnaht aufspringend. A2. Gr. endständig. Balgkapseln mehrsamig. Kb. zugespitzt. Neillia (3).

B2. Gr. an der Fr. seitlich. Balgkapseln 1- bis 2-samig. Kb. abgerundet.

B. S.schale häutig oder lederig.

Stephanandra (3).

A1. Frb. mit den Kelchb. abwechselnd. Nebenb. fehlend.

A2. Stb. am Rande der Bl.achse.

A3. Fr. nur an der Bauchnaht aufspringend.

At. Frb. frei. S. ohne Nährgewebe.

Spiraea (40).

a. Bl. in pyramidenförmigen, dichten Rispen. [\$ Spiraria.] ๙. Kb. von der Bl.zeit an zurückgeschlagen. Ohne Drüsemring. I. Triebe kahl oder \pm grau-weichhaarig. B. unterseits grauweissfilzig. Pac. N.-Am. S. Douglasii Hook.

II. Triebe und B.unterseite rostfarbig-filzig. Atl. N.-Am.

S. tomentosa L.

3. Kb. an der Fr. aufrecht. Starker Drüsenring. B. unterseits grün.

b. Bl. in Schirmrispen. [§ Calospira.] 
๑. Stb. kaum länger als die stets weissen Blb. Bl. ?. stets mit gekerbtem Drüsenring. Bl.stand kahl. Krain.

S. decumbens W. Koch

3. Stb. mindestens $1 \frac{2}{3} \mathrm{mal}$ so lang als die Blb.

I. Bl.stand weichhaarig bis filzig. Blb. karminrot. Drüsenring vollkommen. Japan.

II. Bl.stand durchans kahl. Pac. N.-Am.

1. Drüsenring fehlt. Stb. etwa 50. Blb. schön dunkelrosa.

S. rosea (A. Gray) Koehne

2. Drüsenring stark entwickelt. Sth. etwa 20. Blb. \pm gelblichweiss.

+ Stb. 2 bis kaum 3 mal so lang als die Blb. Gr. wenic länger als die Frkn. Auch N.-O.As. S. betulifolia Pall. $++\mathrm{Stb}$. über $3 \mathrm{mal}$ so lang als die Blb. Gr. über 2 mal so lang als die Frkn. S. corymbosa Raf.

c. Bl. in Doldentrauben od. einfachen Dolden. [\$ Chamaedryon.]

$\%$ Doldentrauben auf beblätterten Stielen, die längs rorjähriger Zweige entspringen.

I. Frkh. aufrecht-abstehend. Ndl. C.-As. S. trilobata L.

II. Frkb. zurückgeschlagen. Balk. bis Jap.S. chamaedryfolia L.

¿. Dolden längs vorjähriger Zweige sitzend, am Grunde nackt oder von einigen verkïmmerten Laubb. oder Knospenschuppen umgeben.

I. B. mit zahlreichen, scharfen Sägezähnen, freudiggrün. sehr spitz, lineal-lanzettlicb. O.-As. S. Thunbergii Sieb.

II. B. ganzrandig oder an Langtrieben rorn mit wenigen Kerbzähnen, grau- oder bläulichgrün.

1. B. verkehrt-eiförmig, 3- bis 5-nervig. Sdl. C.-Eur

S. obovata W. et K.

2. B. verkehrt-lanzettl. O.-Russl, C.-As. S. hypericifolia L.

B*. Frb. am Grunde verwachsen. S. mit Nährgewehe. Bl. 1-geschlechtig. Altai, Thianschan.

Sibiraea (1) laevigata (L.) Maxim.

B3. Frb. frei. Teilfr. 2-klappig aufspringend. Stb. am Grunde verwachsen. Nordwestl. N. Am. Eriogynia (1) pectinata Hook.

B. Stb. auf d. Innenfläche der Bl.achse. Aruncus (2) silvester Kost. $B_{1}$. Frb. vor den Kb. stehend. Nebenb. vorhanden.

A2. Blb. dachig. Frb. am Grunde verwachsen. Sa. hängend. - N.As. Basilima [Sorbaria] (4) sorbifolia (L.) Raf.

B.. Blb.ind. Knospe gedreht. Frb. frei. Sa.aufsteigend.Gillenia (2).

2. Bl. wenigstens $3^{1 / 2} \mathrm{~cm}$ im Durchmesser. Teilfr. 2-samig. S. mit Flügelrand. Nebenb. vorhanden. [Quillajeae.]

A. Frb. frei. $10 \mathrm{stb}$ - Chile. Quillaja (3) Saponaria Mol. B. Frb. nur an der Bauchnaht bis über die Mitte rerwachsen. 5 -fächerige Kapsel. $15-30 \mathrm{Stb}$ - China.

Exochorda (3) grandiflora (Hook.) Lindl.

II. Teilfr. nicht aufspringend. Nebenb. fast stets [s. S. 197] rorhanden.

I'. Frb. $2-5$ wenn 5 , mit den Blb. alternierend), mit der ausgehöhlten und zur Fr.zeit fleischig werdenden Bl.achse \pm rerwachsen, oft $z u$ einem unterständigen Frkn. vereinigt, mit allermeist je 2 aufsteigenden Sa. Pomoideae.]

Niedenzu, Botanische Bestimmungsübungen. 
1. Frb. zu getrennten Steinen mit knochenharter Wand werdend. [Crataegeae.]

A. In jedem Frb. 2 gleiche Sa. Frb. an der Bauchseite unter sich völlig oder fast völlig frei.

Cotoneaster (25).

a. 5 Frb. B. gekerbt oder kleingesägt. Doldenrispe sehr reichblütig. Oestl. Mmgbt.

b. 2-3 Frb. B. ganzrandig.

». Blb. ausgebreitet. Gr. dem Gipfel der Frb. eingefügt. B. rundlich, gelbgrünfilzig. Doldenrispen mehrblütig, dicht. Halbfr. rot. Vord.-As. C. nummularia Fisch. et Mey.

Blb. aufrecht. Gr. den Frb. unterhalb des Gipfels eingefügt. I. Halbfr. rot.

1. Bl.achse und Kb. aussen kahl. N. so breit wie d. Gr.

2. Bl.achse und $\mathrm{Kb}$. aussen behaart.

C. integervima Medikus

+ B. beiderseits, Bl.achse u. Kb. bleibend anliegend steifhaarig. Halbfr. glänzend. Himal. C. acuminata (Desf.) Lindl.

++ B. oberseits weichhaarig, bald kahl, unterseits sowie Bl.achse und $\mathrm{Kb}$. weissfilzig. Halbfr. glanzlos ziegelrot.

C. tomentosa (Ait.) Lindl.

II. Halbfr. zuletzt schwarz. Bl.achse kahl. N. doppelt so breit wie Gr. C. nigra Whlbg.

B. In jedem Frb. 2 ungleiche Sa. (die langgestielte unfruchtbar) oder nur 1 Sa.

A1. Frb. in der oberen Partie der Bauchseite frei, Steine mit Vorhemd. B. einfach- oder doppeltgesägt, ausserdem oft fiederlappig bis -teilig. Bl. in Schirmrispen. Stb. 10-20(5). Meist dornig.

Crataegus (36).

a. B. der kurzen Bl.zweige einfach- od. doppeltgesägt od. seichtgelappt ohne Buchtnerven.

ø. Steine innenseits ebenflächig. Atl. N.-Am.

I. B.stiele drüsenlos (selten mit vereinzelten Drüsen).

1. Kb. auf der Halbfr. aufrecht abstehend. C. Crus galli I.

2. Kib. auf der Halbfr. zurückgekrïmmt oder -geschlagen.

C. punctata Jacq.

II. B.stiele mit einigen dicken, schwarzen Drüsen. Alle B. seicht gelappt.

C. coccinea L.

3. Steine imnenseits mit 2 tiefen Eurchen. Kb. auf d. Halbfr. zurückgebogen oder -geschlagen.

I. Frb. mit breiter, freier Gipfelkante, Steine deshalb mit breitem, mindestens 1/3 des (Gipfels bedeckendem Vorhemd.

1. Stb. gegen 20. Halbfr. leuchtend blutrot (selten gelb). Sib., Amurgbt.

C. sanguinea Pall.

2. Stb. etwa 10. Halbfr. schwarz. Pac. N.-Am. C.rivularis Nutt.

II. Frb. mit schmaler, freier Gipfelkante. Vorhemd sehr schmal. Kb. meist dicht- und feindrüsig-gesägt. Halbfr. gelb, oberwärts \pm rot. Atl. N.Am.

C. tomentosa $\mathrm{L}$.

b. B. durchweg deutlich gelappt und mit Buchtnerven

7. Steine innenseits mit 2 Furchen od. nur 1 Stein. Halbfr. blutrot.

I. 2-4 Gr. u. Steine, letztere ohne krustige Hülle. C. Oxyacantha I.

II. 1 Gr. u. Stein (selten 2), mit brüchiger, krustiger Hülle. 
3. Steine innenseits ebenflächig.

I. Kb. auf der Halbfr. bleibend.

1. Halbfr, rot oder gelb.

- B. 3. bis . J-teilig. Kb. innen fast kahl. Stb. wenig länger als Bl.achse. Frb. 2-3. Vord.-As. C. Azarolus L. ++ B. 5 - bis 9 -teilig. Kb. innen dicht behaart. Stb. viel länger als Bl.achse. Frb. (3-) 5. Oestl. Mmgbt. C.tanacetifolia D.C:

2. Halbfr. schwarz oder schwarzviolett. Meist 5 Frb. B. 9- bis 13-lappig. Kroat. bis Siebbürg.

C. nigra $\mathrm{W}$. et $\mathrm{K}$.

II. Kb. auf der korallenroten Halbfr. scharf abgegliedert und zuletzt abfallend. Atl. N.-Am.

C. cordata Ait.

B1. Frb. auch am Gipfel von einer fleischigen. schüisselförm. Scheibe bedeckt. Steine deshalb ohne Torhemd. allseitig rom Fr.fleisch umbüllt. B. ganzrandig (selten etwas stumpfgesägt). Bl. einzeln. Stb. 30-40. Dornenlos. Mespilus (2) germanica L

2. Die $2-5 \mathrm{Frb}$. nicht steinartig. sondern häutig bis pergamentartig werdend.

A. Frb. mit je co Sa. in 2 Längsreihen.

C'ydonia (4)

a. B. ganzrandig, anfangs unterseits filzig. Kíb. bleibend. Blb. blass. rosa. Gr. frei. Halbfr. anfangs wollig. Mmgbt. C. vulgaris Pers.

b. B. gesägt, kahl. Kib. abfallend. Blb. scharlachrot. Gir. unterwärts verwachsen. Halbfr. kahl. Japan. C. japonica Pers. B. Frb. mit je 2 Sa.

A. Bl. in Trauben. Frb. durch falsche Längsscheidewände 2-kammerig.

Amelanchier (9)

a. B. beiderseits gerundet. Blb. aussen wollig. Frkn.gipfel lang. und dichtwollig. Gr. frei. A. vulgaris Mönch

b. B. kurz zugespitzt. Blb. aussen kahl, auch Frkn.gipfel. (ir. bis ïber die Mitte verwachsen. Atl. N.-Am.

A. canadensis (L.) Torr. et Gray

B1. Bl. in Schirmrispen oder Schirmtrauben. Frb. rein 1-fächerig.

A2. Frb. völlig mit einander verwachsen. Kernhausscheitel frei und eine hohle, gewölbte Kuppel bildend. Photinia (2.2).

a. Immergrün. Schirmrispe niedrig-pyramidal. Gr. frei. S.haut ohne Harzgänge. O.-As.

P. glabra Maxim.

b. Sommergrün. Schirmrispe flach. Gr. am Grunde verwachsen. S.haut mit netzigen Harzgängen. O.-As. P. villosa (Thbg.) D.C:

B2. Frb. meist an der Bauchseite einen Hohlraum umschliessend und am Scheitel von d. Bl.achse überdeckt; wenn aber wie bei Photinia, dann der Kermhausscheitel einen soliden Kegel bildend.

Pirus (46).

a. B. in d. Knospenlage gefaltet. Frb. 2-3 (bei \$ronia 5).

э. Frb. innen nur ganz am Grunde verwachsen, aussen bis zur halben Rückenhöhe der Bl.achse eingesenkt, sonst friv. B. gefiedert. [\$ Sorbus, 4.] P. Aucuparia (L.) Grtn.

Frb. längs der Bauchnaht unter sich verwachsen. (\$ Aria, \&. I. Blb. rosa, aufrecht. B. unterseits stets kahl. P. Chamaemespilus (L.) Host.

II. Blb. weiss, ausgebreitet. B. unterseits bleibend weissfilzig.

1. B. doppeltgesägt od. seicht eingeschnitt. P. Aria (L.) Ehrh.

2. B. mit etwa bis ${ }^{1} \cdot 3$ od. ${ }^{1}{ }_{2}$ eindringenden Einschnitten. N.-Kur.

$P$. scandica (L.) Babingt. 
$\because$ Frb. seitlich unter sich verwachsen, aber mit den freien Bauchnähten einen offenen Mittelraum umgebend.

I. Frb. oberwärts von der Bl.achse frei.

1. B. gefiedert (od. doppeltgesägt). Der von der Bl.achse freie Frkn.gipfel kegelig. (ir. kaum verwachsen. \$Cormus, 3.] - Mimgbt. $P$. domestica (L.) Sm.

2. B. einfachgesägt. 5) (4) Frb. Der von d. Bl.achse freie Frkn.gipfel halbkugelig. Gr. unterwärts verwachs. [Aronia, 2.] N.-Am. $+\mathrm{Bl}$.stiel, -achse und $\mathrm{K} \mathrm{b}$. aussen weisslichfilzig. Halbfr. rot. $P$. arbutifolia (L.) Nutt. ++ Kb. und Bl.achse kahl. Halbfr. schwarz. P. nigra Willd. 1I. Fro. bis an den Gr.grund mit der Blachse verwachsen. B. fiederlappig. [\$ Torminaria, 1.] P. torminalis (L.) Ehrh.

b. B. in der Knospenlage gerollt, stets ungeteilt.

\%. A. rot od. rotbram. Gr. frei, aber eine Strecke weit von einer dicken, inneren Anschwellung der Bl.achse eingeschnürt. Fleisch d. Halbfr. mit eingestreuten Steinzellen. [Pirophorum, 14.]

I. K. auf d. Halbfr. bleibend. [\$ Achras. $]$

1. B. gekerbt oder gesägt.

+ Sägezähne begramnt. Amurght., N.-China. P. sinensis Lindl.

++ Sägezähne unbegrannt.

$P$. communis $\mathrm{L}$.

2. B. ganzrandig oder nur sehr schwach kerbig-gesägt.

+ B.filz zur Fr.zeit \pm geschwunden.

Winkel zwischen Mittel- u. Seitenrippen $>1 / 2, \mathrm{R}$.

A Halbfr. birnförmig. B. $6-10 \mathrm{~cm}$ lang, zuweilen vorn mit Zähnen. S.-Eur., Alp. 1'. nivalis Jacq.

A^ Halhfr. kugelig. B. 2-6 $\mathrm{cm}$ lang, ganzrandig. Vord.-As. P. persica Pers.

Winkel zwischen Mittel-u. Seitenrippen $<1 / 2$ R. Halbfr. kugelig. Balkanhalbins., Kleinas. I'. amygdaliformis Vill. ++ B.filz unterseits bleibend. Halbfr. birnförmig.

B. \pm länglich-lanzettlich, anfangs wollfilzig. Gir. bis üker die Mitte wollig. Kírim, Vord-As. P. clacagrifolia Pall.

.) B. schmal-lanzettlich, anfangs seidenhaarig. Gr. nur am Grunde wollig. 'T'ranskaukas. I'. salicifolia L. f.

II. K. abfallend, Ringnarbe auf d. Halbfr. zurïcklassend. [ Pashia - Orient.

1. cordata Desv.

‘. A. gelb. Gr. unterwärts verwachsen. Fleisch d. Halbfr. ohne Steinzellen. Malus, 11.]

I. K. auf d. Halbfr. bleibend. [\$ Calycomeles.]

1. Halbfr. unmittelbar vom K. gekrönt, oben und unten vertieft. + Erwachsene B. glänzend, nur unterseits an d. Nerven etwas flaumhaarig, plötzlich zugespitzt. P. Malus L. ++ Erwachsene B. wenigstens unterseits dauernd weichhaarig-filzig, glanzlos. S.-O--Russld., Kleinas. bis Altai.

$P$. paradisiaca Med.

2. Scheitel und Grund der Halbfr. nicht eingedrückt, Bl.achse röhrig darüber hinaus verlängert. O.-As. P. spectabilis Ait.

II. K. abfallend, eine Ringnarbe zurücklassend. [\$ Gymnomeles. | - Himal. bis Sibir.

P. baccata L.

II'. Frb. völlig unter sich und von der Bl.achse getrennt. 
I“. Frb. meist zahlreich. Teilfr. meist nüsschenartig, selten steinfrüchtig (u. dann immer $x$ ). Bl.achse bleibend, verschieden gestaltet. [Rosoideae.

1. Bl.achse flach od. schwach concav, bisweil. mitten gewölbt.

1'. Stf. aus breiterer Basis nach oben verschmälert.

1“. Frb. wenige, meist so viele als Kíb., quirlig. Sa. hängend. Stb. ss.

1“i. Nebenb. fehlend. Bl. klein, in endständigen, sehr reichblïtig. Rispen, schmutzigweiss. [Schizonoteae (Holodisceae).

Schizonotus [Holorliseus] (3) discolor (Pursh) Köhne

20“" Nebenb. deutlich. Bl.gross, einzeln od. zu wenigen.[Kerrieae.]

A. B. wechselständig. Aussenkelch fehlend. Blh. und neist auch Itynaeceum 5-gliederig. Blb. dottergelb. O.-As.

Kerria (1) japonica D.C.

B. B. gegenständig. Aussenkelch vorhanden. Blh. und meist auch fiynaeceum 4-gliederig. Blb. weiss. Japan.

Rhodotypus (1) kerrioides Sieb. et Zucc.

2“" Frb. meist sehr zahlreich, an der Wölbung der Bl.achse in ein Küpfchen geordnet, selten wenige, dann aber auch die Zahl der Stb. vermindert. [Potentilleae.]

1“". Kein Aussenkelch. Teilfr. steinfruchtartig. Frb. mit 2 Sa. Rubinae.

Rubus (200).

a. Stauden. Die blühenden Sprosse aus unterirdischen oder dem Boden angepressten Achsen entspringend.

\% B. einfach, gelappt. Bl. diöcisch, einzeln an aufrechten. beblätterten Stengeln endständig. Frb. zahlreich. Teilfr. saftreich. [\$ Chamaemorus.] Subarkt.-circumpol.

R. Chamaemorus L.

B. 3-zählig oder fussfürmig. selten nur gelappt. Bl. oder polygam. einzeln oder zu mehreren endständig. [\$ Cylactis.]

I. Stachellos. B. 3-zählig. Bl. rot. Subarktisch. R.arcticus L.

Il. Schwach bestachelt. B. 3-zählig. Bl. weiss. Palaearktisch. $R$. saxatilis $\mathrm{L}$.

b. Sträucher. Die blühenden Sprosse aus rerholzenden, 2bis mehrjährigen Stämmen entspringend.

\%. Teilfr. einzeln sich ablösend oder zu einer Sammelfr. unter sich, aber nicht mit der Bl.achse verbunden.

I. Wehrlos. B. einfach, gelappt. Bl. gross, aufrecht. B].achse flachgewölbt. [§ Anoplobatus.]

Blb. schön rot. N.-Am. $R$. odoratus L.

II. Meist an allen Achsen u.B.stielenStacheln. [\$Batothamnus.]

1. B. 3-zählig, unterseits nie filzig. Pac. N.-Am.

R. spectabilis Pursh

2. B. teils 3-zählig, teils $\cdot$-bis 7 -fiederig, unterseits meist weissfilzig. Bl.stand ohne Borsten. $R$. idaeus L.

$\therefore$ Die rotbraunen od. schwarzen Teilfr. samt dem erweichenden oberen Teile der Bl.achse (Frb.träger) abfallend. [§ Eubatus.]

I. Bl.stiele ohne Stieldrüsen. Schössling aufrecht oder hochboyig, mit gleichförm. Stacheln. meist unbereift und drüsenlos.

1. Schüssling kahl oder sehr schwach behaart. 
+ Bl.stand einfach traubig od. seine Aestchen traubig-wenigblütig, wenig bewehrt. Kb. grün, weissfilzig berandet. Aeussere B.chen sitzend oder sehr kurzgestielt. [\$\$ Suberecti.]

. Schösslingsstacheln klein, pfriemelig od. kegelig. Schüssling stumpfkantig, unten rund. $R$. suberectus Anderson

(.) Schösslingsstacheln am Grunde breit zusammengedrïckt. Schössling kantig.

$\uparrow$ Stb. die Gr. nicht überragend. $R$. plicatus W. et N. $\uparrow \uparrow$ Stb. die Gr. überragend.

R. nitidus W. et $\mathrm{N}$.

++ Rispe, oft dicht bestachelt. Kb. aussen graufilzig. Aeussere B.chen deutlich gestielt. [\$\$ Rhamnifolii.] R. vulgaris W. et N. +++ Bl.stand straussähnlich. Bl.stiele kaum bewehrt. K. weissfilzig. [§§ Candicantes.] 1 . thyrsoideus Wimm.

2. Schössling deutlich behaart. Rispe. K. aussen graufilzig. [§§ Villicaules.]

R. villicaulis Köhler

II. Áchsen mit Stieldrüsen. Schössling meist niedrig.bogig oder kriechend, im Herbst an d. Spitze wurzelnd.

1. Stacheln gleichförmig. Stachelhöcker u. -borsten oft fehlend: wenn aber solche vorhanden, damn keine Uebergänge zwischen ihmen u. d. grossen Stacheln. [\$\$ Tomentosi.] R.tomentosus Borkh.

2. Stacheln ungleichförmig; mancherlei Uebergänge zwischen Stacheln, Stachelhöckern u. Drüsen.

+ Aeussere B.chen wenigstens anfangs sitzend.

- Schössling oberwärts kantig. Teilfr. ohne deutlichen Reif. R. dumetorum Wh. et $\mathrm{N}$. O. Schössling stielrund. 'Teilfr. stark blau bereift. Ti.caesius L. ++ Aeussere B.chen deutlich gestielt. Alle Stacheln borstlich oder pfriemelig. Bl.stiele u. K. durch dichte, dunkle Stieldrüsen schwarzrot.

R. hirtus W. et $\mathrm{K}$.

2“". Aussenkelch meist verhanden. 'Trockene Schliessfr. Frb. meist mit 1 Sa.

1““. Sa. hängend. Schliessfr. nussartig. Gr.hinfällig. [Potentillinae.]

A. Bl.achse zur Reifezeit vergrössert, erweichend, saftig.

a. Nüsschen nicht in Gruben der Bl.achse eingesenkt.

Fragaria (8).

\%. Kb. zuletzt aufrecht.

I. Bl.stiele abstehend behaart. Chile, Pac. N.-Am.

F. chiloënsis (L.) Ehrh.

II. B].stiele angedrückt behaart. [F. collina Ehrh.] F.viridis Duch. K. Kib. zuletzt abstehend oder zurückgeschlagen.

[. Bl.stiele angedrückt behaart. Bl. \&.

II. Bl.stiele abstehend behaart. Bl. unvollständig diöcisch.

F. moschata Duch.

b. Nüsschen in Gruben der Bl.achse eingesenkt. Frk. abstehend. Bl.stiele angedrückt behaart. Atl. N.-Am. F. virginiana Mill.

B. Bl.achse trocken, saftarm.

A. Frb. 5-12. Stb. 4-10; Stf. fädlich. B. gefingert.-GlacialpHlanze.

B. Frb. $\infty$.

Sibbaldia (8) procumbens L.

A2. Bl.achse zur Reifezeit sehr vergrössert, gefärbt. Aussenkh. grösser als die Kb. Giog. von S.-As.

Duchesnea (2) indica (Andr.) Focke 
B.. Bl.achse meist wenig vergrüssert, ungefärbt. Aussenkb. meist kleiner als die $\mathrm{Kb}$.

Potentilla (200).

a. Fr. zottig. Niedrige Stauden. B. 3-bis 5 -zählig gefingert. Bl. weiss. э. B. 3-zählig, unterseits zottig.

Entere B. meist 5-zählig; B.chen unterseits seidenhaarig.

b. Fr. kahl. Bl. meist gelb.

P. alba L.

э. Bl.stengel endständig.

I. B. gefingert.

1. Stengel aufsteigend, nie wurzelnd. Bl.standsäste endständig. + Stengel \pm kräftig. Bl.stand \pm gedrängt. B. う̌-bis 7-zählig. - Stengel aufrecht, nebst den B. rauhhaarig. Bl. gross.

$P$. recta $\mathrm{L}$.

. . Stengel aufrecht bis fast niederliegend, nebst den $\mathrm{B}$. filzig. Bl. mässig gross.

1 Stengel aufrecht oder aufstrebend.

$\times$ B.chen nicht umgerollt. unterseits dünn graufilzig.

$P$. canescens Bess.

$X \times$ B.chen am Rande umgerollt, unterseits dicht weissfilzig.

$P$. argentea $\mathrm{L}$.

il Stengel zahlreich im Kreise ausgebreitet, fast niederliegend. B.chen unterseits dünn graufilzig.

$P$. Wiemanniana Günth. et Schummel

$+\div$ Stengel schlaff, fast niederliegend. Bl.stand locker. Grundb.

beiderseits griin, 7 - bis 9 -zählig. $P$. thuringiaca Beruh.

2. Stengel niederliegend, wurzelnd. Bl.standsäste seitlich. armblütig, meist anliegend behaart.

- Grundständige B. 7. (5- bis 9-) zählig. P. heptaphylla Lehm.

++ Grundständige B. meist 5- (bis 7-) zählig.

. Stengel, B.stiele und B. von Sternhaaren dichtgraufilzig.

$\odot$ Pflanzen mässig, nicht filzig behaart.

$P$. arenaria Borkh.

Grundständige B. zweizeilig angeordnet. B.chen am Rande und unterseits an den Nerven seidenhaarig glänzend.

$P$. aurea $\mathrm{L}$.

1/ Grundständige B. spiralig angeordnet. B.chen am Rande nicht seidenglänzend.

$\times$ B.chen länglich, einfach gesägt.

P. opaca L.

$\times \times$ B.chen verkehrt-eiförmig, am Rande abstehend behaart, vorn eingeschnitten-stumpfgezähnt. P.verna L.

II. B. getiedert, 5- bis 7-zählig.

1. Pflanzen ausdauernd. Individuen mehrstengelig.

† Bl. schwarzpurpurn. Stauden. P. palustris (L.) Scop. ++ Bl. weiss. Stauden. II.-Eur., Sibir. P. mupestris L. +++ Bl. gelb. Sträucher. Pyren., Engld., Sibir., N.-Am. P. fruticosa L.

2. Pflanzen einjährig, einstengelig. Obere B. 3-zählig.

+ Stengel aufrecht. Bl.stiele nach dem Verblühen aufrecht oder abstehend.

$P$. norvegica $\mathrm{L}$.

+ - Stengel aufsteigend oder liegend. Bl.stiele nach dem Verblühen abwärts gebogen.

$P$. supina $\mathrm{I}_{1}$. 
F. Bl.stengel in den Achseln der grundständigen B.rosette.

I. Stengel ohne Ausläufer. B. 3- (oder 5-) zählig. Blh. meist 4.gliederig.

1. Stengel aufsteigend, nicht wurzelnd. T. silvestris Neck.

2. Stengel ausläuferartig niederliegend, an den Gelenken oft wurzelnd.

II. Stengel mit Ausläufern. Blh. J̌ gliederig.

1. B. gefingert-5-zählig.

1'. procumbens Sibth.

P. reptans $\mathrm{L}$

2. B. unterbrochen gefiedert, unterseits weiss-seidenhaarigfilzig. Bl, einzeln.

$P$. anserina L.

2“". Sa. aufrecht. Schliessfr. oft mit bleibendem Gr. [Dryadinae.]

A. Gr. am Grunde abfallend. 3-5 Frb. Stb. nach dem Blühen vertrocknend.

a. Blb. am Grunde abgerundet. Siebbg., Sibir.

Waldsteinia (4)

W. trifolia (Roch.) Koch

b. Blb. am Grunde geöhrt. Galizien bis Krim. W.gcoides Willd. B. Gr. teilweise oder ganz an der Fr. bleibend.

A1. Blh. 8- bis 9-gliederig. - Glacialpflz. Dryas (2) octopetala L.

B1. Blh. 5-gliederig.

Geum (36).

a. Stengel mehrblütig. Gr. in der Mitte hakig-gegliedert: der obere Teil des $i r$. nach dem Verblühen abfallend.

\%. Bl. aufrecht. Kb. zurückgeschlagen. Fr.köpfchen ungestielt. I. Blb. gelb.

1. Unteres Glied des Grr. kahl, fast 4 mal länger als das am Grunde weichhaarige obere.

G. urbanum L.

2. [nteres Glied des Gr. am Grunde borstig, etwas länger als das fast bis zur Spitze mit feinen Borstenhaaren besetzte obere.

G. strictum Ait.

II. Blb. rot. Balkanhalbinsel. $G$. coccineum Sibth. et Sm.

¡. Bl. nickend. Kb. aufrecht. Blh, hlassrotbräunlich. Fr.köpfchen gestielt.

G. rivale I.

1). Stengel 1-, sehr selten 2-blütig. Gr. nicht gegliedert: der ganze Gr. an der Fr. bleibend.

๘. Ohne Ausläufer. B.chen ungleich gekerbt, das endstãndige fast herzförmig, stumpflappig. $\quad G$. montanum L.

$\checkmark$ Mit liegenden, beblätterten Ausläufern. B.chen scharf gesägt, das endständige 3- bis 5-spaltig. G. reptans L.

2'. Stf. mit verschmälerter Basis aufsitzend, fast keulenförmig, gleich nach dem Verblühen abfallend. [Ulmarieac.] Ulmaria (9).

a. Frb. länglich-lanzettlich od. eiförmig, mit ihrer Basis aufsitzend.

a. Frb. ganz kahl. Bl. fleischrot. Atl. N.-Am. U. rubra Hill.

F. Frb. borstig gewimpert. Bl. weiss oder hellrosa. N.O.-As.

U. palmata (Pall.) Focke U. palmata (Pall.
chseite aufsitzend.

๘. B.chen gross, eiförmig, ungeteilt, das endständige handförmig, 3-bis 5-spaltig. Fr. kahl. U. palustris Mönch

F. B.chen klein, länglich, fiederspaltig-eingeschnitten. Fr. hehaart.

U. Filipendula (L.) Hill.

2. Bl.achse becher- oder krugförmig oder röhrig.

1'. 1-5. Frb. 
1“. 1 (selten 2) Frb. Bl.achse der Schliessfr. anhängend, nicht mit ihr vïllig verwachsen. Nebenb. nur schwach entwickelt. [Cercocarpeae.]

Cercocarpus $(6)$

2“. Frb. 2-5 (selten nur 1). Bl.achse die Fr. völlig einschliessend. meist erhärtend. [Sanguisorbeae.]

A. Aussenkelch vorhanden oder durch einen Kranz von Weich. stacheln ersetzt.

A1. Gr. fast endständig. Blb. vorhanden.

A2. Statt des Aussenkelches ein mehrreihiger Kranz von hakigen Weichstacheln.

Agrimonia (10).

a. F. unterseits fast drüsenlos. Bl.achse dicht-rauhhaarig, bei der Reife mit tiefen. fast bis zum Grunde reichenden Furchen und abstehenden Stacheln besetzt. Blb. eiförmig. A. Eupatoria L.

b. B. unterseits mit zahlreichen, kleinen. gelblichen Drüsen besetzt. Bl.achse locker behaart. bei der Reife mit seichten. $n u r$ bis zur. Witte reichenden F urchen und zurückgeschlagenen Stacheln. Blb. länglich-verkehrt-herzförmig. A. odorata Mill

B2. 4- bis 5-blättriger Aussenkelch.

A3. Bl. polygam-diöcisch. Deckb. frei. Bandwurmmittel ..Flores koso". Abyssinien. Hagenia (1) abyssinica Willd.

B. Bl. D. Deckb. unter der Bl. zu einer kelchartigen. die Bl. umgebenden Hülle verwachsen. S.-O.-Eur.

Aremonia (1) agrimonioides Neck.

B. Gr. banchseitig grundständig. Blb. fehlend. Alchemilla 30.

a. Bl. in end- und seitenständigen Trugdolden. 4 Stb. Stauden.

\%. Grundb. rundlich-nierenförmig, höchsterıs bis zur Mitte 5- bis 9-lappig.

I. Lappen der unteren $\mathrm{B}$. fast halbkreisförmig, ringsum gesägt.

A. vulgaris $\mathrm{L}$.

II. Lappen der unteren B. verkehrt eiförmig, am Grunde ganzrandig. Grundb. bis ${ }^{1}$ ? eingeschnitten; B. fast oder ganz kahl. A. fissa Schummel

Grundb. bis zum Grunde 5- bis 7-teilig. A. alpina L.

b. Bl. in dichten, sitzenden, geknäuelten Trugdolden. 1 Stb. Einjährig. B. handförmig 3-teilig, am Grunde keilförmig.

A. arvensis (L.) Scop.

B. Ohne Aussenkelch und Blb. Bl.achse mit oder ohne Stacheln, aber die Stacheln keinen Kranz bildend.

A. Bl. alle @ oder Blütenachse der ơ Bl. nicht wesentlich verschieden.

A2. Blachse ohne Stacheln, an der Fr. trocken. ungefärbt. grubig, runzelig oder geflügelt. Sanguisorba (30).

a. Bl.ähren gestreckt, walzlich, rötlich. Stb. vielmals länger als die Kelchb. N.-Am. S. canadensis L.

b. Bl.ähren eirund bis kugelig. Stb. so lang oder kürzer als die Kelchb.

๘. Köpfchen eilänglich, braumrot. Alle Bl. 1 Frb. B.chen herzförmig.

$S$. officinalis $L$.

$\therefore$ Köpfehen kugelig, anfangs grünlich. später rötlich. Obere Bl. ㅇ. untere $\jmath ; 2$ Frb. B.chen eiförmig. S.minor Scop. 
B2. Bl.achse an der Fr. bestachelt. Bl. گ̧. Acaena (40). A1. Bl. diöcisch. Bl.achse an den o Bl. kurz, an den $q$ sackförmig, zur Fruchtzeit knorpelig. S.-Afr. Cliffortia (40). 2'. so Frb. Bl.achse zur Fr.zeit erweichend. [Roscae.] Rosa (100). a. B. einfach, ohne Ausgliederung von Nebenb. u. Fiederb. Blb. dottergelb. A. intrors. [Hulthenia, 1.] Pers., Turkestan.

$R$. persica D. Michaut

b. B. mit Nebenb., unpaarig gefiedert. A. seitlich aufspringend. [Eurosa.]

Gr. frei.

I. N. ein halbkugeliges Köpfchen bildend, dessen Aussenrand die innere Einfügungslinie der Stb. nicht überragt.

1. Nebenb. fast oder ganz frei, gleich den Hochb. pfriemelig u. abfallend.

+ Bl. einzeln. Kb. bleibend, nach dem Verblühen aufrecht. W.-Ind., südl. Ver. Staat. $R$. laevigata Mich.

++ Bl.stand doldig. Kb. nach dem Verblühen zurück. geschlagen, vor der Reife abfallend. S.China.

R. Banksiae R. Br.

2. Nebenb. dem B.stiel weit angewachsen, wie die Hochb. bleibend.

+ Bl. meist einzeln, ihr Stiel ohne hochblattartige Vorb. Kb. nach dem Verblühen aufrecht, bleibend.

(.) Mittlere B. der Bl.zweige meist 9-fiederig. Klb. ganzrandig. [ş Pimpinellifoliae.] R. pimpinellifolia $\mathrm{I}_{\text {. }}$.

.6. Mittlere B. der Bl.zweige 5-bis 7-fiederig. Aeussere Kb. meist mit einigen Fiederanhängseln. [Ş Luteae.] - Vord.-As. $\quad R$. Eglanteria L. (R. lutea Mill.) ++ Bl. u. Schirmrispen mit hochblattartigen Tragb. oder, wenn Einzelbl., dann 1 oder mehr Vorb.

(-) Schösslinge wie die übrigen Achsenteile mit gleichartigen, zerstreuten Stacheln. Kb. mit Fiederanhängseln. [\$s Caninae.]

| Kb. nach dem Verblühen aufgerichtet, niemals abfallend. Stacheln ganz gerade.

$R$. villosa $\mathrm{L}$.

$11 \mathrm{~Kb}$. spätestens an der ganz reifen Fr. abfallend. Stacheln meist hakig.

$\times$ B.chen beiderseits weich- und etwas seidig-behaart, bes. bei der Entfaltung dicht seidenglänzend-filzig.

R. tomentosa Sm.

$\times \times$ B.chen nur unterseits 11 . am Rande \pm driisig-behaart oder kahl.

[ B.chen unterseits auch auf d. Fläche zwischen den Nerven drüsig.

* B.chen nur unterseits drüisig. Bl.stiele meist drüsig. Kb. nach d. Verblühen allmählich aufgerichtet. Gr. stark rauhhaarig od. wollig.

$R$. rubiginosa $\mathrm{L}$.

** B.chen auch oberseits drüsig. Bl.stiele drüsenlos. Ǩ̉b. nach dem Verblïhen zurückgeschlagen. Oestl. Mmgbt. R. ferox M. Bieb. 
$\square \square$ B.chen unterseits ganz drüsenlos, meist auch die kurzen Bl.stiele.

* Kib. nach dem Verblühen aufgerichtet, bis zur Reife bleibend.

R. glauca Vill.

* * Kb. nach dem Verblühen zurückgeschlagen, \pm früh abfallend.

$R$. canina $\mathrm{L}$.

$(\odot$ Wenigstens die Schösslinge am Grunde mit zahlreichen. geraden, in die stärkeren Stacheln allmählich übergehenden Borsten.

A Kb. nach dem Verblïlien aufgerichtet, ganzrandig, stets bleibend. Stacheln meist an den Stengelknoten gepaart. [sS Cinnamomeae.]

$\times$ Stengel zwischen den Stacheln filzig. Stacheln $\doteq$ behaart u. gerade. O.-As.

R. rugosa Thbg. $X X$ Stengel und Stacheln nicht filzig behaart. Stacheln meist gekrümmt.

$\uparrow \uparrow \mathrm{Kb}$. vor der Reife abfallend.

$\times$ Kb. nach d. Verblühen ausgebreitet od. etwas erhoben.

Mittlere B. d. Bl.zweige meist 7 - bis 9-fiederig.

[S\$ Carolinae.]

Stacheln krumm, gepaart. Atl.N.-Am. R. carolina L.

$\times \times K b$. nach dem Terblühen zurückgeschlagen. Nittlere B. d. Bl.zweige 5-fiederig. [§§ Gallicae.]

$\square$ Stacheln ungleichartig. Nebenb. kurz drüsig gewimpert. B.chen mit breiten, stumpflichen, meist drüsig gewimperten Sägezähnen. Bl. zu 1-3.

R. gallica L.

$\square$ Stacheln gleichartig. Nebenb. kammförmig zerschlitz und drüsig gewimpert. B.chen nicht drïsig gekerbt. Bl.stand schirmtraubig. Syrien? R. damascena Mill.

II. Gr. die innere Einfügungsstelle der Stb. ‡ weit überragend. Nebenb. weit angewachsen, obere mit schmalen, spreizenden Oehrchen. China.

$R$. chinensis Jacq.

¡. Gr. zu einer Säule vereinigt, manchmal schraubig um eineinander gebogen.

1. Gr.säule kurz, wenig vorragend, die Gr. nicht immer fest verbunden. [\$\$ Stylosae $=$ Systylae $\times \mathrm{x}$.] $R$. stylosa Desv.

II. Gr.säule schlank, weit vorragend. [§ Systylae.]

1. Nebenb. frei oder fast frei, zuletzt abfallend. China.

2. Nebenb. weit angewachsen, bleibend.

$R$. indica $\mathrm{L}$.

+ Nebenb. tief kammförmig zerschlitzt. O.As.

R. multiflora Thbg.

++ Nebenb. nicht kammförmig zerschlitzt, aber oft drüsig. gewimpert oder gezähnelt.

(-) K. in d. Knospe sehr schlank eiförmig, allmählich lang zugespitzt. Gr.säule behaart. As., Abyssin.

R. moschata Mill.

(-) K. in der Kinospe kurz u. dick eiförmig, plötzlich kurz zugespitzt. B.chen etwas lederig, oberseits glänzend, im Winter bleibend. Umght. $T$. semperirens $L$. 
II". Frb. einzeln (bei Nuttalia bis 5), nicht mit der Blachse verwachsen. Steinfr.

I“". Gr. fast oder ganz endständig. 2 hängende Sa. Bl. strahlig. [Prunoideae.]

A. 5 Frb. 1-5 Teilfr., Endocarp lederig. Bl.zweige sympodial. Pac. N.-Am.

Nuttalia (1) cerasiformis Torr. et Gr.

B. 1 Frb. Trransatz auch an d. Fr. endständig. Endocarp \pm steinig.

Prumus (75).

a. B. in d. Knospenlage gefaltet.

\%. Trauben verlängert, viel- (mehr als 12-) blïtig. [\$ Padus.]

I. Traubenstiele beblättert. [\$§ Eupadus.]

1. K. unter d. Fr, vollständig bleibend. Stein fast glatt. Atl. N.-Am.

$P$. serotina Ehrh.

2. K. unter d. Fr. bis auf einen scheibenförmigen Rest abfällig.

+ Blb. kreissund. Stein \pm glatt. Atl. N.-Am.

P. virginiana $\mathrm{L}$. ++ Blb. breit verkehrt eirund. Stein netzig-grubig.

$$
\text { P. Padus L. }
$$

II. Traubenstiele nicht beblättert. [\$\$ Laurocerasus.]-B. lederig, immergrï. Balkan, Orient.

P. Laurocerasus I.

Verkürzte, 3- bis 5-(selten bis 12-) blütige Trauben, Dolden od. Einzelbl.

I. Bl. mit oder nach d. Belaubung erscheinend, \pm langgestielt. Bl.achse ineist kurz, weitmündig. Frkn. u. Fr. kahl, selten sparsam zottig. Fr. saftig. [§ Cerasus.]

1. Bl.stand am Grunde von d. bleibenden Knospenschuppen umgeben.

+ Bl. in gestielten, kurzen, 3- bis 12-bliitigen 'I'rauben, von sehr kleinen Tragb. gestiitzt. [§§ Mahaleb.] - S.-Eur.. Orient.

P. Nahaleb I.

++ Bl. in 2- bis 4-blütigen Schirmtrauben von ziemlich grossen, \pm laubigen Tragb. gestuitzt oder in sitzenden Dolden oder einzeln.

(-) Kb. aufrecht abstehend. Bl.achse röhrig. [Sร Pseudocerasus.]

$\uparrow$ Frkn.spitze u. Gr.grund zerstreut zottig. O.-As.

P. Pseudocerasus Steud.

$\uparrow \uparrow$ Frkn. u. Gr. kahl. China. P. serrulata Lindl.

(.) Kb. zurückgeschlagen. Bl.achse halbkugelig bis kurzglockig.

$\uparrow$ Dolde am Grunde von sehr grossen Knospenschuppen und oft 1 bis wenigen kleinen Laubb. aus derselben Knospe begleitet. [§§ Eucerasus.]

$\times 1$ oder wenige Laubb. unter der Dolde. B.stiel oder B.grund oft mit 1-3 Drüsen.

$\square$ Aeste u. Zweige dünn, überhängend. Stein eiförmig. Spanien.

$P$. acida Dum.

Aeste und Zweige stärker, aufrecht od. aufrecht abstehend. Stein kugelig. Kleinas., Kauk. P. Cerasus L. 
Keine Laubb. unter d. Dolde. B.stiel 1- bis 2-drüsig. $P$. avium $\mathrm{L}$.

11 Bl. zu 1-3, am Grunde ron nur kleinen Knospenschuppen u. keinen Laubb. begleitet. [\$\$ Spiracopsis.] - Blh. aussen kahl. Fr. scharlachrot, erbsengross. O.As.

$P$. japonica Thbg.

2. Knospenschuppen am Grunde des Bl.standes zur Bl.zeit abgefallen. [\$s Prunocerasus.] - Atl. N.-Am.

I. pennsylvanica L. f.

II. Bl. kurzgestielt oder sitzend. Frkn. u. Fr. meist dicht behaart od.. wenn diese kahl, damn die Bl. lange vor der Belaubung erscheinend.

1. Bl. 1-2 neben einem Laubtrieb, mit der Belaubung erscheinend. Bl.achse meist röhrig.

+ Fr. saftig. B. unterseits filzig. [\$.Microcerasus.] - S.-Eur.. W.-As.

P. prostrata Lab.

+ + Fr. saftarm. B. kahl. [S Chamacamygdalus] NiederOesterreich bis O.-Sibir. P. nana (L.) Focke

2. Bl. vor der Belaubung. Bl.achse fast halbkugelig. Frkn. u. Fr. dicht sammethaarig. Stein gefurcht und grubig. [\$ Amygdalus.]

+ B. scharf u. tief doppelt-gesägt, breitelliptisch. O.-As. P. triloba Lindl.

-+ B. gleichmässig klein-gesägt, elliptisch-lanzettlich.

(.) B.stiel kürzer als die halbe Breite des B. Bl. meist einzeln. Fr.fleisch sehr weich, saftig. N.-China.

P. Persica (L.) Sieb. et Zuce.

(-) B.stiel meist so lang als die halbe B.breite. Bl. meist zu 2. Fr.fleisch saftarm. Turkestan.

P. Amygdalus Stokes

h. B. in der Knospenlage eingerollt. Bl. zu 1-3. Frkn.. Gr.

u. Fr.mit Längsfurche. Stein $=$ zusammengedrückt, $\doteq$ glatt.

[S Prunophora.]

\%. Frkn. u. Fr. kahl. [\$s Euprunus.]

I. Zweige anfangs sammethaarig. Fr. kugelig.

1. Bl. meist einzeln. Stiel kahl. Blb. länglich. Fr. aufrecht. etwa $1 \mathrm{~cm}$ dick, hartfleischig, sehr herb. I'. spinosa L.

2. Bl. meist zu 2, Stiel weichhaarig. Blb. kreisrund, hohl. Fr. hängend, grösser, weichfleischig, süss. $P$. insititia L. II. Zweige kahl (bei $P$. italica auch dünn- u. feinhaarig).

1. B. tief u. scharf doppelt-gesägt. Bl.stiel kaum doppelt so lang als die Bl.achse. Stein schwer löslich. S.-Frankreich.

P. Brigantiaca Vill.

2. B. seicht kerbig-gezähnt. Bl.stiel 3-6mal so lang als Bl.achse.

$+K b$. auf d. ganzen Innenfläche etwas weichhaarig.

- B. oberseits stets ganz, unterseits später fast kahl. Blb. rein weiss. Fr. kugelig, meist grünlich: Stein nicht löslich. Orient.

P. italica Borkh.

$\odot \odot$ B. oberseits anfangs zerstreut feinbehaart. unterseits 
bleibend weichhaarig. Blb, grünlich-weiss. Fr. länglich, blauschwarz; Stein löslich. Vord.-As.

$P$. oeconomica Borkh.

$++\mathrm{Kb}$. innen ganz am Grunde fein graufilzig. Fr. kugelig. rot od. gelb. Vord.-As. bis W.-Sibir. P. Myrobalana L.

3. Frkn. u. Gr.grund dichtzottig. Fr. sammetfilzig. Bl. sitzend oder ihr Stiel kaum länger als die Bl.achse. [S§ Armeniaca.] - B. fast pappelähnlich. Fr. gelb mit roter Backe. Transkaukas, bis N.-W.-Ind. u. N.-China.

II“'. 1 Frb. Gr. bauchseitig grundständig. 2 grundständige, aufrechte Sa. [Chrysobalanoideae.]

1. Bl. fast völlig strablig. [Chrysobalaninae.] Chrysobalanus (3).

2. Bl. deutlich zygomorph. [Hirtellinae.]

Parinarium (15).

\section{Leguminosae $(434 ; 7000)$.}

I. Bl. strahlig. Knospendeckung der Blb. klappig. [Mimosoideac.] Knospendeckung der Kelchb. klappig.

1. $\infty$ (über 10) Stb.

1. Stb. frei, seltener die inneren in einen sehr kurzen Ring verwachsen. [Acacieae.]

Acacia (450).

2'. Stb. am Grunde oder höher hinauf in eine Röhre verwachsen. [Ingeae.]

A. B. einfach gefiedert.

B. B. doppelt gefiedert.

Inga (140). Albizzia (50).

2. Androeceum diplostemon oder haplostemon. A. drüsenlos. [Eumimoseae.]

Mimosa (300).

a. Fiedern 1-, B.chen 2-jochig. Trop. Amer. $M$. sensitiva $\mathrm{I}_{\mathrm{A}}$.

b. Fiedern 1- bis 5-, B.chen vieljochig. Trop. Amer. M. pudica L.

II. Bl. \pm zygomorph. Knospendeckung der Blb. cochlear.

I’. Blb. meist nicht schmetterlingsförmig, Kinospendeckung anfsteigend, zuweilen Blb. abortiert. [S Caesalpinioideae.]

1. Kb. in der Knospe bis oder fast bis zur Bl.achse frei.

1'. Vordere Blb. entwickelt, abortiert oder reduziert, aber nicht. zu fleischigen Drüsen umgebildet.

1“. B. einfach gefiedert. A. \pm basifix, meist mit endständigen Poren aufspringend. [Cassieae.]

A. Bl. ohne Discus, mit 5 Blb. Androeceum meist diplostemon. - N.Am.

Cassia (380) marylandica L.

B. Bl. durch Verkümmerung polygam-diöcisch, mit stark verbreitertem, schildförmigem Discus, ohne Blb. Androeceum haplostemon. Mmgbt. Ceratonia (1) Siliqua L.

2". B. sämtlich oder teilweis doppelt gefiedert. [Eucaesalpinieae.]

A. Bl. sämtlich \&, mit 10 etwa gleich langen Stb.

B. Bl. polygam oder diöcisch.

Caesalpinia (40).

A1. Bl. klein, mit kurzer Bl.achse. Stb. 6-10, länger als die Blb.-Mittl. u. sdl. N.-Am. Gleditschia (11) triacanthos L.

$B_{1}$. Bl. mittelgross, mit verlängerter Bl.achse. 10 Stb., kürzer als die Blb. - Atl. N.-Am.

Gymnocladus (2) dioeca (L.) C. Koch 
’. Die beiden rorderen Blb. zu grossen, fleischigen. schuppenartigen Drüsen ausgebildet. A. mit endständigen Poren. B. einfach oder gefingert. [Kramericae.] Krameria (1:;).

2. $\mathrm{Kb}$. I zu einer die hohle Bl.achse fortsetzenden Röhre verwachsen. B. einfach oder 2-lappig bis 1-paarig-fiederig. [Bauhinieae.]

A. Bl. nicht schmetterlingsförmig', mit ziemlich gleichen Blh. Hülse ungeflïgelt.

Banhinia (159)

B. Bl. schmetterlingsförmig, mit sehr ungleichen Blb. Hülse an der Bauchnaht schmal geflïgelt. - Nmgbt.

Cereis (5) Siliquastrum L.

II'. Bl. schmetterlingsförmig, mit absteigender Knospendeckung der Blkr. (das oberste B. das äusserste). [Papilionatae.]

1. Stb. frei, selten ganz am (irunde sämtlich mit einander rerwacbsen.

1'. B. gefiedert. [Sophoreae.]

A. Frkn. mit $3-\infty$ Sa.

A. Frkn. sitzend. Kapld. Virgilia (1) capensis Lam. $B_{1}$. Frkn. \pm gestielt.

A. Hülse linealisch, flach gedrückt.

a. Blättchen eilänglich, stumpf, kahl. O-As.

C. amurensis (Rupr, et Max.) Bth.

b. Blättchen elliptisch, spitz, unterseits an den Nerven etwas behaart. Atl. N.-Am.

C. tinctoria Raf.

B. Hülse stielrund, rosenkranzförmig oder 4-flügelig. O.-As.

B. Frkn. mit 2 Sa.

2'. B. 3-fingerig oder einfach. [Podalyrieae.]

A. B. 3-fingerig. Kb. ziemlich gleich.

A. Sträucher mit scheidig verwachsenen, den B. opponierten Nebenb.

B1. Kräuter mit freien Nebenb.

A2. Frkn. und Hülse sitzend. - O.As., N.-Am.

Thermopsis (15) fabacea D. C.

B.. Frkn. und Hülse deutlich gestielt.

a. Bl. gelb. Nebenb, borstenförmig. N.Am. Baptisia (14, B. tinctoria R. Br.

b. Bl. blau. Nebenb. lanzettlich. N.-Am. B. australis R. Br. B. B. einfach. Die 2 oberen Kíb. breiter u. höher hinauf verwachsen.

A1. $4-\propto$ Sa. S. ohne Nabelwulst. Schiffchen meist gerade. Chorizema (15).

Bı. 2- Su. S. mit Nabelwulst. Schiffchen eingekrümmt.

Pultenaea (76)

2. Stb. sämtlich unter einander hoch hinauf verwachsen.

1'. Meist Halbsträucher od. Kräuter. Flügel nicht querfaltigrunzelig.

A. Fr. eine gewöhnliche Hülse.

A. B. 3-zählig; B.chen gezähnelt. [Zu Trifolieae; cf. S. 211.]

Ononis $(70)$.

a. Bl.stiel nicht gegliedert. Blb. rosenrot (selten weiss). 
\%. Hülse kürzer als $K$.

I. Stengel niederliegend, am Grunde wurzelnd, meist mit Dornen. B.chen oval bis länglich.

O. repens L.

II. Stengel aufrecht; dornenlos. B.chen länglich-elliptisch, oft spitzlich.

F. Hülse so lang od. länger als K. Dornig. O. spinosa $L$.

b. Bl.stiele am Grunde gegliedert. Blb. gelb, aussen rotgestreift.

B1. B. gefiedert; B.chen ganzrandig.

O. Natrix Lam.

A.. 5 od. alle Stf. oberwärts verbreitert. [Zu Loteae; cf. S. 211.$]$ Anthyllis (20) Vulneraria L.

B2. Alle Stf. fädlich ${ }^{1}$ ). [Zu Galegeae; cf. S. 213.]

A3. Kräuter. 5 Blb. $\infty$ Sa. - S.-Europa, bes. Osten.

Galega (3) officinalis L.

B3. Sträucher. Nur Fahne vorhanden. 1-2 Sa. - N.-Am.

Amorpha (8) fruticosa L.

B. Gliederhülse, unterirdisch reifend. [ZuHedysareae; cf. S. 210.] Brasilien.

Arachis (7) leypogaea L.

2'. Meist Holzgewächse. Flügel am oheren Rande fein querfaltiglunzelig. [Genisteae.]

1“. Stf. zu einer vor der Fahne offenen Scheide verwachsen. S. ohne Nabelwulst. [Crotalariinae.]

Gr. oberwärts längs der Innenseite gebärtet oder gewimpert.

a. Bl.stiel gegliedert. $3 \mathrm{Bl}$.chen.

Crotalaria (250).

$\because B l . s t a n d$ endständig. Schiffchen kaum geschnäbelt, stumpf. Kapld.

C. purpurea Vent.

Bl.stand scheinbar blattgegenständig. Schiffchen lang geschnäbelt. Ind.-mal. Gbt.

b. Bl.stiel nicht gegliedert. 1 B.chen.

C. laburnifolia L.

$\because$ Hülse fuchsrot sammethaarig. Ind.-mal. Glot. C.juncec L.

$\therefore$ Hülse kahl. Trop. O.-Afr. bis N.-Austral. C. speciosa Hayne

2“. Sämtliche Stf. zu einer geschlossenen Röhre verwachsen.

1“. S. ohne Nabelwulst. [Spartiinac.]

A. Abschnitte oder Lippen des $K$. viel länger als die K.röhre.

A. Flügel frei; Schiffchen stumpf. B. 3-zäblig; Nebenb. meist frei.

Argyrolobium (40).

B1. Flügel an der Spitze verwachsen; Schiffchen geschnäbelt. B. einfach oder 3. bis co-fingerig; Nebenb. dem B.-stiel angewachsen.

a. B. gefingert.

Lupinus (100).

\%. Bl. alternierend oder zu 2 eine Traube bildend.

1. Ausdauernd. B.chen 13-15. Kelchlippe fast ungeteilt. Kaliforn.

II. Kinjährig. B.chen etwa 7-9.

1. K.unterlippe ungeteilt.

+ B!. weiss. K.oberlippe ungeteilt. B.chen verkehrteilänglich. Orient. $L$. albus L. 
++ Bl. blau. K.oberlippe 2 -spaltig. B.chen lineal. Ningbt.

$+t+$ Bl. rot. K.oberlippe 2 -spaltig. B.chen fast spate-

lig. S.-Eur. L. pilosus L,

L. angustifolius $\mathrm{L}$.

2. K.unterlippe 3-zähnig, Oberlippe fast 2-teilig. Stengel rostbraun-rauhhaarig. Mmgbt. L. hirsutus L.

B. Bl. in deutlichen, \pm entfernten Quirlen eine unterbrochene Traube bildend. K.unterlippe 3-zälnig, Oberlippe 2-teilig. Blb. gelb. Mmgbt.

L. luteus L.

b. B. ungeteilt. Atl. N.-Am. L. villosus Willd. B. Abschnitte oder Lippen des K. kürzer, selten etwas länger als die K.röhre.

d. Nägel aller Blb. frei. K. sehr kurz 2-lippig. Laburnum (3).

a. Trauben und Hülsen kahl. $L$ alpinum Gris.

h. Trauben angedrückt-behaart. Hülsen seidenhaarig.

I. vulgare Gris.

B1. Nägel der unteren Blb. mit der Stf.röhre verwachsen.

A2. K. scheidig, nach der Bl. gespalten. mit. .j sehr kurzen Zühnen. Schiffchen zugespitzt, engekrümmt.

Spartium (1) junceum L.

B2. K. glockig, obere Abschnitte frei oder rerwachsen, untere zu einer 3-zähnigen Unterlippe verwachsen. B. fehlend. einfach (so d. nachfolg. Art.) oder 3-zählig. Genista ( 80 .

a. Hülse langlinealisch bis lanzettlich. viel länger als K. x s..

a. Unbewehrt.

I. Zweige stielrund.

1. K. abfallend. Blkr. u. Hülse kahl. Bl. an den jungen Zweigen traubig.

G. tinctoria L.

2. K. bleibend. Fahne, Schiftchen u. Hülse seidenhaarig. Bl. an den jährigen Zweigen einzeln oder zu 2 unterbrochene 'Trauben bildend.

II. Aeste und Zweige mit 2 herablaufenden Flügeln.

G. pilosa L.

G. sagittalis L.

Mit Axillardornen. Bl. am Ende der jungen Zweige traubig. Deckb. eiförmig.

G. anglica L.

b. Hülse rhombisch. Bis $4 \mathrm{~S}$. Mit Axillardornen. Deckh. pfriemelig. $\quad G$ germanica L.

2““. S. mit Nabelwulst. [Cytisinae.] K. 2-lippig.

A. K. kurz 2-lippig, grün. B. meist vorhanden, meist 3-zählig.

Cytisus (44).

a. Schiffchen bald hängend, Stb. und Gr. herrorragend; 4 Stb. fast doppelt so lang als die übrigen; Gr. an der Spitze verbreitert, sehr lang. ein- oder mehrmals eingerollt.

C. scoparius (L.) Lk.

b. Schiffchen die Stb. und den (ir. einschliessend. Gr. pfriemelig, höchstens eingebogen, mit oft schiefer $\mathrm{N}$.

๑. K. kurz-glockig, nicht oder nur wenig länger als breit. B. in unbeblätterten, aufrechten Trauben. Schiffchen geschnäbelt. C. nigricans L. F. K. doppelt so lang als breit, Röhre länger als die Lippen. I. Rücken der Fahne kahl. 
1. Bl. gelb.

C. hirsutus L.

2. Bl. purpurrot.

II. Rücken der Fahne in der Mitte behaart.

1. Bl. gelb.

+ B. von langen, angedrückten Seidenhaaren mattschimmernd. C. austriacus $\mathrm{L}$.

++ B. beiderseits von abstehend. Haaren rauh. C. capitatus Jacq.

2. Bl. weisslich. Mähren bis Balkan. C. albus Jac\%. B. K. tief 2-spaltig, häutig, gefärbt. B. sehr klein oder fehlend. Ulex (20) europaeus L.

3. Androeceum diadelphisch, Fahnenstb. getrennt bleibend.

1. Gliederhülse oder Bruchfr. [Hedysareae; cf. Arachis, S. 208.] $1^{\prime \prime}$. Bl. in Trauben. Fahne dachig vorgestreckt. Schiffchen stumpf.

1“'. Bl. meist paarweise in den Achseln der 'Tragb. Flügel so lang oder länger als das Schiffchen. B. 3-zählig, selten nur Endb.chen. [Desmodiinae.]

A. 2- bis $\infty$-samig. Frkn.stiel am Grunde ohne Becherchen. B.chen mit Stipellen.

Desmodium (125).

a. B.chen länglich-lanzettlich, etwa gleich. Hülse dichtsteifhaarig.

D. canadense L.

b. B.chen elliptisch-länglich, seitliche periodisch sich bewegend, Endb.chen viel grösser. Trop. As. D. gyrans (L.) D. C.

B. 1-samig. Frkn.stiel am Grunde innerhalb der Stf.röhre von einem kleinen Becherchen umgeben. Stipellen fehlend.

Lespedeza (25)

2““. Bl. einzeln in den Achseln der Tragb. Flügel so lang oder länger als das Schiffchen. B. unpaarig gefiedert od. einfach. [Hedysarinae.] B.gefiedert. Hïlse zusammengedrückt.

A. Hülse nicht zerfallend bei der Reife (1-bis 2-samig).

Onobrychis (80) sativa Lam.

B. Hülse bei der Reife in Glieder zerfallend, 2- bis $\infty$-samig.

Hedysarum $(60)$.

a. Hülsengl. nackt (od. mit kurzen Dörnchen). H. obscurum I.

b. Hülsenglieder mit langen Stachelborsten bekleidet. Italien.

$H$. coronarium $\mathrm{L}$.

2"“. Bl. in Dolden. Fahne zurïckgeschlagen. Schiffchen meist geschnäbelt. [Coronillinae.]

A. Schiffchen stumpf. Hülsenglieder quadratisch oder kugelig bis lineal.

Ornithopus (8).

a. K.zähne eiförmig, 3 mal kürzer als die Röhre. O. perpusillus L.

b. K.zähne pfriemelig, fast so lang als die Rölıre. O. satirus Brot. B. Schiffchen gespitzt oder geschnäbelt.

A1. Hülsenglieder gerade.

A2. B. fiederig. Dolde reichblütig. Hülse gerade oder gekrümmt.

Coronilla (20)

a. Nägel der Blb. $3 \mathrm{mal}$ so lang als der $\mathrm{K}$. Hülse fast stielrunr. gestreift, nicht leicht in Glieder zerfallend. C. Emerus L.

b. Nägel der Blb. etwa so lang als der K. Hülse 4-kantic oder 4-flügelig, leicht in Glieder zerfallend.

a. Blb. weiss, Fahne rot. Nebenb. lanzettlich, nicht verwachsen.

C. varia $\mathrm{L}$.

f. Blb. gelb. Wenigstens die unteren Nebenb. verwachsen. 
I. Dolde 15- bis 20-blütig. Nebenb. klein, fädlich, die unteren in ein einziges verwachsen, die oberen getrennt; das unterste B.chenpaar am Grunde des B.stieles stehend. C.montana Scop.

II. Dolde 6-bis 10 -blütig. Nebenb. eiförmig, verwachsen, ebenso gross, wie die B.chen; das unterste B.chenpaar vom Grunde des B.stieles entfernt.

C. vaginalis Lam.

B2. B. einfach. Dolde wenig- bis 1-blütig. Hülse schneckenförmig eingerollt.

$B_{1}$. Hülsenglieder gebogen bis hufeisenförmig.

Scorpiurus (6).

Hippocrepis (12) comosa L.

2'. Hülse bei der Reife 2-klappig (selten gar nicht) aufspringend.

$1^{\prime \prime}$. Keimb. duinn, blattartig.

1“'. B. 5-fingerig oder 3-zählig.

1“i. B.chen ganzrandig. [Loteae; cf. Anthyllis, S. 208.]

A. Schiffchen stumpf oder undeutlich geschnäbelt.

B. Schiffchen deutlich geschnäbelt.

Dorycnium (6) suffruticosum Vill.

a. Hülse ungeflügelt.

«. K. glockig-röhrig.

I. Bl.stand etwa 5-blütig. K.zähne vor d. Aufblïhen zusammenneigend.

Lotus (100).

II. Bl.stand etwa 10- bis 16-blütig. K.zähne vor d. Aufblïhen abstehend od. zuriickgekriimmt. L. uliginosus Schk.

3. K. 2-lippig. Mmgbt.

b. Hülse geflügelt-kantig.

$\alpha$. Blb. weissgelb.

3. Blb. purpurn. Mmgbt.

L. ornithopodioides L

2*“. B. 3-zählig (nur bei Trif. Lupinaster 5-fingerig). B.chen gezähnelt. [Trifolieae; cf. Ononis, S. 207.]

A. Nägel aller Blb. frei; Blkr. nach der Bl. abfallend.

A1. Bl. in meist langen, ährenförmigen Trauben. Hülse kurz. dick, fast kugelig oder verkehrt-eiförmig. Melilotus (20!.

«. Hülse mit leicht gebogenen Querrunzeln. Nebenb. pfriemelig-borstig, ganzrandig. Bl. goldgelb. M. officinalis Desr.

b. Hülse netzadrig-runzelig.

\%. Nebenb. pfriemelig-borstig, ganzrandig. Bl. weiss. Hülse eiförmig, stachelspitzig.

M. albus Desr.

3. Nebenb. aus gezähntem Grunde pfriemelig. Bl. gelb. Hülse eiförmig, spitzlich. M. dentatus Pers.

$\gamma$. Nebenb. aus breiterem Grunde pfriemelig. Bl. blau. Hülse eilänglich, geschnäbelt.

M. coeruleus Desr.

B1. Bl. in kurzen Trauben, Köpfchen od. Dolden, selten einzeln.

A.. Hülse gerade oder gekrümmt. linealisch, oft geschnäbelt.

Trigonella (70).

a. Hülsen aufrecht. Mmgbt.

T. Foenum graecum L.

b. Hülsen herabgebogen. S.-Eur., Kleinas. T. corniculata L.

B.. Hülse seltener breit oval und gebogen oder nierenförmig. meist spiralig gewunden.

Medicago (50).

a. Hülse entweder nicht spiralig oder, wenn spiralig, damn mit offenem Centrum, mit $1-\infty \mathrm{S}$.; ein der Rückennaht paralleler Seitennerv fehlt. 
a. Gr. zur Bl.zeit so lang als der Frkn. Hülse nierenförmig, an der Spitze spiralig gebogen, biconvex, meist nur 1-samig. S. glatt.

M. lupulina L.

Gr. zur Bl.zeit viel (bis 6mal) kürzer als der Frkn. Hiilse zusammengedrückt, meist $\infty$-samig.

I. Hülse breit-nieren- oder eiförmig. \&. tief querrunzelig.

II. Hülse linealisch-sichelförmig. S. glatt. $M$. sativa L.

b. Hülse spiralig zusammengerollt, mit geschlossenem Centrum und $\infty \mathrm{S}$.

๑. Ein der Rückennaht der Hülse paralleler Seitemnerv fehlt; die von der Bauchnaht ausgehenden Adern laufen in die Rückennaht oder direkt in die Stacheln. Mmgbt. M. scutellata All.

5. Die von der Bauchnaht der Hülse ausgehenden Adern laufen in einen der Rückennaht parallelen Seitennerv zusammen.

1. S. nicht durch Scheidewände getrennt. Nebenb. ganzrandig oder am Grunde gezähnelt und sehr fein geadert.

M. minima (L.) Bartalini

2. S. durch Scheidewände getrennt. Nebenb. fiederspaltig-eingeschnitten.

M. hispida Gärtn.

b. Nägel aller oder nur der vier unteren (vorderen)Blb. mit der Stb.röhre verwachsen. Blkr. nach der Bl. meist vertrocknend und bleibend.

Trifolium (250).

a. Bl. meist \pm lang gestielt in lockeren Köpfchen, von \pm grossen, selten undeutlichen Hochb. umgeben. K. mit kahlem, offenem Schlunde. Hülse seltener 1-, meist 2- bis 8-samig, meist aus dem K. hervorragend. [Trifoliastrum.]

a. K. \pm strahlig oder gleichmässig 2-lippig, niemals einseitig aufgetrieben. Fahne mit den ïbrigen Blb. nicht oder nur im untersten Teile kurz verwachsen.

I. Aeusserste Hochb. frei.

1. K. J-rippig (ohne Commissuralrippen). Blb. gelb, Fahne allmählich zum Grunde verschmälert. Hülse gestielt, 1-samig. Hochb. sehr kurz, 1-spitzig, an den Rändern mit gefärbten Wimpern pinselartig besetzt. [§ Chronosemium.] + Fahne fast glatt, kaum gefurcht, zusammengefaltet.

T. filiforme. Koch ++ Fahne vorn löffelförmig erweitert, gefurcht; Fï̈gel ausgebreitet.

- Alle B.chen sitzend; Nebenb.länglich-lanzetti. T.agrarium L.

○) Mittleres B.chen länger gestielt; Nebenb. eiförmig.

T. procumbens L.

2. K. 10-rippig (mit Commissuralrippen). Blb. weiss od. rot; Fahne mit kurzem, breitem Nagel. Hülse meist sitzend, mit 2-8 S. Hochb. häufig 2-spitzig, einfach gewimpert. [\$ Euamoria.]

+ Stengel lang niederliegend, wurzelnd. Bl.weiss oder rötlich-weiss.

T. repens $\mathrm{L}$.

+ + Stengel aufsteigend, nicht wurzelnd. Bl. rötlich.

T. hybridum L.

II. Aeusserste Hochb. zu einer sehr kurzen, gezähnten Hülle verwachsen.

[§ Lupinaster.] 
1. B. 3-zählig, mit gemeinsamem B.stiel.

+ Bl.stand köpfchenförmig. Bl. weiss, mässig gross, nach dem Verblühen herabgeschlagen.

T. montanum L. ++ Bl.stand doldenförmig. Bl. hellrot, seltener weiss, nach dem Verblühen nicht herabgeschlagen.

T. aipinum L.

2. B. 5-fingerig, ohne gemeinsamen B.stiel. T. Lupinaster L.

3. K. ungleichmässig 2-lippig; Oberlippe nach dem Verblühen blasig aufgetrieben, netzaderig. Bl. fast sitzend. [\$ Gulearia.] Fahne mit d. übrigen fleischrot. Blb. verwachsen. T. fragiferum $\mathrm{L}$.

b. Bl. ohne Hochb. K.schlund durch einen wulstigen, bisweilen behaarten Ring oder einen Haarkranz geschlossen. Hïlse fast stets 1-samig. Stets \pm behaarte Kräuter. [Lagopus.]

\%. K.schlund \pm offen; $\bar{K}$. 10-nervig. Blkr. bleibend oder schliesslich abfallend.

I. Haare der ganzen Pflanze nur gezähnelt.

1. K.röhrenschlund nackt oder mit einem einfachen Haarring ausgestattet. Blkr. einfach fleischfarben. T. arvense L.

2. K.zähne an d. Fr. sternförmig abstehend; Schlund mit 2lippiger oder gleichmässig kahler Schwiele oder mit dichten Zottenhaaren ausgestattet. Blkr. purpurrot. T. incarnatum L.

II. Haare der ganzen Pflz. gezähnelt und am Grunde mit Höckerchen besetzt. K.röhrenschlund ohne Schwiele, aber durch einen deutlichen, zottig beharten Hautring verengert. Blkr. rot.

T. pratense $\mathrm{L}$.

F. Kchlund durch einen 2-lippigen Wulst fast geschlossen. Blkr. bleibend, rot.
I. K. 10-nervig.
T. flexuosum Jacq. (T. medium L.)

II. K. 20-nervig.

1. K.röhre aussen kahl. Köpfchen walzlich. T. rubens L.

2. K.röhre aussen \pm zottig. Köpfchen länglich. T.alpestre L.

$\because$ K.schlund durch einen 2-lippigen oder völlig gleichmässigen

Wulst geschlossen: K. 10-nervig. Blkr. schmell abfallend. gelblich-weiss.

T. ochroleucum L.

2“". B. gefiedert. [Galegeae; cf. Galega u. Amorpha S. 208.]

A. A. mit einer stachelspitzigen Connectivdrüse gekrönt. Pflz. mit "Malpighiaceenhaaren" bekleidet. Indigofera (220).

B. A. einfach stumpf, ohne Anhängsel.

A1. Trauben end- oder scheinbar blattgegenständig [bei Kraunhia japonica blattwinkelständig, dann aber Discus].

A2. B.chen mit \pm parallelen Seitennerven. K.zähne etwa gleich. Fahme ohne Schwielen; Flïgel dem Schiffchen leicht anhängend. Frkn. sitzend; kein Discus. Tephrosia (90.)

B2. B.chen netzadrig. Obere 2 K.zähne kürzer. Fahne gross. mit 2 Schwielen; Flügel frei. Frkn. gestielt, um d. Stiel eine intrastaminale Discusscheide. - O.-As.

Kraunhia (Wistaria) (4) japonica (Sieb. et Zucc.) Taub. $B_{1}$. Trauben blattwinkelständig. Nie ein Discus.

A2. Gr. oberwärts einseitig oder ringsum gebärtet. B. unpaarig gefiedert.

A3. Hülse flach zusammengedrückt, 2-klappig aufspringend. Gr. nur an d. Spitze behaart.

Robinia (6). 
a. Trauben ohne Borsten. Blkr. weiss mit gelblichen Saftmalen oder nur hellrosa überlaufen.

๑. Zweige kahl und glatt. Blkr. duftend. Atl. N.-Am.

R. Pseudacacia I.

3. Zweige mit klebrigen Drüsenwarzen besetzt. Blkr. geruchlos. Atl. N.-Am.

R. glutinosa Sims

b. Trauben meist drüsenborstig. Blkr. hell karminrot, geruchlos. Atl. N.-Am.

R. hispida L.

B3. Hülse angeschwollen oder aufgeblasen, oft nicht oder nur an der Spitze aufspringend. Gr. innenseitig lang herab bebärtet.

A4. Hülse dick, mit trockenfleischiger Wand, 2-klappig. Blb. zugespitzt. Bl. gross, hängend. Donia (Clianthus) (2).

B4. Hülse aufgeblasen, mit häutiger Wand, nur an der Spitze aufspringend.

A5. N. endständig, oft kaum bemerkbar. 'Tragb. deutlich, oft häutig.

Swainsonia (23).

B5. N. unterhalb der Gr.spitze, dicklich aus einer Vertiefung der Biegung vorragend. Tragb. sehr klein oder fehlend.

Colutea (8).

a. Fahnenschwielen fast rechiwinkelig zu einander. Frkn. und Hülse am oberen Rande nahe dem Gr. mit Spalt. S.-Eur.

C. orientalis Mill.

b. Fahnenschwielen parallel. Frkn. u. Hülse geschlossen. S.-Eur.

C. arborescens $\mathrm{L}$.

B2. Gr. kahl.

A3. B. unpaarig gefiedert.

A4. Bl.stand reichblütig, meist Trauben, seltener (bei Astragalus) Aehren, sehr selten Dolden. Blb. schmal.

A5. Hülsen nicht gekammert oder gefächert. A.fächer an der Spitze verschmelzend.

Glycyrrhiza (12).

a. Hülse glatt. Mmgbt., S.-O.-Eur., Vord.-As. G. glabra I.

b. Hülse stachelig. Oestl.Mmgbt., S.-Russl., Vord.-As.

G. echinata L.

B5. Hülsenwände an der Bauchnaht eingebogen und einwärts erweitert. A.fächer getrennt.

A6. Hülse nur von der Bauchseite her gekammert. Schiffchen geschnäbelt. Oxytropis (150) pilosa (L.) D. C.

B6. Hülse durch eine zugleich von der Rückennaht ausgehende und diese mit der Bauchnaht verbindende Scheidewand 2-fächerig. Schiffchen stumpf.

A7. Hülse meist \pm eiförmig bis kugelig, seltener einfach flach. Astragalus (1200).

a. Haare einfach, am Grunde angeheftet.

\%. K. glockig od. röhrig, am Grunde stumpf od. buckelig. I. Bl. deutlich gestielt, locker traubig. (\$ Phaca.]

1. Nebenb, unter sich frei. Bl. grünlich-gelb.

2. Nebenb. mit einander \pm verwachsen.

A. glycyphyllos L.

+ Frkn. sitzend. Turkestan, W.-Sibir. A. sulcatus L. ++ Frkn. gestielt.

$\odot$ Schiffchen ungefähr so lang wie Fahne, vorn violett, 
Fahne blau, Flügel weiss, ganz stumpf. B. 8. bis 12-jochig.

A. alpinus $\mathrm{L}$.

Schiffchen kürzer als Fahne, dunkelviolett, sonst Blkr. gelblich-weiss, Flügel ausgerandet oder 2spaltig. B. meist 5-jochig. Pyren., Alp., daur. Gbg.

A. australis Lam.

II. Bl. fast sitzend, in dichten Köpfehen od. Aehren. [\$ Hypoglottis.]

1. Blkr. gelblich-weiss. Hülse rundlich, aufgeblasen. 3 bis $6 \mathrm{dm}$ hoch. A. Cicer $\mathrm{L}$.

2. Blkr. violett. Hülse eirundlich, am Grunde herzförmig. $1-2^{1}: 2 \mathrm{dm}$ hoch. A. hypoglottis L. [A. danicus Retz.]

3. K. kreiselförmig mit zugespitztem Grunde. B.achse dornig endend, stehen bleibend. [\$ Tragacantha.]

b. Malpighiaceenhaare, d. h. 2-schenklig, in d. Mitte angeheftet. Bl. grünlich-gelb. Hülse linealisch-sichelförmig. S.-Russld., Transkauk.

A. falcatus Lam.

B7. Hülse schiffchenförmig, vom Rücken zusammengedrückt, linealisch. Klappen flach, mit (falschen) buchtig gezähnten Rändern. Mmgbt.

Biserrula (1) Pelecinus L.

B4. Bl.stand wenig-bis 1-blütig, kurztraubig bis doldig. A.fächer getrennt. Hülse einfächerig.

B3. B. paarig gefiedert, mit 2 od. mehr oft fingerig genäherten B.chen.

At. Blkr. gelb, orange oder rötlich-weiss, geruchlos. Hülse linealisch, drehrund, sitzend.

Caragana (15).

a. Bl.stiele so lang oder länger als die Bl. B.spindeln im Herbst abfallend. Nebenb. oft als kleine Stacheln stehen bleibend.

I. B.chen (6-) 8-10. Sib., Mandschurei. C. arborescens Lam.

II. B.chen genähert. Sib., Mandschurei. C. digitata Lam.

b. Bl.stiele erheblich kürzer als die Bl. B.spindeln meist als Stacheln stehen bleibend.

a. K., Frkn. und Hülse dicht behaart. Sib. C. jubata Pall.

3. K. kahl.

1. Verdornte B.spindeln 2-3 cm lang. Sibir. C. spinosa D.C.

II. Verdornte B.spindeln höchtens $1 / 2 \mathrm{~cm}$ lang. Kauk. bis Sib.

C. pygmaea D. C.

B4. Blkr. hell lila-rosa, abends nach Rebenbl. duftend. Hülse stark aufgeblasen. Transkauk. bis Altai.

Halimodendron (1) argenteum Fisch.

2“. Keimb. dick, fleischig. B. gefiedert oder 3-zählig.

1“. Hülse nicht aufspringend, meist 1-od.2-samig. [Dalbergieae.]

Fahne aussen seidenhaarig. B.unpaar.-gefied. Machaerium (60).

2'“. Hülse aufspringend, meist vielsamig.

1“". B. gefiedert. Endfiederchen, oft auch ein oder mehrere Paare der anstossenden Fiederchen auf Ranken oder blosse pfriemelige Spitzen reduziert. [Vicieae.]

A. 10 Sth.

A1. Gr. fädlich, an der Spitze nicht behaart. Hülse aufgeblasen. Oestl. Mmgbt.

$B_{1}$. Gr. an der Spitze \pm behaart. Hülse seitlich zusammengedrückt, nicht aufgeblasen. 
A2. Stf.rühre schief alugeschnitten, d. h. die unteren Stf. gradweise länger und länger verwachsen.

A3. Gr. entweder an d. Spitze ringsum gleichmässig behaart od. auf $d$. Schiffchenseite gebärtet.

Vicia (120).

a. Bl. in langgesticlten Trauben (selten einzeln). Nehenb. ohne Nectarien. Gr. unter d. N. ringsum behaart.

๙. N. einfach. Bl. klein und blass. Trauben 1- bis 6-blütig. Hülse mit 2-6 S. Nebenb. halbpfeilförmig.

I. Hülse an der Spitze ungeschnähelt, abgerundet. B. mit Wickelranke.

1. B.chen meist in 6 Paaren, gestutzt. 'Trauben bis 6-bliitig. Hïlse länglich, 2-samig, weichhaarig. $V$. hirsuta (L.) Koch

2. B.chen 2- bis 4-paarig, gewöhnlich spitzlich. Trauben 1bis 3-blütig. Hülse lineal, meist 4-samig, kahl.

V. tetrasperma (L.) Mnch.

II. Hülse gestielt, kurz geschnäbelt, etwas zusammengedrückt, rosenkranzartig-holperig. B.chen meist 10-paarig, länglich, gestutzt, stachelspitzig. B. mit Stachelspitze. Siidl. M.-Eur.. Mmgbt.

V. Ervilia (L.) Willd.

5. N. \pm kopfförmig. Hülse mit geschnäbelter Spitze.

I. Trauben meist 1-blütig. Bl. klein, blass. Das eine Nebenb. linealisch, sitzend, das andere gestielt, halbmondförmig. borstlich-gezähnt. W.-Eur.! V. monanthos (L.) Desf.

II. Trauben reichblütig. Bl. ziemlich gross. Nebenb. \pm gleich.

1. B.chen eiförmig bis eilänglich. (tr. nicht von der Seite zusammengedrückt.

+ Hülse verlängert, schwertförmig. Nehenb. gezïhnt.

(-) Nebenb. halbmondförmig.

$\uparrow$ 6-9 B.chenpare; Nebenb. eingeschnitten. Bl. weiss, blau-violett geadert.

$V$. silvatica L.

$\uparrow \uparrow$ 3 -5 B.(henpare; Nebenb. mit verlängert-haarspitzigen Zähnen. Bl. trübrot. Gr. von oberi nach unten flach gedrückt.

$V$. dumetorum L.

$\odot \odot$ Nebenb. halbpfeilförmig. 3-5 B.chenpaare. Bl. hellgelb.

$V$. pisiformis L.

+t Hülse kurz u. breit. Nebenb. ganzrandig, halbpfeilförmig. 9-12 B.chenpaare. Bl. purpurviolett.

V. cassubica L.

2. B.chen lineal-lanzettlich, 6-12-paarig: Nebenh. halbspiessförmig, ganzrandig. Gr. von der Seite zusammengedrückt. Bl. blau oder violett.

+ Pflz. nicht zottig, 24. B.chen meist 10-paarig. Platte $\mathrm{d}$. Fahne so lang oder länger als ihr Nagel.

$\odot$ Hülse verlängert, schwertförmig. Stengel meist kahl. Bl. hellblau.

V. tenuifolia Bth.

$\odot \odot$ Hïlse kurz u. hreit. Stengel weichhaarig. Bl, violett. V. Cracca I.

++ Pflz. zottig, $\odot$ od. $\odot$. B.chen meist 8-paarig. Platte d. Fahne halb so lang als d. Nagel. $\Gamma$. villosa Bth. b. Trauben 6-bis 1-blütig, kurzgestielt. Nebenh. mit Nectarien. 
İr. unter d. $\mathbf{N}$. auf d. Schiftchenseite gebärtet. Hülse an d. Spitze schief gestutzt, geschnäbelt. Bl. = gross.

a. B. mit 4-8 B.chemparen und meist mit geteilter Wickelranke.

I. 'Trauben 3- bis 5-blütig. K.zähne ungleich. Hülse bei der' Peife kahl. B.chen eiförmig bis länglich. Blkr. schumutziglila.

V. sepium L.

II. Bl. einzeln oder zu 2 blattwinkelständig:

1. K.zähne ungleich, die beiden oberen kürzer. Blkr. hellgelb. Huilse rauhhaarig, kurz.

V. lutea L.

2. K.zähne ziemlich gleich. Blkr. bläulich oder purpurn. Hiilse \pm lang.

+ Fahne bläulich, Flügel purpurn. Hïlse aufrecht. kurzhaarig, braun. Alle B.chen verkehrt-eiförmig. T. sativa L.

+ + Fahne und Flügel purpurn. Hïlse abstehend, bei der Reife kahl und schwarz. Ohere B.chen lineal-lanzettlich

$V$. angustifolia All

j. B. 2- oder 3-paarig, meist nur mit einfacher, selten wickeliger Stachelspitze endigend.

I. Stengel $\doteqdot$ niederliegend. Bl. klein, einzeln blattwinkelständig. K.zähne fast gleichlang. Blkr. hellviolett. Hülsen kahl.

V. lathyroides L.

II. Stengel aufrecht. Bl. gross, in 2- bis 4-blütigen Trauben. Die 3 unteren K.zähne viel länger als die 2 oberen. Blkr. weiss, selten purpurn. Flïgel meist mit schwarzem Fleck. Hiilsen sammethaarig.

T. Faba L.

B3. Fr. flach, unterhalb der Spitze auf der Fahnenseite gebärtet. Nimgbt.

Lens (8) esculenta Mönch

b. Stf.röhre senkrecht abgeschnitten, d. h. der freie Teil sämtlicher verwachsenen Stf. gleichlang. Gr. fahnenseitig behart. schiffchenseitig kahl.

A3. Gr. von oben und unten flachgedrückt, längs der ganzen Falınenseite bebärtet.

Lathyrus (150)

a. B. ohne Wickelranke, nur mit Stachelpitze endigend. B]. purpurrot, später blau (selten weiss).

. Stengel thïgellos oder nur oberwärts schmal gefliigelt.

I. B. 4- bis 6-parig. L. niger (L.) Bernh.

II. B. 2- bis 3-paarig. L. vernus (L.) Bernh.

3. Stengel deutlich gefligelt. B. 2- his 3-paarig. L. montanus Bernh.

Ђ. B. mit Tinkelranke endigend. Stengel kletternd.

๙. Alle B. mit B.chen.

I. Gr. nicht gedreht, unterseits rinnig.

1. Stengel kantig, ungeflügelt. B. mit 1 B.chempaar. Nebenb. breitlanzettlich-pfeilförmig.

2. Stengel geflügelt.

+ Meist 3-5 B.chenpaare. Nebenb. fast grüsser als die B.chen, ei-halbpfeilförmig.

L. pisiformis L.

+1 Meist $2-3$ B.chenpare. Nebenb. melmmals kleiner als die B.chen, lineal-lanzettlich.

(- B.stiel ungefliigelt. Traube 4- bis 5-blütig. Blkr. schmutzigblau.

L. paluster L. 
$\odot \odot$ B.stiel geflügelt. Traube vielblütig. Blkr. purpurrot L. heterophyllus $\mathrm{L}$.

II. Gr. gedreht. Stengel meist geflügelt. Meist nur 1 B.chenpaar.

1. Gr. gebogen, unterwärts röhrenförmig. Nebenb. lineal bis pfriemelig. Traube mehrblütig.

+ Stengel kantig, ungeflügelt. Wurzel mit Knollen.

++ Stengel geflügelt. Wurzel ohne Knollen.

L. tuberosus L.

- Traube mehrmals länger als ihr Tragb. Blkr. karminrot. B.chen elliptisch oder länglich-lanzettlich, stumpflich, bespitzt.

L. latifolius L.

$\odot(\odot$ Traube etwas länger als ihr Tragb. Blkr. grün-gelblich, rosenrot überlaufen.

$\uparrow$ Flügel des Stengels wenig breiter als die der B.stiele. B.chen länglich-lanzettlich, meist stumpflich, bespitzt.

L. piatyphyllos Retz.

$\uparrow \uparrow$ Flügel des Stengels etwa doppelt so breit als die der B.stiele. B.chen lineal-lanzettlich, verschmälert zugespitzt.

L. silvester L.

2. Gr. gerade, unterseits rinuig. Traube 3- bis 1-blütig.

+ B.chen eielliptisch. Fabne violett oder rosa, Flügel und Schiffchen bläulich oder weiss. S. glatt. L. odoratus L. ++ B.chen lineal-lanzettlich.

- Pflanze rauhhaarig. Hülse lineal-länglich, zusammengedriickt. Blkr. violett, dann blau. S. kugelig, runzelig. L. hirsutus L.

$\odot \odot$ Pflanze kahl. Hülse 2-flügelig. Blkr. weiss, rötlich, bläulich. S. kantig, glatt. L. sativus L.

B.chen fehlend oder nur an den unteren B.stielen vorhanden. B.stiele rankenförmig oder lanzettlich.

I. B.stiele meist rankenförmig. Nebenb. sehr gross, laubigeiförmig, am Grunde spiessförmig. Bl. gelb. L. Aphaca L.

II. B.stiele phyllodienartig, lanzettlich, rankenlos. Nebenb. sehr klein, pfriemelig, am Grunde halbspiessförmig. Bl. purpurn.

L. Nissolia L.

B3. Gr. nach dem Schiffchen zurückgekrümmt, die Teile oberwärts verwachsen; Gr. somit seitlich zusanmengedrückt, am Grunde auf der Schiffchenseite rinnig, oberwärts auf der Fahnenseite bärtig.

Pisum (2).

a. B.chen ganzrandig. Blkr. meist weiss, seltener die Fahne rosenrot. S. kugelig, gleichfarbig. $P$. sativum L.

b. B.chen fein gekerbt. Schiffchen weiss, Flügel purpurn, Fahne bläulich. S. eingedrückt-kantig, gescheckt. $\quad P$. arvense L.

B. Fahnen-Stb. fehlend. (tr. nicht bebärtet. S. glänzend, oft leb-

haft rot mit schwarzem Nabel. Tropen. Abrus (5) precatorius L.

2“". B. 3-zählig (bei Apios gefiedert), ohne Ranken; B.chen (ausser bei Cajanus) mit Stipellen. An den Hauptspindeln der Bl.stände (ausser bei Cajanus, Glycine u. Kennedya) reducierte Seitenzweiglein in Form kleiner Knötchen. [Phascoleae.]

A. Gr. oberwärts völlig kahl.

A. K.zipfel \pm gleich, nur die beiden oberen \pm weit mit einander verwachsen. 
A2. K.zipfel meist ziemlich gross. Fahne nicht aussergewöhnlich gross.

A3. S. ohne Nabelwulst.

A4. Hülse aussen quergerieft, innen nicht gefächert. Fahnenstb. ron Anfang an frei. B.chen ohne Stipellen. Afr.

Cajanus (1) indicus Spreng.

Bł. Hülse aussen glatt, innen quergefächert. Fahnenstb. meist erst später frei werdend. B.chen mit Stipellen. O.-As.

Glycine (12) Soja Sieb. et Zucc. (G. hispida Maxim.)

B3. S. mit Nabelwulst. Bl. prächtig rot. Kennedya (11).

B2. K.zipfel meist sehr klein. Fahne sehr gross, Flügel zuweilen fehlend, sonst wie das Schiffchen klein. - Brasil.

Erythrina (25) Crista galli L.

B1. K. \pm 2-lippig, die Oberlippe aus der Verwachsung von $2 \mathrm{~B}$. gebildet, mächtiger als die Unterlippe.

A2. Fahne geöhrelt, kleiner als das oberwärts \pm spiralig eingekrümmte Schiffchen. B. unpaarig gefiedert. Pflz. milchend. - Wurzel knollenförmig. N.Am. Apios (3) tuberosa Mönch

B2. Fahne beträchtlicher als das oberwärts mässig einwärts gekrïmmte Schiffchen. - Trop. Canaralia (12) ensiformis D.C. b. Gr. oberwärts längs der Fahnenseite gebärtet oder rings um die $\mathrm{N}$. behaart.

A1. Schiffchen stumpf oder mit bogigem Schnabel.

A2. Gr. an der Spitze fädlich oder pfriemelig. N. endständig. - Trop. Afr. Dolichos (20) Lablab L.

B2. Gr. an der Spite angeschwollen. N. seitlich herablaufend, länglich.

A3. Hülse vielsamig, oberirdisch reifend.

Vigna (30).

B3. Hülse 1-samig, fast kugelig, unterirdisch reifend. Trop. Afrika.

Voandzeia (1) subterranea Thouars

$B_{1}$. Schiffchen spiralig geschnäbelt. Gr. und N. wie bei Vigna. Phaseolus (60).

a. N. auf der Innenseite des Gr. Hülse glatt, ziemlich gerade. Traube kürzer als das B. S.-Amer. $P$. vulgaris $\mathrm{L}$.

b. N. auf der Aussenseite des Gr. Hülse rauh, sichelförmig. Traube länger als das B. Südl. N.-Am., Mexiko.

P. multiflorus Willd.

\section{Geraniaceae $(11 ; 350)$.}

A. Bl.stiel olıne Spornaussackung. Bl. mit Drüsen, meist strahlig. Androeceum 10-gliederig.

A. Alle Stb. mit A. Gr. innen kahl, bei der Reife sich bogenförmig aufwärts ablösend.

a. Pflanzen mit ansdauerndem Wurzelstock.

๗. Wurzelstock kurz, schief, an der Unterseite lange Fasern aussendend.

I. Frb. vorn querfaltig, behaart. Bl.stiele 2-blütig. Blb. nicht ausgerandet, rotbraun bis schwarz-violett. G. phaeum $\Gamma_{1}$. II. Frb. glatt.

1. Bl.stiele 2-blütig. B. meist 7-spaltig. Blb. nicht ausgerandet. 
+ Stengel oberwärts drüsenlos behaart. Blb. purpurn.

G. palustre L.

+- Stengel oberwärts nebst den Bl.stielen drüsig behaart.

$\odot$ Blb. blau. Stf. aus eiförmigem Grunde plötzlich verschmälert. Bl.stiele nach dem Verblühen abwärts gebogen, später oft wieder aufrecht. B.zipfel fast fiederspaltig.

G. pratense L.

$\odot \odot$ Blb. violett. Stf. lanzettlich, allmählich verschmälert. Bl.stiele stets aufrecht. B.zipfel eingeschnitten-gesägt

G. silvaticum L.

2. Bl.stiele 1-blütig. B. tief 7-spaltig, Zipfel 3-bis vielspaltig, Zipfelchen linealisch. Blb. ausgerandet, blutrot.

G. sanguineum L.

3. Wurzel dünn, spindelfürmig, absteigend. Frb. glatt. Blb. klein.

G. pyrenaicum L.

b. Pflanzen 1-jährig. Bl.stiele 2-blütig.

a. Kb. zur Bl.zeit ausgebreitet. Blb. kaum benagelt, klein.

I. Frb. glatt, aber oft behaart.

1. Stengel kurz-, nicht drüsenhaarig. B.tief-5-bis 6-teilig. $\quad$. netzförmig-grubig.

+ Stengel abstehend behaart. Bl.stände höchstens so lang als das 'T'ragb. Blb. karminrot. $G$. dissectum L.

+- Stengel abwärts-angedriickt-behaart. Bl.stände die Tragh. ïberragend. Blb. hellpurpurn.

G. columbinum L.

2. Stengel drüsenhaarig. B. etwa bis zur Hälfte 5- bis 9spaltig.

+ S. netzförmig-grubig. Blb. rosenrot, länglich-keilförmiæ. Frb. abstehend-weichhaarig.

G. rotundifolium L.

+ + S. glatt, nicht punktiert. Blb. blassviolett oder bliu lichrot, länglich-verkehrt-herzförmig. Frh. angedrïcktweichhaarig.

II. Frb. querrunzelig. S. glatt.

G. pusillum $\mathrm{L}$.

1. B. im Umriss rundlich. Kb. kurz stachelspitzig. Stengel kurz-weichhaarig und zugleich zottig, oben drüsenhaarig.

G. molle L.

2. B. im Umriss eckig, oft auffallend ungleichseitig. Kb. begrannt. Stengel abstehend kurzhaarig. G. divaricatum Ehrh.

९. Kb. schon zur Bl.zeit aufrecht-zusammenschliessend. Blb. lang benagelt, rosa. Frb. runzelig. S. glatt.

I. Stengel fast kahl. B. handförmig-geteilt, Zipfel eingeschnitten-gekerbt. K. querrunzelig, stachelspitzig.

G. lucidum L.

II. Stengel abstehend behart. B. 3- his 5-fingerig, B.chen gestielt, doppelt-fiederspaltig. Ko. glatt, begrannt.

G. Robertianum L.

B1. Die äusseren Stb. ohne A. Gr. innen behaart, bei der Reife sich vom Grunde her schraubig zusammendrehend.

Erodium (50).

a. B. 3-schnittig. Blb. blauviolett. Oestl. Mmgbt. E'.gruinum Willd.

b. B. fiederschnittig' oder gefiedert. 
๙. Stengel fast fehlend. B. fiederschnittig; Fiedern eiförmiø, fiederspaltig. Blb. purpurn. Ital.

E. romanum Willd.

९. Stengel \pm verlängert. $B$. gefiedert.

I. Fruchtbare Stf. am Grunde verbreitert, kahl. Blb. purpurn.

1. B.chen sitzend, tief eingeschnitten-fiederspaltig. Fruchtbare Stf. ohne Zähne.

E. cicutarium L'Hér.

2. B. kurzgestielt, ungleich doppelt-gesägt. Fruchtbare Stf. 2-zähnig. Mmgbt.

E. moschatum L'Hér.

II. Fruchtbare Stf. vom Grunde bis zur Mitte lanzettlich und gewimpert, oberhalb der Mitte fädlich und kahl. Blb. hellblau, dunkler geadert. S.-Eur. E. Ciconium Willd.

B. Bl.stiel mit spornartiger, äusserlich nicht bemerkbarer Aussackung. Bl. ohne Staminaldrüsen, deutlich zygomorph. Einzelne (meist 3) Stb. reduziert.

Pelargonium (175).

a. Stengel kurz, dick, fleischig. B. kreisrund-herzförmig, gekerbt, sammethaarig, sehr weich, wohlriechend. Blb. lichtrosa od. weiss. Kapld.

$P$. odoratissimum Ait.

b. Stengel länger, verholzend. Die 2 oberen Blb. genlihert u. kürzer. Kapld.

a. B. fast kreisrund, scharf gesägt, steif, kahl. Blb. weiss, die 2 oberen am Grunde blutrot mit satteren Linien.

$P$. elegans Willd.

3. B. herzförmig-kreisrund, etwas gelappt, gezähnt, behaart, oben mit dunklerem Giirtel. Blb. weiss od. rot. P. zonale Willd.

\section{Tropaeolaceae (Tropaeolim, 40).}

a. B. fast kreisförmig-schildstielig, seicht ausgeschweift, an den Enden der Handnerven ausgerandet. Sporn nach dem Ende zu schwach ausgebogen. Blb. orange od. gelb, rotbraun gezeichnet.

\%. B. an d. Nervenenden meist einfach ausgerandet. Peru. T. majus L.

今. Nervenenden in den Ausrandungen bes. am Mittelnerv) stets deutlich stachelspitzig vortretend. Peru.

T. minus L.

b. B. fast herzförmig-schildstielig, 5 -bis 7-lappig, Lappen stachelspitzig. Sporn stärker gekrümmt. Blb. einfach gelb. Peru.

T. aduncum Sm.

\section{Oxalidaceace $(7 ; 250)$.}

A. B. mit 6-15 Fiederpaaren. Kapselklappen sich sternförmig ausbreitend. - Tropen.

Biophytum (20) sensitivum D.C.

B. B. 3-zählig. Kapselklappen der Mittelsäule anhängend.

a. Stengel mehrblütig. Bl. gelb.

Oxalis (220).
๘. Zwiebel. Kapld.
¡. Stengel krautig.
O. cernua Thbg.

I. Stengel einzeln, aufrecht. B.stiele ohme Nebenb. Blb. ahgerundet. Er.stiele aufrecht-abstehend. N.-Am. O. stricta L.

Il. Stengel zu mehreren, niederliegend, am trunde wurzelnd. B.stiele am Grunde mit 2 kleinen Nebenb. Blb. ausgerandet. Fr.stiele abwärts gebogen. M.-u.S.-Eur., Canar. O. corniculata L.

b. Stengel 1-blütig, nur mit 2 Vorb. Bl. weiss oder rötlich, rot geadert.

O. Acetosella L. 


\section{Linaceae $(9 ; 150)$.}

A. Bl. 5-zählig. Kb. ganzrandig. Kapsel 10-fächerig. Wuchs meist weniger regelmässig. Linum (90).

a. Kb. driisenlos. Blb. frei, blau, rosa oder weiss. Fr.stiele verlängert.

a. Kb. fast so lang als die Kapsel, eiförmig, fein gewimpert.

I. Pflanze einstengelig, einjährig. Kaukas. L. usitatissimum L.

II. Pflanze mehrstengelig, meist perennierend. Mmgbt.

L. angustifolium $\mathrm{L}$.

ß. Kb. eiförmig, kahl, bedeutend kürzer als die Kapsel.

I. Bl.- und Fr.stiele steif aufrecht.

II. Die abgeblühten Bl.stiele bogig herabhängend.

b. Kb. am Rande drïsig gewimpert. Fr.stiele kurz.

L. austriacum L.

u. Blb. frei.

I. Blb. hellrötlich. B. spiralig.

II. Blb. weiss. B. gegenständig.

L. tenuifolium L.

L. catharticum L.

3. Blb. vor dem Aufblïhen an ihrem unteren Teil zusammenhängend.

I. Stengel zottig, rund. Blb. pfirsichbliitrot. L. viscosum L.

II. Stengel kahl, oberwärts scharfkantig. Blb. gelb. L. flavum L.

B. Bl. 4-zählig. Kb. 2- oder 3-spaltig. Blb. weiss. Kapsel 8-fächerig.

Wuchs dichasial.

Ratiola (1) linoides Gmel.

\section{Zygophyllaceae (21; 140).}

A. B. gegenständig. Kb. eiförmig bis lanzettlich. Frkn. 5-fächerig. A1. B. einfach oder 3-zäblig. Discus undeutlich. - Mmgbt.

Fagonia (18) cretica I. $B_{1}$. B. paarig gefiedert, selten einfach. Discus \pm deutlich.

A2. Discus fleischig, kantig, becherförmig oder concav. (ir. pfriemelig; N. klein, knopfig. B. meist 1-paarig.

Zygophyllum $(60)$.

a. B: 1-paarig gefiedert. Kapseln lang, fachspaltig. S.-Russld., Vord.-As.

Z. Fabago L.

b. B. ungeteilt. Kapseln kurz, scheidewandspaltig. Afr. bis zum Indus.

Z. simplex L.

B2. Discus dïnn, 10-lappig. Gr. sehr kurz; N.kopf gross, abgestutzt pyramidenförmig, 5-kantig, durch die zusammenschliessenden N.lappen gebildet, an den Kanten papillös. B. mehrpaarig. - Afr., Mmgbt. bis Tibet.

Tribulus (12) terrestris L.

B. B. wechselständig. unregelmässig vielspaltig. $\mathrm{Kb}$. lineal oder laubig-fiederspaltig. Frkn. 3-fächerig. - Mmgbt., S.-Russl. bis Tibet.

Peganum (4) Harmala L.

\section{Rutaceae (83; 750).}

1. Kapsel. Frb. hänfig schon in der Bl. nur durch die Gr, vereint und unten frei, bei der Reife \pm getrennt, nach innen fachspaltig sich öffnend.

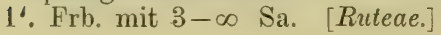


A. Gipfelbl. 5-, seitliche 4-zählig. sämtlich strahlig. Stb. aufrecht. Endocarp und Exocarp stets zusammenhängend. b. 2- bis 3-fach gefiedert.

Ruta (40) graveolens L.

B. Bl. sämtlich J̈-zählig, zygomorph. Stb. abwärts geneigt. Endocarp und Exocarp sich trennend. B. einfach gefiedert.

Dictamnus (1) albus L.

2'. Frb. mit 2 oder 1 Sa.

1". Keimb. dickfleischig, das Stämmchen nicht umschliessend. B. einfach (nur bei manchen Boronia-Arten unpaarig-gefiedert .

1“". 8 oder 10 fruchtbare Stb. S. mit fleischigem Nährgewebe. Austral. [Boronieae.]

A. B. spiralig. Blb. getrennt.

Eriostemon (28)

B. B. gegenständig.

A. Blb. getrennt, ausgebreitet.

Boronia $(50)$

Bi. Blb, aufrecht, mit einander verklebend oder verwachsen.

Correa (15)

2“". 5 fruchtbare Stb. S. ohne Nährgewebe. S.Afr. [Diosmeae.]

A. Ausser den fruchtbaren Stb. noch 5 Staminodien.

A. Blb. deutlich genagelt, am Nagel $\doteqdot$ behaart. Staminodien nicht von den Blb. umschlossen. Gr. lang. N. einfach.

A gathosma (100).

B1. Blb. lang genagelt, längs der Mittellinie rinnig, die Rinne das Staminodium einschliessend. Gr. kurz. N. kopfig.

B. Staminodien fehlend.

Coleonema (4).

Diosma (11).

2". Keimb. flachlaubig. B. unpaarig gefiedert oder 3-zählig (selten bei Tanthoxylon einfach). [Xanthoxyleae.]

A. 3-5 Stb. B. spiralig. - Atl. N.-Am.

Xanthoxylon (80) americanum Mill.

B. 10 Stb. B. gegenständig, 3-zählig. - Nexiko.

2. Steinfr. oder Beere. Frb. völlig vereint.

Choisya (80) ternata Kth.

1'. S. mit Nährgewebe. Frb. mit je 1-2 Sa. Stb. meist 4 bis 5 (nicht über 8), frei. [Toddalieae.]

A. B. 3-bis 5-zählig. ganz drüsig punktiert. Blb. imbricat. N.-Am.

Ptelea (6) trifoliata L.

B. B. unpaarig gefiedert, nur am Pande durchscheinend drüsig. Blkr. klappig.

Phellodendron (2).

a. B.spindel u. Lnterseite der B.chen Kahl.O.-As. P. amurense Rupr.

b. B.spindel mit kurzen Härchen bedeckt. B.chen unterseits an Mittel-u. Seitennerven zottig. Japan. P. japonicum Maxim.

C. B. einfach, ganzrandig, spiralig. Blkr. klappig. - Japan. Sacchalin.

Skimmia (4) japonica Thbg.

2`. S. ohne Nährgewebe. Fr. oft mit Periderm. [Aurantieae.

Androeceum polyadelphisch, $20-60$ Stb. Frkn. ss-fächerig.

B. einfach, aber B.stiel öfter's geflügelt.

Citrus (5).

a. B.stiel \pm breit geflügelt. Beere an beiden Enden nicht gebuckelt: Brei süsssäuerlich.

\%. B. meist stumpf, stark ausgerandet; Stiel breit geflügelt. Fr. rundlich oder birnförmig. Rinde sehr dick. China, Cochinchina.

C. decumana $\mathrm{L}$. 
3. B. spitz; Stiel schmal geflügelt. Fr. kugelıund, Rinde mässig dick. Südl. Himalaya.

C. Aurantium L.

b. B.stiel ungeflügelt. Beere ellipsoidisch, an beiden Enden gebuckelt; Brei säuerlich. Vord.-Ind.

C. medica L.

\section{Meliaceae (37; 300).}

10 fruchtbare Stb; ihre Fäden zu einer Röhre verwachsen, die unter und zwischen den A. viele ungleiche, pfriemelige Auswïchse trägt. B. meist doppelt-gefiedert.

Melia (5).

a. B.chen eingeschnitten-stumpflich-gesägt, kahl. Griechenld., Orient, O.-As.

M. Azedarach L.

b. B.chen am Grunde und an der Spitze ganzrandig, sonst seicht gekerbt, mit zerstreuten Sternhärchen, später oberseits kahl. Japan.

M. japonica Don

\section{Malpighiaceae $\left.{ }^{1}\right)(56 ; 650)$.}

B. gegenständ. (ausser bei Acridocarpus). Bl.stiele articulierend.

I. Frb. der pyramidenförmigen Bl.achse ansitzend. [Y'yramidotorac.] A. Alle 10 Stb. fruchtbar.

A1. Gr. kurz; alle 3 Frb. fruchtbar.

A2. Gr.ende rund; N. endständig; oft knopfförmig: Der oberwärts dickrandige Rückenflügel der Teilfr. schon in der Bl. bemerkbar. Bl. \pm schwach zygomorph. Banisteria (70).

$B_{2}$. Gr.ende + abgeflacht. Bl. strahlig.

A3. N. strichförmi schräg am Scheitel des Grendes. Die Seitenflïgel der Fr. schon in der Bl. bemerkbar. Vorb. in der unteren Hälfte des Bl.stieles. Tetrapteris (60).

B3. N. punktförmig, an der vorderen Ecke des oft rückwärts hakigen Gr.endes. Der unterwärts dickrandige Rückenflügel der Teilfr. schon in der Bl. bemerkbar. Vorb. im mittleren Drittel des Bl.stieles. Heteropteris (90).

B1. Gr. langpfriemelig; das unpaare Frb. verkümmernd. B. spiralig.

Acridocarpus (11).

B. Die 4 vor den drüsentragenden Kb. stehenden Stb. unfruchtbar, die ïbrigen 6 abwechselnd grösser. Gr.ende meist fussoder blattförmig.

II. Frb. der flachen Bl.achse aufsitzend. [Planitorae.]

A. Bl. in endständigen Trauben. Gr. langpfriemelig.

A1. K.drüsen nur ausnahmsweise vorhanden und dann klein. Stb. ganz kahl. B. mit Drüsen.

Galphimia (11).

B1. Meist 10 K.drüsen. Stf. wenigstens am Grunde dicht behaart. B. drüsenlos.

B. Bl.stände achselständig. Gr. kurz, gestutzt und oberwärts verdickt.

A1. Gr. immer frei. Bl.standsachse stark verkürzt. Vorb. drüsenlos.

Malpighia (20).

B1. Gr. häufig teilweise od. ganz verwachsen. Bl. in gestreckter Traube. Vorb. mit Drüsen, ähnlich d.K.drüisen. Bunchosia(30).

1) Weil die Malpighiaceac in unseren Gewiichshäusern kaum reifen, ist hier die Beschaffenheit dor Fr. nicht berücksichtigt worden.

$\mathrm{Zu}$ den 55 in der "Nat. Pflzf." angegebenen Gattungen kommt noch eine nouo aus Afrika (Rhinopteris Ndz.) 


\section{Polygalaceae $(15 ; 400)$.}

Bl. pseudoschmetterlingsförmig, indem von den $5 \mathrm{~Kb}$. die beiden hinteren, seitlichen flïgelartig und das vordere Blb. schiffchenförmig ist; 2 Blb. fehlend, die beiden anderen klein. Kapselfr.

Schiffchen ohne Kamm. Flügel Folygala (200). weiss. N.-Am.

Blb. rosa oder $P$. Senega L.

b. Schiffchen mit Kamm. Flügel eiförmig oder elliptisch, 3-nervig. \%. Schiffchenkamm 4-lappig. Bl. gelb. P. Chamaebuxus L.

3. Schiffchenkamm vielspaltig. Bl. blau, rosa oder weiss.

I. Stauden.

1. Bl. zahlreich in endständiger Traube. B. spiralig.

+ Untere B. rosettig, rerkehrt-eiförmig, grösser als die oberen.

$P$. amara $\mathrm{L}$.

++ Untere B. nicht rosettig, elliptisch, kleiner als die oberen.

- Deckb. die Bl.knospen nicht überragend, halb so lang als die Bl.stielchen.

$P$. vulgaris $\mathrm{L}$.

(-) Deckb. die Bl.knospen überragend und so schopfig erscheinend, später so lang als die Bl.stielchen.P. comosa Schk.

2. Bl. meist $z u 5(3-8)$ in zuletzt seitenständiger Traube.

Untere B. fast gegenständig.

$P$. depressa Wender.

II. Sträucher.

1. B. spiralig, keilförmig. Deckb, abfallend. Bl. weiss und purpurn. Kapld.

P. speciosa Sims

2. B. gegenständig, aus herzfürmigem Grunde verschmälert. Deckb. sehr stumpf. Bl. purpur- und blassrot. Kapld.

$P$. cordifolia Thbg.

\section{Euphorbiaceae (209; 4000).}

I. 2 Sa. in jedem Frkn.fach. Niemals Milchröhren oder markständiger Weichbast. [Phyllanthoideae.] Pliyllanthus (400). Bl. tragende Zweige gekerbte Phyllocladien, in den Kerben die Bl. entwickelnd. Trop. Amer.

$P$. speciosus Jacq.

II. 1 Sa. in jedem Frkn.fach. Milchröhren meist und markständiger Weichbast oft vorhanden. [Crotonoideae.]

1. Partialbl.stand kein Cyathium.

1'. Stf. in der Knospe scharf nach imnen gebogen, die Spitze der A. nach unten wendend. B. und junge Triebe mit Sternhaar- und Schuppenbekleidung. Innerer Weichbast: langgestreckte Secretschläuche und einzelne Oelzellen im Rindenparenchym und Treichbast. Crotoncae.] Croton (600).

2'. Stf. in der Kinospe aufrecht. Sternhaare u. Schuppen fehlend.

1“. Milchröhren fehlend, dafür oft Gerbstoffzellen. Innerer Weichbast vorhanden oder durch dünnwandiges, aus langgestreckten Zellen bestehendes Gewebe vertreten. [Acalypheae.] A. Stb. nicht verästelt.

A1. Gr. frei oder nur am Grunde kurz verwachsen. B. einfach.

A2. Thecae cylindrisch-länglich. - Abyss., ostind.-mal.Gbt. Acalypha (220) brachystachys Hornem. 
$B_{2}$. Thecae \pm kugelig.

Mercurialis (7).

a. Ausdauernd. Stengel einfach, stielrund. stielt. B. eilänglich.

․ Bl. lang-geM. perennis L.

b. Einjährig. Stengel ästig, 4-kantig. $+\mathrm{Bl}$. fast sitzend. B. eilanzettlich. $M$. annua L.

$B_{1}$. Gr. in eine lange, fleischige, ausgehöhlte Säule verwachsen. Bl.stand von 2 grossen, weissen oder lebhaft gefärbten Bracteen eingehüllt. $B$. verschieden. Dalechampia (60).

B. Stb. wiederholt verästelt. Thecae \pm getrennt, kugelig. B. handförmig, 7- bis viellappig. Afr. Ricinus (1) communis L.

2". Gegliederte (oft ununterbrochen verlaufende) Milchröhren vorhanden.

1“". Bl. in einfachen terminalen Trauben oder Aehren. [Manihoteae.]

Manihot (80).

$\mathbf{2}^{\prime \prime \prime}$. Bl. in dichasial gebauten Rispen. [Jatropheae.] Jatropha (70).

2. Partialbl.stand ein Cyathium. Ungegliederte Milchsaftschläuche. [Euphorbieae.]

a. Drüsen des Cyathiums ohne Anhängsel.

๙. Stengel krautig. B. deutlich laubig, die obersten meist gegenständig.

I. Obere Zweige nie trugdoldig. Cyathien an der Spitze der Zweige in geringerer Zahl cymös gedrängt, von häufig gefärbten Hochb. umgeben. Nebenb. auf Borsten oder Stacheln reduciert. [\$ Poinsettia.]

Hochb. blutrot. Mexikan. Gibt.

E. pulcherrima Willd.

II. Bl.zweige dichotomisch verzweigt, die oberen doldig angeordnet. Nebenb. fehlend. [\$ Tithymalus.]

1. Stengelb. sämtlich in gekreuzten Paaren. Bl.standsäste trugdoldig. Drüsen 2-hörnig.

2. Hauptmasse der B. spiralig.

+ Aeste dick, unterwärts blattlos. Cyathien 1 bis mehrere, doldig oder rispig. Makaronesien. E. Regis Jubae Webl) ++ Aeste dünn, durchaus beblättert. Bl.stand trugdoldig, seltener dichotomisch. S. allermeist mit Caruncula.

$\odot$ Drüsen eiförmig; nicht abgestutzt oder 2-hörnig. $\times$ S. glatt.

$\uparrow$ Kapsel glatt.

$E$. villosa $\mathrm{IV}$. et $\mathrm{K}$.

$\hat{\wedge}$ Kapsel mit rundlichen bis fädlich verlängerten Warzen. Trugdolde 3- bis 5-strahlig.

* B. am Grunde verschmälert, kurzgestielt oder sitzenı. Kapselwarzen kurz.

$\triangle$ B. ganzrandig oder vorn klein-gesägt. Strahlen der 3- bis 5-strahligen Trugdolde einmal 2-spaltig. Deckb. eiförmig-3-eckig, am Grunde abgestutzt oder herzförmig. Kapselwarzen stumpf, ungleich. E. dulcis Jacq.

$\triangle \triangle$ B. klein-gesägt. Die 5 Strahlen der Trugdolde 3-spaltig, die Teilstrahlen 2-spaltig. Deckb. stumpfelliptisch, am Grunde verschmälert. Kapselwarzen kurz-walzlich.

E. verrucosa Lam. * * B. mit herzförmigem Grunde sitzend. 
$\triangle$ B. unterseits fein behaart. Trugdolden meist 5-strahlig. Kapselwarzen fast halbkugelig.

E. platyphyllos L. B. kahl. Trugdolden meist 3-strahlig. Kapselwarzen walzlich.

E. stricta L.

Trugdolde vielstrahlig. B. lanzettlich, kahl. E. palustris L. $\times \times$ S. grubig-netzig. Trugdolde 5-strahlig. E. helioscopia L. $\odot \odot$ Drüsen teils querelliptisch-gestutzt, teils halbmondförmig. S. glatt.

E. Gerardiana Jacq.

$\odot \odot \odot$ Drüsen ausgerandet oder halbmondförmig-zweihörnig.

$\times$ S. glatt. Kapsel feinpunktiert-raub. Trugdolde vielstrablig. $\uparrow$ Deckb. frei.

B. über der Nitte am breitesten, nach dem Grunde keilförmig verschmälert. Drüsen gelb.

E. Esula L.

$\square$ Drüsen gelb, zuletzt braun.

* B. gleichbreit, schmal-linealisch.

E. Cyparissias L. ** B. \pm lineal-lanzettlich, unter der Mitte breiter.

$\therefore$ B. glanzlos oder schwach fettglänzend. Seitennerven sehr spitzwinkelig abgehend. $E$. virgata IV. et K. $\triangle$ b. oberseits glänzend. Seitennerven am Rande netzigverbunden.

E. Tucida W. et K.

$\uparrow \uparrow$ Oberste Deckb. am Grunde verwachsen. E. amygdaloides L.

XX S. nicht glatt. Kapsel glatt. Trugdolde 3-(bis 5-) strahlig. A S. kleinhöckerig. Deckb. aus breitem Grunde lineal. E. exigua L.

$\uparrow \uparrow$ S. unregelmässig grubig oder netzig.

$\uparrow \uparrow \uparrow \mathrm{S}$. gefurcht oder reihenweise grubig-punktiert.

S. quer-gefurcht oder mit quer gehenden Grubenreihen. Kapselfächer ohne Flügelleisten. B. sitzend, keilförmig. lanzettlich.

E. falcata L.

$\square \square$ S. längs-gefurcht oder mit Längsreihen von Grübchen. Kapselfächer auf dem Rücken mit 2 flügelartigen Längsleisten. B. gestielt, verkehrt-eiförmig. E. Peplus L.

3. Stamm fleischig, oft dick, bisweilen cactusartig, rund oder kantig, blattlos oder mit hinfälligen B. besetzt; an den Kinoten häufig Dornen. [\$ Euphorbium.]

I. Knoten erhaben, \pm warzenförmig, gedrängt, nicht in Reihẹl stehend, nicht bedornt; selten B.stiel verdornend. S.-Afr.

E. cereiformis L.

II. Knoten zerstreut oder in erhabene Rippen oder Flïgel verschmolzen, mit Dornen bewehrt.

1. Stamm rundlich, holzig werdend, beblättert. Reichliche, dunklere Stacheln. Madagaskar. $E$. splendens Bojer

2. Stamm stumpf 5-kantig, mit wenigen, gipfelständigen B. O.-Ind.

3. Stamm scharf 4- oder 3-kantig, blattlos.

+ Stamm 4-kantig. Canaren.

++ Stamm 3-kantig. O.-Ind.

b. Drüsen des Cyathiums mit petaloidem Anhängsel.

E. neriifolia L.

\%. B. spiralig, die oberen zuweilen gegenständig oder quirlig. Meist 5 Drüsen. [\$ Adenopetalum.]

I. Mit Nebenb. Bl.stand ebensträussig. Pac. N.-Am.

E. marginata Pursh 


\section{Ohne Nebenb.}

1. Bl.stand dichotomisch, ebensträussig. Atl. N.-Am. E.corollata L.

2. Schönrote Cyathien axillär einzeln oder in armen Cymen. Mexiko.

E. fulgens Karw.

¡. B. durchweg gegenständig, paarweis ganz kurz scheidig verwachsen; Nebenb. meist vorhanden. Meist 4 Drüsen. [\$ Anisophyllum.] - Mmght., S.-Engld.

E. Peplis L.

\section{Callitrichaceae (Callitriche, 25).}

a. B. am Grunde etwas breiter, an der Spitze ausgeschnitten; obere B. nie zu einer Rosette gehäuft. Seitliche Fr.hälften bei der Reife durch tiefe Buchten getrennt. Spaltöffnungen und Sternhaare fehlend.

C. autumnalis $\mathrm{L}$.

b. B. am Grunde verschmälert, die obersten meist zu einer Rosette gehäuft. Seitliche Fr.hälften bei der Reife verbunden. Epidermis der Stengel u. B. mit Spaltöffnungen u. Sternhaaren. a. N. aufrecht. Fr.kanten gekielt oder geflügelt.

I. Fr.kanten mit kurzem, scharfem Kiel.

C. verna $\mathrm{L}$.

II. Fr.kanten Hügelig-gekielt, durchscheinend. C. stagnalis Scop.

३. N. zurückgeschlagen, sehr hinfällig. Fr.kanten scharf oder abgerundet. C. hamulata Kütz.

\section{Buxaceae $(6 ; 30)$.}

B. gegenständig, sanzrandig. 4 Blhb. 4 Stb. Gr. kurz. Buxus (19).

a. Zweige kurzhaarig. Verkümmerter Frkn. der ơ Bl. kaum halb so lang als die Blh. B. sempervirens $\mathrm{L}$.

b. Zweige kahl. Verkïmmerter Frkn. der y Bl. so lang oder länger als die Blh.

B. microphylla Sieb. et Zucc.

\section{Anacardiacene $(58 ; 500)$.}

1. 1 Frb. B. stets einfach, ganzrandig. [Mangifereac p. p.]

A. Steinfr. mit saftreichem Mesocarp, hartem, faserigem Steinkern und nur wenig verdicktem Stiel. - Ostind.-mal. Gbt.

Mangifera (27) indica L.

B. Steinfr. mit harzreicher Fr.schale und sehr stark verdicktem Stiel. - W.-Ind., Bras.

Anacarilium (8) occidentale L.

2. 3 mit einander zu einem Frkn. verwachsene Frb.; 2 Fächer abortierend. [Rhoideae.]

A. Blh. einfach, homoiochlamydeisch oder 0 .

Pistacia (5).

a. Steinfr. erbsengross, eiförmig oder verkehrt-eiförmig. B. 2bis 5-paarig.

a. B.stiel breit geflügelt. B. ausdauernd, olıne Endblättchen. Mmgbt. P. Lentiseus L.

3. B.stiel nicht geflügelt. B. abfällig, mit Endblättchen. Nmgbt. P. Terebinthus L.

b. Steinfr. bis $2 \mathrm{~cm}$ lang, länglich. B. 1- bis 2-paarig. Syr., Mesopotam.

P. vera L.

B. Bl, mit doppelter Blh.

Ai. 10 Stb. 
A. Sa. hängend. - B. 7-bis 13-paarig. Anden. Schinus (12) Molle L. B. Sa. aufsteigend. B einfach od. unparig gefiedert. Lithraea (3). B1. 5 Sth.

A2. Gr. oder $\mathbb{N}$. seitlich an der Fr. B. einfach, eiförmig bis rund. - Mmgbt. bis C'hina.

Cotinus (2) Cosgygria Ścop.

B.. Gr. oder N. \pm endständig an der Fr. B. allermeist unpaarig gefiedert.

Rhus (120).

a. Steinfr. rot, behaart; Mesocarp zuletzt rom Endocarp sich loslösend. Bl. in endständigen Rispen oder Aehren. Milchsaft nicht giftig.

\%. Tragb. eilanzettlich oder lanzettlich, krautig. Blb. abfüllig. Rispen gross, lange vor der Belaubung erscheinend. B. gefiedert.

I. Fr. dicht behaart.

1. B.spindel ungeflügelt. B.chen lanzettlich.

+ Rispen kurz behaart. B.chen ganzrandig oder entferntgesägt. Atl. N.-Am.

R. glabra L.

- Pispen sehr dicht und lang behaart. Blättchen dichtgesägt. Atl. N.-Am.

2. B.spindel gefliigelt. B.chen länglich, grob gesägt.

+ Zweige. B.spindeln und Bl.stände rostgelb-weichhaarig. Fr. mit Drüsen und kurzen. weichen Härchen. - Japan, bis Himal. u. Hawaii.

K. semialata Murr. +- Zweige, B.spindeln und Bl.stände weisszottig. Fr. mit Drüsen und ziemlich dichten, roten, rauhen Haaren. Mmgbt.

R. Coriaria L.

II. Fr. grösser, zerstreut behaart. B.spindel geflügelt. B.chen länglich oder lanzettlich, ganzrandig oder mit vereinzelten Sägezähnen. Atl. N.-Am.

R. copallina L.

3. Tragb. breit eiförmig oder fast kreisrund: Torb. breit, den Tragb. anliegend. Blb. unter der Fr. bleibend. Aebren klein. vor oder mit der Belaubung. B. 3-zählig, B.chen gekerbt oder kerbig-gesägt. Atl. N.-Am.. Mexiko. R. aromatica Ait.

b. Steinfr. glatt, glänzend. meist kahl, gelblichweiss (seltener hraun). Mesocarp und Lndocarp stets zusammenhängend. Rispen blattwinkelständig. Nilchsaft giftig.

a. B. mit 7-15 (selten nur 5) Fiedern.

I. B.chen länglich-elliptisch. am Grunde spitz. Atl. N.-Am.

$R$. venenata D.C.

II. B.chen eilänglich, am Grunde stumpf. Japan. R. vernicifera D.C: 3. B. meist 3-, selten zum Teil ら-zählig. Kletternd oder kriechend und wurzelnd. B.chen ganzrandig oder seicht grob. gekerbt. Fr. gelblich-weiss, kahl. Japan. Sachalin, N.-Am., Nexiko.

$R$. Toxicodendron $\mathrm{L}$.

\section{Aquifoliaceae (j; 180) (Ilex, 170).}

a. B. häutig, abfallend, einfach-, kerbig-oder doppelt-gesägt. Bl. 5- bis 9-zählig. Fr. rot, selten gelb.

I. B. fein- (hisweilen kerbig-) gesägt. K. unbehaart. Atl. N.-Am. I. laevigata Gray

II. B. einfach- oder doppelt-gesägt. K. behaart. Atl. X.-Am. 
b. B. lederartig, bleibend. Bl. meist 4-zählig.

o. B. fein kerbig-gesägt, meist klein und dicht.

I. Bl. oder Bl.stände am vorjährigen Holze in den B.achseln gebüschelt. Blb. der $q \mathrm{Bl}$. nur am untersten Grunde verwachsen. Fr. rot. Kerne am Rücken gestreift. Südatl. N.-Am.

I. caroliniana Loesener

1I. Bl. oder Bl.stände einzeln in den Blattachseln am neuen Holze. Blb. der $\bigcirc \mathrm{Bl}$. bis fast zur Hälfte verwachsen. Fr. schwarz. Kerne am Rücken glatt. Japan. I. crenata Thbg.

\%. B. ganzrandig oder meist \pm stachelig-gezähnt. Fr. rot, selten gelb.

I. Bl. meist einzeln in den Achseln frischer Laub- od. Schuppenb.

1. B. oval bis elliptisch-lanzettlich. Südatl. N.-Am. I. opaca Ait.

2. B. länglich-verkehrt-eiförmig bis lineal. Südatl. N.-Am.

I. Cassine L.

II. Bl. oder Bl.stände am vorjährigen Holze in den B.achseln gebüschelt.

1. B. meist $14(10-23) \mathrm{cm}$ lang und $6(3-9) \mathrm{cm}$ breit, gesägt, nicht stachelig. Japan. I. latifolia Thbg.

2. B. meist nicht über $12 \mathrm{~cm}$ lang und (incl. Stacheln) höchstens $7 \mathrm{~cm}$ breit, ganzrandig oder gezähnt, oft stachelig.

C Kerne auf dem Rücken gerippt, gefurcht oder runzelig. B. im Umriss eiförmig bis lanzettlich, gleichmässig stachelig. W.-Eur., Mmgbt., China.

I. Aquifolium L.

$\odot \odot$ Kerne auf dem Rücken nur mit 1 Längsfurche, sonst glatt. B. \pm lïnglich, ganzrandig und ohne Spitzenstachel. Japan.

I. integra Thbg.

\section{Celastraceae $(36 ; 280)$.}

A. Gynaec. isomer. B. gegenständ. [Evonymeae.] Bl. ?. 4-5 Frb., N.lappen einfach. Discus ausgebreitet.

a. B. lederig, ausdauernd. A. gell). Japan. E. japonica Thbg.

b. B. häutig, abfallend.

a. S. dunkel, vom Arillus nicht ganz umschlossen. A. gelb. Blb. grünlich.

1. Zweigrinde glatt, mit 4 erhabenen Streifen. B. \pm lineal. Podol., Bessarab., Kaukas., Tianschan.

E. nana Marsh.

II. Zweigrinde mit zahlreichen schwarzen Warzen. B. meist eilanzettlich.

ア. S. ganz vom Arillus umhüllt.

I. A. gelb. Blb. gelblichweiss.

+ Zweige ungeflügelt, höchstens 4-streifig. S. weiss.

- Knospen klein. stumpf. Bl. meist 4-zählig. Kapselkanten stumpf oder etwas gekielt.

○) Knospen schlank, spitz. Bl. meist 5-zählig. Kapselkanten breit geflügelt.

++ Aeltere Zweige mit 2-4 breiten Korkflügeln. B. scharf gesägt. S. braun. O.As. E. alata (Thbg.) C. Koch II. A. u. Blb. dunkelpurpurn. S. weiss. N.-Am. E atropurpurea Jacq.

B. Gynaeceum oligomer. B. spiralig. [Celastreae.]

Bl. eingeschlechtlich, meist diöcisch. Frkn. meist 3-fücherig. 3 gabelige N.lappen. Discus concav. - N.-Am.

Celastrus (27) scandens $L$. 
Staphyleaceae. - Aceraceae.

\section{Staphyleaceae $(5 ; 22)$.}

Fr.fächer blasig aufgetrieben, dünnwandig, an der Spitze von einander getrennt. Gr. frei od. oben verwachsen. Staphylea (7). a. Unterstes Bl.paar in den Achseln der obersten Laubb. B. 3-zählig, Endb.chen sitzend. Japan. S. Bumalda D.C.

h. Unterstes Bl.paar von den obersten Laubb. weit entfernt, von Hochb. gestïtzt.

๗. B. sämtlich 3-zählig, Endb.chen deutlich gestielt. Atl. N.-Am. S. trifoliata L.

3. B. teilweise 7-fiederig; wenn B. 5-fiederig, dann Endb.chen gestielt. M.-Eur. bis Vord.-As.

S. pinnata L.

\section{Aceraceae $(2 ; 100)$.}

Teile der Spaltfr. einseitig geflügelt.

a. Discus fehlend oder sehr schwach entwickelt. Bl. lange vor der Belaubung erscheinend.

\%. B. handförmig gelappt. Bl.stände büschelig. [\$ Rubra.] I. Blb. vorbanden. Frkn. kahl. Atl. N.-Am. A. rubrum L. II. Blb. fehlend (selten 1-3). Frkn. dicht filzig. Atl. N.-Am. A. dasycarpum Ehrh.

Э. B. 3-zählig oder gefiedert. б Bl.stände büschelig, † traubig. [\$ Negundo.]

I. Junge Zweige u. B.stiele ganz kahl. Atl. N.-Am. A. Negundo L. II. Jüngere Zweige und B.stiele sammetfilzig. Pac. N.-Am.

A. californicum C. Koch

b. Discus deutlich entwickelt. Bl. mit (selten kurz vor) der Belaubung. B. handförmig gelappt (bei A. tataricum nicht deutlich).

ж. $\mathrm{Kb}$. vom Discusrand an getrennt. Blb. vorhanden.

I. Discus intrastaminal, d. h. Stb. entweder an der äusseren Lmgrenzung des gerumdeten oder in den Einkerbungen des gelappten Discus. Traube lang. [\$ Macrantha.] - Atl. N.-Am. A. pennsylvanicum L.

II. Discus inter- oder extrastaminal, d. h. Stb. in tiefen Gruben mitten auf dem Discus od. ganz innerhalb desselben eingefügt.

1. B. 3- bis 5- (selten 7-) lappig, selten nur scharfgesägt.

+ Stb. \pm dem Aussemrande des Discus genähert, auch in den $\sigma$ Bl. kaum länger als Blb. B.lappen scharf zugespitzt. Schirmrispe. [\$ Platanoidea.]

$\odot$ Blb. doppelt so lang als Ḱb. Fr.flügel $1-1^{2 / 3}$ mal so lang wie die Fächer. O.-As. A. pictum Thbg. $\odot \odot$ Blb. kaum länger als Kb. Fr.flügel 2-bis 4 mal so lang wie die Fächer.

$\times$ B.lappen buchtig-gezähnt. K. kahl. A. platanoides L. $\times \times$ B.lappen ganzrandig. K. kurzrauh haarig. Mmgbt., Him. A. Lobelii Tenore

++ Discus \pm extrastaminal. Stb. der $\sigma^{-} \mathrm{Bl}$. länger als $\mathrm{Kb}$. und $\mathrm{Bb}$.

Deutlich gestielte Rispen oder Trauben. Frkn. dicht behaart. [\$ Spicatae.] 
$\times$ Blb. 2- bis $3 \mathrm{mal}$ so lang wie Kib., schmal. Atl. N.-Am.

$\times \times$ Blb. kaum länger als $\mathrm{Kb}$.

A. spicatum Lam.

$\uparrow$ B. nicht gelappt oder nur 3-lappig. Stf. u. Fr. kahl.

B. herz-rundlich bis -länglich, ungelappt od. mit 2 schwachen Seitenlappen, doppelt gesägt. S.-O.-Eur., Vord.-As.

A. tataricum L.

$\square \square$ B. 3-lappig bis 3-teilig. Cent.- u. O.-As. A. Ginnala Max.

$\uparrow \uparrow$ B. sehr deutlich 5-lappig.

Stf. und Fr. kahl. Balkan.

A. Heldreichii Orph. Stf. zottig mit kahler Spitze, in den $\sigma^{-1} \mathrm{Bl}$. mindestens 2 mal so lang wie der $K$. Rispe traubenförmig, hängend. * Stb. auf der Mitte des Discus. Fr. gelb-steifhaarig. Pac. N.-Am. * * Stb. am Innenrande des Discus. Fr. kahl.

A. Pseudoplatanus L.

$\odot \odot$ Kurzgestielte Schirmrispen oder -trauben. Frkn. meist sparsam zottig. Teilfr. gewölbt. B.lappen stumpflich. [\$ Campestria.]

$\times$ Fr.flügel aufrecht oder spitzwinklig-gespreizt.

$\uparrow$ B. sämtlich klein (Nittelrippe bis $5 \mathrm{~cm}$ lang), 3-(selten 5-1 lappig oder ungelappt.

$\square$ B. eiförmig, ohne oder mit nur sehr kurzen Lappen, stets kahl. Oestl. Mmgbt.

A. orientale C. Koch $\square \square$ B. etwa bis zur Mitte 3-(bis 5-) lappig, anfangs unterseits weichhaarig, später nur am Grunde bärtig. Mmgbt.

A. monspessulanum L.

$\uparrow \uparrow$ B. meist gross (Mittelrippe $6-18 \mathrm{~cm}$ ), mit einzelnen kleinen untermischt, 5- (hie und da 3-) lappig.

* B. anfangs unterseits dünn behaart, bald ganz kahl. Blütenstiele fast kahl. Mmgbt.

A. italum Lauth ** B. unterseits anfangs dicht weisswollig-filzig, später bleibend grauhaarig. Blütenstiele besonders am Grunde weichzottig. Mmgbt.

A. obtusatum W. et K.

$\times \times$ Fr.flügel wagerecht. B. 5- (bis 3-) lappig. A. campestre L.

2. B. 7- bis 11-lappig oder -teilig, scharf-gesägt. Schirntrauben lang gestielt. Blb. viel kürzer als Kb., kahn- oder kapuzenförmig. Stb. der $\sigma^{7} \mathrm{Bl}$. länger als Kb. [\$ Palmata.] - Japan. A. palmatum Thbg.

ß. Kb. weit hinauf verwachsen. Blb. fehlend. B. meist 5-lappig. Stb. auf der Immenseite des Discus. (\$ Saccharina.) - Atl. N.-Am. A. saccharinum Wgh.

\section{Hippocastanaceae (Aesculus, 16).}

a. Stf. oder A. oder beide behaart.

a. Winterknospen klebrig. B.chen sitzend. Blb. meist 5, ihre Nägel die Kb. nicht überragend. [§ Hippocastanum.] - Griechld. bis Himal.

3. Winterknospen nicht klebrig. B.chen sehr deutlich gestielt. Blb. 4, ihre Nägel die Kb. überragend. [S Pawia.] 
I. Platte der Blb. am Rande mit kräftigen, fast sitzenden Drüsen. Stb. nicht länger als die oberen Blb.; A. kahl. Fr. ohne Stacheln. Mittl. Ver. Staat.

A. Pawia L.

II. Blb. drüsenlos gewimpert. Stb. länger als die 2 oberen Blb. A. behaart. Fr. gleich nach dem Abblühen mit feinen. weichen Stacheln, später warzig. Atl. N.-Am. A. glabra WVilld.

b. Stf. und A. kahl. Nïgel der Blb. die Kb. weit überragend. Winterknospen nicht klebrig. B.chen gestielt. [\$ Macrothyrsus.] - Südatl. N.-Am.

A. parviflora Walter

\section{Sapindaceae (1000).}

A. B. mit völlig entwickeltem Ende, einfach oder doppelt unpaarig gefiedert. Rispen. Bl. zy gomorph. Discus gelappt. Gr. pfriemelig. N. klein. China.

Koelreuteria (1) paniculata Laxm.

B. B. mit reduciertem Ende, einfach gefiedert. Rispe. Bl. strahlig. Mit den Blb. abwechselnd j orangegelbe Discushörmer. Gr. kurz: N. 3-lappig. N.-China, Mongolei. Xanthoceras (1) sorbifolia Bge.

\section{Balsaminaceae (Impatiens. 140).}

a. Sporn fast gerade. Bl. in langgestielten Trauben, aufrecht, klein. gelb mit braunroten Stellen. Kapsel lang, cylindrisch. Mongolei.

I. parviflora D.C.

b. Sporn zurückgekrïmmt. Bl. gross.

a. Sporn so lang oder länger als Blkr. Bl.stand 1- his 4-blïtig: kurzgestielt, kürzer als d. Tragb.

I. Echte Traube. Bl. gelb mit roten Punkten oder Stricheln. Kapsel lang, cylindrisch.

1. Pflz. kahl. B. eiförmig, grobgesägt. Torderes Blb. nicht gehörnt.

I. Nolitangere L.

2. Pflz. behaart. B. lanzettlich, feingesägt. Vorderes Blb. 2-lappig, auf dem Rücken gehörnt. Nördl. Ind. I.tricornis Lindl.

II. Schirmtraube. B]. verschiedenfarbig. Kapsel eiförmig, krausflaumhaarig. O.-Ind.

I. Balsamina L.

F. Sporn sehr kurz, grün. Bl. karmoisinrot, in langgestielten Schirmtrauben. Pflz. glatt, mit zahlreichen Drüsen. O.-Ind. I. glanduligera Royle

\section{Rhamnacene $(37 ; 500)$.}

I. Dornen, wenn vorhanden. Zweigdornen. Steinfr. mit $3(2-4)$ Steinkernen oder in 3 Körner zerfallende Kapsel. Nie windend.

1. Meist blattlos; Zweige \pm flach, stark verdornt. Bl. perigyn. Irkn. frei, im Grunde der Bl.achse stehend. Colletia (13).

2. Reichlich beblättert, wenig rerdornt; Zweige rund.

A. Frkn. frei im Grunde der Bl.achse. Bl. perigyn.

A1. Bl. in gestielten, oft aus Dolden zusammengesetzten Rispen, weiss, rosa oder blau.

A2. Blb. kappenförmig. Gr. oben 3-spaltig. Fr. zuletzt trocken, auf dünn bleibendem Stiel. - Atl. N.-Am.

Ceanothus (30) americanus $\mathrm{L}$.

B2. Blb. um die Stb. gerollt. Gr. einfach; N. 3-lappig. Fr. mit lederig-fleischiger Aussenschicht, auf fleischig-verdicktem Stiel. O.-As., Him. Hovenia (1) dulcis 'Thbg. 
B1. Bl. in kleinen, achselständigen Büscheln oder kurzgestielten Dolden oder einzeln, meist in den untersten B.achseln diesjähriger Triebe, grünlich oder grünlichgelb. Rhamnus (60).

a. Dornen und Knospenschuppen fehlend. B. spiralig. Bl. in Büscheln, 8, 5-zählig. Gr. einfach, dick; N. kopfig, 3-lappig. R. Frangula L.

b. Knospen mit Knospenschuppen. Bl. einzeln oder in Büscheln (selten Trauben) am Grunde der Zweige, meist 1-geschlechtig und 4-zählig. Gr. oberwärts 2- bis 4-spaltig.

a. Dornenlos. B. und Zweige spiralig.

I. B. lederig, ausdauernd. Bl. in kurzen Trauben. Südl. Fur.

II. B. häutig, abfällig. Bl. in Büscheln oder einzeln.

1. B. mit 3-9 Nervenpaaren. Zweige dicht weichhaarig. Blb. sehr klein oder fehlend. R. pumila L.

2. B. mit 10-30 Nervenpaaren. Zweige und B.stiele kahl. R. alpina $\mathrm{L}$.

¡. Sparrig, mit grossenteils dornigen Zweigspitzen. B. und Zweige \pm gegenständig; B. höchstens $3^{1 / 2}$ mal so lang als breit, dicht stumpf-gesägt, selten gezähnt.

I. B.stiele kaum länger als die Nebenb.

1. Junge Zweige und B.stiele fast kahl oder sehr kurz weichhaarig.

+ B. kahl oder fast kahl.

++ B. beiderseits weichhaarig. Südl. Eur., Orient.

$R$. tinctoria W. et $\mathrm{K}$.

2. Zweige u. B.stiele dicht weichhaarig. S.-Eur. $R$. infectoria L.

II. B.stiele meist 2-3mal so lang wie die Nebenb., aber nicht halb so lang als die B.

$R$. cathartica L.

B. Frkn. mit der Bl.achse verwachsen, halb oder ganz unterständig.

A1. Bl. \pm gestielt. Blb. \pm hohl oder fehlend. Stf. lang; A. länglich, nicht von den $\overline{\mathrm{B}}$ lb. eingeschlossen. Pomaderris (16).

B1. Bl. meist sitzend. Blb. kapuzenförmig, die kurzen Stb. verhüllend. A breit, kurz.

Phylica (65).

II. Mit Stipulardornen oder bei fehlenden Dornen windend. Fr. mit einem einzigen 1- bis 3-fächerigen Kern.

A. Aufrecht. B. 3-nervig; der eine Stipulardorn gerade, der andere gekrümmt, kürzer.

A1. Kurzgestielte, doldenähnliche Trugdolden. Blb. 2-lappig, seitlich eingebogen. Gr. 3-teilig. Fr. trockenlederig, mit wagerechtem, kreisförmigem Flügel ringsum. - S.Eur., Orient.

Paliurus (2) australis Gaertn.

B1. Knäuelförmige Trugdolden. Blb. stumpf oder etwas ausgerandet. Gr. meist 2- (bis 4-) teilig. Fleischige Steinfr. - Syr. bis China. Zizyphus (50) vulgaris Lam. b. Dornenlos, \pm windend. B. fiedernervig. Berchemia (10).

Vitaceae $(9 ; 270)$.

A. Schirmrispen. Blb. frei, beim Aufblühen sich ausbreitend. Rinde 2-jähriger Zweige nicht gestreift, mit Rindenhöckerchen ; Stammrinde nie in Streifen losschälend. Mark 2-jähriger Zweige weiss. 
A. Rankenenden mit Haftscheibe. Discus sich vom Frkn. nicht abhebend.

a. B. teils ungelappt, teils 3-lappig, teils 3-zählig. Schirmrispen blattwinkelständig. O.-As. Q.tricuspidata (Sieb. et Zucc.) Köhne

b. B. 丂.fingerig. Schirmrispen scheinbar blattgegenständig.

э. Haftscheiben mässig stark. Ranken meist mit 2-4 Zweigen. Blattknospen im Frühjahr und Sommertriebe hellgrün. Atl. N.-Am.

Q. quinquefolia (L.) Köhne

3. Haftscheiben sehr stark. Ranken mit 6-12 zweizeiligen, zierlich gebogenen Zweigen. B.knospen im Frühjahr rosenrot, Sommertriebe meist anfangs rötlich. Verein. Staat.

Q. radicantissima Köhne

B1. Rankenenden ohne Haftscheibe. Discus stark, von der Frkn.mitte schüsselförmig abstehend.

a. B. herzeiförmig-rundlich. Atl. N.-Am. A cordata Vichy.

b. B. teils seicht 3-lappig, teils tief 3-oder 5-lappig mit \pm geschweiften Buchten. O.-As. A. heterophylla Sieb. et Zucc.

B. Verlängerte Rispen. Blb. mützenförmig verklebt und beim Aufblühen gemeinsam abfallend. Rinde gestreift, in Streifen losschälend. Mark 2-jähriger Zweige gelbbraun. Discus unterhalb des Frkn. stark abstehend, gekerbt.

Vitis (28).

a. Zweigrinde mit Rindenhöckerchen, erst an älteren Stämmen sich in Streifen lösend. Mark ohne Querwände. Ranken einfach. B. rundlich, nicht oder undeutlich gelappt. S. auf $d$. Innenseite mit deutlichen Querfalten. Südatl. N.-Am.

V. rotundifolia Michx.

b. Ohne Rindenhöckerchen. Mark meist mit Querwand in jedem Knoten. Ranken meist gegabelt. S. auf d. Innenseite glatt oder mit kaum merklichen Querfalten.

๙. Ranken an mehreren Stengelknoten ununterbrochen auf einander folgend. B. unterseits grau- oder gelblich-spinnwebigfilzig. Atl. N.-Am.

ß. Ranken an jedem dritten Knoten fehlend.

I. B.unterseite wenigstens anfangs spinnwebig-filzig; Behaarung an d. Nerven dichter bleibend. Stielbucht d. B. offen, abgerundet.

1. Junge Zweige kantig. Haarfilz d. B.unterseite bleibend. O.-As.

$V$. Thunbergi Sieb. et Zucc.

2. Junge Zweige nicht kantig. B.unterseite (ausser d. Nerven) kahl blaugrün werdend. Suidatl. N.-Am. V. aestivalis Mchx.

1I. B.unterseite glänzend grün, Nerven meist mit abstehenden Haaren.

1. Stielbucht der B. weit offen, abgerundet.

+ Markscheidewände dick. Jüngste B. sehr schnell völlig flach ausgebreitet. Ostasiat. Festland. V. amurensis Rupr. ++ Markscheidewände dünn. Jüngste $B$. einige Zeit zusammengefaltet od. wenigstens oberseits vertieft. Atl.N.-Am.

V. riparia Michx.

2. Stielbucht der B. spitzwinkelig, meist eng.

+ B. eirundlich, ungelappt oder seicht 3-lappig, grobgesägtgekerbt, unterseits in den Winkeln gebärtet. Atl. N.-Am. 
++ B. fast kreisrund, \pm tief 3-oder 5-lappig, grobgesägt, unterseits nicht in d. Winkeln gebärtet. Mmglot. V. vinifera L.

\section{Tiliaceae $(35 ; 270)$.}

1. Bl. ohne Androphor. Blb. ohne Drüsenfeld. |Tilicae.| A. Fr. kapselartig aufspringend, mehrsamig.

A1. Alle Stb. fruchtbar.

a. Kapsel schotenförmig.

Corchorus (30).

\%. Kapsel geschnäbelt, aber nicht gehörnt. Unterste Sägezähne der gesägten, eilanzettlichen $B$. in 2 dünne, abwärts gewendete Schwänze ausgezogen. Palaeotrop. C. olitorius L.

3. Kapsel mit 3-5 zuweilen gespaltenen Hörnern. Sägezähne der B. ungeschwänzt. Trop.

C. acutangulus Lam.

b. Kapsel fast kugelig, an der Spitze eingedrückt. O.-Ind.

C. capsularis $\mathrm{L}$.

$B_{1}$. $\infty$ Staminodien aussen um die $\propto$ fruchtbaren Stb. Kapsel kugelig.

B. Fr. nüsschenartig.

Sparmannia (3) africana L. f.

Tilia (10).

a. Blb. aufrecht oder aufrecht-abstehend, länger als die Stb.

Vor den Blb. 5 schmal-blumenblattartige Staminodien (Nebenkrone). Stb. meist 50-75; Connectiv breit. (ir. zuletzt viel länger als die Stb.

๘. B. unterseits sternfilzig, weiss oder grau- bis grünlichweiss. N. kurz, breit 3-eckig, zusammenschliessend.

I. Fr. 5-samig, durch Furchen seicht 5 lappig. Stb. meist doppelt so lang als der Frkn. Atl. N.-Am. T. alba Ait.

II. Fr. 1- (bis 3-) samig, ganz ungefurcht, mit 5 feinen $( \pm$ erhabenen) Linien, am Grunde nicht vertieft. Stb. wenig länger als der Frkn. Ungarn bis Kleinas. T. tomentosa Mönch

3. B. unterseits grün, feim sternhaarig bis kahl. N. eiförmig, spitz. Fr. furchen- und rippenlos, 1-(bis 3-) samig.

I. B. meist sehr schief herzförmig. Gr. die Blb. zuletzt weit ïberragend. Atl. N.-Am.

T. pubescens Ait.

II. B. gleichseitig herzförmig oder abgestutzt. Gr. die Blb. zuletzt wenig überragend. N.-Am. T. americana L.

b. Blb. ausgebreitet, kürzer als die Stb.; nebenkronenartige Staminodien nur bei T. ulmifolia var. japonica, sonst fehlend. Stb. meist 25-30; Connectiv schmal. Gr. kürzer als die Stb.

\%. B. unterseits hellgrün und von einfachen Haaren weichhaarig, in den Nervenwinkeln graubärtig. Trugdolden 2- bis 3. (bis 5-) blütig. Reife Fr. mit 5 starken, schmalen Rippen und holziger Schale. T. platyphyllos Scop. (T. grandifolia Ehrh.

¡. B. unterseits kahl blaugrün, in den Nervenwinkeln rostfarben-gebärtet. Trugdolden 5- bis 7-(bis 9-)blütig. Fr. ungerippt oder sehr schwachrippig, dünnschalig.

T. ulmifolia Scop. (T. parvifolia Ehrh.).

உ. Bl. mit Androphor. Blb. mit einem Drüsenfelde am Grunde. [Grewieae.]

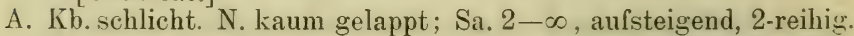
Fr. unbewehrt.

Grewia (70).

B. Kb. meist an der Spitze kappenförmig zusammengezogen und mit einem Anhängsel versehen. N. 2- bis 5-spaltig; Sa. 2, 
absteigend. Fr. mit geraden oder hakig gebogenen Stacheln bewehrt.

Triumfetta $(60)$.

\section{Malvaceae (39; 800).}

1. Frb. $\propto$, in mehreren Längsreihen über einander stehend, die in 5 den Blb. gegenüber gestellte Felder gruppiert sind. [Malopeac.] A. Hüllk. 3-blättrig. Teilfr. nicht aufspringend.

a. B. eiförmig, gekerbt. Mmght.

b. B. 3-nervig, 3-spaltig, gezähnt. Jimght.

Ialope (3). 1I. malacoides L. B. Hüllk. mehrblättrig. Teilfr. am Rücken aufspringend. Untere Donauländer.

Kitaibelia (1) vitifolia Villd.

2. Frb. in einer Ebene kreisförmig angeordnet.

1'. Fr. in Teilfr. zerfallend.

1“. Gr.äste so viele als Frb. [Malveae.]

1“. $\infty-2$ Sa. in den einzelnen Frb. [Abutilinue.]

A. Hïllk. fehlend.

A1. Frb. faltenlos.

Abutilon (80).

a. 1-jähr. Kraut, weichfilzig. B. rundlich, zugespitzt, gezähnt. Blb. klein. S.-Eur., Mitt.-As. A. Avicennae Grtu.

b. Strauch, kahl. B. 3-lappig, gesägt. Blb. ansehnlich. Mexiko. A. striatum Dicks.

B1. Frb. durch eine Querfalte in 2 ïber einander liegende Fächer geteilt.

B. 3-gliedriger Hüllk. vorhanden.

Wissadula (10).

A1. Frb. 1-fächg. - S.-Afr. Sphaeralcea (25) elegans (Cav.) Don

B1. Frb. durch eine horizontale Lamelle 2-fächerig. Amer. Modiola caroliniana (L.) Don

2"“. Sa. einzeln in jedem Frb.

1““. Sa. aufsteigend. [Malvinae.]

A. Gr.äste am Ende kopfig; N. endständig. Malvastrum (7) .

B. Gr.äste spitz; N. auf ihrer Innenseite.

A1. Bl. 8 .

A2. Stb. in einem Kreise stehend.

A3. Hiillk. fehlend oder freiblätterig.

a. B. herzförmig-rundlich, 5- bis 7-lappig. Bl.stiele büschelig-beisammenstehend.

a. Bl.stiele wenigstens zur Fr.zeit mehrmal länger als der K. B. am Rande eben.

I. Bl. klein. Hüllb. lineal-lanzettlich. Fr.stiele abwärts gebogen.

1. Kb. kraus. Blb. seicht ausgerandet, so lang oder kürzer als der K., weisslich. Teilfr. scharf berandet, grubig-runzelig. $M$. rotundifolia $\mathrm{L}$.

2. Kh. flach. Blb. tief ausgerandet, doppelt so lang als der K., rosa oder weisslich. Teilfi. glatt, am Rande abgerundet.

M. neglecta Wallr.

II. Bl. ziemlich gross. Blb. 3-4mal so lang als der K. Fr.stiele aufrecht oder abstehend.

1. Stengel rauhhaarig, nicht kräftig. Hüllb. länglich. Blb. tief ausgerandet.

M. silvestris L.

2. Stengel fast kahl. kräftig. Hüllb. breit-eiförmig. Blb. ausgeschweift. Westl. Mmgbt. M.mauritiana L. 
3. Fr.stiele höchstens doppelt so lang als der K. B. am Rande kraus. Oestl. Mmgbt.

M. crispa L.

b. Stengelb. bis zum Grunde handförmig 5-teilig. Bl.stiele meist einzeln, 1- oder doch armblütig.

๑. Stengel, B. und K. \pm durch angedrïckte Sternhaare graugrün. Hüllb. eilänglich. Teilfr. kahl, fein querrunzelig.

M. Alcea L.

ß. Stengel, B. und K. \pm durch abstehende, meist einfache Haare rauh. Hüllb. lineal-lanzettlich. Teilfr. dicht rauhhaarig, glatt.

B3. Hüllb. verwachsen.

A4. Mittelsäule die Teilfr. überragend. M. moschata L.

a. Mittelsäule scheibenartig verbreitert. Mmgbt. L. trimestris I.

b. Mittelsäule kegelförmig hervorragend.

๙. Bl. langgestielt. Obere B. 3-lappig, untere eckig. Salzliebend. Mitt.-Eur. bis Kaukasus. L. thuringiaca I.

3. Bl. sitzend. Obere B. 3-lappig, untere spiessförmig5-lappig. O.-Eur.

L. olbia L.

c. Mittelsäule gestutzt, in so viele häutige Kämme ausgebreitet, als Teilfr. vorhanden sind. B. stumpfeckig. Westl. Mmgbt.

L. maritima Gouan

d. Mittelsäule vertieft. Untere B. kreis-herzförmig, obere 3- oder 5-lappig. Mmgbt.

$L$. arborea $\mathrm{L}$.

B. Mittelsäule die Teilfr. nicht überragend. Althaea (15).

a. Frb. nicht berändert.

๑. Bl.stiel viel kürzer als das B. B. weichfilzig, untere 5-, obere 3-lappig.

A. officinalis $\mathrm{L}$.

F. Bl.stiel länger als das B. B. rauhhaarig, untere handförmig geteilt, obere gefingert, oberste 3-zählig. S.-Eur., W.-As.

A. cannabina $\mathrm{L}$.

b. Frb. von einem häutigen, gefurchten Rande umzogen.

\%. Stengel kahl. B. herzförmig, eckig. China. A. sinensis Cav.

9. Stengel behaart.

I. B. herzförmig, 7-eckig. Balkanhaibins., Creta.

A. rosea (L.) Cav.

11. B. bis über die Mitte handförmig-7-lappig, die obersten 3-lappig u. spiessförmig. Sibir., Griechld. A. ficifolia Cav.

B2. Stb. deutlich in 2 Kreisen. die äusseren in 5 Phalangen. Hiillk. 0. Pac. N.-Am. vidalcea (10) candida A. Gray B1. Bl. diklin. Hüllk. 0. B. geteilt. N.-Am. Napaea (1) dioica L. $2^{\text {w }}$. Sa. hängend mit dorsaler Rhaphe. Hüllk. fehlend. [Sidinae.] A. Teilfr. ungeflügelt.

A1. Scheidewände zwischen den Frb. bleibend; Rückenwand der Teilfr. sich nicht ablösend.

Sida $(70)$.

$\mathrm{B}_{1}$. Scheidewände $\mathrm{z}$ wischen den Frb. schwindend; Rückenwand der Teilfr. sich ablösend.

Anoda (8).

B. Teilfr. mit 2 häutigen Scheitelflügeln.

2". Gr.äste doppelt so viele als Frb. [Ureneae.]

A. Hüllk. fehlend. Deckb. den Bl.stielen angewachsen. Malachra (6).

B. Hüllk, vorhanden.

A. Frb. aussen glatt. Fr. fleischig.

Malraviseus $(10)$. 
B1. Frb. aussen stachlig oder höckerig, bei der Reife netzig oder gleichförmig widerhakig-stachlig. - Trop. Lrena (3) lobata L. 2'. Fr. eine fachspaltige Kapsel. [Hibiscecie.]

A. Gr. lang, so viele als Frb. S. nierenförmig. A1. Frb. mit $\infty-2$ Sa.

A2. K. bei der Fruchtreife bleibend.

a. Hüllb. frei. Fruchtfächer ohne Scheidewände.

๙. K. nicht aufgeblasen.

I. S. kahl. Nalay. Gbt.

II. S. wollig. Vord-As.

¡. K. aufgeblasen. S. kahl. Mmgbt.

H. Rosa sinensis L. H. syriacus L.

H. Trionum L.

b. Hüllb. am Grunde verbunden. K. nicht aufgeblasen. Fr.fächer mit Scheidewänden. S. etwas behaart. Trop. Küsten.

H. tiliaceus L.

B., K. vor der Fr.reife abfallend.

Bosteletzkya (6). Frb. mit 1 Sa.
B. Gr. einfach, am Ende kopfförmig oder in kurze, aufrechte

Aestchen geteilt. S. eckig oder verkehrt-eiförmig, wollig.

A. Hüllb. klein oder abfällig.

B1. Hülíb. gross, herzförmig, bleibend.

Thespesia (3).

a. B.lappen lanzettiich, 4-5mal so lang als die Entfernung der Buchten vom B.grund.

э. Wolle leicht vom S. trennbar, dieser dann glatt. Trop. Am.

G. barbadense L.

Wolle schwer vom S. trennbar, zwischen den Wollfäden ein dichter, kurzer Filz. Bl. purpurrot. Trop.Afr. G. arboreum L.

b. B.lappen eiförmig-kurzzugespitzt, höchstens doppelt so lang. als die Entfernung ๙. Buchten vom B.grund. S. wie bei a O.-Ind.

G. herbaceum L.

\section{Sterculiaceae $(48 ; 660)$.}

1. Ohne Androphor. Stb.röhre kurz.

1'. Blb. gross.

1". Blb. flach.

A. Stf. am Grunde oder über der Mitte verbreitert, frei. Frb. episepal, mit je $\infty$ Sa. Frkn. J-fächerig. Hermannia $(120)$.

B. Stf. am Grunde zu ein. Röhre verbunden, im freien Teile nicht verbreitert. Frb. epipetal. Frkn. 1-fächerig. Waltheria (30).

2“. Blb. kappenförmig. [Buettnerieae.]

1“. Zwischen den Staminodien einzelne Stb. [Buettneriinae.]

A. Blb. nicht der Stb.röhre angewachsen. Ruelingia (15)

B. Blb. d. Stb.röhre angewachsen.

Buettneria (50).

2““. Zwischen den Staminodien Stb.bündel von 2-5 dithecischen Stb. [Theobrominae.]

Fr. saftig, nicht aufspringend. - Mexiko bis Brasil.

Theobroma (12) Ciacao L.

2'. Blb. sehr klein, schuppenförmig oder fehlend. [Lasiopetaleae.]

A. A. mit Längsspalten aufspringend.

B. A. mit Poren sich öffnend.

Thomasia (21).

2. Bl mit Androphor. Blb flach. [Helictereae] Helicteres to 


\section{Dilleniaceae $(11 ; 280)$.}

I. A. den Stf. fest angewachsen. Frb. oberwärts unter sich frei. [Dillenioideae.]

1. Frb. unter sich völlig frei. B. netz- oder 1-nervig, meist schmal, ericoid. [Hibbertieae.]

Hibbertia (90).

Stb. bis zur Mitte oder noch höher zu 5 Bündeln vereinigt. Frb. 5-3, mit meist $2(3-1)$ Sa. [\$ Candollea.] - W.-Austr.

H. cuneiformis (Lab.) Gilg

2. Frb. \pm fest mit einander verwachsen. B. gross, parallel-fiedernervig. - Ostind.-malay. Gbt. Dillenia (25) indica L.

II. A. versatil. Frb. wenigstens seitlich völlig fest mit einander verwachsen, an der Achse oft frei. Gr. frei. [Actinidioideae.]

Actinidia (8).

a. (ir. unterwärts zu einem hohlen Schnabel verwachsen. B. am Grunde herzförmig. O.-As. A. Kolomikta (Rupr.) Maxim.

b. Gr. unterwärts zu einem derben Schnabel verwachsen. B. am Grunde abgerundet. Japan. A. polygama (Sieb. et Zucc.) Planch.

Theaceae $(16 ; 200)$.

1. A. beweglich. Fr. kapselartig. [Theeae.]

A. Beim Aufspringen der Fr. ein Mittelsäulchen bleibend. In jedem Frb. 4-6 $(-\infty)$ Sa. in 2 Längsreihen.

A1. S. ungeflügelt. Gr. \pm frei.

Thea (16).

a. Bl. gestielt, nickend. $\bar{K} b$. nicht abfallend. Assam. T. sinensis L.

b. Bl. sitzend, aufrecht. Kb. abfallend. O.-As. T. japonica (L.) Nois.

$B_{1}$. S. geflügelt. (ìr. in ihrer ganzen Länge und N. verwachsen. - Trop. As.

Gordonia (16) axillaris (Don) Szysz.

B. Fr. ohne Mittelsäulchen. In jedem Frb. 2 Sa. neben einander.

- Südatl. N.-Am.

'Stewartia (5) pentagyna L'Hér.

2. A. unbeweglich. Fr. nicht aufspringend. [Taonabeae.]

Frkn. halb unterstindig. Canaren. Visnea (1) Mocanera L.

\section{Guttiferae (42; 450).}

A. $\infty$ Sa. in jedem Fach bez. an jeder Placenta.

A1. Bl. 8 .

A2. Fr. eine scheidewandspaltige Kapsel.

A3. Blh.4-zihl. Atl.N.-Am., Mitt.-Am.Ascyrum (5) hypericoides L.

B3. K. und Blkr. 5-zühlig.

a. Ohne Drüsen von der Kelchb.

Нурегісum (200).

a. Stb. siimtlich frei od. sehr kurz in 1 Bündel verwachsen. 3 Frb.

I. Stengel stielrund. N.-Am.

H. mutilum L.

II. Stengel wenigstens oberwärts 4-kantig. S.-O.-As. bis Neuseeland.

$\beta$. Stb. in 3-5 Bündel verwachsen.

H. japonicum Thbg.

I. Stb. in 5 (oder selten 4) Bündeln.

1. 5 Frb.

+ Blb. nach der Bl.zeit abfällig.

$\odot$ Kb. nach der Bl. sich stark vergrössernd, abstehend od. zurïckgeschlagen. Bündel mit etwa je $60-100 \mathrm{Sth}$. Orient. 
(C) Krb. an der Fr. aufgerichtet. Bündel mit bis $60 \mathrm{Stb}$. Himal. bis Japan.

H. patulum Thbg. +- Bll). gedreht, bleibend. Kb. laubig. nach der Bl. auf2. 3 Frb. gerichtet. Sib. bis N.-Am.
H. Ascyron L.

+ Gr. kurz. Frb. vor der Rieife fleischig werlend. Engld. S.-Eur.. Orient.

H. Androsaemum L.

+ + Gr. so lang oder mehrmal länger als der Frkn. Kapsel lederartig.

(- Stengel mit 2- Leisten. Sth. so lang wie die Blb. N.-Am.

H. elatum Ait.

Cᄃ Stengel rundlich (oder schwach 4-kantig). Stb. länger als die Blb. Mmgbt.

II. Stb. in 3 Bïndeln. $3 \mathrm{Frb}$.

1. Blb. nicht oder nur ganz kurz genagelt, bleibend.

+ B. gegenständig. Kb. dachig. Stb. bleibend.

( Sa. mehrreihig. Bündel mit etwa 25 Sth. S.-O.-Eur.. Kleinas.

$H$. olympicum L.

C) Sa. 3-reihig. Bündel mit etwa .) Sth. H. humifusum L.

++ B. quirlig oder kreuzständig. Kh. nicht dachig.

$\odot$ B. nadelfürmig. Bündel mit $7-9$ Sth., bleibend.

$\hat{\uparrow}$ B.quirle 4-zählig. Frankr., Alp., Ital. H. Coris L.

$\hat{\uparrow} \uparrow$ B.quirle 3-zählig. Griech.. Kleinas. H. empetrifolium Tilld.

$\odot$ B. laubig. Bündel mit $15-25$ Stb.

$\mathrm{Kb}$. am Rande drüsenlos. Stengel kantig. S. \pm grubiggestreift.

X Stengel 2-kantig, derh. Kib. lanzettlich, doppelt so lang als d. Frkn. H. durchscheinend-punktiert. H. perforatum L.

$\times \times$ Stengel 4-kantig, hohl. Kib. so lang als der Frkn.

* Stengel schlicht 4-kantig. B. nur wenig durchscheinend punktiert. Kb. eielliptisch. stumpf. H.quadrangulum L. $\Varangle \Varangle$ Stengel geflïgelt-4-kantig. B. dicht punktiert. Kb. lanzettlich, zugespitzt. $\quad H$. tetrapterum Fr.

$\uparrow \uparrow$ Kb. am Rande driisig-gesägt oder gewimpert. Stengel stielrund.

X S. grubig-gestreift. Pflanze kahl. B. am Grunde herzförmig, sitzend.

Ұ Kb. lanzettlich, spitz. Blb. blassgelb. B. spitz, am Rande schwarz punktiert. $H$. montanum $\mathrm{L}$.

$\Varangle \Varangle \mathrm{Kb}$. verkehrt-eiförmig, sehr stumpf. Blb. goldgelb. B. stumpf, am Rande ohne schwarze Punkte.

H. pulchrum L.

XX S. papillös. Pflanze behaart. B. gestielt. H. hirsutum L.

2. Blb. lang genagelt, aufrecht abstehend. hohl. Canar.

H. canariense $\mathrm{L}$.

b. Vor den drüsig gewimperten Kb. schuppenfürmige, hypogrne Drüsen. Blb. mit gefransten Nectarien. :3 Bündel mit je $3-5$ Stb. W.-Eur.

H. Elodes L.

B. Fr. eine Beere. Blb. ober- bez. innenseitig wollig. Tismia (24). B1. Bl. diöcisch (selten polygam).

B. In jedem Fach 1 Sa.

Clusia (80). 
A1. Frkn. 2- bis 12-fächerig. Fr. eine Beere. B1. Frkn. 1-fächerig. Steinfr.

Garcinia (150). Calophyllum (55).

Elatinaceae (2; 29) (Elatine, 12).

a. Stengel aufsteigend oder aufrecht. B. quirlig (Luftb. zu 3, Wasserb. etwa zu 12), sitzend. Bl. sitzend. 4 grünlichweisse Blb. 8 Stb. Wasserb. lineal-lanzettlich, Luftb. eiförmig. E. Alsinastrum L. b. Stengel kriechend, wurzelnd. B. flügelig-gestielt, gegenständig. Blb. rötlichweiss.

a. 4 Blb. 8 Stb. S. hufeisenförmig gekrümmt. Bl. sitzend. B. länglich-elliptisch.

3. 3 Blb. 3 oder 6 Stb. S. kommaförmig.

I. Bl. gestielt. 3 gleiche Kb. Stb. 6. B. länglich. E.paludosa Seub.

II. Bl. sitzend. Das unpare (hintere) Kb. kleiner oder fehlend. Stb. 3. B. länglich bis lineal.

E. triandra Schk.

\section{Tamaricaceae $(5 ; 95)$.}

A. Androeceum meist haplostemon. Stf. nichtverwachsen; A. extrors. 3-4 + deutliche Gr. Haarbüschel der S. sitzend. Tamarix (64).

a. K., Blkr. und Androeceum 5-zählig; 3 Frb. Stf. mesodiscisch, d. i. mit schmalem Grunde zwischen den Drüsen eingefügt. Aehren an diesjährigen Zweigen endständig. Canar., westl. Mmgbt.

T. gallica L.

b. Bl. durchaus 4-zählig. Stf. epidiscisch, d.i. mit breiterem Grunde dem Discus aufsitzend. Aehren seitlich an vorjährigen Zweigen. Oestl. Mmgbt.

T. tetrandra Pall.

B. Androeceum obdiplostemon; Stf. bis ${ }^{1} 3$ oder zur Hälfte weitröhrig verwachsen; A. intrors. 3 sitzende $N$. Haarbüschel der S. langgestielt. Myricaria (10) germanica (L.) Desv.

Cistaceae $(4 ; 160)$.

A. 5 (selten nur 3) Frb. E. spiralig.

Cistus (45).

a. Die 2 äusseren Kb. grösser als die inneren. Blb. weiss. Gr. fast 0.

a. B. sitzend, lineallanzettlich, beiderseits klebrig-zottig. Einseitswendige Trugdolde. S.-W.-Eur. C. monspeliensis L.

ß. B. gestielt, eiförmig, stumpf, runzelig, unterseits filzig. Einzelbl. S.-Eur.

C. salviifolius $\mathrm{L}$.

b. Aeussere Kib. schmaler, oft kleiner. Blb. purpurn. Gr. walzlich. Creta, Kleinas.

c. Die 2 äusseren Krb. fehlend. Blb. weiss. N. gross, sitzend. Iber. Halbins. C. creticus L. C. ladaniferus $\mathrm{L}$.

B. $3 \mathrm{Frb}$. E. hakig oder $\sim$-förmig gekrümmt. Helianthemum (110).

a. Bl. in endstïndigen, traubenartigen Wickeln mit Hochb. Alle Stb. fruchtbar. Frb. vor den Kb.

a. B. sämtlich gegenständig. Gr. am Grunde \pm gekrümmt.

I. Nebenb. vorhanden.

1. Blb. gelb.

2. Blb. rot, rötlich oder weiss.

H. Chamaecistus Mill. H. polifolium Pers.

II. Nebenb. fehlend (selten bei den oberen B. vorhanden). Blb. gelb. Kapsel länger als der K.

$H$. oelandicum Whlbg.

ア. Untere B. gegenständig, obere spiralig. Blb. citronengelb, am Grunde oft schwarzgefleckt. Gr. fast 0 . $\odot$. H.guttatum (L.) Mill. 
b. Bl. einzeln achselständig. Aeussere Stl). oft unfruchtbar. Frb. mit den inneren Kb. abwechselnd. B. spiralig, linealisch, am Rande zurückgerollt. Blb. gelb.

H. Fumana (L.) MIill.

\section{Violaceae $(21 ; 250)$ (Viola, 150).}

a. Die 4 oberen Blb. aufwärts gerichtet und aufwärts dachziegelig. Gestengelte Pflanzen ohne Ausläufer.

๙. N. flach, fast 2-lappig. Blb. citronengelb. B. breiter als lang.

$V$. biflora $\mathrm{L}$.

₹. N. gross, krugförmig ausgehöhlt. Wenigstens die oberen B. meist länger als breit.

I. Nur grundständige B. vorhanden. Nebenb. bis über die Nitte dem Blattstiel angewachsen, an der Spitze 2-spaltig. Blb. azurblau.

$V$. alpina $\mathrm{L}$.

II. Grund- und Stengelb. vorhanden. Nebenb. nicht angewachsen. Blb. verschiedenartig violett und gelb gefärbt.

1. Nebenb. länglich-lanzettlich, eingeschnitten, mit spitzen Zähnen. Blb. sehr gross, verschieden gezeichnet. Sib., Krim.

V. altaica Pall.

2. Nebenb. handförmig geteilt, Zipfel lineal, meist ganzrandig, der mittlere breiter. Sporn kaum länger als die Kb.anhängsel.

V. lutea $\mathrm{Sm}$.

3. Nebenb. meist leierförmig-fiederspaltig. Sporn doppelt so lang als die Kb.anhängsel.

V. tricolor L.

b. Die beiden mittleren Blb. seitlich abstehend.

๙. N. in ein herabgezogenes Schnäbelchen verschmälert.

I. Kb. spitz. Blb. meist hellblau. Gestengelte Pflanzen ohne Ausläufer. Fr.stiele aufrecht.

1. Nebenb. ganzrandig, drüsig-gewimpert.

2. Nebenb. gefranst oder gezähnt.

+ B. in gewöhnlicher, offener Spirale stengelständig.

C Nebenb. klein, kürzer als der halbe ungeflügelte Blattstiel. Sporn doppelt so lang als die Kb.anhängsel. $V$. canina L.

(-) Nebenb. wenigstens halb so lang als der geflügelte Blattstiel. Sporn kaum länger als die Kb.auhängsel.

V. persicifolia Schk.

++ B. in mittelständiger Rosette, aus ihren Winkeln beblätterte Stengel sprossend.

(. Stengel und B. behaart. B. rundlich-herzförmig, stumpflich; Nebenb. eilänglich.

$\odot$ Stengel und B. kahl oder fast kahl. B. herzeiförmig; Nebenb. lanzettlich.

^ Kb.anhängsel sehr kurz. Blb. schmal-länglich. Sporn dünn, kaum gefurcht, violett.

V. silvativa Fr.

$\uparrow \uparrow$ Kb.anhängsel 3-eckig-länglich. Blb. rerkehrt-eiförmig. Sporn dick, gefurcht, weisslich.

V. Riviniana Rehb.

II. Kb. stumpf. Stengellose Pflanzen; B. und Bl.stiele aus dem Wurzelstock hervortretend. Fr.stiele niedergestreckt, gerade.

1. Ausläufer fehlend oder nur kurz.

+ B. kurzhaarig, grüin; Nebenb. spitz oder stumpflich, nebst den Fransen am Rande kahl. Blb. violett.

I. hirta L. 
++ B. weichhaarig, grau; Nebenb. mit Haarspitze, nebst den Fransen am Rande fein rauhhaarig. Blb. lila, am Grunde nebst dem Sporn weisslich. $V$. collina Bess.

2. Auslïufer vorhanden, langhin kriechend. V. odorata L. ß. N. in ein schiefes Scheibchen ausgebreitet. Fr.stiele aufrecht. I. Nebenb. frei. Blb. blasslila.

1. B. kahl, stumpf herznierenförmig. An oder unter der Mitte des Bl.stieles 2 Vorb. Sporn kaum länger als die Kb.anhängsel.

$V$. palustris L.

2. B. unterseits kurz behaart, nierenförmig, meist spitz. Vorb. über der Mitte des Bl.stieles. Sporn etwa doppelt so lang als die Kb.anhängsel. $\quad V$. epipsila ledeb.

II. Nebenb. bis über die Mitte dem geflügelten B.stiel angewachsen. B. dicht braundrüsig, unbehaart. Blb. dunkelviolett.

V. uliginosa Schrad.

\section{Pittosporaceae $(9 ; 105)$.}

Bäume oder Sträucher ohne Dornen, mit lederigen, immergrünen B. Kapselfr. S. gefliigelt.

Pittosporum (70). a. B. verkehrteiförmig, etwa ${ }^{1 / 2} \mathrm{dm}$ lang. O.-As. P. Tobira (Thbg.) Ait. b. B. elliptisch-lanzettlich, beiderseits spitz, am Rande kraus. $1 \mathrm{dm}$ lang. O.-Austr. $P$. undulatum Vent.

\section{Flacourtiaceae $(61 ; 510)$.}

A. Blh. spiralig, homoiochlamydeisch. Stf. sehr kurz. Chile.

Berberidopsis (1) corallina Hook. 1 .

B. Blh. cyclisch, heterochlamydeisch oder apetal. Stf. lang.

A1. Blb. vorhanden. - S.-Afr. Ścolopia (16) Closiana (Baill.) Warb. B1. Blb. fehlend.

A2. Bl. Bl.stand achselständig. B. klein, lederig, fiedemervig. - Chile.

Azara (22) microphylla Hook. f.

B2. Bl. diöcisch. Bl.stand endständig. B. gross, dünn, handnervig. Japan.

Idesia (1) polycarpa Maxim.

\section{Passilloraceae (15; 320) (Passiflora, 250).}

a. Bl. ohne Involucrum. Corona aus Fäden bestehend.

œ. Blb. vorhanden, weiss. Mexiko. $P$. holosericea L.

ア. Blb. fehlend. Trop. S.-Am. P. gracilis Jacq.

b. Unter den Bl. ein Involucrum freier oder verwachsener Hochb.

a. Bl.achse glockenförmig. Corona aus langen Fäden bestehend. Androphor oft mit rollenähnlichen Anschwellungen. [\$ Granadilla.]

I. Involucrum freiblättrig.

1. Stengel mit 4 Flïgelleisten. B. einfach.

+ B. lang zugespitzt. Nebenb. und Deckb. eifürmig, ganzrandig. Bll). rosenrot. Trop. Am. P. quadrangularis L. ++ B. spitz. Nebenb. lanzettlich-sichelförmig, nebst Deckb. etwas gesägt. Blb. sattrot. Trop. Am. P. alata L.

2. Stengel ohne Flügelleisten. B. 3- bis j-lappig.

+ B. 5-lappig, Lappen ]änglich, ganzrandig. Nebenb. sichelförmig. Blb. weiss. Corona violett, in der Mitte weissberingt. Brasil. 
+ + b. 3-lappig, Lappen eiförmig, gesägt. Nebenb. pfriemelig. Blb. weiss. Fadenkranz purpurrötlich mit gelblichem Kreis. Brasil. $P$. edulis Sims

IJ. Involucrum verwachsenblättrig. R. einfach. Trop. Am.

P. maliformis L.

¡. Bl.achse langcylindrisch. Corona meist nur aus Knötchen oder häutigen Schüppchen, seltener längeren Fäden bestehend. [S Tacsonia.] - B. 3-bis 5-nerrig, gelappt; Nebenb. Kammförmig.

I. Involucrum freiblättrig, Involucralb. $=$ eingeschnitten. B. unten flaumhaarig-grau. Nebenb. gezähnt. Andin. S.-Am.

P. pinnatistipula Cav.

II. Involucrum verwachsenblättrig. B. unten weissfilzig. Nebenb. fiederspaltig. Andin. S.-Am.

P. manicata Pers.

\section{Loasaceae $(13 ; 200)$.}

I. Stb. meist sämtlich fruchtbar, selten die äusseren in fädliche oder petaloide Staminodien umgeformt. [Mentzelioideae.]

- 1. Frb. 3, selten 5 (-6) mit den Kelchb. alternierende. Placenten faden- bis breit-bandförmig mit 1-2 Längsreihen von Sa. Haare verschieden, namentlich mit Widerhaken; keine Brennborsten.

Mentzelia (46).

Bl. gross, prächtig goldgelb. Kalif. M. aurea (Lindl.) Baill.

2. Frb. stets 5. Placenten im Querschnitt kreisförmig, mit $\propto$ Längsreihen von Sa.

Eucnide (7).

II. Androeceum stets in fertile und sterile Gruppen gesondert: erstere oppositipetal; letztere alternipetal. [Loasoideae.]

Staminodialgruppe zu einer Schuppe mit 2 (sehr selten 4) die Oeffnung derselben nach innen rerschliessenden, meist freien Staminodien verwachsen. [Loaseae.]

A. Kapsel gerade, keulig oder verkehrt-kegelig, selten fast kugelig, an der Spitze mit 3 (seltener 5) Klappen aufspringend. Loasa (81).

a. B. spiralig. Sehr zahlreiche, kleine S. Peru bis Mexiko.

L. triphylla Juss.

b. B. gegenständig. Meist nur bis 10 grosse S. Chile. L. tricolor Ker

B. Kilpsel meist gedreht, bei der Reife an der Spitze stets geschlossen bleibend und nur längs der Placenten aufspringend.

A1. Stengel rund. Bl. in Cymen. Kapsel dünnwandig. Placenten durch eine dünne Lamelle mit der Fruchtwand verbunden, äusserlich nicht vortretend. - Argentin.

Cajophora (50) lateritia (Hook.) Klotzsch

B1. Stengel 4-kantig. Bl. einzeln achselstïndig, mit 2 Torb. unterhalb des Frkn. Kapsel dickwandig. Placenten äusserlich als breite Wülste sichtbar. - Argentin.

Blumenbachia (3) Hieronymi Urb.

\section{Begoniaceae (4; 410) (Begonia, 405).}

a. Placenten nicht gespalten. 3 Gr., 2-ästig. Fr. mit 3 ziemlich gleichen Flügeln. Stf. frei.

๙. N. die Gr.äste rings umgebend. B.handfiedernervig, mit Cystolithen. Trop. Amer. [\$ Pritzelia mit viel. cult. Arten.] 
I. Kriechend od. stengellos. Connectiv nicht hervorragend. Ostind.mal. Gebiet. [\$ Reichenheimia.] B. albococcinea Hook. f.

II. Aufrecht, selten mit verkürztem Stengel. Connectiv etwas hervorragend. Natal. [§ Augustia.] B. Dregei O. et D.

b. Placenten 2-flügelig, Flügel beiderseits mit Sa. Fr. ungleich 3-flügelig. B. meist handnervig, zuweilen schildstielig.

๙. Stf. unter sich allermeist frei. $3 \mathrm{Gr}$. Trop. Amer.

I. 24, meist ohne Knollen. Gr. 2-spaltig. N. ein continuierliches Schraubenband. Cystolithen fehlend.

1. ㅇ Bl. mit 2 (selten 3-4) Blhb. [\$ Magnusia.] - Mexiko. B. imperialis Lem.

2. Bl. mit $5(4-6)$ Blhb. B. handfiedernervig. [\$ Begoniastrum.] - Brasil. B. semperflorens Lk. et 0.

II. $\odot$, mittelst Knollen perennierend. Bl. sehr gross. Gr. meist mehrmals gespalten; N. muschelförmig geöhrt. Boliv., Peru, Columb. [\$ Huszia mit viel. cult. Art.] B. Veitchii Hook. f.

[. Stf. am Grunde zu einer kurzen, dicken Säule verwachsen. o Bl. mit 4-6 Blhb. 2 Gr., 2-ästig, Aeste gewunden. N. ein continuierliches Schraubenband. Ostind.-mal. Gebt. [§ Platycentrum mit viel. als Blattbegonien cult. Arten.] B. Rex Putz.

\section{Cactaceae $(20 ; 900)$.}

I. Ohne Glochiden (d. i. einzellige Widerhakenstacheln). [Cereoideae.]

1. Terrestrische Succulenten; Bl. trichter- oder präsentiertellerförmig mit dentlicher Perigonröhre.

1`. Bl. auf oder nahe bei den Areolen sitzend. [Echinocacteae.]

A. Stamm verlängert, einfach kantig od. gerippt. Cereus (120). Stamm gegliedert, mittelst Luftwurzeln kletternd.

a. Stamm 8-bis 12-furchig, schwach, mit schlaffen, peitschenförmigen Giliedern u. meist sehr dicht gedrängten Areolen. Bl.purpurrot. Mexiko. „Sichlangencactus. “C flagelliformis Mill.

b. Stamm 3-bis 6-kantig oder mit breiteren Furchen.

a. Zweige lang, wenigstens im Alter 5- bis 7-kantig, fast cylindrisch.

I. Areolen mit 4-8 kurzen Stacheln, ohne Haare. Bl. nach Vanille riechend, mit gelben, äusseren, strahlenden Blb. Mexiko, W.-Ind. "Königin der Nacht." C. grandiflorus Mill.

II. Areolen mit 1-4 Stacheln und krauser Wolle. Bl. geruchlos, mit bräunlichen,äusseren, strahlenden Blb. Mexiko. "Prinzessin der Nacht". $\quad$ C. pteranthus O. et D.

$\beta$. Stengel scharf 4-kantig, aufstrebend, rot überlaufen. Bl. rot. Mexiko. C. speciosus (Cav.) K. Sch.

B. Stamm verlängert, ästig, gegliedert, wenigstens die blühenden Glieder flach blattartig.

Phyllocactus (12).

C. Stamm verkürzt, kugel-, keulen- oder kurzsïulenförmig.

$A_{1}$. Blkr. sehr verlängert präsentiertellerförmig mit allmählich erweiterter Röhre, aus d. älteren Teilen der Rippen.

Eehinopsis (10).

B1. Blkr. kürzer präsentierteller- oder trichterförmig.

A2. Stamm gegliedert, kurz cylindrisch. Bl. seitenständig. 
B. Stamm ungegliedert, meist kugel- oder keulenförmig. Bl. scheitelständig.

A3. Ohne "Cephalium" od. Wollschopf. Echinocactus (200).

B3. Mit ,Cephalium " (d. i. Teränderung der Stammoberfläche und der Stacheln und Austreibung eines Wollhaarschopfes).

Melocactus (30).

2'. B1. aus den Axillen der Warzen hervortretend. [Mamiliarieae.] Warzen kegelförmig. zitzenartig od. kantig. Mamillaria (80).

2. Epiphyten nit radförmigen $\mathrm{Bl}$.

Rhipsalis $(.50)$.

II. Areolen mit Glochiden. Stamm mit flach-dickblattartigen od. cylindrischen Gliedern. Areolen in den Achseln linealischer. Heischiger, $\doteq$ früh abfallender B., in gewundenen Zeilen angeordnet. [Öpuntioideae.]

Opuntia (150).

\section{Thymelaeaceae $(38 ; 415)$.}

A. Zwischen Perigonzipfeln und Stb. Blb.schüppchen in einfacher, doppelter oder dreifacher Zahl stehend.

A1. Androeceum diplostemon. Bl. 4- od. 5-zählig. Gnidia (90). $\mathrm{B}_{1}$. Androeceum haplostemon. Bl. 4-zählig. Struthiola (24). B. Keine Schüppchen zwischen Perigonzipfeln und Stb.

A1. Androeceum diplostemon.

A2. Kib. auf einen undeutlichen Saum des Receptaculums reduciert. Alle Stb. in gleicher Höhe (an der Mitte der Höhlung der Bl.achse) stehend. (ir. langfädlich. - Atl. N.-Am.

Direa (2) palustris L.

B2. Kb. deutlich ausgebildet, zur Bl.zeit ausgebreitet. Die beiden Stb.kreise in verschiedener Höhe der Höhlung der Bl.achse eingefügt.

A3. Discus fehlend oder einen sehr kurzen Ring unterhalb des Frkn. bildend. Gr. kurz bis fehlend; N. knopfig od. kopfig.

At. Bl.achse cylindrisch. Gr. sehr kurz oder fehlend. N. sehr gross, kugelig oder halbkugelig. Fruchtwandung fleischig.

a. B. lederig, bleibend. Nährgewebe reichlich.

Daphne (40).

ๆ. Seitenständige, 3- bis mehrblütige, racemöse Bl.stände, zuweilen zunächst dem Zweigende kopfig gehäuft. Frkn. kahl. [§ Laureola.]

I. Kurze, fast sitzende, 5- bis 10-blütige Aehren mit hochblattartig.Tragb. W.-u.S.-Eur.,Azor., Kleinas. D.Laureola L.

II. Gestielte Köpfch. (zuweil. 1-blütig). Pont. Grbt. D. pontica L.

3. Einzeln endständige Dolden od. Köpfchen. [\$ Daphnanthes.]

I. B. wenigstens unterseits behaart. Frkn. dicht behaart, sitzend oder sehr kurz gestielt.

1. Zweige dicht zottig. B. am Rande zurückgerollt. Küpfchen mit hochblattartigen Tragb. Kib. eiförmig, stumpf oder ausgerandet. S.-Ital. bis Kleimas. D. sericea Tahl

2. Zweige zuletzt kahl. B. flach. Küpfchen obne Tragb. Kib. lanzettlich, spitz. Mmght. bis Himal. D. oleoides Schreb.

II. B. von Anfang an kahl.

1. Frkn. behaart. K. sehr selten kahl. 
+ Frkn. viel länger als sein Stiel. Bl.achse dicht weichhaarig-filzig.

(-) Köpfchen 6- bis 10-biuitig; Tragh. oft krautig. Kb. oval, stumpf. Gbg. Eur. D. Cneorum L.

$\odot \odot$ Köpfchen 3- bis 5-blütig; Tragh. gefürbt. Kb. eiförmig, spitz. Tirol.

D. petraea Leybold

+ + Frkn. kürzer als sein Stiel. Bl.achse kahl od. sparsam weichhaarig. Krain, Siebbg., Macedon. D. Blagayana Freyer

2. Frkn. und K. kahl. Alpen. D. striata Tratt.

b. B. häutig, abfallend. Nährgewebe spärlich. [\$ Mezereum.]

๘. Bl.köpfe nach der Belaubung, auf beblätterten diesjährigen Zweigen.

I. Frkn. ganz kahl. Bl.achse kahl oder fein weichhaarig. Altai.

D. altaica Pall.

II. Frkn. dicht behaart. Bl.achse seidenhaarig. D. alpina I. F. Bl. vor der Belaubung, an vorjährigen Zweigen zu $1-\bar{\tau}$ büschelig, seitenständig, sitzend.

I. Frkm. kahl. B. spiralig.

D. Mezereum L.

II. Frkn. zottig. B. gegenstiindig. China. D. Genlwa Sieb. etZuce.

bı. Bl.achse t krugförmig. Gr. kurz; N. meist klein. Fr.-

wandung hïutig. Thymelaea (20) Pusscrina (L.) Coss. et Gren.

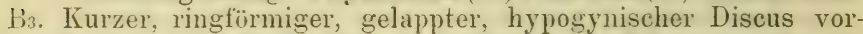
handen. (ir. verlïngert: N. cylindrisch. Elgeworthia (2). B1. Androeceum oligomer (2 Stb., 4 Kb.). Gr. lang. Pimelea (76). Bl. in endständigen, von 4-6 ausdauernden, breiten Involu(cralb. umhïllten Kö̈pfchen. Austral. P. ligustrina Lab.

\section{Elaeagnaceae $(3 ; 17)$.}

A. Bl. 8. 4 Stb. B. spiralig.

Elaeag'nus (12).

a. Ohne Discusring im oberen Teile der Blachse. B. eiförmig bis breitlanzettlich. Nuss schwach 8-rippig. Pac. N.-Am.

E. argentea Pursh

b. Oberer Teil der Bl.achsenhöhlung durch einen breiten Discusring schormsteinartig verengt. B. der Bl.zweige schmallanzettlich, stumpflich; B. der Langtriebe länglichlanzettlich. Nuss mit breiteren, hellen und schmaleren, dunklen Streifen. Mmgbt. bis China.

B. Bl. diöcisch.

$E$. angustifolia L.

A1. B. spiralig. K. 2-blättrig. б: 4 Stb., ohne Drüsenkörper. : Bl.achse keulig-röhrig. Hippophaë (9) rhamnoides L.

$\mathrm{B}_{1}$. B. gegenständig. (3-) $4 \mathrm{~Kb}$. $\mathrm{o}^{7}:(6-) 8$ Stb., innerhall) derselben gleichviele Drüsenkörper. 오 : Bl.achse krugförmig, mit $(6-) 8$ Drüsenschüppchen. - N.-Am.

Lepargyea (Shepherdia) (3) canadensis (Nutt.) Greene

\section{Lythraceae $(21 ; 250)$.}

1. Scheidewände des Frkn. oberwärts unvollständig. [Lythreae.]

A. Bl. strahlig (höchstens die Stb. etwas abwärts gebogen oder an der Rückenseite der Bl.achse tiefer eingefügt).

A1. Fr. nicht od. unregelmässig sich öffnend. $0-4$ bez. 6 abfällige Blb. 
A:. Blattwinkelständige, 3- bis mehrblittige Dichasien. Kapsel dünnhäutig, unregelmässig zerreissend. Ammannia (18).

B:. Blattwinkelständige Einzelbl. Fr. nicht aufspringend. Bl.achse glockig. $6 \mathrm{~Kb}$. 0-6 Blb. Peplis (3) Portula $\mathrm{I}$.

B1. Kapsel wandspaltig oder septifrag. mit 2 einfachen oder oben 2-spaltigen Klappen.

Lythrum (23).

a. Untere B. gegenständig. Bl. in ährenartig gestellten Dichasien (Scheinquirlen). 12 Stb.

๙. B. lanzettlich, am Grunile ahgerundet. Kỉb. gleichlang.

L. virgatum $\mathrm{L}$,

3. B. herz-lanzettlich. Kb. abrechselnd länger. L. Salicaria L.

b. B. lineal-lanzettlich, sämtlich spiralig. Bl. cinzeln blattwinkelständig. $2-6$ Stb.

L. Hyssopifolia L.

B. Bl. zrgomorph. Ton den histl. fehlt mindestens das riickenständige.

a. Blb. purpurn. Stb. gleichartig. N.-Am. C. viscosissima Jacy.

b. Blb. purpurn. $11 \mathrm{Stb}$., woron die 2 längeren über den $A$. wollhaarig. S.-Am.

C. procumbens Car.

2. Scheidewände d.Frkn. absolut vollständig. Bl. strahlig. [Nesaceac.]

A. Achselständige Einzelhl. S. ungeflügelt. - Mexiko, Bolivia bis Montevideo. Heimia (2) salicifolia Lk.

B. Bl. in Rispen oder Trauben. S. geflügelt. Lagerstroemia (23).

a. Bl.achse aussen glatt und ungeöhrt. selten mit 12-2 schwachen Längsstreifen. Malay. Gbt.

L. indica $\mathrm{L}$.

b. Blachse mit doppelt so viel Rippen als $\mathrm{K} b$. . in die Buchten und Zipfe] verlaufend. O-tind.-mal. Glut. L. speciona Pers.

\section{Myrtaceae $(72 ; 2750)$.}

I. Beeren- (sehr selten steinfr.-' artige scheinfr. Myrtoideac-Myrteac.

1. E. hufeisenförmig oder spiralig eingerollt. Stämmchen meist viel umfangreicher als die meist kleinen Lieimb. [Myrtinac.] A. S.schale hornartig.

A1. Frkn. 1-fächerig; die heiden Placenten direkt wandständig. Mal. Gbt. bis N.-S.-Tales. Phodamnia 12 trincria Bl.

B1. Frkn. mehrkammerig oder mehrfächerig.

A2. Frkn. ohne falsche Scheidewände.

A3. Kb. schon in der Knospe frei.

At. Kib. schon in der Knospe $\doteq$ zurückgebogen. Stf. $=$ banåförmig, ohne deutliche irenze in das commectiv ïbergehend. welches die vorn ansitzenden $A$. üherragt. - Chile, Bolivia. Ugni (11) Molinae Turcz.

B. Kb. in der Knospe anliegend. Stf. fädlich. deutlich gegen das oben mit punktförmiger Drüse rersehene Connectir abgesetzt. A. dorsifix, \pm versatil.

Myrtus (60).

a. Kb. unter sich frei oder nur ganz kurz rerwachsen, spitz oder zugespitzt.

๘. Krb. länger als breit. B. flach, elliptisch bis lanzettlich. Nmgbt.

M. communis $\mathrm{L}$.

¿. Thb ebenso lang als breit. B. blasig oberseits convex, unterseits concar, rundlich. Neu-Seeland.

M. bullata Banks et Sol. 
b. Kb. kurz und meist doppelt so breit als lang, oben abgerundet, am Grunde zu einem ziemlich breiten Saum verwachsen. Austral.

M. tenuifolia Sm.

B3. Kb. in der Knospe hoch hinauf oder zu einer Kappe verwachsen. - Trop. Am. Psidium (100) Guayava Raddi

B2. Fächer des Frkn. durch 1 falsche Längs- und os Querscheidewände gefächert, in jedem Teilfach 1 Sa. - Ostind.-mal. Gbt.

Rhodomyrtus (6) tomentosa (Ait.) Wight

B. S.schale häutig. Frkn. 2-fächerig mit dünner Mittelscheidewand. - W.-Ind.

Pimenta (5) acris (Swartz) Lindl.

2. E. und insbesondere die laubartigen Keimb. knitterig zusammengefaltet. Stämmchen und Keimb. gleichlang. [Myrciinae.]

In jedem Fache des Frkn. $\infty$ (bei den übrigen Gattungen 2) Sa. - Chile.

Myrceugenia (15) apiculata (D.C.) Ndz.

3. Stämmchen meist sehr kurz und ganz zurücktretend gegen die dickfleischigen Keimb. [Eugeniinae.]

A. Frkn. mitten in dem soliden Teile der dentlich vom Bl.stiel abgesetzten Bl.achse. $4-\infty \pm$ horizontale Sa. in jedem Fache des Frkn. - Uruguay, S.-Bras. Engenia (625) uniflora L.

B. Blachse meist beträchtlich über den Frkn. hinaus verlängert und in dem soliden Teile in den dicken Stiel verschmälert; Frkn. in der oberen Partie dieses Teiles.

A1. Blb. einzeln abfallend. Dentlicher Staminaldiscus.

Jambosa (120).

a. Bl.achse verkehrt kegelig, trichterig oder gestielt becherförmig, unterhalb der Frkn.höhlung oft plötzlich zusammengezogen, meist glatt. Laubb. meist mit wenig zahlreichen, bogig-netzig verlaufenden Primärseitennerven. [§ Eujambosa.] - Ostind.-mal. Gbt. J. vulgaris D.C.

F. Bl.achse in der Hauptsache cylindrisch oder gerieft-prismatisch. Laubb. meist mit sehr zahlreichen parallelen Primärseitennerven. [§ Clavimyrtus.] - Molukken.

J. Caryophyllus (Spreng.) Ndz.

Bı. Blb. \pm verklebend zu einer beim Aufblühen häufig als Ganzes abfallenden Kappe. Kein deutlicher Staminaldiscus.

II. Trockenfr. [Leptospermoideae.]

Syzygium (140).

1. Frkn. mehrfächerig oder mehrkammerig. Fr. fast stets eine fachspaltige Kapsel. [Leptospermeae.]

1'. E. gerade oder schwach gekrümmt. Keimb. fast ebenso lang oder länger als das Stämmchen.

1“. Fr. in Coccen zerfallend. - O.-Austral.

$2^{\prime \prime}$. Fr. eine facbspaltige Kapsel.

Backhousia (5) myrtifolia Hook. et Harv.

1 i“. A. versatil-dorsifix.

1“\%. Bl. in achselständigen, schirmrispigen Blütenständen, selten einzeln (manche Eucalyptus).

1“w. Blb. mit schmaler Basis, unter sich frei. [Metrosiderinae.] Stb. frei, in einfacher Reihe ringsum \pm gleichmässig verteilt.

Metrosideros (20).

2“u!. Blb. mit breiter Basis. [Eucalyptinae.] 
K.zähne allermeist undeutlich oder fehlend. Blb. verwachsen, mützenförmig abfallend.

Eucalyptus (140).

a. Bl. einzeln achselständig, gross. A. länglich, mit 2 in der ganzen Länge verlaufenden, parallelen Spalten aufspringend. S.-O.-Austral. $\quad E$. Globulus Lab.

b. Bl. in doldenförmigen Schirmrispen, ziemlich klein. A. nierenförmig, die Fächer unten spreizend, oben zusammenneigend oder verschmelzend. S.-O.-Austral. E. amygdalina Lab. 2“"'. Bl. einzeln in den Achseln von Laubb. oder schuppigen Tragb. sitzend. [Leptosperminae.]

A. Stb. die Blb. nicht iiberragend, unter sich frei.

A. $\infty$ Sa. von schildförmiger Placenta herabhängend.

Leptospermum (25).

B1. 2-6 Sa. von fast grundständiger, schildförmiger Placenta aufsteigend.

B. Stb. die Blb. weit überragend.

Agonis (13).

A1. Stb. frei.

A2. Kb. bleibend. Sa. hängend.

B. Kb. abfallend. Sa. aufsteigend.

Kunzea (17).

$B_{1}$. Stb. in oppositipetale Adelphien verwachs. Melaleuca (100).

a. Aehren schon vor dem Aufblüben übergipfelt, meist einfach. K. bleibend.

๘. Einfache, kurze und dichte Aehren an Hauptzweigen. Bl. gross. Stb. über $1^{1 / 2} \mathrm{~cm}$ lang. B. gegenständig.

M. hypericifolia (Salisb.) Sm.

F. Dichte Aehren an Seitenzweigen oder aus Knäueln zusammengesetzte Aehren an Hauptzweigen. Stb. kürzer als $1^{1 / 2} \mathrm{~cm}$. B. gegenständig. M. thymifolix $\mathrm{Sm}$.

$\because$. Bl. in einfachen, lockeren Aehren an Hauptzweigen. B. spiralig.

M. pulchella R. Br.

b. Bl. in endständigen, vor dem Verblühen nicht übergipfelten Köpfchen.

๙. B. in gewöhnlicher Weise am Grunde gestielt.
I. B. gegenständig.
II. B. spiralig.
M. calycina R. Br.
M. thymoides Lab.

3. B. schuppenförmig, auf der dem Stamm angedrückten Innenseite kurzgestielt.

M. thuyoides Turcz.

2"'. A. basifix; sonst wie die Leptosperminae. [Calothamninae.] Stb. in langgenagelten Adelphicen. W.-Austr. Calothamnus (23). a. Bl. 5-zählig, \pm aktinomorph.

b. Bl. 4-zählig, \pm median zygomorph.

a. Alle Stb.bündel etwa gleich mächtig. C. quadrifidus R. Br.

F. Untere Bündel stark reduciert, antherenlos. C. sanguineus Lab.

2‘. Keiml, gegen das viel mächtigere Stämmchen zurückgeschlagen. [Baeckeinae.]

Baeckea (58).

a. A. versatil, das spitze Ende des Stf. deutlich gegen das Connectiv abgesetzt. N.-Austr. B. fascicularis (Lab.) Ndz.

b. Stf. fast rechtwinkelig-krückenartig in das keulenförmig angeschwollene Connectiv umbiegend. O.-Austr.

B. virgata (Forst.) Andr. 
¿. Frkn. 1-fächerig mit 1 Placenta. Fr. nüsschenartig, meist 1-samig. [Chamaclauciece.] - Kb. meist lang grannenartig auslaufend. IV.-Austr.

Calycothrix (38) tetragona Lab.

\section{Melastomataceae $(148 ; 2800)$.}

I. Fr. eine geschlossen bleibende Beere.

A. Stb. gleich, \pm gerade. Connectiv nur wenig erweitert.

Clidemia (100).

b. Stb. \pm ungleich, \pm schwanenhalsartig gekrümmt. Connectiv stark nach vorn und hinten in höcker- oder spornartige Auswïchse erweitert.

A1. Stb. meist wenig ungleich. (Fig. 13 D.) Scheitel des Frkn. glatt. - Luzon.

Medinilla (100) magnifica Lindl.

B1. Stb. sehr ungleich. (Fig. 13 C.) Scheitel des Frkn. von 4 Kämmen gekrönt.

Diplectria (17).
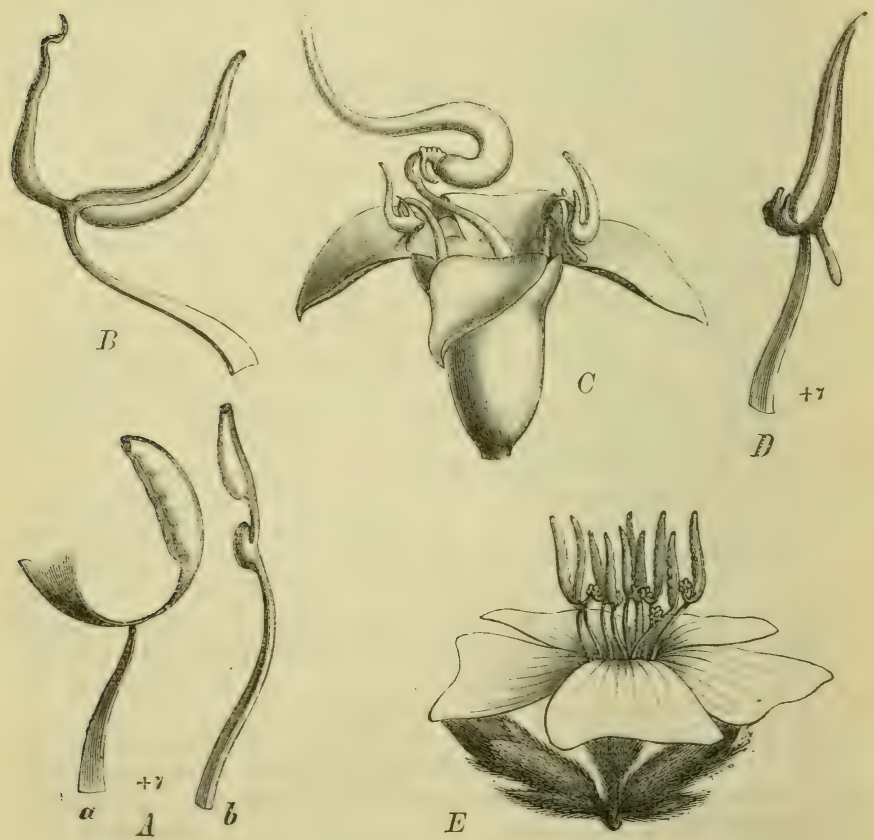

Fig. 13.

A Stb. von Centralenia incequilateralis (Ch. ot Schl.) Don. - B K Kleineros Stb. ron Monochactum multiforum (Bonpl.) Naud. $-C$ Bl. von Diplectria divaricate (Willd.) Triana, $-D$ Stb. von Mledinilla javanensis Bl. $-E$ Bl. von Tilouchina heteromalla (D. Don) Cogn. 
II. Fr. eine Kapsel oder umregelmässig aufreissende Beere.

1. Frkn. u. Fr. walzlich od. kantig mit kegelig. od. convex. Scheitel.

1. Anhängsel der Stb. vorn (innenseitig).

1". Bl. meist perigyn: zwischen den Kb. meist keine Anhangsgebilde. [Tibouchineae.]

A. Stb. fast gleich. Frkn. am Scheitel borstig.

A. Blb. t spreizend. (Fig. 13 E.) Tibouchina (190).

B1. Blb. dicht glockig zusammenschliessend. Brachyotum (30).

B. Stb. sehr ungleich.

A1. Kb. schmal, spitz, so lang wie Bl.achse. Heterocentron (6).

B1. Kb. breit, kurz, 3-eckig.

A:. B. desselben Paares gleich, eifürmig. Arthrostema ( 8 ).

B. B. desselben Paares an Grösse sehr ungleich, lanzettlich. Mexiko. (Fig. 13 A.)

Centradenia (4) inaequilateralis: (Ch. et Schll.) Don

2". Bl. meist epigyn. Zwischen den Kib. meist sternhaarartige Anhängsel. [Osbeckieae.

A. Fr. eine unregelmässig aufreissende Beere.

A1. Stb. gleich. Otanthera (8).

B1. Stb. sehr ungleich; Connectiv der grösseren am Grunde weit vorgezogen.

B. Kapselfr.

2'. Anhängsel der Stb. hinten (aussenseitig). [Rhexieae.]

A. Stb. fast gleich; Connectiv hinten höckerig od. kurzgespornt. Frkn. kahl. - Siidatl. N.-Am. Einzige Freiland-Melastomatacee.

Rhexia (7) virginica L.

B. Stb. abwechselnd ungleich; Comnectiv hinten mit keil-oder schwanzfürmigem Anhängsel. Scheitel des Frkn. borstig oder zottig. (Fig. 13 B.)

Monochaetum (30).

2. Frkn. u. Kapsel 3- bis 5-seitig oder -flügelig. am verbreiterten Scheitel breit ausgestochen.

1.. Gynaeceum isomer. [Cassebeerieae.

A. Stb. gleich; Connectiv nicht vorgezogen.

A1. Bl. 5-zählig.

B1. Bl. 3-zählig.

Gravesia (10).

Cassebeeria (60).

B. Stb. sehr ungleich; Connectiv d. grösseren weit vorgezogen.

Amphiblemma (5).

2'. Gynaeceum oligomer (5-4 Blb., 3 Frb.). [Bertolonieae.]

A. Connectiv vorn einfach oder höckerig.

A. Connectiv hinten am Grunde der A. höckerig oder undeutlich gespornt. - Bahia. Bertolonia (9) marmorata Naud.

$B_{1}$. Connectiv hinten mit einem kurzen, abwärts gerichteten Sporn und einem langen Anhängsel.

Salpinga (3).

B. Connectiv vorn mit aufsteigendem, fast spatelförmigem, stumpfem Anhängsel, hinten mit einem kurzen, gekrümmten Sporn.

Monolena (4).

Onagraceae $(36 ; 470)$.

I. Frkn.fücher mit $\infty$ Sa. Fr. eine vielsamige Kapsel oder Beere.

1. Bl.achse nicht über den Frkn. hinaus verlängert. K. nicht abfällig. Bl. mit Vorb., 4- bis 6-zählig, strahlig. [Jussieueae.] 
2. Bl.achse \pm über den Frkn. hinaus verlängert, dieser Teil abfällig. Bl. ohne Vorb.

1'. Bl. strahlig, eucyclisch, 4-zählig.

1“. Fachspaltige Kapsel.

1“. S. nackt oder häutig gerändert oder mit einem Krönchen.

[Onagreae.]

A. N. 4-teilig, mit langen, linealen od. kurzen, stumpfen Zipfelı. A1. Kapsel lang, walzlich oder keulig oder 4-seitig-prismatisch, schwachkantig.

A2. Stb. nahezu gleichlang; A. linealisch, dorsifix, versatil. N.schenkel langlineal. Bl. meist gelb. S. ohne Krause.

A3. S. rundlich-eiförmig, aufsteigend. Oenothera (20).

a. Stengel ästig. Blb. sattgelb, später purpurn, ungeteilt. Stb. und Gr. so lang als Blb. Patagon. O. odorata Jacq.

b. Stengel einfach. Blb. hellgelb, 2-lappig. Stb. und Gr. von den Blb. überragt. Argentin. O. longiflora Jacq.

$\mathrm{B}_{3}$. S. unregelmässig kantig, häutig berändert, horizontal. N.-Am.

Onagra (8) biennis Scop.

B.. Die epipetalen Stb. kürzer oder verkümmert; A. nahezu basifix, aufrecht bleibend. N.schenkel kurz. Bl. nie gelb, meist rot. S. von einem fransigen Rande gekrönt.

A3. Bl. strahlig.

Godetia (20).

a. N.lappen lineal, sattgelb. Kapsel unten verschmälert.

a. Blb. hellrosa mit 1 oder 2 dunkleren Flecken unterwärts. Californ. $G$. amoena Lilja

3. Blb. weiss, unterwärts rötlich, nicht gefleckt. N.-Am. G. grandiflora Lindl.

1. N.lappen kurz, purpurn. Kapsel oben verschmälert. Californ.

B3. Bl. schwach zygomorph.

A4. Bl.achse kurz. 8 Stb. G. lepida Lindl.

a. B. eilanzettlich, entfernt gezähnelt. Nagel der Blb. ungezähnt. Alle \& Stb. fruchtbar, die kürzeren am Grunde mit behaarter Schuppe. Pac. N.-Am. C.elegans Dougl.

b. B. lineallanzettlich. Nagel der Blb. etwa in der Mitte jederseits mit einem schmalen, zurückgebogenen Zahn. Die 4 fruchtbaren Stb. am Grunde mit drïsiger Schuppe. Pac. N.-Am. C. pulchella Pursh

Bt. Bl.achse langcylindrisch. 4 Stb. Californ.

Eucharidium (3) concinnum Fisch. et Mey.

B. Kapsel kurz-pyramiden- bis lang-keulenförmig, kantig, die Kanten hervortretend oder breit geflügelt.

A2. S. zahlreich nistend, mit verlängertem Nabelstrang, nackt.

A3. Bl. gielb. Gemäss. N.-Am.

Kneiffia (6).

a. B. länglich-lanzettlich. Kapsel 8-streifig od. 8-kantig.

a. B. fast gezähnt, spitz. Bl. ziemlich gross. Stengel bis $6 \mathrm{~cm}$ hoch.

K. fruticosa (L.) Spach

3. B. ganzrandig, stumpf. Bl. ziemlich klein (wie bei Potentilla). Stengel bis $3 \mathrm{dm}$ hoch. $K$. pumila Spach

b. B. breit-eiförmig, ausgeschweift. Kapsel 4-seitig, kurz. Blb. sehr gross. 
B3. B1. rot oder weiss.

Xylopleurum (10).

a. Blb. rosenrot, klein, verkehrt-eiförmig. Peru.

$X$. roseum (Ait.) Raim.

b. Blb. weiss, am Grunde gelb, gross, verkehrt herzförmig. Louisiana.

X. speciosum (Nutt.) Raim.

B.. S. 1- od. 2-zeilig, sitzend. Megapterium (3) missouriense Spach B. N. kugelig oder scheibenförmig, ungeteilt, seltener 4-kerbig.

A1. N. schildförmig, schwach 4-kerbig. Bl.achse breit trichterig. Gemäss. N.-Am.

Meriolix (1) serrulata Walp.

B1. N. kopfig. Bl.achse glockig, vielmals kürzer als der Frkn.

2"i. S. mit Haarschopf. [Epilobieae.]

A. Bl.röhre kurzglockig.

A1. Bl. strahlig. Stb. 2-reihig, aufrecht. Epilobium (160).

a. N. 4-spaltig. Stengel rund.

a. B. alle ungestielt. Bl. stets aufrecht.

I. B. mit abgerundetem oder verschmälertem (irunde sitzend, spitz, gezähnelt. Stengel von einfachen Haaren zottig oder weichhaarig. Blkr. klein, helllila. E. parviflorum Schreb.

II. B. stengelumfassend, stachelspitzig, kleingesägt. Stengel mit kurzen Drüsen- und längeren abstehenden Haaren besetzt. Blkr. gross, dunkelrot. E. hirsutum L.

‘. B. sämtlich oder wenigstens die unteren gestielt. Bl. vor dem Aufblühen nickend.

I. B. eilanzettlich, \pm kurz gestielt. Stengel kurz-angedrïcktbehaart.

1. B. und Bl. ziemlich gross. B. grasgrün, mittlere dicht gezähnt. Bl.knospen kurz bespitzt. E. montanum I.

2. B. und Bl. klein. B. graugrün, derb, mittlere entferntgezähnelt. Bl.knospen stumpf. $\quad E$. collinum Gmel.

II. B. lanzettlich, länger gestielt, entfernt gezähnt, am keilförmigen Grunde ganzrandig. Stengel weichhaarig. Blkr. klein.

E. lanceolatum Seb. et Mauri

b. N. keulig, schwach gefurcht. Stengel meist durch herablaufende B.spuren kantig.

a. S. verkehrt-eiförmig mit abgerundeter Spitze, papillös.

I. B. kurz gestielt oder sitzend.

1. B. mit blattartigem Grunde herablaufend-angewachsen.

2. Nur die Blattränder herablaufend.

E. adnatum Griseb.

+ Wurzelstock zur Bl.zeit ohne verlängerte Ausläufer.

E. Lamyi F. Schultz

++ Wurzelstock schon zur Bl.zeit mit verlängerten, beblätterten Ausläufern.

II. B. ziemlich langgestielt. E. obscurum Rchb. E. roseum Schreb.

ß. S. nach beiden Enden hin verschmälert.

I. Stengel mit herablaufenden B.leisten.

1. B. eilanzettlich, zugespitzt, geschweift- und etwas entfernt-gezähnelt.

E. alsinifolium Vill.

2. B. länglich-verkehrt-eiförmig, stumpf, meist ganzrandig. $E$. anagallidifolium Lam. 
II. Stengel ohne herunterlaufende B.leisten. $E$. palustre L. B1. Bl. schwach zygomorph, kreuzförmig flach ausgebreitet. Stb. 1-reihig, herabgebogen.

Chamaenerium (4).

a. B. lanzettlich, unterseits netzaderig. Traube verlängert. Blb. genagelt, verkehrt-eiförmig. Gr. zuletzt abwärts gebogen.

C. angustifolium (L.) Scop.

b. B. lineal, unterseits aderlos. Traube kurz. Blb. sitzend, länglich. Gr. zuletzt gerade. $\quad C$. palustre Scop.

B. Bl.röhre langtrichterig, innen mit einem S-lappigen Ringe. Californ., Nord-Mexiko. '/ausehmeria (1) californica Pres!

"2". Fr. eine fleischige Beere. [Fuchsieac.] Fuchsia (60).

a. Bl. Blb. gross, zusammengerollt oder flach abstehend. Stb. alle aufrecht. Beeren vielsamig. Andin. S.Am.

๑. Bl. in endstïndigen, 3-teiligen Rispen. F. arborcscens Sims

ß. Bl. einzeln oder gehäuft in den B.winkeln.

1. Nectarium mit d. Grunde der Bl.achse verschmolzen, einen gelappten Wulst bildend. Bl.achse eylindrisch, selten am Grunde aufgetrieben.

1. Stf. sehr lang, herausragend. Ḱ̉b. so lang als d.Bl.achse.

+ Aeste flaumhaarig. B. gegenständig, lanzettlich.

F. gracilis Lindl.

++ Aeste kahl. B. wirtelig zu 3, eiförmig.

F. macrostema Rz. et Pav.

2. Stf. so lang oder kürzer als die $K b$.

+ Bl.achse 3mal länger als die Kb. Blkr. glockig.

$\odot$ B. beiderseits flaumliarig. Blb. gelbgrïn.

F. splendens Zuce.

$\odot \odot$ B. kahl. Blb. scharlachnot. F. fulgens Mocino et Sessé

++ Bl.achse trichterig, am (irunde aufgetrieben. Blb. fehlend.

F. macrantha Hook.

II. Nectarium am Gruncle des (ir. einen 4-lappigen, von der

Wand freien Ringwulst bildend. Bl.achse langtrichterig, an Grunde kugelig aufgetrieben. $F$. spectabilis Hook.

b. Bl. polygam. Blb. Hach. Stb. kurz, gleichlang, die epipetalen nach innen herabgebogen. Beeren wenigsamig. Centr.-Am.

F. microphylla H. B. K.

2'. Bl. zygomorph, 4-zühlig, heterocyclisch; nur 2-1 Stb. [Lopezieae.] - Mexiko. Lopezia (12) coronata Andr.

II. Frkn.fächer mit 1-2 (-4) Sa. Nussartige Schliessfr. Bl.achse über den Frkn. verlängert, dieser Teil abfällig. Vorb. fehlend.

1. Bl. (3- bis) 4-zählig. 8 Stb. 1-bis 4-samige Nuss. [Gaureae.] - N.-Am.

Gaura (20) biennis L.

2. Bl. 2-zählig; encyclisch. 1- bis 2-samige, hakenborstige, birnförmige Nuss. [Circaeeae.)

Circaea (7)

a. N. ausgerandet 2-lappig. Fr. 2-fächerig, jedes Fach 1-samig. Keimb. der Scheidewand parallel. Blb. so lang als Kb.

a. Sehr kleine, borstenförmige Deckb. vorhanden. Stengel kahl. B. fettglänzend, am Grunde etwas herzförmig, geschweiftgezähnt.

C. intermedia Ehrh.

$\because$ Deckb. fehlend. Stengel behaart. B. am Grunde abgerundet, nicht glänzend, gezähnelt. 
I. B. kahl, matt.

C. lutetiana L.

II. B. weichhaarig, wie d. ganze PHanze. Japan. C. mollis Sieb. et Zucc.

b. N. schwach ausgerandet. Fr. schief bimförmig, von der Seite zusammengedrückt, 1-fiucherig, 1-samig. Keimb. dem breiteren Durchmesser derselben parallel. Blb. kürzer als die Kelchb. Deckb. vorhanden.

C. alpina $\mathrm{L}$.

\section{Halorrhagidaceae $(8 ; 95)$.}

A. Bl. polygam, 4-zählig. Gynaeceum 2- bis 4-bliitterig mit 2-t S. Wasserpflanzen; B. fiederteilig mit linealen Abschnitten.

Myriophyllum (18).

a. Obere Deckb. ungeteilt, kürzer als die Bl. B.quirle meist tzählig.

a. Aehren stets aufrecht. Bl. sämtlich in Quirlen. B.zipfel meist gegenständig.

II. spicatum L.

5. Bl. einzeln, spiralig in anfangs ïberhängender Aehre, an deren Grunde die $\%$ in einem Quirl. B.zipfel meist abwechselnd.

M. alterniflorum D.C.

b. Deckb. sämtlich kammförmig-fiederspaltig oder gefiedert. so lang oder länger als die Bl. B.quirle 5- oder 6-zählig. Aehren stets aufrecht. Bl. sämtlich in Quirlen. M. verticillatum L. B. Bl. polygam, 2-zühlig. Gynaeceum 2-blättrig, mit 2 Gr.. aber 1 s. Landptlanzen mit breiten B. - Chile. Gumnera (17) chilensis Lam.

C. Bl. \&, apetal; 1 Stb.; Gynaeceum 1-blättrig, mit 1 Gr. u. 1 S. Wasserpflanzen mit quirlständigen, linealischen B. Hippuris (1) rulgari. L.

\section{Araliaceae $(51 ; 400)$.}

A. Gr. frei. Nährgewebe nicht zerfressen. Pflanze ohne Kletterwurzeln. A. Blb. dachziegelig. Bl.stiele unterhalb der Bl. gegliedert.

A.. N. endständig. B. spiralig, gefiedert.

a. Stengel unbewehrt, glatt.

a. Schaft blattlos, 3 der Huillen entbehrende Dolden tragend.

Aralia (30).

\section{N.-Am.}

f. Stengel beblättert, in den Achseln d. B. Dolden mit kleinen, wenigblättrigen Hïllen tragend. N.AAm. A. racemo*a L.

b. Stengel \pm baumartig, stachelig.

a. B. einfach 5-fingerig. O.-As. A. pentaphylla Thbg.

F. B. doppelt- bis 3 -fach-fiederig-zusammengesetzt.

I. Am Grunde jedes Hauptfiederastes ein kurzgestieltes B.chen. B.chen nur unterseits behaart. China. A. chinensis L.

II. Am Grunde jed. Hauptfiederast. ein 6-15 mm langgestielt. B.chen. B.chen beiderseits borstig-behaart. N.-Am. A. spinosa L.

B2. N. innenseits \pm herablaufend. B. quirlig, gefingert. Panax (25). B. Blb. klappig. Bl.stiele nicht gegliedert. N. endständig. klein. - Formosa. Fatsia (3) papyrifera (Hook.) Dene. et Planch. B. Gr. in ein kurzes Säulchen oder Kegel verwachsen. Nährgerrebe zerfressen. Pflanze mit Kletterwurzeln. Blb. klappig.

Hedera (2) Helix L.

\section{Umbelliferae (152; 1300).}

I. Halbfi, ohne Oelstriemen. Dolden einfach oder unregelmässig zusammengesetzt. B. meist fingernervig. [Heterosciadieae.]

Niedenzu, Botanische Bestimmungsübungen. 
1. Halbfr. seitlich zusammengedruickt. Hydrocotyleae.

A. B. mit trockenhäutigen Nebenb., handnervig, meist nur gekerbt.

Hydrocotyle (70) vulgaris $L$.

B. B. ohne Nebenb., meist 3-spaltig. - Austral.

Trachymene (15) coerulea Grah.

2. Halbfr. in Querschnitt etwa kreisrund; Teilfr. mit Hacher Fugenseite an einander schliessend. [Saniculeae.]

A. Frkn. 2-fächerig, mit 2 Sa.

A. Bl. in einfachen Dolden oder Köpfchen (bez. Körbchen).

A2. Bl. in einfachen Dolden mit grossen, \pm gefärbten Hüllh. Laubb. nicht stachelig, Grundb. handförmig-5-teilig.

A3. T'eilfr. mit 5 stumpfen, faltig gezähnten, hohlen Rippen.

Astrantia (5) major L.

B3. Teilfr. - glatt, mit 5 farlenförmicen, inwendig von einem Kanal durchbohrt. Rippen. Hacynetia (1) Epipactis (L.) D.C'.

B:. Bl. in einem Köpfchen (bez. Körhchen). Laubb. stachelig. Pflanze häufig distelartig.

Eryngium (150).

a. B. \pm lang-linealisch, parallelnervig, gezähnt. Hüllb. u. Spreuh. ziemlich gleich. - S.-Am. E. pandanifolium Ch. et Schl.

h. B. nicht linealisch. verzwoigt-nervis. Hüllh. und sprenh. \pm verschieden.

o. Girundb. mit herzförmig. (irunde, ungeteilt od. etwas gelappt.

I. Hüllh. etwa so lang als das liöpfehen, lanzettlich, entferntgesaigt. Sprenh. ungeteilt. Auch die mittleren Stengelh. ungeteilt.

E. planum I.

II. Hüllb. das Käpfchen - ïh rragend, eirund, dornig-gezïhnt. Spreub. (wenigstens die äusseren) 3-spitzig. Stengelh. handförmig geteilt.

F. Auch die Grundb. gespalten. Spreub. ungeteilt

I. Grundb. dreischnittig mit tirderspaltigen Abschnitten. Hïllb. lineallanzettlich. fast ganzrandig. E. campestic L.

II. (xrundh. \pm doppelt fiederspaltig. Hüllh. \pm gezähnt bis gespalten. O.-Alpen.

B. Bl. in unregelmässig. Köpfchendolde. Untere B. handförm.geteilt. Ziptel :)-spaltig, cesiant. Simicula (10) europaca l. B. Frkn. 1-fächerig, mit 1 Sa.

A1. 2 Gr. Fr. kahl. B. handförmig geteilt. Sicil.

Petagnia (1) saniculifolia Guss.

B1. 1 Gr. Fr borstig-hehaart. B. gefiedert, mit begrannten Zähnen. Mmgbt.

Lagoecia (1) cuminoides $\mathrm{I}_{\text {. }}$.

3. Teilfr. seitlich verbreitert, auf der Fugenseite convex, auf dem Rücken meist hohl. [Mrulineae.] - S.-Am.

Bowlesia (12) tenera Spreng.

II. Halbfr. (ausser bei Aeyopodium) mit Oelstriemen. Zusammengesetzte Dolden. B. meist fiederneryig und fiederig-zerteilt.

I'. Halbfr. nur mit Hauptrippen: Oelstriemen meist unter den Tälchen. [Haplozygieae.]

1. In jedem Döldchen zahlreiche fruchtbringende $\mathrm{Bl}$.

1. Halbfr. seitlich zusammengedrückt oder an der Fugensuite zusammengezogen oder gefurcht. [Ammineae.]

1". Teilfr, an der Fugenseite convex orf. fast flach. [Ammininac.] 
A. $0-\infty$ wenig deutliche Oelstriemen an der Teilfr.

A. Dolden unregelmässig. B. 3-bis 5-schnittig, Abschnitte tiefgesägt. Japan. N.-Am. Cryptotaenia (1) canadensis (L.) D.C.

Bi. Dolden regelmässig.

A. Oelstriemen fehlend. b. einfach-od. doppelt 3-zühlig, B.chen eilänglich, gesägt.

$B_{2}$. Oelstriemen vorhanden.

A3. K.zähne deutlich, spitz. Hülle u. Hüllchen vielblättrig. Sium i4 .

a. Stengel kantig gefurcht. Dolden endständig. Halbfr. länglich. Striemen oberflächlich gelegen. [Eusium.]

๑. WVurzeln fädlich. Wasserb.doppelt fiederteil.mit lineal.Zipfeln. Luftb. gefiedert mit schief lanzettlichen B.chen. S. latifolium I.

अ. Wurzeln knollig, büschelig. Untere B. gefiedert mit länglichen B.chen, obere 3-zäblig.

S. Sisarum I.

b. Stengel stielrund, gestreift. Dolden scheimbar blattgegenständig. Halbfr. \pm 2 -knotig. Striemen rom Fruchtgehäuse bedeckt. [Berula.] S. angustifolium L.

B3. Ki.saum undeutlich. Hülle und Hüllchen aus $0-2$ unbeständigen B.chen bestehend.

a. Pflanze ausdauernd. Halbfr. kahl.

๘. Stengel kantig gefurcht, ziemlich grosse. fiederspaltige B. tragend. B.chen der Grundb. gewöhnlich gestielt, eilänglich. Gr. zur Bl.zeit länger als der Frkn.

P. magna L.

f. Stengel rund, gestreift, oberwärts blattlos oder nur mit kleinen B. B.chen der fiederteiligen Grundb. meist sitzend. rundlich. (ir. zur Bl.zeit kürzer als der Frkn. P. Saxifraga T.

b. PHanze einjährig. Halbfr. weichhaarig. Untere B. herzrundlich. gesägt, mittl. gefied.. oberste 3-spalt. od, ungeteilt. P.Anisum L.

B. Deutliche Oelstriemen zu je 1 (seltener 2) unter den Tälchen. A . Blb. ganzrand., an d. Spitze aufwärts eingerollt. K. saum undeutlich. A. B. völlig ungeteilt und ganzrandig.

a. B. nicht durchwachsen.

a. Fr. glatt. Dolden 4- bis 8-strahlig.

I. B. netzaderig, mit schwächeren Seitennerven, mittlere und obere sitzend, mit tief herzförmigem Frunde stengelumfassend.

II. B. mit starken Längsnerven.

1. Lntere B. lineal-lanzettlich, obere aus herz- oder eifürmigem Grunde verschmälert.

$B$. ranunculoides $\mathrm{I}$.

2. Entere B. länglich od. elliptisch, obere lanzettl. B. falcatum I.

₹. Fr. körnig-rauh. Fnddolde 3̂-strahlig, seitliche unvollkommen.

B. tenuissimum L.

b. Nittlere und obere $B$. durchwachsen. B. rotundifolium $\mathrm{L}$.

B. B. geteilt oder zusammengesetzt.

A3. Rippen der Halbfr. von je 1 Kanal durchbohrt.

Trinia (8) glauca (L.) Dumort.

B3. Rippen der Halbfr. ohne Kanal.

Apium (14).

a. Hülle und Hüllchen aus $0-2$ unbeständigən $B$. bestehend. A. graveolens $\mathrm{I}$.

b. Hülle und Hüllchen vielblättrig.

Sect. Helosciadium.

B1. Blb. verkehrt-herzförm. mit einem einwärts gebogenenLäppchen. 
A2. K.saum deutlich 5-zähnig.

A3. Halbfr. kugelig-2-knotig. Nährgewebe im Querschnitt kreisrund. B. 3-fach fiederteilig, B.chen lineal. Cicuta (3) virosa L.

B3. Halbfr. länglich. Nährgewebe auf der Fugenseite flach. B. \pm 3-zählig, B.chen 3-spaltig. Falcaria (1) vulgaris Bernh.

B2. K.saum undeutlich.

A3. Hülle reich entwickelt, aus o langen, meist fiederspaltigen B. bestehend. B. fiederspalt., B.chen lanzettl. A mmi (7) majus L.

B. Hülle fehlend oder aus ungeteilten, meist kurzen $B$. bestehend.

Carum (50).

a. Blb. grïnlich-gelb, nicht deutlich verkehrt-herzförmig. Untere B. 3-fach fiederspalt., B.chen eiförm. C. Petroselinum(L.) Bth.

b. Blb. weiss oder rötlich, deutlich verkehrt-herzförmig.

». Hülle u. Hüllchen vielblättrig. B. fast 3-fach fiederspaltig. Zipfel lineal.

C. Bulbocastanum (L.) Koch

3. Hülle u. Hüllchen armblättrig od. fehlend. B. doppelt fieder-

teilig, B.chen vielteil.-fiederspalt., Zipfel lineal. C. Carri L.

2". Teilfr. an der Fugenseite gefurcht oder hohl.

1'“. Halbfr. breit eiförmig. [S'myrniinae.] B. bis 4-fach fiederteilig, Zipfel gesïgt-stachelspitz.

Conium (2) maculatum L

2“". Halbfr. länglich-eiförmig oder lineal. [Scandicinac.]

A. Halbfr. kaum $1 \mathrm{~cm}$ lang. Dolden vielstrahlig.

A1. Halbfr. ungeschnäbelt, stumpf, gerippt, kahl.

\section{Chaerophyllum (30).}

a. Blb. nicht gewimpert. Stengel unter d. Gelenken \pm verdickt.

a. Gr. so lang als das Stempelpolster.

I. Stengel allseits zerstreut-haarig u. rot gefleckt. B. doppelt gefiedert mit fiederspalt. B.chen u. stumpfen, kurz stachelspitzigen Zipfeln. Haillchenb. gewimpert. C. temulum L.

II. Stengel nur unterwärts steifhaarig u. rot gefleckt. B. :;bis 4-fach gefiedert mit spitzen, lanzettlichen bis linealen Zipfehn. Hiillchenb. fast immer kahl. C. bulbosum L.

3. Gr. länger als das Stempelpolster. Hüllchenb. gewimpert.

I. B. 3-fach fiederteilig; Fiedern eilanzettlich, am Grunde fiederspaltig, oberwärts gesägt.

C. aureum $\mathrm{L}$.

II. B. 3-fach 3-zählig; Fiedern eilänglich, ungeteilt, gesägt.

C. aromaticum L.

h. Blb. gewimpert. Stengel unter den Gelenken nicht verdickt. Gr. länger als das Stempelpolster. C. hirsutum I.

B1. Halbfr. kurz geschnäbelt: Schnabel ein gerippter Hals, höchstens halb so lang als die rippenlose Halbfr. Anthriscus (10).

a. Gr. länger als das Stempelpolster. Halbfr. doppelt so lang als der Schnabel.

a. Dolden 8- bis 15-strahlig, saimtlich gestielt.

I. Die beiden unteren Hauptteile viel kleiner als das übrige B.; Zipfel länglich-lanzettlich. Randbl. wenig grösser als die mittleren, die gleichfalls fruchtbar sind. Gr. fast doppelt so lang als d.Stempelpolster. A silvestris(L.) Hoffm.

II. Die 3 Hauptteile des B. fast gleich gross; Zipfel eilänglich. Vittlere Bl. kleiner und meist - Gr. kaum länger als das Stempelpolster. A. nitida (Whlbg.) Garcke 
b. Gir. sehr kurz. Halbfr. etwa 3 mal so lang als der Schnabel. Dolden 5- bis 7-strahlig.

B. Halbfr. $2 \mathrm{~cm}$ und mehr lang, kahl, gerippt.

A. Halbfr. ungeschnäbelt,schwarzbraun, firnisglänzend. Dolde vielstrahlig. B. 3-fach fiederteilig. Mrrrhis (2) odorata (L.) Scop.

$B_{1}$. Halbfr. sehr lang geschnäbelt; Schnabel viel länger als die Halbfr. Dolde 1-bis 5 -strahlig.

Scandix (10).

Dolde 1- bis 3-strahlig. B. eiförmig, 3-fach fiederschnittig. Mmgbt.

S. Pecten Veneris L.

$2^{\prime}\left(\right.$ cf. $\left.\mathbf{3}^{\prime}\right)$. Halbfr. stielrundlich ouler vom Rücken her zusammengedrückt, mit breiter Fugenfläche; riickenständige Hauptrippen deutlich, die seitlichen Rippen getrennt oder in eine nervenförmige oder verdickte vereinigt. [Seselinae.]

1“. Rippen sämtlich ungeflügelt, stumpfkantig.

1'“. Seitliche Rippen vor den anderen nicht hervortretend. Halbfr. ungeschnäbelt. Tälchen 1-striemig. [Euseselininae.]

A. Blb. rundlich. ganzrandig, eingerollt. Ki.saum undeutlich. B. mehrfach fiederteilig, 'Zipfel lineal pfriemelig, Scheidenspitze mit mützenförm. Oehrchen. Foeniculum (4) capillaceum Gilib.

B. Blb. $\doteq$ ausgerandet (verkehrt-herzförmig) mit eingebogenem Läppchen. K.saum 5־zähnig. B. 3-fach fiederteilig. Seseli $(60)$. a. Hüllchen freiblättrig. Dolde 20-bis 30-strahlig. S. annu 2 L.

b. Hüllchen verwachsen-blättrig. gezähnt-beckenförmig. Dolde 9- bis 12-strahlig.

2u. Seitliche Rippen dickwulstig. [Ocnanthinae.].

A. Halbfr. im Querschnitt \pm kreisrund.

A. K.saum gezähnt. Fruchtträger angewachsen, undeutlich. B. 1- bis 3-fach fiederteilig.

Oenanthe (35).

a. Dolden endständig, 3-strahlig: Hülle fehlend od. 1-blättrig. Blkr. strahlend. Wurzelfasern knollig-rerdickt. O. fistulosa L.

b. Dolden scheinbar blattgegenständig, hüllenlos, vielstrahlig. Blkr. nicht strahlend. Trurzeln fädlich. O. aquatica (L.) Lam.

$B_{1}$. K.saum undeutlich. Fr.träger deutlich 2-teilig. B. doppelt bis 3-fach fiederteilig, Zipfel fiederspalt.Aethusa (1) CynapiumL.

B. Halbfr. vom Rücken her zusammengedriickt, stark gerippt. B. 3-zählig, Teile breit-keilförmig. Siler 3) trilobum Scop. 2“". Halbfr. 亡 vom Rücken her zusammengedrückt. Alle oder wenigstens ein Teil der Rippen geflügelt od. doch scharfkantig.

1“". Die im Endocarp gelegenen so Oelstriemen dem S. dicht anliegend, vom Exocarp $\doteq$ losgelöst. [Cachrydinae.]

A. Teilfr. auf der Fugenseite eben oder seicht ausgehöhlt.

At. Halbfr. wenig zusammengedrückt, nicht geflügelt. B. 3-fach gefiedert. IV.-Eur., Mmgbt. Crithmum (1) maritimum L.

$B_{1}$. Halbfr. stark zusammengedrückt, breit geflügelt. B. doppelt fiederschnittig. Imgbt. Lophosciadium (4) meifolium D.C.

B. Teilfr. auf der Fugenseite tief ausgehöhlt, am Rande eingerollt.

A1. Halbfr. nicht geflügelt. Mmgbt. Cachrys (7) laevigata Lam.

$B_{1}$. Alle oder einzelne Rippen der Halbfr. flügelig. - Mmgbt. Prangos (30) ferulacea (L.) Lindl.

2“". Das die Oeldruisen enthaltende Endocarp mit dem Exocary fest verwachsen.

1“". Alle od.nur die Kielrippen der Halbfr. geflügelt. [Selininae.] 
A. $\infty$ Oelstriemen. B. fiederig zusammengesetzt.

A. Fugenseite des S. eben od. seicht ausgehöhlt. Ligusticum (20).

a. K.saum gezälnnt. Oelstriemen mit blossem Auge nicht sichtbar.

L. simplex (L.) All.

b. K.saum undentlich. Oelstriemen deutlich. L. Mutellina (L.) Bth.

$B_{1}$. Fugenseite des $\mathrm{S}$. tief ausgehöhlt oder rinnig.

Meum (1) athamanticum Jacq.

B. Oelstriemen einzeln unter den Tälchen.

A1. Fugenseite des S. eben.

a. Flügel der Halbfr. unter sich etwa gleich breit.

Selinum (25).

S. apioides (Lam.) Bth.

b. Seitentlügel der Halbfr. breiter als die anderen. S. Carvifolia I.

B. $_{1}$ Fugenseite des S. \pm ausgehöhlt od. rinnig. B. 3-zählig, Zipfel länglich. Pleurospermum (15) austriacum (L.) Hoffm.

2ّ““. Nur die Seitenrippen der Halbfr. geflügelt. [Angelicinae.]

A. Die geflügelten Seitenrippen der Halbfr. dünnhäutig. Hüllchenb. fehlend oder grannenartig. B.chen \pm herzeiförmig.

A1. Bl. grünlich. $\infty$ Oelstriemen. Schale der Teilfr. nicht mit dem S. verwachsen. Archangelica (5) officinalis Hoffm.

Bı. Bl. weiss oder rosa. Tälchen 1-striemig. Schale der Teilfr. mit dem S. \pm verwachsen.

Angelica (18).

a. Schale der Teilfr. nur längs der Tälchen mit dem S. verwachsen. [Ostericum.] A. palustris (Bess.) Bth.

b. Schale der 'T'eilfr'. vollständig mit dem S. verwachsen. Seitenflügel vor der Fr.reife verwachsen. [Angelica s. s.]

A. silvestris L.

B. Seitentlïgel der Halbfr. dick. Hüllchenb. am Grunde verwachsen. Bl. grünlich-gelb. Tälchen einstriemig. B. fiedern verkehrt-eiförmig, tiefgezähnt. Levisticum (1) officinale Koch

:3‘. Halbfr. vom Rücken her stark zusammengedrückt, linsenförmic.

Die 3 rïckenständigen Hauptrippen undeutlich oder fehlend, höchstens fadenförmig, die Seitenrippen in einen Flügel od. einen vor dem Aufspringen ungeteilten Wulst erweitert. [Peucedaneac.] A. Seitemrippen der Halbfr. dickwulstig. B.chen \pm breit.

A. os Oelstriemen. K.saum undeutlich.

Bi. 'Tälchen gewöhnlich 1-striemig.

A2. K.saum undeutlich. Frkn. kahl.

(Opopanax (3).

B:. K.saum deutlich gezähnt. Frkn. rauhhaarig. Tordylium (12). B. Seitenrippen der Halbfr. \pm dünn.

A. Teilfr. am Rücken flach. $\infty$ Oelstriemen.

B1. 'Tälchen 1-(selten 2- bis 3-) striemig.

A2. Oelstriemen meist bis zum Grunde laufend. 'Teilfr. auf dem Rücken \pm convex. B.zipfel meist fädlich. Peucedanum (100).

a. Alle 5 Rippen d. Teilfr. etwa gleich weit von einander abstehend.

๑. Hülle und Hüllchen vielblättrig, bleibend.

I. Seitenflügel dünn und breit. [Selinoides.]

$P$, ausiriacum (Jacq.) Koch

II. Seitenflügel dick oder schmal. Blkr. weiss. [Cervaria.]

1. K.saum 5-zähnig. Stengel gefurcht. P. palustre (L.) Mönch

2. K.saum undeutlich. Stengel stielrund, gestreift.

C Verzweigungen des B.stieles gerade abstehend. B.chen scharf gesägt, unterseits graugrïn. P. Ccriaria (L.) Cuss. 
Verzweigungen des B.stieles abwärts gehogen. Bl.chen eingeschnitten bis fiederspaltig (Zipfel länglich-lanzettlich), beiderseits grün, glänzend. P. Oreoselinum (L.) Münch $\therefore$ Hülle fehlend od. armblättrig u. abfallend. [Eupeucedanum.]

1. B. doppelt 3-zühlig: B.chen breit eiförmig. Blkr. weiss. [Imperatoria.] P. Ostruthium (L.) Koch.

II. B. vielfach zusammengesetzt; Zipfelchen lineal od. pfriemelig. Blkr. grünlich-gelb.

1. Stengel gefurcht. K. J-zähnig. [l'euccdanums.s.] Hüllchen vielblättrig, borstlich. Doldenstrahlen kahl. P. officinale L.

2. Stengel glattrund, gestreift. K.saum undeutlich. [Ancthum.]

P. graveolens (L.) Bth.

๖. Die beiden Seitenrippen der Teilfr. von den Rückenrippen entfernt. Blkr. sattgelb. B.chen eilänglich, \pm 3-lappig. Pastinaca.] P. sativum (L.) Bth.

B2. Oelstriemen meist keulig und nicht bis zum Grunde laufend. 'Teilfr. auf dem Rüicken flach.

a. B. fiederteilig. Fiedern meist breit, gelappt.

๘. Blkr. nichtstrahlend. grïnlich-gelb. H. sibiricum I.

¡. Blkr. strahlend, weiss.

I. B. beiderseits rauhharig. Halbfi. schliesslich kahl.

H. Sphondylium L.

II. B. oben kahl, unten weichhaarig. 'Teilfr. auf d. Rücken spinnwebig, am Rande stachelig. O. Mmgbt. H. pubescens M. Bieb.

b. B. handförmig gelappt, unterseits graufilzig. Oestl. MImght.

$H$. villosum Fisch.

2. Düldchen mit einer einzigen $q \mathrm{Bl}$. in der Mitte, deren Fr. ron den erhärteten Stielen der $; \mathrm{Bl}$. umhüllt wird. Das eine Frb. steril. [Echinophoreae.]

Echinophora (8).

II'. Halbfr. mit Haupt- und Nebenrippen, letztere häufig stärker entwickelt als erstere. Oelstriemen in den Tälchen oder unter den Nebenrippen. [Diplozygieae.]

1. Pippen der Halbfr. meist ungefliigelt oder in tief gelappte Flügel auswachsend oder stachelig. B.chen meist lineal. [Caucalineae.]

A. Halbfr, kahl, mit niedrigen,stumpfen, glatten oder nur runzeligen Rippen. S. auf der Fugenseite \pm tief grübchenförmig ausgehöhlt. A. Schmale, ungeteilte Hüllb. vorhanden. Halbfr. schmallänglich, im Querschnitt stumpf 4-kantig. Nebenrippen warzig. Teilfr. an der Fugenseite nur seicht vertieft. Oestl. Mmght.

Cuminum (1) Cyminum L.

B1. Hüllb. fehlend. Halbfr. kahl, kugelig oder doppelkugelig. Teilfr. tief ausgehöhlt.

A2. Halbfr.kugelig. - Oestl. Mmgbt. Coriandrum (ㄹ) sativum L. $\mathrm{B}_{2}$. Halbfr. doppelkugelig. - Mmgbt. Bifora (3) radians .I. Bieb.

B. Halbfr. borstig- oder grannig-behaart oder stachelig. Fugenseite des S. eben oder mit einer Längsfurche. Hüllb. $=$ zerschlitzt. Fugenseite des S. eben.

a. Nebemrippen 1-reihig-stachelig. [Eudaucus.] D. Carota L.

b. Nebemrippen 2- oder 3-reihig-stachelig. [Orlaya.]

D. grandiflorus (L.) Scop.

2. Alle oder wenigstens die seitlichen Nebenrippen in $\doteq$ holre, ungeteilte, glatte oder wellige Flügel auswachsend. [Laserpiticae.] 
A. Sämtliche Nebenrippen geflügelt.

a. Stengel stielrund, fein gerillt, kahl. B. kahl.

๙. Entere B. 3-zählig-doppelt-fiederspaltig; B.chen eiförmig, am Grunde herzförmig, ungeteilt, gesägt. L. latifolium L.

ß. B. 3-fach-fiederspaltig; B.chen lanzettlich, ganzrandig, ungeteilt oder 3-lappig.

I. Siler L.

b. Stengel gefurcht, unterwärts rauhhaarig. B. teilweis rauhhaarig.

๙. B. doppelt-fiederteilig; B.chen fiederspaltig mit lanzettlichen Zipfeln.

L. prutenicum L.

3. B. 3-zühlig-3-fach-fiederspaltig; B.chen eiförmig, ungleichgesägt.

L. Archangelica Wulf.

B. Die mittleren Nebenrippen fädlich, die seitlichen geflügelt.

Thapsia (4).

\section{Cornaceae $(12 ; 75)$.}

1. B1. F. Frkn. 2-fächerig. B. meist gegenständig. Cormus (2.). a. Bl. weiss, in kurzen Rispen oder Schirmrispen ohne Hochb.hülle. \%. Haare der B.unterseite gerade, fest angedrückt. Fr. weisslich bis himmelblau. Pac. N.-Am. C. alba L.

3. Haare der B.unterseite etwas wollig-kraus-abstehend. Fr. schwarz, selten rot oder sattgrün.

b. Bl. in Dolden oder Köpfchen mit Hochb.hülle.

๙. Bl. gelb, in Dolden; die 4 gelben Hochb. dic Dolde nicht überragend.

C. mas L.

F. Bl. grülich, in Köpfchen; die 4-6 weissen Hochb. die Köpfchen weit überragend.

I. Hüllh. ei-elliptisch, lang zugespitzt. Japan. C.japonica 'Thbg.

II. Hüllb. verkehrt-eiförmig, abgerundet und ausgerandet, dam auch wohl mit kurzen Spitzchen. Atl. N.-Am. C. florida L.

2. B1. eingeschlechtig, 2-häusig. Frkn. 1-fächerig.

A. Pflanze sommergrün. B. wechselständig. o Bl. mit co Stb. - Atl. N.-Am.

b. Pflanze immergriin. Japan. Nyssa (6) aquatica L. B. gegenständig. S Bl. nit 4 Stb. Aucuba (5) japonica Thbg.

\section{Clethraceae (Clethra, 24).}

a. B. elliptisch, zugespitzt. A. mit spaltenförmigen Poren. Frkn. langrauhhaarig. Fr.stiele \pm abwärts gebogen.

a. Bl.stiele kürzer als der K. Stf. locker wollzottig. Atl. N.-Am.

ß. Bl.stiele viel länger als der K. Stf. kahl. Japan.

\section{C. acuminata Mchx.}

C. barbinervis Sieb. et Zuce.

b. B. elliptisch od. verkehrt-lanzettlich. A. mit rundlichen Gipfelporen; Stf. kahl. Frkn. mit sehr kurzen Härchen. Fr.stiele aufrecht abstehend. Atl. N.-Am. C. alnifolia $\mathrm{L}$.

\section{Pirolaceae $(10 ; 30)$.}

1. A. vor der Bl.zeit nach aussen überkippend, dann aufrecht, mit 2 Gipfelporen aufspringend. Pollen meist in Tetraden. B. grün. laubig. [Pirolcae.] 
A. Gr. sehr kurz, dick, fünfriefig: N. platt, 5-buchtig. Bl. in Schirmtrauben.

Chimaphila (4) umbellata L.) Nutt.

B. Gr. verlängert, rund; N. 5-zähnig.

Pirola (15).

a. A. mit 2 breit geöffneten Gipfelporen, ohne Hörner; Pollen einfach. 10 kleine Nectarien am Grunde des Frkn. Bl. in einseitswendiger Traube. Gr. gerade. B. spitz-eirund. P. secunda I.

b. Am Scheitel der A. 2 sehr kurze Hörner mit Gipfelporen. Pollen in Tetraden. Nectarien fehlend oder rudimentär. Bl. in allseitswendiger Traube.

\%. Irr. kurz, $\doteq$ gerade. Androeceum stıahlig. Blb. kugelig zusammenschliessend.

I. Gr. kürzer als Blb., ganz gerade, ohne Ring. N. doppelt so breit als der Gr.

P. minor L.

II. Gr. länger als Blb., schwach abwärts gekrümmt. mit Ring: $\mathrm{N}$. höchstens so breit als der Ring.

P. media Sw.

F. Gr. lang, herabgebogen, Stb. emporgebogen. Androeceum u. Gynaeceum somit zygomorph. N. kaum breiter als der (irr. Bl̉b. offen, glockig.

I. Kb.rundlich-eiförmig. B. länger als ihr Stiel. P. chloranthaSw.

II. Kb. eilanzettlich, zugespitzt. B. kürzer als ihr Stiel, kreisrundlich.

$P$. rotundifolia $\mathrm{L}$.

c. Am Scheitel der A. 2 vorgestreckte Hörner; Pollen in Tetraden. Gr. gerade, oberwärts breit scheibenförmig mit zinkenartigen N.strahlen. Discusrand mit 10-zähnigem Nectarium. B]. einzeln.

P. uniflora L.

2. A. immer aufrecht, mit einer gemeinsamen Querspalte aufspringend. Pollen einfach. Bleiche Saprophyten; B. chlorophylllos, $\doteq$ schuppig. (Monotropeae. Monotropa (3) Hypopitys L.

\section{Ericaceae $(67 ; 1350)$.}

I. Blkr. nach dem Verblühen abfallend.

I'. Blkr. bisweilen getrenntblättrig. A. obne borstliche Anhängsel. Septifrage Kapsel. S. oft geflügelt; Schale stark gerippt. [Rhododendroideae.]

1. Bl. choripetal. S.Hügel vielmal länger als der winzige Keimling. [Ledeae.]

Ledum (3).

a. B. lineal-]änglich. Filz d. B.unterseite sofort rostrot. 10 Sth. L. palustre $\mathrm{L}$.

b. B. oval-länglich. Filz d. B.unterseite anfangs weiss. 5-7 Stb. Ndl. atl. N.-Am.

L. latifolium Ait.

2. Bl. sympetal, schwach zygomorph. S. klein, flach, von Flügeln breit umsäumt. [Rhododendreae.] Rhododendron (200.

a. Bl. in endständigen Dolden, aus eigenen. zapfenartig umhüllten Knospen hervorgehend.

a. B. immergrün. $10 \mathrm{Stb}$. [Eurhododendron.]

I. Knospenschuppen vielreihig. innere allmählich länger. Frkn. und B. ohne Schülferhaare.

1. B. unterseits kahl, heller griin. Mmgbt. R. ponticum L.

2. B. unterseits dicht behaart.

+ B. unterseits rostfarben. Lib. kurz. Frkn. kahl. Himal. $R$. campanulatum Don 
++ B. unterseits weiss. Kho, ziemlich lang. Frkn. flaumfilzig. Himal.

R. arboreum Sm.

II. Knospenschuppen wenigreihig, fast gleichlang. Frkn. dichtschülferig ; \pm auch B. mit Schülfer-od. Drüsenhaar. bekleidet.

1. Triebe, B. u. Bl.stiele langzottig. B.unterseite mit Drüsenhaaren.

$R$. hirsutum I.

2. B. unterseits dicht rostschiilferig; sonst Pflanze kahl.

R. ferrugineum L.

F. B. einjährig. [Azalea.

I. $10 \mathrm{Stb}$. Bl. vor den B. erscheinend. Ndl. atl. N.-Am.

II. 5-9 Stb. Bl. nach den B. erscheinend.

R. Rhodora Don

1. Bl. tragende 'Triebe aus besonderen Knospen.

-t Blkr. fast vom Grunde an allmählich erweitert, aussen wie auch K. u. Frkn. drüisenlos weichhaarig. Stb. kürzer als Blkr. China, Japan.

$R$. sinense Sw. + Blkr. etwa bis zur Mitte walzlich, dann plötzlich erweitert, aussen drüisig behaart. Stb. so lang oder viel länger als Blkr.

๑) Blkr. weiss oder rosa. Frkn. drüsenlos-steifhaarig.

$\uparrow \mathrm{Bl}$.stiel u. K. drüsenlos-behaart. Atl. N.-Am.

$R$. nudiflorum 'T'orr.

if Bl.stiel u. K. drüsenharrig. Atl.N.-Am. R.viscosum'Torr.

(.) Blkr. gelb mit orange Saftmalen. Bl.stiel, K. u. Frkn. drüsenhaarig. Or.. Kaukas. $\quad R$. flavum Don

2. Bl. и. B. tragende Triebe aus der gleichen, sehr kleinen, nur 2-4 Schuppen führenden Kinospe. O.-As. R. indicum(L.) Sw.

b. Bl. in den Achseln der obersten B. vorjähriger Triebe seitenständig, aus Knospen mit eigenen Schuppen und ohne B. hervorgehend; sonst wie a $\alpha$ II. Sibir. bis Kiusiu. R. dahuricum L.

3. Blkr. verwachsenblättrig, strahlig. S. rundlich oder 3-kantig, dick, ungeflügelt. [Phyllodoceae.]

A. Androeceum obdiplostemon. Gynaeceum isomer.

A. Bl. 5-zählig, aus vorjährigen Knospen endständig.

A2. A. nicht in Gruben der Blkr, eingeschlossen.

A3. Blkr. radförmig ausgebreitet. O.-Alp., Siebenbürg., O.-Sib.

Rhodothamnus (1) Chamaecistus (L.) Rehb.

B3. Blkr. glocken- oder krugförmig. - Arkt.-alpin in W.-Eur., N.-Am., O.-As. Phyllodoce (7) taxifolia Salisb.

B.. Blkr. napfförmig, mit 10 hohlen, die A. bis zum Ausstäuben einschliessenden (iruben. Atl. N.-Am.

Kalmia (6).

a. Schirmtrauben einzeln endständig. Frkn.kahl. K. glauca Ait.

b. Schirmtrauben gehäuft. Frkn. kurz-drüsenhaarig.

o. B. länglich. Gesamtbl.stand vom Laubtrieh übergipfelt. Blkr. $1 \mathrm{~cm}$ breit. Gr. gleichdick. $K$, angustifolia L.

9. B. elliptisch. Gesamtblütenstand endstïndig. Blkr. $2 \mathrm{~cm}$ breit. Gr. oben dicker.

K. latifolia L.

B. Bl. 4-zählig, an den Spitzen beblätterter Zweige. Blkr. glockigkrugförmig. Atl. Eur., Azoren. Daboecia (1) polifolia Don B. Bl. 5-gliederig. Blkr. glockig-trichterig. Androeceum haplostemon. Frkn. 2- bis 3-fäclierig. Arkt.-alpiu-circumpolar. 
II'. Blkr. stets (ausser bei Vaccinium Lntg. Oxycoccus) verwachsenb]ättrig. A. vielfach mit borstlichen Anhängseln oder in lange Röhren vorgezogen, den Pollen oben entlassend. Fachspaltige Kapsel oder Beere oder Steinfr. S. ungeflügelt.

I“. Frkn. oberständig, nicht mit dem K. verwachsen. Arbutoideae.

1. 'Trockene. von dem kleinen $K$. am Grunde umhüllte, fachspaltige Kapsel. [Andromedeae.]

A. B. einander cypressenartig dicht überdeckend. Cassiope (T). B. B. sich nicht überdeckend.

A. Klappen der Kapsel ohne schwieligen Rand.

A2. Blkr. krugförmig. S. eirundlich. - Circumpolar.

Andromeda (6) polifolia L.

B2. Blkr. flaschen- bis kegelförmig. S. klem. sägespänartig.

Leucothoë (32).

B. Klappen der Kapsel mit dickem, hellem, schwieligem Rande. - Circumpolar. Lyonia (17) calyculata (L.) Rehb.

2. Fr. eine Beere oder Steinbeere oder eine vom fleischig oder lang blattartig auswachsenden $K$. umhüllte Kapsel.

1'. K. fleischig oder blattartig. At über den Gipfelporen stumpf oder mit kurzen, aufrechten Grannen. [Gaultherieae.]

A. K. um die Kapsel Heischig anwachsend. - Atl. N.-Am.

Gaultheria (100) procumbens L.

B. K. trockenblättrig. Beere. Pernettya (26) angustifolia Lindl.

’. K. an der Beere oder Steinbeere klein. A. mit 2 langen, abgegliederten, herabgebogenen Anhängseln. [Arbutcae.]

A. B. immergrün, lederig. Beere oft gekörnelt, mehlig. Einzelkrystalle.

A. Kileine Bäume oder höhere Sträucher. Bl. in grossen Rispen. Beere.

Arbutus (20).

a. Bl.stand nickend. Bl. weiss od. rütlich. Fr. weichstacheligwarzig. B. länglich-lanzettlich, stumpfgesägt. Mmgbt. A. Unedo L.

b. Bl.stand aufrecht, drüsig-behaart. Bl. grünlich-weiss. Fr. glatt. B. oval, meist ganzrandig. Oestl. Mmgbt.

A. Andrachne L.

B. Zwergsträucher. Bl. in kleinen Rispen oder 'Trauben. Steinbeere. Aretostaphylos (18) Uva ursi (L.) Sprg.

B. B. einjährig, dünn. Steinbeere saftig mit glatter Oberhaut. Drusen. Arkt.-alpin circumpol. Aretous (1) alpina (L.) Nilz. II“. Frkn. völlig unterständig. [Vaccinioideae.]

1. Blkr. radförmig, glockig oder krugförmig. Stb. unter sich getrennt. Frkn. vom Stiel scharf abgesetzt und oft abgegliedert. Epidermis der B. 1-schichtig. [Vaccinicae.].

A. Frkn. 10-fächerig; 1. Sa. in jedem Fache. Steinbeere.

Gaylussacia (40).

B. Frkn. 4- bis j-fücherig, selten 10-kammerig, mit je melreren Sa. Beere.

a. Frkn. 10-kammerig.

a. Blkr. offen, glockenförm. A. lang gespornt. Ĺntg.Batodendron.

3. Blkr. cylindrisch krugförm. A. ungespornt. Unte. Cyanococcus.

b. Frkn. 4- bis 5-fächerig. 
\% Blb. unter sich frei, aufwärts zurïckgerollt. A. ungespornt, Frkn. 4-fächerig. [Untg. Oxycoccus.]

I. Einzelbl. od. Döldchen endständig. Stf. so lang als die A. B.rand stark umgerollt.

V. Oxycoccus L.

II. Bl. einzeln blattwinkelständig. Stf. halb so lang als die A. B.rand wenig umgerollt. Ndl. atl. N.-Am. V.macrocarpum Ait.

$\therefore$ Blkr. krugförmig. A. \pm gespornt. Frkn. 5-fächerig. [Untg. Euvacrinium.]

I. B. einjährig. Bl. einzeln oder zu wenigen in den Achseln der unteren B. an den jungen Trieben. Beeren blau.

1. Stengel 4-kantig. B. eiförmig, spitz, gekerbt, mit Drüsenhaaren und Einzelkrystallen, hellgrün. V. Myrtillus T.

2. Stengel rund. B. verkehrt-eiförmig, stumpf, ganzrandig, ohne Drüsenhare u. Krystalle, blaugrün. V. uliginosum I.

II. B. immergrï. Bl. in kurzen Trauben oder Schirmtrauben aus besonderen, blattlosen Knospen. Beeren rot. V. Vitis idaea L.

2. Blkr. aus bauchigem fírunde röhrig oder lang cylindrisch, lederigfleischig. Sth. getrennt oder zu einer Säule verwachsen; obere Epidernis der B. 2-schichtig. ['Thibaudieae.] Thibaudia (50).

II. Blkr. nach der Bl. trockenhäutig-stehenbleibend, verwachsenblättrig. A. mit sehr kurzem Connectiv ; Fächer oben mit Löchern aufspringend, unten spreizend und geschwänzt. [Ericoideae.]

1. Frkn.fïcher mit je so Sa. Kapsel vielsamig. [Ericeae.]

A. Kapsel scheidewandspaltig. K. petaloid, länger als die Blkr.

Calluna (1) vulgaris L.

B. Kapsel fachspalt. Blkr. gross, d. grünen K. \pm lang überragend. A1. Discus hoch, an den Einfügungsstellen der freien Stb. gefurcht.

a. Bl. 4-gliederig.

Erica (420).

c. Stb. aufrecht lang keulenförmig; A. die Fortsetzung der Stf. bildend, mit seitlichen Gipfelspalten, oft lang aus der Blkr. vorgestreckt. Untg. Ectasis. Blkr. eirund-glockenförmig. S.-Wur., Irland. E. carnca T.

. A. dorsifix, meist olıne Anhängsel. Blkr. lang röhrenförmig. oft gekrïmmt: der Saum aufrecht oder kurz umgerollt.

Untg. Syringodea.

$\gamma$. A. tief dorsifix und meist mit Schwanzpar oder kammförmigen Anhängseln. Blkr. aus bauchigem oder erweitertem Grunde zusammengezogen; Saum strahlig ausgebreitet.

Untg. Stellanthe.

j. A. dorsifix, stumpf od. geschwänzt. Blkr. krug-od. glockenförmig; Saum kurz geöffnet oder glockig. Untg. Eu-Erica.

I. K.zipfel grau-wollig-filzig, von langen Drüsenzotten gewimpert. Frkn. steif haarig. B. zu 4 quirlig, lang-drüisenzottig, gewimpert. W.-Eur., N.-Deutschl. E. Tetralix L.

II. K.zipfel kahl, ungewimpert. Frkn. kahl. B. zu 3 quirlig, kaum gewimpert. W.-Eur.

E. cinerea L.

b. Bl. 5-gliederig. [Untg. Pentapera.] - Mmgbt. E. sicula Guss. B1. Discus rudimentär; Stb. dem Grunde der Blkr. eingefügt. Siebbg., Balkan.

Bruckenthalia (1) spiculiftora Rehb.

2. Frkn.fächer mit je 1 Sa., zuweilen der Frkn. durch Abort 1-fächerig und 1-samig. [Salaxideae.] 
Epacridaceae. - Diapensiacene. - Mrrsinaceae. - Primulaceae. 269

\section{Epacridaceae $(21 ; 305)$.}

1. Mehrere Sa. in jedem Fache des Frkn. Fachspaltige Kapsel. [Epacrideae.]

A. B. lang, mit scheidigem tirunde weit umfassend angewachsen.

Dracophyllum (11).

B. B. kurz. mit stielfürmigem, eine N. hinterlassendem Grunde sitzend oder deutlich gestielt.

Epacris (30).

a. Blkr. 4 mal länger als Ki., rot mit hellem Saum, ohne Grübchen am Grunde. Austr.

E. longiflora Cav.

b. Blkr. 2-3 mal länger al↔ K., gleichfarbig, mit j- Grübchen am Grunde. Austr.

‥ In jedem Fache des Frkn. 1 Sa. Schliessfr. [Styphelieae.]

styphelia (172).

\section{Diapensiaceae $(6 ; 9)$.}

1. jepipetale Staminodien und 5 alternipetale Stb. [Galacineac.] Südl. atl. N.-Am.

Galax (1) aphylla L.

2. Nur 5 alternipetale Stb. [Diapensieae.] - Arkt. circumpolar. Diapensia (2) lapponica L.

\section{Myrsinaceae $(23 ; 520)$.}

I. ; : iussere alternipetale Staminodien und 5 innere epipetale Stb. [Theophrastoideae.]

A. Connectiv über die $d$. hinaus verlängert. Staminodien am Grunde der cylindrischen Kr.röhre eingefügt. - S. Domingo.

Theophrasta (4) Jussieui Lindl.

B. Connectiv nicht über die A. hinaus verlängert. Staminodien vor den Buchten der kurzen Blkr. eingefügt. - Guiana, Venezuela. Clavija (22) ornata Don

II. Staminodien fehlend : nur jepipetale Stb. vorhand. [Myrsinoideae.]

A. Blkr.dachziegelig. [Myrsineae.]-S.-Afr. Mrrsine (80) africana L. B. Blkr. gedreht. [Ardisieae.] - Malay. Gbit.

Ardisia (200) crenata Roxb.

\section{Primulaceae $(28 ; 350)$.}

1. Bl. strahlig. K. nicht stachelig.

1‘. Abschnitte der Blkr. aufrecht od. abstehend, nie zurïckgebogen. 1“. Blkr. quincuncial.

1“.. Frkn. oberständig. [Primulcae.]

1“\%. Kr.lappen ganz oder 2-spaltig, höchstens noch am Rande seicht gezähnelt. Klappenkapsel. Landptlanz. [Primulinae.]

A. Stf. der Kr.röhre eingefügt. Connectiv stumpf.

A1. Kr.röhre verlängert, länger als der Samm. Primula (146).

a. B. in der Jugend eingerollt.

a. B. dünnhäutig. Bl. meist in über einander stehenden Quirl.[\$Floribundae.] - Abyss.,Sinai.P.rerticillata Forsk.

$\therefore$ B. lederig. Bl.stand einfach doldig. [\$ Auricula.]

I. Schaft verlängert. mehrblïtig. B. verkehrt-eiförmig, sägezähnig.

P. Auricula L.

II. Schaft kurz, 1- (-2-) blütig. B. keilfürmig, vorn abgestutzt und gezähnt.

P. minima L. 
b. B. zurückgerollt.

๑. B. deutlich gelappt, Lappen gezähnt od. gekerbt. [\$ Sinenses.] I. K. schmal cylindrisch. Bl. violett. O.-Russl. bis Japan. $P$. cortusoides $\mathrm{L}$.

II. I. aufgeblasen, am Grunde gestutzt. Bl. weiss, rot oder blau. S.-China. $\quad P$. sinensis Lindl.

3. B. nicht deutlich gelappt. K. nicht vergrössert. Ohne Ausläufer. Bl. oder Bl.stand mit Involucrum.

I. B. hehaart.

1. Bl. dentlich gestielt. B. dünnhäutig, runzelig, in den geflügelten B.stiel verschmälert, seltener am Grunde herzförmig. [\$ Vernales.]

+ Schaft sehr kurz, Bl. langgestielt. K. ei-cylindrisch. Kr.saum flach. $\quad P$. acaulis.(L.) Jacq. ++ Schaft im Verhältnis $\mathrm{zu}$ den Bl.stielen lang.

○ K. schmal. Kr. \pm schwefelgelb, Saum flach. $P$. elatior (L.) Jace.

尺ि K. hreitglockig, bisweilen aufgeblasen. Kr. goldgelb. Saum glockig vertieft. $P$. officinalis (L.) Jacq.

2. Bl. sitzend oder sehr kurz gestielt oder Hinzelbl. Hüllh. pfriemelig oder lanzettlich. [\$ Capitatae.]

+ Khizom mit zahlreichen fleischigen Schuppen. Bl. blau. die eines Bl.standes gleichzeitig blühend. Himal.

P. denticulata Sm.

- - Rhizom mit wenigen Schuppen. Bl. blau, centripetal langsam aufblühend. Himal. P. capitata Hook.

II. B. kahl oder spärlich weichhaarig.

- Hüllb. am (xrunde sackförmig vertieft oder spornartis verlängert. Kapse] cylindrisch, den K. iiberragend. [\$ Farinosae.]

Pl. fleischrot. B. in den geflügelten B.sticl verschmälert. unterseits oft gepudert. Arkt.-alpin. P. farinosa L. ++ Hiillh. nicht vertieft od. spornartig. Kapsel kugelig. Dolden reichbliitig. B.in den $B$ stiel verschmälert, pergamentartig.|\$ I'roliferac.] - Bl.rot. Japan.P.japonica (tray

Br. Trrröhre kurz, selten so lang als der Saum. Bl. doldig.

Androsace (50).

^. 2. durch lange, an den Knoten rosettenbliittrige Auslänfer rasig. Himalaya.

b. $\odot$, ohne Ausläifer.

A. sarmentosa Wall.

B. Stf am Grunde der Kr rïhre ringefiigt Connectiv zumespitat.

Mitteleurop. Hochgbg., N.-As.. Himal. Cortusa (1) Matthioli I.

2“". Kr.lappen geschlitzt. Deckelkapse]. Landpflanzen. [Soldanellinae.]

Soldanella (4).

a. B. seicht entfernt gekerbt.Bl.stiele drüsig-flaumig. S. montana L.

b. B. ganzrandig. Bl.stiele drüsig-rauh. S. alpina L.

:3““. Kr.abschnitte ganz. Klappenkapsel. Schwimmende Wasserpflanzen mit fein zerschlitzten B. [Hottoniinae.]

Hottonia (2) palustris L.

“․ Frkn. halb unterständig. [Samoleac.] Samolus (8) Valerandi I. 2". Blkr. gedreht (bei Glau fehlend). [Iysimachieae.] 
1““. Klappenkapsel. B. gegenständig orl. quirlig. [Lysimachiinac.] A. Bl. mit Kr. Kr.röhre kurz.

A1. Bl. 5- bis 6-zählig. Zahlreiche B.quirle.

A. Keinerlei Staminodien zwischen den Blb. Lysimachia 601.

a. Bl. in Rispen. Pflanze halbstrauchig.

\%. Stengel rundlich-kantig. Kb. rütlich berandet. Blb. einfach goldgelb, am Rande kahl.

L. vulgaris $\mathrm{L}$.

F. Stengel flügelig-kantig. Kh. nicht berandet. Blb. am Grunde braun. am Riande drüsig gewimpert. L. punctata I.

b. Bl. einzeln achselständig. Stengel kriechend.

э. B. stumpf. Bl.stiele kurz. Ǩb. herzförmig. L. Nummularia I.

ß. B. spitz. Bl.stiele lang. Kb. lineal-lanzettlich.

L. nemorum L.

B.. I fädliche Staminodien zwischen den Blb. N.-Am.

Steironema (4) ciliatum (L.) Raf.

(.. Kleine Schuppen zwischen den Blb. Bl. in dichten, achselstaindigen Aehren. Naumburgia 1) thyrsitora (L.) llönch

B. Bl. meist 7-zählig. Nur 1 B.quirl. Trientalis (2) europaca I.

B. Bl. apetal. einzeln achselständig. 5 alternisepale Stb. B. etwas fleischig. Halophyt.

Glaux (1) maritima I.

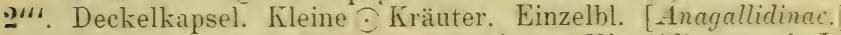

A. Blkr. grösser als K. Anagallis (12) arvensis L

B. Blkr, kleiner als $\mathrm{K}$.

C'entunculus (3) minimu L

2. Abschnitte der Blkr. zurïckgebogen. |Cyclamineae.]

A. Schaft 1-blütig. Blkr. gedreht. Cyclamen (10) europaeum L.

B. Bl.stand doldig. Blkr. dachziegelig. - Atl. N.-Am.

Dodecatheon (5) Meadia L.

2. Bl. median zygomorph. K. stachelig. [Corideae. ('oris (2)

Plumbaginaceae $(10 ; 290)$.

1. Bl.stand einfach, trauhig, ährig oder kopfig. Sth. meist frei. Gr. verwachsen. nur im oheren Teile frei. sklerenchymring des Bastes geschlossen. [Plumbagineae.]

A. Blkr. röhrig. Klein. K. nach der Bl.zeit sich vergrüssernd Altai. Plumbagella (1, micranthe 1 Ledeh.) Sirach

B. Blkr. präsentiertellerförmig, ansehnlich. Plımbağo 10.

a. Kr.saum strahlig. B. gestielt. P. capensis 'Thbg.

b. Die oberen hrr.lappen etwas kürzer als die unteren. B. I mit Ausnahme der unteren stengelumfassend, mit geöhreltem Grunde.

$P$. europaea L.

2. Bl.stand aus Wickeln zusammengesetzt. Stf. \pm der hrr. eingefügt. Gr. nur am Grunde rerwachsen. Sklerenchymbünde! nicht zu einem geschlossenen Pinge vereinigt. [Staticeac.]

A. N. kopfig.

A. Gr. kahl. Niedrige, Polster bildende Halbsträucher mit Nadelb.

Acantholimon ( 80$)$.

Bı. Gr. papillös-rauh. Kräuter mit flachen B. Groniolimon 10). B. N. cylindrisch-fädlich.

A1. Gr. kahl. Bl.stand schirmrispig.

a. Bl.zweige breit-2-od. 3-schneidig. Blkr. gelb. Deckelkapsel. Mmgbt. 
b. Stengel und Aeste rundlich. Blkr. rötlich. Nïsschen. Mmgbt. S. Limonium L.

$B_{1}$. Gr. hehart. Bl.stand kopfig. Armeria (50) vulgaris Willd.

\section{Styracaceae $(6 ; 75)$.}

A. Frkn. oberständig. Fr. rundlich oder eiförmig, nicht gerippt oder geflügelt.

Styrax (60).

a. Blh. häutig, \pm elliptisch, dachziegelig. Mmgbt. S. officinalis L.

b. Blb. lederig, länglich-lanzettlich, klappig. Mal. Gbt.

S. Benzoin Dryand.

B. Frkn. unterständig. Fr. länglich, von den K.zähnen gekrönt, der Länge nach gerippt ofler geflügelt. - Südl. atl. N.-Am.

Halesia (7) tetraptera L.

\section{Oleaceae $(21 ; 400)$.}

1. Sa hängend. Fr. ungeteilt. [Olcoideae.].

1. Fr. trocken.

1'. 2-10 Sa. in jedem Fach. Fachspaltige Kapsel. [Syringeac.]

A. Krr.röhre kurz, breit; die viel lüngeren Zipfel dachziegelig. 4-10 Sa. in jedem Fach.

a. Zweige \pm ïberhängend. B. einfach, länglich-lanzettlich. O.-As.

F. suspensa Vahl

b. Zweige aufrecht. B. teils 3-zählig, teils einfach und damn eirautenförmig bis eilanzettlich. China. F. viridissima Lindl.

B. Kr.röhre länger als die eingefaltet-klappigen Zipfel. 2 Sa. in jedem Fach.

Syringa (10).

a. A. kaum iiber der Röhrenmitte eingefiït. B. elliptisch, fein schärflich gewimpert. Ungarn. S. Josikaea Jacq. f.

b. A. dem Schlunde eingefügt.

๑. B. aus breit abgestutztem oder herzförmigem Grunde eiförmig. Unteres Donaugebiet. S. vulgaris L.

ङ. B. am Grunde verschmälert.

I. B. lamzettlich od. fiederteilig. Kaukasus bis Afghanistan. S. persica L. II. B. eilanzettlich, zugespitzt. China? S. dubia Pers. 2. Je 1 Sa. in jedem Fach. Flügelfr. [Fraxineae.]

A: Fr. rundlich, fast ringsum geflügelt, sich nicht öffnend od. schliesslich scheidewandspaltig aufspringend, meist 2-samig. B. einfach. Sicil., östl. Mmgbt., China.

Fontanesia (1) pkillyreoides Lab.

B. Fr, eine lanzettliche, lineale od. längliche, besonders an der Spitze gefliigelte, meist 1-samige Nuss. B. \pm fiederspaltig oder gefiedert.

Fraxinus (40).

a. Bl.stand endständig, ausgebreitet. Bl. polygam, mit Blkr. Stf. ziemlich lang. Fr. braun. S.-Eur. F. Ornus L.

b. Bl.stand achselständig, meist kurzbüschelig. Bl. polygam oder diöcisch, apetal. Stf. kurz. Fr. grün oder braungelh.

a. Bl. mit K., diöcisch. N.-Am. $F$. americana $\mathrm{L}$.

ß. Bl. asepal, polygam. F. excelsior L.

2. Steinfr. oder Beere. [Oleineae.] 
A. Kr.lappen dachziegelig.

A. Endocarp papierartig, zerbrechlich. N. kopfig. Phillyrea (6).

$\mathrm{B}_{1}$. Endocarp dick, knochenhart. N. klein, ungeteilt od. 2-lappig.

B. Kr.lappen eingefaltet-klappig.

Osmanthus (10).

A. Kr.lappen lang-lineal oder lineal-spatelig, nur am Grunde vereinigt.

B. Kr.lappen kurz und ziemlich breit, Röhre deutlich.

A. Bl.stände meist achselständig. 1- bis 2-samige Steinfr. Orient. Olea (31) europaea L.

B2. Bl.stände endständig. 2- bis 4-samige Beere.

Ligustrum (35) vulgare L.

II. Sa. aufrecht. Fr. durch eine Einschnïrung vom Scheitel her sehr tief geteilt. [Jasminoideae.] Jasminum (160).

\section{Loganiaceae $(32 ; 330)$.}

I. Pflanze ohne Drüsenhaare, mitintraxylär.Phloëm. [Lnganioidcae.] 1. Kr.lappen dachig. Gr.ende 4-teilig. Kapsel. [G'clsemieae.] $\propto$ Sa.in jed.Fach. Südatl. N.-Am. Grelsemium (2) sempervirens Ait.

2. Kr.lappen klappig oder gedreht (seiten dachig). N. einfach.

1'. Kr.lappen klappig.

1“. Kräuter. Gr. scheinbar gegliedert. Kapsel. [Spigelieae.] Kapselgrund cupularart.-Atl.N.-Am.Spigelia(40)marylandica L. 2“. Holzpflz. Gr. nicht gegliedert. Beere od. Steinfr. [Strychneac.] B. 3- bis 5-nervig. Meist $\infty$ Sa.

$2^{\prime}$. Kr.lappen gedreht (selten dachig).

1“. Kr.lappen linksgedreht (oder dachig). Kapsel. [Loganieac.] Logania (21).

2". Kr.lappen rechtsgedreht. Beere. [Fagraecae.] Fagraea (20).

II. Pflanze mit Drüsenhaaren, ohne intraxyläres Phloëm. [Buddleioideae.]

Buddleia (70).

a. Bl. in kugeligen, an kurzen (gegenständigen, rispig gruppierten) Zweigchen endständigen Köpfchen. Blkr.röhre gerade. Andin. S.-Am.

B. globosa Lam.

b. Bl. in kleinen, kurzgestielten, in eine lange, endständ., ährenförm. oder pyramidale Rispe vereinigten Cymen. Blkr.röhre gekrümmt.

a. Zweiye schmal-4-flügelig. Kr.lappen wenig länger als breit. A. kurzgestielt. Japan.

B. japonica Hemsl.

F. Zweige 4-kantig. Kr.lappen sehr kurz. A. fast sitzend. China. B. Lindleyana Fortune

\section{Gentianaceae $(70 ; 750)$.}

I. Kein inneres Phloëm. B. spiralig. Kr.lappen eingefaltet-klappig. Pollenkörner dreieckig. [Menyanthoideae.]

A. Kr. radförmig, Schlund bärtig. N. 2-teilig; am Grunde des Frkn. 5 mit den Stb. abwechselnde Drüsen. Pflanze Seerosen ähnlich. Limnanthemum (24) nymphaeoides (L.) Lk.

B. Krr trichterig, Saum innen gebärtet. N. ungeteilt; am Grunde des Frkn. ein gewimperter Drüsenring. Menyanthes (2) trifoliata L.

II. Inneres Phloëm. B. gegenständig. Kr.lappen gedreht. Pollenkörner rundlich, meist kugelig. [Gentianoideae.] 
1. Pollen gross, Exine feinhöckerig, Höcker in Reihen od. Netzen. [Gentianinae.] Gr. meist sehr kurz oder fehlend, nicht verwachsen. Placenten einfach parietal, nicht tiefer einspringend.

A. Kr. glockig, trichter-oder stieltellerförmig, 4- bis 9-spaltig; Zipfel ohne Honiggruben.

Gentiana (300)

a. K. mit innerer Verbindungshaut. Kr. überhaupt ohne Nectarien, weder im Schlunde gebärtet, noch Zipfel gefranst. [Eugentiana.] a. Bl. in Scheinquirlen.

I. Bl. 5- bis 7-zählig. Kr. gelb oder purpurn.

1. K. halbiert-scheidenförmig.

+ Bl. gestielt. Kr. gelb, radförmig; Zipfel lanzettlich, 3mal so lang als die Röhre. A. frei.

G. lutea L. $++\mathrm{Bl}$. sitzend. Kr. aussen purpurn, innen gelblich, glockig, nur auf ${ }^{1 / 3}$ gespalten, Zipfel eiförmig. A. zusammengewachsen.

2. K. glockig.

G. purpurea L.

+K.zihhne aufrecht. Kr.hellgelb, schwarzpunktiert.G. punctata L. ++ K.zähne zurückgekrümmt. Kr. purpurn mit dunkleren Punkten.

G. pannonica Scop. II. B1. 4-zählig, blau. B. am Grunde scheidig verwachs. G. cruciata L. ß. Bl. einzeln od. zu zwei achsel-oder endständig. Kr. meist blau. I. Kr. keulig-glockig.

1. Stengel hoch, ohne grundständ. B rosette, meist mehrblütig. + B. eilanzettlich, zugespitzt, meist 7-nervig. K.röhre 4-5mal so lang als die Zipfel. Bl. auch gelblich. G.asclepiadea L. t-t B. lineal-lanzettlich, 1- bis 3-nervig. K.röhre kaum länger als die Zipfel.

G. Pneumonanthe L.

2. Stengel niedrig, mit grundständiger B.rosette, 1-blütig.

+ K.zähne aus breitem Grunde verschmälert, zugespitzt, fast angedrückt; Buchten spitz. $\quad G$. acaulis L.

++ K.zähne aus schmalerem Grunde eilanzeitlich, etwas abstehend; Buchten gestutzt.

G. excisa Presl

II. Kr. stieltellerförmig, Röhre walzlich. Untere B. rosettig.

1. Pflanze einjährig, ohne nichtblühende B.rosetten. Stengel \pm ästig. mehrblütig.

G. utriculosa L.

2. Pflanze ausdauernd, mit nichtblühenden B.rosetten. Stengel einfach, einblütig.

+ Rosettenb. nicht grösser als die Stengelb. B. verkehrteiförmig. abgerundet-stumpf.

G. bavarica L.

++ Rosettenb. grösser als die Stengelb. B. elliptisch od. lanzettlich, spitz.

G. verna L.

b. K. ohne Verbindungshaut. Kr. gebärtet od. gefranst, unten in der Röhre je 1-2 Nectarien auf jedem Krb. [Gentianella.]

$\alpha$. Die $4 \mathrm{Kr}$.zipfel in ihrer unteren Hälfte lang gefranst, Schlund kahl. Kr. blau. Stengel (bez. Aeste) 1-blütig. G. ciliata L.

§. Kr.schlund innen gebärtet, Zipfel nicht gefranst. Kr. purpurn, gelb oder weiss.

I. Bl. meist 5-, selten 4-zählig. Kb. bis zur Mitte verwachsen, nahezu gleich.

1. B. länglich, wenigstens die unteren stumpf. K.zipfel lanzettlich, 2 oft etwas breiter.

G. obtusifolia Willd. 
2. B. eilanzettlich, spitz oder zugespitzt. K.zipfel lineal-larzettlich, gleich.

+ Kr. cylindrisch-röhrig. Kapsel sitzend. G. Amarella L. ++ Kr. cylindrisch-glockig, nach oben deutlich erweitert. Kapsel meist lang gestielt. G. germanica Willd.

II. Bl.4-zählıg. Kib. nur am Grunde verwachsen, die beiden äusseren sehr gross, breitelliptisch, breiter als die Kr. G. campestris L.

B. Kr. tief 5-teilig radförmig, Zipfel am Grunde mit je 2 ringsum fransigen Honiggruben.

Swertia (65) perennis L.

๖. Pollen mittelgross, Exine glatt. [Erythraeinae.] Gr. 亡 langfädlich. Placenten \pm tief einspringend.

A. Bl. 6- bis 8-zählig. Kr. stieltellerförmig. Gr. mässig lang; N. doppelt '2-spaltig. Wärmeres M.-Eur., Mmgbt. Chlora (3).

a. Stengelb. am abgerundeten Grunde mit einander verwachsen. Bl.stand spirrig.

C. serotina Koch

b. Stengelb. in ihrer ganzen Breite mit einander verwachsen. Bl. ebensträussig. $\quad$ C. perfoliata (L.) IVillu. B. Bl. 4- oder 5-zählig. Kr. trichterig. Gr. lang; N. \pm 2 -lappig. A1. Bl. 4-zählig. A. eiherzförmig, nach dem Ausstäuben unverändert. N. schwachgelappt. Microcala (1) filiformis (L.) Lk.

B1. Bl. う-zählig. A. limeal, nach d. Ausstäuwen gewunden. N. deutlich gelappt.

Erythraea (30).

a. Stengel sehr gabelästig. Unt. B. keine Rosette bildend. B. eiförm., meist J̄-nervig. K. beim Aufblühen so lang als Kr. E. pulchella Fr.

b. Stengel einfach. Untere B. eine Rosette bildend.

a. B. lineal, meist 3-nervig. K. beim Aufblühen so lang als $\mathrm{Kr}$.

E. lınariifolia Pers.

ß. B. länglich-eiförmig bis lineal-lanzettlich, meist 5-nervig. K. beim A ufblühen halb so lang als Ḱr. E. Centaurium(L.) Pers.

\section{Apocynaceac $(100 ; 900)$.}

I. Frb. unterhalb des Gr. getrennt.

1. A. vom Gr. frei, ohne Anhängsel am Grunde. S. schildförmig ansitzend. [Plumerieae.]

A. Sa. vielreihig. Discus fehlend oder fleischig und dem $K$. angewachsen.

B. Sa. 2-reihig. Discus 2-schuppig.

Alstonia (30).

2. A. am Grunde mit 2 Anhängseln; alle zusammen rings um die N. kegelig zusammenneigend u. mitihr verschmelzend. [Echitideae.]

A. Kr.röhre kurz, ohne Schlundschuppen. Frb. halbunterständig, weil am Rücken mit dem dem $\mathrm{K}$. angewachsenen, fleischigen Discus verwachsen. - N.-Am. A pocynum (5) cannabinum L.

B. Kr.röhre lang, mit $5-10$ Schlundschuppen. $5-\infty$ Discusdrüsen innen am $K$.

A1. Kr.lappen nicht geschwänzt. - S.-Eur. Nerium (3) Oleander L. $B_{1}$. Kr.lappen in einen Schwanz auslaufend. Strophanthus (25).

II. Frb. völlig vereinigt. A ohne Anhängsel, von der N. frei. [Carisseae.] Frkn. 2-fächerig.

Carissa (21).

Frkn. 1-fächerig, mit 2 parietalen Placenten. Landolphia (16).

\section{Asclepiadaceae $(150 ; 1300)$.}

I. Stf. völlig oder doch an der Spitze frei. Pollen frei. [Periplocoideae.]

Periploea (12) graeca L. 

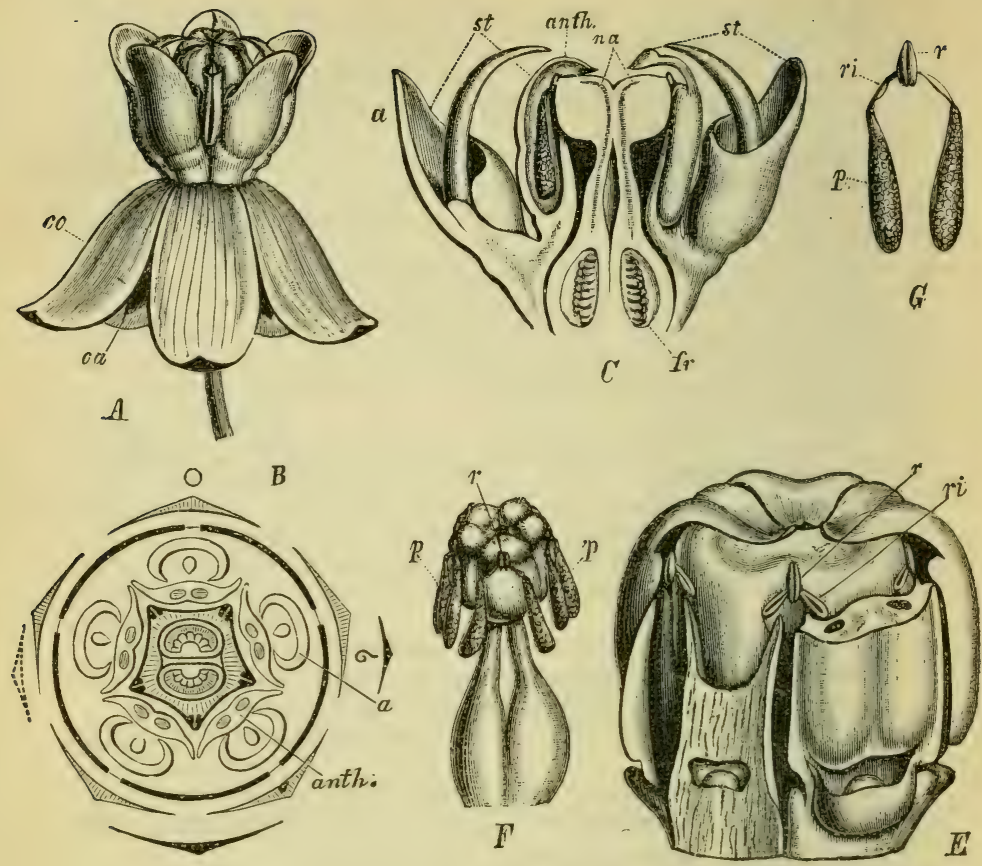

Fig. 14.

Aeclepias Cormuti Dene. At Geöffnete BL, mit zurückgeschlagenen $\mathrm{Kb} .(c a)$ und Blb. (co), Stb. um das Gynarceum herum zusammenneigend; $L$ Diagramm (anth. die fertile, « sterilo Hälfte der A.): C Längsschnitt durch das Androeceum (st ganzes Stb., $a$ und anth. wie in $E$ ) und Gynaeceum (na N.kopf, fr Frkn.); $E$ Junges Stadium des Androeceums, ron zwei A. sind Teilo weggeschnitten, die staminodialen Honigtaten noch schwach entwickelt $(r$ Anlage der Lilemmkörper, $r i$ die ron ihnen nach den A.fächern hingehenden Rinnen); $F$ Gynaeceum mit den mittelst der Klemmkörper $r$ anhaftenden Pollinarien; $G$ zwei mittelst des Klemmkörpers $r$ und der Verbindnngsfäden $r i$ verbundeno Pollinarien $p$.

II. Stf. in eine meist kurze Röhre verwachsen. Pollen in eigenartigen Pollinarien. (Fig. 14.) [Asclepiadoideae.]

1. A.fücher in gleicher Höhe mit der N. oder dieselbe überragend.

1'. Connectiv ohne Anhängsel. [Ceropegieac.] Ceropegia (50).

$2^{\prime}$. Connectiv oben mit einem häutigen. aufrechten oder einwärts schlagenden. Anhängsel. [Marsdenicae.]

A. Blkr. rechts gedreht. - O.-Eur., Or. Marsdenia (60) erecta R.Br.

B. Blkr. klappig. - O.-Ind Hoya (50) carnosa R. Br.

2. A.fächer der N. \pm aufliegend oder eingesenkt. Connectiv olne Anhängsel. [Stapelicae.]

3. A.tächer unterhalb der N.

Stapelia (60). 
1'. Connectiv ohne Anhängsel. [Gonolobeac.] Gonolobus (10).

2'. Connectiv mit häutigem Anhängsel. [Cynancheae.]

A. Antheridien (d. h. die unfruchtbaren Hälften der A.) unter sich nicht wiederum verwachsen, aus einer T'ute und einem darin steckenden Horn bestehend.- N.-Am. Asclepias (60) Cornuti D.C'.

B. Antheridien neuerdings verwachsen u. eine verwachsenblättrige, 5-zipfelige Innenkrone bildend.

A1. Innenkr. ring-, becher- oder breit topfförmig.

Vincetoxicum (70) officinale Mönch

$\mathrm{B}_{1}$. Innenkr. \pm rad- oder glockenförmig. Cynanchum (18).

\section{Convolvulaceae $(40 ; 1000)$.}

I. Autobiotisch mit Laubb. Keimling gerade oder gekrümmt, mit gefalteten Keimb. [Convolvuloideae]

A. N. 2-lappig oder 2-teilig, mit fädlichen, länglichen, eiförmigen oder abgeplatteten Lappen.

A1. Vorb. klein, vom $K$. entfernt stehend. Frkn. 2-fächerig. N.lappen fadenförmig oder dicklich. Convolvulus (160).

a. Pflanze einjährig, nicht windend. Mmgbt. C. tricolor L.

b. Pflanze ausdauernd, windend.

a. Kb. stumpf. Kr. rosa od. weiss mit rosigen Streifen. C. arvensis L.

अ. Kb. ungleich, äussere kürzer, nach aufwärts verbreitert u. oft unregelmässig kleingelappt. Krr. gelblichweiss. Kleinasien.

C. Scammonia L.

B1. Vorb. breit, \pm blattartig, den K. einschliessend. Frkn. 2kammerig oder 1-fächerig. N.lappen abgeflacht, eiförmig oder länglich.

a. B. pfeilförmig. Torb. herzförmig. C. sepium (L.) R. Br.

b. B. nierenförmig. Vorb. eiförmig, stumpf. C. Soldanella (L.) R.Br.

B. N. 2-knöpfig mit kugeligen Hälften oder ungeteilt- (bez. ganz schwach gelappt-) kopfig.

A1: Sexualorgane herausragend.

A.. Bl. in Dichasien oder doldenartigen bis kopfigen Bl.ständen. $\mathrm{Kr}$. strahlig.

A3. Kr. sehr gross, präsentiertellerförmig; Röhre lang, eng, cylindrisch; Saum breit und \pm flach. Trop. Am.

Calonyetion (4) speciosum Choisy

B3. Kr. ansehnlich, röhrig, nach oben etwas erweitert; Saum mittelgross. - Mexiko.

Exogonium (15) Purga (Wender.) Benth.

$\mathrm{C}_{3}$. Kr. mittelgross; Röhre schmal trichterig; Saum wenig ausgebreitet. Fr. mit falschen Scheidewänden zwischen den S. Quamoclit (10).

a. B. fiederteilig mit schmal-linealen Lappen. O.-Ind.

Q. vulgaris Choisy

b. B. handnervig, meist \pm gelappt. Trop. u. subtrop. Am. u. As.

Q. coccinea Mönch

B2. Bl. in Doppelwickeln. Lb. behörnt. Kr.röhre aus kurzem, engem Basaiteil plötzlich erweitert, gekrümmt. - Mexiko.

Mina (2) lobata Llave et. Lex.

$B_{1}$. Sexualorgane eingeschlossen. 
A2. Frkn. 4-samig, 2- oder 4-fächerig. Kb. häutig oder lederig, stumpf bis spitz. - Centr.-Am. Ipomoea (300) Batatas Lam.

B2. Frkn.6-samig, 3-fächerig. Kb. krautig, allmählich verschmälertspitz oder meist lang und schmal zugespitzt. -- S.-Am.

Pharbitis (60) hispida Choisy

II. Nichtgrüne, wurzel- und blattlose, nur Haustorien und Schuppen tragende Schmarotzer. Keimling \pm spiralig, ohne oder mit rudimentären Keimb. [Cuscutoideae] Cuscuta (90).

a. 2 getrennte, gleichlange $\mathrm{Gr}$ mit fädlichen oder pfriemeligen $\mathrm{N}$.

๙. Kr.röhre so lang als der Saum, walzlich. Stengel \pm ästig.

I. Schuppen der Kr.röhre angedrückt, diese also offen. Gr. höchstens so lang als der Frkn. und die $\mathrm{Kr}$. C. europaea L.

II. Kr.röhre durch die zusammenneigenden Schuppen geschlossen. $\mathrm{Gr}$. länger als Frkn. und $\mathrm{Kr}$.

C. Epithymum Murr.

3. Kr.röhre doppelt so lang als der Saum, \pm kugelig, offen; Schuppen angedrückt. Stengel meist einfach. C. Epilinum Weihe

b. 2 getrennte, ungleichlange Gr. mit kugeligen N. C.racemosa Mart.

c. Gr. + verwachsen mit kopfig-2-lappigen N. C. lupuliformis Krocker

\section{Polemoniaceae (8; 200).}

1. Pflanzen mit B.ranken kletternd. B. gefiedert, oberste Fiedern in Ranken verwandelt. Kb. laubig. Kapsel wandspaltig. S. breit geflïgelt. [Cobaccae.] - Mexiko. Cobaea (6) scandens Cav.

2. Pflanzen nicht kletternd. B. ohne Ranken. Kb. nicht laubig. Kapsel fachspaltig. (Polemonieae.)

A. Stb. gleichhoch inseriert.

A. Stf. gerade, am Grunde nicht behaart. B. fiederig eingeschnitten oder geteilt.

Gilia (90).

a. Bl.stände etwa 3-bis 5-blütig, locker. B.3-fach fiederschnittig, Hauptfiedern fast fingerförmig ausstrahlend.

๑. Fiederchen 3. Ordnung langlineal. Kr. verhältnismässig gross, Röhre goldgelb, Schlund braun-, Saum hellviolett. Californ.

G. tricolor Benth.

ß. Fiederchen 3. Ordnung kurzlineal, scharfspitz. Kr. klein, Röhre fast weiss. Schlund dunkelviolett gestreift, Saum hellviolett. Calif. G. multicaulis Benth.

b. Bl.stände bis 15 -blütig, kopfig gedrängt. B. fiederschnittig mit langlinealen Fiedern. Kr. violettblau. Pac.-N.-Am.

G. capitata Dougl.

B1. Androeceum schwach zygomorph, herabgebogen. Stf. am Grunde behaart. B. gefiedert. Polemonium (14) cocruleum L.

B. Stb. ungleichhoch inseriert.

A1. B. \pm eingeschnitten, wechselständig. Kr.röhre mit erweiterter Mündung. Samenschale mit Schleimschicht. - Pac. N.-Am.

Collomia (18) grandiflora Dougl.

B1. B. ungeteilt, sämtlich oder zumteil gegenständig. Kr.röhre eng. Samenschale ohne Schleimschicht. Phlox (30).

a. Pflanze einjährig, schlaff, durchaus drïsenhaarig. Obere B. spiralig. B. länglich-lanzettlich. Texas. P. Drummondii Hook.

b. Pflanze ausdauernd, nur oberwärts drüsenhaarig. Alle B. t gegenständig. 
u. Pflanze mit niedergestreckten Aesten. B. sehr schmallinealisch, stechend steif. N.Am.

P. subulata L.

f. Pflanze hochwüchsig, steifstengelig. B. 亡 eilanzettlich. N.-Am. P. paniculata L.

\section{Hydrophyllaceae $(17 ; 170)$.}

1. 2 getrennte Gr. Knospenlage der Kr. dachig. Kapsel \pm 2 fächerig. [Hydroleeae.]

2. Gr. \pm mit einander verwachsen.

1. Kúnospendeckung der Kr. dachig. Kapsel 1- (bis 2.) fächerig. Placenten schmal, auf der Mitte der Kilappen der fachspaltigen Kapsel. [Phacelieae.]

a. Kr. innen ohne oder mit kaum bemerkbaren Falten.

a. Stf. olne Anhängsel. Pflanze sehr klebrig-drüsig. S.-Californ. $P$. viscida (Bth.) Torr.

3. Stf. innenseits mit einem kleinen, schuppenförmigen Anhängsel. Kr. cylindrisch-glockig. S.-Calif.

P. Whitlavia Gray

b. Kr. innen $\mathrm{zwischen}$ den Stf. mit 10 deutlichen, schuppenförmigen Falten.

๙. Placenten mit je $6-\infty$ Sa.

F. Placenten mit je 2 Sa. [Sect. Euphacelia.]

Sect. Eutoca.

I. B. fiederteilig, mit spitzen Zipfeln. Texas. P.congesta Hook.

II. B. doppelt fiederschnittig. Pac. N.-Am. P.tanacetifolia Benth.

'2'. Knospendeckung der Kr. \pm gedreht. Kapsel 1-fächerig. Placenten breit, fast die ganze Kapsel auskleidend. [Hydrophylleae.]

A. Stb. hervorragend. B. wechselständig. 21. N.Am.

Hydrophyllum (6) virginicum L.

B. Stb. eingeschlossen. Wenigstens die untersten B. gegenständig. $\odot$.

Nemophila (11).

\section{Borraginaceae $(85 ; 1500)$.}

I. Gr. endständig; unter der Spitze mit einem Haarring. [Heliotropioideae.]

a. Klausen anfangs zu je 2 zusammenhängend, später getrennt. Tropen.

Heliotropium (220).

b. Die 4 Klausen deutlich von einander geschieden.

๙. Bl. nach Vanille riechend. Pflanze strauchig (bis über $1 \mathrm{~m}$ hoch). Peru, Ecuador.

э. Bl. ohne Vanillegeruch. Pflanze $\odot$. H. peruvianum L.

II. Gr. zwischen den 4 Lappen des tief gespaltenen Frkn. eingesenkt. Fr. aus einsamigen, unter sich freien Klausen bestehend. [Borraginoideae.]

1. Bl. strahlig.

1'. Stempelpolster \pm kegelig.

1 “. Klausen mit den Spitzen über die Ansatzfläche nicht hinaus ragend. [Cynoglosseae.]

A. Kr. radförmig. Klausen kah], am Rücken napfförmig, weil mit häutigem, an der Spitze einwärts gebogenem Saum.

Omphalodes (24).

a. B. gestielt, untere herzeiförmig, obere eilanzettlich. Bl.stand armblütig. Kr. blau. Klausen kürzer als Gr. O. verna Mönch 
b. Untere B. spatelig, obere sitzend, lanzettlich. Einzelbl. Kr. blau. Schlundschupp. gelb. Klausen länger als Gr. O.scorpioides Lehm.

B. Kr. stieltellerförmig. Klausen klettenartig, kurz weichstachelig, unberandet od. mit \pm dickem, nicht eingebogenem Rande.

Cynoglossum (50).

a. Klausen mit ziemlich dickem, hervortretendem Rande. B. dünn graufilzig.

C. officinale $\mathrm{L}$.

b. Klausen ohne Rand. B. oberseits kahl,glänzend, unterseits durch zerstreute Haare rauh. C.germanicum Jacq. (C. montanum Lam.)

¿". Klausen mit d. Spitzen d.Ansatzfläche überragend. [Eritrichieae.]

A. Kr. tellerförmig. Ansatzfläche der Klausen ihre untere Hälfte oder mehr einnehmend.

A1. Klausen gerandet-3-kantig, an den Kanten durch widerhakige Borsten weichstachelig.

Lappula (50).

a. B. angedrückt behaart. Bl.stiele zuletzt aufrecht. Klausenborsten 2-reihig.

L. Myosotis Mönch

b. B. abstehend behaart. Bl.stiele zuletzt zurückgebogen. Klausen flach zusammengedrückt. Borsten 1-reihig.

L. deflexa (Lehm.) Gcke.

B1. Klausen nicht gerandet, ohne Stacheln. Eritrichium (30).

B. Kr. trichterig. Ansatzfläche der Klausen klein, nicht gerandet. K. zur Fr.zeit zusammengedrückt zu 2 flachen, parallelen, buchtig-gezähnten Klappen.

Asperugo (1) procumbens L.

$2^{\prime}$. Stempelpolster wenig convex oder ganz flach.

1“. Ansatzfläche der Klausen concav, häufig von einem Ringe umgeben. [Anchuseae.]

A. Kr.schlund innen mit 5 Haarbüscheln, ohne Schuppen. Klausen glatt.

Pulmonaria (10).

a. Grundständige Sommerb. langgestielt, herzeiförmig, plötzlich in den Stiel zusammengezogen, meist weiss gefleckt. B.oberseite und Stengel borstig-rauh.

P. officinalis L.

b. Grundständige Sommerb. ei- bis lineal-lanzettlich, allmäblich in den Stiel verschmälert.

a. Die grünen Organe sehr steifhaarig, rauh. P.angustifolia L.

$\beta$. Die grïnen Teile weichhaarig, \pm durch gestielte Drüsen klebrig.

I. B. grün. A. schwarzviolett.

II. B. graugrün. A. gelblich.

$P$. montana Lej.

P. mollissima Kerner

B. Kr.schlund innen mit 5 Schuppen vor den Blb. Klausen meist runzelig.

A1. Kr. radförmig; Röhre sehr kurz; Saum ausgebreitet. Stf. auf d. Rücken mit Anhängsel. - Mmgbt. Borrago (3) officinalis L.

B1. Kr.röhre lang, cylindrisch. Stf. ohne Anhängsel.

A2. Kr.saum ausgebreitet. Schlundschuppen klein, stumpf.

A3. Kr.röhre gerade.

At. K. zur Fr.zeit aufgeblasen. Schlundschuppen sehr klein.

Nonnea (30)

a. K.zipfel zugespitzt. Kr.röhre länger als der K. Kr. dunkel-purpurbraun, selten gelb. N. pulla (L.) D.C.

b. K.zipfel stumpf. Kr.röhre so lang als der K. Kr. rosa, zuletzt bläulich. Kaukas., Armen.

N. rosea (M. B.) Fisch. et Mey. 
B. K. nicht aufgeblasen. Schlunçschuppen cien Schlund rerschliessend.

Anchusa (40).

a. Schlundschupp. sammethaar. B. nicht glänzend. A. of ficinalis L.

b. Schlundschuppen pinselig behaart. B. glänzend. A. italica Retz.

B3. Kr.röhre gekrümmt. Sonst wie $\mathrm{A}_{3} \mathrm{~B}_{4}$. Lycopsis (3) artensis L.

B. Kr.saum röhrig aufrecht. Schlundschuppen lanzettlich oder lineal, sehr lang.

Symphytum (17).

a. Stengel sehr ästig. B. lang herablaufend. Wurzel spindelig. \pm vertikal. Klausen glänzend, fast glatt. Schlundschuppen kaum so lang als die Stb., kürzer als der Kr.saum.

a. B. herzeiförmig, obere nicht herablaufend. S. asperrimum M. B.

ß. Lntere B. eilanzettlich, in den Stiel verschmälert, obere lanzettlich, alle herablaufend.

S. officinale L.

b. Stengel einfach oder sehr wenig verzweigt. B. halb herahlaufend. Wurzel schief oder horizontal, \pm verdickt. Klausen matt, höckerig. Schlundschuppen länger als die Stb.

c. Kr. weisslich mit hellgelbem Saum, Schlundschuppen herausragend. Stengel etwas ästig. Wurzel mit rundlichen Knollen. Mmgbt. bis S.-W.-Deutschland

S. bulbosum Schimper

ค. Kr. gelb, Saum die Schlundschuppen überragend. Stengel unverzweigt oder gabelig. Wurzel schief, zackig-ästig, fleischig verdickt.

2". Ansatzfläche der Klausen flach. [Lithospermeae.]

A. Kr. trichterig bez. stieltellerförmig. A. länglich, am Grunde abgerundet, am Scheitel stumpf oder spitz.

A1. Bl.stand beblättert, bez. BI. achselstäudig. Krr. trichterig. in der Knospe dachziegelig; im Schlunde 5 behaarte Falten oder ganz k]eine Schuppen.

a. Klausen glatt, glänzend.

a. Stengel sehr ästig. Seitennerven der B. hervortretend. Kr. kurz.grünlich-weiss, mit kleinen Schlundschupp. L.officinale L.

३. Nichtblühende Stengel rankenartig kriechend. Kr. ziemlich lang, erst rot, dann blau, ohne Schlundschuppen.

L. coeruleo-purpureum L.

b. Klausen runzelig-rauh. Stengel nur oberwärts ästig. B. ohne hervortretende Seitennerven. Blkr.weisslich, am Schlunde mit behaarten Längsfalten.

$L$. arvense $\mathrm{L}$.

B1. Bl.stand nicht od. nur zu unterst beblättert. 5 kahle Schlundschuppen den Schlund verschliessend. Kir. in der Knospe gedreht.

Myosotis (30).

a. K. angedrückt behaart. zur Fr.zeit offen. Kr.saum flach.

c. Wurzelstock schief. kriechend. Stengel kantig. B. spitzlich. Gr. so lang als der K. M. palustris Roth

ק. Wurzelstock absteigend, faserig. Stengel rund. B. stumpf. Gr. halb so lang als der $K$.

b. K. mit abstehenden, am Grunde mit Hakenhaaren.

a. Kr.saum flach, 6-10 $\mathrm{mm}$ im Durchmesser. M. silvatica Hoffm.

ß. Kr.saum \pm vertieft. $3-5 \mathrm{~mm}$ im Durchmesser.

I. Bl.stand blattlos. Fr.stiele wagerecht- od aufrecht-abstehend.

1. Kr.röhre zuletzt doppelt so lang als der K. Kir. erst gelb, dann violett, dann blau. Fr.stiele kürzer als der $\bar{K}$. 
2. Kr.röhre im K. eingeschlossen. Kr. blau.

+ Fr.stiele höchstens so lang als der zur Fr.zeit offene K.

M. hispida Schltd.

++ Fr.stiele bis doppelt so lang als der zur Fr.zeit geschlossene $K$.

$M$. intermedia Lk.

II. Bl.stand unterwärts beblättert.

1. Bl.stand reichbluitig. Fr.stiele fast aufrecht, kürzer als der geschlossene Frk.

$M$. arenaria Schrad.

2. Bl.stand wenigblütig. Fr.stiele schliesslich zurückgeschlagen, vielmal länger als der offene Frk.

M. sparsiflora Mik.

B. Kr. röhrig-glockig, dachziegelig; Saum aufrecht. Schlundschuppen fehlend. A. lineal-spiessförmig, am Scheitel lang zugespitzt; die Fächer am Grunde in Grannen auslaufend.

A1. 4 einsamige Klausen. Onosma (70) arenarium W.K. $\mathrm{B}_{1}$. Je 2 Klausen zu einer 2-fächerigen, 2-samigen verwachsen.

Cerinthe (7)

a. Kr.lappen ${ }^{1 / 3}$ so lang wie die ganze Blkr., aufrecht zusammenschliessend.

C. minor L.

b. Kr.lappen kurz, an der Spitze zurückgekrümmt. Mmgbt.

C. aspera Roth

2. Bl. schwach zygomorph. Stempelpolster flach. Klausen mit flacher Ansatzfläche. [Echicae.] Echium (30) vulgare L.

\section{Verbenaceate $(65 ; 750)$.}

1. Bl.stand cymös, schirmrispig.

A. Kr.röhre kurz; Saum 5-zipfelig, sehr schief od. 2-lippig. Steinfr. mit einem 4-fächerig. Kern. - Imgbt. Vitex (60) Agnus castus L.

B. Kr.röhre lang; Saum 4-spaltig. Steinfr. mit vier 1-samigen Kernen.

2. Bl.stand racemös, eine Aehre.

A. Fr. aus 4 einsamigen Steinfr.chen oder Klausen bestehend.

Verbena (80).

a. Bl.klein, in fadenförmigen, rispig geordneten Aehren. Connectiv der oberen A. ohne Anhängsel.

$V$. officinalis $\mathrm{L}$.

b. Bl. sehr gross, in schlaffen Aehren. Kr. im Schlunde behaart. Connectiv der oberen A. mit drüsenartigem Anhängsel. Südatl. N.-Am.

V. Aubletia L.

B. Fr. aus 2 einsamigen Steinfr.chen bestehend.

A1. K. gestutzt oder ausgeschweift-gezähnt. Blkr.zipfel fast gleich. Fr. saftig. - S.-Am. Lantana (50) Camara L.

B1. Blkr. schwach 2-lippig. K. 2- bis 4-spaltig od. -gezähnt. Fr. trocken. - Chile, Peru. Lippia (20) citriodora (Lam.) Kth.

\section{Labiatae (140; 2600).}

I. Frkn. kurz 4-teilig oder bis zu ${ }^{1 / 3}$ seiner Höhe geteilt. S. mit spärlichem Nährgewebe; Keimling gerade. [Ajugoideae.]

1. K. 10-rippig. Kr. scheinbar 1-lippig durch stärkere Entwickelung der Unterlippe. Stb. 4 oder 2 mit zweifächerigen A. Klausen \pm warzig. [Ajugeae.]

A. Kr. bleibend; ihre Röhre innen mit Haarring; Oberlippe sehr kurz, 2-lappig; Unterlippe 3-spaltig. 
a. Scheinquirle. Kr. blau, selten weiss oder rot.

a. Stengel kahl oder wenig behaart, mit Ausläufern. Grundb. langgestielt. Deckb. gekerbt oder ganzrandig, die obersten kürzer als die $\mathrm{Bl}$.

§. Stengel behaart, ohne Ausläufer.

A. reptans $\mathrm{L}$.

I. Stengel zottig behaart. Grundb. lang gestielt, rosettig. Cntere Deckb. 3-lappig, die obersten hüchstens so lang als die $\mathrm{Bl}$.

A. genevensis $\mathrm{L}$.

II. Stengel meist kurzhaarig. Grundb. kurz gestielt. Deckb. fast oder völlig ganzrandig, die obersten doppelt so lang als die $\mathrm{Bl}$.

A. pyramidalis $\mathrm{L}$.

b. Einzelbl. in den B.winkeln. Kr. gelb. B. 3.teilig mit linealen Zipfeln.

A. Chamaepitys Schreb.

B. Kr. abfallend; ihre Röhre ohne Haarring; Zipfel der tief gespaltenen Oberlippe der dadurch scheinbar 5 -spaltigen Unterlippe anliegend.

Tencrium (100).

a. Bl. in end- und blattwinkelständigen Trauben. K. 2-lippig. Kr. blassgelb. B. herzeiförm.-länglich, gekerbt. T. Scorodonia L.

b. Bl. in Scheinquirlen. K. ร̌-zähnig.

. Kr. blassgelb. B. ganzrandig, lineal-lanzettlich. T. montanum L.

3. $\mathrm{Kr}$. rot, selten weiss.

I. B. gekerbt, länglich.

1. Nach Knoblauch riechend. B. sitzend. T. Scordium L.

2. Ohne Knoblauchgeruch. B. gestielt. T. Chamaedrys L.

II. B. doppelt fiederspaltig.

T. Botrys L.

2. K. 11-rippig. Kr. 2-lippig. Stb. 2 mit 1-fächerigen A. Klausen glatt. [Rosmarineae.] - Mmgbt. Rosmarinus (1) officinalis L.

II. Frkn. völlig vierteilig. S. ohne Nährgewebe.

I'. Klausen eiförm., verkehrt-eiförm.od.tetraëdrisch.Keimling gerade.

I“. Stb. nicht der Unterlippe anliegend. A.fächer allermeist nicht verschmelzend ${ }^{1}$ ). [Stachydoideae.]

1. Kr. mit flachen Lappen, entweder fast strahlig oder nur schwach 2-lippig. Stb. 2 oder 4, diese entweder gleichlang: oder vordere länger, etwa gleichweit von einander abstehend. A.fächer eiförmig oder kugelig. [Satureincae.]

A. Kr. fast trichterig oder glockig mit 4 fast gleich grossen Zipfeln. Stb. \pm gerade.

A1. 4 Stb.

A2. Sth. fast gleichlang; A.fächer parallel nebeneinander.

a. K. 5-zähnig, mit offenem Schlunde.

Mentha (40).

\%. Scheinquirle in den Achseln von Hochb., eine endständige Aehre bildend.

I. B. gestielt, länglich. W.-Eur.

II. B. sitzend oder die unteren kurzgestielt.

1. B. rundlich-eiförmig, kerbig-gesägt. $M$. rotundifolia L.

2. B. länglich-lanzettlich, gesägt.

+ B. unterseits graufilzig. Klausen warzig. Ausläufer unterirdisch, beschuppt.

M. silvestris L.

+ + B. unterseits höchstens zerstreut behaart. Klausen fast glatt. Auslïufer oberirdisch, beblättert. MI.viridis L.

1) A.fächer rerschmelzend bei Phlomis, Hyssopus, Meiissa, Mai ribium. 
ß. Scheinquirle in den Achseln von Laubb., von einander entfernt.

I. Alle Scheinquirle von einander entfernt.

1. K. zur Fr.zeit kurz, glockig; Zähne kurz, 3-eckig-eiförmig. M. arvensis $\mathrm{L}$.

2. K. zur Fr.zeit lang, röhrig-glockig od. trichterig; Zähne 3-eckig-lanzettlich, zugespitzt.

+ Scheinquirle gestielt, locker; ihre Tragb. gestielt.

$M$. verticillata $\mathrm{L}$.

++ Scheinquirle sitzend, \pm dicht; ihre Tragb. sitzend.

M. gentilis L.

II. Die oberen Scheinquirle kopfig gedrängt. K. röhrig-trichterig; Zähne aus 3-eckigem Grunde pfriemelig-zugespitzt. IM. aquatica $\mathrm{L}$.

b. K. schwach 2-lippig; sein Schlund durch einen Haarkranz geschlossen.

M. Pulegium L.

B2. Untere Stb. länger. A.hälften unten spreizend. Scheinquirle in einseitswendigen Aehren.

Elssholtzia (18) Patrini (Lepech.) Garcke B1. 2 Stb. und meist noch 2 fädliche Staminodien. Lycopus (10). a. Staminodien fadenförmig, kopfig. B. völlig fiederspaltig.

L. exaltatus L. f.

b. Staminodien fehlend. B. nur am Grunde fiederspalt. L.europaeus L.

B. Kr. schwach '2-lippig. Stb. oberwärts \pm zusammenneigend oder divergierend.

A1. K. 5-zähnig oder doch nicht 2-lippig.

A2. A.fächer schief an dem verbreiterten Connectiv sitzend. Die beiden oberen Stb. unter der Oberlippe zusammenneigend.

A3. Oberlippe der Kr. schwach ausgerandet. Alle 4 Stb. unter der Oberlippe zusammenneigend und nicht aus der Kr. hervortretend. - S.-Eur.

Satureja (14) hortensis L.

B3. Oberlippe der Kr. tiefer eingeschnitten. Die unteren Stb. divergent und ein wenig hervorragend. Origanum (25).

a. K. 5-zähnig. B. eiförmig, spitz, fast kahl. $O$. vulgare $L$.

b. K. nicht gezähnt, vorn fast bis zum Grunde gespalten. B. elliptisch. stumpf, graufilzig. Mmgbt. O. Majorana L.

B:. A. quer halbmondförmig, Fächer oben verschmelzend. Alle $4 \mathrm{Stb}$. aus der Krone hervorragend und divergierend. Mmgbt.

Hyssopus (1) officinalis L.

B1. K. deutlich 2-lippig; Oberlippe 3-, Unterlippe 2-zähnig.

A2. A.fächer schief an etwas verbreitertem Connectiv.

A3. Alle 4 Stb. divergent. Gr. und wenigstens die beiden längeren Stb. aus der $\mathrm{Kr}$. hervorragend. Thymus (£0).

a. Stengel \pm niederliegend. B. flach od. schwach zurïickgerollt.

a. Stengel uberwärts dentlich vierkantig. Scheinquirle \pm ährig.

I. Stengel an den Kanten deutlich stärker behaart. B. kahl, unterseits schwachnervig.

T. Chamaedrys Fr.

II. Stengel und B. rauhhaarig-zottig. B. unterseits tief punktiert.

T. pannonicus All.

3. Stengel durchgehends fast stielrund. Scheinquirle \pm köpfchenartig geordnet. B. gewimpert, unterseits stark nervig. 
b Stengel \pm aufrecht, fast stielrund, gleichmässig kurz hehaart. B. stark zurückgerollt. T. vulgaris $\mathrm{L}$.

B3. Gr. und die sämtlich zusammenneigenden Stb. nicht heråusragend.

Calamintha (40).

a. Scheinquirle von linealpfriemeligen Deckb. umgeben.

b. Scheinquirle ohrэ Deckb.

C. Clinopodium Spenner

ə. Scheinquirle aus 3 - bis j-blütigen Trugdöldchen zusammengesetzt. Kr. purpurn.

F. Scheinquirle aus $6 \mathrm{kurz}$ gestielten Bl. bestehend. Kr. hellviolett.

C. Acinos (L.) Clairv.

B. A.fächer oben verschmelzend, fast einen gestreckten Winkel bildend. Stb zusammenneigend, nicht herausragend. Oberlippe des $K$. flach, die der Kr. schwach gewölbt. S.-Eur.

Melissa (4) officinalis L.

2. Kr. \pm deutlich 2-lippig. Stb. unter der Oberlippe genähert und gleichlaufend.

1'. Hintere Stb. ]änger oder allein ausgebildet. [Nepetcac.

A. K. röhrig, 丂̆-zähnig. Schlund der Kr.röhre trichterig; Oberlippe ziemlich flach.

A. Uberlippe der Kr. zweispaltig; Mittellappen d. Cnterlippe sehr gross, rundlich, hohl, gekerbt-gezähnt Stb. anfangs parallel, später seitlich gebogen; A.fächer parallel. Nepeta (120).

a. Klausen glatt, kahl. B. herz-eiförmig, spitz, unterseits graufilzig.

N. C'ataria L.

b. Klausen knotig-rauh, an der Spitze beha๙rt. B. länglich, kahl.

N. nuda L.

B1. Oberlippe der Kr. ausgerandet; Nittellappen der Lnterlippe mässig gross, flach, ausgerandet, sonst ganzrandig. A.fächer zweier neben einander stehender Stb. ein hreuz bildend.

Glechoma (1) hederacea L.

B. K. 2-lippig. Schlund der Kr.röhre aufgeblasen; Oberlippe gewölbt. A fächer ein Kreuz bildend. Diacocephalum (30).

a. Bl. in Aehren. A. wollig.

๙. B. lineal-lanzettlich, ganzrandig. D. Ruyschianum L.

ค. B. fiederig-fünfteilig.

D. austriacum $\mathrm{L}$.

b. Bl. in Scheinquirlen. A. kahl. B. stumpf tiefgesägt. S-O.-Eur.

2'. Vordere Stb. länger oder allein fruchtbar.

1“. Kx. rundlich mit breitgedrückter Oberlippe od. überhaupt von vorn nach hinten zusammengedrückt. Alle $4 \mathrm{Stb}$ fruchtbar. 1“". Kr. im K. schlunde verborgen oder nur wenig hervorragend. Stb. in der $\mathrm{Kr}$. verborgen. [Marrubieae.]

A. K. J-zähnig. A.fächer stets deutlich getrennt. Sideritis (ち0). B. K. 10-zähn. A.fächerspäter verschmelzend. Marrubium (30)

a. K.zähne pfriemelig, gerade. B. elliptisch-lanzettlich. S.-O - Eur.

M. creticum Mill.

b. K.zähne hakig zurückgekrümmt. B. stumpf eiförmig, ungleich gekerbt.

2““. Kr. \pm die K.röhre überragend. Stb. der Oberlippe anliegend. [Stachydeae.] 
A. Oberlippe der Kr. fast kreisrund, wenig gewölbt. A.fächer ein Ḱreuz bildend. K. aufgeblasen, unregelmässig '2-lippig.

Melittis (1) Melissophyllum L.

B. Oberlippe der Kr. deutlich gewölbt. A.fächer parallel.

A1. K. quer flachgedrückt, 2-lippig.

Brumella (5).

a. Kr. $1^{1}$, 2 mal so lang als $K$., mit gerader Röhre. Die längeren Stb. in einen pfriemligen Zahn endigend.

๑. Zähne der K.oberlippe sehr kurz. Kr. blauviolett, rötlich oder selten weiss. Zähne der Stb. gerado oder schwach gebogen. B. nie fiederspaltig.

B. vulgaris $\mathrm{L}$.

ア. Zähne der K.oberlippe länger zugespitzt. Kr. gelblichweiss, selten hellpurpurn. Zähne der Stb. stark nach vorn gebogen. B. oft fiederspaltig.

B. alba Pall.

b. Kr. fast $3 \mathrm{mal}$ so lang als K.; Röhre aufwärts gekrümmt. Die längeren Stb. mit kleinem Höcker. B. grandiflora Jacq.

Bı. K. cylindrisch, trichterig oder glockig, 5-zähnig.

A2. Klausen deutlich dreikantig, Scheitel abgestutzt.

A3. Seitenzipfel der Kr.unterlippe stumpf.

At. K.zähne kurz. A.fücher schliesslich verschmelzend. S.-Eur.

Phlomis (50) tuberosa L.

Bt. K.zähne lang pfriemelig-stachelig. A.fächer stets getrennt.

Leonurus (10).

a. Kr.röhre ohne Haarring. B. unterseits graufilzig, untere eiförmig, obere lanzettlich mit wenigen Sägezähnen.

L. Marrubiastrum L.

b. Kr.röhre innen mit Haarring. B. unterseits hellgrün, untere handförmig 5-spaltig, obere 3-spaltig. $\quad L$. Cardiaca L.

B3. Seitenzipfel der Unterlippe spitz oder fehlend. Lamium (40).

a. Kr. gelb; ihre Unterlippe mit 3 ziemlich gleichen, spitzen Zipfeln. A. kahl. L. Galeobdolon Crntz.

b. Mittelzipfel der Kr.unterlippe sehr gross, stumpf; Seitenzipfel sehr klein oder fehlend.

๙. Kr.röhre ohne Haarring. Obere B. nierenförmig, stengelumfassend, untere herzeiförmig oder rundlich, gestielt.

L. amplexicaule $\mathrm{L}$.

ß. Kr.röhre innen mit Haarring. Alle B. gestielt.

I. Kr.röhre gerade, plötzlich in den Schlund erweitert.

L. purpureum L.

II. Kr.röhre gekrümmt, allmählich in den Schlund erweitert.

1. Kr. hellpurpurn mit dunkler gefleckter Unterlippe.

2. Kr. weiss.

L. maculatum L.

L. album L.

B. Klausen verkehrt eirund oder 2-oder 3-kantig und dann am Scheitel abgerundet.

A3. A.fächer mit gewöhnlichen, aufrechten oder schiefen Spalten aufspringend.

At. K. hervorspringend 10-rippig. Stb. auch nach der Bl. gerade aufrecht; A.fächer stets aufrecht. Ballota (25) nigra L.

B. K. schwach 5-bis 10-rippig. Die längeren Stb. nach dem Verblïhen nach auswärts gewunden; A.fächer schief. 
a. Kr.röhre innen ohne Haarring.

a. K. aderlos. Ganze Kr. aussen wollhaarig. S. Bctonica Bth.

ß. K. netzig-gerippt. Nur die Kr.lippen aussen zottig.

b. Kr.röhre innen mit Haarring.

S. Alopecuros (L.) Bth.

a. Kr. gelb. B. am Grunde abgerundet oder verschmälert. Scheinquirle 4 - bis 10 -blütig.

I. Scheinquirle 6- bis 10-blütig. K.zähne 3-eckig mit kahler Stachelspitze. B. kurzbehaart, kurzgestielt bez. sitzend.

S. recta L.

II. Scheinquirle 4-bis 6-blütig. K.zähne lanzettlich mit behaarter Stachelspitze. B. kahl, länger gestielt. S. annua L.

F. Kr. rot. B. am Grunde abgestutzt oder herzförmig.

I. Deckb. so lang oder halb so lang als der $K$. Scheinquirle 10 - bis vielblütig.

1. Stengel dichtwollig-zottig, meist einfach. B. weisswolligfilzig.

S. germanica $\mathrm{L}$.

2. Stengel rauh-, oberwärts drüsenhaarig und ästig. B. schwach graufilzig.

S. alpina $\mathrm{L}$.

II. Deckb. gewöhnlich sehr klein. Scheinquirle 6- bis 10-blütig.

1. B. breit herzförmig, \ lang gestielt. Scheinquirle 6-blütig. + Stengel steifhaarig. B. stumpf, schwach behaart. Kr. wenig länger als der $\mathrm{K}$.

$S$. arvensis $\mathrm{L}$. ++ Stengel drüsig behaart. B. zugespitzt, rauhhaarig. Kr. doppelt so lang als der $\mathrm{K}$.

S. silvatica $\mathrm{L}$.

2. B. aus herzförmigem Grunde lanzettlich, untere kurz gestielt, obere halbstengelumfassend.

S. palustris L.

B3. A.fächer übereinander liegend, mittelst Querspalten klappenartig aufspringend.

Galeopsis (12).

a. Stengel mit weichen, abwärts angedrückten Haaren besetzt, unter den Knoten nicht oder kaum verdickt.

a. Kr. höchstens mittelgross, hellpurpurn, selten weiss.

I. K. angedrückt behaart, Zähne ungleich, bei der Reife abstehend. B. \pm lineal-lanzettlich. $\quad G$. angustifolia Ehrh.

II. K. abstehend drüsenhaarig, Zähne \pm gleich, bei der Reife aufrecht. B. länglich bis länglich-lanzettlich. G.Ladanum L.

$\beta$. Kr. gross, hellgelblich. G. ochroleuca Lam. b. Stengel \pm steifhaarig, unter den linoten deutlich verdickt.

a. Kr. meist mässig gross, rot oder weiss, an der Grenze ron Schlund und Unterlippe meist gelb gefleckt.

I. Kr.röhre höchstens so lang als der K.

1. Kr.unterlippe am Grunde meist gelb und rot gefleckt; ihr Mittelzipfel fast quadratisch, flach, gekerbt. G. Tetrahit L.

2. Mittelzipfel der Kr.unterlippe länglich, meist ausgerandet, schliesslich am Rande zurückgerollt. G. bifida Boenngh.

II. Kr.röhre beträchtlich länger als der K., oberwärts bräunlich gelb.

G. pubescens Bess.

3. Kr. gross, schwefelgelb; Mittellappen der Unterlippe violett. G. speriosa Mill.

$2^{\prime \prime}$. Kr. seitlich zusammengedrückt; Oberlippe \pm sichelförmig.

Nur die vorderen Stb. fruchtbar. 
1“". K. 5-spaltig. Connectiv nicht verbreitert. [Monardeae.] N.-Am. Monarda (7) fistulosa. L.

2“". K. 2-lippig. Connectiv linear fädlich verbreitert; meist nur 1 A.fach truchtbar. [Salvieae.]

Salvia (450).

a. Oberlippe der Kr. kaum zusammengedrückt; Röhre innen mit Haarring.

a. Scheinquirle bis 12-blütig. Bl. ziemlich gross. $\mathrm{Kr}$. violettblau. Gr. aus der Oberlippe hervorragend. B. länglich, fein gekerbt. S. officinalis $\mathrm{L}$.

5. Scheinquirle bis 30-blütig. Bl.klein. Kr. hellblau. Gr.d. Unterlippe anliegend. B. herzförmig, ungleich-kerbig. S.verticillata L.

b. Oberlippe der Kr. stark zusammengedrückt; Röhre ohne Haarring. Scheinquirle meist 6-blütig.

a. Oberlippe des K. 3-zähnig. Kr. nie gelb. B. runzelig.

I. Oberlippe d. K. Hach; Zähne fast gleich, lang dornig begrannt.

1. Stengel zottig, oberwärts drüsig. B. klebrig, doppelt gekerbt. Deckb. drüsig, länger als K. S.- u. O.-Eur. S. Sclarea L.

2. Stengel, B. u. K. weisswollig. B. gekerbt. Deckb. kürzer als K. Mmgbt.

S. Aethiopis L.

II. Oberlippe des K. ausgehöhlt, 2-furchig, mit 3 zusammenneigenden, kurz stachelspitzigen Zähnen.

1. Grundb. rosettig, der übrige Stengel blattarm. Deckb. grün, kürzer als $K$.

S. pratensis L.

2. Stengel dichtbeblïttert, ohne grundständige Rosette. Deckb. meist purpurn, so lang als K. S. silvestris L.

ß. Oberlippe des K. kaum gezähnt. Kr. schwefelgelb, braun punktiert.

S. glutinosa L.

II". Stb. der Unterlippe anliegend. A.fächer \pm kugelförmig, zuletzt oberwärts verschmelzend. [Ocimoideae.]

1. Kr. schwach zygomorph, Oberlippe 2-, Unterlippe 3-lappig. Stb. nicht herausragend. Discuslappen vor den Klausen stehend. [Lavanduleae.] - S.-Eur.

Lavandula (20) vera D.C.

‥ Kr. deutlich zygomorph, Oberlippe 4-lappig, Unterlippe einfach. Stb. meist herausragend. Discuslappen mit den Klausen alternierend. Ocimeae.

A. Der die Unterlippe bildende Lappen den anderen nahezu gleichend. - 0 -Ind.

Ocimum (50) basilicum L.

b. Der die Unterlippe bildende Lappen von den anderen deutlich verschieden.

A1. Unterlippe hohl oder kahnförmig.

A2. Stb. unter sich frei.

Plectranthus (70).

B.. Stb. am Grunde zu einer Röhre verwachsen. Coleus $(60)$. $B_{1}$. Unterlippe gestielt sackartig.

Hyptis (250).

II'. Klausen auf einem Gynophor, kugelig. Keimling gekrümmt. Stb. wie bei I'I'"2. K. 2-lippig. [Scutellarioideae.] Sentellaria (90).

a. Kr. ziemlich kurz, mit gerader Röhre, rötlich. B. ganzrandig oder am Grunde beiderseits mit 1 oder 2 Zähnen. S'.minor L.

b. Kr. lang, blauviolett; Röhre am Grunde scharf emporgekrümmt.

o. B. am Grunde beiderseits mit 1-2 Zähnen, fast spiessförmig.

K. drüsig-weichhaarig.

S. hastifolia L.

3. b. entfernt gekerbt. K. kahl od rauhhaarig. S. galericulata I. 


\section{Nolanaceae $(3 ; 40)$.} zerfallend.

Frkn. schon während der Bl. in vollkommen getrennte Teile

a. 5 je 4 - bis 6-samige Teilfr. Chile. N. prostrata L.

b. $10-25$ je 1 - bis 2 -samige Teilfr. Chile. N. atriplicifolia Don

\section{Solanaceae $(68 ; 1300)$.}

1. Krümmung des Keimlings mehr als einen Halbkreis betragend. 5 ganz oder nahezu gleichlange Stb., sämtlich fruchtbar.

1. Frkn. 3- bis 5-fächerig. [Nicandreae.] Peru.

Nicandra (1) physaloides (L.) Gärtn.

2. (cf. 3.) Frkn. bis zum Grunde 2-fächerig (nur bei der Culturform von Solanum Lycopersicum falsch $\infty$-fächerig). [Solaneae.]

1'. Stamm oberirdisch, verlängert.

1". Connectiv dünn.

1“. Fr. eine Beere.

1““. Kr. radförmig od. glockig, mit breitem Saume. [Solaninae.]

A. A. unter sich frei; ihre Fächer seitenständig und mit Längsspalten aufspringend.

A1. K. bei der Fr.reife auffallend vergrössert.

A. K. die Beere nicht verhüllend. Saracha (12).

$\mathrm{B}_{2}$. K. die Beere ganz verhüllend, blasig, gerippt.

A3. Bl. einzeln. Kr. radförmig. Physalis (45).

a. Blkr. rein weiss. Beere rot. Frk. sehr aufgeblasen, scharlachrot. $\quad P$. Alkekengi L.

b. Blkr. gelb mit 5 dunkelbraunen Flecken am Grunde. Beere gelb. Frk. wenig verändert, blass. Peru.

$P$. peruviana $\mathrm{L}$.

B3. Bl. gebüschelt. Kr. röhrig-glockig. Withania (5). $B_{1}$. K. bei der Fr.reife nicht auffallend vergrössert.

Capsicum (30).

a. Fr. beträchtlich verlängert; Fr.stiel aufrecht. Trop. Am. C. annurem $\mathrm{L}$.

b. Fr. hängend, sehr verlängert. Trop. Am. C. longum D.C. B. A. deutlich intrors, \pm unter sich verklebend; ihre Fächer mit meist in einen introrsen Spalt sich verlängernden Endporen aufspringend.

Solanum (900).

a. A. kurz, überall gleich breit; Endporen gross, später in einen Spalt sich erweiternd.

a. Knollige, unterirdische Stengel an d. Wurzeln. B. unterbrochen-gefied. Beeren gelb. And. S.-Am. S.tuberosum L.

३. Wurzeln ohne knollige Stengel. B. einfach.

I. Ausdauernd. Aeste klimmend. Beeren rot.S.Dulcamara L.

II. ๑. Aeste nicht klimmend. B. buchtig.

1. Beerun gelb. Stengel filzig-zottig. S. villosum Lam.

2. Beeren rot. Stengel mit zahnartigen Höckern, \pm kahl. $S$. alatum Nönch (S. miniatum Bernh.)

3. Beeren schwarz. Auf dem kahlen Stengel 2 Längskanten mit zahnartigen Höckern.

S. nigrum. L.

b. A. lang, vom Grunde nach dem Scheitel allmählich verengt; Poren klein. 
a. Poren endständig, sich nicht merklich abwärts verlängernd. Fr. ei- oder gurkenförmig. O--Ind.

S. Melongena L.

$\beta$. Poren seitenständig, sich in einen Spalt verlängernd. Fr. gedrückt-kugelig, durch falsche Scheidewände $\propto$-fächerig. S.-Am

S. Lycopersicum L.

2"“. Kr. röhrig oder schmalglockig, mit schmalem Saume. [Lyciinae.]

A. Holzpflanzen. Kr. trichter-od. stieltellerartig. Lycium (70).

a. Kr.röhre cylindrisch; Zipfel kürzer als die halbe Röhre. a. Stb. kahl. Mmgbt. L. europaeum L.

3. Stf. oberhalb der Ansatzstelle ringsum behaart. Mmgbt. L. afrum $\mathrm{L}$.

b. Kr.röhre trichterig; Zipfel länger als die halbe Röhre. Stb. kahl. Vord.-As.

L. barbarum L.

B. Ausdauernde Kräuter. Kr. röhrig-glockig. Stb. am Grunde der Röhre eingefügt.

Atropa (2) Belladonna L.

2'“. Fr. eine Kapsel, meist Deckelkapsel. [IIyoscyaminae.]

A. Kr. weitglockig.

Scopolia (4).

a. Saum der Kr. sehr kurz, schwach 5-zähnig. Frk. wenig grösser als die Kapsel. O.-Alp., Karpath. S. carniolica Jacq.

b. Saum der Kr. breit, 5-lappig. Frk, viel grösser als die Kapsel. Himal.

S. lurida (Lk. et Otto) Dun.

B. Kr. trichterig.

A1. Bl. achselständig, die oberen zu einer beblätterten, oft einseitswendigen Traube oder Aehre vereinigt.

Hyoscyamus (11) niger L.

B1. Bl.stand cymös, endständig, unbeblättert. - Armen.

Physochlaena (5) orientalis (M. B.) Don

2". Connectiv dick; A. intrors. [Mandragorinae z. T.]

Cyphomandra $(30)$.

2'. Stengel eine stark verkürzte Grundachse bildend. [Mandragorinae z. T. J-Mmgbt. Mandragora (4) officinarum (L.) Vis.

3. Frkn. wenigstens in seinem unteren Teile durch falsche Längsscheidewände 4-, oben 2-fächerig. [Datureae.]

A. Knospenlage der Kr. dachig. Frk. bedeutend vergrössert, die Fr. einhüllend od. auf einer Seite aufgeschlitzt. Solandra (6).

B. Knospenlage der Kr. faltig, K. - ausser dem untersten Teile - nach dem Verblühen abfallend.

Datura (15).

a. Bäume mit hängenden $\mathrm{Bl}$. Fir. eine längliche, grosse, hängende Beere. Chile, Peru. D. arborea L.

b. Kräuter mit aufrechten Bl. Fr. eine aufrechte, vierklappige Kapsel.

a. Kapsel ohne Stacheln. Abyssinien. D. inermis Jacq.

ß. Kapsel mit etwa gleichlangen Stacheln bewehrt.
I. Kr. weiss. Nordhalbkugel.
II. Kr. blau. Nordhalbkugel.
D. Stramonium L.
D. Tatula L.

II. Krümmung des Keimlings weniger als einen Halbkreis betragend oder Keimling gerade.

1. Alle $5 \mathrm{Stb}$. fruchtbar, gleichlang oder $1-3$ kürzer. [Cestreae.] 1. Fr. eine Beere. Holzgewächse. [Cestrinae.] Cestrum (140).

a. K. 5-spaltig. Kr. rot. Mexiko. C. roseum H.B.K. 
b. K. mit 5 kurzen Zähnen. Kr. orangegelb. Guatemala.

\section{C. aurantiacum Lindl.}

2'. Fr. eine septicide Kapsel. Meist Kräuter. [Nicotianinae.]

A. Bl. in cymösen Rispen oder Trauben. Nicotiana (40).

a. Kr. trichterig, mitspitzen Lappen, rot. S.-Am. N. Tabacum L

b. Kr. stieltellerförmig od. ziemlich weitröhrig, grün od. gelb, mit stumpfen Lappen.

a. Pflanze krautig, ○. Bl. grünlich. Trop. Amer. N.rustica L.

3. Pflanze holzig, 24. Bl.gelb. S.-Am., Mexiko. N. glauca Grah.

c. Kr. stieltellerförmig mit sehr langer, enger Röhre, weiss.

a. Frkn. 2-fächerig. Chile. $N$. longiflora Cav.

ア. Frkn. 4-fächerig. Südwestl. N.-Am. N. quadrivalvis Pursh B. Bl. einzeln end- oder seitenständig.

A1. Pflanze strauchig. - Chile. Fabiana (14) imbricata Rz. et P. B. Pflanze krautig.

A2. Kr.röhre allmählich in den Saum erweitert; Stf. unter oder in ihrer Mitte eingefügt.

a. $\mathrm{Kr}$. weiss. Argentin.

b. Kr. violett oder purpurn. Argent.

Petunia (14).

P. nyctaginiflora Juss.

$B_{2}$. Kr.röhre plötzlich in den Saum erweitert; Stf. oberhalb ihrer Mitte eingefügt. - Chile. Nierembergia (20) gracilis Hook.

2. Nur 2 od. 4 Sth. fruchtbar, immer verschiedenlang. [Salpiglossideac.] A. Kräuter.

A1. B. gezähnt oder fiederschnittig. Kr. netzaderig.

A2. Saum der Kr. schwach zygomorph, Zipfel ziemlich gleich. - Chile. Salpiglossis (8) sinuata Rz. et P.

B2. Saum der Kr. zweilippig, mit 5 sehr ungleichen Zipfeln. Chile.

B1. B. ganzrandig. $\mathrm{Kr}$. netzaderig.

A2. Kr.saum 5-zähnig mit Zwischenlappen, in der Knospe faltig.

Schwenkia (20).

B2. Kr.saum 5-lappig, 2 Lappen die anderen klappig deckend. B. Holzgewächse. - Trop. Am. Browallia (6) demissa L.

A1. Kr. röhrig-glockig, mit weiter Röhre.

B1. Kr. stieltellerförmig, mit enger Röhre.

Duboisia (2).

a. Kr.röhre $1-5$ mal so lang als der $K$. Kr. violett oder b]äulich-weiss.

Sect. Franciscea.

b. Kr.röhre 8-10 mal so lang als der K. Kr. gelb oder gelblichweiss. Sect. Eubrunfelsia.

\section{Serophulariaceae $(179 ; 2000)$.}

I. Die hinteren Kr.lappen (bez. Oberlippe) deckend.

I'. B. wechseltändig. Oft 5 Stb. vorhanden. [Pseudosolaneae.]

Kr. mit sehr kurzer Röhre, radförmig od.kurzglockig.[Verbasceae.] A. 5 Stb.

Verbaseum (160).

a. Alle A. gleich, halbkreisförm., mit einem Querriss aufspringend.

$\alpha$. Teile des Bl.standes kahl od. schwach behaart. Kr. und Wolle der Stf. violett.

$\beta$. Alle grünen Teile der Pflanze wollig od. filzig. 
I. Wolle der Stf. weiss. V. Lychnitis L.

II. Wolle der Stf. violett oder rot.

b. A. der beiden unteren Stb. am Stf. herablaufend.

a. Bl. einzeln, selten gebüischelt. Stengel und B. kahl oder drüsig behaart.

$\beta$. Bl. geknäuelt. Stengel und B. filzig.

I. Kr.saum ziemlich flach, über $3 \mathrm{~cm}$ breit. Längere Stf. $1^{1 / 2} \mathrm{mal}$ so lang als ihre A. N. keulenförmig, herablaufend.

1. B. kurz herablaufend. $\quad V$. phlomoides L.

2. B. meist bis zum nächsten B. herablaufend.

$V$. thapsiforme Schrad.

II. Kr.saum vertieft, unter $3 \mathrm{~cm}$ breit. Längere Stf. 4 mal so lang als ihre A. N. kopfig.

1. B. kurz herablaufend. Alle Stf. wollig. V.montanum Schrad.

2. B. meist bis zum nächsten B. herablaufend. Die 2 längeren

B. 4 Stb. Stf. fast oder ganz kahl.

V. Thapsus L.

Celsia (37).

II'. Wenigstens die unteren B. gegenständig. Das 5. Stb. staminodial oder fehlend. [Antirrhinoideae.]

1. Vielsamige Kapselfrucht.

$1^{\prime}$. Kr. fast strahlig od. 2-lippig mit flachen od. convexen Lippen. $1^{\prime \prime}$. Kr. weder gespornt, noch sackartig.

1“. Bl.stand cymös, zusammengesetzt. [Cheloneae.]

A. Kapsel scheidewandspaltig.

A1. 5. Stb. staminodial, sehr selten fehlend. Kräuter.

A2. Staminodium fädlich oder keulig.

A3. Kapselklappen häufig geteilt. S. kantig, ungeflügelt.

Pentstemon (82).

$\mathrm{B}_{3}$. Kapselklappen ungeteilt. S. häutig-geflügelt. Chelone (4).

B. Staminodium schuppenförmig, selten fehlend.

A3. Das unterste Blb. schiffchenförmig. - Californ.

Collinsia (17) bicolor Benth.

B3. Zipfel der Unterlippe sämtlich flach. Scrophularia (114).

a. Staminodium breit, schuppenförmig. Bl. in armblütigen, achselständigen $\mathrm{Cymen}$, die oberen eine endständige Rispe bildend. B. ungeteilt.

$\alpha$. Stengel scharf 4-kantig, ungeflügelt.

I. Stengel und B.stiele spärlich kurzhaarig. B. kahl. Kb. eiförmig, schmal, häutig berandet. S. nodosa L.

II. Stengel und B.stiele zottig. B. beiderseits weichhaarig. Kb. rundlich, mit breitem, bräunlichem Hautrande.

S. Scopolii Hoppe

$\beta$. Stengel und B.stiele breitgeflügelt. Kb. breit häutigberandet.

I. B. herzförmig-länglich, am Grunde oft geöhrelt. Staminodium rundlich-nierenförmig. S. aquatica L.

II. B. eilänglich, selten am Grunde etwas herzförmig.

1. Staminodium zweilappig, verkehrt-herzförmig. Alle B. scharfgesägt, spitzlich.

S. alaita Gil.

2. Staminodium hinten abgestutzt, vorn schwach ausgerandet, 3mal breiter als lang. Untere B. gekerbt, stumpf.

S. Neesii Wirtg. 
b. Staminodium lineal, spitz. Bl. in reichblütigen, endständigen cymösen Rispen. B. gefiedert

S. canina L.

c. Staminodium fehlend. Bl. in 1-oder armblütigen, achselständigen Cymen. Kr. krugförmig, vorn stark eingeschnürt. B. ungeteilt.

B1. 5. Stb. winzig oder fehlend. Holzpflanzen.

A2. Stb. herausragend; A fächer parallel. Kapselklappen nicht gespalten. Kapld. Phygelius (1) capensis E. Mey.

B2. Stb. nicht herausragend; A.fächer spreizend, am Scheitel verschmelzend. Kapselklappen gespalten. Russelia (6).

B. Kapsel fachspaltig.

A1. Kraut. Staminodium sehr kurz. Mexiko.

Tetranema (1) mexicanum Benth.

B1. Baum. Staminodium fehlend. Japan.

Paulownia (1) tomentosa (Thbg.) Baill.

2“". Bl.stand nicht cymös, meist einfach.

1““. A. immer 2-fächerig. [Gratioleae.]

A. Alle Stf. in der Kr.röhre entspringend.

A1. A.fächer nicht verschmelzend.

A2. A.fächer \pm weit von einander getrennt Stb. 4 ..

B2. A.fächer sich berührend. Stb. 4 .

A3. K. glockig, nicht kantig.

$\mathrm{B}_{3}$. K. röhrig, kantig.

Lindenbergia (11).

a. Stengel aufrecht. Kr.zipfel zurückgerollt. A. zottig. Pacif. N.-Am., Chile.

$M$. cardinalis L.

b. Stengelgrund \pm niederliegend. Kr.zipfel nicht zurückgerollt.

๙. Pflz. nicht nach Noschus duftend. Bl. gross. B. eiförmig, spitz, gezähnt. Chile.

M. luteus L.

3. Pflz. nach Moschus duftend. Bl. klein. B. kreisrund bis eilänglich, ausgebissen-gezähnt. Columb.

M. moschatus Dougl.

C2. A.fächer sich berührend. Vordere Stb. staminodial.

B. lanzettlich, meist 3-nervig. Gratiola (24) officinalis L.

$B_{1}$. A.fächer am Scheitel verschmelzend. $3-6 \mathrm{~cm}$ hobes Schlammkraut; B. lineal-spatelig oder länglich, in grundständiger Rosette.

Limosella (7) aquatica L.

B. Die beiden vorderen Stb. am Schlunde der Kr. entspringend; an ihrem Grunde Höcker, Zäbne oder fädliche Anhängsel.

A1. K.röhre nicht geflügelt, nur streifig.

$B_{1}$. K.röhre mit $3-5$ hohen Flügelrippen.

Lindernia (26).

2““. A.fächer von vornherein am Scheitel zu einem einzigen halbmondförmigen Fache verschmolzen. [Manuleae.]

A. Bl. in zusammengesetzten, selten einfachen Trauben. Kr.röhre immer gerade.

Manulea (26).

B. Bl. einzeln achselständig oder in einfachen Trauben oder Aehren. Kr.röhre oft gekrümmt. Chaenostoma (62). 2“. Kr. am Grunde der Vorderseite sackartig erweitert oder gespornt. 1““. Kr.röhre lang. [Antirrhineae.]

A. Kr.schlund offen. Pflanze kletternd mittelst B.stielranken. 
B. Kr.schlund durch Einstülpung der Unterlippe geschlossen. ( Maskierte $\mathrm{Bl} . "$ )

A1. Kr.röhre am Grunde (der Unterseite) sackartig erweitert. Antirrhinum (32).

a. Einjährige Kräuter. K.zipfel länger als die Kr. Kapselfächer ungleich. A. Orontium L.

b. Ausdauernde Kräuter. K.zipfel viel kürzer als die Kr. Kapselfächer gleich.

B1. Kr.röhre am Grunde gespornt.

A2. B. fiedernervig.

A3. Bl. in endständigen Trauben und Aehren. Zahnkapsel mit 4-10 Klappen.

Linaria (95).

a. S. kantig, meist höckerig oder grubig, nicht berandet. u. B. durchgehends spiralig. L. genistifolia (L.) Mill.

$\beta$. Untere B. quirlig. L. striata D.C.

b. S. flach, meist glatt, häutig geflügelt.

u. Bl. tragende Achse niederliegend oder aufsteigend. Sterile B. quirlig.

ß. Bl. tragende Achse aufrecht

I. Kr. sehr klein, hellblau. Untere B. quirlig.

II. Kr. gross, gelb.

$L$, arvensis (L.) Desf. L. vulgaris $\mathrm{L}$.

B3. Bl. einzeln achselständig. Deckelkapsel mit 2 Deckeln.

Elatinoides (23).

a. B. eirundlich. Sporn bogig. E. spuria (L.) Wettst.

b. B. eispiessförmig. Sporn gerade. E. Elatine (L.) Wettst.

B2. B. handnervig. Die beiden Kapselporen mit je 3 Klappen.

Cymbalaria (9) muralis Baumg.

2"“. Kr.röhre sehr kurz. [Hemimerideae.]

A. Schlund wenig vertieft.

B. Schlund bauchig ausgehöhlt.

2'. Kr. 2-lippig, Lippen blasig-concav.

Alonsoa (6). Angelonia (24).

[Calceolarieae.]

Calceolaria (134).

a. A.fächer an der Spitze zusammenhängend od. verschmelzend, vom Stf. freiu. abstehend. B. spatelig. Chile. C.plantaginea Sm.

b. A.fächer durch das verbreiterte Connectiv getrennt, vom Stf. abstehend. B. gefiedert. Peru. C. chelidonioides H.B.K.

2. Fr. in 2 einsamige Nüsschen zerfallend. [Selagineae.]

A. Kr. vorn tief eingeschnitten, 4-lappig. - S.-Afr. bis Abyssin.

B. Kr. olme diesen Einschnitt, 5-lappig.

Hebenstreitia (20) dentata L.

II. Die 2 hinteren Kr.lappen (bez. die der Oberlippe) in der Knospe gedeckt. [Rhinanthoideae.]

1. Kr.lappen sämtlich flach u. abstehend od, die 2 hinteren aufrecht.

1'. Kr.lappen sämtlich flach u. abstehend. A.fächer immer getrennt, manchmal ein Fach reduciert. [Gerardieae.] Gerardia (30).

$2^{4}$. Die zwei hinteren Kr.lappen oft aufrecht. A.fächer zuletzt am Scheitel verschmelzend. [Digitaleae.]

A. Kr.röhre kurz.

A1. Stb.4-5. B. spiralig. - W.-Eur. Sibthorpia (6) europaea L.

B1. Stb. 2. 
A. Vorderster Kr.zipfel grösser als die benachbarten. Kapsel loculicid und zugleich septicid, also 4-klappig. B. fast grundständig. - Kärnthen.

Wulfenia (3) carinthiaca Jacq.

B.2. Vorderster Kr.zipfel ebenso gross oder kleiner als die benachbarten, hintere Kr.lappen meist in 1 verwachsen. Kapsel loculicid. Wenigstens die unteren B. gegenständig. Veronica (200).

a. Aehren oder Trauben achselständig.

๙. Klappen schliesslich 2-teilig, eine oder beide vom Mittelsäulchen frei. Stengel und B. kahl.

I. Stengel 4-kantig. B. \pm lanzettlich, spitz, halb stengelumfassend.

V. Anagallis L.

II. Stengel rund. B. \pm elliptisch, stumpf, kurz gestielt.

V. Beccabunga L.

3. Klappen mit dem Mittelsäulchen verbunden bleibend. Stengel und $B$. fast immer \pm behaart.

I. K. 5-teilig, wenigstens bei den untersten $\mathrm{Bl}$.

1. Pflanze niederliegend, nur die blïtentragenden Stengel aufstrebend. B. kurz gestielt. Kapsel schwach ausgerandet.

V. prostrata L.

2. Alle Stengel am Grunde aufstrebend, sonst aufrecht. B. sitzend. Kapsel spitz ausgerandet.

II. K. aller Bl. 4-teilig.

1. Bl.trauben reichblütig.

+ Bl.trauben steif, aufrecht. B. verkehrt eiförmig, keilig.

$V$. officinalis L.

++ Bl.trauben zart,abstehend. B. eiförmig bis lineallanzettlich.

$\uparrow$ Kapsel länger als breit. Stengel zweizeilig behaart.

$\uparrow \uparrow$ Kapsel breiter als lang.

V. Chamaedrys L.

- Stengel ringsum behaart.

B. lang gestielt, eiförmig.

V. montana $\mathrm{L}$.

$\odot \odot$ Stengel und B. kahl. B. sitzend, lineal-lanzettlich. Trauben locker, immer nur in der Achsel eines der gegenständigen $\mathrm{B}$.

V. scutellata L.

2. Bl.trauben 2-bis 4-blüt. B. verkehrt-eiförm., keilig. V. aphylla L.

b. Aehren oder Trauben endständig.

a. Alle B. gegenständig.

I. Kapsel nur leicht seitlich zusammengedrückt. Bl.trauben scharf begrenzt. Tragb. der Bl. deutlich von den Laubb. verschieden.

1. Trauben sehr gedrungen, fast ährig.

+ B. gekerbt-gesägt, an der Spitze ganzrandig. \pm stumpf.

V. spicata L.

++ B. scharf doppelt-gesägt, spitz.

T. longifolia L.

2. Trauben ziemlich locker. B. einfach oder fast doppelt gesägt, spitz.

V. spuria L.

II. Kapsel stark seitlich zusammengedrückt. Bl.trauben nicht scharf abgesetzt, indem die laubartigen Tragb. der Einzelbl. allmählich in Hochb. übergehen.

1. Pflanzen ausdauernd.

+ Pflanzen rasig, ästig. Traube armblütig. 
$\uparrow$ Traube von kraus., drüsenlos. Haaren flaumig. V. saxatilis Scop.

$\uparrow$ Traube von drüsigen Haaren flaumig. $V$. fruticulosa L. ++ Stengel aufrecht.

$\uparrow$ Traube armblütig, kurz.

$\odot$ Grundb. rosettig.

V. bellidioides L.

$\odot \odot$ Grundb. nicht rosettig. Traube drüsenlos-rauhhaarig.

$V$. alpina $\mathrm{L}$.

$\uparrow \uparrow$ Trauben reichblütig.

2. Pflanzen einjährig.

$V$. serpyllifolia L.

+ Alle B. ungeteilt.

() Kapsel gewimpert. B. herz-eiförmig. $\quad V$. arvensis L.

$\odot \odot$ Kapsel kahl. B. verkehrt-eiförmig-länglich, am Grunde keilförmig.

$V$. peregrina L.

++ Mittlere B. fieder- oder fingerteilig. V. verna L.

ß. Bl.tragende B. wechselständig. Pflanzen 1-jährig. S. beckenförmig vertieft.

I. Frkn.fächer vielsamig. B. fiedernervig.

1. Bl.tragende $B$. von den unteren verschieden, die obersten lanzettlich.

+ Mittlere B. fingerförmig 3- bis 5-teilig. $V$. triphyllos L. ++ Mittlere B. ungeteilt.

2. Bl.tragende $B$, von den unteren nicht verschieden.

+ Bl.stiele mehrmals länger als die Tragb.V.Tournefortii Gmel. ++ Bl.stiele wenig länger als die Tragb.

$\uparrow$ Stf. dicht über dem unteren Rande der $\mathrm{Kr}$. eingefügt.

○.zipfel länglich-eiförmig, stumpf. Kapselfächer doppelt so hoch als breit.

$V$. agrestis $\mathrm{L}$.

$\odot \odot$ K.zipfel breit eiförmig, spitz. Kapselfächer kaum höher als breit.

$\uparrow$ Stf. in der Mitte der Kr. eingefügt. $\quad V$. opaca $\mathrm{Fr}$.

II. Frkn.fächer 1- bis 2-samig. B. handnervig, 3- bis 7-lappig.

B. Kr.röhre lang, cylindrisch oder bauchig-glockig.

$V$. hederifolia L.

A1. Kr.röhre cylindrisch. Kleines Kraut. Pyr., Alp.

Erinus (1) alpinus L.

B1. Kr.röhre bauchig-glockig. Hohe Kräuter. Digitalis (22).

a. Mittelzipfel der Unterlippe kürzer als die nicht bauchig erweiterte Röhre.

D. lutea L.

b. Mittelzipfel der Unterlippe kürzer als die weit bauchige Röhre.

a. Kr. gelb.

ß. Kr. rot.

D. ambigua Murr.

D. purpurea L.

c. Mittelzipfel der Unterlippe länger als die weit bauchige Röhre.

๙. K.zipfel abgerundet. S.-O.-Eur. bis Armen. D. ferruginea L.

ß. K.zipfel spitz. Pont. Gbt., Griechld.

I. B.spindel kahl.

II. Bl.spindel wollig behaart.

D. laevigata W. et K.

D. lanata Ehrh.

2. Die 2 hinteren Krb. eine helmartige Oberlippe bildend.[Rhinantheae.] A. Fächer des Frkn. mit je 2 Sa.

A1. Kr.oberlippe schwach concav, 2-lappig. Tozzia (2) alpina L.

$\mathrm{B}_{1}$. Kr.oberlippe helmartig, seitlich zusammengedrückt. 
a. Bl. einzeln achselständig oder in lockeren, einseitswendigen, beblätterten Trauben.

a. Kr.schlund offen. Kr. dunkelgelb. Deckb. grün. M. silvaticum L.

F. Kr.schlund durch die zusammenneigenden Lippen geschlossen. I. Kr. gelblichweiss, vorn dunkler. K. kahl. Deckb. grün.

M. pratense $\mathrm{L}$.

II. Kr. goldgelb. K. behaart. Obere Deckb. blau. MI. nemorosum L. b. Bl. in dichten, endständigen, allseitswendigen Aehren.

a. Deckb. eilanzettlich, flach, am Grunde schwarz punktiert, obere hellpurpurn. $\mathrm{Kr}$. rot. M. arvense $\mathrm{L}$.

f. Deckb. rundlich-herzförm., aufwärts zusammengelegt, grünlichweiss od.rötlich. Kr.gelblich, purpurn überlaufen. M. cristatum L.

B. Frkn.fächer mit zahlreichen Sa.

A1. Kr.oberlippe helmartig, mit zurückgeschlagenem Rande. K. röhrig-glockig, 4-spaltig.

Euphrasia $(50)$ officinalis L.

$\mathrm{B}_{1}$. Kr.oberlippe helmartig, mit geradem Rande.

A2. K. glockig, 4-teil. Kapsel eiförm. B. eiförm. od. lanzettlich. А3. Sa. wenig zahlreich, hängend.

Odontites $(20)$.

a. Kr. rosenrot, am Schlunde purpurn, selten weiss. Connectiv und A.spitze zottig.

a. Stengel ästig. B. eilanzettlich, spitz. Aehre lang, dichtblïtig.

O. serotina (Lam.) Rehb.

3. Stengel meist einfach. B. eilänglich, stumpf. Aehre kurz, locker.

b. Kr. goldgelb. A. kahl.

O. verna (Bell.) Rehb.

$\mathrm{B}_{3}$. Sa. zahlreich, wagerecht abstehend. Bartschia (6) alpina L.

B2. K. seitlich zusammengepresst, bauchig, 4-zähnig. Kapsel rund, scheibenförmig. B. längl. bis lineal. Fistularia (9).

a. Kr.röhre fast gerade, kürzer als der K., immer gleichlang bleibend. Gr. schliesslich am Ende scharf zurückgekriimmt, dadurch N. unter den A. F. Crista galli (L.) Wettst.

b. Kr.röhre gekrümmt, zum Schluss verlängert. Gr. gerade oder schwach gekrümmt.

a. Kr.lippen zusammenneigend u.dadurch d.Schlund schliessend.

I. K. dicht zottig. $F$. Alectorolophus (Poll.) Wettst.

II. K. kahl oder spärlich behaart.

1. Deckb. bleich, scharf gezähnt. Zähne der Krroberlippe oval.

F. major (Ehrh.) Wettst.

2. Deckb. blassgrün, grannenartig gezähnt. Zähne d. Kr.oberlippe schmallänglich od. länglich-linealisch.

$F$. serotina (Schönh.) Wettst.

3. Kr.lippen nicht zusammenneigend. Schlund also offen.

I. Kr.röhre allmählich in die Oberlippe emporgebogen.

$F$. angustifolia (Gmel.) Wettst.

II. Kr.röhre plötzlich in die stark gekrümmte Oberlippe übergehend.

$F$. alpina (Baumg.) Wettst.

C2. K. röhrig oder glockig, 2- bis 5-zähnig, oft rorn aufgeschlitzt. Kapsel meist schief. B. fiederig zerteilt. Pedicularis (250).

a. Helm abgerundet, ungeschnäbelt, ungezähnt.

a. Unterlippe dem Helm nicht anliegend, Schlund also offen. $\mathrm{Kr}$. gelb. Kapsel schief eiförmig. P. foliosa L. 
3. Unterlippe dem \pm sichelförmigen Helm anliegend, Schlund also geschlossen. Kr. schwefelgelb, Rand der Unterlippe blutrot. Kapsel kugelig.

$P$. Sceptrum Carolinum L.

b. Helm \pm sichelförmig, mit sehr kurzem, breitem, unter der Spitze zweizähnigem Schnabel. Kr. rosenrot. Kapsel schief eiförmig.

a. K. 5-zipfelig, Zipfel oben blattartig, gezähnt, am Rande zottig. $P$. silvatica $\mathrm{L}$.

३. K.2-spaltig, mit blattartigen, krausen, eingeschnitten-gezähnten, am Rande kahlen Lappen.

$P$. palustris L.

\section{Utrieulariaceae (Lentibulariaceae) $(5 ; 250)$.}

A. Kr. rachenförmig, mit offenem Schlunde. K. 5-blätterig. B. elliptisch-länglich,ganzrandig, in grundständ.Rosette. Pinguicula(30).

a. Kr. weiss; Sporn kegelig, mehrmals kürzer als die ganze Kr. Kapsel zugespitzt-geschnäbelt.

$P$. alpina $\mathrm{L}$.

b. Kr. blauviolett; Sporn pfriemelig, halb so lang als die ganze $\mathrm{Kr}$. Kapsel eiförmig, am Scheitel rund. $\quad P$. vulgaris L.

B. Kr. maskjert, d. i. Schlund durch einen Gaumen verschlossen. K. 2-teilig. B. fein zerteilt, mit Schläuchen. Utricularia (200). a. B. spiralig gestellt, gleichgestaltet. Fr.stiele zurückgebogen. ๙. B. wiederholt gabelspaltig, mit linealischen, ganzrandigen, ungewimperten Zipfeln. Kr. blassgelb; Unterlippe am Rande zurïckgerollt; Sporn sehr kurz, kegelig.

$U$. minor L.

$\beta$. B. 2- bis 3-fach fiederig-vielteilig, mit haarförmigen, entfernt. borstig-gewimperten Zipfeln. Sporn so lang als Unterlippe.

I. Kr. dottergelb; Oberlippe wenig länger als der 2-lappige Gaumen.

$U$. vulgaris $\mathrm{L}$.

II. Kr. citronengelb; Oberlippe $2-3 \mathrm{mal}$ so lang als der rundliche Gaumen.

$U$. neglecta Lehm.

b. Zweierlei B., zweizeilig gestellt; die einen wiederholt gabelteilig mit linealischen, wimperig gezähnelten Zipfeln, die anderen \pm verkümmert und wenige grosse Schläuche tragend. Kr. schwefelgelb, am Gaumen und der mindestens doppelt so langen Oberlippe purpurn gestreift; Sporn dünnwalzlich, fast so lang als die Unterlippe. Fr.stiele \pm aufrecht. $\quad T$. intermedia Hayne

\section{Orobanchaceae $(12 ; 125)$.}

A. K. glockig, 4- bis 5-zipfelig. Vorn unter dem Frkn. ein beuteloder schuppenförmiges Nectarium. Placenten 2, meist 2-schenkelig. Unterirdische Schuppen dicht dachig, 4-reihig, fleischig, ain Rücken Hohlräume einschliessend

Lathraea (5).

a. Stengel dünn, kurz. Trauben armblütig, büschelig. Bl.gross, violett. W.- u. S.-Eur.

b. Stengel kräftig, lang. Trauben reichblütig. Bl. kleiner; K. hell-, Kr. carminrot.

L. Squamaria L.

B. K. vereintblättrig 2- bis 5-zähnig oder in 2 seitliche, 2-zähnige oder einfache Teile zerspalten. Placenten 4, im oberen Teile des Frkn. oft paarweise verbunden. Unterirdischer Stengel spärlich beschuppt.

Orobanche (90).

a. Unter jeder Bl. 2 Vorb. K. vereintblättrig, 4- bis 5-zähnig. Die 4 Placenten oberwärts paarweise zusammenfliessend. 
a. Stengel meist einfach. Bl, ziemlich gross. K. 5-zähnig.

I. Kr. blau oder blauviolett, fast gerade; Zipfel stumpf, am Rande oft umgerollt. A. wollig behaart. N. hochgelb. Auf Artemisia campestris.

$O$. arenaria Borkh.

II. Kr. lila, dunkler geadert; Zipfel spitz, flach. A. fast kahl. N. blassgelb. Auf Achillea Millefolium. O. coerulea Vill.

3. Stengel meist ästig. Bl. klein. K. 4-zähnig. Kr. gelblich, vorn blauviolett überlaufen. Auf Hanf, Tabak etc. O. ramosa L.

b. Vorb. fehlend. K. in 2 seitliche, 1- oder 2-zähnige Hälften gespalten. Die 4 Placenten durchaus getrennt.

๑. Stb. nahe am Grunde der Kr.röhre eingefügt. Gr. drüsenhaarig. Auf Galium.

O. caryophyllacea Sm.

3. Stb. über dem unteren Drittel der Kr. angeheftet. Gr. kahl.

I. N. wachsgelb. Stf. in der unteren Hälfte dichtzottig. Kr. gelblich, rötlich überlaufen. Auf Medicago. O. rubens Wallr.

II. N. purpurn oder lila. Stf. spärlich behaart. Kr. weisslich, lila oder rötlich geadert. Auf Trifolium. O. minor Sutton

\section{Gesneriaceae $(86 ; 1000)$.}

A. allermeist zusammenneigend oder zusammenhängend.

I. Frkn. frei, oberständig. [Cyrtandroideae.]

1. Kapsel wandspaltig-zweiklappig. [Ramondieae.]

A. Blkr. radförmig oder ausgebreitet-glockig. Androeceum isomer. - Pyren.

Ramondia (4) Myconi (L.) F. Schultz

B. Blkr. mit oben trichterig erweiterter Röhre u. 2-lippig-ち-fünfzipfeligem Saume. Stb. 4, didynamisch. Balkan.

Haberlea (1) rhodopensis Friv.

2. Kapsel fachspaltig, 1- oder 2-klappig.

1'. Kapsel nicht gedreht. Didymocarpeae.]-2 Stb.Roettlera(100). 2'. Kapsel gedreht. [Streptocarpeae.] - 2 Stb. Streptocarpus (30).

a. Alle B. in grundständiger Rosette. Kapld. S. Rhexii Lindl.

b. Blühende Pflanze mit einem einzigen, grossen Laubb. (Keimb.) Kapld.

S. polyanthus Hook.

3. Fr. nicht aufspringend, \pm beerenartig. Nur die 2 vorderen Stb. fruchtbar, ausserdem 2-3 Staminodien. [Cyrtandreae.]

Cyrtandra (180).

II. Frkn. teilweis oder ganz unterständig. [Gesnerioideae.]

1. Discus ringförmig, Ring bisweilen 5-lappig.

14. B. gegenständig oder wirtelig. [Gloxinieae.]

A. Bl. in endständigen Trauben. Tragb. spiralig, sehr klein.

Smithiantha (6).

B. Bl. einzeln oder gebüschelt in den Achseln gegenständiger B. A. Kb. ziemlich breit. Blkr.röhre weitglockig. Gloxinia (6). Bı. Kb. meist schmal. Blkr. cylindrisch-röhrig. Achimenes(25). 2'. B. spiralig. [Gesnerieae.

Gesneria (25).

2. Discus aus 5 (oft zum Teil abortierten) Drüsen bestehend.

1'. Kräuter mit stark verdickten, knolligen Rhizomen, ohne Ausläufer. [Sinningieae.]

Sinningia (30).

'2. Kräuter mit beschuppten Ausläufern oder Sträucher, ohne Rhizomknollen. [Kohlerieae.]

Kohleria (40). 
300 Bignoniac. - Martyniac. - Globulariac. - Acanthac. - Plantagivac.

\section{Bignoniaceae $(100 ; 500)$.}

A. B. gefiedert. 4 didyname Stb. Discus ring- bis becherförmig, A1. K.zähne langpfriemelig. Fr. balgkapselartig. $\odot$ oder $\odot$ Kraut. Incarvillea (5). B1. K.zähne kurz. Fr. 2-klappige, fachspaltige Kapsel. Strauch. - N.-Am.

Tecoma (23) radicans $\mathrm{L}$.

B. Fliederblättriger Baum. 2 Stb. u. 3 kurze Staminodien. Discus undeutlich. - Südatl. N.-Am. Catalpa (6) syringifolia Sims

\section{Martyniaceae $(3 ; 9)$.}

Bl. in endständiger Traube. Kr.röhre schiefglockig-fingerhutförmig. 4 fruchtbare Stb. $\quad$ Proboscidea (6).

a. B. ganzrandig. K. vereintblättrig, vorn tief geschlitzt. Blkr. weiss oder rötlich mit purpurnen oder gelben Flecken. Arizona u. Texas bis Illinois. P. Jussieui Steud. (Martynia proboscidea Glox.)

b. B. fast gezähnt, samt Stengel flaum-drüsenhaarig. K. freiblättrig. Blkr. aussen grüngelb, innen orange, rotgezeichnet. Süd-Brasilien, Paraguay u. Uruguay. P.lutea (Lindl.) Stapf (Marlynia lutea Lindl.)

\section{Globulariaceae $(3 ; 20)$ (Globularia, 17).}

a. Stengel krautig, aufrecht, durchaus beblättert. Grundb. spatelig, ausgerandet, oft mit Spitzchen in der Ausrandung. G. vulgaris L.

b. Stengel holzig, niederliegend, fast blattlos. Grundb. \pm verkehrteiherzförmig. G. cordifolia L.

\section{Acanthaceae $(173 ; 2000)$.}

1. Knospendeckung der Kr. gedreht.

1. Kr.saum mit 5 ziemlich gleichen, flachen Zipfeln. Furchenpollen. Frkn.fächer mit je 2 Sa. Kapsel geschnäbelt. Jaculatoren papillenförmig. S. \pm kugelig. [Thunbergieae.] - W.-Afr.

Thunbergia (72) alata Hook.

2‘. Kr.saum \pm 2 -lippig. Wabenpollen. Frkn.fächer mit je $2-\infty$ Sa. Kapsel nicht geschnäbelt. Jaculatoren hakenförmig. S. flach. [Ruellieae.] Ruellia (200).

2. Knospendeckung der Kr. aufsteigend. Kapsel nicht geschnäbelt. Jaculatoren hakenförmig.

1`. Kr.saum fast aktinomorph oder \pm 2-lippig. [Justicieae.]

A. Kr.saum mit 5 flachen Zipfeln. 4 Stb. A.fächer einfach spitz oder stumpf. Rahmenpollen. Asystasia (20).

B. Kr.saum mit 4 fast gleichen Zipfeln od. 2-lippig. $2 \mathrm{Stb}$. Unteres A.fach meist mit Spitzchen oder langem Sporn. Knöt. chenpollen. Justicia (250).

2'. Kr.saum durch einen Schlitz an der Hinterseite einlippig. 4 Stb. A. 1-fächerig. Spaltenpollen. [Acantheae.] Acanthus (20).

a. B. fiederspalt.; Zipfel eckiggezähnt,unbedornt. Mmght. A.mollis L.

b. B. fiederspaltig; Zipfel 3-eckig-zugespitzt, tief gezähnt, Zähne in weissliche Dornen auslaufend. Oestl. Mmgbt. A. spinosus L.

\section{Plantaginaceae $(3 ; 200)$.}

A. Frkn. 2- (bez. auch falsch 4-) fächerig. Fr. eine Deckelkapsel. Bl. meist zwitterig.

a. Stengel ästig, beblättert. B. gegenständig. P. arenaria W.K. 
b. Stengel einfach, unbeblättert. B. grundständig.

a. B. ungeteilt und ganzrandig.

I. Kr.röhre kahl.

1. B. eiförmig oder elliptisch. Schaft stielrund.

$+\mathrm{B}$. langgestielt, breiteiförmig, 3- bis 5-nervig, kahl oder schwach behaart. Schaft wenig länger als die B. Deckb. stumpflich. Kr. bräunlich. Stf. weisslich. P. major I.

++ B. kurzgestielt, elliptisch, 7- bis 9-nervig, kurzhaarig. Schaft mehrmals länger als die B. Deckb. spitzlich. Kr. durchscheinend. Stf. lila.

$P$. media L.

2. B. lanzettlich, 3- bis 5-nervig.

+ Schaft stielrund. Deckb. breit verkehrt-eiförmig, ganz stumpf, am Ende bärtig. P. montana Lam.

++ Schaft gefurcht. Deckb. eiförm., zugespitzt. P. lanceolata L.

II. Kr.röhre behaart. B. 3-nervig.

1. Wurzelstock kurz. B. laubig, Seitennerven dem Rande näher als der Nittelrippe. Aehre 2-6 mal so lang als dick.

$P$. alpina $\mathrm{L}$.

2. Wurzelstock lang. B. fleischig, Seitennerven in der Mitte zwischen Rand und Mittelrippe. Aehre $8-15$ mal so lang als dick.

$P$. maritima $\mathrm{L}$.

अ. B. fiederzähnig od. fiederspaltig. Kr.röhre behaart. P. Coronopus I

B. Frkn. 1-fächerig, 1-samig. Fr. ein Nüsschen. Bl. 1-geschlechtig, monöcisch.

Littorella (1) lacustris L.

\section{Rubiaceae $(346 ; 4500)$.}

I. Frkn.fächer mit je 2- $\infty$ Sa. [Cinchonoideae.] Bouvardia (30).

II. Frkn.fächer mit je 1 Sa. [Coffeoideae.] Sa. aufrecht, Mikropyle und Stämmchen des E. unten. [Psychotriinae.]

1. Blkr. gedreht. [Ixoreae.]

A. Bl. mit einfachem oder doppeltem Calyculus, 5- oder mehrgliederig. - Afrikan. Steppengebiet. Coffea (25) arabica L.

B. Bl. ohne Calyculus, 4-gliederig.

2. Blkr. klappig.

1'. Sa. am Grunde d. Frkn. stehend. Makarones. Phyllis (1) Nobla L.

2'. Sa. an der Scheidewand befestigt.

1“. Nebenb. zerschlitzt. [Spermacoceae.] - S.-Am.

2". Nebenb. laubig. [Galieae.

Richardsonia (9) brasiliensis Gomez

A. 6 verhältnismässig grosse, 3-eckig-lanzettliche, am Grunde verwachsene K.zipfel.

B. K.zipfel winzig, frei oder fehlend.

A1. Kr. radförmig.

A2. Fr. fleischig, beerenartig. Kr. und Androeceum 5-teilig.

- S.-Eur.

Rubia (7) tinctorum L.

B. Fr. trocken, nüsschenartig. Kr. und Androeceum t-teilig. A3. Bl. unter sich frei.

a. Ausdauernde Kräuter.

Galium (250).

a. Stengel ohne rückwärts gekrümmte Stacheln.

I. An den Knoten je 6-10 einnervige, schmale B. Stengel glatt, kahl.

1. Kr.zipfel \pm langspitzig. 
+ Bl. weiss.

- Kr.zipf.haarspitzig. Wurzelstock nicht knollig.G.MollugoL.

$\odot \odot$ Kr.zipfel kurz bespitzt. Wurzelstock fast knollig verdickt.

++ Bl. blassgelb.

G. silvaticum L.

+++ Bl. goldgelb.

2. Kr.zipfel einfach spitz. Kr. weiss.

G. ochroleucum Wolff

G. verum $\mathrm{L}$.

+ Fr. mit wenigen schwachen Knötchen besetzt. B meist 8-ständig.

G. silvestre Poll.

++ Fr. dicht körnig-rauh. B. meist 6-ständig. G. saxatile L.

II. An den Knoten je 4 meist dreinervige, breitere B. Stengel öfters behaart od. rauh, aber auch glatt und kahl. Kr. weiss.

1. Bl. \&, in endständigen Rispen. Fr.stiele gerade. Kr. weiss.

+ Stengel steif aufrecht. B. lanzettlich, stumpf, ohne Stachelspitze. Fr. kahl oder filzig.

G. boreale L.

++ Stengel schlaff niederliegend. B. oval, kurz stachelspitzig. Fr. borstig-steifhaarig. G. rotundifolium L.

2. Bl. polygam-monöcisch (die Mittelbl. ㅇ), in achselständigen Bl.ständen. Fr.stiel zurückgekrümmt. Kr. gelb od. grünlich. + Stengel rauhhaarig. Bl.stiele mit Deckb. G.Cruciata(L.) Scop. + + Stengel kahl. Bl.stiele deckblattlos. G. vernum Scop.

$\beta$. Stengel sehr schlaff, durch hakig rückwärts gekrümmte Stacheln rauh.

I. B. zu 6-8, stachelspitzig, am Rande und dem Rücken des Hauptnerven rückwärts rauh. G. uliginosum L.

II. B. zu 4, oben abgerundet, nur am Rande rïckwärts rauh.

b. Einjährige Kräuter. B. zu 6-8.

G. palustre L.

a. Fr.stiele aufrecht. Stengel schlaff, rauh.

I. Bl. weiss.

II. Bl. rötlich.

G. Aparine L.

G. parisiense L.

$\beta$. Fr.stiele zurückgekrümmt. Bl, weisslich oder gelblich-weiss. B. stachelspitzig.

I. Bl. $\$$, in zuletzt endständigen Bl.ständen. B. rückwärts rauh.

G. tricorne With.

II. Bl. polygam-monöcisch, in blattwickelständigen Bl.ständen.

B. aufwärts stachelig rauh.

G. saccharatum All.

B3. Je $3 \mathrm{Bl}$, eine mittlere 4 -gliederige o und 2 seitliche 3-gliederige $\sigma$, breit mit einander verbunden. Fr. von dem verbreiterten, stachelig gewimperten Stiele umfasst. Mmgbt.

Vaillantia (2) hispida L.

$\mathrm{B}_{1}$. Kr. trichterig, glockig, oder präsentiertellerförmig.

A2. Gr.äste gleichlang.

a. Ausdauernde Kräuter. N. kugelig.

Asperula (80).

๑. Kr. kurz glockenförmig, weiss. B. lineal bis lanzettlich.

I. Fr. kahl oder zerstreut-kurzhaarig, glatt oder körnig.

1. B. meist 8-ständig.

+ B. lanzettlich, am Kiele und Rande rauh. Fr. körnig.

A. Aparine M. B.

++ B. schmal-lineal, am Rande umgerollt. Fr. glatt. A. glauca (L.) Bess. 
2. Untere B. 6-, obere 4-ständig, schmallineal. A, tinctoria L. II. Fr. mit steifen, hakigen Borsten dicht besetzt. B. 6. bis 8-ständig, lanzettlich.

$\beta$. Kr. trichterig. B. 4-ständig.

I. Kr. rosa oder fleischrot. B. lineal. A. cynanchica L.

II. Kr. weiss. B. eiförmig-länglich, zugespitzt. A. taurina L.

b. Einjährige Kräuter mit kopfigen Bl.ständen. B.6-od. 8-ständig. lineal-lanzettlich, stumpf. Bl. blau. N. keulig. A. arvensis L. B2. Gr.äste ungleichlang.

Crucianella (26).

\section{Caprifoliaceae $(10 ; 270)$.}

1. A. extrors. B. fiederig. Krr.radförm. [Sambuceae.] Sambucus (20). a. Bl.stand straussartig, meist 3-teilig. Beeren rot. Kr. dachziegelig.

b. Bl.stand schirmförmig. Beeren schwarz.

a. Bl.stand gewöhnlich 3-strahlig. Kr. klappig.

3. Bl.stand meist 5-strahlig. Kr. dachziegelig.

I. Meist $5 \mathrm{Frb} .7(5-11)$ B.chen. N.-Am. S. canadensis L.

II. Meist 3 Frb. $5(3-7)$ B.chen.

2. A. intrors. B. ungeteilt, höchstens gelappt.

1. Frkn.fächer wenigstens teilweise mit mehreren Sa. Kr. glockig oder trichterig.

1“. Frkn.2-bis 5-(-8-) fächerig, alle Fächer mehreiig. [Lonicereae.]

A. Fr. eine 2-fächerige Kapsel. Bl. strahlig. Diervilla (8).

a. Blkr. weiss bis karminrot, mit 5 gleichen Abschnitten, innen über der kinfügungsstelle d. Stb. kahl. Gr. kahl.

a. K.zipfel lanzettlich, meist halbverwachsen. S. ungeflügelt 3-kantig. N.-China. D. florida (Bge.) Sieb. et Zucc.

F. K.zipfel linealisch, ganz getrennt. S. mit einseitigem, quergeripptem Flügelrand. Japan. D. japonica (Thbg.) D.C.

b. Blkr. gelb, fast 2-lippig, die 3 oberen Einschnitte viel tiefer, Unterlippe oberhalb der Einfügungsstelle der Stb. bärtig. Gr. unterwärts behaart. Nördl. N.-Am. D. trifida Mnch.

B. Fr. eine Beere. Bl. \pm zygomorph. Lonicera (100).

a. Aufrechte Sträucher. Kr.röhre in der Regel nicht länger als der Saum; dieser regelmässig 5-zipfelig oder 2-lippig. Beeren oft \pm verwachsen. Bl. gepaart an gemeinsamen, blattwinkelständigen Stielen.

a. Kr. nahezu strahlig.

I. Beeren nur teilweis verwachsen. Sib., China. L. hispida Pall.

II. Beeren ganz vollständig verwachsen, schwarz. Kr. gelblich. Pyren., Alp., N.-Eur., N.-As., N.-Am. L. coerulea L.

३. Kr. 2-lippig.

I. Frkn. getrennt oder nur am Grunde verwachsen.

1. Deckb. gross, breit eirund. Bl. gelblich. Beeren rot oder schwarz. Pac. N.-Am. L. involucrata Banks

2. Deckb. klein, lineal-lanzettlich bis pfriemelig.

+ Bl.standstiele 3-4 mal so lang als die Bl., kahl. Kr. rötlich oder weisslich. Beeren schwarz. L. nigra L. ++ Bl.standstiele kaum länger als die $\mathrm{Bl}$.

(- B. herzeiförmig, stumpf, kahl. Krr. rosa oder weiss. Beeren gelblich oder rot.

L. tatarica L. 
$\odot \odot$ B. eiförmig oder elliptisch, spitzlich, weichbaarig. Kr. gelblichweiss. Beeren scharlachrot. L. Xylosteum L.

II. Frkn. ganz oder wenigstens bis über die Mitte verwachsen. Kr. rötlich. Beeren rot.

L. alpigena $\mathrm{L}$.

b. Windende Sträucher. Kr.röhre deutlich länger als der 2lippige Saum.

$\alpha$. Bl. gepaart an gemeinsamen Stielen, diese zu Büscheln oder Köpfchen vereinigt. Beeren getrennt, schwarz.

I. Deckb. gross, blattartig. Kr. aussen rot, innen gelblichweiss. China, Japan.

L. japonica Thbg.

II. Deckb. klein. Kr. weiss, dann gelblich. China. İ. confusa D.Cे.

ß. Bl. nicht gepaart, in köpfchenartigen Büscheln. Beeren getrennt, rot oder orange.

I. Blkr.röhre innen behaart, Saum fast strahlig. Oberste B.paare verwachsen. Südatl. N.-Am.

L. sempervirens $\mathrm{L}$.

II. Blkr.röhre innen kahl.

1. B. sämtlich getrennt. Bl. in gestielten Köpfen. K. behaart. L. Periclymenum L.

2. Obere B. zusammengewachsen. Bl. in einem endständigen, sitzenden Köpfchen, kahl.

L. Caprifolium L.

2". Frkn. 3- oder 4-fächerig, 2 Fächer mehrreiig, 1 oder 2 eineiig. [Linnaeeae.]

A. Stb. gleichlang. Frkn. 4-fächerig. - N.-Am., Mexiko.

Symphoricarpus (8) racemosus Michx.

B. 4 Stb., didynamisch. Frkn. 3-fäch. Limnaea (12) borealis Gronov.

2`. Frkn. 1-bis 5-fächerig; Fächer immer 1-eiig. Kr. meist radförmig, selten mit verlängerter Röhre. [Viburneae.] Viburnum (100).

a. Fr. unvollständig 2- bis 3-füch. Oreinotinus. Solenotinus. Microtinus.

b. Fr. streng 1-fächerig.

a. Steinfr. trocken. Endocarp und S. eiförmig. B. lederartig, immergrün. Mmgbt.

3. Steinfr. saftig. Endocarp und S. zusammengedrückt. B. 1-jährig.

I. B. ungeteilt, unterseits graufilzig. Fr. erst rot, dann schwarz. Endocarp 4- bis 5-rippig. Mmgbt. V. Lantana L.

II. B. 3- bis 5 lappig, beiderseits grün. Fr. rot. Endocarp nicht gerippt, höchstens undeutlich 1-rippig. $V$. Opulus L.

\section{Valerianaceae $(8 ; 220)$.}

A. Fr. meist 3-fächerig. Frk. nie pappusartig. Kräuter mit meist ungeteilten, ganzrandigen oder gezähnten $\mathrm{B}$.

A1. 3 Stb.

Valerianella (40).

a. K.saum strahlig, 6-zähnig, breitbecherig; die Zähne in hakig nach aussen gekrümmte Grannen endigend. Mmgbt.

V. coronata D.C.

b. K.saum zygomorph, schief abgestutzt oder gezähnt.

a. Fr. länglich, fast 4-seitig.

V. carinata Loisl.

3. Fr. eiförmig oder eikegelig. K.saum halb so breit als die Fr.

$V$. dentata Poll.

$\gamma$. Fr. kugelig-eiförm. K.saum ${ }^{1 / 3}$ so breit als die Fr. V.rimosa Bast.

c. K.saum fast fehlend.

$V$. olitoria Mönch 
B1. 2 Stb. Mmgbt.

Fedia (1) Cornucopiae D.C.

B. Fr. meist 1-fächerig. Frk. pappusartig. B. fiederteilig.

A1. 3 Stb. Kr. nicht gespornt, aber am Grunde oft mit kurzem Höcker.

Valeriana (150).

a. Grundachse mit einigen gestreckten Gliedern. B. etwas fleischig verdickt, allmählich in den Stiel übergehend, meist mit gekrümmten Nerven.

๙. Mit Ausläufern. $\sigma^{\top} \mathrm{Bl}$. grösser als

I. Cntere B. eiförmig, spitzlich, mittlere leierfürmig, obere meist 3-paarig-fiederteilig.

$V$. dioica $\mathrm{L}$.

II. Lntere B. am Grunde herzförmig, oben abgerundet, mittlere meist ungeteilt, oberste oft 3-spaltig. $\quad V$. polygama Bess.

. Ohne Ausläufer. Alle Bl. gleichförmig. Halbfr. auf der einen Seite zwischen den Nerven 2-reihig behaart. B. länglich-lanzettlich bis 4-paarig-fiederteilig. Ural, Kauk., Armen. V. Phu L.

b. Grundachse meist mit lauter verkürzten Gliedern. B. meist fiederteilig, deutlich gestielt, krautig, mit kaum gekrïmmten Nerven. B.chen länglich-lanzettlich.

$T$. officinalis $\mathrm{L}$.

c. Grundachse aus abwechselnd verlängerten und verkürzten Gliedern gebildet. Unterste B. rundlich, stengelständige 3-zählig, sonst B. wie bei b.

$\mathrm{B}_{\text {i. }} 1 \mathrm{Stb}$. $\mathrm{Kr}$. gespornt.

$V$. tripteris L.

Centranthus (12).

a. CKräuter. Sporn der Kir. kürzer als der Frkn. Stengelb. fiederteilig. Grundb. etwas gezähnt oder, wenn ganzrandig, fast so breit wie lang.

ж. B]. weiss. Obere B. fiederspaltig. S.-Eur. C. Calcitrapa Dufi.

3. Bl. sattrosa. Obere B. am (trunde \pm tief eingeschnitten. Span.

C. macrosiphon Boiss.

b. Stauden. Sporn der Krr. länger als Frkn. B. ganzrandig, sitzend, nach oben zugespitzt, länger als breit. Mmgbt. C. ruber D.C.

\section{Dipsacaceae $(10 ; 150)$.}

1. Bl. in Scheinähren, nach Art mancher Labiatenbl.stände. Morina (9).

2. Bl. in Küpfchen, mit einfachem Aussenkelch.

A. B. der Hülle vielreihig, dachziegelig, meist kleiner als die Spreub., gewöhnlich starr.

a. Stengel fast sammethaarig. B.chen lanzettlich. Alpen. C. alpina (L.) Schrad.

b. Stengelgrund und B.stiele rückwärts zottig. B.chen oval-lanzettlich. Oestl. MImgbt. u. Steppengbt. C. tatarica (Gmel.) Schrad. B. B. der Hülle meist 1- bis 2-reihig, selten starr und dann immer 1-reihig und grösser als die Spreub.

A1. Spreub. (meist auch Hïllb.) starr, scharf zugespitzt.

\section{Dipsacus (12).}

a. B. gestielt, nicht verwachsen, an der Spitze des B.stieles geöhrt.

b. B. sitzend, die Stengelb. am Grunde breit verwachsen.

๘. Spreub. so lang als die Bl., steif, länglich; Spitze zurückgekrümmt. S.-W.-Eur.

ア. Spreub. länger als die Bl., biegsam, gerade. 
I. Hüllb. lanzettlich pfriemelig, weit abstehend. B. borstig gewimpert, die untersten lappig-gekerbt, die übrigen fiederspaltig.

D. laciniatus L.

II. Hüllb. lineal-pfriemelig, bogig. B. sitzend, gekerbt-gesägt, am Rande kahl oder zerstreut stachelig, meist ungeteilt.

D. silvester Mill.

B. Spreub. krautig od. durch Haare ersetzt. Hüllb. nicht verwachsen.

A2. Spreub. fast so gross als die Bl.

Succisa (4).

a. Wurzelstock abgebissen. Köpfchen erst halbkugelig, dann kugelig.

S. pratensis Mönch

b. Kriechend. Fr.köpfchen eilänglich. S. australis (Wulf.) Rchb.

B2. Spreub. klein oder fehlend.

A 3. Aussenk. ohne deutliche Furchen; Rippen wenig hervortretend; Saum höchstens durch Zähne angedeutet. Knautia(13).

a. Stengel kurz-grau- und lang-steifhaarig. Nittlere B. \pm fiederspaltig.

$K$. arvensis (L.) Coult.

b. Stengel ziemlich kahl, am Grunde mit steifen, zwiebeligen, oberwärts mit kurzen, weichen und längeren, steifen Haaren. B. breiteiförmig bis elliptisch-lanzettlich, gekerbt, ungeteilt oder am Grunde eingeschnitten. $K$. silvatica (I.) Dub.

B3. Aussenk. deutlich 8-furchig oder 8-rippig; Saum desselben tellerförmig ausgebreitet.

A4. K. 10- oder mehrstrahlig, oft hinfällig.

As. Aussenk. der ganzen Länge nach 8-furchig.

Pterocephalus (20).

B5. Aussenk. nur im oberen Teil 8-furchig. Oestl. Mmgbt.

Callistemma (1) bracchiatum (Sibth.) Boiss.

B. K. 5-strahlig, ausdauernd.

Scabiosa (50).

a. Aussenk. oben 8-furchig. B. lineal-ganzrandig, silberseidenhaarig. S.-Eur.

S. graminifolia L.

b. Aussenk. der ganzen Länge nach 8-furchig; Saum häutig.

๙. K.borsten doppelt so lang als der Saum des Aussenkelches, gelblichweiss. Die untersten B. lanzettlich, spitz, ganzrandig, die übrigen fiederspaltig.

S. suavcolens Desf.

F. K.borsten 3-4 mal so lang als der Saum des Aussenk. Unterste B. ungeteilt, gekerbt od. leierförmig, obere fiederteilig.

I. K.borsten schwarzbraun. Kr. blauviolett. Fr.köpfe kugelig. B. fein behaart. S. Columbaria L.

II. K.borsten anfangs fuchsrot mit bleicherem Grunde. Kr. hellgelb. Fr.köpfe \pm eiförmig. Pflanze meist stärker behant. S. ochroleuca I.

c. Aussenk. d. ganzen Längenach 8-rippig. Mmgbt. S.maritima T.

\section{Cucurbitaceae $(87 ; 650)$.}

I. A.fächer nicht zu einem kreisförmigen Ringe verschmolzen.

1. Alle $5 \mathrm{Stb}$. frei [Fcrilleae.], aber zweimal 2 einander zugeneigt. - C.-As.

Thladiantha (8) dubia Bge.

2. Von den 5 Stb. zweimal $2 \pm$ vollständig verwachsen.

1'. A.fächer gerade oder nur wenig gebogen. [Mclothrieac.] Trop. O.-Afr., Maskarenen.

Telfairia (2) pedata Hook. 
2`. A.fächer $L$ - oder ¿s-fürmig gekrïmmt. Cucurbiteac.

1“. Kr. radförmig.

1i“. Blb. ganzrandig. '[Cucumerinae.]

A. K.röhre der Bl. kurz. A. frei od. locker zusammenhängend.

A1. Stb. dem K.schlunde angeheftet.

A. K. ohne Schuppen im Grunde. - S.-W.-Afr.

Acanthosicyos (2) horrida Welw.

B. Im Grunde des K. 2-3 Schuppen. - Palaeotrop.

Momordica (25) Charantia L.

B1. Stb. der K.röhre eingefügt.

A2. 万 Bl. traubig.

A3. Fr. saftig, nicht mit Deckel aufspringend. Ranken einfach oder fehlend.

At. Ranken einfach. $+\mathrm{Bl}$. traubig oder gebüschelt.

Bryonia (8).

a. Bl. monöcisch. K. der $O \mathrm{Bl}$. so lang als die $\mathrm{Kr}$. N. kahl. Beere schwarz. B. alba L.

b. Bl. diöcisch. K. der $\mathrm{Bl}$. halb so lang als die $\mathrm{Kr}$. N. rauhhaarig. Beere kirschrot. B. dioica Jacq.

Bt. Ranken fehlend. $O$ Bl. einzeln. Nmgbt.

Ecballium (1) Elaterium (L.) A. Rich.

B3. Fr. trocken, sich mit Deckel öffnend. Ranken 2-bis vielspaltig.

Luffa (7).

a. Fr.nicht scharfkantig. Palaeotrop. L.cylindrica (L.) Röm.

b. Fr. scharfkantig. Trop. As. L. acutangula (L.) Roxb. $\mathrm{B}_{2}$. $\mathrm{O}^{\mathrm{B}} \mathrm{B}$. einzeln oder gebüschelt.

A3. K.zipfel pfriemelig, ganz.

At. Connectiv nicht verlängert. Kanken 2- bis 3-spaltig.

Citrullus (4).

a. Pflze. ausdauernd. Palaeotrop. C.Colocynthis (L.) Schrad.

b. Pflanze 1-jährig. S.-Afr. C. vulgaris Schrad.

$B_{*}$. Connectiv über die $A$. verlängert. Ranken einfach. S. nicht berandet.

Cueumis (26).

a. Fr. glatt, kahl oder behaart. Palaeotrop. C. MLelo L.

b. Fr. stachelig oder mit Emergenzen besetzt.

ж. Pflanze ausdauernd. Fr. wallnussgross, oft igelstachelig.Afrik.-arab.Steppengebiet. C.prophetarum L.

ङ. Pflanze einjährig.

I. Fr. langgestreckt. O.-Ind. C. sativus L.

II. Fr. kugelig, von Taubeneigrösse. Trop. Amer.

C. Anguria L.

B3. K.abschnitte blattartig, gesägt, zurückgekrimmt. Trop. As.

B. K.röhre der $\mathrm{Bl}$. verlängert, $\mathrm{K}$. glockig od. trichteriy. Blb. u. A. frei. Palaeotrop. Lagenaria (1) vulgaits Ser. 2“". Blb. haarförmig zerschlitzt. [Trichosanthinae.] - Stb. durch Vereinigung scheinbar nur 3. Trichosanthes (42).

a. B. ungeteilt. O.-Ind.

b. B. gelappt. O.-Ind. T. nervifolia L. T. Anguina L. 2“. Kr. glockig. [Cucurbitinae.] - S. berandet. Cucurbita (10). a. Pflanze einjährig. 
\%. K.röhre fast fehlend, B.weich. Trop. Amer. C.moschata Duch.

ß. K.röhre glockig. B. steif.
I. B.lappen abgerundet. Trop. Amer.
C. maxima Duch.
II. B.lappen spitz. Trop. Amer.
b. Pflanze ausdauernd. W.-Ind.
C. Pepo L.

2. Sämtliche Stf. zu einer Säule vereinigt. [Sicyodcae.]

A. A. frei. Fr. fleischig. Trop. Amer. Sechim (1) cdule $\mathrm{Sw}$.

B. A. vereinigt. Fr. lederartig oder fast holzig. Sicyos (30).

a. Fr. weichhaarig. B. 5-eckig, tief herzförmig. N.Am.

S. angulatus $\mathrm{L}$.

b. Fr. zuletzt glatt oder warzig. B. 5-lappig. Chile, Peru.

S. bryoniifolius Moris.

II. A.fächer zu einem Ringe verschmolzen. [Cyclanthereae.]

Cyclanthera (30).

a. B. ganz oder gelappt. Trop.-andin. S.-Am.

C. cxplodens Naud.

b. B. zusammengesetzt. Mexiko, Centr.-Am. C. pedata Schrad.

Campanulaceace $(59 ; 1000)$.

I. Bl. actinomorph. Kr. klappig. [Campanuloideae-Campanulcac.] I'. A. frei.

1. Frb. vor den Kb. und Stb., wenn mit diesen gleichzählig.

1'. Fr. eine Porenkapsel.

A. Epigyner Discus fehlend oder flach.

A1. Bl. normal 5-gliederig.

A2. Blb. schmal, frei oder an der Spitze zusammenhängend.

Phyteuma (40).

a. Bl.stand rispig, die Partialbl.stände meist kopfig. Ungarn bis Kaukas.

P. canescens IV.K.

b. Bl. in dichten Aehren oder Köpfchen.

\%. Bl.stand eirund, zuletzt fast walzlich.

I. Kr. schmutzig-weiss, an der Spitze grünlich, selten schwach bläulich. Untere B. doppelt-gekerbt-gesägt. $P$. spicatum L.

II. Kr. dunkelblau oder schwarzviolett. Untere B. einfach- und ungleich-gekerbt.

1. nigrum Schmidt

3. Bl.stand kugelig oder nach dem Verblühen oval. Bl. blau oder violett.

I. Deckb. lineal, meist viel länger als das vielblütige Köpfchen. Alp.

I. Scheuchzeri All.

II. Deckb. rundlich-eiförmig bis eilanzettlich.P'orbiculare L.

B., Kr. glocken-, seltener rad- oder trichterförmig.

A3. Gr. bedentend lïnger als die $\mathrm{Kr}$. - Westl. Mmgbt.

Trachelium (7) coeruleum L.

B3. Gr. etwa so lang als die Kr.

A4. Kapsel rundlich, seitlich mit 3-5 Klappen od. Deckelchen aufspringend.

a. Kapsel nahe am Grunde aufspringend.

\%. Kapsel 5-fächerig. K.buchten mit Anhängseln. S.-Eur.

ß. Kapsel 3-fücherig.

C. Medium L.

I. Bl. \pm lang gestielt, zuweilen einzeln endständig. 
1. K.buchten mit Anhängseln. Bl.stand traubig oder rispig. Stattliche Kräuter.

+ K.zipfel lanzettlich-pfriemelig.

(.) Kurzhaarig. Blkr. an der Spitze kahl. C. sibirica L. $\bigodot \odot$ Wollig-zottig. Blkr. an der Spitze spärlich behaart, kaum so lang als K.; K.anhängsel kurz. C. alpina Jacq. ++ K.zipfel eilanzettlich; K.anhängsel so lang als Krr.röhre.

Blkr. an der Spitze dichtbärtig, dreimal so lang als $K$. Pflanze rauhhaarig. $\quad C$. barbata $\mathrm{L}$.

2. K,buchten ohne Anhängsel.

+ Bl.stand reichblütig-traubig oder rispig. Stattliche Kräuter.

(.) Bl. abstehend oder aufrecht. K.zipfel eilanzettlich.

1 B. u. der scharfkantige Stengel steifhaarig. C. Trachelium L.

I1 Stengel stumpf kantig, kahl. B. weichhaarig. C. latifolia L.

$\odot \odot \mathrm{Bl}$. überhängend. K.zipfel lanzettlich.

I Stengel stielrund, weichhaarig. B. unterseits graufilzig. Rispe allseitswendig.

C. bononiensis $\mathrm{L}$.

11 Stengel stumpfkantig und, wie die B., kurzhaarig-rauh. Rispe einseitswendig.

C. rapunculoides $\mathrm{L}$.

++ Bl.stände wenigblïtig-traubig. Kleine Kräuter.

(.) Untere Stengelb. elliptisch, meist kerbig-gesägt. Bl.stielchen vor dem Aufblühen aufrecht. Traube einseitswendig. Kr. halbkugelig-glockig, blassblau. C. pusilla Haenke

$\odot \bigodot$ Grundb. nieren-od. herzförmig, gekerbt. Untere Stengelb. lanzettlich. Bl.stielchen vor dem Aufblühen zurückgekrümmt. Kr. fast bauchig-glockig, dunkelblau.
1. Untere Stengelb. ganzrandig.
C. rotundifolia $\mathrm{L}$.

1) Untere Stengelb. gekerbt.

C. Scheuchzeri Vill.

II. Bl.stand ährig. K.buchten olıne Anbängsel. C. thyrsoidea L. III. Bl.stand kopfig oder knäuelig. K.buchten ohne Anhängsel.

1. Stengel und B. steif haarig. Untere B. lanzettlich. K.zipfel eiförmig, stumpf.

C. Cervicaria L.

2. Meist grau-weichhaarig, selten kahl. Untere B. $\doteq$ eiförmig. K.zipfel lanzettlich, lang zugespitzt. C. glomerata L.

b. Kapsel nahe der Spitze, seltener etwas oberhalb der Mitte sich öffnend, 3-fächerig. K.buchten ohne Anhängsel.

$\alpha$. Bl.stand rispig oder traubig.

I. Bl, in Rispen. $\mathrm{Kr}$. mittelgross, trichterig.

1. Rispe fast ebensträussig. Wurzel dïnn. C. patula L.

2. Rispe fast traubig. Wurzel dick, fleischig. C.Rapunculus L.

II. Bl. in Trauben. Kr. gross, weitglockig. C. persicifolia L.

3. Bl. einzeln endständig. Kr. gross, weitglockig. C. carpathica Jacq.

$\mathrm{B}_{\ddagger}$. Kapsel prismatisch oder verlängert-umgekehrt-kegelig oder cylindrisch, mit 3 Poren oberhalb der Mitte.

Specularia (10) Speculum D.C. f.

Bı. Bl. normal mehr als 5.gliederig. - Kleinas.

Michauxia (6) campanuloides L'Hér.

B. Epigyner Discus tassen- od. röhrenförmig; sonst wie Campanula.

Adenophora (10) liliifolia L.

2`. Fr. eine Beere; Bl. normal mehr als 5-gliederig. Canar.

Canarina (1) Campanula Lam. 
3`. Fr. eine am Scheitel fachspaltige Kapsel.

A. N.lappen breit.

B. N.lappen schmal. Blb. breit. - Makarones.

Codonopsis (13).

Wahlenbergia (70) lobelioides D.C.

2. Frb. mit den Kb. u. Stb. gleichzählig u. mit ihnen abwechselnd.

A. Kapsel am Scheitel fachspaltig. O.-As.

Platycodon (1) grandiflorum (Jacq.) A.D.C,

B. Kapsel seitlich mit vielen über einander liegenden Querrissen aufspringend. Madeira.

a. Kraut. Bl. goldfarbig.

Musschia (2).

b. Halbstrauch. Bl. dunkel purpurrot oder gelblich-grün.

M. Wollastoni Lowe

II'. A. verwachsen.

1. A. vollständig zu einer Röhre verwachsen; sonst wie Campanula.

Symphyandra (7).

2. A. nur unten verwachsen, oben frei. Bl. in Köpfchen mit Involucrum.

II. Bl. zygomorph. A. verwachsen.

A. Kr.röhre nicht geschlitzt, kurz. - Californ.

Downingia (3) pulchella (Lindl.) Bth.

B. Kr.röhre wenigstens an einer Stelle bis zum Grunde aufgeschlitzt. A. Kr. nicht gespornt.

A2. Fr. eine rundliche, an der Spitze mit 2 Klappen fachspaltig aufspringende Kapsel.

A3. Bl. mit d. unpaaren Kb. nach vorn, homogam. Monopsis (9).

B3. Bl. mit dem unpaaren $\mathrm{Kb}$. nach hinten, proterandrisch.

Lobelia (200).

a. Bl. langgestielt in den Achseln der Laubb. oder kurzgestielt in endständigen Trauben, orange oder violett. Die 3 grösseren A. an d. Spitze nackt. Mexiko. L. laxiflora H.B.K.

b. Bl. kurzgestielt in endständigen Trauben, scharlachrot od. violett. Die beiden vorderen $A$. an der Spitze nackt.

a. Bl. intensiv rot. N.-Am.

I. cardinalis $\mathrm{L}$.

ß. Bl. violett.

I. B. länglich. N.-Am.

I1. B. eiförmig. N.-Am.

I. syphilitica L. L. inflata L.

c. Bl. blau, nicht gross. Die 3 hinteren A. an der Spitze nackt, die beiden vorderen behaart oder mit einer Borste versehen.

๑. B.in grundständ. Rosette, untergetaucht, lineal-cylindrisch, hohl. Kr.röhrebläulich, sonst Blkr. weiss. L.Dortmanna L.

f. Stengel beblättert; B. verkehrt-elförmig bis lineal, nicht hohl. Kr. himmelblau. Kapland. L. Erinus L. B2. Fr. eine Beere.

Bi. Kr. gespornt. Mexiko.

Pratia (16). Heterotoma (4).

\section{Goodeniaceae $(12 ; 200)$.}

A. Jedes Fach oder Kammer des Frkn. mit 2 oder mehr Sa.

A. A. mindestens nach dem Aufblühen frei.

A:. Frkn. in bezug auf den K. ganz oberständig. Velleia (12).

B2. Frkn. \pm unterständig. 
A3. Fr. eine mit 2, seltener 4 Klappen aufspringende Kapsel. Stengel aufrecht, heidekrautartig.

Goodenia (70).

a. B. eiförmig. Austral.

G. ovata Sm.

b. B. unregelmässig gefiedert. Austral. G. grandiflora Sims

B3. \pm fleischige Schliessfr. Stengel kriechend. - Austral., Neuseeland, extratrop. S.-Am.

Selliera (2) radicans Cav.

B. A. um den Gr. herum verwachsen. Pollenbecher 2-lippig.

B. 2 Sa. im Frkn. Steinfr.

Leschenaultia (16).

Scaevola $(60)$.

\section{Candolleaceae (Stylidiaceae) (3; 100).}

Vorderer Kr.zipfel ( Labellum“) von den übrigen verschieden, schuppenförmig oder länglich, schmal. Candollea (Stylidium) (85).

a. Kapsel fast eiförmig.

\%. B. starr, grasähnlich. Bl.stand eine Aehre auf langem Schaft.

K. 2-lippig. Austral, Neuseel. C.graminifolia (Sw.) F. v. Müll.

9. Aehnlich $\alpha$, aber kleiner. Austral. C.linearis (Sw.) F.v. Müll.

b. Kapsel lanzettlich oder lineal, an der Spitze in einen zarten Schnabel ausgezogen. Austral. C. adnata (R. Br.) F. v. Müll.

\section{Compositae $\left.^{1}\right)(806 ; 12150)$.}

I. Pflanzen ohne Milchsaft. Blkr. der Scheibenbl. nicht zungenförmig. [Tubuliflorae.]

1. Blkr. d. Scheibenbl. röhrig, die derRandbl. röhrig od.zungenförmig.

A. Gr. der \& Bl. an oder unterhalb der Teilungsstelle weder verdickt, noch mit einem Kranz längerer Fegehaare versehen, noch auch besonders gefärbt.

a. Die \& Scheibenbl. fruchtbar; ihr Griffelende in 2 lange Schenkel geteilt.

๙. A. am Grunde stumpf, spitz od.pfeilförm., aber nicht geschwänzt.

I. Köpfchen homogam. Blkr. aktinomorph, niemals gelb. Gr.schenkel halbcylindrisch.

1. A. am Grunde pfeilförmig spitz, ziemulich dorsifix. Vernoni eengr. (Fig. 15 A), d. h. Schenkel lang halbcylindrisch, spitz zulaufend; N. auf deren Innenseite, kaum hervorragend; Fegehaare auf der Aussenseite noch abwärts unterhalb der 'T'eilungsstelle.

I. Vernonieae $(41 ; 635)$ [Vernonia (450)].

2. A. am Grunde stumpf, basifix. Eupatorieengr. (Fig. $15 B$ ), d. h. Schenkel lang halbeylindrisch, oben stumpf oder keulenförmig oder flach verbreitert; an jedem die N. als 2 randständige, wenig hervortretende Streifen. Fegehaare kurz und stumpf, die Innenseite oberhalb der N., die Aussenseite nicht bis unter die Teilungsstelle bedeckend.

II. Eupatorieae (S. 313).

II. Köpfchen homogam oder heterogam. Oft zungenförmige Randbl., meist wenigstens die aktinomorphen röhrigen \& Scheibenbl. gelb, ihre Gr.schenkel \pm flach.

1. A. basifix, am Grunde stumpf. Aster eengr. (Fig. $15 C$ ), d. h. Schenkel flach, mässig lang; N. als je 2 deutlich

1) Die Halbfr. der Compositae (Achaenium) ist im Nachfolgenden der Kürze halber mit Fr. bezeichnet. 


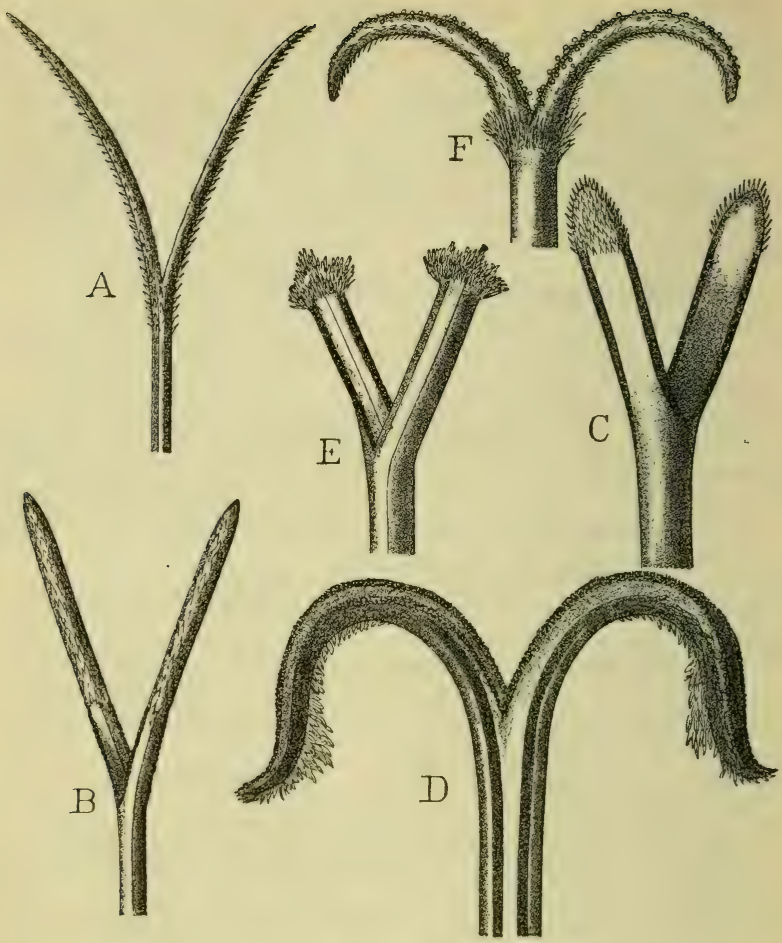

Fig. 15.

Gir.formen der Composilae: A Vernonieengr. von Veruonia fasciculata Mchx.; $B$ Eupatorieengr. von Eupatorium purpureum L.; $C$ Astereengr. von Aster Amellus L.; I) Heliantheengr. von Helianthus annuus L.; E Senecioneengr. von Cineraria lobata Pers.; F Gr. von Echinops sphaerocephalus L.

hervortretende, randständige Streifen, oberhalb derselben die Schenkel in ein \pm langes und spitzes, aussen dicht, innen nicht oder nur spärlich mit Fegehaaren besetztes Anhängsel verlängert.

III. Astereae (S. 313).

2. A. basifix, am Grunde abgerundet. Heliant he engr. (Fig. $15 D$ ) oder Senecioneengr. (Fig. $15 E$ ). Ersterer dem Astereengr. ähnlich, nur das behaarte Anhängsel an irgend einer Stelle mit einem Kranz längerer Fegehaare besetzt und die N.streifen an der Spitze meist zusammenfliessend. Rei letzterem die Schenkel an der Spitze abgestutzt oder sogar verbreitert und rings herum eine Krone langer Fegehaare. 
+ Pappus nicht haarförmig, sondern fehlend oder krönchenartig oder aus Schuppen, federigen Borsten oder starken Grannen bestehend.

$\odot$ Hüllb. ohne trockenhäutigen Rand oder, wenn ein solcher schmaler vorhanden, dann ein sehr deutlicher Pappus.

$\uparrow$ Bl.boden mit Spreub.

$\uparrow \uparrow$ Bl.boden ohne Spreub.

V. Heliantheae (S. 316).

VI. Helenieae (S. 318).

$\odot$ Hüllb. am Rande und der Spitze mit trockenhäutigem Saum. Pappus verkiimmert oder fehlend. Senecioneengr.

VII. Anthemideae (S. 318).

++ Pappus haarförmig. VIII. Senecioneae (S. 322).

§. A. am Grunde 2-schwänzig. Köpfchen homogam oder heterogam. Alle oder wenigstens die Scheibenbl. röhrig, aktinomorph, meist gelb. Gr. verschieden. IV. Inuleae (S. 315).

b. Die $\$$ Scheibenbl. unfruchtbar; ihr Gr.ende \pm keulig, ungeteilt oder in 2 sehr kurze Schenkel geteilt.

a. A. am Grunde stumpf.

I. Spreub. vorhanden.

II. Spreub. fehlend.

1. Hüllb. vielreihig. Astereae-Baccharidinae (S. 313, 314).

2. Hüllb.1-reihig. Petasites u. Tussilago (Senecioneae S. 324).

F. A. am Grunde \pm lang 2-schwänzig. IX. Calenduleae (S. 324).

B. Gr. an oder unterhalb der Teilungsstelle mit einem Kranze

längerer Fegehaare versehen oder verdickt oder auffällig gefärbt. (Fig $15 \mathrm{~F}$.)

a. Köpfchen mit o oder ungeschlechtlichen, zungenförmigen Strahlenbl.

X. Aretotideae (S. 324).

b. Köpfchen homogam oder mit nicht zungenförmigen, ungeschlechtlichen oder seltener $\bigcirc$ Randbl. XI. Cynareae (S. 325).

2. Sämtliche Bl. 3; ihre Blkr. 2-lippig. XII. Mutisieae (S. 328). II. Pflanzen mit Milchsaft. Blkr. aller Bl. zungenförmig. [Liguliflorae.]

XIII. Cichorieae (S. 329).

II. Eupatorieae $(42 ; 860)$.

1. A. ohne Anhängsel. [Fiqueriinae.]

Adenostemma (6).

2. A. mit Anhängseln.

1. Fr. 3-bis 5-rippig. [Ageratinae.]

A. Pappus ein Kreis von 5-20 freien oder in einen Becher od. Ring verwachsenen Schuppen. - Bl. blau. Tropen.

Ageratum (30) conyzoides L.

B. Pappus aus \pm rauhen, 1 - bis 2 -reihigen Borsten bestehend. A1. Hülle 6- bis $\infty$-blätterig. Eupatorium (400) cannabinum L.

B1. Hülle 4-b]ätterig, zuweilen mit noch einem kurzen, äusseren Schüppchen.

2'. Fr. 8- bis 10-rippig. [Adenostylinae.]

Mikania (150).

Adenostyles (5) albifrons (L. f.) Rchb.

III. Astereae $(99 ; 1600)$.

1. Köpfehen homogam oder monöcisch.

1'. Köpfchen homogam oder mit zungenförmigen $\bigcirc$ Strahlbl.

1“. Strahlbl. den Scheibenbl. gleichfarbig. [Solidagininae.] 
A. Pappus aus 2-8 sehr leicht abfallenden Grannen bestehend. - Californ. Grindelia (25) squarrosa Dun.

B. Pappus aus $\infty, 1$ - bis 2-reihigen, ziemlich gleich langen Borsten bestehend.

Solidago (80).

a. Köpfchenrispen aufrecht, allseitswendig. S. Virgauiea L.

b. Köpfchenrispen einseitswendig überhängend. N.-Am.

S. canadensis L.

2“. Strahlbl, von anderer Farbe als die Scheibenbl.

1“". Pappus verkümmert oder fehlend. [Bellidinae.]

Bellis (10) perennis L.

2“". Pappus gut entwickelt, meist borstig. [Asterinae.]

A. Fr. an der Spitze weder geschnäbelt, noch verschmälert. Pflanze krautig. $\odot$, $\odot$ oder 4.

A1. Pappus doppelt, der innere borstig, der äussere ein kurz fransig-gewimpertes Krönchen. O.-As.

Callistephus (1) chinensis (L.) Cass.

B1. Pappus aus gleich-od. verschiedenlangen, 1- bis mehrreihigen Borsten bestehend, zuw eilen mitfreien, äusseren Schüppchen.

A2. Zungenbl. meist 1-reihig und länglich. Fortsätze der Gr.schenkel lanzettlich.

a. Pflanzen ausdauernd.

Aster (200).

๑. Fr. schmal, wenig zusammengedrückt, gerippt. Randbl.. .

९. Fr. zusammengedrückt.

I. Pappus kurz. Sect. Biotia.

II. Pappus normal.

1. Köpfchen heterogam.

+ Stengel einfach, 1- bis wenigköpfig.

Sect. Alpigenia (A.Bellidiastrum (L.) Scop.)

+ + Köpfchen in Ebensträussen, Trauben od. Rispen.

Sect. Euaster (A. Amellus L.)

2. Köpfchen homogam, ausnahmsweise mit Strahlbl.

Sect. Linosyris (A. Linosyris (L.) Bernh.)

b. Pflanzen 1- oder 2-jährig.

๑. B. ganzrandig. Hülle ungefähr 2-reihig.

Sect. Tripolium (A. Tripolium L.)

$\beta$. B. gezähnt oder 1- bis 2-fach fiederspaltig.

Sect. Machaeranthera.

B. Zungenbl. meist mehrreihig, schmal lineal. Fortsätze der Gr.schenkel meist kurz dreieckig. Erigeron (150).

a. Kr.saum der äusseren Bl. zungenförmig, ziemlich lang, der der inneren röhrig-fädlich.

E. acer L.

b. Strahlbl. sehr kurz, die Hülle nicht od. kaum überragend.

B. Fr. geschnäbelt. Pflanze strauchig. $E$. canadensis L. Olearia (90).

''. Köpfchen mit fadenförmigen oder ganz kurz zungenförmigen, seltener blumenkronlosen, meist mehrreihigen o Randbl. $\infty$ Pappusborsten. [Conyzinae.]

Conyza (50).

2. Köpfchen einfach- oder polygam-diöcisch. [Baccharidinae.] 


\section{Inuleae $(152 ; 1400)$.}

1. Vernonieengr.

1'. Bl.boden mit Spreub. vor allen oder vor den $\bigcirc$ Bl. [Filagininac.]

Filago (12).

a. Hüllb. haarspitzig, zur Fruchtzeit nicht ausgebreitet. Köpfchen zu 10-30 geknäuelt.

$F$. germanica L.

b. Hüllb. stumpflich, zur Fruchtzeit sternförmig ausgebreitet. Köpfchen zu 2-7 geknäuelt.

๘. B. lineal oder lineal-lanzettlich, die blütenständigen so lang oder kürzer als die Knäuel.

I. Stengel oberwärts traubig-ästig. Hüllb. nicht gekielt, bis zur Spitze dicht-wollig.

$F$. arvensis $\mathrm{L}$.

II. Stengel gabelig-ästig. Hüllb. gekielt, die inneren mit trockenhäutiger, glänzender, gelber Spitze.

F. minima Fr.

э. B. lineal-pfriemelig, die blütenständigen die Knäuel weit überragend.

2'. Bl.boden ohne Spreub. [Plucheinae.

F. gallica L.

Pluchea (30).

2. Senecioneengr. od. bei unfruchtbaren Bl. Gr.stumpf. [Gnaphaliinae.] A. Alle Bl. \& oder doch die \& zahlreicher als die .

A. Pappus aus Schuppen bestehend oder ein Krönchen oder Becherchen. - N. S.-Wales. Ammobium (2) alatum R.Br.

B1. Pappus aus einfachen, rauhen od. federigen Borsten bestehend. A2. Bl.boden spreublättrig.

B2. Bl.boden ohne Spreub.

Cassinia (18).

A3. Pappusborsten rauh oder an der Spitze etwas federig.

Helichrysum (300) arenarium (L.) D.C.

B3. Pappusborsten vom Grunde an federig. - Austral.

Helipterum (50) Manglesii Lindl.

B. Köpfchen entweder heterogam mit mehr o als \& Bl. oder durch Ueberwiegen des einen oder anderen Geschlechts 2-gestaltig oder völlig eingeschlechtig.

A1. \& Bl. sämtlich oder zum grössten Teile fruchtbar. Köpfehen einhäusig; Randbl. O Scheibenbl. 3. Pappusborsten nicht federig, getrennt.

Gnaphalium (120).

a. Köpfchen im oberen Teile des Stengels ährenförm. angeordnet.

a. B. 3-nervig, oberseits dünnfilzig. Wenige Köpfchen in verkürzter, gedrungener, einfacher Aehre. G. norvegicum Gunn.

$\because$ B. 1-nervig, oberseits kahl werdend. Zahlreiche Köpfchen in verlängerter, meist ästiger Aehre. G. silvaticum L.

b. Köpfehen knäuelartig gehäuft.

a. Stengel vom Grunde an ausgebreitet-ästig. B. am Grunde verschmälert.

₹. Stengel meist einfach. B. halb stengelumfassend.

G. luteo-album L.

$\mathrm{B}_{1}$. Bl. sämtlich unfruchtbar, mit ungeteiltem oder sehr kurz 2-spaltigem Gr.

A2. Köpfchen heterogam, in der Verteilung der Geschlechter 2-gestaltig.

Leontopodium (4) alpinum Cass.

B.. Pflanzen 2-häusig. Antennaria (15) dioica (L.) Gärtn. 
3. Inulinengr., d. h. Schenkel stumpf oder abgerundet, Narbenstreifen randständig, am Scheitel zusammenfliessend; Fegehaare nur am oberen Teile der Schenkel.

1'. Bl.boden ohne Spreub. [Inulinae.]

A. Pappus einfach, borstig.

Inula (90).

a. Aeussere Hüllb. laubig, breit eiförmig, innere lineal-spatelig.

b. Hüllb. lineal-lanzettlich, spitz.

I. Helenium L.

I. Strahlbl. zungenförmig, gelb.

1. Fr. kahl.

+ Strahlbl. kaum länger als die Scheibenbl. I. germanicaL.

++ Strahlbl. viel länger als die Scheibenbl.

$\odot$ Stengel rauhhaarig. B. mit verschmälertem Grunde sitzend, stumpflich, gewimpert. Aeussere Hüllb. so lang als die inneren, aufrecht, gewimpert, rauhhaarig. I. hirta L.

$\odot \odot$ Stengel \pm kahl. B. am Grunde herzförmig, stengelumfassend, spitz, kahl. Aeussere Hüllb. kürzer, an der Spitze abstehend, gewimpert, sonst kahl. I. salicina L.

2. Fr. kurzhaarig.

I. Britannica L.

II. Strahlbl. fast röhrig, mit 3-zähnigem Saum. I. Conyza D.C.

B. Pappus doppelt, der innere ein Borstenkreis, der äussere krönchenförmig.

Pulicaria (30).

a. Strahlbl. aufrecht, wenig länger als die Scheibenbl. B. \pm mit abgerundetem Grunde sitzend. P.prostrata (Gil.) Aschers.

b. Strahlbl. ausgebreitet, viel länger als die Scheibenbl. B. mit herzförm. Grunde stengelumfassend. P.dysenterica (L.) Gärtn. 2'. Bl.boden spreublättrig. [Buphthalminae.]

Buphthalmum (4) salicifolium L.

\section{Heliantheae $(144 ; 1350)$.}

1. Bl.boden durchweg spreublättrig.

1'. O Bl. fehlend od. mit entwickelter Blkr. Kf. 2-geschlechtig. 1“. Randbl. fehlend oder vor der Fr.reife abfallend.

1'i. Scheibenbl. fruchtbar.

1““. Pappus, wenigstens bei den Scheibenbl., aus grösseren Schuppen oder kammartig gefiederten Borsten bestehend, bei den Randbl. zuweilen fehlend. [Galinsoginae.] - Peru.

Galinsoga (4) parviflora Cav.

$2^{\prime \prime \prime}$. Pappus aus winzigen Schüppchen, oder aus starken, zuweilen rückwärts rauhen Borsten oder aus einfachen Grannen bestehend oder krönchenförmig oder fehlend.

1“". Fr. \pm vom Rücken her zusammengedrückt. [Coreopsidinae.]

A. Pappus aus 2-4 rückwärts gezähnten Borsten bestehend. Bidens (90).

a. Fr. wenig zusammengedrückt, \pm vierkantig. Amer.

b. Fr. stark zusammengedrückt, breit.

B. pilosus L.

a. B. lanzettlich, sitzend, etwas verwachsen. Kf. nickend. Fr. mit 3-4 Grannen.

B. cernuus L.

ß. B. 3- bis 5-teilig, kurzgestielt. Kf. aufrecht, immer ohne Strahlbl. Fr. mit 2 Grannen. B. tipartitus L. 
B. Pappus entweder nur ein schmaler, zuweilen kurz zweizähniger Rand oder die Zähne in \pm lange, glatte oder mit aufwärts gerichteten Zähnchen besetzte, bisweilen am Grunde schuppenförmige Grannen verlängert.

A1. Anhängsel der Griffelschenkel der $§ \mathrm{Bl}$. kurz od. fehlend. Kf. mittelgross. - N.-Am. Coreopsis (70) tinctoria Nutt.

B1. Anhängsel der Griffelschenkel der $\$$ B]. lang. Kf. gross. Mexiko.

Dahlia (9) variabilis (W.) Desf.

C. Pappus fehlend. - Abyssin. Guizotia (5) abyssinica (L.) Cass. 2."w. Fr. nicht oder von der Seite her zusammengedrïckt. [Verbesininae.]

A. Innere Hüllb. flach.

A1. Spreub. sehr schmal. - S.-Am. Eelipta (4) alba (L.) Hassk.

$B_{1}$. Spreub. breit, gewölbt oder kielförmig zusammengefaltet, die $\Theta$ Bl. \pm umfassend, aber nicht die reifen Fr. ringsum einschliessend.

A. Fr. der 3 Bl. dick, 4- bis 5-kantig oder nur schwach seitlich zusammengedrückt, die der $\bigcirc \mathrm{Bl}$. oft 3-kantig oder vom Rücken her zusammengedrückt.

A3. Pappus aus Schüppchen oder starken Grannen oder beiden zusammen bestehend.

A4. Pappus ein aus verwachsenen Schuppen bestehendes Becherchen mit oder ohne Grannen. Wedelia (60).

B. Pappus '2 trockenhäutige Schuppen oder 2 leicht abfallende Grannen.

Helianthus (55).

a. Pflanze einjährig. Hüllb. breit herzförmig, abgebrochen zugespitzt. Mexiko.

H. annuus $\mathrm{L}$.

b. Pflanze mit knolligem Wurzelstock ausdauernd. Hüllb. lineallanzettlich, gewimpert. N.-Am. H.tuberosus L.

B3. Pappus ein kurz krönchenförmiger Saum oder fehlend.

a. Fr. prismatisch, 4-kantig.

Rudbeckia (30).

๘. Stengel kahl. Untere B. fiederschnittig. N.-Ám.

$R$. laciniata $\mathrm{L}$

F. Stengel \pm behaart. B. breit- oder verkehrt-eiförmig, gesägt, kurzhaarig. N.Am. $R$. hirta $\mathrm{L}$.

b. Fr. fast cylindrisch, s-streifig. B. herzförmig-stengelumfassend. N.-Am., Mexiko. $R$. amplexicaulis Tahl

$\mathrm{B}$. Scheibenständige Fr. flach zusammengedrückt, mit scharfen Kanten. - Tropen. Spilanthes (30) oleracea Jacq.

B. Innere Hïllb. die Fr. der Randbl. umfassend oder einhüllend.

Pappus fehlend. - Tropen. Siegesbeckia (4) orientalis L.

2“". Scheibenbl. unfruchtbar. [Mclampodiinae.]

A. Fr. dick, \pm cylindrisch, von den inneren Hüllb. völlig eingeschlossen. - Trop. Amer. Melampodium (25) divaricatum (Rich.) D.C.

B. Fr. vom Rücken her zusammengedrïckt, nicht eingeschlossen.

Silphium (13).

a. Fr. 2-zähnig oder 2-grannig. Atl. N.-Am. S.terebinthaceum L.

b. Fr. unbegrannt. Atl. N.-Am.

S. perfoliatum L.

2". Randbl. auf der Fr. stehen bleibend $u$. mit ihr abfallend. [Zinniinae.] 
A. Fr. der Scheibenbl. dick, nicht zusammengedrückt. B. meist gezähnt oder gesägt. - N.-Am. Heliopsis (7) laevis Pers.

B. Fr. der Scheibenbl. zusammengedrückt oder 3-kantig. B. ganzrandig.

Zimnia (12).

a. Spreub. ganzrandig, stumpf. Scheibenfr. 1- bis 2-grannig.

\%. B. sitzend, herzförmig-lanzettlich, fast stengelumfassend, spiralig. Amer. Z. pauciflora L.

ア. B. länglich-lanzettlich, oft scheinquirlig, aber auch spiralig. Mexiko.

$Z$. verticillata Andr.

b. Spreub. gesägt-kammartig, an der Spitze gefranst. Scheibenfr. unbegrannt. Mexiko.

$Z$. elegans Jacq.

2'. Blkr. der Bl. stark verkümmert oder fehlend. Kf. (bei den vorliegenden Arten) eingeschlechtig, einhäusig. [Ambrosiinae.]

A. Hüllb. der $\S\left(\delta^{7}\right)$ Kf. frei.

a. Keine Stacheln am Grunde der B.stiele.

Xanthium (4)

๙. Fr.kf mässig gross, mit geraden Schnäbeln. X. strumarium L.

F. Fr.kf. doppelt so gross (etwa $25 \mathrm{~mm}$ lang), mit meist hakigen Schnäbeln.

X. italicum Moretti

b. B.stiele am Grunde mit 1 oder 2 starken, 3-teiligen Stacheln. $X$. spinosum L.

B. Hülle der $\hat{\gamma}\left(\sigma^{\top}\right)$ Kf. verwachsenblättrig. Ambrosia (15). 2. Spreub. meist nur in einer Reihe vor den äusseren $\$$ Bl. stehend, in der Mitte des Kf. fehlend. [Madiinae.]

a. Zungenbl. kurz. Chile.

b. Zungenbl. lang. Californ.

Marlia (12).

M. sativa Mol. M. elegans Don

VI. Helenieae $(55 ; 400)$.

1. Pflanzen ohne Oeldrüsen. [Heleniinae.]

A. Bl.boden mit os spreublattähnlichen Borsten. Gaillardia (12). B. Bl.boden kahl.

A. Bl.boden cylindrisch oder kegelig.

A2. Hüillb. frei. Californ. Baeria (20) chrysostoma Fisch, et Mey.

B2. Hüllk, verwachsenblättrig. - N.-Am.

Lasthenia (5) glaberrima D.C.

B1. Bl.boden höchstens halbkugelig gewölbt bis flach.

A2. Hüllb. am Rande und an der Spitze trockenhäutig. Trop. Am.

B2. Hüllb. krautig.

Schkuhria (11) abrotanoides Roth Helenium (30) autumnale L.

2. Pflanzen mit grossen: Oeldrüsen in den Laubb. und Hüllb. [Tagetininae.]

Tagetes (20).

a. Kf.stiele an der Spitze bauchig verdickt. Bl. einfarbig, citronengelb. Mexiko.

T. erectus L.

b. Kf.stiele verlängert, an der Spitze nicht oder kaum verdickt. Bl. braunrot-gelb. Mexiko.

T. patulus L.

VII. Anthemideae $(49 ; 800)$.

1. Bl.boden spreublättrig. [Anthemidinae.]

A. Kf. einzeln gestielt oder in ebensträussigen oder rispigen Bl.ständen. Spreub, ohne behaarte Querleiste.

A1. Fr. nicht oder nur schwach zusammengedrückt. 
A. Halbsträucher. Kf. homogam. Blkr. mit einseitigem, die Spitze der Fr. üherragendem Anhängsel. Pappus fehlend. S.-TV.-Fur.

Santolina (8) Chamaecyparissus L.

B2. Kräuter.

A3. Kf. homogam. Blkr. mit regelmässiger Röhre. Pappus ein trockenhäutiges, zerschlitztes Becherchen. Südwestl. IImgbt.

Lonas (1) inodora (L.) Grtn.

B3. Kf. meist heterogam. Röhre der Blkr. zusammengedrückt. geflïgelt, höckerig oder gespornt. Pappus ein Krrönchen, das in homogamen Kf. nur einseitig, röhrenförmig ist oder ganz fehlt.

Anthemis (100).

a. Bl.boden walzlich oder verkehrt-kegelig. Spreub. nicht gekielt. Fr. nicht zusammengedrückt, kreiselförmig oder verkehrt-pyramidenförmig.

a. Spreub. stumpf, eiförmig, rings am Rande trockenhäutig. Fr. am Scheitel abgerundet. W.-Eur.

A. nobilis $\mathrm{L}$.

३. Spreub. spitz. Fr. am Scheitel gestutzt.

I. Spreub. lanzettlich, mit deutlichem Mittelnerv. A. arvensis L.

II. Spreub. schmal lineal-lanzettlich bis pfriemelig.borstlich. nervenlos.

A. Cotula L

b. Bl.boden fast halbkugelig. Spreub. spitz, gekielt. Fr. etwas zusammengedrückt, mit rhombischem Querschnitt. am Scheitel scharf gerändert.

\%. Strahlbl. weiss. B.zipfel ganzrandig. A. austriaca Jacq.

¡. Strablbl. gelb. B.zipfel sparsam gesägt. A. tinctoria L.

B1. Fr. stark zusammengedrückt.

A2. Fr. ungeflügelt.

Achillea (80).

a. Bl. gelb. B.abschnitte schräg zur Nittelrippe gestellt und sich gegenseitig deckend. Südl. Eur.

A. tomentosa $\mathrm{I}$.

b. Bl. weiss oder $\doteq$ rosa B.ahschnitte nicht schräg zur Mittelrippe gestellt und sich nicht gegenseitig deckend.

๙. Hüllb. eiförmig oder eiförmig länglich. $4-5$ kurze Strahlbl. I. B. 2- bis 3-fach fiederteilig.

1. Strahl noch nicht halb so lang als die Hülle. B.spindel von der Mitte bis zur Spitze des B. gezähnt; Stengelb. im Umriss elliptisch-eiförmig. A. nobilis L.

2. Strahl halb so lang als die Hülle. Stengelb. im Umriss \pm lineal-länglich; B.spindel nicht gezähnt. A. Millefolium L.

II. B.3-fach fiederteilig, am Grunde deutlich geöhrt. A. magna L.

f. Hülle glockig bis halbkugelig. $6-x$, die Hülle weit überragende Strablbl.

I. B. einfach gefiedert.

1. Pflanze grün, kahl oder schwach behaart.

+ B. nicht punktiert; Fiedern 2. bis fiederig-5̌-spaltig.

A. atrata $\mathrm{L}$.

++ B. punktiert; Fiedern ganzrandig od. höchstens 3-zähnig. A. moschata L.

2. Pflanze von anliegenden Seidenhaaren grau. A. Clavennae L. II. B. ungeteilt, nur gezähnt, lineal-lanzettlich. A. Ptarmica L. B2. Fr., wenigstens die randständigen, geflügelt. Mmgbt. 
a. Pflanzen ausdauernd. Kr.lappen aller Scheibenbl. gleich.

a. Hüllkb. eilanzettl, spitzlich, braunrandig. A.Pyrethrum(L.) D.C.

. Hüllkb. stumplich (die äusseren länglich. nach oben stark verschmälert, die inneren verkehrt-eiförmig), dunkelgrün, mit weissem Hautrande und öfter schmalem, braunem Saum.

A. officinarum Hayne

b. Pflanzen einjährig. Von den $5 \mathrm{Kr}$.lappen der Scheibenbl. (bes. der mittleren) 2 länger und aufrecht. $A$. clavatus (Desf.) Pers.

B. Kf. in den Gabelungen zwischen meist 4-5 Seitenzweigen sitzend. Spreub. in halber Höhe mit einer behaarten Querleiste.

Cladanthus (1) arabicus (L.) Cass.

\section{Bl.boden ohne Spreub. [Crysantheminae.]}

A. $\Varangle$ Bl. 5-zählig (nur bei Matricaria discoidea 4-zählig). Kf. entweder homogam (nur\& Scheibenbl.) od. heterogam u. dann die $q$ Randbl. mit meist lang zungenförmiger, seltener röhriger Blkr. A1. Kf. rispig oder traubig, sehr klein (kaum $5 \mathrm{~mm}$ im Durchmesser), eiförmig oder kugelig, homogam oder mit 1 Reihe röhriger Randl,l., deren (Gr.schenkel häufig weit hervorragen. Blkr. gelblich, rötlich oder bräunlich. Artemisia (200).

a. Kf. heterogam.

a. Alle Bl. fruchtbar.

I. Bl.boden zottig behaart. B. weissgrau-seidenhaarig, 2- bis 3-fach fiederteilig.

1. Stengel aufrecht, oberwärts rispig. B.zipfelchen stumpflanzettlich. B.stiel ohne Oehrchen. A. Absinthium Is.

2. Stengel aufstrebend, einfach, die nichtbliihenden rasig. B.zipfelchen lineal-lanzettlich, die blütenständigen fast fingerig. B.stiel oft geöhrelt. A. Mutellina Vill.

II. Bl.boden kahl. B. vielspaltig.

1. B.stiel ohne Oehrchen. B. unterseits grau behart. S.-Eur.

2. Am Grunde des B.stieles Oehrchen. B. unterseits weissfilzig.

+ B.zipfel lanzettlich, zugespitzt, meist eingeschnitten od. gesägt. Kf. längl.-eiförmig, aufrecht, filzig. A. vulgaris L. ++ B.zipfel linealisch. Kf. fast kugelig, graubehaart.

ß. Scheibenbl. unfruchtbar. Bl.boden kahl.

A. pontica L.

I. B. 2. bis 3-fach fiederteilig.

1. Pflanze ausdauernd, halbstrauchig; nichtblühendle Stengel rasenförmig. B. kahl oder seidenhaarig. A. campestris L.

2. Pflanze einjährig; Stengel einzeln, steif aufrecht, nebst den $\mathrm{B}$. rauhhaarig oder kahl. A. scoparia W. et $\mathrm{K}$.

II. B. ungeteilt, höchstens die untersten 3-spaltig. Russl., Mongolei.

b. Kf. homogam. Bl.boden kahl. A. Dracunculus L. A. maritima L.

$\mathrm{B}_{1}$. Kf. einzeln od. in flachen Doldentrauben, meist \pm halbkugelig, \pm mittelgross bis gross. Blkr. der Röhrenbl. goldgelb.

A2. Hüllb. o-reihig, die äusseren kürzer. Chrysanthemum (140).

a. Pfl. ausdauernd.

a. Fr. sämtlich gleichmässig 5- bis 10-rippig. 
I. Randbl. nicht länger als die Scheibenbl, mit röhriger. gelber Blkr. B. doppelt-fiederspaltig.

\section{C. [Tanacetum] vulgare (L.) Bernh.}

II. $\bigcup$ Randbl. sehr kurz zungenförmig, weiss. B. fiederteilig. B.spindel geflügelt.

C. macrophyllum W. et $\mathrm{K}$.

III. T Randbl. \pm lang zungenförmig oder seltener fehlend.

1. B \pm weit fiederteilig.

+ Pflanze strauchig.

¿ Zungenbl. wenig länger als die breit trockenhäutigen Hüllb. B. grasgrün. O.-As. $\quad C$. indicum L.

$\odot \odot$ Zungenbl. viel länger als d. weniger breit trockenhäutigen Hüllb. B. grau- oder meergrün. O.-As. C. sinense Sabine ++ Pflanze krautig.

Hüllb. am Rande (und oft auch an der spitze) fuchsrot oder braun.

A Strahlbl. meist rosa oder fleischfarben.

$\times$ B. doppelt fiederförmig geteilt. Vord.-As.

C. Marschallii Aschers.

$\times \times$ B. einfach fiederig. Tord.-As. C. rosenmi Web. et Mohr

i) Strahlbl. meist weiss. C. corymbosum IVilld.

$\odot$ Hüllb. am Rande weisshäutig.

| Strahlbl. 2mal länger als die Hülle. B. grestielt, fiederschnittig, mit fiederspaltigen, gezähnten Abschnitten.

C. Parthenium (L.) Bernh.

$1 \uparrow$ Strahlbl. 5mal länger als die Hülle. B. sitzend, lanzettlich, tief eingeschnitten-gesägt. C. uliginosum $\mathrm{W}$. et K.

2. B. ungeteilt, höchstens grob gezähnt.

+ Kf. mässig gross, 士 ebenstrïussig, am öftesten homogam (ohne Strahlbl.). Orient.

C. Balsamita L.

++ Kf. gross, gewöhnlich einzeln. C. Leucanthemum L.

3. Fr. der $\bigcirc$ und $\Varangle \mathrm{Bl}$. verschieden, die ersteren 3-kantig, zuweilen mit geflïgelten Kanten. Canar. C. frutescens L.

b. Pflanzen einjährig. Strahlbl. gelb.

$\alpha$. Strahlbi. fruchtbar.

I. Scheibenfr. ziemlich gleichmässig 10-rippig, nicht auf der Innenseite geflügelt. Pflanze kahl.

C. segetum L.

II. Scheibenfr. auf der Innenseite \pm geflügelt. mit 6-seitigem bis rhombischem Querschnitt.

1. Flügel der Scheibenfi. schmal, ohen spitz. Pflanze \pm kahl. Nimgbt.

C. coronarium L.

2. Flügel der Scheibenfr. ziemlich breit, oben stachelspitzig. Pflanze klebrig-kurzhaarig. N.-Afr., Span., Syr. C. viscosum L.

F. Strahlbl. unfruchtbar, mit rerkïmmertem oder bäufiger ganz fehlendem Gr. Westl. Mmgbt.

B2. Hüllb. 1- bis 2-reihig, ziemlich gleichlang. Matricaria (50).

a. Bl.boden markig, halbkugelig. Fr. etwas zusammengedrückt, mit starken Rippen auf der Innenseite.

II. inodora I.

b. Bl.boden kegelig, hohl. Fr. auf der Rückseite J'streifig, auf der Vorderseite abgerundet, rippenlos.

э. Kf. heterogam. Ranłh). zungenförmig, Scheibenbl. j.zählig. II. Chamomilla L. 
3. Kf. homogam. Strahlb]. fehlend, Scheibenbl. 4-zählig. $M$. discoidea D. C.

B. \& Bl. 4-zählig. hf. meist heterogam; Blkr. der ○ Randbl. \pm reduciert oder ganz fehlend. Kf́. höchstens mittelgross, einzeln.

Cotula (50).

a. Kf.stiele unter d. Kf. nicht oder nur schwach verdickt.

$\sigma$. Bl. $\infty$-reihig, mit kurz und dick kegelförmiger Blkr. Mmgbt. bis China.

3. O Bl. 1- bis 2-reihig, ohne Blkr. C. anthemoides $\mathrm{I}_{\mathrm{L}}$. C. coronopifolia L. b. Kf.stiele unter $d$. Kf. keulig verdickt. Kapld. C. turbinata L.

VIII. Senecioneae $(51 ; 1500)$.

Hüllb. frei, 1- bis 2-reihig. [Senecioninae.]

A. \& Bl. fruchtbar. Kf. gleichförmig.

$A_{1}$. Kf. homogam oder mit zungenförmigen $\bigcirc$ Randbl.

A2. B. gegrenständig.

Arnica (18).

a. Pflanze kräftiger, rauhhaarig, mit $3-\infty$ Paaren Stengelb. und 5 u. mehr Kf. Zungenbl. mässig lang. Sibir. A. Chamissonis Less.

b. Pflanze schwächer, drüsenhaarig, mit 1-3 Paaren Stengelb. und $1-3 \mathrm{Kf}$. Zungenbl. lang.

A. montana $\mathrm{L}$.

$B_{2}$. B. abwechselnd oder wurzelständig.

A3. Bl.boden stark gewölbt, kegelig oder halbkugelig.

a. Grundb. herzförmig.

Doronicum (25).

o. Wurzelstock an der Spitze knollig, unterirdische, fleischige, beschuppte Ausläufer treibend. D. Pardaiianches L.

6. Wurzelstock kurz, schief oder wagerecht, ohne Ausläufer.

D. cordifolium Sternb.

b. (irumdb. fehlend: unterste $B$. viel kleiner als die iibrigen. B. herzförmig.

B3. Bl.boden flach.

D. austriacum Jacq.

A4. Fr. prismatisch oder cylindrisch 4-bis .;-kantig oder 5bis 10-rippig.

A5. Blkr. der $\Varangle$ oder aller Bl. gelb, seltener rot.

Ac. Hüllb. zumteil mit breiten Hauträndern, welche von den benachbarten Hüllb. bedeckt werden, und dadurch scheinbar 2-reihig.

Ligularia (30).

a. B. herznierenförmig. Kf. mittelgross. L. sibirica (L.) Cass.

b. B. handförmig eingeschnitten. Kf. sehr gross. Japan. L. japonica ('Thbg.) Less.

Bis. Hüllb. einreihig, sich mit den Rändern nicht oder nur sehr wenig deckend.

Senecio (1200).

a. Heliantheengr. Kf. homogam, ohneAussenhülle. Bl. orange, gelb oder purpurn. Palaeotrop. S. sagittatus (Vahl) D.C.

b. Senecioneengr.

a. Kf. meist ziemlich gross. Aussenhülle fehlend od. wenigb]ättrig. Hüllb. an der Spitze nicht oder kaum gefärbt.

I. B. (höchstens mit Ausnahme der untersten) ungeteilt, gezähnt.

1. Stengel einfach, spinnwebig-wollig oder fast kahl. Alle B. ungeteilt. 
+ Untere B. am tirunde rundlich od. al)gestutzt. Fr. kurzhaarig.

$\odot$ B. sparsam spinnwehig-wollig, obere mit verschmälertem Grunde sitzend. S. campestris (Retz.) D.C.

$\odot \odot$ B. oberseits spinnwebig, unterseits dicht weisswollig, obere halbstengelumfassend. S. spathulifolius (Gimel.) D.C'.

++ Lntere B. mit herzförmigem Grunde, mittlere mit breitgeflügeltem Stiele, obere halbstengelumfassend, alle welligkraus.

S. crispatus D.C.

2. Stengel 亡 ästig, besonders oberwärts klebrig-zottig, dick, hohl. Unterste B. buchtig-gezähnt.

S. palustris (L.) D.C.

II. B. meist eingeschnitten, unterseits oder beiderseits graufilzig. Stengel ästig. Mmgbt.

S. Cineraria D.C.

F. Kf. mit vielblättriger Aussenhïlle. Hüllb, an der Spitze gefleckt.

I. B. ungeteilt.

1. B. lanzettlich bis eiförmig-länglich.

$+10-20$ Strahlbl. 10 und mehr Hüllb.

( Stengel vielköpfig, über $1 \mathrm{~m}$ hoch. B. verlängert-lanzettlich, unterseits spinnwebig-filzig, die untersten gestielt.

S. paludosus L.

$\odot$ Stengel selten mehr als dreiköpfig. B. kurzhaarig-rauh oder fast kahl, sitzend, untere eiförnig, obere länglich.

S. Doronicum L.

+ + 5-8 Strahlbl.

C Hülle glockig. walzlich, 10 - bis 12-blättrig. 6 bis \& Strahlbl., goldgelb. B.zähne vorwärts gerichtet. Wurzelstock kriechend, mit Ausläufern.

S. saracenicus L.

○) Hülle walzlich, meist 8-blättrig. Strahlbl. meist 5, hellgelb. B.zähne gerade abstehend. Wurzelstock kurz, ästig.

$\hat{i}$ B.stiel der mittleren und oberen B. breitgeflïgelt, am Girunde ohrförmig verbreitert.

S. nemorensis L.

^† B.stiel der oberen B. schmalgeflügelt, nicht geöhrelt.

S. Fuchsii Gmel.

2. B. herzeiförmig; Stiel am Grunde oft geöhrelt. S. cordatus Kioch

II. B. buchtig-fiederspaltig bis fiederteilig.

1. Pflanzen meist ausdauernd. Hülle glockig. Hüllb. eifürmig bis lanzettlich. Strahlbl. ziemlich lang, ahstehend.

+ Aussenhüllb. wenig zahlreich (meist nur bis 3), mehrmals kürzer als die Hülle. Randfr. kahl.

(.) Scheibenfr. sparsam behaart oder kahl. Untere B. oft ungeteilt.

S. erraticus Brot.

(.) Scheibenfr. dicht behaart. Lntere B. zur Bl.zeit meist abgestorben. leierförmig-fiederteilig.

S. Jacobaca L.

$++4-12$ Aussenhüllb. Fr. kurzhaarig.

-) PHlanze ausdauernd. Hüllb. verkehrt-eiförmig. Aussenhüllb. 4-6, halb so lang als die Hïlle.

S. erucifolius L.

.2 Pfianze einjährig. Hüllb. ianzettlich, spitz. Aussenhïllb. $6-12,{ }^{1}+4$ so lang als die Hülle, zur Hälfte schwarz.

$S$. vernalis $\mathrm{W}$. et $\mathrm{K}$.

2.. Pflanzen einjährig. Hülle walzlich. Hüllb. lineal. Strahlbl. sehr kurz und meist zurückgerollt oder fehlend.

+ Strahlbl. kurz, meist zurüickgerollt. 
- Pflanze spinnwebig-weichhaarig. Aussenhüllb. angedrückt, $1 / 6$ so lang als die Hülle.

S. silvaticus L.

(-) Pflanze klebrig-drüsenhaarig. Aussenhüllb. locker, halb so lang als die Hülle.

$S$. viscosus L.

++ Strahlbl. fehlend. Aussenhiillb. sehr kurz. S. vulgaris L.

B. Kf. homogam; Blkr. weiss oder seltener fleischfarben.

Cacalia (40).

B. Fr. vom Rücken her zusammengedrückt. (ineraria (25). Bı. Kf. mit 1 Reihe Randbl., deren Blkr. kurzröhrig.

Homogyne (3) alpina (L.) Cass.

B. \& BI. unfruchtbar.

A1. Kf. gleichförmig. Bl. gelb. Tussilago (1) Farfara L. $B_{1}$. Kf. 2-gestaltig. Pflanzen \pm vollkommen 2-häusig oder polyyamisch.

Petasites (14).

a. B. dreieckig-herzförmig, unterseits dicht- und fast schneeweiss-filzig.

a. Blkr. rötlichweiss. Gr. der $\mathrm{Bl}$. tief 2-spaltig, mit langen, lineal-lanzettlichen $\mathrm{N}$.

¡. Blkr. hellgelb. Gr. der eiförmigen $\mathrm{N}$.

$P$. niveus (Vill.) Baumg.

BI. seicht 2-spaltig, mit kurzen, P. tomentosus (Ehrh.) D. C.

b. B. rundlich-herzförmig, unterseits dümn grauwollig oder dünnfilzig.

\%. Blkr. gelblichweiss. (tr. der Bl. an der Spitze tief 2-spaltig, mit langen, lineal-lanzettlichen N. P. albus (L.) Gärtn.

Blkr. rötlich. Gr. der Bl. an der Spitze nicht 2-spaltig. mit sehr kurzen, eiförmigen N. $P$. officinalis Mönch

IX. Calenduleate $(8 ; 115)$.

Bl. zumgenförmig. Stf. frei. Scheibenbl. unfruchtbar. Randfr. dreigestaltig, einwärts gekrümmt. Calendula (15). a. Aeussere Fr. lineal. nicht seitlich berandet, aber innenseitig oben und unten mit Kamm, auf dem Ruicken lang-weichstachelig; mittlere (kahnförmige) Fr. sehr zahlreich ; innere (lineale, kreisringförmige) in geringer Anzahl. Unterste B. spatelig. Mmgbt.

C. officinalis $\mathrm{L}$.

b. Aeussere Fr. durch den sehr breiten, tief stachelzähnigen Saum breiteilanzettlich-zugespitzt, am Rücken höckerig-stachelig: innere (lineal-kreisringförmige) Fr. sehr zahlreich.

\%. 5 mittlere (kahnförmige) Fr. Untere B. spatelig. Westl. Nimgbt.

C. stellata Cav.

Füchstens 3 mittlere (kahnförmige) Fr. Auch die unteren B. länglich-lanzettlich.

C. arvensis $\mathrm{L}$.

\section{Aretotideae $(11 ; 240)$.}

1. Hüllb. frei. [Arctotidinae.]

A. Pflanzen kahl. Bl.boden spreublättrig. - Kapld.

Ursinia (54) anthemoides (L.) Bth. et Hook.

B. Pflanzen \pm filzig. Bl.boden ohne Spreub.

Fr. wollig; Pappus in d. Wolle versteckt. Kapld.

2. Hüllb. verwachsen. [Gorteriinac.] - Kapld.

Gazania (24). 
a. B1. gleichfarbig gelb, ungefleckt.

G. unitora Sims

b. Zungenbl. gelb, am Grunde schwarzgefleckt. G. epeciosa Less.

\section{Cynareae $(34 ; 1300)$.}

1. Kf. mehrblütig, selten 1-blütig und dam getrennt.

i. Fr. mit grundständiger Anheftungsstelle.

1“. Fr. kahl, an der Spitze gerändert. [Carduinac.]

A. Bl.boden \pm glatt, mit Borsten besetzt (nur bei Sausurea kahl).

A1. Stf. frei.

Az. Stf. kahl.

A3. Hüllb. in hakige Granmen auslaufend. Arctium (4).

a. Alle Hüllb. mit hakiger (nur wenige innerste mit gerader) Spitze. Kf. kahl oder nur wenig spinnwebig.

\%. Kf. rispig oder traubig. Innere oder alle Huillb. an der Spitze rot. Stiele der grundständigen B. hohl.

I. Aeste aufrecht. Kf. etwa haselnussgross, etwas spinnwebig. Hüllbl. kürzer als die Bl. A. minus Schrank

II. Aeste rutenförmig. abstehend, zuletzt überhängend. If. gross, fast kahl. Hüllb. etwa so lang als die $\mathrm{Bl}$. A. nemorosum Lejeune

Kf. locker doldentraubig. ziemlich gross, fast kahl. Hüllb. sämtlich grün. Stiele der grundständigen B. markig.

A. Lappa L.

b. Innere Ḧ̈llb. stumpflich, mit gerader, kurzer Stachelspitze. rot. fast strahlend. If. mässig gross, genähert-doldentraubig. dicht-spinnwebig. A. tomentosum (Lam.) Schrank B3. Hüllb. ohne hakige Grannen.

At. B. ohne Stacheln.

A. Pappushorsten mehrreihig, nach innen allmählich an Länge zumehmend. Jurinea (50) cyanoides (L.) D.C.

B5. Pappushorsten 2- oder 1-reihig, alle oder die inneren federig.

Saussurea (125).

B. B. stachelig.

A5. Pappus borstig.

B5. Pappus federig.

Cousinia (210).

B. Stf. warzig, behaart oder federig gewimpert.

Аз. Pappusborsten nicht federig.

Blkr. rot oder gelegentlich bei Abarten weiss.

๙. Hüllb. aufrecht angedrückt oder bogig-abstehend bez. zurückgekrümmt.

I. Stengel meist bis zur Spitze stachelig-getlügelt. B. fiederspaltig bis fiederteilig.

1. Kf. gehäuft. B. unterseits \pm dicht spinnwebig.

+ Aeste breit-kraus-geflïgelt. B. buchtig-fiederspaltig. mit 2- oder 3-lappigen Zipfeln, die oberen B. bisweilen nur seicht-buchtig-gelappt.

C. crispus L.

+ - Aeste schmal und nicht kraus-geflügelt. Untere B. leierförmig-fiederteilig, mit vorn gelappten Zipfeln, oder nur buchtig gelappt. obere ungeteilt, dorniggezähnt und gewimpert.

C. Personata Jacq. 
2. Kf. einzeln, aufrecht, kurzgestielt. B. beiderseis meergrün, oberseits fast kahl, unterseits kurzhaarig. C. acanthoides L.

II. Stengel ungeflügelt. B. lanzettlich, stachelig gewimpert, fast kahl, unterseits meergrïn. Kf. einzeln, zuletzt nickend.

C. defloratus $\mathrm{L}$.

f. Hïllb. über dem breiten Grunde in eine (bes. bei den mittleren Hüllb.) zuriickgeknickte, abstehende, stechende Spitze eingeschnürt. Kf, einzeln, nickend. Stengel ungeflügelt. B. fiederteilig.

B3. Pappusborsten federig.

A4. Bl.boden nicht fleischig. C. nutans $\mathrm{L}$.

a. Kr.saum bis zum Grunde j-teilig. Pappus zuletzt länger als die Bl. Kf. zuweilen 2-häusig, meist gehäuft. B. oberseits nicht rauh. Blkr. lila od. weiss. C. arvense (L.) Scop.

b. Kr.saum bis zur Mitte 2-spaltig. Fr. mit häutiger, nicht oder kaum gerippter Schale; Pappus kürzer als die Bl.

๘. B. oberseits nicht stachelig rauh.

I. B. sämtlich nicht herablaufend.

1. Blkr. gewöhnlich gelblich-weiss.

+ Kf. aufrecht. B. \pm kahl. C. oleraceum (L.) Scop. t+ Kf. nickend. B. hehaart. C. Erisithales (L.) Scop.

2. Blkr. purpurn.

+ Stengel $1 / 3{ }^{4} / 3 \mathrm{~m}$ hoch.

- B. beiderseits gleichfarbig, zerstreut- u. weich-kurzhaarig, geöhrt umfassend. Kf. meist $\mathrm{zu} 2-4$ gehäuft. Aeussere Hüllb. mit klebrigen Kielnerven.

C. rivulare (Jacq.) Link

$(\bullet$ B. unterseits dünn-spinnwebig-graufilzig, nicht oder halbumfassend. Kf. einzeln. Aeussere Hüllb. mit schwachen, nicht klebrigen Kielnerven, C. bulbosum D.C. ++ Stengel höchstens ${ }^{1}+\mathrm{m}$ hoch. B. meist rosettig.

C. acaule (L.) All.

II. Untere, nicht aber obere B. herablaufend. Stengel 1-köpfig od. in 1-köpfige Aeste geteilt. Blkr. rot. C. canum (L.) M.B.

III. Sämtliche B. I herablaufend. Kf. traubig-geknäuelt, klebrig. Blkr. purpurrot.

P. B. oberseits stachelig rauh.

I. B. nicht herablaufend, stengelumfassend, am Rande stark zurückgerollt, unterseits weissfilzig. Kf. sehr gross; Hülle kugelig, meist dicht-spinnwebig. C. eriophorum (L.) Scop.

II. B. herablaufend, am Rande wenig zurückgerollt, unterseits kurzhaarig, dünn-spinnwebig. Kf. mittelgross; Hülle eiförmig, wenig spinnwebig. C. lanceolatum (L.) Scop.

B. Bl.boden fleischig.

Cynara (11).

a. B. unbewehrt. Hüllb. stumpf oder ausgerandet mit einem knorpeligen Höckerchen in der Bucht. Mmgbt. C. Scolymus L.

b. B.abschnitte und Hüllb. ganz kurzstachelig. Mmgbt.

C. Cardunculus L.

$B_{1}$. Stf. verwachsen. Pappusborsten nicht federig. Mmgbt., Canar. Silybum (2) Marianum (L.) Gärtı. 
B. Bl.boden wabenförmig oder grubig. olme Borsten.

A1. Gruben flach, mit schwach schuppigen Ründern.

B. Gruben tief, mit häutigen, gezähuten Rändern.

Iyopordon (2).

Onopordon (20) Acanthium L.

2." Fr. (wenigstens der $\cong \mathrm{Bl}$.) zottig, ungerändert. [Carlininac.]

A. Pappusschuppen zugespitzt oder in eine einfache Granne auslaufend. Kf. heterogam; Randbl. unfruchtbar, mit kleiner. 2-lippiger Blkr. Mmgbt. Xeranthemum (6) annu $\mathrm{L}$. B. Pappusschuppen oberwärts federig.

A. Innerste Hüllb. aufrecht, nicht strahlend. Atractylis (15).

$\mathrm{B}_{1}$. Innerste Hüllb. trockenhäutig, strahlig ausgebreitet.

Carlina (17).

a. Stengel verlängert, mit 1 bis mehreren ziemlich grossen, fast ebensträussigen Kf. Strahlende Hüllb. am Grunde breiter. bis zur Mitte gewimpert.

C. vulgaris $\mathrm{L}$.

b. Stengel meist völlig reduciert, mit 1 sehr grossen Kf. zwischen der grundständigen B.rosette. Strahlende Hüllb. vom Grunde an lineal, nicht gewimpert.

2.' Fr. mit schiefer, seitlicher Anheftungsstelle. [Centaureinae.]

Fr. an der Spitze einfach berandet.

A. Kf. ohne Hülle von Laubb., seltener (bei einigen CentaureaArten) am Grunde mit einigen unbewehrten Laubb.

A. Fr. mit doppeltem Pappus und einem gekerbten Ringe innerhalb desselben.

Crupina (2).

B1. Fr. ohne gekerbten Ring innerhalb des Pappus, dieser zuweilen fehlend.

A2. Hüllb. ohne Anhängsel. kurz begramnt bis stumpf. Pappus einförmig, aus ung!eichlangen Borsten bestehend, selten fehlend.

B2. Hüllb. mit trockenhäutigen oder dornigen Anbängseln. Pappus sehr mannigfaltig.

Centanrea (470).

a. Hüllb. häutig gerändert u. mit breitem, häutigem, ganzrandigem od. im Alter unregelmässig zerschlitztem Anhängsel.

a. Pappus gleichförmig.

I. Pappus schuppig. [Amberboa.] X.-Afr., Span.. Arab.

C. Lippii L.

II. Pappus borstig. [Rhaponticum.] Alpen. C. Rhapontica L

$\therefore$ Pappus doppelt, der innere kürzer als der iussere. Mitt.Russld. bis Orient.

C. glastifolia L.

b. Hüllb. mit trockenhäutigem Anhängsel, welches (zuweilen nur bei einigen äusseren Hüllb.) fiederig gewimpert ist; mittlere Franse nicht stärker als die iibrigen. Pappus doppelt oder fehlend. Kf. heterogam.

a. Nur das nicht herablaufende, häutige Anbängsel oberhalb des krautigen Teiles der Hüllb. gefranst. $\mathrm{B}$. meist ungeteilt, \pm lanzettlich. [Jacea.]

I. Pappus meist fehlend oder sehr kurz. Anbängsel der Hüllb. rundlich, breit.

1. Fransen der bräunlichen, oft fast schwärzlichen Hüllb. kurz. zuweilen nur bei wenigen äusseren Hüllh, vorhanden. 
2. Fransen der Hüllb. so lang, als das Mittelfeld breit ist, schwärzlich.

I1. Pappus ${ }^{1 / 3}$ so lang als die Fr. Anhängsel der Hüllb. lanzettlich bis pfriemelig, borstig-gefranst.

1. Anhängsel der Hüllb. aufrecht, lanzettlich. Randbl. meist \&, gleichgross.

C. nigra L.

2. Anhängsel der Hüllb. zurückgekrümmt, aus lineal-lanzettlichem Grunde pfriemelig, die der innersten rundlich. Randbl. geschlechtslos, strablend.

+ Anhängsel der 3 inneren Reihen der Hüllb. über die der äusseren hinausragend. Kf. eiförmg. C. phrygia L.

++ Anhängsel der innersten Reihe der Hüllb. von d.Fransen d.

folgenden bedeckt. Kf.rundlich. C.pseudophrygia C. A.Mey.

F. Anhängsel herablaufend und sowohl oberhalb als auch an den seitlichen Rändern der Hüllb. gefranst. [Cyanus.]

I. B. herablaufend, länglich-lanzettlich, ungeteilt oder die unteren buchtig. Hülle kugelig.

II. B. nicht herablaufend, lineal, untere zuweilen 3̈-teilig. Hüille eiförmig.

C. Cyanus L.

c. Hüllb. wie bei b, aber die mittlere Franse stärker als die übrigen und \pm stachelig oder dornig oder Huillb. mit mehreren fiederig oder fingerig gestellten Dornen an der Spitze. B. meist \pm fiederig-geteilt.

ฯ. Enddorn beträchtlich stärker als die Seitenwimpern. Bl. purpurn. B.zipfel lanzettlich, mit einem schwieligen Punkte endigend.

C. Scabiosa L.

3. Huillb. mit handförmig geteiltem, starkem Endstachel, sonst nicht gefranst.

I. Endstachel nur am firunde mit einigen schwächeren Seitendornen. B. herablaufend.

II. Endstachel mit stärkeren und längeren Seitendornen. Ohere B. herablaufend od. mit geöhreitem Grunde. C.solstitialis L.

B. Kf. von einer Hülle dorniger Laubio. ungeben.

A. Pappus einfach, aus Schuppen oder Borsten bestehend oder fehlend. - Mmgbt.

B1. Pappus doppelt, aus 2 Reihen ungleichlanger Borsten bestehend. Mimgbt.

Cnicus (1) Benedictus L.

2. Kf. einblütig, zu Kf. 2. Ordnung vereinigt. Hülle der Einzelkf. aus os B. und 1 bis melr Reihen in Borsten zerteilter Schüppchen (dem sog. Pinsel) bestehend. [Echinopsidinae.] Echinops (60).

a. Einzelkf. mit 20 Hüillb. Pinsel höchstens ${ }^{1}{ }_{3} 3$ so lang als die Hülle. S.-Eur. bis Altai.

b. Linzelkf. mit 16 Hüllb. Pinsel halb so lang als die Hülle.

$\%$ Stengel filzig. B. oherseits rauh, dreifach fiederteilig mit lanzettlichen Zipfeln. S.-Em.

E. Tourncfortii Ledeb.

;. Stengel drüsig. B. oberseits klebrig-zottig, einfach fiederspaltig mit länglich-dreieckigen Zipteln. - S.-Eur. bis Altai.

XII. Mutisieae $(57 ; 635)$.

E. sphaerocephalus L.

1. Fegehaare der Gr. der $\mathrm{Bl}$. fehlend oder keinen endständigen Kranz bildend. [Mutisiinae.] 
A. Stengel beblättert, mehrköpfig. Pappusborsten federig, eimreihig. Mutisia (50).

B. Stengel unverzweigt, einköpfig. B. grundständig. Papjusborsten nicht federig, 2- bis mehreihig. Gerbera (32).

2. Gr. der $\because$ Bl. mit einem endständigen Kranz von Fegehaaren. [Nassauviinae.]

A. Kf. homogam. Bl.boden ohne Spreub.

A1. Pappus aus 2 oder mehr Reihen einfacher Borsten bestehend.

Perezia (70).

Bi. Papuns aus 1 Reihe federiger, selten kurz gewimperter Borsten bestehend.

Leuceria (58).

B. Scheibenbl. unfruchtbar, ohne Pappus. Bl.boden spreublättrig. Pappus der Randfr. aus einer Reihe kurzer. federig zerschlitzter Schïppchen bestehend. Chile. Moscharia(1)pinnatifida Rz. et Par.

XIII. Cichorieae $(63 ; 1300)$.

1. Distelartige Kräuter. Fr. vom Rücken her zusammengedrückt. jede ringsum von einem zusammengefalteten Spreub. eingeschlossen. Pappus ein niedriger Ring oder $2-3$ Borsten. [Scolyminae.] Mmgbt. Scolymus (3) maculatus L.

2. Nicht distelartige Kräuter. Spreub. fehlend oder doch die Fr. nicht einschliessend.

1. Pappus fehlend oder krönchenförmig oder schuppié oder aus Schuppen und Borsten bestehend, bei den Rand- und Scheibenfr. zuweilen rerschieden, aber hei letzteren niemals federige Borsten. [Cichoriinae.]

A. Bl.boden durchweg langborstig und wenigstens vor den äussersten Bl.reihen spreublättrig. Catananche (j).

B. Bl.boden kahl oder kurz gewimpert, zuweilen mit einigen Borsten in der Mitte.

A. Bl. blau, rosa oder weiss. Fr. j-kantig, vielstreifig. meist mit kurzen Pappusschüppchen.

Cichorium 81.

a. Pflanze steifhaarig. Pappus \&- bis 10-mal so kurz als die Fr.

C. Intybus L.

b. Pflanze ziemlich kahl. Pappus 4-mal so kurz als die Fr. Mmght.

B1. BI. gelb.

A2. Hüllb. bei der Fr.reife nicht oder kaum verändert. höchstens am Grunde etwas hohl verbreitert.

A3. Fr. länglich oder eiförmig. vom Rücken her zusammengedrückt, an der Spitze abgerundet, gleichmässig etwa 20-streitig. Pappus fehlend. Lampsana (9) communis L.

B3. Fr. an der Spitze abgestutzt od. verschmälert, 6- bis 8-rippig.

A. Pappus fehlend. Aposeris (1) foctida (L.) Cass.

B. Pappus aus 1 Reihe ss kurzer Schïppchen u. gewöhnl. noch 1-10 Borsten bestehend. - Mmgbt.

Tolpis (5) barbata (L.) Gärtn.

B:. Hüllb. bei der Fr.reife stark verhärtet oder doch bedeutend verlängert und vergrössert. Iif.stiele oft kenlenförmig verdickt. Fr. vom Rücken her zusammengedrückt.

As. Scheibenfr. schmal geflügelt. IImgbt. Hyoseris (3) radiata I. 
$B_{3}$. Fr. ungeflügelt.

A4. Fr. klein, viel kürzer als die Hüllb.

A.s. Fr. an der Spitze breit abgestutzt und gerändert, sonst ohne Pappus. Arnoseris (1) minima (L.) Link

B5. Fr. an der Spitze abgerundet oder die äusseren mit ganz. kurzem, schiefem Schnabel, sämtlich mit $\infty$ kurzen Pappusborsten; innere Fr. \pm stielrund, ïussere seitlich zusammengedrückt. Mmgbt.

Zacyutha (1) verrucosa Gärtn.

Bt. Fr. langlinealisch, ungeführ so lang wie die Hüllb., bei der Reife sternförmig ausgebreitet. Mmgbt.

Rhagadiolus (1) stellatus (L.) Willd.

C. Fr. ungefähr so lang oder die inneren länger als die Hüllb., gerade oder gekrümmt, aber nicht sternförmig ausgebreitet. Mmgbt. Hedypnois (3) cretica (L.) Willd. 2'. (cf. 3'.) Pappus aus rauhen oder haarförmigen Borsten bestehend. [Crepidinae.]

A. Bl.boden grubig, mit gewimperten oder borstigen Rändern der Gruben. - Westl. Mmgbt. Andryala (12) candidissima Desf. B. Bl.boden nackt, \pm glatt.

A1. Fr. entweder ungeschnäbelt oder, wenn geschnäbelt, dann ohne pappusartiges Gebilde am Grunde des Schnabels.

A2. Fr. cylindrisch oder prismatisch, am Grunde verschmälert. $\mathrm{A}_{3}$. Fr. an der Spitze breit abgestutzt.

At. Fr. nicht oder undeutlich gerippt. Bl. purpurrot, violett, weiss oder weisslich.

Prenantles (27) purpurca L.

B. Fr. mit deutlichen Rippen. Bl. gelb, seltener orange oder braunrot.

Hieracium (400).

a. Hüllb. 2-reihig, äussere sehr kurz, innere ohne Uebergänge viel länger. Fr. dünn, spindelförmig, stumpfkantigwalzlich, ungerippt. Pappusstrahlen 1-reihig, schneeweiss, weich, biegsam. [Chlorocrepis.]

H. staticifolium (Schultz bip.) Vill.

b. Hüllb. meist spiralig, die äusseren, kürzesten allmählich in die längeren, inneren übergehend. Fr. 10-bis 13-rippig.

Pappus meist schmutzig-weiss, steif, zerbrechlich.

\%. Fr. klein (höchstens 2,5 mm lang), ihre Rippen am oberen Rande in kurze Zähne auslaufend. Pappushaare sehr fein, einreihig, fast gleichlang. Wurzelstock meist mit Ausläufern. B. in grundständiger Rosette, meist ganzrandig; Stengel \pm blattlos. [Pilosella.]

1. Stengel einköpfig oder gegabelt-wenigköpfig. Kf. ziemlich gross. B. gras- oder hellgrün, unterseits graufilzig. (irundachse kriechend; oberirdische Ausläufer.

1. Stengel blattlos, einköpfig. Hülle kurzwalzlich

H. Pilosella L.

2. Stengel meist einblättrig, gabelig 2-bis 5-köpfig; Ausläufer oft blühend. Hülle bauchig-eiförmig.

$H$. flagellare. Willd.

II. Stengel an der Spitze doldenrispig, 2- bis c-köpfig; Kf. mittelgross oder klein. B. unterseits ohne oder mit zerstreuten Sternhaaren (nie graufilzig).

1. B. grau- oder bläulichgrün. 
+ Stengel 2-bis 15-köpfig; Kf. kurzgestielt. Grundachse kriechend.

(Stengel blattlos oder einblättrig, 2- bis 6-(meist 3-)köpfig. oberwärts mit Stern- und Drüsenharen. B. nur am Grunde durch geschlängelte Borsten gewimpert. Blkr. hellgelb.

H. Auricula L.

$\bigodot \odot$ Stengel 1- oder 2-blätterig, 4- bis 15-köptig. oberwärts drüsenhaarig. B. am Rand und Mittelrippe borstig gewimpert. H. floribundum Wim. et Grab.

++ Stengel 20- bis 50-köpfig, locker doldenrispig, unterwärts 1- oder wenigblättrig. Grundachse kurz, schief.

2. B. gras- bis gelblich-grün.

H. pracaltum Vill.

+ Stengel 1- bis 5-blättrig. Grundb. meist zur Bl.zeit noch frisch.

(.) Grundachse kriechend; unter- und oberirdische Ausläufer. Stengel wenigstens unterwärts mit langen Haaren, oberwärts schwarz-drüsenhaarig.

$\uparrow$ Blkr. orange bis rötlich; Gr. braun. Kf. 3-10, ziemlich gross, locker doldenrispig; Hülle breiteiförmig. H.aurantiacum L.

$\uparrow \uparrow$ Blkr. gelb; Gr. gelb. Kf. zahlreich, ziemlich klein. dicht doldenrispig. Hülle eiwalzlich. H. pratense Tausch

(-) Grundachse kurz, schief, selten mit kurzen Auslïufern. Stengel nur steifhaarig, die Haare kaum so lang als der Stengeldurchmesser. Kf. zahlreich, ziemlich klein. Blkr. hell-goldgelb.

H. cymosum L.

++ Stengel 8- bis 20-blättrig, dicht borstig. Grundb. zur Bl.zeit vertrocknet. $10-30 \mathrm{Kf}$. in lockerer Doldenrispe.

H. eckioides W. et Kit.

F. Fr. grösser (3-5 mm lang), am oberen Rande mit ungekerbtem, ringförmigem Wulste. Pappushaare ungleich, fast 2-reihig. Ausläufer fehlend. Stengel \pm beblättert. [Archhieracium.]

I. Grundständige B.rosette zur Bl.zeit noch vorhanden. Stengelb. nach oben an Grösse abnehmend.

1. Hüllb. zahlreich, regelmässig dachziegelig, mehrreihig, von innen nach aussen allmählich kleiner werdend.

+ B. und meist auch Stengel und Kf. ohne Drüsenhaare.

(-) Hülle von langen, weissen Haaren dicht zottig. H.villosum L.

1.- Hülle sternhaarig, olme oder nur mit zerstreuten einfachen und Drüsenhaaren.

H. bupleuroides Gmel.

+ + Haare der B. sämtlich oder teilweise drüsig. Hüllen und Köpfchenstiele drüsenhaarig.

C Stengelb. lanzettlich oder länglich, allmählich gegen den Grund verschmälert od. die unteren gestielt. $H$. alpinum L.

(-) Stengelb. eiförmi halbumfassend. Ueberall drüsenhaarig. H. amplexicaule L.

2. Hüllb. weniger zahlreich, unregelmässig dachziegelig, eine innere fast gleichlange Reihe u. 2 äussere viel kürzere Reihen. Obere Stengelb. mit verschmälertem Grunde sitzend od. kurzgestielt.

- $\odot$ Stengel 0 - oder 1 -, selten bis 5-blättrig.

$\uparrow$ B. blaugrün, mit $\doteq$ steifen Borsten, am Rande \pm borstig gewimpert. Gr. gelb.

H. Schmidtii Tausch 
$\uparrow \uparrow$ B. oberseits gras- oder blaugrün, weichhaarig. selten etwas borstig. Gr. wenigstens zuletzt \pm dunkel.

$\times$ Grundb. am Grunde abgerundet bis herzförmig, meist mit grossen, rückwärts gerichteten Zähnen. Kf. zahlreich, mittelgross, an bogig aufsteigenden Stielen. H.murorum L.

$\times \times$ Girundb. in den Stiel herablaufend. 1-6 ziemlich grosse Kf. an aufrechten Stielen.

$\triangle$ Kf.stiele und Hüllb. grau sternfilzig und mit einzelnen Borsten, aber ohne Drüsenhaare.

H. caesium Fr.

$\triangle$ If stiele und Hüllb. mit Stern- und schwarzen Drüsenhaaren dicht besetzt.

H. atratum Fr.

$\odot \odot$ Stengel 3- bis mehrblättrig. B. lanzettlich oder länglich, mit vorwärts gerichteten Zähnen, unterste in den B.stiel herablaufend. Kf.stiele und Hülle stern- und drüsenhaarig.

H. vulgatum Fr.

II. Grundständige B.rosette und die untersten, kleineren Stengelb. zur Bl.zeit fehlend, sonst der Stengel \pm reich beblättert.

1. B. nicht stengelumfassend, untere und inittlere gestielt, obere sitzend. Hüllb. wenigreihig, unregelmässig dachziegelig, die innersten fast gleichlang und nach oben verschmälert.

H. Inevigatum Willd.

2. B. sitzend oder umfassend, untere gestielt. Hüllb. vielreihig, dachziegelig, innere stumpf.

+ Mittlere und obere B. \pm umfassend. Kf.stiele und Hülle drüsenhaarig, äussere Hüllb. abstehend. B. länglich-lanzettlich oder ei-länglich, gezähnelt; untere und mittlere am (irunde geigenförmig verschmälert. H. prenanthoides Vill.

++ Mittlere und obere B. mit breitem Grunde sitzend. Hüllb. regelmässig dachziegelig. Kf.stiele und Hüllb. drüsenlos.

○ Hüllb. sümtlich angedrückt.

1 Obere B. eilanzettlich. Hüllb. blattgrün. H. silvestre Tausch $A \hat{\imath}$ Obere B. mit herzförmigem Grunde stengelumfassend. Hüllb. graugrün.

H. sabaudum L.

$\odot \odot$ Aeussere Hüllb. abstehend mit zurückgeschlagener Spitze. H. umbellatum $\mathrm{L}$.

$B_{3}$. Fr. an der Spitze verschmälert oder geschnäbelt.

A4. Stengel schaftförmig, 1-köpfig. - Pac. N.-Am.

B4. Stengel nicht schaftförmig.

Troximon (22) glaucum Nutt.

a. Fr. nicht oder nur kurz geschnäbelt. Crepis (170).

๘. Stengel beblättert (doch zuweilen nur mit 2-1 B.).

I. Stengel 2- bis $\infty$-köpfig:

1. Pflanze ausdauernd. Fr. 20- bis 30-rippig. + Pappus schneeweiss.

$\odot$ Kf.stiele und Hüllen driisenlos. Blkr. hellgelb.

C. blattarioides Vill.

๑) Kf.stiele und Hüllen drüsig. Blkr. goldgelb.

Hülle drüsig-kurzhaarig. B. kahl oder behaart, ganzrandig oder undeutlich gezähnt; Stengelb. am Grunde \pm herzförmig. 
$\uparrow \uparrow$ Hülle rauh-u. dicht drüsenhaarig. B. drüsig-weichhaarig, gezähnt; Stengelb. am Grunde pfeilförmig. C.grandiflora Tausch ++ Pappus schmutzig-weiss, zerbrechlich. C. sibirica L.

2. Pflanze ausdauernd. Fr. 10- bis 13-rippig. Pappus schmutzigweiss, unten bräunlich, zerbrechlich. Hüllb. meist drüsigbehaart. Untere B. schrotsägeförmig gezähnt, eiförmig, lang zugespitzt. herzförmig-stengelumfassend. C. paludosa (L.) Mönch 3. Ptlanze 1- oder 2-jăhrig. Stengel an der Spitze ebensträussig. Fr. 10- bis 12-rippig. Pappus schneeweiss. biegsam.

+ Aussenhülllb. \pm abstehend; Hüllb. graufilzig.

C Blkr. 'goldgelb. Fr. 13-rippig. Stengelb. flach, am Grunde kurz geöhrt-gezähnt.

C. biennis $\mathrm{L}$.

$\odot \odot$ Blkr. hellgelb. Fr. 10-rippig. Stengelb. am Rande umgerollt, Oehrchen meist aufwärts gerichtet. C. tcctorum L.

++ Aussenhïllb. anliegend. Fr. 10-rippig.

$\odot$ Hïllb. aussen etwas graufilzig. Stengelb. pfeilförmig-stengelumfassend, mit abwärts gerichteten Oehrchen, gezähnt bis fiederspaltig.

C. virens Vill.

(๖) Hüllb. kahl, äussere sehr kurz. Stengelb. am Grunde abgestutzt, nebst dem Stengel $\doteq$ drüsenhaarig, untere \pm schrotsägeförmig, mittlere gezähnt oder ganzrandig. C. pulchra $\mathrm{L}$.

II. Stengel meist einköpfig und einfach, wenigblättrig. Fr. j- bis 13-rippig.

1. Kf. mässig gross. Stengel unter dem Kf. nicht merklich verdickt. Pappus schneeweiss, biegsam.

+ Stengel oberwärts nebst Hïlle schwarz-zottig. Blkr. orange.

C. aurea (L.) Cass.

++ Stengel oberwärts filzig; Hülle graufilzig oder kurzhaarig. Blkr. goldgelb.

C. alpestris (Jacq.) Tausch

2. If. gross, 4-5 cm im Durchmesser. Stengel unter dem Kf. keulenförmig verdickt. [Soyeria.] C. montana (L.) Tausch P. Stengel blattlos. Fr. 10- bis 13-rippig.

I. Stengel c-köpfig. Wurzelstock abgebissen. Blkr. gelb. C. praemorsa (L.) Tausch II. Stengel einköpfig. Blkr. orange (cf. $\alpha$. II. $1 .+$ ). C. aurea (L.) Cass.

b. Alle oder doch die mittleren Fr. langgeschnäbelt. Stengel stets ästig und beblättert. B. schrotsägig.

๙. Kf. stets aufrecht. Alle Fr. langgeschnäbelt.

I. Kf.stiele und Hülle = kurzhaarig-grau. Bl.boden behaart. Pappus nach dem Verblühen die Hülle weit überragend.

C. taraxacifolia (D.C.) Thuill.

II. Kf.stiele und Hülle grün, \pm mit steifen Borsten besetzt. Bl.boden kahl. Pappus wenig länger als d.Hülle. C. setosa Hall.f. F. Kf. vor dem Aufblühen nickend. Randfr. nicht oder nur kurz geschnäbelt.

I. Kr. gelb, unterseits rötlich.

II. $\mathrm{Kr}$. rosenrot. S.-O.-Eur.

C. foetida $\mathrm{I}$. C. rubra $\mathrm{L}$.

B. Fr. zusammengedrïckt.

A3. Pappus ohne Kranz weicher Haare am Grunde. 
At. Fr. ungeschnäbelt, nach der spitze zu kaum rerschmälert. Bl. gelb.

Sonchus (45).

a. Hülle kahl od.weissflockig, selten mitwenigen Drüsen. Wurzel senkrecht, spindelförm. Stengel \pm ästig, Aeste ebensträussig.

๑. B. mit abstehenden, zugespitzten Oehrchen. Fr. querrunzelig, beiderseits 3-rippig.

S. oleraceus L.

$\therefore$ B. mit stumpfen, angedrïckten Oehrchen. Fr. glatt.

S. asper All.

b. Hülle dicht drüsenhaarig. Wurzel schief oder wagerecht, weit kriechend. Stengel meist einfach, an der Spitze ebensträussig oder einköpfig

๙. B. wie bei S. oleraceus. Nebenwurzeln lang, mit Knospen.

S. arvensis $\mathrm{L}$.

3. B. wie hei $S$, asper. Nehenwurzeln kurz, ohne Knospen. S. paluster L.

B. Fr. an der Seite stark verschmälert oder geschnäbelt.

Lactuca (90).

a. Fr. beiderseits mit mehreren erhabenen Rippen. Bl. gelb.

๘. Stengel meist gelblich-weiss, fest (markig). B. derb (ausser den untersten), herz- od pfeilförmig stengelumfassend. Blkr. blassgelb. Kf. 10 - bis 16-bliitig.

I. Fr. graubräunlich, schmal berandet.

1. Fr. so lang als der Schnabel.

+ B. + senkrecht gestellt, am Grunde pfeilfürmig, untere meist buchtig-fiederspaltig. $\quad L$. Scariola L. ++ B. meist wagerecht abstehend, am Grunde herzförmig.

2. Fr halb so lang als der Schnabel $L$ saligna II. Fr. schwarz, breit berandet. L. virosa L.

₹. Stengel grün, hohl. B. zart, gefliigelt-gestielt, leierförmigfiederspaltig mit rundlichen. eckig-gezähnten Zipfeln. Kf. mit 5 Bl. blkr. helldottergelb. Fr. mehrmals länger als der Schnabel.

L. muralis (L.) Fresen.

b. Fr. auf d.Uitte mit 1 Rippe. Bl. lila. Stengel fest. L.perennis L.

B3. Pappus am Grunde von einem Kranze kurzer Haare umgeben.

Mulgedium (22).

a. Lf. in drüsig behaarter 'Traube. Fr. lineal-länglich. an der Spitze wenig verschmälert, $\propto$-rippig. $M$. alpinum (L.) Cass.

b. Kf. in kahlem Ebenstrauss. Fr. elliptisch, von der Iitte aufwärts verschmälert, beiderseits 5-rippig. M.Plumieri(L.) D.C.

B1. Fr. geschnäbelt, mit einem aus einer bis mehreren Reihen von Höckern oder Schuppen bestehenden, pappusartigen Gebilde am Grunde des Schnabels.

A.. Kf. cc-blütig. Schmabelgrund von spitzen Höckern umgeben. (trundb.rosette; Schaft 1-köpfig, blattlos, hohl.

Taraxacum (22) officinale (With.) Wiggers

B. Kf. mit höchstens $15 \mathrm{Bl}$. in 2 Kreisen. Schnabelgrund von 5 knorpeligen Schuppen umgeben. Zweige rutenförmig. wenigblättrig.

Chondrilla (18) juncea L.

:3'. Pappus aus federigen, zuweilen am Grunde etwas verbreiterten Borsten, bei den Randfr. zuweilen aus einem Kírönchen kurzer Schuppen bestehend. [Leontodontinae.] 
A. Bl.boden spreublättrig.

a. Pappus bei allen Fr. gleich.

Hypochoeris $(50)$.

๑. Pappus einreihig, federig. [Achyrophorus.] Fr. geschnäbelt.

I. Hüllb. ganzrandig.

H. maculata $\mathrm{L}$.

II. Aeussere u. mittlere Hüllb. zerrissen-gefranst. H. unifora Vill.

₹. Pappus doppelt. der innere federig, der äussere kürzer und borstig. [Euhypochoeris.]

I. Alle oder wenigstens die Randfr. ungeschnäbelt. Bl. so lang als die Hüille.

II. Fr. sämtlich geschnäbelt. Bl. länger als die Hiille. H. ylabra L. H. radicata $\mathrm{L}$.

b. Pappus der Rand- und Scheibenfr. verschieden.

a. Pappus der Randfr. aus kurzen, am Grunde zusammenhängenden Schüppchen bestehend, Pappus der Scheibenfr. federig. [Metabasis.] Griechld., Kreta, Sibir.

H. cretensis (L.) Boiss.

8. Pappus der Randfr. verkümmert oder fehlenıl: Pappus der lang geschnäbelten Scheibenfr. 2-reihig, der innere aus federigen, am Grunde \pm schuppenförmig verbreiterten Borsten bestehend, der äussere kürzer, borstig. [Seriola.] - Mmgbt.

$H$. aetnensis $(\mathrm{L}$.) Bth.

B. Bl.boden olne Spreub.

A1. Seitenfiedern der Pappusborsten nicht durcheinander gewebt.

A2. Hüllb. 1-reihig. Fr. mit einem hohlen, von der eigentlichen Höhlung durch eine Scheidewand getrennten Schnabel. Stengel schwach-verzweigt.

B2. Hüllb. mehrreihig, ungleichlang.

Urospermum (2).

A3. Stengel beblättert. Pappus meist leicht abfallend. Picris (36).

a. Pappus aller Fr. gleich. Aeussere Hüllb. klein. Eupicris.] $P$. hieracioides $\mathrm{I}$.

b. Pappus der Randfr. ein kurzes, zerschlitztes, stehen hleibendes Becherchen. Aeussere Hüllb. ziemlich gross, breiter als die inneren. am Grunde $\doteq$ herzförmig. [Helminthia.] $P$. echioides L.

B3. B. eine grundständige Rosette bildend: Pappus stehen bleibend.

Leontodon (45).

a. Pappus aller Fr. gleich. Fr. nicht oder kaum geschnäbelt. Wurzelstock oft abgebissen.

๙. Pappusborsten sämtlich federig, am (irunde verbreitert. Stengel meist ïstig, 2- bis $x$-köpfig. $L$. autumnalis L.

. Aeussere Pappusborsten kurz, einfach. Stengel einfach, oberwärts \pm verdickt, 1-köptig.

I. Wurzelstock abgebissen.

1. Pappus schmutzig-weiss. B. kahl oder mit ?- bis 3gabeligen, kurzen Haaren besetzt. L. hispidus L.

2. Pappus schneeweiss. B. kahl oder mit einfachen Haaren bestreut. Stengel und Hülle von langen. schwarzen Haaren zottig. L. Taraxaci Lois.

II. Wurzelstock spindelfürmig. Stengel nebst den fast ganzrandigen $\mathrm{B}$. von ästigen Haaren dicht graufilzig.

L. incanus (L.) Schrank 
b. Pappus der Randfr. ein zerschlitztes Krönchen bildend. Fr. an der Spitze verschmälert oder die inneren geschnäbelt. Wurzel spindelförmig. [Thrincia.] L. hirtus L.

$B_{1}$. Seitenfiedern der Pappusborsten durcheinander gewebt, selten die Borsten nur kurz gewimpert oder am Grunde zottig.

A2. Hüllb. einreihig.

Tragopogon (35).

a. Kf.stiele gleich dick, nur unter dem Kf. etwas verdickt. Bl. gelb. Hülle 8-blättrig.

b. Kf.stiele oberwärts allmählich keulenförmig verdickt.

$\therefore$ Bl. gelb. Hülle 8- bis 12-blättrig, etwas länger als die Bl. Kf. oberseits vertieft.

T. major Jacq.

5. Bl. violett. Hiille 8-blättrig, fast doppelt so lang als die Bl. Kf. oberseits ganz flach. Nmgbt.

B2. Hüllb. mehrreihig.

T. porrifolius L. Scorzonera (100).

a. Fr, oben allmählich verschmälert, am Grunde mit einer sehr kurzen Schwiele. B. ungeteilt. [Euscorzonera.]

. Bl. Jila bis rosenrot.

S. purpurea L.

ค. Bl. gelb.

J. Hülle so lang als die Bl. Fr. gerippt mit glatten Rippen. Stengel 1- bis 3-köpfig, kahl.

II. Hülle halb so lang als die Bl.

1. Fr. glatt. Stengel einfach, meist einköpfig. S. humilis L.

2. Randfr. weichstachelig. Stengel ästig, Aeste einköpfig.

S. hispanica L.

b. Fr, oben nicht verschmälert, am Grunde mit einer den Nabel umgebenden, verlängerten Schwiele, die dicker ist als die Fr. selbst. B. fiederig gespalten oder geteilt. [Podospermum.]

a. Wurzel 2-jährig, einfach. Unfruchtbare B.büschel fehlend. Aeste stielrund. Randbl. so lang oder wenig länger als die Hïlle.

S. laciniata $\mathrm{I}_{\text {. }}$

$\therefore$ Wurzel ausdauernd, vielköpfig, mit blütentragenden Stengeln und unfruchtbaren B.büscheln. Stengel oberwärts gefurcht. Randbl. doppelt so lang als die Hülle.

S.cana (C.A.Mey.) O. Hoffim. (PodospermumJacquinianum Koch). 


\section{$\mathrm{R}$ e gister.}

A belmoschus 239 .

Abies 63.

Abrus 218.

Abutilon 237.

Acacia 206

Acaena 202.

Acalypha 225.

Acanthaceae 136, 300. Acantholimon 271.

Acanthosicyos 307 .

Acanthus 300 .

Acarospora 19.

Acaulon 36.

Acer 231.

Aceraceae 126, 132, 133, 231.

Aceras 117.

Achillea 319.

Achimenes 299.

Achyranthes 157.

Aconitum 168.

Acorus 91.

Acridocarpus 224.

Acrogynae 22, 26.

Acrostichum 56.

Actaea 167.

Actinidia 240.

Adenophora 309.

Adenostemma 313.

Adenostyles 313 .

Adiantum 52.

Adlumia 176.

Adonis 172 .

Adoxa 127.

Adoxaceae 127.

Aechmea 95.
Aegopodium 259.

Aerides 124.

Aerua 157.

Aesculus 232.

Aethionema 178.

Aethusa 261.

Agapanthus 105 .

Agaricaceae 4, 11.

Agaricus 14.

Agathosma 223.

Agave 107.

Ageratum 313.

Aglaonema 92.

Agonis 251.

Agrimonia 201.

Agropyrum 82.

Agrostemma 159.

Agrostis 78 .

Ailanthus 131.

Aira 77.

Ajuga 282.

Aizoaceae 127, 157.

Akebia 126.

Albizzia 206.

Albuca 103.

Alchemilla 201.

Aldrovanda 184.

Alisma 70.

Alismaceae 67, 70 .

Alliaria 178.

Allium 105.

Allosorus 52.

Alnus 142.

Alocasia 94.

Aloë 99.

Aloina 39.
Alonsoa 294.

Alopecurus 79.

Alpinia 113.

Alsine 162.

Alsophila 56.

Alstonia 275.

Alstroemeria 107.

Alternanthera $15 \%$.

Althaea 238.

Alyssum 182.

Amanita 15.

Amarantaceae 125,156.

Amarantus 156.

Amaryllidaceae 68,106.

Amaryllis 107.

Amblyodon 42.

Amblystegium 48.

Ambrosia 318.

Ambrosinia 93.

Amelanchier 195.

Ammannia 249.

Ammi 260.

Ammobium 315.

Ammophila 78 .

Amomum 113.

Amorpha 208.

Amorphophallus 92.

Ampelodesmus 72 .

Ampelopsis 235.

Amphiblemma 253.

Anacamptis 117.

Anacardiaceae126,128, $132,228$.

Anacardium 228.

Anacrogynae 22, 25.

Anacyclus 319. 
Auagallis 271 .

Anagyris 207.

Auanas 95.

Anastatica 182.

Anchusa 281.

Andreaea 35.

Andreaeaceae 31, 35.

Andromeda 267.

Andropogon 84.

Androsace 270.

Andryala 330.

Aneilema 95.

Aneimia 57.

Anemone 170.

Angelica 262.

Angelonia 294.

Angiopteris 57.

Angrecum 124.

Anguloa 122.

Anigosanthus 106.

Anoda 238.

Anomodon 46.

Anona 128.

Anonaceae 128.

Antennaria 315.

Anthemis 319 .

Anthericum 98.

Anthoceros 25.

Anthocerotaceae 22, 25.

Anthoxanthum 80 .

Anthriseus 260.

Anthurium 91.

Authyllis 208.

Antirrhinum 294.

Antitrichia 47.

Apera 79.

Apios 219.

Apium 259.

Aplozia 27.

Apocynaceae 135, 275.

Apoeynum 275.

Aposeris 329.

Aquifoliaceae 132, 134, 229.

Aquilegia 168.

Arabis 181.

Araceae 67, 91.

Arachis 208.

Aralia 257.

Araliaceae 134, 257.

Arbutus 267.
Archangelica 262.

Archidiaceae 31, 35.

Archidium 35.

Arctium 325.

Aretostaphylos 267.

Aretotis 324.

Aretous 267.

Ardisia 269.

Aremonia 201.

Arenaria 162.

Argemone 175.

Argyrolobium 208.

Arisaema 93.

Arisarum 93.

Aristea 110.

Aristida 80.

Aristolochia 150.

Aristolochiaceae 127, 150.

Armeria 272.

Armillaria 14.

Arnica 322.

Arnoseris 330.

Arrhenatherum 77.

Artemisia 320.

Arthropodium 98.

Arthropyrenia 17.

Arthrostema 253.

Arum 93.

Aruneus 193.

Arundinaria 72.

Arundo 72.

Asarum 150.

Asclepiadaceae 135, 275.

Asclepias 277.

Ascyrum 240.

Asparagus 100.

Asperugo 280.

Asperula 302.

Asphodeline 98.

Asphodelus 98.

Aspidistra 101.

Aspidium 54.

Asplenum 53.

Astelia 100.

Aster 314.

Astilbe 186.

Astragalus 214.

Astrantia 258.

Asrstasia 300.
Athyrium 53.

Atractylis 327.

Atraphaxis 152.

Atriplex 155 .

A tropa 290.

Atropis 73.

Aubrietia 181.

Aucuba 264.

Aulacomnium 43.

Auricularia 3.

Auriculariaceae 3.

Avena 77.

Azara 244.

Azolla 58.

Baccharis 314 .

Bacidia 18.

Backhousia 250.

Baeckea 251.

Baeomyces 18.

Baeria 318.

Ballota 286.

Balsaminaceae 132, 233.

Bambusa 72.

Banisteria 224.

Banksia 149.

Baptisia 207.

Barbarea 178.

Barbula 39.

Barringtonia 133.

Bartramia 43.

Bartschia 297.

Basella 157.

Basellaceae 127, 157.

Basilima 193.

Batera 189.

Bauhinia 207.

Bazzania 30.

Beckmannia 80.

Begonia 245.

Begoniaceae 127, 132, 245.

Belameanda 109.

Bellis 314.

Benincasa 307.

Berberidaceae 128, 172.

Berberidopsis 244.

Berberis 173.

Berchemia 234.

Bergenia 186. 
Berteroa 182.

Bertolonia 253.

Beta 153.

Betula 142.

Betulaceae 126, 142.

Biatora 18.

Biatorina 18 .

Bidens 316.

Bifora 263.

Bignoniaceae 135, 300.

Bilimbia 18.

Billbergia 95.

Biophytum 221.

Biscutella 177.

Biserrula 215.

Blasia 25.

Blechnum 53.

Bletia 122.

Blumenbachia 245 .

Boehmeria 149.

Boerhavia 157.

Bolbophyllum 122.

Boletus 10.

Bomarea 107.

Boronia 223.

Borraginaceae 136,279.

Borrago 280.

Botrychium 58.

Boussingaultia 157.

Bouvardia 301.

Bovista 15.

Bowiea 98.

Bowlesia 258.

Brachyotum 253.

Brachypodium 75.

Brachythecium 48.

Brasenia 164.

Brassavola 120.

Brassica 180.

Briza 73.

Brodiaea 106.

Bromelia 95.

Bromeliaceae 68, 94.

Bromus 75.

Broussonetia 148.

Browallia 291.

Bruchiaceae 32, 35.

Bruckenthalia 268.

Brunella 286.

Brunfelsia 291.

Brumsurigia 107.
Bryaceae 33, 41.

Bryonia 307.

Bryophyllum 186.

Bryopogon 21.

Bryum 43.

Buddleia 273.

Buellia 18.

Buettneria 239.

Bulbine 98.

Bulbocodium 97.

Bulgaria 3.

Bulgariaceae 3.

Bunchosia 224.

Bunias 182.

Buphthalmum 316.

Bupleurum 259.

Butomaceae 67, 70.

Butomus 70.

Buxaceae 126, 228.

Buxbaumia 45.

Buxbaumiaceae 32, 45.

Buxus 228.

Byrronima 224.

Cabomba 164.

Cacalia 324.

Cachrys 261.

Cactaceae 132, 246.

Caesalpinia 206.

Cajanus 219.

Cajophora 245.

Cakile 179.

Caladium 84.

Calamagrostis 78 .

Calamintha 285.

Calandrinia 158.

Calanthe 122 .

Calathea 113.

Calceolaria 294.

Calendula 324.

Calepina 180.

Calla 92.

Callistemma 306.

Callistemon 251.

Callistephus 314.

Cailitrichaceae126,228.

Callitriche 228.

Callopisma 19.

Calluna 268.

Calocera 7 .
Calonyetion 277.

Calophaca 215.

Calophyllum 242.

Calothamnus 251.

Caltha 166.

Calycanthaceae 124 , 128. 173.

Calseanthus 173.

Calycothrix 252.

Calypso 120.

Calystegia 277.

Camassia 104.

Camelina 181.

Campanula 308.

Campanulaceae 137. 308.

Camphorosma 155.

Camptothecium 50.

Campylopus 37.

Canarina 309.

Canavalia 219.

Candelaria 19.

Candollea 311.

Candolleacene 137, 311.

Canna 113.

Cannabis 148.

Cannaceae 68, 113.

Cantharellaceae 4, 11.

Cantharellus 11.

Capparidaceae 129,153.

Capparis 183.

Caprifoliaceae 136,303.

Capsella 181.

Capsicum 289.

Caragana 215.

Cardamine 178.

Carduus 325.

Carex 87.

Carissa 275.

Carlina 327.

Carludoviea 91.

Carpinus 144.

Carthamus 328.

Carum 260.

Carya 137.

Caryophyllaceae 125, $127,159$.

Cassebeeria 253.

Cassia 206.

Cassinia 315 .

Cassiope 267. 
Castanea 145.

Catabrosa 72.

Catalpa 300.

Catananche 329.

Catasetum 122.

Catharinaea 44.

Cattleya 120.

Ceanothus 233.

Cedrus 64.

Celastraceae 132, 133, 230.

Celastrus 230.

Celosia 156.

Celsia 290.

Celtis 147.

Cenchrus 84 .

Centaurea 324.

Centranthus 305.

Centunculus 271.

Cephalanthera 118.

Cephalotaxus 61.

Cerastium 163.

Ceratodon 38.

Ceratonia 206.

Ceratophyllaceae 126, 165.

Ceratophyllum 165.

Ceratozamia 61.

Cercis 207.

Cercocarpus 201.

Cereus 246.

Cerinthe 282.

Ceropegia 276.

Ceterach 54

Cetraria 20.

Chaenostoma 293.

Chaerophyllum 260.

Chamaecyparis 65 .

Chamaedorea 91.

Chamaenerium 256.

Chamaerops 91.

Chamissonia 255.

Cheilanthes 52 .

Cheiranthus 182.

Chelidonium 174.

Chelone 292.

Chenopodiaceae 125, 153.

Chenopodium 154.

Chiloscyphus 29.

Chimaphila 265.
Chionanthus 273.

Chionodoxa 104.

Chlora 275.

Chloranthaceae 124.

Chloranthus 124.

Chloris 80.

Choisya 223.

Chondrilla 334.

Chorispora 182.

Chorizema 207.

Chrysanthemum 320.

Chrysobalanus 206.

Chrysosplenium 188.

Cibotium 56.

Cicendia 275.

Cicer 215.

Cichorium 329.

Cicuta 260

Cinclidotus 39.

Cineraria 324.

Ciunamomum 174.

Circaea 256.

Cirrhopetalum 122.

Cirsium 326.

Cistaceae 129, 242.

Cistus 242.

Citrullus 307.

Citrus 223.

Cladanthus 320.

Cladium 87.

Cladonia 20.

Cladrastis 207.

Clarkia 254.

Clavaria 8.

Clavariaceae 4, 8.

Claviceps 6.

Clavija 269.

Claytonia 159.

Clematis 171.

Cleome 183.

Clerodendron 282.

Clethra 264.

Clethraceae 130, 264.

Clianthus 214.

Clidemia 252.

Cliffortia 202.

Climacium 47.

Clivia 107.

Clusia 241.

Clypeola 182.

Cneoraceae 131.
Cneorum 131.

Cnicus 328.

Cobaea 278.

Coccoloba 153

Cochlearia 178.

Cochlioda 124.

Cochliostema 95.

Cocos 91 .

Codonopsis 310.

Coeloglossum 116.

Coelogyne 120.

Coffea 301.

Coix 85.

Colchicum 98.

Coleanthus 79 .

Coleonema 223.

Coleus 288.

Collema 17.

Colletia 233.

Collinsia 292.

Collomia 278.

Colocasia 93.

Colutea 214.

Commelina 95.

Commelinaceae 68, 95.

Compositae 137, 311.

Coniferae 2, 61.

Conium 260.

Conocephalus 23.

Conringia 182.

Convallaria 101.

Convolvulaceae 134, 135, 277.

Convolvulus 277.

Conyza 314.

Coprinarius 13.

Coprinus 11.

Coptis 167.

Coralliorrhiza 120.

Corchorus 236.

Cordyceps 6 .

Cordyline 100.

Coreopsis 317 .

Coriandrum 263.

Coriaria 131.

Coriariaceae 131.

Coris 271.

Corispermum 156.

Cornaceae 134, 264.

Cornicularia 21.

Cornucopiae 79. 
Cornus 264.

Coronilla 210.

Coronopus 177.

Correa 223.

Corrigiola 164.

Corticium 7.

Cortinarius 14 .

Cortusa 270.

Corydalis 176.

Corylopsis 192 .

Corylus 144.

Corynephorus 77 .

Costus 113.

Cotinus 229.

Cotoneaster 194.

Cotula 322.

Cotyledon 185.

Cousinia 325.

Crambe 181.

Crassula 186.

Crassulaceae 128, 134, 184.

Crataegus 194.

Craterellus 7.

Crepis 332.

Crinum 107.

Cristaria 238.

Critbmum 261.

Crocus 109.

Crotalaria 208.

Croton 225.

Crucianella 303.

Crucibulum 16.

Cruciferae 129, 177.

Crupina 327.

Crypsis 79.

Cryptogramme 52.

Cryptomeria 62.

Cryptotaenia 259.

Ctenanthe 113.

Cucubalus 160.

Cucumis 307.

Cucurbita 307.

Cucurbitaceae 136, 306.

Cuminum 263.

Cumninghamia 62 .

Cuphea 249.

Cupressus 65.

Curculigo 106.

Cureuma 111.

Cuseuta 278.
Cyathea 57.

Cyatheaceae 51, 56.

Cyathus 16.

Cycadaceae 60.

Cyeadales 2, 60 .

Cycas 60.

Cyclamen 271.

Cyclanthaceae 67, 91.

Cyclanthera 308.

Cydonia 195.

Cymbalaria 294.

Cymbidium 122.

Cynanchum. 277.

Cynara 326.

Cynodon 80.

Cynoglossum 280.

Cynosurus 76.

Cypella 110.

Cyperaceae 67, 85.

Cyperus 85.

Cyphomandra 290.

Cypripedilum 113.

Cyrtandra 299.

Cystopteris 55.

Cytisus 209.

Daboecia 266.

Dacryomyces 7 .

Dacryomycetaceae 3,7 .

Dactrylaena 183.

Dactylis 76 .

Daedalea 9.

Dahlia 517.

Dalechampia 226.

Danthonia 76.

Daphne 247.

Darlingtonia 183.

Dasylirion 100.

Datisea 126.

Datiscaceae 125.

Datura 290.

Dancus 263.

Delphinium 168.

Dendrobium 122.

Dentaria 179.

Derminus 13.

Deschampsia 76.

Descurainia 181.

Desmodium 210.

Deutzia 189.
Dianella 98.

Dianthus 161.

Diapensia 269.

Diapensiaceae 134, 269.

Dicentra 176.

Dicksonia 57.

Dicotyledoneae 2, 124.

Dicranaceae 32, 36.

Dicranella 36.

Dicranodontium 37.

Dicranoweisia 36.

Dicranum 37.

Dictanınus 223.

Didymodon 39.

Dieffenbachia 92.

Diervilla 303.

Digitalis 296.

Dillenia 240.

Dilleniaceae 128, 130. 240.

Dionaea 184.

Dioscorea 108.

Dioscoreaceae 68, 108.

Diosma 223.

Dipcadi 103.

Diphyscium 45.

Diplectria 252.

Diplotaxis 180.

Dipsacaceae 136, 305.

Dipsacus 305.

Dirca 247.

Ditrichaceae 33, 38.

Dodecatheon 271.

Dolichos 219.

Donia 214.

Doronicum 322.

Dorstenia 148.

Doryenium 211.

Dorningia 310.

Draba 181.

Dracaena 100.

Dracocephalum 285.

Dracophyllum 269.

Dracunculus 93.

Drimys 166.

Drosera 184.

Droseraceae 127, 183.

Drosophyllum 184.

Dryandra 149.

Dryas 200. 
Drymaria 164.

Duboisia 291.

Duchesnea 198.

Dyekia 94.

Ecballium 307.

Echinocactus 247.

Echinocereus 246.

Echinophora 263.

Echinops 328.

Echinopsis 246.

Echium 283.

Eclipta 317.

Edgeworthia 248.

Ehrharta 80.

Eichhornia 95.

Elaeagnaceae 125, 248.

Elaeagnus 248.

Elaphomyces 5 .

Elatinaceae 130, 242.

Elatine 242.

Elatinoides 294.

Elettaria 111.

Eleusine 80.

Elisma 70.

Elodea 70.

Elssholtzia 284.

Elymus 81.

Elyna 87.

Emex 151.

Empetraceae 132.

Empetrum 132.

Enealypta 40.

Encalyptaceae 33, 40.

Encephalartos 61 .

Endoearpon 17.

Endopyrenium 17.

Entosthodon 41.

Epacridaceae 134, 269.

Epacris 269.

Ephebe 17.

Ephedra 66.

Ephemeraceae 32, 35.

Ephemerum 35.

Epichloë 6 .

Epidendrum 120.

Epilobium 255.

Epimedium 173.

Epipactis 118.
Epipogon 118.

Equisetaccae 58.

Equisetales 2, 58.

Equisetum 58.

Eragrostis 72 .

Eranthis 167.

Eremurus 98.

Erianthus 84.

Erica 268.

Ericaceae 130, 133,134. $136,265$.

Erigeron 314.

Erinus 296.

Eriogonum 150.

Eriogynia 193.

Eriophorum 85.

Eriostemon 223.

Eritrichium 280.

Erodium 220.

Eruca 180.

Erucaria 179.

Erucastrum 180.

Eryngium 258.

Erysimum 182.

Erythraea 275.

Erythrina 219.

Erythronium 103.

Erythroxylaceae 131.

Erythroxylon 131.

Escallonia 189.

Eschscholtzia 174.

Eucalyptus 251.

Eucharidium 254.

Eucharis 108.

Euchlaena 85.

Eucnide 245.

Eucomis 104.

Eugenia 250.

Eupatorium 313.

Euphorbia 226.

Euphorbiaceae 126,225.

Euphrasia 297.

Eurhynchium 50.

Eurotia 156.

Euryale 165.

Eustrephus 100.

Evernia 21.

Evonymus 230.

Exidia 7.

Exochorda 193.

Exogonium 277.
Fabiana 291.

Fagaceae 127, 144.

Fagonia 222.

Fagopyrum 153.

Fagraea 273.

Fagus 144.

Falcaria 260.

Farsetia 182.

Fatsia 257.

Fedia 305.

Ferula 262.

Festuca 74.

Ficus 148 .

Filago 315.

Filicales 2, 50.

Fissidens 37.

Fissidentaceae 32, 37.

Fistularia 297.

Fistulina 10.

Flacourtiaceae 125,129, 244.

Foeniculum 261.

Fontanesia 272 .

Fontinalaceae 33, 45 .

Fontinalis 45 .

Forsythia 272.

Fossombronia 26.

Fothergilla 191.

Fourcroya 107.

Fragaria 198.

Francoa 189.

Frankenia 129.

Frankeniaceae 129.

Fraxinus 272.

Fritillaria 103.

Frullania 31.

Fuchsia 256.

Fumaria 176.

Funaria 41.

Funariaceae 33, 41.

Fungi 1, 3.

Gagea 105.

Gaillardia 318.

Galanthus 107.

Galax 269.

Galega 208.

Galeopsis 287.

Galinsoga 316.

Galium 301. 
Galphimia 224.

Galtonia 103.

Garcinia 242.

Gasparinia 19.

Gasteria 99.

Gastridium 79.

Gaudinia 77.

Gaultheria 267.

Gaura 256.

Gaylussacia 267.

Gazania 324.

Geaster 16.

Gelsemium 273.

Genista 209.

Gentiana 274.

Gentianaceae 135, 273.

Geoglossum 6.

Geonoma 91.

Georgia 45.

Gcorgiaceae 32, 45.

Gicraniaceae 131, 219.

Geranium 219.

Gerardia 294.

Gerbera 329.

Gesneria 299.

Gesneriaceae 136, 137, 299.

Geum 200.

Gilia 278.

Gillenia 193.

Gilliesia 106.

Ginkgo 61.

Gladiolus 111.

Glaucium 175.

Glaux 271.

Glechoma 285.

(ileditschia 206.

Gleichenia 51.

Gleicheniaceae 51.

Globaria 15.

Globba 113.

Globularia 300.

Globulariaceae136,300.

Gloeophyllum 9.

Gloriosa 98.

Gloxinia 299.

Glyceria 73.

Glycine 219.

Glycyrrhiza 214.

Gnaphalium 315.

Gnetaceae 66.
Gnetales 2, 66 .

Gnidia 247.

Godetia 254.

Gomphrena 157.

Goniolimon 271.

Gonolobus 277.

Goodenia 311.

Goodeniaceae 137, 310.

Goodyera 120.

Gordonia 240.

Gossypium 239.

Gramineae 67, 71.

Grammanthes 186.

Graphephorum 73.

Graphis 18.

Gratiola 293.

Gravesia 253.

Grevillea 149.

Grewia 236.

Grimaldia 23.

Grimmia 40.

Grimmiaceae 32, 33, 39.

Grindelia 314.

Guizotia 317.

Gunnera 257.

Guttiferae 129, 240.

Gymnadenia 116.

Gymnocladus 206.

Gymnocybe 44.

Gynınogramme 53.

Gymnomitrium 26.

Gynerium 72.

Gypsophila 161.

Gyrophora 20.

Hablitzia 153.

Hacquetia 258.

Haemanthus 108.

Haematomma 18.

Hagenia 201.

Hakea 149.

Halesia 272.

Halimodendron 215.

Halorrhagidaceae 127, 132, 257.

Hamamelidaceae 127, 132, 191.

Hamamelis 192.

Haplomitrium 26.

Harpanthus 29.
Haworthia 99.

Hebenstreitia 294.

Hechtia 94.

Hedera 257.

Hedwigia 39.

Hedychium 111.

Hedypnois 330.

Hedysarum 210.

Heimia 249.

Helenium 318.

Heleocharis 86.

Helianthemum 242.

Helianthus 317.

Helichrysum 315 .

Helicodiceros 93.

Heliconia 111.

Helicteres 239.

Heliophila 177.

Heliopsis 318.

Heliosperma 160.

Heliotropium 279.

Helipterum 315.

Helleborus 167.

Helonias 97.

Helvella 7.

Helvellaceae 3, 6 .

Hemerocallis 99.

Hemitelia 56.

Hepaticae 1, 21.

Heracleum 263.

Hermannia 239.

Herminiumn 116.

Herniaria 164.

Hesperis 182.

Hessea 107.

Heteranthera 95.

Heterocentron 253.

Heteropteris 224.

Heterotoma 310.

Heuchera 188.

Hibbertia 240.

Hibiscus 239.

Hicoria 137.

Hieracium 330.

Hierochloë 80 .

Himantoglossum 117.

Hippeastrum 108.

Hippocastanaceac 132, 232.

Hippocrepis 211.

Hippophaë 248. 
Hippuris 257.

Holcus 77.

Holodiscus 197.

Holosteum 162.

Homalia 48.

Homalomena 92.

Homalothecium 47.

Homogyne 324.

Hordeum 81.

Hosta 99.

Hottonia 270.

Houttuynia 137.

Hovenia 233.

Hoya 276.

Humulus 148.

Hunnemannia 174.

Hutchinsia 181.

Hyacinthus 104 .

Hydnaceae 4, 8.

Hydnum 8.

Hydrangea 189.

Hydrastis 166.

Hydrilla 70.

Hydrocaryaceae 133.

Hydrocharis 70 .

Hydrocharitaceae 67, 70.

Hydrocleis 70 .

Hydrocotyle 258.

Hydrolea 279.

Hydromystria 70 .

Hydrophyllaceae 135, 279.

Hydrophyllum 279.

Hydrosme 92.

Hygrophorus 11.

Hylocomium 49.

Hymenogaster 16 .

Hymenogastraceac 16.

Hymenophyllaceae 51. Hymenophyllum 51.

Hymenostomum 36.

Hyoscyamus 290 .

Hyoseris 329 .

Hypecoum 174.

Hypericum 240.

Hypholoma 13.

Hypnaceae 34, 46.

Hурпит 49.

Hypochoeris 335 .
Hypocreaceae 3, 5.

Hyporrhodius 14.

Hypoxis 106.

Hypoxylon 6.

Hyptis 288.

Hyssopus 284.

Iberis 177 .

Idesia 244.

Ilex 229.

Illecebrum 164.

Illicium 166.

Impatiens 233.

Imperata 84.

Incarvillea 300.

Indigofera 213.

Inga 206.

Inocybe 14.

Inula 316.

Ipomoea 278.

Iresine 157.

Iridaceae 68, 109.

Iris 110.

Isatis 180 .

Ischaemum 84.

Isoëtaceae 60.

Isoëtes 60 .

Isopyrum 167.

Isothecium 47.

Ixora 301.

Jambosa 250.

Jasione 310 .

Jasminum 273.

Jatropha 226.

Jeffersonia 172.

Jonopsidium 177.

Juglandaceae 125, 137.

Juglans 138.

Juncaceae 68, 95 .

Juncaginaceae 67, 69.

Juncus 95.

Juniperus 66 .

Jurinea 325.

Jussieua 253.

Justitia 300 .

Kaempferia 111.

Kalanchoë 186 .
Kalmia 266.

Kaulfussia 57.

Kennedya 219.

Kernera 178.

Kerria 197.

Kitaibelia 237.

Knautia 306.

Kneiffia 254.

Kniphofia 99.

Kobresia 87.

Kochia 155.

Koeleria 73.

Koelreuteria 233.

Kohleria 299.

Kosteletzkya 239.

Krameria 207.

Kraunhia 213.

Kunzea 251.

Labiatae 136, 232.

Laburnum 209.

Lachenalia 105.

Lactaria 12.

Lactuea 334.

Laelia 120.

Lagenaria 307.

Lagerstroemia 249.

Lagoecia 258.

Lagurus 79.

Lamarckia 76.

Lamium 286.

Lampsana 329.

Landolphia 275.

Lantana 282.

Lapageria 100.

Lapeyrousia 111.

Laportea 148.

Lappula 280.

Lardizabalaceae 126.

Larix 64.

Laserpitium 264.

Lasia 92.

Lasiopetalum 239.

Lasthenia 318.

Lathraea 298.

Lathyrus 217.

Lauraceae 128, 174.

Laurelia 174.

Laurus 174.

Lavandula 288. 
Lavatera 238.

Lecanora 19.

Lecidea 18.

Lecidella 18.

Lecythidaceae 133.

Ledum 265.

Leersia 83.

Leguminosae 129, 134, 206.

Lejeunia 30.

Lemna 94.

Lemnaceae 66, 94.

Lens 217.

Lentibulariaceae 136, 298.

Lentinus 12.

Lenzites 8

Leontice 173.

Leontodon 335 .

Leontopodium 315.

Leonurus 286.

Lepargyrea 248.

Lepidium 177.

Lepidozia 29.

Lepiota 14.

Leptobryum 43.

Leptochloa 80.

Leptogium 17.

Leptogyrum 167.

Leptospermum 251.

Lepturus 82.

Leschenaultia 311.

Leskea 46.

Leskeaceae 33, 45.

Lespedeza 210.

Leuceria 329.

Leucobryaceae 32, 37.

Leucobryum 37.

Leucocoryne 106.

Leucodon 47.

Leucojum 107.

Leucothoë 267.

Levisticum 262.

Libertia 109.

Libocedrus 65.

Lichenes 1, 17.

Ligularia 322.

Ligusticum 262.

Ligustrum 273.

Liliaceae 67, 68, 97.

Lilium 102.
Limnanthaceae 131.

Limnanthemum 273.

Limnanthes 131.

Limodorum 118.

Limosella 293.

Linaceae 131, 222.

Linaria 294.

Lindenbergia 293.

Lindera 174.

Linnaea 304.

Linum 222.

Liparis 120.

Lippia 282.

Liquidambar 191.

Liriodendron 166.

Listera 119.

Lithospermum 281.

Lithraea 229.

Littorella 301.

Livistona 91.

Loasa 245.

Loasaceae 132, 245.

Lobelia 310.

Logania 273.

Loganiaceae 135, 273.

Loiseleuria 266.

Lolium 82.

Lomatophyllum 99.

Lonas 319.

Lonchitis 52.

Lonicera 303.

Lophocolea 28.

Lophosciadium 261.

Lophozia 27.

Loranthaceae 124, 149.

Loranthus 149.

Lotus 211.

Luffa 307.

Lunaria 179.

Lunularia 23.

Lupinus 208.

Luzula 96.

Lycaste 122.

Lychnis 160.

Lycium 290.

Lycoperdaceae 5, 15.

Lycoperdon 15.

Lycopodiaceae 59.

Lycopodiales 2, 59. Lycopodium 59.

Lycopsis 281.
Lycopus 284.

Lygeum 83.

Lygodium 57.

Lyonia 267.

Lysimachia 271.

Lythraceae 126, 133, 248.

Lythrum 249.

Machaerium 215.

Macleya 174.

Madia 318.

Madotheca 30.

Magnolia 165.

Magnoliaceae 124, 128, 165.

Majanthemum 101.

Malabaila 262.

Malachra 238.

Malaxis 120.

Malcolmia 182.

Malope 237.

Malpighia 224.

Malpighiaceae 130,224.

Malva 237.

Malvaceae 130, 237.

Malvastrum 237.

Malvaviscus 238.

Mamillaria 247.

Mandragora 290.

Mangifera 228.

Manihot 226.

Manulea 293.

Maranta 113.

Marantaceae 68, 113.

Marasmius 13.

Marattia 57.

Marattiaceae 51, 57.

Marchantia 25.

Marchantiaceae 21, 23.

Marica 110.

Marrubium 285.

Marsdenia 276.

Marsilia 58.

Marsiliaceae 51, 58.

Marsupella 26.

Martynia 300.

Martyniaceae 135, 300.

Masdevallia 120.

Matricaria 321. 
Matthiola 182.

Maurandia 293.

Maxillaria 122.

Mazus 293.

Meconopsis 175.

Medicago 211.

Medinilla 252.

Meesea 42.

Megapterium 255.

Melaleuca 251.

Nelampodium 317.

Melampyrum 296.

Melandryum 160.

Melastoma 253.

Melastomataceae 133, 252.

Melia 224.

Meliaceae 131, 224.

Melica 76.

Melilotus 211.

Melissa 285.

Melittis 286.

Melocactus 247.

Menispermaceae 128, 173.

Menispermum 173.

Mentha 283.

Mentzelia 245.

Menyanthes 273.

Mereurialis 226.

Nerendera 97.

Meriolix 255.

Merulius 8.

Mesembrianthemum 158.

Mespilus 195.

Metrosideros 250.

Metzgeria 25.

Meum 262.

Michauxia 309.

Microstylis 120 .

Mikania 313.

Milium 79.

Mimosa 206.

Mimulus 293.

Mina 277.

Mirabilis 157 .

Mnium 42.

Modiola 237.

Moehringia 163.

Moenchia 162.
Molinia 72.

Momordica 307.

Monanthes 185.

Monarda 288.

Monimiaceae 128, 174.

Monochaetum 253.

Monocotyledonea

2,66 .

Monolena 253.

Monopsis 310 .

Monotropa 265.

Monstera 92.

Montia 159.

Moraceae 126, 147.

Moraea 110.

Morchella 7.

Moricandia 183.

Morina 305.

Morus 147.

Moscharia 329.

Muehlenbeckia 153.

Muehlenbergia 79.

Mulgedium 334.

Musa 111.

Musaceae 68, 111.

Museari 104.

Musei 1, 31 .

Musschia 310.

Mutisia 329.

Myagrum 180.

Mylia 28.

Myoporaceae 136.

Myopordon 327.

Myoporum 136.

Myosotis 281.

Myosurus 169.

Myrceugenia 250.

Myrica 138.

Myricaceae 125, 138.

Myricaria 242.

Myriophyllum 257.

Myristica 125.

Myristicaceae 125.

Myrrhis 261.

Myrsinaceae 134, 269.

Myrsine 269.

Myrtaceae 132, 133, 249.

Myrtus 249.
Najadaceae 67, 69.

Najas 69.

Nandina 172.

Napaea 238.

Nareissus 108.

Nardia 26.

Nardus 83.

Narthecium 98.

Nasturtium 178.

Naumburgia 271.

Neckera 46.

Neckeraceae 34, 46.

Nectria 5.

Neillia 192.

Nelumbo 164.

Nemophila 279.

Neottia 120.

Nepeta 285.

Nephrodium 55.

Nerine 107.

Nerium 275.

Neslia 181.

Nicandra 289.

Nicotiana 291.

Nidularia 16.

Nidulariaceae 5, 16.

Nidularium 95.

Nierembergia 291.

Nigella 167.

Nigritella 116.

Nolana 289.

Nolanaceae 134, 289.

Nolina 100.

Nonnea 280.

Nothochlaena 53.

Nothoscordum 106.

Nuphar 165.

Nuttallia 204.

Nyctaginaceae 125, 157.

Nyctalis 11.

Nymphaea 164.

Nymphaeaceae 126,127, 164.

Nyssa 264.

Ochrolechia 19. Ochroporus 10.

Ocimum 288.

Odontites 297.

Odontoglossum 122. 
Oenanthe 261.

Oenothera 254.

Olea 273.

Oleaceae 126, 130, 135, 272.

Olearia 314.

Omphalodes 279.

Onagra 254.

Onagraceae 133, 253.

Oncidium 122.

Onobrychis 210.

Onoclea 55.

Ononis 207

Onopordon 327.

Onosma 282.

Opegrapha 18.

Ophioglossaceae 51, 58.

Ophioglossum 58.

Ophiopogon 99.

Ophrys 116.

Oplismenus 84.

Opopanax 262.

Opuntia 247.

Orchidaceae 67, 113.

Orchis 116.

Origanum 284.

Ornithogalum 104.

Ornithopus 210.

Orobanchaceae 136, 298.

Orobanche 298.

Orthothecium 47.

Orthotrichaceae 33, 40.

Orthotrichum 40.

Oryza 83.

Oryzopsis 80 .

Osbeckia 253.

Osmanthus 273.

Osmunda 57.

Osmundaceae 51, 57.

Ostrya 144.

Otanthera 253.

Oxalidaceae 131, 221. Oxalis 221.

Oxyria 152.

Oxytropis 214.

Paeonia 166.

Paliurus 234.

Palmae 67, 91.
Paludella 42.

Panar 257.

Pancratiun 108.

Pandanaceae 66.

Pandanus 66.

Panicum 83.

Pannaria 19.

Papaver 175.

Papaveraceae 125, 129, 174.

Paphiopedilum 115.

Pappophorum 76.

Paradisea 98.

Parietaria 149.

Parinarium 206.

Paris 101.

Parmelia 20.

Parnassia 189.

Paronychia 164.

Parrotia 191.

Paspalum 84.

Passiflora 244.

Passifloraceae 125, 132, 244.

Paulownia 293.

Pedaliaceae 135.

Pedicellaria 183.

Pedicularia 297.

Pedinophyllum 29.

Peganum 222.

Pelargonium 221.

Pellia 25.

Peltaria 178.

Peltigera 19.

Pennisetum 84.

Pentstemon 292.

Peperomia 137.

Peplis 249.

Perezia 329.

Periploca 275.

Pernettya 267.

Persea 174.

Pertusaria 17.

Petagnia 258.

Petasites 324.

Petunia 291.

Peucedanum 262.

Peumus 174.

Peziza 6.

Pezizaceae 3, 6.

Phacelia 279.
Phaeodon 8.

Phaeoporus 10.

Phajus 121.

Phalaenopsis 124.

Phalaris 80.

Phallaceae 4.

Phallus 4.

Pharbitis 278.

Phascaceae 32, 36.

Phaseum 36.

Phaseolus 219.

Phegopteris 55.

Phellodendron 223.

Philadelphus 189.

Phillyrea 273.

Philodendron 92.

Philonotis 43.

Phleum 79.

Phlomis 286.

Phlox 278.

Phoenix 91.

Pholiota 14.

Photinia 195.

Phragmites 72.

Phygelius 293.

Phylica 234.

Phyllanthus 225.

Phyllis 301.

Phyllocactus 246.

Phyllocladus 61.

Phyllodoce 266.

Physalis 289.

Physcia 20.

Physcomitrella 35.

Physcomitrellaceae 32, 35.

Physcomitrium 41.

Physocarpus 192.

Physochlaena 290.

Phyteuma 308.

Phytolacea 157.

Phytolaccaceae 125, 157.

Picea 62.

Picris 335.

Pilea 148.

Pilularia 58 .

Pimelea 248.

Pimenta 250.

Pimpinella 259.

Pinaceae 62. 
Pinellia 93.

Pinguicula 298.

Pinus 64.

Piper 137.

Piperaceae 124, 137.

Pirola 265.

Pirolaceae 130, 264.

Pirus 195.

Pistacia 228.

Pistia 94.

Pisum 218.

Pitcairnia 94.

Pittosporaceae 130, 244.

Pittosporum 244.

Placodium 19.

Plagiochila 28.

Plagiothecium 48.

Plantaginaceae 136, 300.

Plantago 300.

Platanaceae 129, 192.

Platanthera 116.

Platanus 192.

Platycerium 56.

Platycodon 310.

Platygyrium 47.

Platystemon 174.

Pleetranthus 288.

Pleuridium 35.

Pleurospermum 262.

Pleurothallis 120 .

Pluchea 315.

Plumbagella 271.

Plumbaginaceae 134, 271.

Plumbago 271.

Poa 73.

Podocarpus 62.

Podophyllum 172.

Pogonatum 44.

Polanisia 183.

Polemoniaceae 134, 278.

Polemonium 278.

Polianthes 107.

Polycarpaea 164.

Polycarpon 164.

Polyenemuim 153.

Polygala 225.

Polygalaceae 130, 225.

Polygonaceae 125, 150.
Polygonatum 101.

Polygonum 152.

Polypodiaceae 51.

Polypodium 56.

Polypogon 79.

Polyporaceae 4, 8.

Polyporus 9.

Polystigma 5.

Polytrichaceae 32, 44.

Polytrichum 44.

Pomaderris 234.

Pontederia 95.

Pontederiaceae 68, 95.

Populus 138.

Portulaca 159.

Portulacaceae 127, 158.

Potamogeton 68.

Potamogetonaceae 67, 68.

Potentilla 199.

Pothos 91.

Pottia 38.

Pottiaceae 33, 38.

Prangos 261.

Pratia 310.

Prenanthes 330.

Primula 269.

Primulaceae 125, 134, 136, 269.

Proboscidea 300.

Protea 149.

Proteaceae 126, 149.

Prunus 204.

Psalliota 13.

Pseudotsuga 63.

Psidium 250.

Psilocybe 13.

Psora 18.

Ptelea 223.

Pteridium 52.

Pteris 52.

Pterocarya 138.

Pterocephalus 306.

Pterygoneurum 39.

Ptilidium 30.

Pulicaria 316.

Pulmonaria 280.

Pultenaea 207.

Punica 133.

Punicaceae 127, 133.

Puschkinia 104.
Pylaisia 47.

Pyramidula 41.

Pyrenula 17.

Quamoclit 277.

Quercus 145.

Quillaja 193.

Quinaria 235.

Racomitrium 40 .

Radiola 222.

Radula 29.

Ramalina 21.

Ramondia 299.

Ranunculaceae 126, 128, 166.

Ranunculus 169.

Reboulia 23.

Reineckia 101.

Remusatia 93.

Renanthera 124.

Renealmia 111.

Reseda 183.

Resedaceae 129, 183.

Rhagadiolus 330.

Rhamnaceae 133, 233.

Rhamnus 234.

Rhaphanus 180.

Rhaphidophora 92.

Rhapis 91.

Rheum 151.

Rhexia 253.

Rhipsalis 247.

Rhizocarpon 18.

Rhizopogon 16.

Rhodamnia 249.

Rhododendron 265.

Rhodomyrtus 250 .

Rhodosporus 14

Rhodothamnus 266.

Rhodotypus 197.

Rhoeo 95.

Rhus 229.

Rhynchospora 86 .

Ribes 190.

Riccardia 25.

Riccia 22.

Ricciaceae 21, 22.

Ricciocarpus 23. 
Richardsonia 301.

Ricinus 226.

Robinia 213.

Rochea 186.

Roemeria 175.

Roettlera 299.

Romulea 109.

Rosa 202.

Rosaceae 126, 128, 129, 133, 192.

Rosmarinus 283.

Rubia 301.

Rubiaceae 136, 301.

Rubus 197.

Rudbeckia 317.

Ruelingia 239.

Ruellia 300.

Rumex 151.

Ruppia 69.

Ruscus 100.

Russelia 293.

Russula 12.

Russulina 12.

Russuliopsis 14.

Ruta 223.

Rutaceae 131, 222.

Sabal 91.

Saccharum 84.

Saccogyna 26.

Saccolabium 124.

Sagina 162.

Sagittaria 70.

Salicaceae 125, 138.

Salicornia 156.

Salix 139.

Salpiglossis 291.

Salpinga 253.

Salsola 156.

Salvia 288.

Salvinia 58.

Salviniaceae 51, 58.

Sambucus 303.

Samolus 270.

Sanguinaria 174.

Sanguisorba 201.

Sanicula 258.

Sanseviera 99.

Santalaceae 124, 149.

Santolina 319.
Sapindaceae 132, 233.

Saponaria 161.

Saracha 289.

Saranthe 113.

Sarcoseypha 6.

Sarracenia 183.

Sarraceniaceae 183.

Sassatras 174.

Satureja 284.

Saururaceae 124, 137.

Saururus 137.

Saussurea 325.

Saxifraga 186.

Saxifragaceae 125, 128, 132, 133, 186.

Scabiosa 306.

Scaevola 311.

Scandix 261.

Scapania 29.

Scheuchzeria 69 .

Schinus 229.

Schismatoglottis 92 .

Schistidium 39.

Schistostega 41.

Schistostegaceae 32, 41.

Schizaea 57.

Schizaeaceae 51, 57.

Schizanthus 291.

Schizonotus 197.

Schizophyllum 12.

Schizostylis 111.

Schkuhria 318.

Schoenocaulon 97.

Schoenus 85.

Schwenkia 291.

Scilla 103.

Scirpus 86.

Scleranthus 164.

Scleroderma 5 .

Sclerodermataceae 5 .

Scolochloa 73.

Scolopendrium 53.

Scolopia 244.

Scolymus 329.

Scopolia 290.

Scorpiurus 211.

Scorzonera 336.

Scrophularia 292.

Scrophulariaceae 135, 291.
Scutellaria 288.

Secale 81.

Secchium 308.

Sedum 184.

Selaginella 60 .

Selaginellaceae 60.

Selago 294.

Selenipedilum 115.

Selinum 262.

Selliera 311.

Sempervivum 185.

Senecio 322.

Sequoja 62.

Serapias 117.

Serpula 8.

Serratula 327.

Sesamum 135.

Seseli 261.

Sesleria 76 .

Setaria 84.

Shepherdia 248.

Sherardia 301.

Sibbaldia 198.

Sibiraea 193.

Sibthorpia 294.

Sicyos 308.

Sida 238.

Sidalcea 238.

Sideritis 285 .

Siegesbeckia 317.

Silene 159.

Siler 261.

Silphium 317.

Silybum 326.

Simarubaceae 131.

Sinapis 180.

Sinningia 299.

Sistotrema 8 .

Sisymbrium 179.

Sisyrinchium 109.

Sium 259.

Skimmia 223.

Smilacina 100.

Smilax 100.

Smithiantha 299.

Solanaceae 134, 135, 289.

Solandra 290.

Solanum 289.

Soldanella 270.

Solidago 314. 
Solorina 19.

Sonchus 334.

Sophora 207.

Sorbaria 193.

Sparassis 8 .

Sparaxis 111.

Sparganiaceae 67, 68.

Sparganium 68.

Sparmannia 236.

Spartina 80.

Spartium 209.

Spathicarpa 93.

Spathiphyllum 92.

Specularia 309.

Spergula 164.

Sphaeralcea 237.

Sphaerobolaceae 4.

Sphaerobolus 4.

Sphagnaceae 31, 34.

Sphagnum 34.

Sphyridium 18.

Spigelia 273.

Spilanthes 317.

Spinacia 156.

Spiraea 192.

Spiranthes 120 .

Spirodela 94.

Splachnaceae 33, 41.

Splachuum 41.

Sporledera 35.

Stachys 286.

Stanhopea 122.

Stapelia 276.

Staphylea 231.

Staphyleaceae 132, 133, 231.

Siatice 271.

Steironema 271.

Stellaria 163.

Sienophragma 182.

Sicphanaudra 192.

Sicreuliaceae 130, 239.

Stereocaulon 21.

Streum 7.

Sicenbergia 107.

siterdnera 93.

Sierartia 240.

Sticta 20.

Stiematophyllum 224.

sitipa 80 .

simatiotes 70 .
Strelitzia 111.

Streptocarpus 299.

Streptopus 101.

Stromanthe 113.

Strophanthus 275.

Struthiola 247.

Strychnos 273.

Stylidiaceae 311.

Stylidium 311.

Styphelia 269.

Styracaceae 134, 136, 272.

Styrax 272.

Suaeda 156.

Succisa 306.

Swainsonia 214.

Sweertia 275.

Symphoricarpus 304.

Symphyandra 310 .

Symphytum 281.

Syngonium 94.

Syringa 272.

Syzygium 250.

'lagetes 318.

Tamaricaceae 127, 129, 242.

Tamarix 242.

'Tamus 109.

Taraxacum 334.

Taxaceae 61.

Taxodium 62.

Taxus 61.

Tecoma 300.

Teesdalea 177.

Telephium 164.

Telfairia 306.

Tellima 188.

Tephrosia 213.

Testudinaria 109.

Tetragonia 157.

Tetranema 293.

Tetrapteris 224.

Teucrium 283.

Thalia 113.

Thalictrum 172.

Thamnium 50.

Thapsia 264.

Thea 240.

Theaceac 130, 240.
Thelephora 7.

Thelephoraceae 4, 7 .

Theobroma 239.

Theophrasta 269 .

Thermopsis 207.

Thesium 149.

Thespesia 239.

Thibaudia 268.

Thladiantha 306 .

Thlaspi 178.

Thomasia 239.

Thuidium 46.

Thuja 65.

Thujopsis 65 .

Thunbergia 300 .

Thymelaea 248.

Thymelaeaceae 128, 247.

Thymus 284.

Tibouchina 253.

Tigridia 109.

Tilia 236.

Tiliaceae 130, 236.

Tillandsia 94.

Tinantia 95.

Tissa 164.

Todea 57.

Tofieldia 97.

Tolpis 329.

Toluifera 207.

Tordylium 262.

Torenia 293.

'Torreya 61.

Tortula 38.

Tozzia 296.

Trachelium 308.

Trachymene 258.

Tradeseantia 95.

Tragopogon 336.

Tragus 72.

Trapa 133.

Trematodon 36 .

Tremella 7.

Tremellaceae 3, 7.

Tremellodon 7 .

Tribulus 222.

Trichocladus 192.

Trichocolea 30.

Trichodon 38.

Tricholaena 84.

'Trichomanes 51. 
Trichopilia 124.

Trichosanthes 307 .

Tricyrtis 97 .

Trientalis 271.

Trifolium 212.

Triglochin 69 .

Trigonella 211.

Trillium 101.

Trinia 259.

Triodia 76 .

Tripsacum 85.

Trisetum 77.

Triticum 81.

Triumfetta 236.

Trollius 167.

Tropaeolaceae 131, 221.

Tropaeolum 221.

Troximon 332.

Tsuga 63.

Tuber 5.

Tuberaceae 3, 5.

Tulipa 103.

Tunica 162.

Tupistra 101.

Turritis 182.

Tussilago 324.

Tylostoma 5.

Tylostomaceae 5.

Typha 68.

Typhaceae 67, 68.

Ugni 249.

Ulex 210.

Ulmaceae 126, 146.

Ulmaria 200.

Ulmus 146.

Ulota 40.

Umbelliferac 134, 257.

Umbilicaria 20.

Uniola 73.

Urceolaria 19.

Urena 239.

Urginea 103.

Urospermum 335.

Ursinia 324.

Urtica 148.

Urticaceae 125, 148.
Usnea 21.

Ustulina 6 .

Utricularia 298.

Utriculariacene 136, 298.

Uvularia 98.

Vaccaria 161.

Vaccinium 267.

Vaillantia 302.

Valeriana 305.

Valerianaceae 136, 304.

Valerianella 304.

Vallisneria 70 .

Vallota 107.

Vanda 124.

Vanilla 118.

Velleia 310.

Veratrum 97.

Verbascum 291.

Verbena 282.

Verbenaceae 136, 282.

Vernonia 311.

Veronica 295.

Verrucaria 17.

Vesicaria 182.

Viburnum 304

Vicia 216.

Victoria 165.

Vigna 219.

Vinea 275.

Vincetoxicum 277.

Viola 243.

Violaceae 130, 243.

Virgilia 207.

Visearia 159 .

Viscum 149.

Vismia 241.

Visnea 240.

Vitaceae 133, 234.

Vitex 282.

Vitis 235 .

Voandzeia 219.

Vriesea 94.

Wahlenbergia 310.

Waldsteinia 200.
Waltheria 239.

Watsonia 111.

Webera 43.

Wedelia 317 .

Weisia 36.

Weisiaceae 33, 36.

Wissadula 237.

Wistaria 213.

Withania 289.

Wolffia 94.

Woodsia 55 .

Wulfenia 295.

Xanthium 318.

Xanthoceras 233.

Xanthoria 20.

Xanthorrhiza 167.

Xanthosoma 94.

Xanthoxylon 223.

Xeranthemum 327.

Xylaria 6.

Tylariaceae 3, 6.

Xylographa 17.

Xylopleurum 255.

Yucca 100 .

Zacyntha 330.

Zamia 61.

Zannichellia 69.

Zantedeschia 92.

Zauschneria 256.

Zea 85.

Zebrina 95.

Zelkowa 147.

Zephyranthes 107 .

Zingiber 113.

Zingiberaceae 67, 68, 111.

Zinnia 318.

Zizania 83.

Zizyphus 234.

Zygadenus 97.

Zygodon 40.

Zygopetalum 122.

Zygophyllaceae 131, 222 .

Zygophyllum 222. 
Druck der Kgl. Universitäts-Druckerei ron H. Stürtz in Würzburg 

(E)

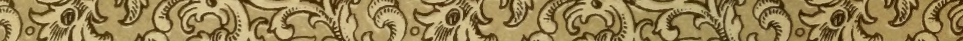
(2)

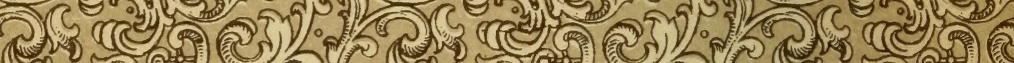
क्ती दू? (1) (1) (c) (2) (3)

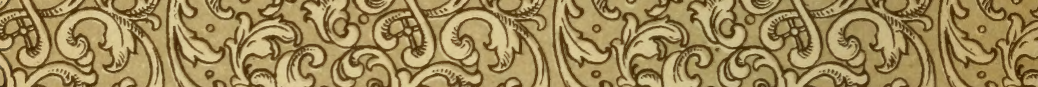
7) (स) (1)

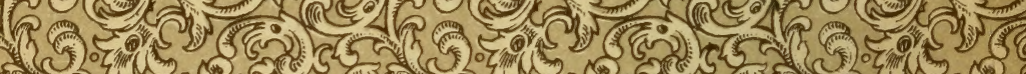
(a.) 5. ए. (10) 3 (c)
क (2)

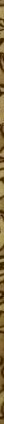


